\title{
THE EFFECT OF LACK OF CITIZENSHIP ON THE WAGES OF LOW-SKILLED NON- PERMANENT RESIDENT WORKERS IN CANADA
}

\author{
by \\ Nelson Mauricio Palacio \\ Master of Arts, Ryerson University, 2010 \\ Philosophical Studies Diploma, Regis College - University of Toronto, 2009 \\ Master of Arts, National University of Colombia, 2000 \\ Bachelor of Science, National University of Colombia, 1994
}

\begin{abstract}
A dissertation
presented to Ryerson University

in partial fulfillment of the

requirements for the degree of

Doctor of Philosophy

in the program of

Policy Studies - Immigration Settlement and Diaspora Policies stream
\end{abstract}

Toronto, Ontario, Canada, 2017

(C) Nelson Mauricio Palacio, 2017 
THE EFFECT OF LACK OF CITIZENSHIP ON THE WAGES OF LOW-SKILLED NONPERMANENT RESIDENT WORKERS IN CANADA

Nelson Mauricio Palacio

Doctor of Philosophy, Policy Studies

2017

Ryerson University

\section{Abstract}

This dissertation explores the effects of lack of citizenship on the wages of lowskilled Non-Permanent Residents (NPRs) in Canada-a category that includes temporary foreign workers, refugee claimants, and people with temporary resident visas on humanitarian grounds. The dissertation uses the 2006 census and quantitative methods (cross-tabulation and regression analysis) to evaluate wage differences between low-skilled workers without citizenship and low-skilled workers with citizenship or permanent resident status. Differences are calculated at the industry sector level and occupation level. The analysis further considers a set of intrinsic characteristics of low-skilled workers (including sex, level of education, official language ability and country of birth) and their occupations (provincial location, rural/urban setting).

Empirically, this dissertation confirms that there is a penalty attached to lack of citizenship for low-skilled workers. In absolute terms, low-skilled NPRs earn low wages. In relative terms, these NPRs earn less than both the Canadian-born and immigrants low-skilled workers employed in the same occupations. Among low-skilled NPRs themselves, the Canadian labour market exhibits a hierarchy of wages and labour experiences on the lines of workers' country of birth, province of residence, and rural/urban place of work. Among low-skilled workers born in the same country, wages improve when either citizenship or the rights attached to permanent residence are acquired. 
From a policy perspective, the dissertation identifies the policy origins and drivers of low wages among low-skilled non-citizens. The thesis makes the case for the relevance of quantitative outcomes analyzed through a critical social lens. From a theoretical perspective too, the dissertation also shows how the state as a biased broker (towards capital) facilitates the implementation of non-citizenship as a means to accessing cheap labour. 


\section{Abbreviated Table of Contents}

Page

$\begin{array}{ll}\text { Abstract } & \text { ii }\end{array}$

List of Figures $\quad$ xii

List of Tables $\quad$ xiv

$\begin{array}{ll}\text { Chapter One: Introduction } & 1\end{array}$

$\begin{array}{ll}\text { Chapter Two: Literature Review and Theoretical Approaches } & 16\end{array}$

Chapter Three: Low-Skilled Temporary Foreign Worker Policies and 62

Programs

Chapter Four: Methods, Considerations and Methodological Challenges 102

Chapter Five: A Profile of Low-skilled Workers in Canada 140

Chapter Six: Wages and Differences in Citizenship Status by Occupation 160

and Industry

Chapter Seven: Wage Analysis Considering Intrinsic Characteristics of 185

Workers and Occupations

Chapter Eight: Regression Analysis $\quad 209$

Chapter Nine: Place of the Findings in the Literature 238

Chapter Ten: Theoretical and Analytical Contributions 275

$\begin{array}{ll}\text { Appendices } & 305\end{array}$

$\begin{array}{ll}\text { List of References } & 374\end{array}$ 


\section{Extended Table of Contents}

Abstract

Page

List of Figures

ii

List of Tables

xii

xiv

Chapter One: Introduction

1.1. Dissertation Focus and Contribution 1

1.2. How will the Research Be Developed? 6

1.3. Context 8

1.4. High Level Outcomes 12

1.5. Dissertation Structure 14

Chapter Two: Literature Review and Theoretical Approaches 16

2.1. Low-Skilled Temporary Foreign Labour in the Canadian Labour Market 17

2.1.1. General labour-related issues $\quad 20$

2.1.2. Wages among low-skilled temporary foreign workers 23

2.2. Rational Choice Theory (RCT) and Critical Social Theory (CST) 26

2.2.1. Rational Choice Theory (RCT) 26

2.2.2. Critical Social Theory (CST) 29

2.3. Labour Migration Theories in Relation to RCT and CST 33

2.3.1. Neoclassical economics and push-pull theory 34

2.3.2. Historical structural theories (neo-Marxist based). 35

2.4. Globalization and Neoliberalism 39

2.5. Citizenship and Low-skilled Labour 44

2.6. Citizenship and the nation-state 48

2.7. Theories of the State, a Neo-Marxist Perspective 51

2.7.1. Class domination and the state: economics and politics. 53

2.7.2. The Strategic Relational Approach, a Definition of the State 56

$\begin{array}{lr}\text { Chapter Summary } & 59\end{array}$

Chapter Three: Low-Skilled Temporary Foreign Worker Policies and 62 Programs 
3.1. Live-in caregivers: Main Policy Changes and Motivation 65

3.2. Agricultural labour: Main Policy Changes and Motivations 71

3.2.1. Caribbean agricultural labor $\quad 72$

3.2.2. Mexican agricultural labour $\quad 76$

3.3. Low-skilled Workers in Other Occupations 84

3.4. The current Low-Skilled Temporary Foreign Worker Program Streams and 89 the Most Relevant Recent Policy Changes

3.4.1. The Live-in Caregiver Program $\quad 91$

3.4.2. The Seasonal Agricultural Workers Program (SAWP) 92

3.4.3. The agricultural stream to hire temporary foreign agricultural workers 94

3.4.4. Stream for low-wage positions $\quad 94$

3.4.5. Most Recent Changes affecting Low-Skilled TFWs 96

$\begin{array}{ll}\text { Chapter Summary } & 101\end{array}$

Chapter Four: Methods, Considerations and Methodological Challenges 102

4.1. Problem and Questions

4.1.1. The Problem 103

4.1.2. Research Questions. 103

4.2 Methods used to test the hypotheses and address the questions.

4.2.1. Cross Tabulation 106

4.2.2. Regression analysis. 107

4.3. Selection of Dataset (2006 census) 109

4.4. Variables Used in the Analysis (Justification) and Data Extraction 112

4.4.1. Dependent variable - Why are wages relevant? 113

4.4.2. Independent variables (justification and selection of categories $\quad 115$

4.4.2.1. Immigration status $\quad 115$

4.4.2.2. Industry sectors $\quad 115$

4.4.2.3. Occupation $\quad 116$

4.4.2.4. Province of residence 119

4.4.2.4.1. The Atlantic provinces $\quad 120$

4.4.2.4.2. Manitoba and Saskatchewan 120

4.4.2.4.3. Territories $\quad 120$

4.4.2.4.4. Other provinces $\quad 120$

$\begin{array}{ll}\text { 4.4.2.5. Age } & 121\end{array}$

4.4.2.6. Level of Education 121 


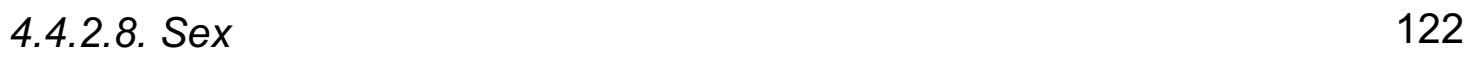

4.4.2.9. Rural - Urban 123

4.4.2.10. First official language spoken 123

4.5. Selection of Population: Criteria and Considerations Prior to Data 124

Extraction

4.5.1. Selection of low-skilled NPRs in the 2006 census 124

4.5.2. Selection of those who did not attend school (to filter out foreign 127

4.5.3. Selection of individuals working in low-skilled occupations 127

4.5.4. Selection of those "employed" and "paid." 128

4.5.5. Selection of those working full-time 129

4.5.6. Exclusion of outliers $\quad 129$

4.6. Data Limitations 131

4.7. Quartiles Analysis 133

4.8. Reliability Tests 134

4.8.1. Anova (Analysis of Variance) test 134

$\begin{array}{ll}\text { 4.8.2. Post hoc (Bonferroni) test } & 137\end{array}$

$\begin{array}{ll}\text { Summary } & 138\end{array}$

Chapter Five: A Profile of Low-skilled Workers in Canada 140

5.1. Temporary Foreign Low-Skilled Worker Programs - Context 141

5.2. What is the Place of Low-skilled Labour in Canada? 143

5.3. Low-skilled Workers in Canada 146

5.3.1. Low-skilled labour in Canada and industry sector $\quad 147$

5.3.2. Low-skilled Labour in Canada and Occupations 149

5.4. How do NPRs Compare to Other Low-skilled Workers by Occupation? 150

5.4.1. NPR low-skilled workers in Canada concentrate around five 150 occupations in caregiving and agriculture

5.4.2. Province of residence: NPR low-skilled workers have the highest 152 share in Ontario

5.4.3. Sex: NPR low-skilled workers have a higher representation of women 153 compared to IMM or CB.

5.4.4. Country of birth (COB): NPR low-skilled workers' COB concentrate around five countries. One of them, the Philippines, has a very high

Chapter Summary 
Chapter Six: Wages and Differences in Citizenship Status by Occupation 160 and Industry

6.1 Industry Sector Analysis (Absolute and Relative Wages) 162

6.1.1. Absolute wages of NPRs by industry sector) 162

6.1.2. Relative wages of NPRs (Compared to CB and IMM) by Industry 165

6.2 Occupation Level Analysis - Absolute Wages of NPRs by Occupation 167

6.3. Assessing Wage Dispersion (Broad Wage Range) in Absolute Wages - 171

Quartile Analysis

6.3.1. NPR cases with high concentration in the first three quartiles $\quad 174$

6.3.2. NPR cases with high concentration in the fourth quartile 175

6.3.3. NPR cases with very low wages in the first quartile 178

6.4. Relative wages of NPRs (compared to CB and IMM or NPR-CB and NPR- 179 IMM) by Occupation

Summary 183

Summary of Hypotheses/Chapter Findings (Tabulation) 184

Chapter Seven: Wage Analysis Considering Intrinsic Characteristics of Workers and Occupations

7.1. Wage Differences by Province of Residence. 187

7.2. Wage Differences by Rural - Urban Location 190

7.3. Wage Differences Within Each Sex by Immigration Status. 193

7.3.1. Wage differences (NPR-CB and NPR-IMM) for females. 193

7.3.2. Wage differences (NPR-CB and NPR-IMM) for males. 195

7.4. Wage Differences by Level of Education. 197

7.5. Wage Differences by Knowledge of First Official Languages. 199

7.6. Wage Differences by Country of Birth (COB) 201

7.6.1. Concentration around low-paid occupations or with significant wage 203 difference (compared to CB and IMM)

7.6.2. Concentration around the highest paying low-skilled jobs. 203

7.6.3. Niche-occupation concentration around certain countries of origin. 204

7.6.4. Wages improve when citizenship is accounted for 205

Summary 206

Summary of Hypotheses/Chapter Findings (Tabulation) 207 
8.1. Regression Models 211

8.2. Outcomes Regression Model Type One - Including All 98 low-skilled 217 Occupations Considered in This Study

8.2.1. Immigration status $\quad 219$

8.2.2. Age 221

8.2.3. Sex 222

8.2.4. Province of Residence 223

8.2.5. Rural- Urban Location 223

8.2.6. Level of Education 224

8.2.7. First Official Language Spoken 225

8.2.8. Place of Birth (Region of the World) 226

8.2.9. Occupations 227

8.3. Outcomes Regression Models Type Two (Selected Occupations) 229

8.3.1. Effect of Lack of citizenship On Wages 232

8.3.2. Females' wages versus males wages 232

8.3.3. Provincial comparison $\quad 233$

8.3.4. Working in rural areas versus urban areas 233

8.3.5. Level of education and wages 233

8.3.6. Effect of speaking either English or French on wages 234

8.3.7. Effect of place of birth on Wages $\quad 234$

8.3.8. Effect of age on wages 235

Summary 235

Summary of Hypotheses/Chapter Findings 236

Chapter Nine: Place of the Findings in the Literature 238

9.1. Industry Sectors and Occupations - General Overview 239

9.1.1. Caregiving Occupations $\quad 242$

9.1.2. Agricultural Occupations $\quad 245$

9.1.3. Other selected low-skilled occupations 248

9.2. Geography (Province of Residence and Rural/Urban Work Location) 251

9.3. Sex 255

9.4. First Official Language Spoken 258

9.5. Level of Education 260

9.6. Country of Birth - Regions of the World 264 
9.6.1. Concentration by country of birth around certain niche occupations

9.6.2. Concentration around occupations with the highest wages

9.6.3. Concentration around occupations with the lowest wages

9.6.4. Wages by country of birth when citizenship is accounted for

10.1. Migration Theories

10.1.1. Neoclassical Theory

10.1.2. Historical Structural Theory $\quad 277$

10.2. The Role of the State $\quad 279$

10.3. Citizenship 285

10.3.1. Othering and citizenship as means of constructing low-skilled TFWs 287

10.3.2. Non-citizenship a means to become globally competitive 289

10.3.3. Non-citizenship in combination with skills (occupations) as another 290 means of constructing labour

10.3.4. Citizenship, recognition and the importance of collective living 292 10.4. A Way Forward with Citizenship (No to Non-citizenship) 295

$\begin{array}{ll}\text { Chapter Summary } & 300\end{array}$

\section{$\begin{array}{ll}\text { Appendices } & 305\end{array}$}

Appendix 1 - Regression - Ordinary Least Square method 305

Appendix 2 - Research data Centre - Project proposal - Nelson Palacio 308

Appendix 3A - Distribution in the Unweighted PUMF files 315

Appendix 3B - Variables Definitions extracted from the Stats Canada's 2006320 Census 2006

Appendix 3C - 2006 NOC System of Classification of Occupations 329

Appendix 4 - List of 157 Low-Skilled Occupations 331

Appendix 5 - List of 98 Occupations Included in the Analysis, ordered top to 334 Bottom by Census Code

Appendix 6 - Procedure to Calculate the Anova (Sirkin, 2006) 336

Appendix 7- Bonferroni Test 
Appendix 8 - Low-skilled population, wage dispersion (broad wage range) and high wages in the fourth quartile

Appendix 9 - Quartiles Analysis

A9.1. Wage Differences by Sex - Second and Third Quartiles

A9.2. Wage differences by Province Residence - Second and Third

342

A9.3 Wage Differences - Rural/Urban Second and Third Quartiles

343

A9.4 Wage Differences - Speaking/Not Speaking English, Second and

343

A9.5 Wage Differences - Level of Education - Second and Third Quartiles

344

Appendix 10A Absolute Wages - 43 Low-skilled Occupations by Immigration

344

Appendix 10B - Quartiles - Low-skilled Canadian-born

345

Appendix 10C - Quartiles - Low-skilled Immigrants

346

Appendix 10D - Quartile Low-skilled NPR, CB and IMM - Summary

348

Appendix 10E - Relative Wages (NPR-CB and NPR-IMM) - 35 Occupations

349

Appendix 11 - Hourly Wages and Wage Differences by Occupation and

351

Appendix 12 - Weekly Hours of Labour by Occupation

352

Appendix 12A - Minimum Wage in Canada - 2005

356

Appendix 13 - Weekly Hours of Labour by Country of Birth

357

Appendix 14A - Regression Analysis -Considerations (Decisions)

358

Appendix 14B - Regression Analysis - Outcomes of Model Type 1 (All

361

Occupations) - Occupations' Outcomes

Appendix 15 - Supply-Demand Analysis

366

Appendix 16 - Summary of All Hypotheses 


\section{List of Figures}

Figure 1: Temporary Resident Work Permit Holders with a Valid Work Permit Present on December 31st versus Permanent Residents

Figure 2: 2015 - Labour Force Characteristics, 15 years and older

Figure 3A: 2015 - Labour Force Characteristics by Skill Level, 15 years and

Figure 3B: 2015 - Full-time employment by Skill Level, 15 years and older

Figure 3C: 2015 - Part-time employment by Skill Level, 15 years and older

Figure 4: 2015 - Employment Rates Lowest for Those Without High School 15 years and older

Figure 5: Low-Skilled Workers in Canada are Concentrated in Manufacturing and Retail Industry Sectors

Figure 6: Low-Skilled Full-time Workers in Top 10 Occupations in Canada

Figure 7: Low-Skilled Workers' Distribution by Sex

Figure 8 Average Hourly Wages by Industry Sector and Immigration Status Listed lowest to highest for NPRs

Figure 9: Statistically Significant Average Hourly Wage Differences by Immigration Category and Industry Sector (NPR-CB and NPR-IMM)

Figure 10A: Average Hourly Wages by Occupation and Immigration Status Listed lowest to highest for NPRs

Figure 10B: Statistically Significant Average Hourly Wage Differences by Occupation (selected occupations) - wages of NPR Babysitters and nannies

Figure 11: Statistically Average Hourly Wage Differences in a Rural Location

Figure 12: Statistically Significant Average Wage Differences in an Urban

Figure 13: Statistically Significant Average Hourly Wage Differences by Sex Females

Figure 14: Average Hourly Wage Differences by Sex - Males

Figure 15: Statistically Significant Average Hourly Wage Differences (NPR-CB) and (NPR-IMM)

Figure 16: Average Hourly Wage Differences Speaking English (NPR-IMM)

Figure A1: Wage Differences by Sex - Second and Third Quartiles

Figure A2: Wage differences by Province Residence - Second and Third

Quartiles

Figure A3: Wage Differences - Rural/Urban Second and Third Quartiles

Figure A4: Wage Differences - Speaking/Not Speaking English, Second and Third Quartiles

Figure A5: Wage Differences - Level of Education - Second and Third Quartiles

Figure A6: Absolute Wages - 43 Low-Skilled Occupations by Immigration 
Figure A7: Relative Wages (NPR-CB and NPR-IMM) - 35 Occupations 


\section{List of Tables}

Table 1: Quartile Ranges Divide

Table 2: Dependent Variable: Mean Differences for "Weekly hours of Labour" in Occupation "X" - Bonferroni

Table 3: Distribution of the Number of Low-Skilled Workers Per Occupation in

Each Immigration Status

Table 4: Distribution of Low-Skilled Workers by Province or Region in Each Immigration Status

Table 5: Distribution of Low-Skilled Workers in Each Province (or Combination of Provinces) by Immigration Status

Table 6: Low-Skilled Workers Share by Occupation and Sex

Table 7: Top 20 Countries of Birth of Low-Skilled Immigrants and Low-Skilled NPRs

Table 8: Low-Skilled NPR Quartiles by Occupation - top 20 Occupations

Table 9: Summary of Hypotheses/Chapter Findings (Cross-Tabulation Absolute Wages)

Table 10: Provincial Wage Differences in Selected Occupations

Table 11: Wage Differences by Occupation, Immigration Status and Country of Birth

Table 11A: Summary of Hypotheses/Chapter Findings (Cross - Tabulation

Table 12: Regression Model for All Occupations (Dependent Variable: LOG Hourly Wages)

Table 13: Regression Models Occupations - Group 1

Table 14: Regression Models Occupations - Group 2

Table 15: Summary of Hypotheses/Chapter Findings

Table A1: Unweighted PUMF files distribution by immigration status

Table A2: High- and Low-Skilled Reported in PUMF files

Table A3: Distribution by Immigration Status, Separating Low- from HighSkilled

Table A4: List of 157 Low-Skilled Occupations

Table A5: List of 98 Occupations Included in the Analysis, Ordered top to Bottom by Census Code

Table A6: Quartiles - Low-Skilled Canadian-born

Table A7: Quartiles - Low-Skilled Immigrants

Table A8: Quartile Low-Skilled NPR, CB and IMM - Summary

Table A9: Hourly Wages and Wage Differences by Occupation and Country of Birth

Table A10: Minimum Wage in Canada - 2005

Table A11: Weekly Hours of Labour by Country of Birth 


\section{Chapter One: Introduction}

In recent decades, the flow of temporary foreign workers (TFWs) to Canada has increased dramatically. A significant body of academic research critical of Canada's migration policies, particularly as they pertain to low-skilled ${ }^{1}$ workers, addresses this phenomenon in several ways. The present study endeavours to deepen our understanding of related labour-market and government policy changes in light of these findings.

The existing literature offers strong evidence that TFWs, particularly those in lowskilled positions ${ }^{2}$, are significantly disadvantaged by their lack of citizenship. There is also a large body of literature that details how low-skilled workers are uniquely vulnerable to exploitation by their employers. To date, most academic research related to this subject has been qualitative rather than quantitative. In contrast, my approach is mainly quantitative: I attempt to calculate the cost of citizenship (or, perhaps more precisely, the value of citizenship) to low-skilled workers in the Canadian labour market.

\subsection{Dissertation Focus and Contribution}

This dissertation focuses on low-skilled temporary foreign labour. A focus on lowskilled temporary foreign labour is linked to their greater vulnerability if compared to the high-skilled temporary foreign labour. As will be presented in detail, low-skilled temporary foreign workers have much less access to citizenship, less opportunities to

\footnotetext{
${ }^{1}$ According to Employment and Social Development Canada (ESDC), skill level is defined "as the amount and type of education and training required to enter and perform the duties of an occupation"

(ESDC/HRSDC, 2011). Low-skilled occupations "require, at most, a high school diploma or a maximum of two years' of job-specific training" (ESDC, 2016a).

${ }^{2}$ In contrast to low-skilled occupations, high-skilled occupations require education above high school (ESDC, 2016a).
} 
bring families and are more likely to work under conditions of exploitation and abuse than high-skilled temporary foreign workers. In addition, low-skilled temporary foreign workers represent the largest proportion coming to Canada under the Temporary Foreign Workers Program.

Of all workers coming under the Temporary Foreign Worker Program between 2006 and 2015, 55\% were low-skilled (IRCC, 2015). My focus on low-skilled temporary foreign labour is also motivated by the gradual shift in immigration policy from permanent to temporary to satisfy labour market needs. Immigration policy used to be guided by economic stands but with a strong nation-building vision. Since 1867 , most foreign born individuals working in Canada were assured citizenship. Nonetheless, it is worth mentioning that racist discrimination selection persisted until 1967 when the point system came into being (Kelley and Trebilcock, 1999). During the last 15 years, a break between migration and citizenship has occurred. Most low-skilled people coming under the TFW program are denied access to citizenship.

The quantitative nature of this dissertation represents a significant contribution. This dissertation quantifies the impact that a lack of citizenship has on the wages of lowskilled "Non-Permanent Resident workers", hereafter in this study identified "NPRs." Statistics Canada's 2006 Census Dictionary defined NPRs as "persons who are lawfully in Canada on a temporary basis under the authority of a temporary resident permit... NPRs include foreign workers, foreign students ${ }^{3}$, [and] the humanitarian population" (Statistics Canada, 2015).

Quantitative knowledge has cognitive benefits, including the potential for

\footnotetext{
${ }^{3}$ Foreign students were out of the scope of this dissertation and were not included in the analysis. This will be further explained in chapter four.
} 
universalization, methodological precision and rigour. My dissertation makes four specific quantitative contributions: 1) it presents a profile of low-skilled labour in Canada; 2) it uncovers pockets of concentration of wages (low and high) in the lowskilled occupations analyzed in this dissertation; 3) it assesses wage differences among low-skilled workers in different categories, including citizenship status and country of birth; and 4) it gauges how much a lack of citizenship and characteristics including sex, province of labour, etc. influence the wages of low-skilled workers in Canada. With all this in mind, it is my hope that this dissertation will provide new knowledge based on a critique of wage discrepancies between low-skilled NPRs and low-skilled Canadian-born and low-skilled immigrants - knowledge that can then inform policy and social action.

The dissertation's theoretical and empirical conclusions are derived from an assessment of relevant literature and government immigration policy; from a consideration of related theoretical debates; and from my own original quantitative research. The findings of this dissertation are empirically significant because no quantitative study to date has explored low-skilled labour in Canada at the same level of detail. The level of detail itself presented in this dissertation represents a significant contribution too, because it helps to focalize outcomes, which is helpful for more precise evidence-based policy making. Such level of detail requires a structure of analysis and presentation of outcomes with many categories and subcategories. The study also engages and enriches a number of theoretical debates - on TFW policy, on the meaning of citizenship (from the perspective of temporary low-skilled labourers), and on the responsibility of the state.

To date, research that employs quantitative methods to assess labour market 
outcomes for low-skilled temporary foreign labour in Canada, particularly with respect to wages, has been extremely limited. While there is extensive research on the lived experience of low-skilled migrants and considerable analysis of their situation in terms of human rights, there is a dearth of econometric and quantitative analyses of lowskilled labour in Canada, which reveals a significant gap in our knowledge. More specifically, a review of the literature reveals a lack of systematic studies (by occupation) that examine wage differences in light of immigration status and other characteristics such as sex, province of residence, rural/urban status, age, level of education, knowledge of Canada's official languages and country of birth. In other words, there has been no basis for assessing the impact that a lack of citizenship has on the wages of low-skilled NPRs.

In my attempt to fill this important gap in our knowledge of TFWs, I am hopeful that more detailed information on wage discrepancies will help us better analyze and formulate policies and programs related to low-skilled labour in Canada. To this end, I raise the following question: to what extent does citizenship status, combined with other key intrinsic characteristics of workers (age, sex, level of education, ability to speak English or French, or place of birth) and their occupations (provincial location, urban/rural setting) affect the wages of low-skilled NPR workers in Canada? This question is relevant for the following reasons: 1) low-skilled NPRs likely receive the lowest wages among labourers working in Canada and, because of their legal status, are among the most vulnerable ${ }^{4}$ (Goldring \& Joly, 2014); 2) among low-skilled workers, comparing the wages of NPRs against those of Canadian-born (CB) and immigrant

\footnotetext{
${ }^{4}$ Undocumented workers may face even harsher conditions than low-skilled NPRs. Unfortunately, the lack of information on this population prevents me from including them in my study.
} 
(IMM) workers will shed light on whether a lack of citizenship is an important contributing factor to NPRs' low-wage levels; and 3) contrasting the wages of low-skilled NPRs against those of CB and IMM will reveal whether a lack of citizenship can be used by employers as a means to access cheaper labour rather than to fulfill genuine labour gaps.

As such, the following study will provide an evidence-based quantitative contribution to the otherwise mostly qualitative debate concerning the effects of lack of citizenship on state-made policies that enforce precarious conditions in the labour market. I hope that the knowledge it provides on the wage differences between lowskilled citizens and noncitizens will inform new policy and program development. More generally, I also hope that it will allow us to consider the extent to which the state may undermine its own capacity to effectively regulate markets and labour conditions. Although temporary foreign workers represent a relatively small proportion of the total Canadian labour force, ${ }^{5}$ it is nevertheless imperative for the government to focus on this population (especially those considered low-skilled). Of all workers legally working in the Canadian labour market, low-skilled temporary foreign workers (especially racialized workers) ${ }^{6}$ are more likely than Canadian-born and immigrant workers to experience precarious conditions in the labour market (Goldring \& Joly, 2014), a likelihood that increases in agricultural and caregiving sectors (Goldring \& Joly, 2014 p.98). On the one hand, the heightened level of precariousness experienced by NPRs can be explained by the specific terms and conditions of their labour contracts: an NPR's legal status is

\footnotetext{
${ }^{5}$ According to Bandali (2015), in Canada TFWs make up about $0.55 \%$ of the total labour force. In Alberta, the province with the highest proportion of foreign labour, TFWs represent $1.7 \%$ of the labour force; In Ontario, TFWs make $0.3 \%$ of the labour force.

${ }^{6}$ According to the Government of Canada's "Snapshot of racialized Poverty in Canada": 'racialized workers' refers to those "who self-described as a visible minority on the 2006 Census" (2013).
} 
tied to the terms of his or her work permit, which, if broken (by the worker) may lead to deportation (Binford 2007; Faraday, 2012a; Hennebry \& Preibisch, 2010b; Preibisch \& Binford 2007; Goldring et al. 2009; Walia 2010; Hennebry \& Preibisch 2010; Faraday 2012 as cited in Goldring \& Joly, 2014). In many cases, the threat of deportation creates an incentive for workers to endure injuries in silence out of fear of being sent back to their countries of origin or of not being invited back to work the following season (Faraday, 2012a). As this example illustrates, such unstable working conditions are also directly related to NPRs' lack of either citizenship or permanent resident status (Goldring \& Joly, 2014). In other words: "their vulnerability is institutionally produced and sanctioned through laws, regulations, and policies that are crosscut by racialization" (Goldring and Joly, 2014 p.98).

\subsection{How will the Research Be Developed?}

In response to the main question raised in section 1.1, this dissertation has four specific objectives: (1) to elaborate a profile of low-skilled labour in Canada; (2) to uncover concentration of wages (around either low or high values) in the low-skilled occupations analyzed; (3) to compare the wages of low-skilled NPR workers with those of low-skilled Canadian-born and low-skilled immigrant workers; and (4) to evaluate, with the use of regression models, the effect that a lack of citizenship has on wages in relation to other characteristics, including age, sex and level of education.

To reach these four objectives, I will focus on the following six research questions related to low-skilled workers in Canada:

Question One: What are the demographics of low-skilled labour in Canada?

Question Two: Do wages of low-skilled workers concentrate around either low or 
high wages?

Question Three: How large are the wage differences between NPRs and CB and between NPRs and IMM in each industry sector and occupation analyzed in this dissertation?

Question Four: How large are the wage differences between NPRs and CB and between NPRs and IMM in view of intrinsic characteristics of workers (sex, level of education, ability to speak English or French, or place of birth) ${ }^{7}$ and their occupations (provincial location, urban/rural setting) analyzed in this study?

Question Five: How large is the effect of a lack of citizenship on the wages of NPRs when the variations in wages linked to intrinsic characteristics above (including age) ${ }^{8}$ are held constant?

Question Six: Are wage differences the result of existing citizenship-related policies?

To address these questions, I will draw on 2006 census data, cross-tabulation and regression analysis (which will be explained in detail in chapter four). The research will be framed within two theoretical lenses: Rational Theory and Social Critical Theory. As will be further explained in chapter two, I draw on these theories because they provide tools compatible with a critical quantitative analysis of this topic. Based on these theories, as well as other theoretical developments in the fields of migration, the state and citizenship, I will then develop a theoretical critique of low-skilled labour (chapter ten).

\footnotetext{
${ }^{7}$ As will be explained in chapter four, this question will be addressed using cross-tabulation analysis. Age is not included in the cross-tabulation analysis, and, therefore is not included in this list.

${ }^{8}$ Also, as will be explained in chapter four, this question will be addressed using regression analysis, which includes the variable Age.
} 


\subsection{Context}

In recent years, Canada has increased its use of temporary foreign workers (TFWs) under the Temporary Foreign Workers program. The number of low-skilled temporary foreign work permit holders increased 88\% from 26777 in 2006 to 50671 in 2013 (IRCC, 2015). The number of workers working temporarily in Canada has increased in most areas of the labour market, including in both high- and low-skilled occupations, (Siemiatycki, 2010) though the labour conditions and rights associated with each group differ greatly.

While temporary foreign high-skilled workers seem to have more avenues and opportunities for immigration, integration and settlement, temporary low-skilled workers face many more barriers (Siemiatycki, 2010; Nakache and Kinoshita, 2010). High-skilled workers have several pathways to permanent residence, competitive salaries and options to bring their families to Canada. In contrast, low-skilled workers have low wages, cannot bring their families to Canada and most of them have no access to citizenship (Nakache and Kinoshita, 2010; Reed, 2008). This study aims to quantify the extent to which Canada's temporary labour migration policies related to a lack of citizenship contribute to NPRs' low wages. Stated positively, it considers whether citizenship provides a means of economic protection against low wages and precariousness.

The phenomenon of precarious labour in Canada has been well researched (Galabuzi \& Block, 2011; Goldring \& Landolt, 2013; Goldring \& Joly, 2014; Vosko, 2006). Temporary foreign worker programs have been structured in a way that entraps workers in a revolving door of perpetual temporariness, which in turn generates other precarious 
working conditions, including "job insecurity, schedule and income unpredictability, little control or autonomy, limited benefits and entitlements, and the absence of regulatory protections" (Goldring \& Joly, 2014, p.94). Other features of precarity include little or no access to unionization, the need to maintain several part-time jobs and an insufficient number of hours worked per week. Such precarious working conditions often generate stress in those unable to meet their financial needs, which can greatly impact their overall health and wellbeing (Dyson et.al, 2013).

Among low-skilled temporary foreign workers, this precariousness is directly related to their lack of citizenship, an unfavourable status that generates unique labour conditions (Aguiar, 2011; Basok, 2000; 2007; 2010; Bauder, 2008b; Hennebry, 2012; Goldring \& Joly, 2014; Preibisch, 2007; Sharma, 2002). Although low-skilled temporary resident workers experience great insecurity related to their employment in Canada, their families back home (especially their children) often benefit from the remittances sent by a family member working abroad, by, for example having improved access to education. In short, they have improved educational resources because their parents earn more money abroad than they could earn in their homeland. Despite this potential advantage, the social price of working abroad remains high: families are separated and communities lose their members (Lewchuk \& Leflèche, 2014), which is the real tragedy behind low-skilled TFWs working in Canada. ${ }^{9}$

Temporary foreign workers come to Canada through different programs and streams: live-in caregivers mainly come through the Live-in Caregiver (LIC) program; agricultural workers through different streams including the Seasonal Agricultural

\footnotetext{
${ }^{9}$ Some authors accordingly highlight the benefits for the workers in contrast with the dire situations they leave behind in their countries of origin (Binford, 2006, 2009; Satzewich, 2007; Zermeño, 2008).
} 
Workers Programs (SAWs or SAWPs), the Agricultural Stream and the Stream for Low Wage Positions; and low-skilled workers in occupations other than agriculture and caregiving mainly come through the last stream.

In Canada, integration (access to permanent residence) via economic pathways is permitted mainly to those possessing high skills. With the exception of LICs and a few low-skilled workers coming through Provincial Nominee Programs (PNP) ${ }^{10}$ in British Columbia, Alberta and Manitoba, low-skilled TFWs have no pathway to citizenship. Most low-skilled permanent residents come through non-economic pathways like family reunification or asylum.

The following study considers different low-skilled occupations beyond caregiving and agriculture. However, as will be shown, occupations in these two areas stand out. Most research related to low-skilled temporary foreign labour in Canada accordingly focus on those areas. After all, workers in these occupations comprise the largest number of temporary foreign workers per occupation (see chapter five) and the streams through which they arrive are the oldest TFW programs in Canada, arguably dating back to the late 1960s for agricultural workers and the early 1970s for live-in caregivers (see chapter three). Workers in other low-skilled occupations started to come to Canada much more recently after the opening of the Low-Skilled Pilot Program in 2001 (see chapter three).

In Canada, many industry sectors including Agriculture, Forestry, Fishing and Hunting and Healthcare and Social Assistance rely overwhelmingly on low-skilled TFWs (these are the top two industry sectors for NPRs). This industry sectors' reliance on low-

\footnotetext{
${ }^{10}$ Provincial Nominee Programs allow provinces and territories to attract and select a small number of immigrants. These programs are very restrictive since immigrant selection is a federal domain.
} 
skilled temporary foreign labour may be linked to the Canadian state's use of policy instruments including citizenship. In this dissertation, it is relevant to study the theoretical underpinnings of both state and citizenship. Theories of the state and citizenship provide a theoretical explanation for the current economically-driven approach to immigration policy, which produces a situation of labour precariousness linked to lack of citizenship (Faraday, 2016; Goldring, 2014; Hennebry, 2012). The use of temporary foreign labour has become a means for employers to achieve higher profits (Hennebry, 2012) - in some cases it is explicitly included in business models to increase overall benefits to employers (ESDC, 2014).

As outlined above, many of these benefits are harnessed at the expense of workers' lack of rights related to their lack of citizenship (Basok, 2002). Jessop (2015) argues that the problem of the struggle for rights lies in the fact that citizenship rights continue to be attached to a model of the state that is no longer representative of the current reality. The state has sacrificed its primary role as a social institution by facilitating the interests of transnational capital. Conversely, the increasing power of financial institutions has usurped the primacy of the state (Jessop, 2015).

Furthermore, the model for capital accumulation in terms of mass production and mass consumption (Atlantic Fordism) ${ }^{11}$ was originally conceived within the confluence of national institutions, including the economy, the state, citizenship and society, all of which were confined to and defined by a nation-state (Jessop, 2014). Economic variables including wages, employment and budgets were all calculated within the

\footnotetext{
11 Jessop (2015) defines Atlantic Fordism as "an accumulation regime based on a virtuous autocentric circle of mass production and mass consumption secured through a distinctive mode of regulation that was institutionally and practically materialized in the Keynesian welfare national state."
} 
confines of these national institutions. By confining the interaction between economic variables and national institutions within the nation-state, it was possible to guarantee welfare rights (which were attached to citizenship and, by extension, to the nation-state) (Jessop, 2014). With the rise of transnational capitalism, the model of mass production and mass consumption has transcended the boundaries of the nation-state. What were once permanent and stable (namely jobs, wages and rights) have been replaced by temporality and instability.

Rich countries have opted for permanent temporariness (to use Jenna Hennebry's term in Hennebry, 2012) in their labour markets to satisfy labour needs in both high- and low-skilled occupations. An inequitable distribution of wealth on a global scale is a significant driving factor in global migration. According to Oxfam International (2017), "Eight men now own the same amount of wealth as the poorest half of the world" (p.2), a discrepancy that provides considerable incentive for someone with little opportunities (poor labour conditions, little education, lack of economic resources and poverty) to move to a country that may offer better conditions, even if it is only on a temporary basis. Countries with developed economies have also identified two main factors that benefit their economies: highly educated immigrants (if they have a high level of proficiency in at least one of the country's official languages) and cheaper foreign labour.

\subsection{High Level Outcomes}

This dissertation makes significant contributions in three areas: empirical (quantitative), theoretical and policy. Briefly, empirically, using quantitative methods, this 
dissertation confirms that there is a penalty to lack of citizenship for low-skilled workers. Five main outcomes stand out: 1) Low-skilled tend to concentrate in Retail (CB and IMM), and occupations in caregiving and agriculture (NPRs); 2) in absolute terms, lowskilled NPRs earn low wages; 3) In relative terms, these NPRs earn less than CB and IMM working in the same occupations; 4) among NPRs, the Canadian labour market exhibits a hierarchy of wages and labour experiences on the lines of province of residence, rural/urban place of work and country of birth; 5) among low-skilled workers born in the same country, wages improve when either citizenship or the rights attached to permanent residence are acquired. The wages of low-skilled immigrants are higher than those of low-skilled NPRs (when both groups of workers are born in the same country).

Significant specific outcomes include: 1) The relative wages of NPRs (compared to the CB and IMM) in 31 occupations, out of 35 analyzed, are negative (NPRs earn less than $\mathrm{CB}$ and IMM); 2) the regression analysis shows that lack of citizenship has significantly negative effect on wages when controlling for variables including immigration status, sex and country of birth. In the agricultural sector, there are significantly negative wage differences when wages of NPRs are compared to those of Canadian-born and Immigrants. Among NPRs in other selected occupations (as will be further discussed in this dissertation), in some of those occupations wages are low, while in others relatively high. Although some workers exhibit high (in some cases very high) wages, there remains a concentration of low wages in some key occupations, predominantly in caregiving and agriculture.

Theoretically this dissertation plays out the tensions and conflicts between the 
two theories used, Critical Social Theory and Rational Choice Theory. The thesis makes the case for the relevance of quantitative outcomes analyzed through a critical social lens. From a theoretical perspective too, the dissertation also shows how the state as a biased broker (towards capital) facilitates the implementation of non-citizenship as a means to accessing cheap labour.

From a policy perspective, the dissertation identifies the policy origins and drivers of low wages among low-skilled non-citizens. The analysis reaffirms the policy process reflecting the emergence of stereotypes linked to constructed characteristics of workers including skills capacity, work ethic and sex. In general, the analysis will demonstrate how temporary labour policy spread over time from caregiving to agriculture and more recently to other selected occupations. Among low-skilled NPRs, occupations in caregiving and agriculture stand out as having concentration around low wages.

\subsection{Dissertation Structure}

This dissertation is organized in the following way: in the second chapter, I consider the main body of literature on low-skilled temporary foreign labour in Canada and on the evaluation of labour market outcomes for low-skilled workers. I then introduce the main theories used in this study (Rational Choice Theory and Critical Social Theory) as well as theories of labour migration, citizenship and the state that help unpack low-skilled temporary foreign labour in Canada. In the third chapter, I show the policy origins of low wages of low-skilled temporary foreign workers in relation to three main groups of occupations (caregiving occupations, agricultural occupations and other selected low-skilled occupations). I then detail how policy, informed by the stakeholders' actions, shaped the labour market outcomes and lived experiences of TFWs. This 
chapter also introduces the low-skilled temporary foreign worker programs in Canada. In the fourth chapter, I present the methods and considerations used to analyze the data. With the 2006 Census data, I use cross-tabulation and regression analysis to compare the wages of low-skilled workers according to immigration status, while accounting for other factors, including, sex, level of education, province of residence and country of birth. In the fifth chapter, I present a general profile of low-skilled workers in Canada. In the sixth chapter, I explore the concentration and distribution of both absolute and relative wages of NPRs (compared to those of the Canadian-born and immigrant) by industry and occupation. In the seventh chapter, I focus on the crosstabulation analysis of relative wages of low-skilled workers (NPRs compared to CB and IMM) by each of the intrinsic characteristics (of workers and of occupations) already mentioned. In the eighth chapter, I introduce the outcomes of the regression analysis. In the ninth chapter, I explore the outcomes of chapters five, six, seven and eight and consider them in relation to each of the variables analyzed in the literature on low-skilled labour by occupation in Canada. Finally, in the tenth chapter, I consider from a theoretical perspective the role of migration, the state and a lack of citizenship on labour market outcomes and experiences of low-skilled temporary foreign workers in Canada. 


\section{Chapter Two: Literature Review and Theoretical Approaches}

The experience of low-skilled temporary foreign ${ }^{12}$ workers in Canada is an important addition to the existing research on immigrants in Canada. This chapter provides an overview of the literature and theoretical approaches guiding this thesis in order to identify the important contributions made in this field as well as uncover critical gaps. It explores seven related themes. In the first section, I present the existing literature on labour related themes affecting low-skilled temporary foreign workers in Canada, which includes the main literature on the evaluation of wages of low-skilled immigrants, to identify the central issues and important gaps in this literature. In the second section, I introduce Rational Choice Theory (RCT) and Critical Social Theory (CST), which together provide the theoretical foundation of my analysis. In the third section, I focus on Labour Migration Theories in relation to RCT and SCT. I draw on three migration theories to explain wage discrepancies among low-skilled temporary foreign workers (TFWs) ${ }^{13}$ and low-skilled Canadian-born (CB) and low-skilled immigrant workers (IMM). These theories help illuminate the relations among and the decisions made by the different actors involved in the labour market experiences of low-skilled NPRs. In the fourth section, I present an overview of neoliberalism, which plays a significant role in providing a justification for the current flow of international migration by invoking discourses on trade and globalization. In the fifth section, I provide a general overview of the most relevant works on citizenship in relation to low-skilled labour. I detail how a lack of citizenship is used to validate the construction of temporary foreign

\footnotetext{
${ }^{12}$ For clarity's sake, the terms 'Temporary Foreign Workers' or 'TFWs' will be reserved for citing research in the literature about TFWs. The term "Non-Permanent Residents" or 'NPRs' will be used in relation to the NPR population and their outcomes in the labour market.

${ }^{13}$ As explained in chapter one, in this dissertation the 'NPR population' includes temporary foreign workers, refugee claimants and people with temporary resident visas on humanitarian grounds.
} 
low-skilled labour. In the sixth section, I present a revision of citizenship and the nation state, as a preamble to the following section. Finally, in the seventh section, I explore Bob Jessop's theoretical work on the state. His work provides the theoretical tools required to tease apart how the state constructs labour (in this case via a lack of citizenship). Together, the two foundational theories (RCT and CST), as well the related theories of migration, the state, and citizenship, will help unpack the complexity behind the current situation of low-skilled TFWs.

\subsection{Low-Skilled Temporary Foreign Labour in the Canadian Labour Market}

Low-skilled TFWs (low-skilled NPRs in this dissertation) refers to temporary foreign workers classified as "low-skilled" in the National Occupational Classification (NOC). The NOC system is "the nationally accepted taxonomy and organizational framework of occupations in the Canadian labour market. It is a four-tiered hierarchical arrangement of occupational groups with successive levels of disaggregation. It contains broad occupational categories, major, minor and unit groups" (Employment and Social Development Canada - ESDC, 2011) ${ }^{14}$. ESDC defines skill level "as the amount and type of education and training required to enter and perform the duties of an occupation" (ESDC/HRSDC, 2011). Skill levels are classified according to the following criteria:

"Skill level 0: Managerial Occupations; Skill level A: University degree (bachelor's, master's or doctorate); Skill level B: Two to three years of post-secondary education at a community college, an institute of technology or CÉGEP or two to five years of apprenticeship training or three to four years of secondary school and more

\footnotetext{
${ }^{14}$ For a detailed explanation see Appendix $3 \mathrm{C}$
} 
than two years of on-the-job training, occupation-specific training courses or specific work experience. Occupations with supervisory responsibilities are also assigned to skill level B. Occupations with significant health and safety responsibilities (e.g., firefighters, police officers and licensed practical nurses) are assigned to skill level B; Skill level C Completion of secondary school and some short-duration courses or training specific to the occupation or some secondary school education, with up to two years of on-the-job training, training courses or specific work experience; Skill level D - Short work demonstration or on-the-job training or No formal educational requirement" (ESDC/HRSDC, 2011). Low-skilled occupations in the NOC system correspond to the skill levels $C$ and $D$. This classification of occupations is based on the level of human capital that a worker possesses.

While human capital is an important driving factor in Canada's immigrant selection, during the last 15 years, federal policies have tended to favour the increase of labour supply via temporary foreign workers. TFW programs are increasingly used because they offer a quick and easy strategy for meeting labour shortages by accessing a vast and diverse labour force, without the economic and infrastructural challenges of immigration. At the same time, these programs are often heralded for providing an opportunity to improve the lives of very poor families, the communities in which they live and, by extension, the economies of their countries of origin (Lenard \& Straehle, 2011). However, some contend that this redistribution of wealth can only be obtained at the expense of justice (Lenard \& Straehle, 2011; 2012). Indeed, the structure of TFW programs that place workers in labour markets functions by segmenting the population of workers on racial grounds (Binford, 2008; Bonacich, 1972; Trumper \& Wong, 2010) 
and then accepting 'unfree' labour ${ }^{15}$ from these 'select' populations (Sharma, 2006). In Canada, unfree labour, comprised mostly of people with temporary visas working under constrained conditions, such as live-in Filipino caregivers and Mexican agricultural workers, remains concealed by ideologies (Sharma, 2006).

Low skilled guest worker programs (also known as low skilled temporary foreign workers programs) are the means used by the state to satisfy short-term labour market needs. Both high- and low-skilled labour demands are increasingly offset through guestworker programs (Siemiatycki, 2010) that commodify workers (Lenard \& Straehle, 2012). These types of programs have been formally established in different parts of the world. Surak (2013) describes in his article "Guest workers: A Taxonomy" the different types of guest worker programs across different countries and time periods. Surak points at the need to not just look into the different programs' structures but to the social structures in which those programs come into being, for they significantly explain the variations from program to program (Surak, 2013).

The use of temporary foreign low-skilled labour in Canada can be traced back to the time of the construction of the Canadian Pacific Railway (Siemiatycki, 2010). As is the case today with Mexican workers in the agricultural industry, in the late nineteenth century, thousands of Chinese workers came to work under conditions that residents would have never accepted. Back then, "Chinese workers were relatively easy to secure, were more servile than most workers, and were willing to work at wages 30 $50 \%$ lower than those paid to white labourers" (Kelley \& Trebilcock, 1999, p.94). As is the case today with temporary foreign workers, especially those in low-skilled occupations, Chinese workers at that time came from impoverished regions, like the

\footnotetext{
${ }^{15}$ Unfree labour refers to labour under significantly restrained conditions.
} 
Guangdong Province in China (Kelley \& Trebilcock, 1999, p.94). They also experienced restrictions in applying for citizenship. Explicating the racial stratification that perpetuates the flow of temporary foreign workers, at that time, race was the main criteria used to control immigration: Chinese workers faced special restrictions, including the Chinese Head-Tax (Kelley \& Trebilcock, 1999). Today immigration restrictions are less apparent and usually focus on education rather than race. Nevertheless, these types of policies set real barriers to entry, which in turn lead to alternative pathways of entry such as temporary worker programs (Preibisch \& Binford, 2007).

The literature on the labour related experiences of temporary low-skilled workers in Canada, from a qualitative perspective is extensive; in contrast quantitative studies are scarce. Two streams of research related to low-skilled TFWs are particularly relevant to this dissertation: 1) issues related to general labour conditions, and 2) wages among low-skilled temporary foreign workers compared to those with citizenship ${ }^{16}$. The first stream opens with issues that directly relate to two specific TFW programs (i.e. The Live-in Caregiver Program - LIC, and the Seasonal Agricultural Worker Program SAWP), which will be explained in more detail in chapter three. The special focus on these two programs follows the fact that they are the oldest and most researched lowskilled TFW programs in Canada; the themes that they raise reflect the central labourrelated issues affecting all low-skilled TFWs in the country.

2.1.1. General labour-related issue. Research on low-skilled labour has often

\footnotetext{
${ }^{16}$ These topics will be explored in more detail in the following chapter in the context of the policy origins of low wages.
} 
focused on the precariousness and exploitation experienced by many low-skilled workers coming to Canada through low-skilled temporary foreign worker programs. Focusing on the LIC program, Faraday (2012a) found that, as of 2012, wages of live-in caregivers were about $\$ 10.56$ per hour, for a maximum of 48 hours per week, with a maximum deduction of $\$ 85.25$ per week for room and board (Faraday, 2012a). Although LICs are officially hired to help with care-related activities, some researchers have documented work performed in other areas (Bakan \& Stasilus, 2012). Within the domain of caregiving, LICs, historically invited to care for children, engage increasingly in elderly care, raising questions about the conditions this program should fulfil to address the specific challenges of working with the elderly (Bourgeault et al., 2010). Regardless of the kind of caregiving responsibility, LIC employment permits are dependent on the employer (Faraday, 2012a); LICs often work long, unpaid hours (Grandea \& Kerr, 1998) and participation in the program has a significant impact on their family life (Cohen, 2000) mainly because of their separation from their husbands and children (Pratt, 2006). Coming to Canada without their family, few financial resources, often owing money, and with little social capital, LICs are typically highly dependent on their employers (Torres et al., 2012), creating opportunities for abuse and exploitation (Brickner \& Straehle, 2010), which have been revealed in the media. Despite these unfavourable conditions, LICs are likely reluctant to voice criticisms out of fear that their employer may impede or delay permanent residence (Faraday, 2012a). Workers have little or no choice of the place of work, the duration of their contract or the type of work they will do and changing employers is allowed only if approved by both sending and receiving employers (Hennebry \& Preibisch, 2012). 
With agricultural workers, the employer has the power to either call or not call the worker for the next season (Faraday, 2012a; Hennebry, 2012; Hughes; 2012). Wages among low-skilled TFW agricultural workers are low (Justice for Migrant Workers, 2006) and sometimes they are simply not paid (Fudge \& MacPhail, 2009). It has also been reported that there are no mechanisms to enforce some contractual rights, including employer-paid transportation (Nakache \& Kinoshita, 2010). Fear of deportation or not being hired the following year often leads workers to put up silently with the abuses at the workplace (Hennebry, 2012). ${ }^{17}$

Some SAWs have been coming to Canada for more than 25 years and are entitled to the same rights as Canadians in terms of access to the Canadian Pension Plan (CPP) and Employment Insurance (EI). However, even though the program started in the late 1960s, most workers were not aware of these benefits and only started collecting in 2003, when activists learned about workers' eligibility and fought for their cause (UFCW, 2014). While this was a significant gain, a study from the United Food and Commercial Workers (UFCW) union details how the Harper government in 2012 curtailed seasonal farm workers' access to El special benefits (parental, maternal and "compassionate care" benefits) (UFCW, 2014). Generally, low-skilled workers tend to be granted fewer rights than high-skilled workers. Ruhs (2008) presents the inverse relation between number of workers and number of rights (vis-a-vis skill levels). Workers with high levels of skills tend to have more rights and tend to be lower in numbers. In contrast, low skilled workers tend to have fewer rights and to be higher in numbers.

\footnotetext{
${ }^{17}$ Some evaluations of labour conditions have had a geographic emphasis: BC (Fairey et al., 2008; Otero \& Preibisch, 2010), Alberta (Nakache \& Kinoshita, 2010), Ontario (Bauder, 2008b; Bridi, 2010; Hennebry, 2009; McLaughlin, 2009), Ontario and Quebec (De Luna-Villalón, 2011).
} 


\subsubsection{Wages among low-skilled temporary foreign workers. A few studies}

consider the effect of immigration in general on the Canadian economy. Some stress the negative effect of immigration on the labour market in the U.S. and Mexico and the positive impact in Canada due to the high-skilled nature of Canadian economic immigration (Aydemir \& Borjas, 2006 as cited in Dungan, Fang \& Gurdenson, 2012, p.9). Other studies report positive impacts, highlighting 1) that there is no identified displacement of Canadian-born workers linked to immigration (Akbari \& Devoretz, 1992); 2) that, while unemployment in British Columbia grows in the short term because of immigration, it decreases over time (Gross 2004); 3) that there is no evidence (from 1991,1996 and 2001 census data) of a negative effect on wage growth for nationals in the Canadian labour market (Tu, 2010); and 4) that additional immigration has a positive effect on Canadian economic factors, including "GDP per capita, aggregate demand, government expenditures, taxes and net government balances" (Dungan, Fang \& Gunderson, 2012, p.23).

There is a dearth of literature focusing on low-skilled labour (as a whole) in Canada, which is why I turn to the American literature. If we consider patterns in America as comparable, some studies examine the macroeconomic impact of the inclusion of low-skilled immigrants in the US (Borjas, 1995; Card, 2005; 1996; Weiner, 1996) with a focus on, for example, the impact on wages, but the results are mixed and inconclusive. When looking at the impact of integrating less-educated, low-skilled immigrants, different pictures emerge. The increase of diversely-skilled (i.e. both lowand high-skilled) immigrants in an economy has two distinct effects, one short-term and the other long-term. In the short-term, because of productivity gains linked to a more 
diverse range of available skills, the wages of nationals (those with citizenship) are not directly affected and hence all workers are likely to be better off. In the long-term, however, when integration takes place, the skill formation of nationals is likely to be negatively affected and, as a result, the wages of citizens may decline (Behrens \& Sato, 2011). Conversely, as low-skilled immigrants accumulate skills, labour stability and wages increase among this population (Zhang, 2002).

Considerations about minimum wage in Canada are also relevant to low-skilled workers and hence to this dissertation. Raising minimum wage is a subject of a vast economic analysis. In Canada, minimum wage is shared responsibility between provincial/territorial governments and the federal government. The media has reported cases of people in Canada with different legal statuses earning less than the minimum wage: Canadian-born (Kurjata, 2015); immigrants (Movilla, 2010), and temporary foreign workers (Pearson, 2015). Statistics Canada reports that it is possible to find cases of employees legally being paid less than minimum wage, since young adults under 18 years of age may be exempt from minimum wage regulations (Statistics Canada, 2004; 2010). Disabled people have also been "lawfully" paid below minimum wage (Fuatai, 2016).

In $2005,{ }^{18}$ the minimum wage in Canada varied from $\$ 6.15 /$ hour in Newfoundland to $\$ 8.50 /$ hour in Nunavut (see appendix). Three arguments are generally made against raising the minimum wage: 1 ) since so few people earn minimum wage, the problem is trivial; 2) most minimum wage earners are teenagers living at home; and 3) increasing wages without increasing production is ultimately harmful to low-wage earners themselves (Stuart \& Hugh, 2007).

${ }^{18}$ Wages in the 2006 Census report all wages and salaries earned in 2005. 
These arguments are weak for the following reasons: 1) The most recent Statistics Canada study on minimum wage shows that in $2009,5.8 \%$ of all workers in Canada earned minimum wage (Langevin, 2010). Although the proportion appears to be small, the actual number (about 817000 ) is not. As chapters one and five in this dissertation indicate, the situation of precarious labour in Canada is increasing and represents a growing problem (PEPSO, 2015). 2) In 2010, teenagers (15-19 years of age) represented $38 \%$ of all minimum wage earners (Langevin, 2010). Is dismissing their situation a good policy response? To exclude a group just because of who they are rather than valuing what they do is discriminatory (Stuart \& Hugh, 2007). Many of these persons, most likely dependent on their jobs to finance their studies, may not live at home; and, if they do, it is evidence of the ways in which precarious working conditions pushes families to increase the number of earners per household (PEPSO, 2015). 3) The impact of minimum wage on employment has been explored significantly in the literature for a very long time.

Two broad types of studies are found in the literature, one of which is based on the principle in economics that "if the price of minimum wage labour goes up, less of that labour will be demanded" (Stuart \& Hugh, 2007, p.34). Although not all economists arrive at the same conclusion, most studies with this focus show that minimum wage mostly affects teenagers (Stuart \& Hugh, 2007, p.34). Even if these studies predict some effect on teenagers' employment, some counter arguments have also been raised, including publication bias, failure to capture dynamic positive effects and disproportionate focus on misemployment effects. The other type of studies argues that "minimum wage impacts are virtually invisible over time because they are swamped by 
other more significant economic changes" (Stuart \& Hugh, 2007, p.35).

Having considered specific factors that impact the lived experiences and working conditions of temporary foreign workers, I will now turn to two theoretical approaches to understanding the flow of migrant workers.

\subsection{Rational Choice Theory (RCT) and Critical Social Theory (CST)}

This section presents the general tenets of these two theories and the reasons why they were chosen for this research.

2.2.1. Rational Choice Theory (RCT). Some link Rational Choice Theory to Max Weber's Theory of Action (Delanty \& Strydom, 2003), which, as in Adam Smith's “The Wealth of Nations," assumes rational choice as one of the determinants of social action. The most relevant writings on this theory appeared in the 1960s and are attributed to Mancur Olson, Peter Blau and TC Schelling (Delanty \& Strydom, 2003). Rational Choice Theory provides the theoretical framework supporting the quantitative methods used in this dissertation, namely cross tabulation and regression analysis, because its fundamental assumption that rational actions are those that maximize benefits and minimize costs lends itself well to mathematical quantification. In short, a rational choice framework provides tools to quantify the effects of certain policies as well as to understand the motivations that prompted them.

Rational Choice Theory assumes that all actions are fundamentally 'rational' and that people make a priori cost/benefit evaluations of their actions before making a decision (Scott, 2000), an assumption that underlies most economic theories (Simon, 1955). In this context, to identify a person as rational assumes that he or she has 
sufficient knowledge of the environment and conditions, a clearly structured system of preferences and a decision-making system that allows him or her to make a decision that maximizes benefits (Simon, 1955) and minimizes costs. The standard constraints found in Rational Choice models include "(1) the set of alternatives open to choice, (2) the relationships that determine the pay-offs ('satisfactions,' 'goal attainment') as a function of the alternative that is chosen, and (3) the preference-orderings among payoff" (Simon, 1955, p.100). Economists see rationality not as choosing different means to an end but choosing "among different goals according to a consistent scale of preferences" (Harsanyi, 1969, p.517). From a wage analysis perspective, "in this theory it is postulated that humankind is inherently seeking the highest profit possible for his/her labour and will move to no matter where as long as it pays off." (Van Houtum \& Van der Velde, 2002). If both employers and workers want to maximize benefits and minimize costs, "on a simple level, employees prefer higher wages and shareholders prefer lower wages (at the same level of productivity)" (Roe, 2003, p.34). From the perspective of Mexican workers working through the SAWP, for example, three main motivations have been identified as driving factors to participate in Canada's SAWP: increase and stable income, better education for the workers' children, possibilities of investment in the house/farm in Mexico and general improvement in the quality of living (Binford, 2002; Stallman \& Carvajal, 2016).

As this example illustrates, comparison is at the heart of making a rational choice. In short, "rational choice is about comparing values of different options" (Jonassen, 2011, p.54). Accordingly, in my cross-tabulation analysis, the aggregated wages are compared by subcategory to explore different levels of preferences among 
those setting wages. For example, the wages of male Canadian-born low-skilled workers are compared with those of male low-skilled Non-Permanent Residents (NPRs). Similarly, the wages of CB with post-secondary education are compared with those of NPRs with post-secondary education. In the regression analysis, preferences are also explored by establishing the degree of relation of dependence (see chapter eight) between wages (dependent variable) and independent variables, for example, the effect of being female on wages. Regression analysis is also used to reveal the preferences of those who set wages.

There are three main limitations (cognitive biases) associated with the judgmental heuristic nature of rational choice based modelling (which is similar to the multi-variate regression analysis used in this dissertation): "(i) representativeness, which is usually employed when people are asked to judge the probability that an object or event A belongs to class or process B; (ii) availability of instances or scenarios, which is often employed when people are asked to assess the frequency of a class or the plausibility of a particular development; and (iii) adjustment from an anchor, which is usually employed in numerical prediction when a relevant value is available" (Tversky \& Kahneman, 1974, p.1131). While some critics point to the unrealistic "behavioral assumptions of rational choice models" (Friedman \& Hechter, 1988, p.212) and argue that they leave out complexities present in the real world (Friedman \& Hechter, 1988), I maintain that Rational Choice Theory nevertheless provides a good foundation for using modelling-based analysis as well as multivariate regression analysis. It links micro and macro levels of analysis (Friedman \& Hechter, 1988), providing a good "agnosticism with respect to types of data and techniques of data reduction," which improves "...the 
quality of empirical analysis" (Friedman \& Hechter, 1988, p.212). It also provides the "theoretical and conceptual underpinning for many of the general policy prescriptions" (Thompson, 2008, p.370). Accordingly, it is within the framework of Rational Choice Theory that, in my study, I will use the outcomes of cross tabulation analysis and regression analysis as elements to help discern the preferences of those who define the wages of low-skilled workers. I will then explore the effects of policy changes as they are reflected in differences in wages based on immigration status among workers working in the same occupations.

Without undermining its analytic value, one significant limitation of Rational Choice Theory is that it overlooks power dynamics in which different individuals have different levels of "free" choice. As a result, this theory is blind to the ethical and structural issues behind decision-making processes.

In short: Rational Choice Theory has a detached approach to social phenomena; it is indifferent to human values (Harsanyi, 1969). In the case of this dissertation, the observation of wages is mathematically analyzed without any embedded agenda. The mathematical methods (cross tabulation and regression analysis) have in themselves no emancipatory intentions; they simply serve an analytic function. Given that wages significantly define the type of lives people live, it is also necessary to analyze the results of the mathematical analysis with a human lens, that is, with a social lens. Critical Social Theory provides the requisite emancipatory tools (Harsanyi, 1969) that allow a critical analysis of mathematical outcomes.

2.2.2. Critical Social Theory (CST). In the following study, the analytical, 
detached work stemming from RCT, in which the observer/analyst is removed from the social phenomenon, is complemented with CST, which explicitly engages social phenomenon. Critical Social theorists "are critical of what they see as pervasive inequalities and injustices in everyday social relationships and arrangements" (Freeman, França and Vasconcelos, 2010, p.7). Stated otherwise, their approach to social analysis addresses moral and ethical aspects of decision-making (Johnson, 2005). Critical Social Theory provides the theoretical tools to not only unveil structures of injustice that may affect low-skilled NPRs, but also to propose ways of transforming them. The following is a brief explanation of the origin and tenets of this theoretical tradition.

Critical Social Theory is the outcome of a series of reflections published in the 1920s by members of the Frankfurt School, originally founded by the Argentine political scientist Felix Weil and his interest in the intersection of Socialism and Marxism (Freeman, França \& Vasconcelos, 2010). Later works were developed by Horkheimer, Adorno and Marcuse who linked Marx's work to Hegel's on the question of 'determinate negation,' that is, of moving from one stage of consciousness to another (Torres, 2012). Determinate negation suggests that in order to learn something new I must negate what I previously held for certain. According to Marx (who was heavily influenced by Hegel's perception of humanity), humanity "creates itself through labour, loses itself in estranged labour and overcomes alienation through re-appropriation of the labour process" (Antonio, 1981, p.333). The possibility for emancipation in Marx relies on humans' struggle to satisfy basic needs (Antonio, 1981; Arendt, 1998; Torres, 2012). Seen historically, social structures created to fulfill basic human needs displace the struggle 
for survival, and inadvertently give rise to complex structures of production that end up exploiting others. Marx argues that the quest for emancipation then continues in our reaction to such exploitation (Antonio, 1981).

In its emphasis on mechanisms of exploitation, Critical Social Theory offers strategies for recognizing the subtler forms of oppression enabled by advances in technology. According to Herf (2012), in their book Dialectic and Enlightenment, Horkheimer and Adorno (1946) bring to light how modern science and technological development become means for dominating humanity and nature, referencing the holocaust and Nazism as paradigmatic examples of this phenomenon (Herf, 2012). From this critical perspective, modern science provides a new structure of domination that masks new ways of exploitation "characterized by 'comfortable, smooth, reasonable, democratic unfreedom', rather than the crude, direct exploitation of early industrial capitalism" (Antonio, 1981, p.335). Critical theorists also offered a way to address some of the weaknesses of Marxism (Marxist reductionism), by replacing "the critique of political economy with a critique of instrumental reason" (Madiraju, 1996, p.8). Yet concepts including "contradiction, dialectics, exploitation, domination, and legitimation," (Torres, 2012, p.118) all understood to serve the accumulation of capital, remain central to CST.

Further highlighting the overlap between Hegel and Marx, according to Torres (2012), Marcuse establishes an important foundation of Critical Social Theory by interpreting Marx's negation of the worker and the worker's labour in light of Hegel's understanding of humans' appropriation of the intelligible world (objects and other subjects of knowledge). This is of particular relevance to this dissertation, which directly 
relates to Marx's (and by extension, Marcuse's) concerns:

Marcuse argues that: 'The traditional epistemological antagonism between subject (consciousness) and object, Hegel makes into a reflection of a definite historical antagonism. The object first appears as an object of desire, something to be worked up and appropriated in order to satisfy a human want. In the course of the appropriation, the object becomes manifest as the "otherness" of man' (Marcuse 1941, 259). This Hegelian premise is taken up by Marx who would argue that: '. . the realization of labor appears as negation to such an extent that the worker is negated to the point of starvation. The objectification appears as a loss of the objects to such an extent that the worker is deprived of the most necessary objects of life and labor. Moreover, labor itself becomes an object of which he can make himself master only by the greatest effort and with incalculable interruption. Appropriation of the object appears as alienation to such an extent that the more objects the worker produces the less he possesses and the more he comes under the sway of his product, of capital' (cited by Marcuse 1941, 277) (Torres, 2012, p.117).

This quotation brings to the fore one of the problems of capitalism, which is exemplified by low-skilled labour: the tendency for the commodification of human transformative capacities to be exploited to the point of sacrificing workers' personal wellbeing. For example, an agricultural worker whose labour would be more than sufficient to feed their family, cannot feed his family even though he works beyond the point of exhaustion. In the world of mass production, low-skilled workers have no other choice but to sell their transformative capacity and, in many cases, to sell it under exploitative circumstances.

In this way, CST provides critical tools for understanding processes of oppression. With this in mind, it is important to note that Critical Social Theory is a theory that not only requires acknowledging a prior "original state" that gave rise to exploitation, but that also seeks to actively "transform it," by creating a new state of consciousness (Torres, 2012).

In line with this tradition, this dissertation will provide evidence to bring about new knowledge based on critiquing labour conditions of low-skilled temporary foreign 
workers. In light of Adorno's, Horkheimer's and Marcuse's work, Habermas finds in Critical Social Theory the place of knowledge creation linked to social action (Scott, 1978).

As will be shown in the following section, along with RCT, CST is regularly embedded in different theories of labour migration. While the literature on international labour migration theories is quite prolific, the following section is based primarily on two key pieces: a 1993 article written by Massey et al., entitled Theories of International Migration: A Review and Appraisal, and a 2013 book by Russell King called Theories and Typologies of Migration: An Overview and a Primer. These pieces are chosen because they are frequently cited in articles about migration theories; most of the theories explored appeal to either rational choice or social critical theory; and they play an important role in the evolution of migration theories. Based on these articles, this dissertation uses three specific migration theories, one based on RCT and two based on CST.

\subsection{Labour Migration Theories in Relation to RCT and CST}

The RCT-based theory informing this dissertation is Neoclassical Economics and Push-Pull Theory. The additional two theories (based on CST) both belong to the group of theories called Historical-Structural (Political-Economy Based) Theories of Migration, which include Dual Market Theory and Segmented Labour Market Theory. Together, these theories help us understand the experiences of low-skilled NPRs moving to Canada. 


\subsubsection{Neoclassical economics and Push-Pull Theory. Based on neoclassical}

principles, push-pull theories focus on microeconomic factors related to one's motivations to temporarily depart one's homeland and then return (Budnik, 2011). This neoclassical approach, which sees migrants as rational individuals who maximize their utility and move according to push and pull economic factors, is at the heart of mainstream econometric analysis of labour migration. It was "developed originally to explain labor migration in the process of economic development" (Massey et al., 1993) and views migration as the consequence of an imbalance of labour supply and demand within different centres of production. The key assumptions of this approach are that: 1) migration depends on differentials in wages and unemployment between countries of origin and destination; 2) an individual's characteristics (social capital, human capital, socio-economic conditions, etc.) influence the likelihood to move; 3) migration flows are the aggregate of multiple individuals' cost-benefit evaluations; and 4) governments control labour inflows through migration policies (Massey et al., 1993).

In contrast with this microeconomic neoclassical approach, which focuses on the individual choices of migrants, a macroeconomics neoclassical approach examines the distribution of labour at the macro level, in terms such as the abundance or scarcity of labour in different countries (Massey et al., 1993). The key assumptions of this approach include: 1) migration is due to wage differentials between countries/regions; 2) if controlled, they have effects on levels of migration; and 3) high-skilled labour responds to returns (compensation) to human capital (Massey et al., 1993).

From this neoclassical perspective, labour migration is a way of optimizing the redistribution of production factors in a way that benefits both sending and receiving 
countries (Haas, 2010). Thus, this theory highlights geographic differences in the supply and demand of labour (Massey et al., 1993). For instance, from a macro perspective, TFWs from Mexico and the Caribbean move from a labour-abundant location to one that is scarce in labour. To be mutually beneficial for both countries, this framework requires the possibility of moving to and remaining in the country of destination. For example, when workers leave their country of origin for higher wages abroad, a neoclassical approach highlights how this decision benefits the receiving country in terms of cheap labour and the sending country in terms of access to foreign capital. ${ }^{19}$ Under perfect conditions, a neoclassicist would expect this dynamic to revert when labour in the country of origin is scarce and wages or labour conditions improve.

Indeed, a neoclassical approach to globalization expects a mere "global economic convergence" (McGrew, 2011, p.270). However, this principle of convergence has been challenged, as has the expectation that migration contributes to economic stability. Migration has been shown to both increase and decrease international economic differences (Termote, 1993). This neoclassical approach has also been challenged from a Marxist perspective, insofar as it does not consider the structural or class aspects of labour migration. In fact, Marx would call the neoclassical approach a superstructure that rationalizes and thus legitimates migrant labour exploitation. It is accordingly helpful to complement this theory with the following perspectives, which acknowledge structural and class factors that influence the flow of migration.

2.3.2. Historical structural theories (neo-Marxist based). Before engaging this

\footnotetext{
${ }^{19}$ Mexican agricultural workers in Canada, for example, earn in eight months what they would earn in five years in Mexico (Basok, 2000).
} 
group of neo-Marxist theories, it is worth examining the differences between traditional Marxism and neo-Marxism, the latter of which has its origins in the Frankfurt School and Critical Social Theory. In contrast with traditional Marxism, which identifies the proletariat as the source for change, Neo-Marxists are concerned with the dormant state of the working class and "with the functioning of science and technology as instruments of domination" (Antonio, 1981, p.337). While classical Marxism approaches labour relations in a capitalist society in terms of a market economy and the means of production owned by private hands (Postone, 2005), neo-Marxism considers economics to be in a constant process of evolution. To neo-Marxists, the economy is part of a larger cultural process (Gruchy, 1984). Highlighting this difference, Axel Honneth, a successor of the Frankfurt School, focuses on the struggle for recognition and advocates for a "broader normative theory of experiences of injustices than the 'more or less utilitarian anthropology' of Marxism" (Therborn, 2006, p.197).

Framed within a neo-Marxist approach to the labour market, historical structural theories consider migration to be the consequence of exploitative structures that have developed throughout history to allocate some people on top and some people at the bottom of a hierarchical labour system. Historical Structural Theory suggests that the current situation of global imbalances in labour and wages is a consequence of our colonial past.

For example, Zolberg (1991a) traces the origins of the use of low skilled foreign labour in slavery. This was done by the different colonial hegemons in history (Spain, France, Portugal and England). These countries at the time required low skilled labour to exploit plantations in their colonies, which gave them access to significant richness 
across time (and space). The author identifies common elements that permitted/eased exploitation. Factors include coercion and use of ethnically different labour. After slavery became controversial, these countries continued to use cheap labour but now in indentured ways. For example, using coercion the British Empire moved peoples mainly from India and China across its colonies to continue to sustain mainly plantation economies and development of projects that domestic labour would not do (e.g. railway construction). Zolberg, explores the interaction of competing forces in economic-political systems bounded by: institutions, like the state and citizenship; concepts, like sovereignty and identity; and, forms of labour like slavery and indentured labour.

Zolberg (1991b) also presents the role the nation state plays domestically and internationally in setting conditions either as a country of origin or as a country of destination to facilitate/restrict the movement of low skilled labour. Ethnically different labour was not originally—and still isn't—meant to be given the opportunity to integrate in the host society. All these are constructed as key elements to have low skilled labour captive and provide cheap labour to developed countries.

These theories focus on socio-economic imbalances that, on a global scale, transform workers into vulnerable individuals who are at the mercy of capitalism (Gabriel \& Pellerin, 2012). Emphasizing the structural mechanisms of oppression that influence migration, historical structural theories tend to overlook migrants' potential for resilience, self-determination, and decision-making, dividing the world, and its relations, into polarized terms with clearly demarcated categories (King, 2013). They also fail to account for the agency that countries, both at the periphery and at the core, may have (via elected officials, bureaucrats and institutions of the state) in either pulling or 
pushing migrants (King, 2013). In short, they overlook the aspects brought to the fore by neoclassical push-pull theories of migration. Of the four theories grouped under historical structural theories - Dual Market Theory, Segmented Labour Market Theory, Dependency Theory and the World Systems Theory (King, 2013) - this dissertation will draw on the first two. These theories are especially relevant for understanding lowskilled temporary foreign migration because they provide a theoretical basis to unveil structures of exploitation affecting low-skilled NPRs.

The Dual Labour Market Theory primarily refers to different kinds of jobs, which can be framed in two different sectors of most labour markets, each holding a different set of labour conditions: one is secure, well paid, with good conditions, and is mostly reserved for citizens; the other is unprotected, has poor labour conditions and low wages, with legal holes that allow exploitation of its workers, most of which are migrants (Doeringer \& Piore, 1971). This theory is considered blind to the economy of decisionmaking at the level of individual agents (for example, the decision to go to school and improve skills, which may result in a change of sectors) and is especially suitable for examining structures of imbalance at an international level that may inform experiences of low-skilled NPRs in Canada.

The Segmented Labour Market Theory, proposed by Edna Bonacich in 1972, has close ties to the Dual Labour Market Theory. Both, for example, highlight the demand-dependent characteristic of labour markets ${ }^{20}$ (King, 2013). Rather than emphasize the different kinds of jobs on the market, however, the Segmented Labour Market Theory focuses on intrinsic characteristics of the workers themselves, such as ethnic origin, that are used to differentiate them. According to Bonacich (1972), the

\footnotetext{
${ }^{20}$ By this King means that labour markets depend more on the demand of labour than on its supply.
} 
precursor to ethnic antagonism is a labour market split along ethnic lines, that is, a labour market that contains at least two groups of workers being paid or offered different prices for the same work. From this perspective, immigrants' needs, determined by their individual conditions, are systematically exploited to establish a lower price for their labour on the market. At an international level, this segmentation occurs along lines of citizenship and culture (Bauder, 2006), a consideration that is particularly relevant for this dissertation, which compares wages of workers with and without citizenship.

\subsection{Globalization and Neoliberalism}

Other key factors that affect the lives of migrants are globalization and neoliberalism, two phenomena that have emerged alongside transnationalism to redefine the ways in which immigration policies are introduced. Globalization refers to the global integration of ideas, policies, cultures, knowledge as well as the establishment of a global economic market (Al-Rodhan, 2006) and neoliberalism refers to the neoclassical principle of liberating the economy from any kind of control, especially government-based. Neoliberal followers advocate for the privatization of public goods, the de-regularization of markets, and a general strengthening of the private sector, agendas that significantly define their labour experiences. Following, I present a broad overview of neoliberalism in relation to migration, labour and citizenship insofar as these topics relate to my inquiry.

Neoliberalism has been central in reshaping economic rules and transforming labour conditions on a global scale. From a neo-Marxist perspective, increases in temporary foreign labour that emerge alongside neoliberalism are related to the state 
using its power to more aggressively support capital through policy and regulation (or, when it is advantageous, privatization and deregulation). From this perspective, expansion of low-skilled TFW programs cannot be explained without considering the increase of state intervention that is needed to open access to foreign, vulnerable lowskilled labour.

As a series of policies and initiatives beginning in the 1970s, mainly in the global North, neoliberalism functioned to boost the asymmetrical accumulation of capital (Glick-Schiller, 2011). After the fall of the Soviet Union, the neoliberal agenda was implemented by American and British leadership throughout the 1980s and 1990s. Jessop (2002) identifies three forms of neoliberalism stemming from this agenda, all related to the nature of accumulation in capitalism: As modulation of policies, as paradigm shift and as a strategy (Jessop, 2002, p.458). As an economic project, Jessop (2002) links neoliberalism with

the liberalization and deregulation of economic transactions, not only within national borders but also-and more importantly—across these borders; the privatization of state-owned enterprises and state-provided services; the use of market proxies in the residual public sector; and the treatment of public welfare spending as a cost of international production, rather than as a source of domestic demand (p.454).

As a political project, neoliberalism closely associates the state with intervention for the sake of capital accumulation:

[neoliberalism] seeks to roll back "normal" (or routine) forms of state intervention associated with the mixed economy and the Keynesian welfare national state (or analogous forms of intervention in the developmental state or socialist plan state) as well as the "exceptional" (or crisis-induced) forms of intervention aimed at managing, displacing, or deferring crises in and/or of accumulation regimes and their modes of regulation in Atlantic Fordism, East Asia, and elsewhere. It also involves enhanced state intervention to roll forward new forms of governance (including state intervention) that are purportedly more suited to a market-driven 
(and, more recently, also allegedly knowledge-driven) globalizing economy. This typically involves the selective transfer of state capacities upwards, downwards, and sideways, as intervention is rescaled in the hope of securing conditions for a smoothly operating world market and to promote supply-side competitiveness on various scales above and below the national level (Jessop, 2002 p.454).

The market- and knowledge-driven economic aspects identified by Jessop directly relate to the state's use of foreign labour although it's power to grant rights is in a way limited. Global neoliberalism is taking away the power states have to grant rights even to their own nationals, leaving citizenship mainly as a means for a romantic sense of national identity (Somers, 2008a; 2008b). Right wing groups and parties across Europe (Askanius \& Mylonas, 2015; Ocak, 2016) and the United States (Gokanksel \& Smith, 2016) harness this national identity (which, in many cases, is interwoven with racism ${ }^{21}$ ) and mix it with the genuine economic dissatisfaction derived from neoliberal economic policies. Then they use the outcome of this mix against non-citizens living in their countries (refugees and migrants), blaming them for their economic misfortunes in recent years (Askanius \& Mylonas, 2015; Gokanksel \& Smith, 2016; Ocak, 2016). According to Monbiot, this race-based antagonism functions to divert attention away from the real underlying issues inciting the anger of nationalists, such as the neoliberal economic policies set in place in the Reagan and Thatcher era in the 1980s (Monbiot, 2016). In fact, neoliberal economic policies are the root causes of the current high levels of unemployment in the US and the UK, especially among low-skilled white workers and their loss of privilege in society (Inglehart \& Norris, 2016). They also played a significant role in the most recent world financial, political and economic crises (ex. 2008 Financial

${ }^{21}$ Though racism undoubtedly has dynamics and roots of its own, in recent years latent and dormant racism have regularly been used to deflect the outcomes of neoliberal policies by rejecting those outside the circle of belonging. 
meltdown and Brexit) (Inglehart \& Norris, 2016). Part of this neoliberal agenda includes the use of a lack of citizenship to access and create a need for foreign labour in a perennial status of temporariness.

The neoclassical principles of Rational Choice Theory maintain that migrants' decisions are based on their desire to both satisfy basic needs and ascend the social ladder, whether within the context of their country of origin or the broader global context (Nonimi, 2012). From the structural-historical perspective provided by Critical Social Theory, such "decisions" are made in the face of class-specific dilemmas that migrants face and are circumscribed by the various regimes that regulate their labour and their lives (Nonimi, 2012). Though epistemologically different, both perspectives help us understand the effects of neoliberalism on policies that impact the experiences of lowskilled temporary foreign workers. Both are central to understanding the decisionmaking processes that are reached at the level of policy (Johnson, 2005). Both help show the interplay between neoliberalism and policies that favour the increase of foreign low-skilled labour in Canada and, more importantly, help illuminate why such labour is likely to experience lower wages than low-skilled CB and IMM.

While approaching a state of global governance, humanity still can have a globalization that works for all. ${ }^{22}$ Nation-states can continue to trade and exchange, each dealing with the inequality brought about by neoliberal agendas. However, in a highly competitive world, skills and prices are the battleground, the former predominantly linked to high skilled, the latter to low-skilled. While both high- and lowskilled foreign labour are market driven, high-skilled labour is associated with a

\footnotetext{
${ }^{22}$ In its purest form, the policy that would best capture this is a complete opening of all borders. While we are not yet equipped for such openness, I maintain that humanity must nevertheless strive toward this goal.
} 
knowledge-market-driven labour and low-skilled labour to a mere market-driven labour. In the case of low-skilled labour, the state can either deregulate or regulate the market to remove barriers to foreign labour, limiting it to temporary contracts (i.e. denying access to a permanent status). From a neo-Marxist perspective, the flexibility demanded of temporary labourers can be interpreted as the outcome of economies shaped to foster the accumulation of capital at the expense of access to citizenship and rights. Ideologies that appeal to the promotion of individual choice at the expense of collective choice have been central to the neoliberal project (Badie, 1993), as has the transformation of labour migration from permanent to temporary, flexible and without mobility in the labour market. Exploitation is part of the mode of production that requires labour immobility, denial of workplace protections and the right to unionize, all to the benefit of capital accumulation (United Food and Commercial Workers Union, 2015).

In Canada, the Harper government's outlook was articulated through a specific alignment of neoliberal agendas, strategies and structures. This means of power took place through specific instruments related to the state, including specific political regimes and policy instruments (Jessop, 2012), like TFW programs. In this respect, the neoliberal agenda of the Harper government was considered extreme: "His efforts to bring in free-market environmentalism and a new land-ownership regime for First Nations are radical, not conservative. The agenda is to create and enforce markets, often where they didn't exist before. Such major transformation of Canadian society must be undertaken incrementally so they don't look like revolution" (Gutstein, 2014, p.245). Part of that transformation included the expansion of low-skilled temporary foreign worker programs. 
The Program for Occupations Requiring Lower Levels of Formal Training was formed in 2001 in response to demands of the oil and gas industry in Alberta and the construction sector in Toronto (Faraday, 2012a). Initially known as the Low-Skilled Pilot Project, this program permits employers to access the vast global pool of low-skilled workers, primarily those working in the construction, manufacturing, service and agriculture industries (Hughes, 2012).

As with Live-In Caregivers, workers who participate in the Program for Occupations Requiring Lower Levels of Formal Training leave families behind, which has a direct impact on the entire social fabric of the sending countries (Palacio, 2010). Nevertheless, many countries promote the opportunity to work abroad. In response to global neoliberal policies from the 1970s and 1980s, for example, countries like the Philippines established programs that encouraged their citizens to emigrate (Law and Nadeau, 1999). Much of the migrant labour force is increasingly transformed into a flexible work force that can respond to labour constraints and meet employer's interests in a timely way.

\subsection{Citizenship and Low-skilled Labour}

Since the presence of low-skilled NPRs in Canada takes place within legal frameworks validated by citizenship, it is helpful to review theoretical analyses of citizenship, which highlight how a lack of citizenship enables exploitation and injustice. This dissertation examines, from a theoretical perspective, how a lack of citizenship has provided a means to bring in low-skilled foreign labourers and how their status as noncitizens simultaneously renders them highly vulnerable and exploitable. This section initially presents the literature on the relation between citizenship and low-skilled 
temporary foreign labour in Canada, and then moves to the broader understanding of citizenship in relation to the nation-state.

An overview of the literature highlights the ways in which a lack of citizenship impacts temporary foreign workers in Canada. ${ }^{23}$ Gabriel and Macdonald (2011) focus on SAWs' lack of citizenship rights and reduced labour protection. Reed (2008) references the case of Canadian temporary foreign worker programs to expose how citizenship is used to control both migration and immigration. Her research examines how controlled international labour migration functions to create a permanent source of temporary foreign labour, such as the SAWP and LIC programs. Nakache and Kinoshita (2010) reflect upon both Canadian and Albertan structures for protecting TFWs. In a similar vein, Faraday (2012a) presents and critiques the legal terms and conditions that surround low-skilled temporary foreign worker programs in Canada. More specifically, she engages in a "critical analysis of the federal and provincial laws that regulate and constrain the rights of low-wage migrant workers, proposes a rights-based framework to assess their treatment, identifies the ways in which the law constructs migrant workers' insecurity through each stage of the labour migration cycle, and examines options for systemic change to increase workers' security" (Faraday, 2012a, p.3).

In her latest work, Faraday (2016) reviews the conditions of low-skilled workers after changes to the TFW program were set in place in $2014^{24}$ (and that will be

\footnotetext{
${ }^{23}$ While some works explore Provincial and Territorial Nominee Programs (PTNPs) as a possible instrument for low-skilled workers to gain citizenship (Canadian Federation of Independent Businesses, 2014; Faraday, 2016; Nakache \& D'aoust, 2102; Palacio, 2010) others evaluate the relations between TFW programs and the PTNPs (Carter, 2012).

${ }^{24}$ In June 2014, Immigration, Refugees and Citizenship Canada - IRCC (formerly known as Citizenship and Immigration Canada - CIC) changed the Temporary Foreign Worker Program. Under the new program temporary foreign workers (TFWs) correspond only to those coming under the Temporary Foreign Worker Program (i.e. requiring Labour Market Impact Assessment - LMIA). Those not requiring LMIAs are now called International Mobility Program workers - IMP. The LMIA is a document that
} 
discussed in more detail in chapter three). This report is a continuation to her 2012 report "Made in Canada: How the Law Constructs Migrant Workers' Insecurity," which focuses on the common experiences of exploitation that cut across all low-skilled temporary labour workers, which make it evident that "exploitation is not isolated and anecdotal. It is endemic" (Faraday, 2012b, p.5). Her 2016 report shows that instead of addressing previously identified instances of exploitation, the changes introduced in 2014 to the TFW policy have further intensified the exploitation of low-wage temporary foreign workers. The report introduces three narratives present throughout TFW policy: (1) some workers' contributions merit a pathway to citizenship, while others do not; (2) some workers can bring their families, while others cannot; and (3) some forms of labour are linked to a "commitment to developing a sustainable labour force with secure status; other forms of work are treated as 'zones of exceptionality.' These zones foster an enduring and expanding reliance on low-wage labour with temporary status and conditions that 'Canadians' are 'unwilling to accept"' (Faraday, 2016, p.7).

The literature also reveals how a lack of citizenship disqualifies low-skilled TFWs from language acquisition programs, which would significantly help them become aware of their rights (Preibisch \& Binford, 2007) and, by extension, help make their labour conditions more humane. From this perspective, citizenship can be viewed as a mechanism of "differential inclusion," (Foster \& Barnetson, 2015, p.110) that is, those who possess it have the "privilege" to claim greater rights than those who do not (Castles \& Miller, 2009; Lister 1997; Stasiulis \& Bakan, 2005 as cited in Foster \&

assesses whether a temporary foreign worker is indeed needed and whether it affects the Canadian labour market. Additionally, in January 2015, CIC introduced a new way of counting temporary residents (TFWs included). This new methodology counts stock not on December $1^{\text {st }}$ but on December $31^{\text {st }}$. With this new methodology, some low-skilled workers may not be counted, since they will have already left by the end of the month. 
Barnetson, 2015, p.110).

Finally, the literature demonstrates how difficult it is to reform the systematic oppression that surrounds the denial of citizenship. It details the challenges faced by advocacy groups fighting for citizenship rights or other legal privileges related to accessing human rights. As Basok reports, advocacy groups face the challenge of "counter-hegemonic human rights values, the ones that in one way or another challenge the status quo, either by undermining the political economic foundations of liberal democracies and/or the principles of national sovereignty" (Basok, 2009, p.184). Triadafilopoulos' (2011) analysis of the use of illiberal means to achieve liberal ends in immigration policy in Europe could be compared with Canadian policy's characterization of low-skilled workers. While Europe's approach is deemed problematic for its reductionist characteristics, Canada's is also problematic for its way of using the socially constructed meanings of skills and race as means to maintain the low-skilled in a revolving door of temporariness. Canada sees low-skilled workers as the 'undesirable' others for citizenship because of their lack of human capital-based skills. Piché et al. (2006) identify the main obstacles preventing Canada from signing the International Convention on the Protection of the Rights of All Migrant Workers and Members of Their Families. Additionally, it is argued that if granted citizenship, agricultural workers are likely to move to other industries and the seasonality of their labour generates uncertainty surrounding their off-season labour activities. Some alternatives have been proposed, including citizenship tied to the agricultural industry for a determined period (Hennebry, 2012; Palacio, 2010), offseason training activities paid by employers and the various levels of government involved (Palacio, 2010); and, working in industries suited 
for the offseason period (ex. winter-related activities including snow removal).

\subsection{Citizenship and the nation-state.}

The current understanding of citizenship in Canada derives from ancient developments of the city states in ancient Greece (Arendt, 1998). For more than a millennium, the meaning of the relationship between collective and individuals (citizenship) has been expanding. In the mid-18th century, for example, Prussia (part of today's Germany) officially formalized belonging via citizenship. This was the outcome not only of control of movement on its territory but also of unification of various levels of sovereignty of cities and regions, which at the time operated with a certain degree of autonomy (Torpey, 2000). Today we have a system that associates citizenship with nation-states interacting within a system of other nation-states (Sassen, 2003). Although both citizenship and nationality speak of belonging, citizenship points to an intra-borders relationship with the nation-state and nationality to the system of nations (Sassen, 2003). In the Canadian context, citizenship (or lack thereof) should be seen from a lens of relations between Canada and the countries in the periphery that provide it with foreign low-skilled labour.

In view of the incredible impact that access to citizenship (or lack thereof) has on the lives of those working and living outside of their country of origin, it is important to consider what exactly citizenship means and its relationship with the nation-state. In the most general terms, citizenship may be understood as the relations of membership an individual has with a political community. These relations are expressed through rights, duties, identities and public participation (Delanty, 2000, as cited in Lister \& Pia, 2008). Stated otherwise, citizenship provides access to identity, legal status, rights, and 
participation (Bloemraad, 2000; 2006; Isin \& Wood, 1999; Lister \& Pia, 2008). It also unites people who share a set of common cultural traits, who live in a bordered territory and who are part of a polity that rules itself (Castles, 2005). And yet, the meaning of citizenship goes beyond identity and nationhood; it also defines the actual lives of many human beings via their labour conditions. As has already been elaborated, the literature on migration in Canada shows that a lack of citizenship represents a barrier to better labour conditions, to increased wages and to further social integration (Faraday, 2016). Conversely, understood as the negation of the rights and freedoms associated with citizenship, temporary foreign workers' status as noncitizens means that they have a constrained legal status and limited rights and participation. Some attempts to improve inclusion of TFWs focus on transnational political activities and possibilities of inclusion that extend beyond the nation-state. Post-national citizenship is an attempt to separate rights from identity (Soysal, 2006). It contends that immigrants moving to a country different than their country of birth should be granted rights based, not on their national identify, which continues to be linked to the geographic limits of the nation-state (Soysal, 2006), but rather on the ideals of universal rights. This post-national understanding of citizenship emerges in response to the rise of transnational political structures, which render obsolete models of citizenship tied to the sovereignty of the nation-state (Lister \& Pia, 2008). As such, it could be considered as a means of proposing new ways to extend inclusion to low-skilled TFWs working in Canada.

Post-national citizenship invokes the "de-territorialisation of citizenship practices and identities" (Lister \& Pia, 2008) and has been proposed in response to: experiences of exclusion, violation or lacking access to rights (Carens, 2008), especially experienced 
by agricultural migrant workers (Basok, 2003; 2004; 2006a; 2010); the active role of citizens and global organizations in improving global wellbeing (Basok, 2006b); and the role of advocacy at the international level in the quest towards rights and justice for migrant workers (Basok, 2009; Hanley \& Shragge, 2009). Advocates of post-national citizenship question the actual validity of borders and consider the trade-offs of opening borders (Carens, 1987; 2000; Sharma, 2012). Some contend that national identity, circumscribed by geopolitical borders, is little more than a means for social exclusion and an enabler of global capitalism (Sharma, 2012). Others argue that the nation-state is losing control of its responsibility to provide "equality, liberty and civic participation" (Tambini, 2001, p.200). Indeed, the nation-state is facing forces from within and from without (for example, global economies, immigration, social media, communications, terrorism, etc.) that challenge its sovereignty. In the words of Keating, challenges to the integrity of the nation-state come "from above and below, and also by the market" (Keating 1998, p.10, as cited in Tambini, 2001, p.200).

In view of those who have been depoliticized by unjust policies of labour migration, appeals to post-national citizenship tend to focus on the global rather than the local (i.e. the nation-state) as the space for re-politicization (Bauder, 2006). While this view is, in my opinion, the final goal, at this point in history it remains unreachable; we are in an "in-between" state. Although influences from within and without have eroded national borders, the world is nevertheless still ruled within the confines of the nation-state ${ }^{25}$. I accordingly advocate a theory of re-politicization that is crafted within the nation-state but aims at future global citizenship (i.e. global mobility) as the most

\footnotetext{
${ }^{25}$ There are also local initiatives, such as sanctuary cities, that contravene nation state policies and may be interpreted as outside the rulings of the nation-state.
} 
desirable. Such an approach demands that we look for solutions not outside the nationstate, but rather within its borders ${ }^{26}$ (Bauböck, 2001a). That is, the focus should be on those lacking citizenship, whose presence questions the way political communities are constituted (Bauböck, 2000).

When it comes to granting rights to foreign nationals, three kinds of rights frame the debate: civil, political and social rights (Marshall, 1973, as cited in Evans, 1998). Social rights, which are the focus of this study, involve the right to seek employment in an occupation of preference; basic economic and welfare rights and protections; as well as access to education (Evans, 1998).

\subsection{Theories of the State, a Neo-Marxist Perspective}

Insofar as the state uses citizenship (or a lack thereof) as a means for maintaining economic conditions that favour its interests, or, conversely, protect migrant workers, an interest in temporary foreign workers in Canada prompts us to turn to theories of the state. The following theories of state are framed within Critical Social Theory and, hence, are supported by neo-Marxist analysis. More specifically, they draw on the analysis of state provided by Bob Jessop.

Considering the state and its origins is relevant to understanding these patterns because, as it will be further explained, the state is the place where different forces and powers converge to affect the labour market experiences of low-skilled workers. While the origin of states can be traced back thousands of years to when wars and means of food production were the primary means of power and dominance (Herb, 1999), the world as we currently know it began to be shaped in large part by the Westphalia peace

\footnotetext{
${ }^{26}$ Within the current structure, this type of initiatives would be of federal domain.
} 
agreement in 1648, which brought an end to the Christian wars (Palacio, 2009). It is worth mentioning that the treaties of Westphalia established the precedent for the autonomy and independence of sovereign states. However, the nation-state and nationalism only began to fully form in the second half of the 19th century, when the state and its power started to be identified with a given nation.

Jessop (a Neo-Marxist theorist) identifies three characteristics of the state: a territory controlled by that state; a structure that makes collectively binding decisions; and all residents who are subject to state authority (Jessop, 2014; 2010). While all sovereign states theoretically have equal rights on the global stage, in reality the asymmetrical distribution of power and resources governs the flow of capital, information and people

In their structural understanding of power, neo-Marxists distinguish themselves from behaviourists and conservatives/liberals, who posit power as something concretely installed in specific people. From a behaviourist perspective, for example, Dahl (1957) centers power analysis on the persons involved in a particular issue. Dahl defines power as "A has power over B to the extent that he can get $B$ to do something that $B$ would not otherwise do" (Dahl, 1957, p.203). Gelb (2009) identifies a similarly localized understanding of power operative in conservative/liberal worldviews. While conservatives have an individualistic worldview that frames power as military might, liberals understand power as based on others' perception of factors including leadership and communications (Gelb, 2009, p.27).

In contrast, in a neo-Marxist analysis, class power is foundational to understanding processes of labour and social interactions of production in relation to the 
state (Jessop, 2011). All power relations are considered within the broader context of the power that is installed in structures of class domination and relations of power across factors including economics, politics, and ideologies (Jessop, 2012). Rather than being localized in particularly powerful individuals, from a neo-Marxist perspective, power is economically rooted in very concrete, tangible capacities located "in the social relations of production, in control over the state, or in intellectual hegemony over hearts and minds" (Jessop, 2012, p.4).

2.7.1. Class domination and the state: economics and politics. In the social relations of production, 'economic class domination' refers to "social control over the allocation of resources to different productive activities and over the appropriation of any resulting surplus" (Jessop, 2012, p.5). In this context, Jessop identifies three modes of control: bureaucratic, technical and despotic, each affecting the distribution of power between the capital and labour in different ways. In view of these mechanisms of control, we can better understand the formation of policies concerning low-skilled workers, which, in turn, account for wage differentials.

In what Jessop calls a "bourgeois democracy," that is, a democracy in which the bourgeoisie make up the dominant class - a characteristic of a capitalist state economic class domination is indicative of the way in which the bourgeoisie are taxed: for the bourgeoisie (transnational companies), taxes are the subject of political negotiation and are linked to their global privileges (Jessop, 2014). In this theory, taxes are relevant because they are one of the most evident links between economics and politics. While the separation of economics from the political is desirable, it is not really 
feasible in a capitalist state. In view of this difficulty, Jessop, drawing on the early work of John Hallowell, suggests that a state should instead strive for a separation in unity instead of a total separation ${ }^{27}$ (Jessop, 2014).

Class domination not only influences economics; it is also political. That is, the state ensures economic class domination through political dominance (Jessop, 1982; 2012). Jessop accordingly understands statehood as "territorialized political power" (Jessop, 2009, p.92). The state fills the gaps resulting from failures in the market and barriers to capital accumulation. It also regulates the different interests at play and manages the consequences derived from any exploitation that may arise (Jessop, 1982). For example, in the case of low-skilled temporary foreign workers, the state has responded to complaints of exploitative conditions, but only when the pressure was sufficiently high (Faraday, 2016) ${ }^{28}$.

Political class domination is of special interest to this dissertation because the demand for foreign low-skilled labour in Canada has been primarily constructed via political actions (Bauder, 2005).

Jessop identifies three approaches Marxist theorists use to consider the state politically: instrumentalist, structuralist, and 'strategic-relational' (Jessop, 1982; 2012). According to instrumentalists, an instrumentalist view of the state is indispensable in capitalist societies, which are characterized by ruling classes using the state through

\footnotetext{
${ }^{27}$ In the current, capitalistic, world, economics is relevant to policymaking. However, economics has a role (a very important one) in society that should not be used as a means to power (via politics). Economics in relation to politics needs to be reframed, perhaps around Amartya Sen's (1977) tenets of self-interest, empathy (via unselfishness) and commitment, "assessed in terms of one's values and instincts" (Sen, 1977, p.344). Sen presents these three values as the foundation of decision-making, as opposed to mere self-interest (in a vacuum) as argued by the first rational choice theorists.

${ }^{28}$ As will be explained in chapter three, in 2014 the federal government introduced legislation to regulate TFWs in Canada because of two principal pressures: a rapid increase in the use of foreign labour and exploitation (Faraday, 2016).
} 
their economic power to dominate society. From an instrumentalist perspective, Marx and Engels see the state as a political subject that lacks autonomy, that is, as "an instrument of coercion and administration which can be used for various purposes by whatever interests manage to appropriate it" (Jessop, 1982, p.12). Different theoretical streams of thought have approached Marx's stance on the state, from an instrumental perspective. Neo-Ricardian theorists, for example, see the state as an instrument of capital "through its interventions to maintain or restore profits at the expense of wages" (Jessop, 1982, p.14). The 'stamocap' (state, monopoly, capitalism) theorists also fall into this category, highlighting the convergence between the state and monopolies (Jessop, 1982).

Jessop argues that a strictly instrumental view of the state makes it necessary to think of the state as "non-partisan and passive in its personnel and orientation" (Jessop, 1982, p.15). It also makes it difficult to account for the reproduction of dominant modes of production when the "dominant class does not actually occupy the key positions in the state system" (Jessop, 1982, p.15). It similarly loses explanatory force when those running the state not only have independence from the dominant class but also actively distance themselves from it.

In a structuralist interpretation of the state, capitalism relates to the state not instrumentally, but essentially. Essentially capitalistic, the state accomplishes its mission by "organizing capital and disorganizing the working class" (Offe, 1984 as cited in Jessop, 2012, p.7). Under these conditions capital needs to be as politically strong as possible without undermining the state's legitimacy.

In contrast, the state can also be understood as a factor of cohesion. Marx and 
Engels "suggest that the conquest of the state power presupposes the successful representation of a class interest as the general interest" (Jessop, 1982, p.17). Engels argued that this is the regulator of differences between polar classes, keeping them "within the bounds of social order" (Jessop, 1982, p.18). Challenging this reading, Jessop notes that "while the state must appear to stand above society and keep class antagonism in check, it is normally the state of the most powerful, economically dominant class" (Jessop, 1982, p.18). He believes that this is a function of the fact that class function overrides social functions and he accordingly understands the state as a "distinct ensemble of institutions and organizations socially constructed and [whose] accepted 'function' is to define and enforce collectively binding decisions on members of a society in the name of their common interests or the general will" (Jessop 2014). This brings us to the third approach.

The strategic-relationist approach (advanced mainly by Nicos Poulantzas and Bob Jessop), uses Marx's observation that the state "is not a thing but a social relation" (Jessop, 2012, p.7). According to Jessop, "Marx showed how continued reproduction of the material and institutional forms of the capital relation shaped the dynamic of capital accumulation and the economic class struggle - but the dominance of these forms could not in and of itself guarantee capital accumulation" (Jessop, 2012, p.8). This is the main approach used by Jessop and the approach that most directly informs the discussion of my results. As such, it will be following elaborated in more.

2.7.2. The Strategic Relational Approach, a Definition of the State. Through its Strategic Relational Approach (SRA), Jessop's work continues the neo-Marxist 
theorization of the state initiated by Poulantzas after his early death in 1978 (Marinetto, 2007). Although Jessop's work is based primarily on Poulantzas' contributions, it also incorporates elements from other thinkers, such as Gramsci (Carlassare, 2010). Drawing on Nicos Poulantzas and Gramsci, advancing the strategic-relationist approach is Jessop's main contribution to the theory of state. This approach elaborates Marx's observation that the state "is not a thing but a social relation" (Jessop, 2012, p.7). According to Jessop (2012),

Marx showed how continued reproduction of the material and institutional forms of the capital relation shaped the dynamic of capital accumulation and the economic class struggle - but the dominance of these forms could not in and of itself guarantee capital accumulation. This depended on capital's success in maintaining its domination over the working class in production, politics, and the wider society. (p.7)

From this perspective, Jessop emphasizes capital's domination not only over production but also over politics and the wider society. Indeed, capital has been successful in supporting political agendas that not only contribute to capital accumulation but also affect the social fabric of society, like temporary foreign labour. The state facilitates capital's domination. Likewise, the state's dominance is activated via the politicians and bureaucrats that rule it (Jessop, 2012), according to their ideologies ${ }^{29}$. The history of temporary foreign labour policy in Canada shows that bureaucrats' have been a mix of gatekeepers and non-neutral policy brokers between elected officials and different forces at play (Satzewich, 2008) but, that power is something that has been challenged

\footnotetext{
${ }^{29}$ While ideologies often play a significant role in influencing policy, policymakers often look for strategies to present the processes behind their decision-making as if they are made within a sort of neutral vacuum (Wedel, Shore, Feldman \& Lathrop, 2005). This apparent neutrality may either be a response to external political pressures (neutrality would not be chosen in other circumstances) or a political response in itself (intentional apparent neutrality with a hidden political agenda) or a genuine way of proceeding politically (no hidden political agenda) ('t Hart, 2010).
} 
by resistance that extends from beyond the state (with its own ideologies) that "transform it, to determine its policies, or simply to influence it at a distance" (Jessop, 2012, p.8).

According to Gramsci (1971), the state is "the entire complex of practical and theoretical activities with which the ruling class not only justifies and maintains its dominance but manages to win the active consent of those over whom it rules" (Gramsci, 1971, p.244 as cited in Jessop, 2012, p.8). Jessop distinguishes between power in a capital state and in a state in a capitalist society. In the former, power is manipulated in a somber way; there is no clear demarcation of its origins. In the latter, "power is contingent and mediated via relations" (Jessop, 2014, 27:38). In either case, the state is not the owner of power but a means to mediate different types of power, which it does with different kinds of biases, including racial, ethnic and class biases. The Canadian state has made use of its political position of privilege at the international level to use geographic place of birth (which is linked to race and ethnic origin) as a means for easy access to exploitable labour (Strauss \& McGrath, 2016). Strategic-relationalist theorists see the state's power as the outcome of the meeting of class forces (Jessop, 2012).

Expanding Gramsci's developments on power and the state (focused on state's power rather than on its mediatory role), Jessop reinterprets the state as "government + governance in the shadow of hierarchy" (Jessop, 2014, 36:00). Jessop's reinterpretation of the state begins to pave the way to understand the state as a mediator of powers and itself with a top down power used to bring a people to conformity, into the shadow of ideological influences. In Jessop's (2014) own words, 
Government is more than the state considered as territory, apparatus, population - it exercises power in ways that go well beyond imperative coordination (Gramsci's point about political society + civil society). [And] government as a social relation (hegemony armoured by coercion or statecraft), involves practices that go well beyond the state, is an attempt to juggle, to rearticulate, to recombine, in different contexts, the different purposes, at different times, governmental power and imperative coordination as law with other ways of influencing, shaping, directing, normalizing society to bring it into conformity, as Gramsci's would say, with the requirements of the dominant mode of production. $(36: 12)$

This coincides with Michel Foucault's interpretation of the state as the "key site for 'strategic codification of power relations'" (Jessop, 2014, 38:08), which serves as the introduction of the state as a social relation by Poulantzas. According to Jessop, "The state, as official 'résumé' of society, has a key role in political domination...all this occurs through selective impact of state form on shaping political opportunities and alliances and through specific state strategies, projects and policies" (Jessop, 2014, 40:24). As the place of confluence of relations, it is also a place of confluence of powers, so it is not uniform.

\section{Chapter Summary}

The first section of this chapter provides an overview of the different aspects found in the literature about low-skilled temporary foreign labour in Canada that relate to this dissertation. This literature review identifies an area that is not addressed in the existing literature, namely systematic studies that examine wage differences at the level of occupation, and helps situate the hypotheses that this dissertation addresses. The second section introduces the broader theoretical lenses guiding this dissertation, namely Rational Choice Theory and Critical Social Theory. The former is chosen because it provides the theoretical tenets supporting the sort of quantitative analysis 
used in this dissertation (cross tabulation and multivariate regression analysis). The latter is used because it provides a way to critique the status quo for low-skilled TFWs and to consider new ways for the state to deal with low-skilled temporary foreign labour. The third section focuses on three migration theories (one based on RCT and two on CST). These theories help interpret the reasons behind decision-making processes of each of the stakeholders involved in the process of migration and wage determination. Stakeholders include workers, employers and the government. The fourth section presents the theoretical foundations of neoliberalism, which is one of the global forces that shapes labour migration and therefore influences the wages of low-skilled NPRs. The fifth section provides a review of the literature on foreign low-skilled labour in Canada in relation to citizenship, which is the main distinguishing factor between the groups whose wages will be compared. This section also addresses theoretical views on citizenship that help interpret non-citizenship as a means to access cheap low-skilled temporary foreign labour. It also presents theoretical proposals to provide new ways of inclusion (via citizenship) for low-skilled temporary foreign workers. No specific studies that explain, from a quantitative perspective, the effect of a lack of citizenship on wages of low-skilled workers in Canada were found. The sixth section introduces the relation between citizenship and the nation state. The seventh section focuses on the theoretical approaches of the state that help interpret how the state constructs the need for temporary foreign labour via citizenship.

Together, these theoretical tools inform the following hypothesis: "The policycreated lack of citizenship significantly accounts for the negative wage differentials for low-skilled NPRs (compared to CB and IMM) even when factors such as sex, province 
of residence, rural/urban workplace, level of studies, knowledge of either official language or country of birth are accounted for." The following chapter explores the policy origins of low wages among non-citizens and the role stakeholders played in shaping policy. 


\section{Chapter Three: Low-Skilled Temporary Foreign Worker Policies and Programs}

This chapter focuses on the main policies related to low-skilled temporary foreign workers in Canada that led them to be particularly disadvantaged in already low wage occupations. It explores the ways in which immigration policy has influenced wage disparity across occupational categories and the role of stakeholders in forging such policies. A revision of the evolution of TFW policy is relevant because it shows the incidence of policy on the low wages of low-skilled temporary foreign workers. One of the contributions of this dissertation is to think of how capitalist labour markets need a super exploitable workforce. In the Canadian context, there are at least two ways: via the low-skilled in general; and by attaching some low-skilled (foreign-born) to temporality and non-citizenship. Some in those low-skilled jobs are paying a high price by earning very low wages derived from their lack of citizenship.

Temporary foreign labour policy has divided low-skilled populations into three main groups: caregiving, agriculture and workers in all other low-skilled occupations. Caregivers were the first to work as noncitizens in the Canadian labour force, followed by agricultural workers and then by workers in all other low-skilled occupations. From policy perspective, employing foreign workers in low-skilled occupations is justifiable when such occupations exhibit genuine labour market shortages (Gross, 2014). However, my analysis will show that a significant number of workers without citizenship in these occupations earn significantly less than Canadian-born and Immigrants. Even if each occupation has a broad range of jobs with an equally broad range of wages, it is nevertheless important to ask: why a significant number of those working on a 
temporary basis (i.e. without citizenship) earn less than those with the rights associated with citizenship? Are such differences dictated by policy?

Regulations pertaining to low-skilled TFW programs have provided a means to maintain an indentured labour force that works for lower wages. Such regulations bind workers to a single employer and deny them access to citizenship or settlement programs that would help them integrate into the larger society (Hennebry, 2012; Preibisch and Binford, 2007). Even if workers can change employers, fear of being sent back to the country of origin or not being called back the following season holds most TFWs captive in their existing job conditions. These programs also allow the state to foster competition in the internal labour market (Hennebry \& Preibisch, 2012), fostering conditions that maintain low wages and help local economies prosper. As cited in Hennebry and Preibisch (2012), Hahamovitch (2003) observes that as "'efforts to make immigration temporary or to 'regularize' illegal immigration, guest-worker programs have failed. Yet as labour supply systems designed to 'regularize' wages, to hold down the cost of sugar cane harvesting in Florida, diamond mining in South Africa, construction work in Europe, and child care in Montreal, and to keep foreign workers segregated in low-wage industries, these programs have been unmitigated success stories" (p.21).

Low-skilled temporary foreign labour policy in Canada designates three groups of low-skilled workers (caregiving, agriculture and other low-skilled occupations). Each group has very distinct origins and policy developments. Insofar as they provide different pathways for foreign low-skilled labourers, each group offers a unique experience of the Canadian labour market. Though some experiences are common among all groups, it is nevertheless important to distinguish the policies operative in 
each group. As the analysis shows, occupations in each of these groups have different labour market outcomes.

The following sections will consider the TFW policy changes affecting each of these occupational groups as well as stakeholders' role in policy making. Employers, policymakers, advocacy groups and the workers themselves have all played a role in shaping policy. While some stakeholders, such as employers, policymakers, advocacy groups and local and foreign governments, have played a more explicit or intentional role in defining program regulations, others, most notably the workers, have played a more tacit or unintentional role. Though no less important, the impact that workers have on developing policy is less a function of agency and more a function of individual circumstances. In this research we will see, a NPRs' lack of citizenship has a predominant role on their low wages.

Academics from different disciplines tend to express very different views on lowskilled temporary foreign labour. Using quantitative tools, economists are more likely to advocate approaches based on rational principles that maximize benefits and minimize costs. In contrast, social scientists, drawing on qualitative methods and critical perspectives, usually focus on the lived experience of TFWs and the influence of powerful interests. The discrepancy between these positions reflects the fundamental tension between Rational Choice Theory and Critical Social Theory (discussed in the previous chapter), a tension that informs the analysis of this dissertation.

With all this in mind, each of the following sections explores the perspectives of various stakeholders in view of their unique role in the historical development of TFWs policies. A historical approach provides clarity on how each group of workers has been affected 
by the specific interests governing stakeholders' actions. As the primary recipients of these policy regulations, the role of the workers is considered in more detail in the subsections that follow.

The chapter is divided in four main sections: In section one, I present the changes associated to temporary foreign labour in caregiving occupations. In section two, I introduce the policy changes related to the temporary foreign labour in agriculture. In section three, I outline the main changes associated to temporary low-skilled foreign labour in occupations other than caregiving and agriculture. Finally, in section four, I introduce the current pathways to access low-skilled TFWs and make a brief overview of the policy changes recently introduced by the federal government that affect lowskilled TFWs in general. Sections one and two cover policies and experiences affecting low-skilled temporary foreign labour linked exclusively to caregiving and agriculture developed from the late 1800 s up until 2010 . The third section outlines the changes from the early 2000 s to 2013 and that opened doors to low-skilled TFWs in occupations other than caregiving and agriculture. The final section covers the current low-skilled pathways and policy changes including those introduced between 2014 and 2016 .

\subsection{Live-in Caregivers: Main Policy Changes and Motivations}

There is a long history to this program; the discussion here goes beyond the very brief treatment in chapter two. Historically, race has been a significant factor in policymaking for domestic workers in Canada. The LIC has historical roots that trace as far back as to the end of the nineteenth century, when British and Scandinavian women migrated as domestic labourers to be considered as potential wives (Cohen, 2000). As 
this example illustrates, policies related to temporary foreign workers usually target a specific sex, a specific country of origin and, by extension, a specific race of foreign workers to fulfill specific labour demands. In line with this trend, women from the Philippines have become the main source of live-in caregivers in Canada.

By 1889 the need for domestic labour was acute so bringing domestic labour from the British Isles became the first solution. British domestic women were brought to Canada in keeping with policies designed to consolidate 'Saxon superiority' and uphold specific expectations concerning the role of women in society (McLaren, 1990; Stasiulis \& Williams, 1992, as cited in Bakan \& Stasiulis, 1994). Unmet demand of domestics (linked to declining relevance of domestic work among woman) made the government to persuade Finish domestics to move to Canada in the early 1900s (Lindström, 2010). British domestics still represented the largest proportion (" $75 \%$ before World War One and 60\% during the 1920s") (Lindström, 2010, p. 36). During the 1920s Finish domestics made $8 \%$ of all female immigrant domestics (Lindström, 2010, p. 36). Most of them were mature women with domestic work experience back in Finland. By the late 1920 s and early 1930s, during the depression years, only women would find work, to the point that women were the breadwinners. Even, by 1937 "when all doors to immigration were shut, the government launched a special scheme to bring in 'Scandinavian and Finish domestics'” (Lindström, 2010, p.38). After World War II, prosperity in rural areas and a consolidation of the middle class in urban Canada led again to an increase in requests for foreign domestic workers (Cohen, 2000). Since domestic labour was scarce in the 1950s, the Canadian government opened its doors to other women, at first from Germany, and then from Italy and later from Greece. 
Between 1911 and 1914, a small group of black women from Guadeloupe was brought to Canada to work as domestics. However, afterwards, black women were not brought to Canada because of their "assumed inability to adapt to the Canadian climate, and their assumed sexual licentiousness" (MacKenzie, 1988; Timoll, 1989, 38-9, as cited in Bakan \& Stasiulis, 1994, p.12).

Up until the 1950s, foreign-born women of colour were rarely offered work as domestics in Canada (Cohen, 2000). In 1955, Canada admitted a few Caribbean women (mainly from Jamaica and Barbados) to work in domestic labour (Cohen 2000, Faraday, 2012). . Although residence was granted upon arrival, a policy was developed that restricted their ability to stay to their employers' satisfaction. They were also subjected to sexually transmitted diseases tests proving this the government assumptions on their assumed licentiousness (Bakan \& Stasiulis, 1994). An official agreement between Canada and the Caribbean nations stipulated that, if they were deemed unsuitable for the work, women could be sent back to their countries of origin (Bakan \& Stasiulis, 1994). By the late 1950s less than one fourth of all Caribbean domestic women were staying more than three years working as domestics (Macklin, 1992). This labour mobility and the intent among some to bring their relatives were concerning factors to the Canadian government (Macklin, 1992). Even though the literature documents labour mobility, by the 1960s, Caribbean women had been left out of many labour regulations, negatively reinforcing their marginal and precarious status in low-wage jobs. They were excluded from legislation that guaranteed a minimum wage and that regulated hours of labour; and in most Canadian provinces, except Prince Edward Island and Saskatchewan, annual vacation legislation did not apply to 
them (Daenzer, 1991). Only in Manitoba were these women included in public holidays laws (Daenzer, 1991). Job discrimination in the Montreal area was also documented (Henry, 1968). This experience contrasted significantly with that of domestic workers of European origin, who did not face the same barriers, as reported by Cohen (2000). As if these barriers were not enough, as of 1973 , Caribbean women were no longer granted residence upon arrival. The temporary nature of foreign domestic work was formally and strategically introduced through policy with the Temporary Employment Authorization Program. Government officials introduced this program because, even though Caribbean domestic workers were not supposed to have a family, some began to sponsor family members (Brickner \& Straehle, 2010). This program allowed them entry with temporary work permits that could be renewed annually for a period of up to three years (Bakan \& Stasiulis, 2002).

After years of pressure from advocacy groups, in 1981 the federal government introduced the Foreign Domestic Movement Program (FDM) (Cohen, 2000). This was a formal response to complaints regarding the violation of domestic workers' human rights. LIC's pathway to citizenship was the outcome of pressures from human rights activist groups, academics, bureaucratic analysts and domestic organizations all denouncing abuses related to domestics' living and labour conditions (Cohen, 2000; Daenzer, 1997). This program allowed them to apply for permanent residence after two years of work (Stratemeyer-Trinczek, 2012). Of all requirements included in this program, the mandatory condition that domestic workers live with their employer contributed most to the vulnerability and abuse experienced by women participating in this program. While most foreign domestics in the past had also lived with their 
employers, previous versions of the program did not stipulate that this condition was mandatory (Daenzer, 1991). The argument for making it mandatory was that live-out domestics were available for the local labour market (Bakan \& Stasiulis, 1994). Whatever the economic reason, it is clear that this mandate led to an increased sense of isolation and fear of deportation among workers (Hodge, 2006) and lower wages (Faraday, 2012). It points to the folly of developing policies based on labour market principles without duly considering their impact on the most vulnerable members of society.

In addition to its domestic policies, global neoliberalism and foreign policies also contributed to Canada's use of low-skilled temporary foreign labour. This is especially apparent in the case of employing workers from the Philippines or the Caribbean. The influx of Filipino caregivers in Canada started to become significant in the 1980s. In 1983, about 3500 people entered Canada through the FDM. By 1990, this number had increased to approximately 10700 (Mikita, 1994). In 1983, 29\% of domestic workers in Canada were European (of which almost 19\% were British); and Filipino and Caribbean workers made up approximately $15 \%$. In 1990, Filipino applicants made up more than $60 \%$ (approximately 6500 entries) of all FDM entries and Europeans made up only 14\% (Mikita, 1994).

This sudden increase in Filipino migration can be understood as a response to economic pressures in the Philippines backed up by emigration policies introduced by the Filipino government. More specifically, "the declaration of Martial Law by President Marcos in 1972 combined with...the promotion of overseas labor export as an economic development strategy to relieve nationwide unemployment, fueled the huge outflow of 
migrant workers in this era" (Garchitorena 2007; Kelly 2006; Lan 2000 as cited in Ronquillo et al., 2011 p.267). While Caribbean migration is the outcome of imperial ties, Filipino migration reveals "aggressive marketing of labour for export on the part of various Philippine governments (from Marcos to Aquino to Ramos)" (Bakan \& Stasiulis, 1997, p.125).

In 1992, the domestic program evolved into the Live-in Caregiver Program, which introduced a more formal assessment of caregiver's credentials (education equivalent to grade 12 and six-month training in a field similar to the job applied). Instead of being called domestics, workers in this occupation were referred to as caregivers. Access to permanent residence (and further citizenship) was dependent not only on two years in caregiving work, but also on proof of social adaptability, occupational upgrading and financial security (Bakan \& Stasiulis, 1994). While the last requirement represents the most vivid disconnect between the regulation and the lived reality of these workers (i.e. low wages), all these requirements were considered unfair since they did not apply to workers in other occupations with a high demand for labour (Arat Koc, 1991, as cited in Bakan \& Stasiulis, 1994).

To mitigate these imbalances, in the spring of 2010 , both the federal government and the government of Ontario passed laws to protect live-in caregivers (Ontario Ministry of Labour, 2010). Ontario enacted the Employment Protection for Foreign Nationals Act (Live-in Caregivers and others), which, as the name suggests, focuses on protection of temporary foreign workers coming under the Live-in Caregiver Program. The act was designed to regulate recruitment practices by "banning recruitment fees, prohibiting reprisals against live-in caregivers for exercising their rights under the 
legislation, and prohibiting an employer or recruiter (the legislation uniquely covers recruiters) in Ontario from taking possession of a live-in caregiver's property, including documents such as passports" (Gellatly et al., 2011, p.89).

The act also gives them up to 3.5 years to make claims on unlawful fees that may have been paid, given the precariousness of their citizenship situation before applying for permanent residence (Gellatly et al., 2011). However well-intended, the act fell short in three specific aspects: 1) its jurisprudence is limited to Ontario and most workers have arrangements with recruiters outside of Canada, which makes enforcement difficult; 2) the legislation targets a small group of workers (LICs), excluding other workers in precarious and unprotected working conditions (Gellatly et al., 2011); and 3) even if caregivers are granted an avenue to issue complaints, this does not resolve the power dynamics, which are driven by fear of reprisal, that prevent workers from speaking out ${ }^{30}$ (Faraday, 2012).

\subsection{Agricultural Labour: Main policy Changes and Motivations}

Since the decrease in the number of LICs coming to Canada, agriculture represents the largest employer of TFWs. The Conference Board of Canada reports that agriculture represented $58 \%$ of all LMIAs ${ }^{31}$ approved in 2015 (Conference Board of Canada, 2016). The general labour and living conditions of agricultural workers in Canada have been defined by three different geographic and historical origins: The Caribbean, Mexico, and other countries (mainly in Central America, the Philippines and

\footnotetext{
${ }^{30}$ In 2015, Ontario also introduced the Immigration Act, which includes clauses addressing some of the issues related to recruitment.

${ }^{31}$ LMIA= Labour Market Impact Assessment, a document that evaluates whether a TFW affects the Canadian labour market. For detailed definition see footnote 24 in chapter 2.
} 
Southeast Asia). This section will focus on Caribbean and Mexican influences. The third group of agricultural workers will be explored alongside workers from other occupations later in this chapter.

The first two groups have historically come to Canada through the Seasonal Agricultural Worker Program (SAWP). In the past, the last group came primarily through the program previously known as the Low-Skilled Pilot Program, which was later transformed into the low-skilled stream. Currently this group comes through the Agricultural stream and the low-wage stream ${ }^{32}$. Through these alternative agricultural streams, employers can hire workers from anywhere other than Mexico and the Caribbean. Thus, workers from outside of Mexico or the Caribbean have a relatively recent history of participation in Canadian agriculture.

3.2.1. Caribbean agricultural labor. The presence of Caribbean workers in Canada stems from the historic relationship that already existed between Britain and the Caribbean. The Caribbean's primary means of production were primarily owned by British citizens who took most of the profits back to Britain, creating a relation of dependency on Britain. In the Caribbean, "Monoculture during slavery has been replaced by monopoly and foreign ownership" (Andre, 1990, p.253). This tradition of dependence and foreign ownership persists to the present day and, as an heir of Britain's colonial past, Canada continues to have strong economic ties to the Caribbean. Canadian banks, for example, have dominated the banking sector in the Caribbean since the early 1900s (Andre, 1990). This permanent dominance by foreign corporations

\footnotetext{
${ }^{32}$ See section 3.4 .
} 
over the Caribbean's means of production has led to a continuous export of revenue and high levels of unemployment in the Caribbean nations (Andre, 1990).

Scarcity of labour in Canada was also a significant driver of temporary foreign labour. The number of agricultural workers in Ontario dropped from about 850000 in 1953 to about 470000 in 1974 (Andre, 1990). Alongside this increased demand for foreign labour, high unemployment rates in the Caribbean led Caribbean governments to introduce policies to encourage emigration (permanent or temporary) to richer countries, including Canada. For example, in 1873 the government of Barbados approved a law to help poor and unemployed Barbadians emigrate (Andre, 1990). Caribbean countries saw the possibility of working in Canada (among other nations) as a means to economic development (Andre, 1990), perhaps via remittances and the future transmission of knowledge.

While the federal government tried to implement programs to attract Canadianborn workers and immigrants to the agricultural sector, the turnouts were not enough to meet labour needs. The government also tried to mobilize indigenous people, prisoners, people in psychiatric hospitals and unemployed French Canadians to work in Southern Ontario farms. However, Ontario farmers found them to be unsatisfactory labourers (Satzewich, 2008). As a result, the Commonwealth Caribbean Seasonal Agricultural Workers Program (CSAWP) was introduced to fulfill labour demands (Andre, 1990). This was the first country-to-country agreement to fulfill labour needs with temporary foreign labour. However, in time this would show to be a way to segment agricultural labour in the lines of race (via ethnic origin). 
As with the LIC program, race has been a significant factor in the development of Canadian TFW agricultural policy. In the years following the second world war, scarcity of agricultural labour in southern Ontario led the government to bring in some of the less desired workers from Eastern Europe willing to move to Canada. The following is an excerpt extracted from Satzewich's ${ }^{33}$ research $(1991,2008)$, which quotes the Deputy Minister of Citizenship and Immigration in the 1960s. It illustrates how Canada's policymakers established a distinction between two types of immigration that is still operative today: immigration by necessity (not so desirable) and immigration by choice (desirable): "The Polish veterans and refugees [Displaced Persons] were in a position where they had little alternative but to emigrate from their European countries of residence. At present, however, most immigrants are employed in their own country and come to Canada not through necessity but as a matter of choice. It is necessary to sell them on the idea of coming to Canada" (Satzewich, 1991, p.120, as cited in Satzewich, 2008, p.264). In contrast with the treatment of veterans and refugees, Dutch immigrants, who came to Canada by choice, were considered too valuable to place them in conditions of 'unfreedom' (Satzewich, 2008).

Canada also has a history of discriminating against black workers. However, in the 1960s the government finally responded to pressure from employers and agreed to give up its position on the inability of black people to integrate (Kelley \& Trebilcock, 1999). In response to an obvious scarcity of labour and the criticism of advocacy groups and academics about the racial characteristics of Canadian immigration policies, black

\footnotetext{
${ }^{33}$ Satzewich (2008) presents the evolution of Canadian temporary foreign labour policies in agriculture by reviewing internal communications from the Department of Manpower, old Immigration, Refugee and Citizenship Canada (IRCC).
} 
people were officially allowed to work in Canada (Satzewich, 2008). This opened the doors of Canadian temporary agricultural work to Caribbean employees. The first labour agreement was with Jamaica and in 1966 the first 264 Jamaican agricultural workers came to Canada (Andre, 1990). Numbers grew to about 3000 by 1973 and in 1976 other Caribbean nations signed similar agreements with Canada (Andre, 1990). In this way, the incorporation of Caribbean temporary labour responded to economic and racial rationales designed to benefit Canada (Satzewich, 2008). The presence of Caribbean workers on a temporary basis was not only the result of pressure from employers, but also the outcome of pressure from other fronts and policymaker's decision-making processes and negotiations:

By admitting workers from the Caribbean on a seasonal basis to come to Canada, Canadian immigration officials could offer this as further proof that immigration policy was not tinged by racial considerations. Employer interests were not the sole determining factors in shaping policy decisions. If employer interests and their associated lobbying were all-powerful, then employers would have had access to migrant labour well before 1966. Immigration officials did play a determining role insofar as they were the gatekeepers and were unconvinced that employers' preferred solution to labour force recruitment and retention problems - migrant labour from the Caribbean - would be in the best long-term economic and social interests of the country (Satzewich, 2008, p.265).

Thus, low wages among Caribbean workers in agriculture is the continuation of a historically exploitative relationship between Britain and the Caribbean that goes back to colonial times. It was the continuation of a pre-existing kind of labour force that would, out of necessity, eventually respond to the labour needs of Canada.

Canada's exploitative use of foreign workers, however, is certainly not limited to Caribbean workers. Workers from other nationalities have come to replace the role of Caribbean workers in the Canadian economy. As will be further explored, race-related 
stereotypes surrounding Caribbean people's culture and behaviour have led to their replacement with Mexican labour (Preibisch \& Binford, 2007).

3.2.2. Mexican agricultural labour. Temporary low-skilled Mexican labour in the Canadian agricultural sector coming through a government-run TFW program has its origins in 1974 when the first 208 agricultural workers from Mexico joined the 5500 plus Caribbean workers working on Canadian farms (Preibisch \& Binford, 2007). Over the next 10 years, their number gradually increased, reaching approximately 1000 workers in 1984 (Weston \& Scarpa Marsellis, 2003). Between 1985 and 1990, the number started to increase even more rapidly and in the early 1990s it exceeded the number of Caribbean workers (Weston \& Scarpa Marsellis, 2003). By 2001, Mexican labour accounted for $51 \%$ of all seasonal agricultural workers coming through the SAWP (Preibisch \& Binford, 2007). But the increase in Mexican labour was not entirely due to the growth of production that took place during the 1990 s.

The replacement of Caribbean workers with Mexican labour is relevant to this analysis because it demonstrates how pressure from different stakeholders has the power to inform policy. Documents from the Department of Manpower and Immigration (DMI) and the Department of External Affairs identified two main issues that defined seasonal agricultural labour in the early 1970s. On the one hand, although farmers had access to Caribbean labour through the CSAWP, the labour provided via this program was becoming economically inefficient. As a way to control the number of Caribbean workers coming to Canada, during the first years of agreements Caribbean countries 
had the power to annually negotiate the workers' wages. Not surprisingly, annual wage increases made these workers less attractive to farmers in Ontario:

As a result, the wage rates specified in the contracts for Caribbean seasonal workers tended to increase from year to year. According to documentation provided to government officials by the Ontario Fruit and Vegetable Growers Association, the wage rate for workers from the Caribbean had increased $32 \%$ from $\$ 1.25$ per hour in 1966 to $\$ 1.65$ per hour in 1970 . At the same time, the Association noted that the price of apples (one of the main crops harvested by seasonal workers) increased by only $8 \%$ during the same period (Satzewich, 2008, p.266).

On the other hand, investigations in the early 1970s reported Ontario farmers employing seasonal workers from Mexico and Portugal, many of whom were undocumented and received low wages. DMI reports state that Mexican workers and their families were Mennonites from the Mexican provinces of Chihuahua and Durango and many were driven to their destinations in buses from the US-Mexican border. The report describes the deplorable accommodations and general labour conditions endured by these Mexicans and their families. Some of them, for example, were lodged in abandoned shacks and barns. Wages were paid to the father and perhaps to the mother and children over 18 (Satzewich, 2008).

Farmers' complaints about the economic unviability of bringing in Caribbean workers and the growing use of undocumented hyper-exploited Mexican labour prompted government leaders to officially include Mexico in the agricultural temporary foreign worker program (Satzewich, 2008). Including Mexico served several purposes: it curtailed the bargaining power of Caribbean nations when negotiating wages for Caribbean workers; it regularized the use of a significantly exploited labour force; and it 
helped the DMI recover control over certain aspects of immigration that had been somewhat out of control (Satzewich, 2008).

As previously discussed, in contrast with English-speaking Caribbean workers, Mexicans' lack of English proficiency resulted in a labour force facing more challenges to complain ${ }^{34}$ than those who spoke English. In agricultural occupations, a lack of skills in English or French proved to be detrimental to workers' health (Henebry, McLaughlin \& Preibisch, 2015) and to limit workers' access to their rights (Basok, 2004), prompting some authors to make a case for certified interpreters (Mysyk et al., 2009). A lack of language skills also restricts access to social spaces of inclusion, human relations, identities, services, as well as responsibilities (De Luna-Villalón, 2011). Despite their lack of English or French proficiency, they are desirable because of their willingness to work under less desirable conditions. Though motivated, in part, by a genuine desire to do their best, Mexicans' willingness to work is also related to a lack of language skills and knowledge of their rights and the fear of being sent back home to the desperate labour conditions back in Mexico (Preibisch \& Binford, 2007). Thus, some employers use a workers' lack of official language skills to segment the labour market (Binford, 2008). In contrast, the required capacity for live-in caregivers to speak either English or French enables them to know their rights and to voice their experiences. Nevertheless, it is important to note that speaking an official Canadian language does not guarantee a positive labour experience; Caribbean workers who speak English, for example,

\footnotetext{
${ }^{34}$ In a similar vein, reports reveal that, among Caribbean workers, farmers preferred Jamaicans because they were known to complain less than other Caribbean workers. Trinidadians and Tobagonians, for example, had a reputation for demanding better accommodation and labour conditions (Satzewich, 2008), which made them less desirable.
} 
nevertheless experience discrimination linked to their accent, let alone race (Henebry, McLaughlin \& Preibisch, 2015)

As with LICs, foreign policies once again favoured Canada's use of low-skilled foreign labour. Neoliberal policies in Mexico, including privatization and agreements such as NAFTA, led to reductions in the government's capacity to help Mexican farmers (peasants) (Binford, 2009). The Mexican economy has been flooded with American products. Even agricultural products that were staple items of the Mexican diet ended up being cheaper to purchase abroad (from producers who received large subsidies) than to produce them locally (Binford, 2009).

In view of the racialized and gendered nature of selecting temporary foreign workers, research also explores how the host society plays a role in constructing stereotypes of foreign workers - often ethnically-related - that reinforce discourses of separation between locals and workers and provide tools to perpetuate exploitation (Bauder, 2008a). From this perspective, conditioning at birth and at work (interiorexterior conditioning) work together to construct the essential aspects of a "productive workforce that can be profitably deployed" (Binford, 2009, p.505). Indeed, it is only with the right conditioning that a dual wage framework, for example, which differentiates Mexican (lower) wages from Canadian wages, can be portrayed as a great opportunity for poor Mexican workers (Binford, 2009) rather than as a form of systematic exploitation. Underlying these instances of systemic racism is the global ethnic hierarchy, a consequence of our colonial past, which privileges white people of European origin and marginalizes people from non-white ethnic origins (Gradstein \& Schiff, 2004). 
Through temporary foreign worker programs, farmers have access to a labour force that competes transnationally with the local labour force and that is willing to work for significantly lower wages. But it is important to remember that the apparent eagerness exhibited by many low-skilled workers is usually generated by a desperate situation in their countries of birth (Basok, 2002; Binford, 2006). Indeed, the program specifically targets peasants who live in desperate conditions and can only find rural jobs that have very low wages. In 2001, they were paid at about 40 to 60 Mexican pesos a day, which was between 6 and 10 Canadian dollars a day (Binford, 2002). In 2006, the exchange rate was about 9.6 pesos per dollar (Canadian Forex, 2015). As such, Mexican wages between 40 to 60 pesos were equivalent to between 3.3 and 6.4 Canadian dollars a day. In contrast, Canadian wages in the same year (the year of the census) were about $\$ 7.45 /$ hour, (the 2006 minimum wage in Ontario), at least 10 times higher than what they would earn in Mexico. The Canadian program is attractive to them not only because it has better wages but also because it is safer than illegally crossing the border to the United States and is cheaper (in 2001, approximately 120 dollars) than the high cost of legally doing so (Binford, 2002). However, even if these wages allow them to educate their children and to improve their general living standards, the price for doing so is high: family separation, long (sometimes unpaid) hours of employment and, in some cases, abuse and exploitation. The wage discrepancy between Mexican and Canadian workers is also an outcome of neoliberal policies established in Mexico in the 1970s and 1980s, which left the peasant population in miserable condition. Privatization and the implementation of maquiladoras ${ }^{35}$ led the

\footnotetext{
35 'Maquiladoras' is a Spanish word that refers to companies (mainly manufacturing companies) located in Mexico, generally near the border with the United States.
} 
Mexican economy into a relationship of dependency on foreign investment (Arzate 2001; Ramirez 1992; Ramos 1998 as cited in Binford, 2002).

Neoliberal principles in Canada have also defined the structure of agri-food production and its participation in the global agricultural market. The highly competitive nature of modern agriculture has transformed agriculture in Canada into economies of scale. This, in turn, has led to an increase in volume of production and farm size and a reduction in costs, which is typically accomplished by cutting wages. As the number of large farms increases to meet the demands of production, the number of small farms decreases: "The most recent census of agriculture shows that between 2001 and 2006 there was a seven percent decline in the number of farms; this compares to an 11 percent decline between 1996 and 2001" (Agriculture and Agri-food Canada, 2008b as cited in Preibisch, 2010, p.430). In contrast, in 1996, "farms with more than $\$ 250,000$ in sales represented 10 percent of all farms and 56 percent of total farm receipts; by 2006, these farms represented 17 percent of all farms and contributed almost 75 percent to total farm receipts" (Agriculture and Agri-food Canada, 2008b as cited in Preibisch, 2010, p.430).

As with Caribbean workers, the introduction of Mexico into the SAWP provided employers with means to continue with now more elaborated labour segmentation practices along the lines of race. Over time some employers found strategies for using and adapting stereotypical characteristics of Mexican and Caribbean workers according to their needs. Stereotypes linked to workers' origin and their language skills (or lack thereof) have been translated into reduction/increase in their desirability. Concerns from employers and locals about Caribbean workers being prone to have sex with Canadian 
women have made them less desirable. Employers also complain that Caribbean workers' extended social networks in Canada make them more likely to acquire commitments outside the workplace compared to Mexicans. In contrast, Mexicans' perceived docility, eagerness to work longer hours and to put up with tough labour conditions without complaining have increased their appeal among Canadian farmers (Preibisch \& Binford, 2007). Fluctuations in the number of workers representing different nationalities also reflect employers' methods of coping with difficulties linked to globalization, international competition, environmental factors, etc. In the tobacco industry, for example, changes in policies, reduction in tobacco consumption, changes in weather and crop diseases have significantly altered the need for Caribbean labour, which have also affected their wages (Ramsey, Stewart, Troughton \& Smit, 2003 as cited in Preibisch \& Binford, 2007).

Unfortunately, the converse is not always true and significant increases in production do not necessarily translate into better conditions for workers. Strong competition against US producers and changes in regulations make it difficult to stay afloat in the market, even if a good crop is yielded. One notable exception is in apple production, primarily in Ontario, which grew between the 1980s and 1990s, where prices fell relative to a growth in foreign workers' wages (Preibisch \& Binford, 2007). In other sectors, however, genuine economic growth did not translate into an increase in wages for TFWs. Horticulture and floriculture, for example, grew significantly during the 1990s, however, it is documented that foreign workers continued to be paid less than Canadian workers (Basok, 2002). In fact, in Ontario, "wages fell in real terms for most crops by an estimated 7\% between 1992 and 2003" (Preibisch \& Binford, 2007 p.11). 
Thus, what seems to be a common denominator is that "many Canadian growers seek to displace the rising costs of agricultural land and inputs, as well as to mitigate the effects of highly competitive, globalized markets in which retailers hold the upper hand, by minimizing the wages of the most vulnerable sector of the work force" (Binford, 2006 as cited in Preibisch \& Binford, 2007). As a result, the agricultural labour force ends up being racially segmented (Binford, 2002) by commodity and/or country of origin (Preibisch \& Binford, 2007).

In this way, both the LIC and the SAWP programs function by racializing and gendering temporary foreign workers (Faraday, 2012a), which in a way continued the racialized immigration policies that existed prior to the points system (Kelley \& Trebilcock, 1999; Triadafilopoulos, 2004). While many theorists have questioned the stereotypical, gendered and ethnic basis for migration operative in the selection of women for live-in caregiving jobs (Bakan \& Stasiulis, 1994; Brickner \& Straehle, 2010; Grandea \& Kerr, 1998; Hsiung \& Nichol, 2010), the continued existence of programs such as LIC and SAWP reaffirms the highly gendered and racialized nature of international migration programs (Dauvergne, 2000). All in all, in contrast with LICs, temporary foreign agricultural workers do not have a pathway to permanent residence or, by extension, to citizenship, which contributes significantly to their exploitability (Basok, 2004; Hennebry \& Preibisch, 2012; Preibisch \& Binford, 2007; Preibisch, 2010). Except for live-in caregivers, low-skilled workers by and large do not count with a pathway to citizenship. However, some provinces like Manitoba, Alberta and British Columbia allow employers to nominate some low-skilled (NOC C and D) workers through their Provincial Nominee Program - PNP (Manitoba's PNP Website, Alberta's 
PNP Website and BC's PNP Website, 2017). In Ontario, the only low-skilled workers with access to permanent residence are LICs (Faraday, 2012a). Thus, both citizenship laws and migration laws and programs, which are economically conceived, are the primary means to impede citizenship (Dauvergne, 2000). Migration laws serve as façades of citizenship laws by taking charge of the hurdles linked to migration (Dauvergne, 2000, p.309) in a way that contradicts principles of citizenship such as inclusion, belonging and freedom.

While mainly Caribbean and Mexican male workers ${ }^{36}$ have supplied labour needs in the agricultural sector since the 1960s (Palacio, 2010), (and Filipino women caregiving needs), the Canadian government has recently opened doors to workers from other regions. Now employers can select workers from almost anywhere in the world, though in agriculture workers from Guatemala, the Philippines and other Asian countries represent now the main sources. These workers started to come through the former low-skilled Pilot Program (LSPM), which provided access not only to foreign agricultural workers but also to low-skilled workers in other occupations.

\subsection{Low-skilled Workers in Other Occupations}

The third group is comprised of all other low-skilled temporary foreign workers coming to Canada (including agricultural workers coming through pathways other than the SAWP). These workers come to Canada through the old Low-skilled Pilot Program,

\footnotetext{
${ }^{36}$ Although SAWP women represent a small proportion of the total SAWPs, and research on female temporary foreign workers in agriculture is scarce (Edmunds et al., 2011), it is evident that the impact of working temporarily in Canada on these women is significant. Research on female seasonal agricultural workers in the SAWP reports mothers' separation from their children as well as specific experiences of indentured labour (Edmunds et al., 2011; Hanson, 2007; Preibisch, 2005; Preibisch \& Encalada-Grez, 2010). Female SAWs experience issues often specific to being a woman, and issues that can only be fully understood within the context of globalization, a globalization that is gendered, economically driven and mostly neoliberal (Edmunds et al., 2011).
} 
which was later transformed into the low-skilled stream of the TFW program and then into the current Temporary Foreign Worker Program, which includes most "low-wage" workers. In 2002, the federal government departed from "government to government" low-skilled programs (Veena et al., 2002) and introduced the Low-skilled Pilot Program. In contrast with the SAWP, this program opened the door to low-skilled temporary foreign workers from anywhere in the world for any low-skilled occupation (including agricultural-related occupations).

Scarcity of labour in Alberta's tar sands and Toronto's construction sector prompted the government to introduce the Low-skilled Pilot Program (LSPP) in 2002 (Fudge \& MacPhail, 2009). This program was designed to complement the previous LIC and SAW programs. When the program was set in place, the CIC made a case for avoiding dependency on cheap labour and ensuring that workers came to fill genuine gaps in the labour market. Only jobs ranked in occupations C or D in the NOC system of classifications were eligible (Fudge \& MacPhail, 2009). In the first stages of the program, work permits were one-year long. In contrast with high-skilled workers, lowskilled workers were not (and still are not) allowed to bring their families. The Canadian government raised concerns about the workers' financial capacity to cover airfares and general expenses of their families while in Canada (Fudge \& MacPhail, 2009). To ensure that a low-skilled TFW was not taking a job from a Canadian, employers had to obtain a Labour Market Opinion (LMO), recently transformed into Labour Market Impact Assessment (LMIA). ${ }^{37}$ Following employers' lobbying efforts, in 2006 the elected

\footnotetext{
${ }^{37}$ This requirement was also in place for high-skilled workers not coming via either provincial or international agreements (i.e. GATs and NAFTA). It also did not apply to workers coming under Canadian interest categories and other non-LMIA required pathways.
} 
Conservative government modified the TFW program to make it more accessible to employers. TFW support centers were opened in the main urban centers across Canada to assist employers in obtaining LMOs and work permits. In coordination with the provincial governments of Alberta and British Columbia, the government initiated working groups, which were tasked with establishing lists of occupations under pressure to help employers with the process of obtaining temporary foreign labour (Fudge \& MacPhail, 2009). The first list in BC included more than 230 occupations; in future iterations, this list would change to have a heavier low-skilled composition (Fudge \& MacPhail, 2009).

In 2007, the duration of work permits was extended from one year to two years. Between 2007 and 2010 the Expedited Labour Market Opinion (E-LMO) pilot project (Gross, 2014) was set in place. This pilot project allowed select employers in select occupations to obtain LMOs in three to five days (Fudge \& MacPhail 2009). These changes boosted the use of the TFW program significantly (more than a 100\% increase), especially in low-skilled occupations. These selected occupations, which include low-skilled positions in construction, hospitality, and tourism, accounted for $25 \%$ of the combined volume of regular requests for LMOs in Alberta and British Columbia. In 2008, twenty-one additional occupations, including food and beverage services and residential cleaning and support workers, were added to the pilot, covering $50 \%$ of the combined total of requests for LMOs from the two provinces. More than 230,000 requests for temporary foreign workers were received by HRSDC in 2007, up from 150,000 requests in 2006 (Fudge \& MacPhail 2009, p. 27). 
According to Foster (2012), the Temporary Foreign Worker Program in Canada transitioned from a program designed to address short-term labour market needs into a program that has brought a significant number of TFWs, especially low-skilled workers, to Canada (Foster, 2012). Between 2006 and 2007, TFW applications grew four-fold in Alberta (Fudge \& MacPhail, 2009). In response to a corresponding increase in abuse and complaints, unions voiced their concern with the exponential increase of the TFW program. Although the TFW program is federally operated, the federal government objected that, because labour protection is a provincial domain, it was up to the provinces to introduce mechanisms of protection. Despite this initial effort to shirk responsibility, the federal government later introduced protective measures, including: "developing memoranda of understanding with provincial governments to improve cooperation on matters concerning employment standards; amending the IRPA to prevent vulnerable foreign workers from being exploited or abused; and developing mechanisms to monitor employer compliance with the terms and conditions of the TFWP as well as a formal process to address instances of noncompliance" (Fudge \& MacPhail, 2009, p. 29).

In 2007, mechanisms, including changes to the contract between employer and employee, were set in place. Such changes, however, were not enforceable by the federal government and each party was responsible for being informed about its rights and responsibilities (Fudge \& MacPhail, 2009). Provinces also passed laws to protect foreign workers (ex. Manitoba's Worker Recruitment and Protection Act and Ontario's Employment Protection for Foreign Nationals Act (Live-in Caregivers and Others)). However, some provinces (including those with the highest number of TFWs, namely 
Ontario and Alberta) still do not allow agricultural workers to unionize, depriving them of collective bargaining rights (Fudge \& MacPhail, 2009). Quebec, however, does allow it. Mechanisms of enforcement were also introduced, but most of them were voluntary (Fudge \& MacPhail 2009). Further changes were made to the TFW program to ease hiring processes. In 2009 lists of occupations were eliminated and employers only had to advertise their job postings for 14 days (Gross, 2014). In 2011, the maximum length of time that foreign workers could stay in Canada was increased from two to four years. The E-LMO process was introduced in 2007 , initially for 12 occupations but then was further expanded in 2008 to include 33 occupations, only to be eliminated in 2010 (Gross, 2014). Other policies were designed to regulate wages for TFWs. Since 2012, employers can pay low-skilled workers $5 \%$ below the median wage, ostensibly to avoid paying TFWs wages above those of some nationals. In fact, TFWs were likely to be paid the median wage for the specific occupation in the region/province where the job takes place.

Other measures were taken to allow employers "to offer high-skilled TFWs up to 15 percent less than the median wage and low-skilled TFWs 5 percent less as long as it remained above the minimum wage" (Gross, 2014, p.7). The Accelerated LMO (A-LMO) was introduced to allow employers hiring workers in occupations NOC 0, A and B to obtain the LMO within 10 business days (Gross, 2014). Both measures functioned to significantly increase the number of TFWs coming to Canada. In 2008, British Columbia and Alberta had accessed more than twice the number of workers in the rest of Canada, combined (Gross, 2014). Complaints from advocacy groups and pressure from the media prompted the government to make changes, including the elimination of the very 
unpopular pay of $5 \% / 15 \%$ below median wage and the A-LMO; posts were to be advertised for four weeks; and jobs were to require speaking only one of Canada's official languages (Gross, 2014). An LMO processing fee was also introduced and requiring other languages (different to Canada's official languages) was allowed only if it was strictly related to the job description.

All these changes led to significant increases in TFWs, which in some cases appears to have harmed provincial economies. Gross argues that temporary foreign worker programs make sense when there are low unemployment rates in specific regions or in specific industries or occupations. Between 2002 and 2012, policy changes were implemented that eased employer's access to TFWs, but unemployment rates either remained the same or even increased. Some of those increases were caused in part by the employers' easy access to TFWs (Gross, 2014).

Easing the rules to access TFWs was a response to supposed shortages in the labour market. A lack of accurate information with which to nuance and identify clear labour needs led to the creation of the Accelerated LMO and the E-LMO pilot projects that ended up increasing unemployment rates, especially in provinces with the highest consumption of TFWs: Alberta and British Columbia (Gross, 2014).

Up to the present day, the Canadian government still seems to be experimenting with the Canadian labour market. Under the government of Stephen Harper, temporary foreign labour was used to respond to labour needs, but lacked the substantial research needed to evaluate policy outcomes. Policies were simply set in place with little empirical evidence about labour shortages or consultation. The number of policy changes between 2002 and 2013 was significant and many policies came and left in a 
matter of a few years. In general, policies were introduced to create incentives for employers to use temporary foreign labour as opposed to domestic labour (Gross, 2014). While pressure from the media, academics and advocacy groups prompted an entire overhaul of the system presented in 2014, which included changing basic methodologies and assumptions underlying foreign low-skilled labour (i.e. a move from skills to wages) (CIC, 2014), many of these changes have been criticized, especially in how they relate to low-skilled workers (Faraday, 2016). Critics argue that some changes extended and even exacerbated the precariousness workers' conditions (Faraday, 2016). The significant number and rapid turnover of changes, both in the economy and in policy, have made immigration policy analysis and research incredibly volatile and, by extension, difficult to analyze. Not surprisingly, the practice of introducing a significant number of changes without a significant body of research and analysis led to ineffective policymaking that needed constant revisions.

\subsection{The current Low-Skilled Temporary Foreign Worker Program Streams and the Most Relevant Recent Policy Changes}

\section{Low-Skilled Temporary Foreign Worker Pathways}

Live-in

Caregover

Program
The Seasonal

Agricultural

Workers

Program

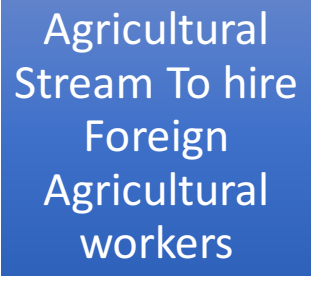

Agricultural

Foreign

Agricultural

workers
Stream for Low Wage Positions 
As of July 1, 2016, ESDC offers employers four pathways to hire low-skilled workers: The Live-in Caregiver Program, the Seasonal Agricultural Worker Program, the Agricultural Stream, and the Low Wage Stream.

3.4.1. The Live-in Caregiver Program. This stream allows employers to hire live-in caregivers for children and for people with high medical demands. Caregivers for children work in occupation NOC 6474-Live-in Caregivers and Nannies. Caregivers for high medical needs can work in any of the four following occupations: NOC 3413 Nurse Aides, Orderlies and Patient Service Associates, NOC 6471 Visiting Homemakers and Housekeepers and Related Occupations (ESDC, 2016c). Employers hiring workers under this program are required to apply for a Labour Market Impact Assessment (LMIA), which provides a way to signal that the worker will not affect the Canadian labour market. Live-in caregivers require fluency in either English or French and demonstrated work experience $(\text { ESDC, 2016c })^{38}$. Employers are required to provide proof of the individual requiring care and financial ability and to pay transportation fees for low-wage ${ }^{39}$ LICs (from their country of origin to the place of work in Canada) (ESDC, 2016c). The previously long-standing requirement that caregivers live in the employer's house no longer holds. However, if the employer does offer accommodations, they must be private, furnished, with a bedroom door that has a lock and bolt, and in the home of the person in need of care.

Employers must also provide health Insurance and an employment contract, which meets the minimum wage for the occupation in the region of work. They must pay

\footnotetext{
${ }^{38}$ In addition to at least six months of training and relevant caregiving experience, eligibility to the LIC program also demands fluency in one of Canada's official languages (Sweetman \& Warman, 2010)

${ }^{39}$ See Stream for Low-wage Positions in this chapter.
} 
any overtime and ensure provision of due breaks and holidays as well as a safe workplace (ESDC, 2016c). Live-in caregivers are eligible to apply for permanent residence after two years of work. The Live-in Caregiver Program is the only federally run temporary foreign worker program with a pathway to citizenship (ESDC, 2016c). However, as will be explained in this chapter, changes introduced in 2014 made eligibility more restrictive and not entirely guaranteed (Faraday, 2016).

\subsubsection{The Seasonal Agricultural Workers Program (SAWP). This program} was initially conceived as a government to government program. In contrast with other low-skilled TFW programs in agriculture, in this program, the sending country is also involved (Hennebry \& Preibisch, 2012). This program is the outcome of agreements reached between the Canadian government and the governments of Barbados, Jamaica, Mexico, Trinidad and Tobago and the Organization of Eastern Caribbean States (Hennebry, 2012). Under this program, employers can only hire TFW workers from these countries and must follow the regulations stemming from the agreements with these countries (Hennebry, 2012). Participants of the program must be experienced farm workers and at least 18 years old. The work is restricted to primary farm work (within the confines of a farm, nursery or greenhouse) and the worker can be hired for a maximum of eight months (ESDC, 2016d). The employer is responsible for paying for the worker's round-trip, although a portion of the expenses may be recovered through payroll deductions. Employers are expected to provide housing (except in British Columbia), an employment contract, proof of a functioning business, and to pay work 
permit fees. ${ }^{40}$ Employers must ensure that workers are registered on a provincial or territorial health plan as soon as they become eligible (ESDC, 2016d). Health coverage during the waiting period represents a bit of a grey area because there is no explicit regulation, except in Ontario, where health care is provided upon arrival (Hennebry \& Preibisch, 2016).

Employees are technically allowed to transfer from one farm to another, but only with the approval of both sending and receiving employers, which is very difficult to obtain (Hennebry, 2012). Adding to this difficulty, the worker's legal status is tied to the employer (Hennebry, 2012), which means that the process of job termination ends in deportation. Employers are required to prove attempts to recruit Canadians (or permanent residents), before offering a position to a TFW. They must then obtain a LMIA. ${ }^{41}$ Wages and benefits must be the same for TFWs as what is offered to Canadians and permanent residents, a legislation that is brought into question in this dissertation.

Interviews with a former official in charge of the SAWP suggest that the program provides a model for temporary migration because it "recognizes and responds to legitimate labor shortages in the economy, ... [has a] formal structure... [ensuring] that all the key players are engaged and that the workers' rights are clearly understood, outlined, and enforced through agreements, memoranda of understanding, and operations guidelines" (Basok, 2007). However, the program's emphasis on the employer and its restriction of workers' mobility, both in the labour market and various social contexts, lead to flaws at the level of integration and access to rights (Basok,

\footnotetext{
${ }^{40}$ Permit fees can be recovered for Mexican workers and for Caribbean workers they are paid by the governments of their countries of origin.

${ }^{41}$ Labour Market Impact Assesment
} 
2007).

\subsubsection{The Agricultural Stream to Hire Temporary Foreign Agricultural}

Workers. Employers in the agriculture sector also have the option to hire low-skilled temporary workers. In contrast with SAWP, which restricts the countries from which workers can be hired, the agriculture stream is not the outcome of a concerted agreement between nations and employers are allowed to hire workers from any country in the world (Preibisch, 2012). Workers can be hired for up to two years, which can then be extended to four years. This is the maximum period a TFW can work continuously in Canada, after which point it is necessary to wait another four years before being eligible to apply for another TFW work permit (ESDC, 2016d). Depending on the province or territory in which the job takes place, specific application processes may apply. Before applying for a TFW, employers must demonstrate attempts to hire Canadians or permanent residents. They must then apply for a LMIA. Employers must cover round-trip travel expenses and provide either onsite or offsite housing, the costs of which can be deducted from a worker's salary up to a maximum of 30 dollars per week. Employers must pay for the private health insurance of their employees. As with SAWPs, workers under this stream must be paid the same wage as Canadians and permanent residents (ESDCd, 2016d).

3.4.4. Stream for Low-wage Positions. This stream officially allows employers to hire full-time temporary foreign workers for a wage that is below the provincial/territorial median hourly wage for the occupation and in the region where the 
job will take place. Any employer offering wages below the provincial/territorial median must abide by the regulations of this stream. Applications in this stream will be rejected if the three following rejection criteria are met: the unemployment rate in the region where the job will take place is $6 \%$ or higher; the occupation is classified within the North American Industry Classification System (NAICS) as either NAICS 72 Accommodation and Food Service or NAICS 44-45 Retail Trade; or the position is in any of the following NOC occupations:

1. Food counter attendants, kitchen helpers and related occupations (NOC 6641);

2. Light duty cleaners (NOC 6661);

3. Cashiers (NOC 6611);

4. Grocery clerks and store shelf stockers (NOC 6622);

5. Construction trades and labourers (NOC 7611);

6. Landscaping and grounds maintenance labourers (NOC 8612);

7. Other attendants in accommodation and travel (NOC 6672);

8. Janitors, caretakers and building superintendents (NOC 6663);

9. Specialized cleaners (NOC 6662);

10. Security guards and related occupations (NOC 6651)

Employers are charged \$1 000 for each position requested (LMIA fees), and recovering this fee is forbidden. Employers hiring workers with wages below the provincial or territorial median are subject to a cap on the number of TFWs hired (a maximum of $20 \%$ of the employer's labour force). Exemptions to the cap are made for: agricultural and caregiving occupations; positions that will become permanent via 
express entry ${ }^{42}$; employers with less than 10 employees nationally (including the position to be filled) (ESDC, 2016e). From February 2016 until the end of 2016, the federal government extended exemptions to all seasonal jobs (up to 180 days)

(Faraday, 2016). It is noteworthy that exemptions to the cap primarily cover agricultural workers and live-in caregivers, which comprise the highest number of TFWs in Canada. Exploitation in these occupations has already been amply documented (Hennebry, 2012; Preibisch \& Binford, 2007) and a two-tiered wage system creates a "patchwork of differential rights and pockets of permanent precarity" (Faraday, 2016, p.31). Eligible jobs cannot require languages other than English or French, unless the employer can demonstrate that another language is essential for the job, but low-skilled occupations may require previous work experience. Round-trip transportation costs are borne by the employer and must be presented up front in order to protect the workers from being offered other transportation arrangements in exchange for a contract (ESDC, 2016e). The employer is not obliged to provide housing but must ensure that affordable housing is available; he or she must arrange and to pay for employee safety insurance; and, if the job is unionized, must follow specific regulations. Employers must also prove that they attempted to hire Canadians (or permanent residents) and then they need to obtain an LMIA. (ESDC, 2016e).

3.4.5. Most Recent Changes Affecting Low-Skilled TFWs. The report on the TFW program presented at the Standing Committee on Human Resources, Skills and

\footnotetext{
${ }^{42}$ Express Entry is the system used by the Canadian federal government to manage applications for permanent residence in some federal and provincial programs including the Federal Skilled Worker Program, the Federal Skilled Trades Programs and the Canadian Experience Class Program (IRCC, 2017).
} 
Social Development and the Status of Persons with Disabilities in September 2016 (HUMA) states that employers hiring low-wage workers are subjected to a cap in the number of workers, now at $20 \%$ of the total employed labour force in an enterprise. In July 2017 it will be lowered to 10\% (HUMA, 2016). The cap does not apply to "employers with fewer than ten employees nationally or to positions in on-farm primary agriculture, caregiving, highly mobile positions that cross provincial, territorial and/or international boundaries, and positions that last for fewer than 120 days. In February 2016, the government added an exemption for any low-wage 'seasonal' positions that last no more than 180 days" (Faraday, 2016 p.24). Affected employers, especially in the seafood industry in the Maritimes, meat processing industry in Manitoba and fishing industry in Prince Edward Island, complained that the cap negatively affects productivity (HUMA, 2016). Another complaint is that the cap's calculation for exempted seasonal occupations was unfair (HUMA, 2016). Some of these regions experience significant labour shortages linked to interprovincial migration and migration of youth (HarlingStalker \& Phyne, 2014).

While some industries and occupations may experience genuine labour shortages, it is worth noting that some exemptions take place in occupations with the highest number of TFWs (caregiving and agriculture). Proposed suggestions for effectively implementing the cap on TFWs include the suggestion that "greater micro labour market data be collected and that the cap be frozen at levels that are supported by LMIA labour needs ... [and, that] the seafood sector be covered under the primary agriculture stream" (HUMA, 2016, p.17). The committee recommended the cap to be set at a minimum of $20 \%$ with "further review sector and geographic considerations" 
(HUMA, 2016, p.32).

Another restriction extracted from the changes introduced in November 2014 is to refrain from processing "LMIA applications for certain low-wage positions in the Accommodation, Food Services and Retail Trade sectors in economic regions with a $6 \%$ or higher unemployment rate" (HUMA, 2016, p.16). Representatives of the Hotel Association of Canada explained how these restrictions have significantly affected their industry, arguing that they have tried "multiple initiatives to recruit Canadians first, including some targeting Indigenous peoples" (HUMA, 2016, p.16). The report also raises concerns on inaccuracies on regional unemployment rates, since such calculations are based on high-level data, which is not granular enough and hence unreliable (HUMA, 2016). Proposed solutions include the creation of a "Seasonal Lodging Worker Program to recognize the seasonality of the hospitality industry and that some tourism jobs, such as foreign language tour guides, be moved from the lowskill to the high-skill category" (HUMA, 2016, p.17). Acknowledging the need for further studies to evaluate the impact on workers and industries of introducing other seasonal temporary foreign worker programs, the committee proposed that "Employment and Social Development Canada take immediate steps to improve the collection of labour market data and review the geographic zones used for determining unemployment rates, with a view to aligning the labour market conditions of more localized economies with the requirements of the Temporary Foreign Worker Program" (HUMA, 2016, p.31).

One more restriction introduced in 2014 to address low-skilled workers is a reduction in the length of stay for low-wage workers' work permits from two years to one year (Faraday, 2016). Another significant recommendation was number 16: "That 
Immigration, Refugees and Citizenship Canada review the current pathways to permanent residency for all temporary foreign workers, with a view to facilitating access to permanent residency for migrant workers who have integrated into Canadian society and are filling a permanent labour market need" (HUMA, 2016, p. 32). The committee acknowledged the need for workers who are contributing to the Canadian economy to have a pathway to Canadian Citizenship (HUMA, 2016).

The introduction of the 2014 changes also resulted in specific policy changes in the Live-in Caregiver Program (LCP), especially related to its pathway to permanent residence. The former LIC program guaranteed all participants access to permanent residence after two years of work as TFWs. Under the new program, the federal government created two capped streams (The Caring for Children Class and the Caring for People with High Medical Needs Class), each of which allowed up to 2750 places for permanent residence a year (Farady, 2016). In the year before the ruling came into place (November 2014), the federal government had approved 13335 caregiving positions on $\mathrm{LMIAs}^{43}$ (Faraday, 2016). In 2015 and 2016 the number of approved caregiver LMIAs dropped significantly to 3983 in 2015 and to 3128 in the first two quarters of 2016 (ESDC, 2016i). If the quota is already filled when applying for permanent residence, IRCC advises caregivers to either wait until the next year or to apply in any of the other PR streams (Faraday, 2016). This new approach introduces considerably more insecurity since permanent residence is no longer guaranteed (Faraday, 2016). Although the number of caregivers coming to Canada dropped significantly after the changes, there is no legislation that caps the number of LMIAs issued, which depends on employers' demand (Faraday, 2016). The low numbers of

\footnotetext{
${ }^{43}$ See footnote 24 in chapter two.
} 
LICs also raises questions of an imminent scarcity of caregivers, since the number of caregiving-LMIAs has dropped by approximately $70 \%$ (from 13335 to 3983 ).

In summary, recommendations in the HUMA report address issues including LMIA processes and fees, pathways to permanent residence, monitoring and enforcing. The report raises issues related to the LIC program, including the existence of a backlog of 38000 applicants expecting a decision and cases taking an average of 49 months to process (HUMA, 2016). Although there is no mention of removing the cap on the LIC program, the report recommends pathways to permanent residence for all migrant workers (HUMA, 2016).

As this thesis is being written, more changes in the TFW program have occurred. On December 13, 2016, Immigration, Refugees and Citizenship Canada issued changes to the TFW program, including, 1) the elimination of the four cumulative year rule (four years in and four years out) in place since April 2011; 2) low-wage employers are now obliged to "advertise to more than one, and up to four, under-represented groups in the workforce-youth, persons with disabilities, Indigenous people and newcomers" (IRCC website, 2016a) before trying to hire a low-wage TFW; and 3) the cap on low-wage workers will be kept at 20 "for employers who accessed the program prior to June 20,2014 , and at 10 percent for new users of the program after that date. The exemption on the cap for seasonal industries seeking temporary foreign workers for up to 180 days during the 2017 calendar year will be extended until December 31, 2017" (IRCC website, 2016a). 


\section{Summary}

The reasons for low wages among low-skilled non-citizens are diverse and range from a colonial legacy to policy makers' entrenched ideas, from lobbying efforts of employers to the economic devastation abroad caused by neoliberal policies. Whatever the reasons, citizenship or a lack thereof has been used as a means to articulate and validate low wages among low-skilled non-citizens. While variables related to either the workers themselves (gender, age, country of birth, level of education, etc.) or to the work setting (rural/urban location, province of residence) are likely to influence wage difference, citizenship (or lack thereof) is the most significant factor.

The low wages earned by TFWs can be traced back to the time when programs were introduced to bring temporary foreign workers to Canada. While employer needs significantly drive TFW policy, this chapter detailed the ways in which they are not the sole factor determining the number of TFWs in the labour market. If that were the case, the number of TFWs would be significantly higher (as shown in chapter one, the proportion is very small, around $1.7 \%$ of the labour force). Government policies also exert influence, insofar as they respond to labour needs and weigh the needs of different stakeholders and regions in Canada. The ruling government party navigates these needs while keeping its own political agenda in mind (Carty et al., 2007). The next chapter provides the methodology followed to evaluate wage differences as well as the impact of lack of citizenship and other variables including sex and province of residence on wages of low-skilled Non-Permanent Residents (NPRS). It will also introduce the methodology to evaluate whether wages concentrate around either low or high values (as demonstrated through quartile analysis of wages). 


\section{Chapter Four: Methods, Considerations and Methodological Challenges}

Using quantitative methods, this dissertation compares the wages of low-skilled NPRs against those of two specific groups: low-skilled immigrants (IMM) (naturalized immigrants and permanent residents) and low-skilled Canadian-born workers (CB). The data source used must accordingly include information about all three groups (NPR, IMM, CB) as well as the variables that will serve to compare the three groups. This chapter is divided into eight main sections. In the first section I provide a general description of the problem, the research questions. In the second section I present a general description of methods used in this dissertation. In the third section I present the process I used to select the dataset (2006 census data). In the fourth section I gather information about all the variables I used in the analysis, including justifications for their use and criteria for selection of categories in each variable. Variables include: wages (dependent variable), age, province of residence and country of birth (independent variables). In the fifth section I focus on the criteria for selection of populations used in the analysis (i.e. who is included in the NPR population). In the sixth section I present the limitations I faced throughout the analysis. In the seventh section I introduce a highlevel explanation of the quartile analysis. This type of analysis is of central importance in the wage analysis in chapter six to evaluate whether wages concentrate around either low or high values. In the eighth section I explain the tests used in the analysis (ANOVA and Post Hoc (Bonferroni)). These tests evaluate the comparability of the means.

\subsection{Problem and Questions}

4.1.1. The Problem. Existing research suggests that a lack of citizenship renders foreign low-skilled workers vulnerable to exploitation. This dissertation explores the 
effect that citizenship (or a lack thereof) ${ }^{44}$ has on the wages of low-skilled NPRs compared to those with citizenship (or with access to most citizenship rights) in different layers of analysis including sex, province of residence, level of education and country of birth. Because the layers of analysis are central to this research work, most of the dissertation introduces a significant level of detail that is presented in many categories and subcategories of analysis. These categories and subcategories help to guide the granularity of analysis present across the dissertation, especially this chapter on methodologies as well as the quantitative chapters (five, six, seven and eight).

4.1.2. Research Questions. This dissertation addresses the following question: To what extent does the policy-created lack of citizenship, combined with intrinsic characteristics of workers (age, sex, level of education ability to speak English or French, or place of birth) and their occupations (provincial location, urban/rural setting) affect the wages of low-skilled NPR workers in Canada?

In Canada, no study has compared wages among low-skilled workers from the perspectives of legal status and occupation. A literature review also reveals a lack of systematic studies in Canada that examine wage differences by immigration status and other intrinsic characteristics (of NPRs themselves and their occupations) already mentioned. Understanding wage differences in view of these characteristics allows us to

\footnotetext{
${ }^{44}$ While both naturalized immigrants (immigrant with citizenship) and permanent residents (immigrants without citizenship) have somewhat similar rights and privileges in Canada, some differences persist. Only citizens have the right to vote and have access to the Canadian passport; and permanent positions that require high-level security clearance are restricted to those individuals with Canadian citizenship (Government of Canada, 2015). However, most low-skilled occupations have no restrictions linked to citizenship status. Since both naturalized citizens and permanent residents have equal rights with respect to access to most low-skilled occupations, there is no distinction in this research between the two groups. Both are merged together and considered as one group throughout the analysis. In this analysis, this group is called 'immigrants' or 'IMM' whether naturalized or not.
} 
zero in on the specificities of wage discrepancies. More detailed information also stands to improve future analyses and achieve more accurate policymaking. Finally, reviewing the literature on TFW policymaking helps us evaluate the role of the state in maintaining workers' status as noncitizens. Let me now recall the specific questions that this research addresses:

Question One: What are the demographics of low-skilled labour in Canada?

Question Two: Do wages of low-skilled workers concentrate around either low or high wages?

Question Three: How large are the wage differences between NPRs and CB and between NPRs and IMM in each industry sector and occupation analyzed in this dissertation?

Question Four: How large are the wage differences between NPRs and CB and between NPRs and IMM by intrinsic characteristics of workers (sex, level of education, ability to speak English or French, or place of birth) and their occupations (provincial location, urban/rural setting) in all occupations analyzed in this study?

Question Five: How large is the effect of lacking citizenship on the wages of NPRs if the variations on wages linked to intrinsic characteristics of workers above (age included) of low-skilled NPRs are held constant?

Question Six: Are wage differences the consequence of citizenship-related policies in place?

While no studies have compared NPRs with other low-skilled workers in Canada, the literature review anticipates that NPRs would likely have lower wages than other lowskilled CB, and low-skilled IMM and that low-skilled workers in general concentrate 
around low wages. From this perspective, question one will require elaborating a profile of low-skilled labour in Canada; question two will require exploring the wage ranges of the occupations analyzed through a quartile analysis; questions three to six are explored by investigating the following hypotheses: Among low-skilled workers in Canada,

Hypothesis 1: All NPRs earn lower wages than CB and IMM when NPR wages are compared to those of the CB and IMM by

a. Sub-Hypothesis 1a: industry sector and occupation

b. Sub-Hypothesis $1 b$ : sex, province of residence, work location (rural/urban), level of education, ability to speak English or French and place of birth all in each occupation analyzed in this study

Hypothesis 2: Controlling for age, sex, immigration status, province of residence, work location (rural/urban), level of education, ability to speak English or French and place of birth, being a NPR has a significant negative impact on wage compared to being Canadian-born.

Hypothesis 3: These previous statements are the consequences of policies in place that prevent NPRs from accessing citizenship.

To determine the number and distribution of low-skilled workers, this research will present a profile of low-skilled labour (including information of low-skilled NPRs) in Canada in chapter five. To evaluate the wage differences between low-skilled workers according to citizenship status, this study will compare the wages of low-skilled workers without citizenship (NPRs) with the wages of low-skilled Canadian born and low-skilled immigrants (who are either citizens or permanent residents). The study will further 
nuance these differences by evaluating wage differentials not only by citizenship status but also by intrinsic characteristics.

\subsection{Methods used to test the hypotheses and address the questions.}

Addressing these questions and their respective hypotheses requires a quantitative analysis following two main methods: cross tabulation and regression analysis.

4.2.1. Cross Tabulation. Also known as contingency analysis, cross tabulation consists of tabulating two or more variables to establish the degree of interrelatedness between or among them. This contrast takes place by comparing the values of a variable, for example by comparing the average wage of population $\mathrm{A}$ against the average wage of population $\mathrm{B}$. In contrast with regression analysis, it does not treat variables as dependent or independent. However, in this dissertation, I will use cross tabulation to analyze how changes in the independent variable ${ }^{45}$ (wages) are related to changes in the dependent variables (sex, country of birth, etc.). I will also use cross tabulation to explore correlations between intrinsic characteristics of the workers and their occupations with wages.

The outcomes of cross tabulation analysis provide information on the relation between variables (for example, the relation between wage and sex in each occupation or the average wage by sex in each occupation). A limitation of this method is that it does not permit us to simultaneously consider multiple effects that independent

\footnotetext{
${ }^{45}$ As the name indicates, an independent variable has no dependency on other variables (ex. sex). In contrast, dependent variables build their outcomes in a relation of dependency on other variables (ex. wages).
} 
variables may have on a dependent variable. For example, higher wages among those working in urban settings does not necessarily mean that working in an urban area is the only causal factor influencing high wages. Other characteristics may also affect wages. While simultaneous analysis accordingly provides a more accurate picture of the effects of multiple variables, a single variable trend analysis is nevertheless valuable insofar as it can deliver a basic picture that is easy to interpret. In other words, a cross tabulation approach provides an accessible tool for gauging intervariable relations, a considerable asset when it comes to policymaking. I accordingly use this method in my analysis and compensate for its limitations by also engaging in a regression analysis of the data.

4.2.2. Regression analysis. Regression analysis is a mathematical method that establishes complex relationships between variables. More specifically, it allows us to simultaneously explore the effects of a set of multiple independent variables on a specific dependent variable.

$$
y=a+b_{1} x_{1}+b_{2} x_{2}+\ldots+b_{n} x_{n}
$$

Where:

$\boldsymbol{y}=$ observed values of the dependent variable $\boldsymbol{a}=$ constant (captures any bias due to unaccounted effects) $b_{1}, b_{2}, \ldots b_{n}=$ coefficients (capture the effects of the independent variable on the dependent variable)

$x_{1}, x_{2} \ldots x_{n}=$ observed values of the independent variables 
In a mathematical model, the observed values of the independent variables

$\left(x_{1}, x_{2} \ldots x_{n}\right)$ are mathematically transformed to establish their impact on the dependent variable. In this research, the independent variables are the intrinsic characteristics of workers (age, sex, etc.) and their occupations (province of residence, etc.). The dependent variable is hourly wage.

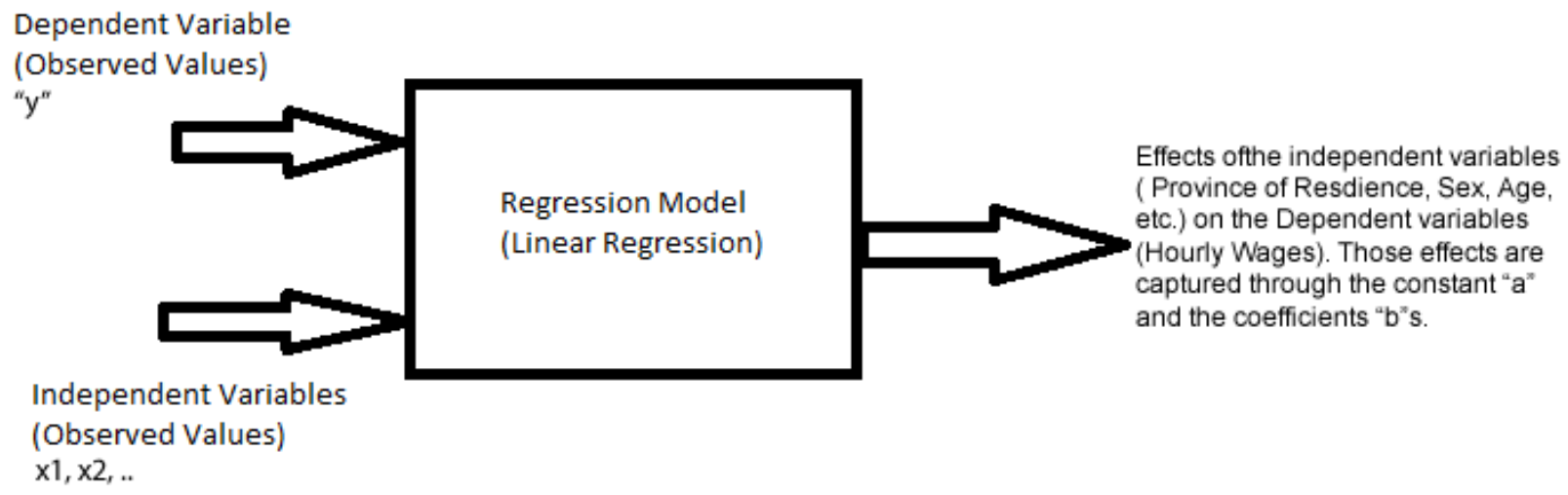

The effects are captured through the constant ' $a$ ' and the coefficients. This research uses Linear Multiple Regression with categorical variables, a model based on the method known as Ordinary Least Squares (OLS). For further details on this method see appendix one.

This methodology requires the transformation of all categories of the independent variables into dummies. ${ }^{46}$ The number of categories transformed into dummies minus one is accordingly introduced in each of the models developed. Linear multiple regression with categorical variables also needs the dependent variables to be normally

\footnotetext{
${ }^{46}$ Transforming into dummy variables implies recoding each category in a categorical variable into either zeros (0s) or ones (1s). For example, in a "Yes/No" variable, all 'Yes' entries become ' 1 ' and all 'No' entries become ' 0 .' In variables with multiple categories, each category is treated as a Yes/No variable.
} 
distributed. ${ }^{47}$ Finally, it requires that there is no co-linearity between subcategories in a variable or between variables (Stockburger, 1998). This is very important; otherwise it is impossible to distinguish where an effect is coming from.

\subsection{Selection of Dataset (2006 census)}

After evaluating the available datasets, including the Survey of Labour and Income Dynamics (SLID) and Labour Force Survey (LFS), I found the census data to be the most comprehensive. Census data is preferred because it contains information of all groups to be compared in my analysis, including temporary foreign workers. To evaluate the outcomes in the labour market of the three groups of low-skilled workers, I preferred 2006 census data, which was the most recent census available when I began my research and the dataset with the largest sample of low-skilled temporary foreign workers. This database includes information related not only to the labour market but also to different characteristics of workers. It is worth mentioning that the census data is collected on one day of the year, which means that some temporary low-skilled workers may be under-represented.

While this research intends to participate in the academic debate concerning the dramatic increase in low-skilled TFWs and its effect on wages, the most recent available data dates to the years in which this growth was in its infancy. That is, at the time that I began my research, the 2006 census was still the most comprehensive dataset available. Even if it had been available, the 2011 National Household Survey (NHS) data would not have been a reliable data source for the type of patterns examined in

\footnotetext{
${ }^{47}$ In statistical analysis, a normal distribution concentrates most of the values around the mean. Thus, a normal distribution contains about $68 \%$ of the observation within one standard deviation (Encyclopedia of Mathematics, 2015).
} 
this dissertation. The $2011 \mathrm{NHS}$ had a response rate lower than that of the 2006 Census ( $77 \%$ and $94 \%$, respectively) (Verret, 2013), which would have been problematic for this study. Although the occupation level information has been deemed reliable (Statistics Canada has provided the public information at the occupation level),${ }^{48}$ data by occupation at deeper levels of analysis (sex, level of education, etc.) would have included significantly fewer counts. This is even more critical for analyses of the NPR population, which is already very small. In short, the 2011 NHS would have provided smaller sample sizes than the 2006 Census, which in turn would have altered the reliability of the present study. Furthermore, although the 2006 Census may seem dated, in some ways it provides an ideal dataset because it acts as the take off point of the growth of low-skilled labour in Canada. ${ }^{49}$

To evaluate trends in temporary foreign workers and how their wages compare with other immigrant or Canadian workers, it would be necessary to consider information from subsequent years. Since the amount of detail required for this kind of comparative analysis is obtained only through the Canadian census, which is conducted every five years, we will have to wait until more information becomes available. Ideally, future research will compare the results from the present study with a similar analysis of other censuses (i.e. the 2016 Census), which will allow us to evaluate changes over time.

Originally, I wanted to use the 2006 Public Use Microdata File (PUMF) files, which is a small sample of the 2006 Census. I identified this as a potential dataset to develop this study; however, the PUMF was not used because its sample size was

\footnotetext{
${ }^{48}$ The 2011 National Household Survey Tables include information on employment income at the occupation level (Statistics Canada, 2017a).

${ }^{49}$ This will be explained in more detail in the following chapter.
} 
inadequate (too small). Exploring this dataset was nevertheless useful because it provided an overview of the proportions and numbers within a larger dataset: the whole 2006 census data. The census comprises approximately $20 \%$ of the entire Canadian population or more than 6 million cases (Canada's population in 2006 was about 32.6 million). In contrast, the Public Use Microdata File (PUMF) contains only 844476 records, representing $2.7 \%$ of the Canadian population. Having such a small proportion of the total population makes it difficult to extract meaningful information about the NPR population. This is even more problematic in the present study, which explores outcomes at a very granular level (i.e. at the level of occupation).

These records were drawn from a sample of one fifth of the Canadian population, a sample data from questionnaire 2B (from the whole census). The 2006 PUMF includes 123 variables. Of these, 102 variables, or $83 \%$, come from the individual universe and 21 variables, or $17 \%$, are drawn from the family, household and dwelling universes. For details on the distribution in the unweighted PUMF files, as well as the procedure used to evaluate why the PUMF files were not sufficient for this analysis, see appendix 3A.

Given that the PUMF was inadequate, I had to focus my attention on the entire 2006 census database. To access this dataset, a proposal was presented to the Statistics Canada and the Social Sciences and Humanities Research Council (SSHRC) (see appendix two). As with PUMF files, the 2006 census database was explored using the SPSS statistical analysis software. The use of this dataset (among the largest and most complex datasets in Canada) represented a massive research undertaking. 


\subsection{Variables Used in the Analysis (Justification) and Data Extraction}

The same variables selected for the PUMF files were also used for the whole dataset. It is important to keep in mind that some variables were used to analyze the outcomes and other variables were used to select the population to be analyzed. This section focuses on the former and the next section on the latter.

Using the methods previously described to evaluate the hypotheses, this research draws on a set of independent variables, including immigration status, age, sex, etc., which will then be contrasted against wages. Detailed definitions of the variables as per the 2006 Census Codebook are found in appendix 3B. Justifications for why each of these variables is used in this study as well as the decisions made for each independent variable will be addressed in this section. The following are the dependent and independent variables used in the analysis.

\section{Dependent variable:}

- Hourly Wages

\section{Independent variables}

- Occupation

- Industry Sectors

- Immigrant Status (CB, IMM, and NPR)

- Province of Residence

- Age

- Sex 
- Rural/Urban setting

- Level of Education

- First Official Language spoken

- Country of birth/Region of Birth

4.4.1. Depended variable - Why are wages relevant? Wage is generally the main source of income for workers and is an indirect indicator of economic growth. When viewed in relation to prices, wages provide information on the purchase power of individuals and, by extension, their level of poverty. In association with variables, including employment, working hours and type of work, wages also provide a window into the general conditions of a labour market. The level of wages provides information about the economic strength of a specific industry sector and the situation of scarcity or abundance of labour in the regions of employment. Wages may also be a means to gauge the level of fairness vis-a-vis labour conditions within specific industry sectors. According to the International Labour Organization (ILO),

Wages are undoubtedly among the most important conditions of work and employment at the enterprise level. Being a cost for employers as well as the main source of income for workers, wages may be a potential source of conflict and have thus become the major focus of collective bargaining all over the world. At the same time, wages can represent a major source of discrimination and deprivation if no decent floor is guaranteed to the workers. On the economic side, wages represent an important part of labour costs and are an essential variable for enterprises' competitiveness which needs to be analysed, also with regard to their interaction with other key economic variables, such as employment, productivity and investment. All the above factors have led States, together with employers' and workers' representatives, to reconsider their wages policies and undertake crucial reforms in this field or to consider new approaches for which the help of the ILO has been required (2009). 
As this passage indicates, wages deserve special attention for various reasons of social, political and economic importance. Wages are often the battleground for social conflicts between the forces that control the means of production and those who actually produce. They are a constant point of tension between the promotion of economic growth and the quest for humane living conditions. While social organizations have accomplished certain historical gains, such as setting a minimum wage, in the current context of neoliberalism, many instruments are set in place to drive wages down.

After exploring the implications of analyzing weekly wages and hourly wages, I chose Hourly Wages ${ }^{50}$ as a variable because it allows direct comparisons with external data, which primarily use hourly wages, and because it is the most fundamental remuneration marker. The variable 'Weekly Wages' is the base for developing the variable 'Hourly Wages.' 'Wages' corresponds to "the gross wages and salaries before deductions such as includes income tax, pensions, employment insurance, etc.," (Statistics Canada, 2008, p.997), earned in 2005 and 'Weeks' refers to the number of weeks worked in 2005.

Hourly wages are calculated in two steps. First, weekly wages are obtained by dividing the variable 'Wages,' which is annual, by the variable 'Weeks,' which gathers information on the number of weeks worked during the year (2005) (for detailed definitions, see appendix 3B). This calculation yields 'Weekly Wages,' which is then divided by the variable 'Hours,' which gathers information on the number of hours worked during the week prior to the census (for a detailed definition, see appendix 3B).

This calculation of hourly wages has some limitations since it assumes that the

\footnotetext{
${ }^{50}$ It considered only for those workers who reported employment income from low-skilled occupations.
} 
average number of hours worked during the week for all cases is equivalent to the number of hours worked during the week prior to the census. However, this is the only way to calculate hourly wage using census data. As explained earlier in this chapter, the census was chosen because it is the only database that includes significant information on NPRs, which is the main population to be analyzed in this dissertation. In order to have the most accurate calculation possible, the selected population includes only those reported in the census as working "full-time" (working 30 hours or more per week). This ensures that all included cases worked the minimum number of hours considered by Statistics Canada as 'full-time.' This is the best possible way to calculate hourly wage rates with the available data and corresponds with how other research studies have analyzed wages based on census data (Fortin \& Huberman, 2002; Pellerin, 2015).

\subsubsection{Independent variables (justification and selection of categories}

criteria). The following independent variables were included in the analysis:

4.4.2.1. Immigration status. This variable is arguably the most important independent variable since it separates the population according to their legal status, which is central to this study. This variable captures whether low-skilled workers either have or do not have access to citizenship. Therefore, the quantitative research in this study is anchored in three different status circumstances: NPR, CB and IMM. As previously explained, the immigrant category includes both naturalized citizens and permanent residents since both have the same access to citizenship and labour market rights. The criteria to select who is considered NPR are included in the next section on the selection of populations. 
4.4.2.2. Industry sectors. ${ }^{51}$ This variable groups individuals according to the economic sector to which their occupations belong. It is relevant to the analysis because an industry sector-level analysis offers insight into the general labour market outcomes at the sectoral level, which is also central for policy analysis. For the industry sector-level analysis, the three kinds of low-skilled populations (IMM, CB and NPR) correspond to the populations also selected at the occupation-level analysis (see the next section).

Given that occupations are grouped into industry sectors, the number of people by industry sector in each of the populations (NPR, IMM and CB) comes from selecting only those working in the 98 occupations designated as low-skilled and that fall into each industry sector. The main criterion for selecting low-skilled workers was occupation, not sector. The selection of low-skilled workers by sector is done via occupations because skill-level is more closely related to the occupation than to the industry sector. While occupations are either low- or high-skilled, industry sectors include both low- and high-skilled occupations. Although the industry sector analysis provides a good first approach to wage differences, it is not granular enough, which makes the analysis at the occupation level necessary. This will be explained in more detailed in the next chapters.

4.4.2.3. Occupation. Like immigration status, occupation is another important pillar of this research. Analysis at the occupation level is necessary because this is the level at which federal and provincial levels of government prepare labour market

\footnotetext{
${ }^{51}$ This variable followed the classification followed by ESDC and recreated in the census. The variable considers 21 industry sectors. Of the 21 industry sectors classified by Statistics Canada, only the 13 with a reliable number of counts and that passed the Bonferroni test were included (these criteria will be later explained in this chapter).
} 
projections. From the perspective of citizenship, occupation specific analyses provide a more accurate view of the relation between the labour market and legal status.

Occupations provide a means to establish a more granular analysis of industry sectors. Having information of outcomes at the level of occupations nuances and differentiates the relations of other independent variables (intrinsic characteristics) on the dependent variable (wages).

The variable 'occupation' specifies the labour activities undertaken by low-skilled workers. Recall from chapter two that the concept of low-skilled occupation stems from the classification of occupations based on skill levels included in the NOC system of classification of occupations. This system considers five skill levels ( $0, A, B, C$ and $D)$. The first three (0, A and B) are high-skilled (requiring education above high school) and the last two $(C$ and $D)$ are low-skilled (requiring specific short training after high school (C) or high school or below (D)). In addition to skill level, the NOC system of classification also groups occupations according to skill type, occupational mobility and industry. What I refer in this analysis as "occupations" corresponds to what the NOC system calls NOC 4 occupations ${ }^{52}$. Appendix 3 C presents specific details of how occupations are classified in the NOC system. By the same token, section 4.5.3. in this chapter details the selection process of the occupations included in this analysis.

The NOC system is the outcome of significant research and consultation, especially on determining "the knowledge and skill requirements, paths of progression and occupational mobility" (Roberts, 2003, p.7) related to each job. While these

\footnotetext{
${ }^{52}$ Additional to skill levels, the NOC data is also configured and presented in digits, which refer to the system to code the grouped occupations. NOC 4 refers to the occupations grouped at the four-digit level. This level groups types of jobs. NOC 4 occupation is the most granular level of classifications of occupations. For further details, see appendix 3C.
} 
principles are evident for high-skilled occupations, in low-skilled occupations they are not as clear. Although the system is defined by the levels of education required to perform a job, in low-skilled occupations the connection between skills and education is often very weak. The system is based on formal educational requirements, which are not reflective of the skills needed to perform many low-skilled jobs, which require levels of education below high school.

The academic literature related to skills in the labour market points to their degradation. Form (1987), for example, shows that early studies on the industrial revolution showed not only the disappearance of many crafts, but also the overall decline of skills (Form, 1987). Drawing on later, more complex, studies, he concludes that industrialization "may have created as many new skills as it destroyed" (Form, 1987, p.29). Braverman's work (1974), which focuses on the structure of and changes in the American working class, also reinforces this trend by detailing the deskilling of clerical jobs (Steinberg, 1990). Literature that focuses on skills (linked to education) in relation to wages highlights the detachment of skills from the actual tasks of a job: "Among those engaged in the debate over human capital versus structural determinants of wages, skill has come to be measured as the level of education and experience that an individual brings to a job rather than as a characteristic of a job requirement" (Mincer \& Polachek, 1974 as cited in Steinberg, 1990, p.450). This observation reinforces the work of others, which reveals the socially-constructed nature of skills (Steiger, 1993).

A system structured on occupational categories that are, in turn, based on skills linked only to education seems to be reductive (Esposto, 2008) and to reinforce the effects of class organization (Braverman, 1974, as cited in Jonna \& Foster, 2014). 
Another consequence of the "social definition and evaluation of skills" is the invisibilization of women's skills (Steinberg, 1990, p. 475). This system also provides a means of stratifying people according to citizenship status. It marginalizes many lowskilled workers who perform activities that are essential for human life (ex. agriculture and childrearing) but that not everybody is willing (or capable) of doing.

Designating low-skilled occupations as those that require either high school or other specific training (skill level C) or on-the-job training (skill level D), is a rather imprecise way of defining a set of jobs that require skills acquired neither in high school nor through on-the-job training. For example, agricultural labour is highly physically demanding and requires many years of work in agriculture-related occupations to be able to endure long hours working in very uncomfortable positions. When recruiters look for foreign agricultural workers, they often look for people with significant experience working in agriculture in their countries of origin (Basok, 2002). The NOC system does not account for that type of experience, even if it is required to perform the job; it only accounts for skills acquired via formal education. Truck driving provides another example of this tendency, as it requires specific skills that do not register under the requirements of the skill level C (education below high school). This will be explained in more detail in chapter nine.

4.4.2.4. Province of residence. Consideration of a worker's province of residence is important because it provides a more regional/localized analysis of lowskilled labour. That said, it is important to disaggregate data at the provincial level because the economies vary from province to province. Given that some provinces offer pathways to citizenship for low-skilled workers (Palacio, 2010), a provincial analysis is 
highly desirable. Furthermore, labour regulations change from province to province, which may influence wages. Due to sample size, in this analysis, a provincial analysis is only done to the point of evaluating wages by occupation, without introducing other independent variables. To analyze wages some rearrangements are required to adjust for the sample size:

\subsection{The Atlantic Provinces. Prince Edward Island, Newfoundland, Nova} Scotia and New Brunswick were grouped together due to small sample sizes of NPRs at the provincial level in both occupations and industry sectors. Even after being grouped together, the number of NPRs by occupation was still extremely small, which required the analysis to be restricted to the total for the entire region. However, by including the group in the regression analysis it was possible to overcome these restrictions and obtain information on outcomes of low-skilled workers in the main occupations for the region.

4.4.2.4.2. Manitoba and Saskatchewan. Manitoba and Saskatchewan were also grouped together because of the small number of NPRs at the levels of occupation and industry sector. Sample size and privacy restrictions allowed the analysis of only a few occupations. These provinces were included in the regression analysis, which yielded a more accurate picture when the outcomes were statistically significant.

4.4.2.4.3. Territories. Once again due to sample size and privacy restrictions, the territories were left out of the descriptive analysis but were included in the regression analysis as a single group.

4.4.2.4.4. Other Provinces. Quebec, Ontario, Alberta and British Columbia were all analyzed individually. 
4.4.2.5. Age. Age is relevant to this study because it is often overlooked as a factor affecting the wages and legal integration of low-skilled temporary foreign workers in Canada. The variable 'age' will be used linearly. Regression analysis allows us to evaluate the effects of age on wages for the entire population. It also permits a linear view of the effects of age in combination with the other variables used in this study, which is a more effective way of gauging whether wage has any effect on labour market outcomes. This will be explained in more detail in the chapter on regression analysis (chapter eight). No cross-tabulation analysis was done because sample sizes did not allow grouping the variable for an occupation level analysis. As will be explained in the limitations section (section 4.6.), a prime age (25-54 years of age) analysis was intended but not pursued because sample sizes did not allow it.

4.4.2.6. Level of Education. Information on education levels among low-skilled workers allows us to analyze the influence (if any) of education on wages. Difficulty having their foreign credentials recognized, demands for Canadian work experience and a lack of social capital lead many highly educated immigrants to take low-skilled jobs (Bauder, 2003; Galarneau \& Morissette, 2008; Reitz, 2005). While this research does not intend to analyze the experiences of highly educated immigrants working in lowskilled jobs, it does provide a way to determine the proportion of highly-educated NPRs working in low-skilled occupations as well as the type of occupations in which they tend to work. The categories of this variable (see appendix 3B) reflect Statistics Canada's classification of the labour force according to level of education.

4.4.2.7. Place of birth. Does country of origin affect wages among low-skilled 
workers? Do low-skilled workers from certain countries tend to group around certain occupations?

Knowing the extent to which workers' country or region of birth affects their wages sheds insight into specific wage-related experiences of immigrants in relation to their identity. It also contextualizes the outcomes of low-skilled Canadian-born vis-a-vis immigrant and migrant (NPR) workers according to their region of origin, which, on a global scale, have varying degrees of economic strength. In the 2006 census, the variable 'Place of Birth' refers to the place in which the respondent was born and has 241 categories (countries/places of birth). In the cross-tabulation analysis, only countries with a significant number of NPRs were included in the analysis (more than 90 - for details see section 4.5.3. in this chapter). In the regression analysis, this variable is transformed into the variable 'Regions of the World,' which groups countries together by regions (see appendix 3B).

4.4.2.8. Sex. ${ }^{53}$ Sex analysis in this research explores the impact that sex type has on the outcomes in the labour market cross-checked with immigration status. Existing literature documents wage differences between men and women and among women in the labour market. The male/female wage gap in Canada is about $20 \%$, which is comparable to the United States and the United Kingdom, but larger than it is in most European OECD countries (below $10 \%$ ) (Kahn, 2015). The gender wage gap is also larger in Canada than in Australia. This is likely a function of Australia's compressed wage structure, which is heavily influenced by the relatively strong presence of

\footnotetext{
${ }^{53}$ This variable helps consider the differences in labour market outcomes by occupation between males and females. The variable name "Sex" and the categories "Male" and "Female" are used in this analysis because those are the words given by Statistics Canada. Using other words would misrepresent Statistics Canada's outcomes.
} 
expanded collective bargaining structures in Australia (Kahn, 2015). Wage gaps related to immigration status among low-skilled females are also brought to light by the literature. The present research provides quantitative evidence of these differences by occupation. Again, nuancing outcomes is important, since it allows us to address such differences in a more efficient way.

The chapter on wage analysis by intrinsic characteristics (of NPRs themselves and their occupations $)^{54}$, includes analysis on differences in wages among people of the same sex by occupation and further nuanced by immigration status. The regression analysis addresses wage discrepancies between low-skilled males and low-skilled females.

4.4.2.9. Rural Urban. Exploring differences in labour market outcomes according to occupation in both rural and urban settings provides a window into rural/urban economic differences. Some occupations, such as occupations in agriculture, are predominantly (if not completely) rural, while others, such as occupations in caregiving, are predominantly urban. In this thesis, introducing this variable provides a more nuanced outcome for workers in agricultural occupations.

4.4.2.10. First official language spoken. The ability to speak an official Canadian language is another central variable in labour market analysis. Most research and policies designed to integrate immigrants into the labour market identify the inability to communicate in either official language as the major barrier to labour market integration. But If immigration status is accounted for, do the wages of low-skilled workers who report speaking either English or French differ?

The census evaluates one's ability to communicate in either English or French

\footnotetext{
${ }^{54}$ Chapter 7
} 
with the following question: "Can this person speak English or French well enough to conduct a conversation?" (Census Questionnaire and Guides, 2006). In this dissertation, analysis of this variable will focus only on differences between NPRs and IMM in order to evaluate whether speaking an official language actually makes a difference after acquiring citizenship. A comparison with Canadian-born workers is omitted because they are expected to speak one of the official languages.

\subsection{Selection of Population: Criteria and Considerations Prior to Data Extraction}

The same criteria used for the PUMF files were also used for the whole census data set. Individuals were selected for working in low-skilled occupations with one of the following legal statuses: Canadian-born, immigrant (including naturalized immigrants and permanent residents) and Non-Permanent Resident (including refugees and temporary foreign workers). All were reported to be 15 years of age or older, employed in a paid job (i.e. not self-employed), working full-time, and not undertaking formal studies. The following eight criteria defined the population:

\subsubsection{Selection of low-skilled NPRs in the 2006 census.}

The base population in the 2006 Census includes the NPR population, which is defined as:

persons who are lawfully in Canada on a temporary basis under the authority of a temporary resident permit, along with members of their family living with them. NPRs include foreign workers, foreign students, the humanitarian population and other temporary residents. The humanitarian population includes refugee claimants and temporary residents who are allowed to remain in Canada on humanitarian grounds and are not categorized as either foreign workers or foreign students (Stats Canada, 2015). 
More than 112000 NPRs (high- and low-skilled) are reported in the 2006 long form of the census (Thomas, 2010). For the purpose of this study, I removed all high-skilled and selected only low-skilled cases. Foreign students were also removed (the database allows their removal). Therefore, this study includes only low-skilled TFWs, low-skilled refugee claimants and low-skilled people with a temporary resident visa on humanitarian grounds.

The exclusion of foreign students is linked to the type of jobs they usually have. In contrast to TFWs or refugee claimants or people with a temporary resident visa on humanitarian grounds, foreign students who work in low-skilled occupations are likely to do so in a part-time capacity and for only a very short period of time. Low-skilled TFWs work in full-time jobs and remain in them for longer periods of time. Furthermore, foreign students who decide to remain in Canada and become permanent residents usually find work in high-skilled occupations. For these reasons, foreign students are left out of the analysis and consideration of the low-skilled NPR population is confined to temporary foreign workers, refugee claimants and people with a temporary resident visa on humanitarian grounds.

This study was originally intended to focus only on temporary foreign workers, but since, as will be shown, it was not possible to isolate them entirely, the scope was expanded to include refugee claimants and people with a temporary resident visa on humanitarian grounds. The low-skilled NPR population in this analysis is the reference group against which other low-skilled workers (CB and IMM) are compared since NPRs have neither citizenship nor the rights attached to it.

The reason for including refugee claimants and people with a temporary resident 
visa on humanitarian grounds is that these groups could not be separated from TFWs. More specifically, there is no indicator in the dataset to distinguish TFWs from these populations. Although the literature on refugee claimants (asylum seekers) and people with a temporary resident visa on humanitarian grounds is rather scarce and focuses primarily on refugees (Jackson \& Bauder, 2013), some important differences can nevertheless be identified between these two groups and temporary foreign workers. The groups have different rights vis-a-vis the labour market. For example, low-skilled TFWs face significant challenges to change employers and endure harsh labour conditions in order to be invited the following year (SAWPs) or to become permanent residents after two years as temporary foreign workers (LICs). Cases documented in the literature include both live-in caregivers (Brickner \& Straehle, 2010; Faraday, 2012a) and agricultural workers (Wells et al., 2014). For live-in caregivers, changing employers implies leaving the Live-In Caregiver Program, which complicates finding a new job and obtaining another work permit (Dorow, et al., 2015; Langevin, 2007). In contrast, temporary residents accepted as refugee claimants or on humanitarian grounds have more autonomy in changing employers and have access to many of the rights of permanent residents. That said, refugee claimants' jobs are for the most part in precarious conditions (Jackson \& Bauder, 2013).

Though it would have been ideal to separate the populations, the census database does not include a "type of NPR" flag, which makes it impossible to separate them. But this does not present a serious obstacle since a significant number of NPRs in the humanitarian population can potentially be part of the labour market, making this subpopulation equally relevant for a labour market analysis of non-temporary residents. 
An added advantage of including these populations is that it increases the sample size, which enhances the analysis at the occupation-level.

\subsubsection{Selection of those who did not attend school (to filter out foreign}

students). Foreign students were filtered out of the analysis by using the flag ATTSCHSUM (Attendance at school - summary), which focuses on total attendance. This variable gathers information about those who attended school between September 2005 and May 16, 2006. Those who "did not attend school" were selected.

\subsubsection{Selection of individuals working in low-skilled occupations.}

Occupations describe the kind of activities developed at the workplace. From the occupations variable, nochrd, all low-skilled occupations were chosen. Low-skilled occupations were selected based on the 2006 National Occupational Classification (NOC) system ${ }^{55}$.

This dissertation explores in detail, the absolute wages in 43 occupations and the relative wage differences (NPRs relative to CB and IMM or NPR-CB and NPR-IMM) in 35 occupations. The following describes the way in which these occupations were derived.

Only 43 NOC 4 low-skilled occupations ( $C$ and $D)$ were considered in this analysis. According to ESDC (2016b), there are 521 occupations altogether, of which 157 are low-skilled (see appendix four). Privacy restrictions related to sample size led to the omission of some occupations: only low-skilled occupations with enough NPRs to satisfy privacy considerations were chosen, reducing the number to 98 occupations

${ }^{55}$ See section 4.4.2.3., appendix $3 C$ and appendix eight 
(see appendix five). Occupations were ranked according to the number of NPRs in each occupation and organized from top to bottom with the column of NPRs as the reference. In all cases NPRs are the smallest of all three populations (CB, IMM and NPRs).

With only 98 occupations remaining after fulfilling Statistics Canada's privacy guidelines, this number was further reduced to those occupations with a reliable sample size for the NPR population: a total of 43 occupations. The analysis focused only on the top occupations, ensuring not to go below 90 - 100 counts in the weighted sample. This threshold reflects the fact that the 2006 census consisted of a single sampling of $20 \%$ of households, so the unweighted sample has roughly one fifth of the population. A minimum of between 90 to 100 counts (in the weighted sample) ensures reliability of an original sample of $20 \%$, which also ensures that observations are well above the minimum required by Statistics Canada. This standard is maintained with all populations, although it is particularly relevant for NPRs because of the small size of this group. This number was further reduced to 35 occupations for the relative wages analysis (wage differences NPR-CB and NPR-IMM). The number is smaller because it includes only the occupations that passed the statistical tests to validate comparison of means (Bonferroni tests, which will be explained later in this chapter).

When the population is dissected even more by other characteristics (sex, province of residence, etc.), the number of occupations in each category is again reduced to not to go below $90-100$ counts.

4.5.4. Selection of those "employed" and "paid." This study includes only those who reported being employed to ensure that all cases in the sample are in equal standing vis-à-vis employment at the moment of the census. This selection was made 
using the variable LFTAG (Labour Market Activities: Labour Force Activity), which refers to the type of labour activity developed in the week prior to census (Statistics Canada, 2006 Census Codebook, p.624). For this study, it is important to not only have labour activity, but to also be paid for that activity (i.e. to not be self-employed). This selection was made via the variable COWD (Class of Worker - Derived), which provides information on whether a person was paid for their labour.

\subsubsection{Selection of those working full-time. Since TFWs are expected to} financially support themselves while in Canada, the Canadian government generally approves only those committed to work in full-time jobs (CIC, 2006). To maintain a basis for comparing TFWs with $\mathrm{CB}$ and IMM, this analysis accordingly focuses only on those workers in low-skilled occupations working full-time, which the census designates as 30 hours or more per week (see appendix 3B for a more detailed definition).

4.5.6. Exclusion of outliers. ${ }^{56}$ For statistical reasons and for accuracy, I have excluded outliers. This is a common statistical approach to avoid skewing the outcomes. As Osborne and Overbay (2004) report: "accuracy tends to increase significantly and substantially, and errors of inference tend to drop significantly and substantially once extreme scores [are] removed" (p.1). In this study, less than $0.1 \%$ of the cases were withdrawn, ${ }^{57}$ using the stem and leaf methodology ${ }^{58}$ in SPSS, so as to not alter

\footnotetext{
${ }^{56}$ Econometric analysis shows that wages are usually not normally distributed (Wooldridge, 2012). This means that, when plotted, the distribution of wages is, for the most part, skewed to right, which means that there are significantly high values to the right of the mean. In this research, a distribution of wages skewed to the right means that there are cases in which wages are significantly higher than the mean value (outliers).

${ }^{57}$ Privacy considerations do not allow any explicit information on this matter.
} 
averages. Such outliers have the potential to significantly affect the estimates of a linear model (Andrews \& Pregibon, 1978), which is the model used in the regression analysis included in this research, as well as T-tests and ANOVA tests (Osborne and Overbay, 2004). Even after outliers were withdrawn, average wages in some occupations remained relatively high. A way to address this issue will be explained in detail in section 4.7.

It is important to remember that the census is a database that collects all information about Canadians, which makes it extremely important to have guidelines in place that preserve the privacy of those surveyed. Since relatively small sample sizes have a greater potential for revealing private information concerning individual respondents, census protocols do not allow public dissemination of any information about outliers, which make up a very small sample size. This is especially relevant when dealing with variables with sensitive information, such as wages.

In this analysis, the mean wage (as opposed to the median or mode) was the measure chosen to explore wages of low-skilled workers. While each measure has its

\footnotetext{
${ }^{58}$ A Stem and Leaf Plot is a mathematical/visual tool that permits establishing how numbers in a series of observations are distributed. This methodology is useful to identify outliers. In this procedure, a series of numbers is separated into the "leaf" (usually the last digit), and the "stem" (the other digits). For example, a series of 17 observations $(10,23,28,36,37,39,40,42,44,48,49,50,56,58,63,67,89)$ can be represented as follows:

$\begin{array}{lllll}\text { Stem } & \text { leaf } & \text { leaf } & \text { leaf } & \text { leaf } \\ 1 & 0 & & & \\ 2 & 3 & 8 & & \\ 3 & 6 & 7 & 9 & \\ 4 & 0 & 2 & 4 & 9 \\ 5 & 0 & 6 & 8 & \\ 6 & 3 & 7 & & \\ 8 & 9 & & & \end{array}$

Note that the number 23 is divided into 2 (stem) and 3 (leaf).

From this exercise, numbers below 20 and above 80 have fewer occurrences than numbers between 20 and 70. The software used in this analysis (SPSS), includes a stem and leaf option that determines outliers in a series of observations.
} 
own strengths and weaknesses, the mean wage was chosen because, after withdrawing outliers, it provides a good representation of the sample. Moreover, contrary to the mode or the median, the mean is calculated in light of all of the values in the sample, which makes it a measure that ensures inclusion of all observations. Finally, finding the average wage (i.e. the mean) is a technique used in economic studies comparing wages in relation to immigration (Borjas, et al., 2008; Card, 2009). It is an international measure that may allow the results of this analysis to be compared with other international studies on labour market analysis.

To overcome the limitations of calculating averages, a quartile analysis will be introduced (see also appendix eight).

\subsection{Data Limitations}

This section includes the various data limitations that I faced throughout the research.

- Weekly hours of work. I originally wanted to include in my analysis the weekly hours of labour because this variable not only represents a significant outcome in the labour market; it also encapsulates relevant information about the experiences of lowskilled temporary foreign workers in Canada. However, limitations in the available data did not allow for any robust conclusions about the relationship between hours of work and the labour market experiences of low-skilled workers in Canada.

- Difficulties with the data itself. The Canadian census is a rich and complex database that demands many hours of work of data extraction and imposes a steep learning curve. While providing the most granular data available at the level of 
occupations, the census nevertheless does not provide a complete picture, especially when attempting to account for wage differences. Even after eliminating obvious outliers, ${ }^{59}$ cases with high values still persist, which also drive the average wage to a high value. As will be further explained appendix eight, identified sources of wage dispersion include the way in which occupational groups are grouped together. High average wages will be addressed by dividing the population in each occupation into quartiles, an approach that will be explained in detail later in this chapter as well as in chapter six.

- Prime age (25-54 years of age) analysis. I originally intended to engage in a "Prime Age" cross tabulation analysis, which aimed at comparing the wages, by occupation, of those in the age range $25-54$ with those below and above that age range. However, sample sizes did not allow such analysis at the occupation level. Cross tabulating age against wage by dividing age into other subcategories was also impossible because of inadequate sample sizes. Despite these difficulties, age remains a relevant variable in my analysis and is accordingly factored into the regression analysis.

- Ethnic origin and place of birth analysis. I originally considered analyzing the data in light of ethnic origin, but in the end decided to remain with the variable of one's country of birth as a proxy, which was already included in my analysis. Having 'Ethnic Origin' and 'Place of Birth' at the same time would have introduced co-linearity ${ }^{60}$ to the regression analysis, which should be avoided.

\footnotetext{
${ }^{59}$ See section 4.5.6. of this chapter.

${ }^{60}$ Collinearity effects between two or more categories/variables are present when the observations in each of them are similar in magnitude, proportion or value. Having different categories/variables with similar magnitudes/proportions/values in a regression model makes it difficult to separate the effects of each of them on a dependent variable.
} 


\subsection{Quartiles Analysis}

A way to address the persistence of high wage values (even after eliminating outliers) in some subsamples (or a significant dispersion of the data) is to determine mean wages per quartile. Quartiles refer to the division of a sample into four parts according to an equidistant division of the entire wage range in the sample. Thus, the first quartile groups together the lowest wages and the last quartile the highest. A quartile analysis provides a closer look into the differences within each sub-section (quartile) by occupation. Each population (CB, IMM and NPR) in each occupation is divided according to their wages. The lowest and highest wage in each of these three status categories (CB, IMM, NPR) is used to define the wage range, which is then divided into four equal parts or quartiles. To be clear, then, the quartiles reflect the distribution of hourly earnings from highest to lowest (and the distribution of workers)based on equal proportion of wage ranges and not on equal proportion of number of workers. The average wage is calculated for each quartile since four average wages per group provide a better representation of the differences in wages in each occupation. For example, the following (Table 1) presents a hypothetical case of the wage distribution by quartiles and by population type in occupation $\mathrm{X}$ : 


\begin{tabular}{|c|c|c|c|}
\hline \multicolumn{4}{|c|}{ Table 1: Quartile Ranges Divide } \\
\hline \multirow[b]{2}{*}{ Quartiles } & \multicolumn{3}{|c|}{ Wage ranges by population (dollars per hour) } \\
\hline & $\begin{array}{c}\text { Canadian-born } \\
\text { wage range } \\
\text { from } \$ 15 \text { to } \$ 37\end{array}$ & $\begin{array}{c}\text { Immigrant } \\
\text { wage range } \\
\text { from } \$ 12 \text { to } \$ 31\end{array}$ & $\begin{array}{c}\text { NPR } \\
\text { wage range } \\
\text { from } \$ 8 \text { to } \$ 23\end{array}$ \\
\hline Quartile 1 & from $\$ 15$ to $\$ 20$ & from $\$ 12$ to $\$ 16$ & from $\$ 8$ to $\$ 11$ \\
\hline Quartile 2 & from $\$ 21$ to $\$ 26$ & from $\$ 17$ to $\$ 21$ & from $\$ 12$ to $\$ 15$ \\
\hline Quartile 3 & from $\$ 27$ to $\$ 32$ & from $\$ 22$ to $\$ 26$ & from $\$ 16$ to $\$ 19$ \\
\hline Quartile 4 & from $\$ 32$ to $\$ 37$ & from $\$ 27$ to $\$ 31$ & from $\$ 20$ to $\$ 23$ \\
\hline
\end{tabular}

Table 1: Quartile Ranges Divide

This procedure helps to verify whether the comparison of mean hourly wages of NPRs versus $\mathrm{CB}$ or IMM in a subsample is sound despite the broad dispersion of wages. Although the analysis uses mean wages per immigration category (three categories $\mathrm{CB}, \mathrm{IMM}$ and NPR) and per additional independent variable (ex. mean wages both by immigration status and by sex), mean wages per quartile were used in some parts of the analysis. The average of the second and third quartiles was used in some cases to verify whether what was found for the whole sample persists in quartiles 2 and 3 . It is used as a complement to the mean hourly wage analysis for specific intrinsic characteristics and the results are included in chapter seven and in the appendices (appendix nine).

\subsection{Reliability Tests}

4.8.1. Anova (Analysis of Variance) test. The Analysis of Variance (or ANOVA), is a statistical test used to compare the means of more than two sets of observations. It is based on contrasting the means to be compared in view of dispersions in observations linked to each mean. Dispersion is measured through the standard 
deviation (Sirkin, 2006). In this research, the ANOVA tests help to evaluate whether the mean wages among different types of low-skilled workers are statistically equal.

These methods of comparisons are used for the top occupations and top industry sectors that the privacy restrictions allow to make public. For each occupation and industry sector, mean wages for each legal status categories (CB, IMM and NPR) is compared by type of independent variable (sex, level of education, etc). Thus, the analysis compares the mean wages by immigration status and independent variable in each occupation and industry sector. The ANOVA tests help to establish whether mean wages by type of immigration status are statistically equal. It evaluates the null hypothesis of whether the means to be compared are equal in value (Sirkin, 2006; Quirk, 2012). Since the independent variable is thought to affect the dependent variable, this analysis compares the effects across the different kinds of immigration status. This is done because this research explores the effects of citizenship (or lack of thereof) on wages in each category of each independent variable. For example, the research compares the wages of TFW women working in occupation ' $x$ ' with those of Canadianborn women and immigrant women working in the same occupation.

Independent variables in this research are considered in light of the first, second or third levels of analysis. The first level of analysis refers to the first layer of analysis across which comparisons take place. In this analysis, occupations and industry sectors are independent variables at the first level of analysis (mean wages are considered by occupation and by industry sector). A subsequent level of complexity is introduced by adding a second level of analysis, immigration status, which is considered the only independent variable at the second level of analysis. Thus, wages are compared not 
only by occupation and by industry sector, but also across the different kinds of immigration statuses (CB, IMM and TFW).

The level of complexity is further increased by adding a third layer of analysis. Independent variables including sex, the first official language spoken, and the level of education, are considered to be at the third level of analysis. In summary, the population is first grouped by occupation and by industry sector. Then each occupation and industry sector is subdivided by immigration status. Within the group of occupations, each immigration status is subsequently subdivided by province of residence, sex, level of education, etc. Hence, the analysis compares wages at second and third levels of analysis.

To understand ANOVA, it helps to imagine a sample that is divided into two subsamples. The mean of the whole sample, as well as the means of each subsample, are then calculated. The ANOVA test evaluates how different the variabilities around the mean of each subsample are from the variability around the mean of the whole sample. Knowing this helps to evaluate the subsamples with respect to the whole group of observations (Sirkin, 2006). This test helps to evaluate whether there are differences between subsamples. In this case, it would help us assess whether the mean wage of immigrants working in occupation ' $x$ ' is different from the mean wage of NPRs working in the same occupation.

Mathematically, the ANOVA serves to determine the veracity of the hypothesis of whether or not the means of more than two groups are equal. The test calculates an Ftest value. This value is contrasted against the associated degrees of freedom to see whether it falls within a zone of acceptance or rejection of an F-distribution. 
The F-test in its basic form is:

$\mathrm{F}=$ Mean square between groups (MSb) / Mean square within groups (MSw) $\mathrm{F}=\mathrm{MSb} / \mathrm{MSw}$ (Quirk, 2012).

This is explained step-by-step in appendix six. In the case of comparing more than 2 groups, one sample for which a characteristic is measured under different conditions, for example, a group of people whose body temperature is measured in ' $m$ ' different situations, which generates an ' $m$ ' number of "groups." Thus, all groups have the same number of observations because each group corresponds to the same sample. The procedure used to calculate the ANOVA is found in appendix six. The ANOVA tests and the post hoc test help evaluate whether the mean wages seen at second- and third-levels of analysis are comparable given values and samples sizes. The ANOVA test helps evaluate whether the means are significantly different (in statistical terms), but not which is different from the others (Sirkin, 2006; Quirk, 2012). This is addressed by using a post hoc test (Sirkin, 2006), which, for this research, is the Bonferroni Test.

4.8.2. Post hoc (Bonferroni) test. There are several post hoc tests. The first on the list is the Least Significant Difference (LSD) test. The LSD test, was developed by Ronald Fisher in 1935 and is based on several individual t-tests pulled from all groups to be tested. The LSD test "does not control for the probability of rejecting a hypothesis that some pairs of means are different" (Williams, 2004). Details about the LSD Bonferroni test are found in appendix seven. The Bonferroni test is perhaps the most broadly used to compare multiple means because it is flexible enough and its 
calculation is very straightforward. An SPSS Bonferroni output evaluating the mean differences of "Hours of labour" in occupation "X" would be framed according to Table 2:

\begin{tabular}{|c|c|c|c|c|c|c|}
\hline \multicolumn{7}{|c|}{$\begin{array}{c}\text { Table 2: Dependent Variable: Mean Differences for "Weekly hours of Labour" in } \\
\text { Occupation "X" - Bonferroni }\end{array}$} \\
\hline \multirow[t]{2}{*}{ Group i } & \multirow[t]{2}{*}{ Group j } & \multirow{2}{*}{$\begin{array}{c}\text { Mean } \\
\text { Difference } \\
(\mathrm{I}-\mathrm{J}) \\
\text { (in hours) }\end{array}$} & \multirow[t]{2}{*}{ Std. Error } & \multirow[t]{2}{*}{ Sig. } & $\begin{array}{c}95 \% \\
\text { Confidence } \\
\text { Interval }\end{array}$ & $\begin{array}{c}95 \% \\
\text { Confidence } \\
\text { Interval }\end{array}$ \\
\hline & & & & & Lower Bound & Upper Bound \\
\hline \multirow[t]{2}{*}{ IMM } & $\mathrm{CB}$ & $0.4^{*}$ & & 0.049 & & \\
\hline & $\overline{N P R}$ & $0.3^{*}$ & & 0.001 & & \\
\hline \multirow[t]{2}{*}{ CB } & IMM & $-0.4^{*}$ & & 0.049 & & \\
\hline & NPR & -1.2 & & 0.7 & & \\
\hline \multirow[t]{2}{*}{ NPR } & IMM & $-0.3^{*}$ & & 0.001 & & \\
\hline & $\mathrm{CB}$ & 1.2 & & 0.7 & & \\
\hline
\end{tabular}

Table 2: Dependent Variable: Mean Differences for "Weekly hours of Labour" in Occupation "X" - Bonferroni

\section{Summary}

In summary, this chapter presented the research questions and hypothesis, as well as the methods used and the limitations of each method used. It explained the datasets, variables and decisions made in response to each of the challenges faced. It also discussed why wages are important means for evaluating labour market outcomes of low-skilled NPRs compared to those of Canadian-born and immigrant workers. It recognized the 2006 census as the best dataset to evaluate labour market outcomes of low-skilled temporary foreign workers at the beginning of the exponential increase in temporary foreign low-skilled labour identified in the literature. It also provided a methodology to evaluate wage differences and the impact of lack of citizenship on wages than can be replicated with future censuses.

Having defined the methods used and considerations, the following four chapters 
(five, six, seven and eight) present the quantitative analysis as follows: the profile of low-skilled labour in Canada (chapter five); the outcomes of the descriptive analysis via the quartile analysis and the cross-tabulation analysis at the industry and occupation level (chapter six); The outcomes of the cross-tabulation analysis by each of the intrinsic characteristics (chapter seven); and, the outcomes of the regression analysis (chapter eight). Those four quantitative chapters are shorter than the other chapters in the dissertation. This is because they deal with discrete empirical material, each addressing specific quantitative research aspects of the dissertation. The nature of presenting this material entails more detail and its presentation lends itself to shorter more focused presentation. Nevertheless, throughout, my key research question remains the effect of lack of citizenship on wages of low-skilled NPRs. 


\section{Chapter Five: A Profile of Low-Skilled Workers in Canada}

This chapter presents a demographic profile of all low-skilled workers in Canada, with an emphasis on low-skilled Non-Permanent Residents. Drawing on the 2015 Labour Force Survey (LFS) as well as 2006 census data, this profile provides a context for analyzing the wages of low-skilled NPRs vis-a-vis those of CB and IMM to identify and explain important differences. Thus, this profile runs in two different time frames: 2015 and 2006. The two timeframes provide a nuanced and focused perspective on the current situation of low-skilled labour in Canada, especially NPRs, as well as a general overview of the characteristics typical of the low-skilled population without citizenship in contrast with the low-skilled population with citizenship used in this study. Highlights of the profile include: Retail is the occupation with the highest number of total low-skilled workers in Canada; occupations in caregiving and agriculture stand out as having the highest number of low-skilled NPRs, with caregiving having a significant concentration not only among low-skilled female NPRs but among all low-skilled NPRs. The Philippines and Mexico stand out as the origin-countries with the highest numbers of low-skilled NPRs.

This chapter is divided into five parts. In the first part I situate low-skilled temporary foreign labour within the broader low-skilled labour market in Canada and present the context for low-skilled TFW programs. In the second part, I present the four programs (streams) through which employers can hire low-skilled temporary foreign workers in Canada. In the third part, I provide an overview of the precariousness experienced by low-skilled labourers and demonstrate how they are systematically marginalized from the labour market. In the fourth part I focus on the distribution of low- 
skilled workers throughout Canada's industry sectors and occupations, the focal population of this dissertation. In the fifth part I focus on the characteristics of all lowskilled workers. I present a demographic comparison between low-skilled NPRs and low-skilled Canadian-born and immigrant labourers, in view of occupation, province of residence, sex and country of origin.

\subsection{Temporary Foreign Low-Skilled Workers- Context}

Using the 2006 Census, Derrick Thomas' (2010) identifies 112000 NPRs (high and low-skilled) (Thomas, 2010). Of that total, 94000 work full time (working more than 30 hours a week) (Thomas, 2010). The federal government argues that temporary foreign worker programs are important for "Canada's economic growth" (CIC, 2006, as cited in Nakache \& Kinoshita, 2010, p.3) and that they are a "principal tool to help employers meet immediate skill requirements when qualified Canadian workers cannot be found" (Finance Canada, 2007, as cited in Nakache \& Kinoshita, 2010, p.3).

Temporary foreign low-skilled labour, which is included in the group "noncitizens" in the PEPSO report (Dyson et al., 2013; 2015), belongs to the rapidly expanding labour force, which is characterized by flexibility, vulnerability, and precarity (Fudge, 2012). This new workforce can be viewed as socially-constructed (Sharma, 2006) and as part of the new Post-Fordist labour class (Sharma, 2006 as cited in Fudge, 2012, p. 95).

As explained in chapter three, in June 2014, the old TFW program was divided into two different programs (CIC, 2014): 1) the Temporary Foreign Worker Program, which targets low-skilled workers and is said to fill gaps in the labour market; and 2) the International Mobility Program, which provides access to high-skilled jobs and is designed to fulfill bilateral agreements, such as NAFTA, and meet reciprocity 
requirements (CIC, 2014).

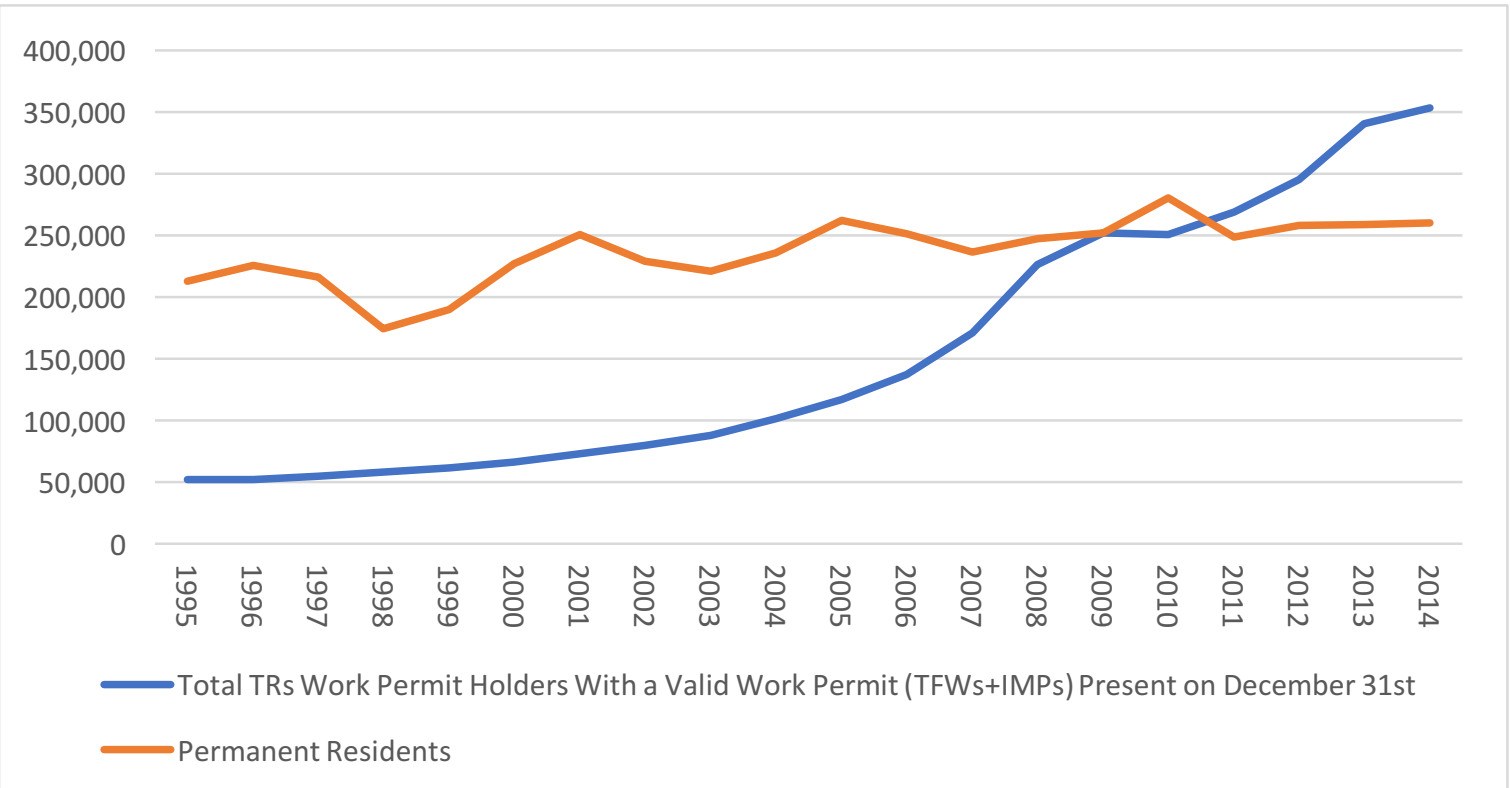

Figure 1: Temporary Resident Work Permit Holders with a Valid Work Permit Present on December 31st versus Permanent Residents - (Source: Facts and Figures, 2014)

Under the new structure, it is accordingly more accurate to consider the number of "Temporary Residence Work Permit Holders", to include both programs. From this perspective, the total number of Temporary Residence Work Permit Holders arriving annually in Canada has significantly increased, surpassing the number of individuals admitted as permanent residents (see Figure 1). Between 2004 and 2014, the total number of Temporary Residence Work Permit Holders has increased by $185 \%$. A study published in 2010, before the split of the Temporary Worker Program, indicates that the highest percentage of increases in TFW are among low-skilled workers, a tendency that corresponds with the intention to ease access to foreign low-skilled labour (Nakache \& Kinoshita, 2010). Having provided a general overview of TFWs in Canada, we will now turn to the place of low-skilled labour in the Canadian economy. 


\title{
5.2. What is the Place of Low-skilled Labour in Canada?
}

\author{
2015 - Total Employment \\ (Millions of People and Percentage)
}

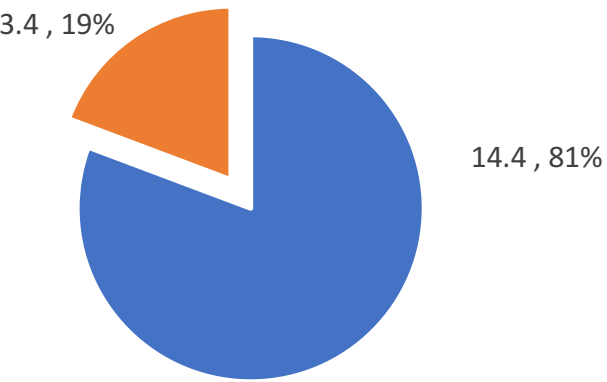

- Full-time employment $\quad$ - Part-time employment

Figure 2: 2015 - Labour Force Characteristics, 15 years and older - Canada (Source: Labour Force Survey)

In 2015, Stats Canada identified 17.9 million employed individuals, of whom 14.4 million (or $81 \%$ ) worked full-time and 3.4 million (or 19\%) worked part-time job (see Figure 2).

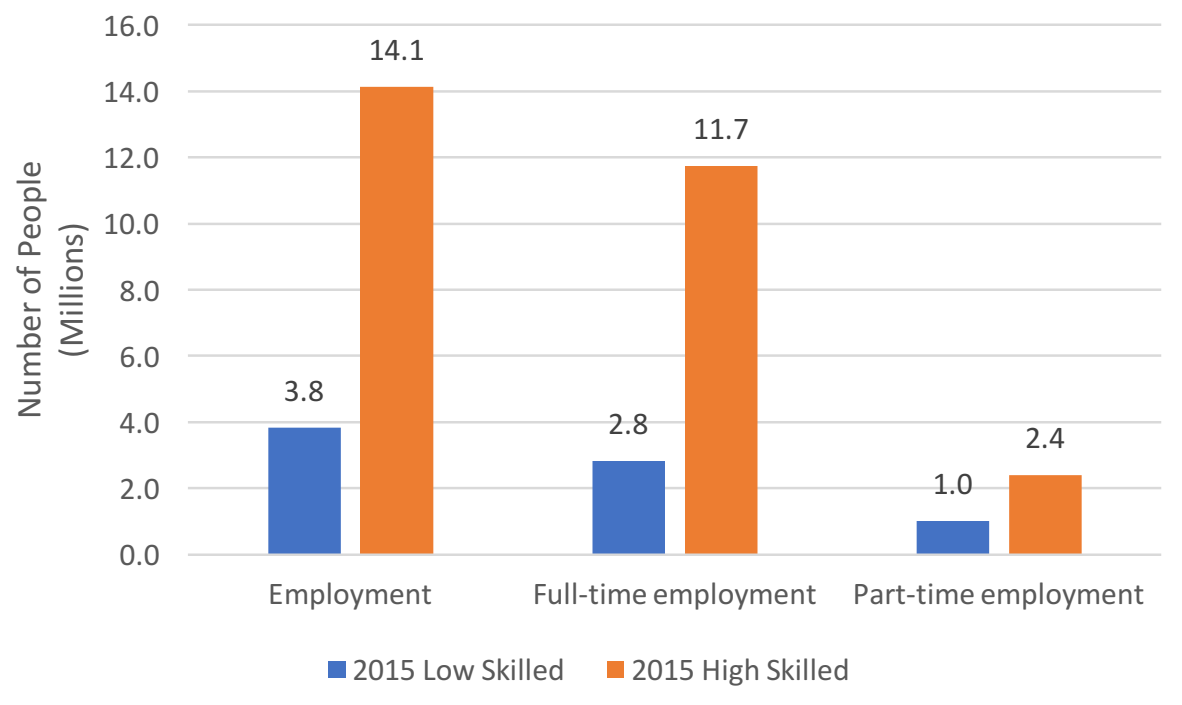

Figure 3A: 2015 - Labour Force Characteristics by Skill Level, 15 years and older - Canada (Source: Labour Force Survey)

As indicated in Figure 3A, of all the 17.9 million people employed, 3.8 million (or 
$21.2 \%$ ) were low-skilled and 14.1 million (or $78.8 \%$ ) were high-skilled. That is, approximately one in every five employed persons is low-skilled.

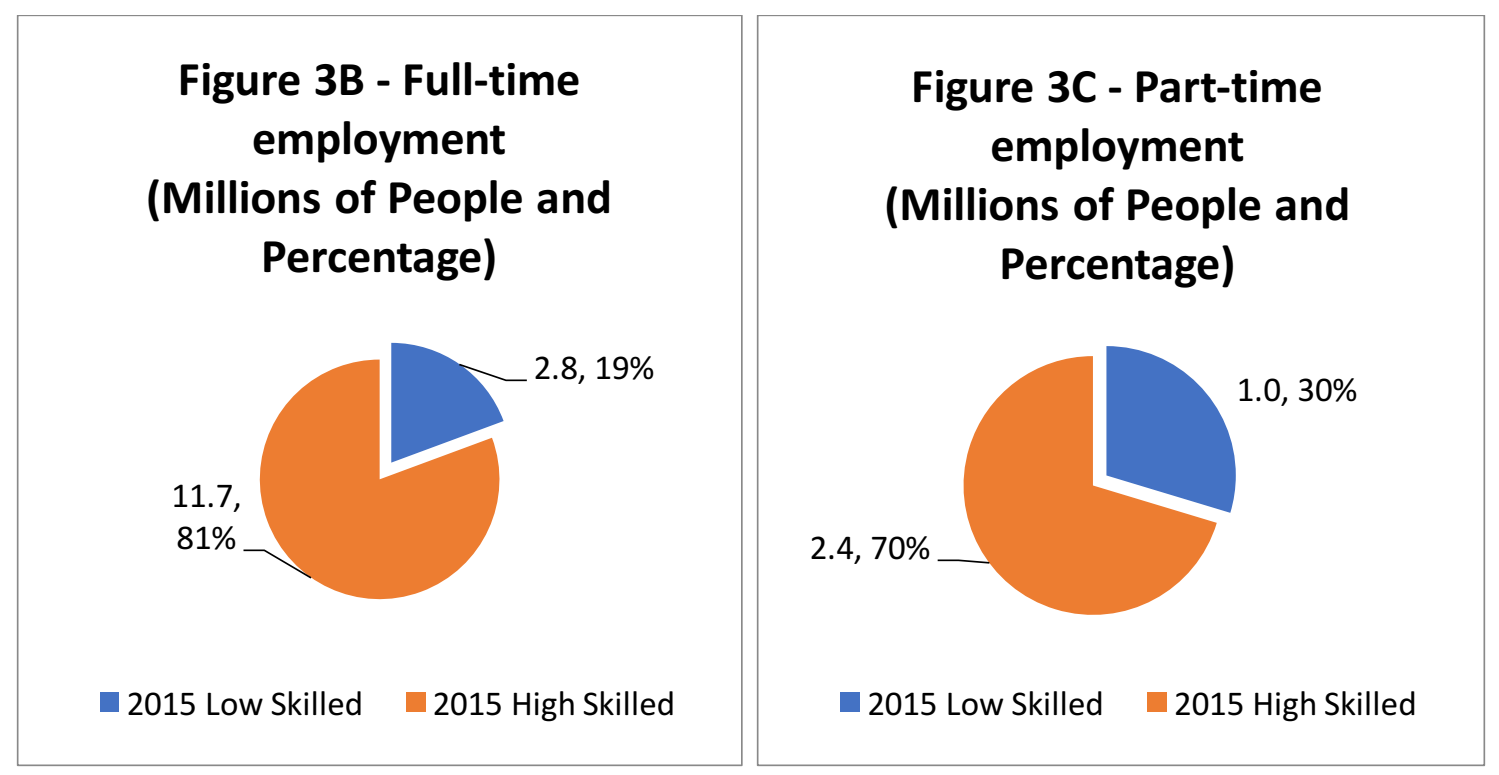

Figures 3B and 3C: 2015: Full-time and Part-time employment by Skill Level, 15 years and older Canada (Source: Labour Force Survey)

Focusing only on those with full-time employment, Figure 3B also shows that the proportion of low-skilled workers in full-time jobs is quite low at $19 \%$ (or 2.8 million), ${ }^{61}$ in contrast, high-skilled workers fill $81 \%$ (or 11.7 million) of the full-time positions. The proportions change when the focus shifts to those working part-time (Figure 3C); while 2.4 million (or 70\%) are high-skilled, 1.0 million (or 30\%) are low-skilled.

Workers without a degree, certificate or diploma (low-skilled), or, with a postsecondary certificate but without high school graduation (also low-skilled), have the lowest rates of employment. In 2015, the employment rate for those without a degree,

\footnotetext{
${ }^{61}$ While the Labour Force Survey (LFS) counted approximately 2.8 million low-skilled workers in full-time occupations in 2015, the 2006 census counted approximately 3.1 million. Although these numbers should not be compared (they come from different sources), it is nevertheless worthwhile to note the following: after February 2015, LFS estimates, originally based on 2006 census, were based on the 2011 census. The 2011 census had a $2.3 \%$ undercoverage rate (which refers to people who were not counted but should have been). Differences in population estimates for each year between 2006 and 2010 (based on the 2006 and 2011 censuses) vary between approximately 1- 4\%. For details refer to Stats Canada (2015).
} 
certificate or diploma was $33 \%$ and for those with a postsecondary certificate but without high school graduation it was $48 \%$ (see Figure 4). These percentages stand in sharp contrast with high-skilled workers in other categories (close to $60 \%$ or above $70 \%$ ). The employment rate in this category dropped from $34 \%$ in 2011 to $32.6 \%$ in 2015 (Labour Force Survey, 2015).

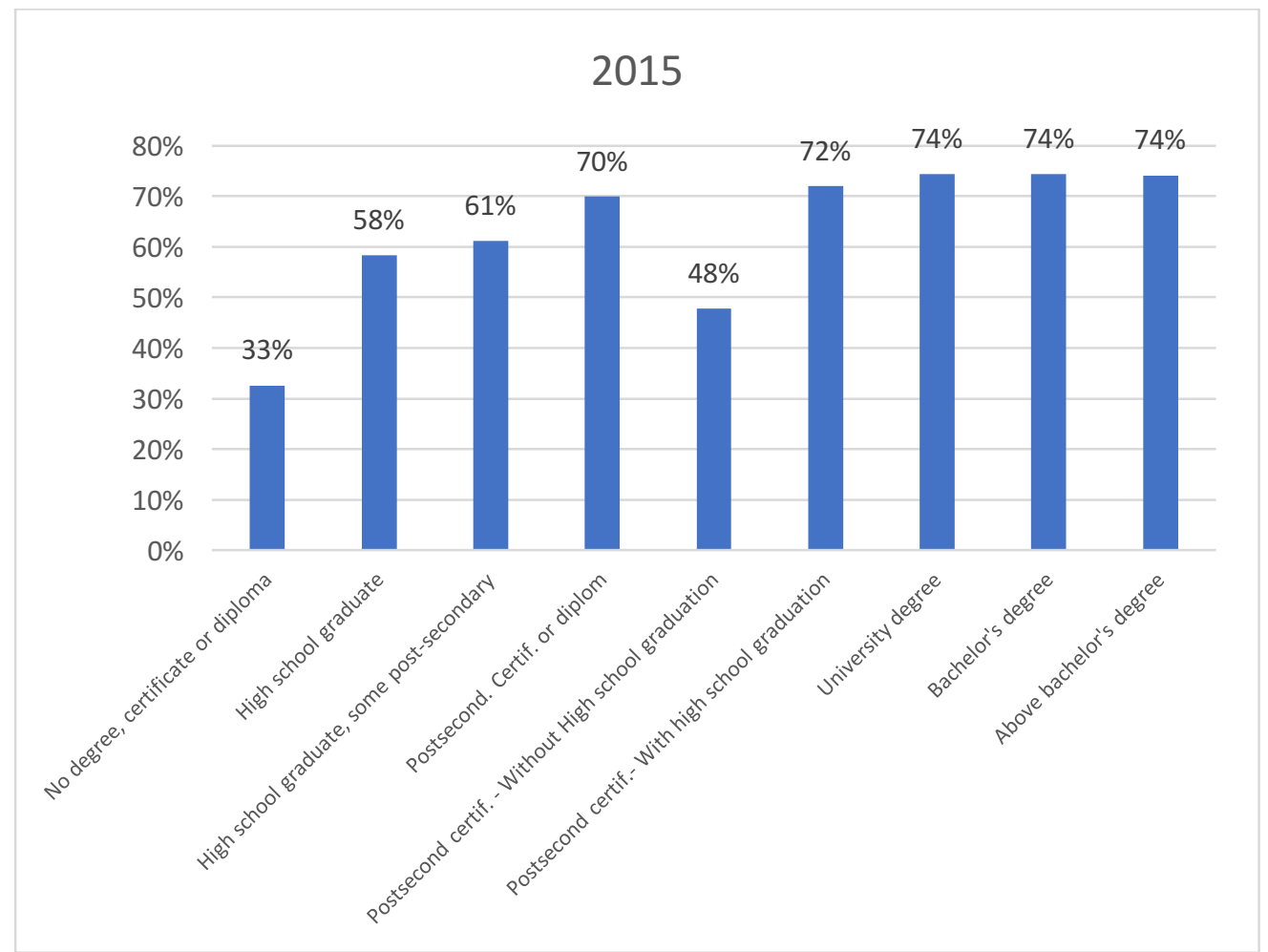

Figure 4: 2015 - Employment Rates Lowest for Those Without High School - 15 years and older (Source: Labour Force Survey)

Not only are employment rates among low-skilled workers low; research also indicates that low-skilled jobs are becoming increasingly temporary (i.e. contract, seasonal or casual) and that the number of temporary jobs has been increasing (Amine, 2012). Employers often favour temporary jobs because they contribute to a flexible labour force, which allows them to compete globally, respond to downturns in the economy and "adapt to changes in the market" (Amine, 2012 p.95).

Most workers employed in low-skilled jobs are racialized immigrants, racialized 
Canadian-born workers and noncitizens (Dyson et al., 2013). These groups are the most likely to work in precarious conditions, experience discrimination and report labour insecurity and poor general health (Dyson et al., 2015). This situation gives rise to a labour class in which workers have to struggle just to survive, juggling different part-time jobs, with low pay, poor benefits, little job security and a very low quality of life (Dyson et al., 2013; 2015).

\subsection{Low-skilled Workers in Canada}

Now the profile of low-skilled labour in Canada draws on 2006 census data, which corresponds only to low-skilled workers working full-time. Full-time cases were selected to enable wage comparisons between Canadian-born and immigrant workers on the one hand and NPRs, who are all full-time, on the other. Most of the labour force in Canada is comprised of Canadian-born individuals (Kustek, 2012) and the low-skilled population detailed in this study reflects a predominance of Canadian-born and immigrant workers. Of approximately 3.1 million full-time low-skilled workers identified in this study (accounting for the case-selection criteria described in chapter four), $0.9 \%$ are NPRs, $76,4 \%$ are CB, and $22.7 \%$ are IMM (which is made up of naturalized Canadians and permanent residents). These proportions correspond closely with the proportions for the total labour force (high- and low-skilled combined), especially between the CB and IMM (77.1\% CB, 21.2\% IMM and 1.7\% NPRs) (Kustek, 2012). As already explained, the differences between 2015 data and 2006 data are linked to the fact that the 2015 data from the Labour Force Survey is based on data from the 2011 National Household Survey, which has been criticized for the low rate of respondents. 
5.3.1. Low-skilled labour in Canada and industry sector. In this analysis industry sectors follow the North American Industry Classification System (NAICS) ${ }^{62}$ from 2006, which divides the economy into 20 industry sectors. Of these 20 sectors, this research reports on those with a statistically significant number of NPRs, which amounts to a total of 13 industry sectors. NPRs are the reference group and generally represent the smaller group vis-a-vis Canadian-born and immigrant workers.

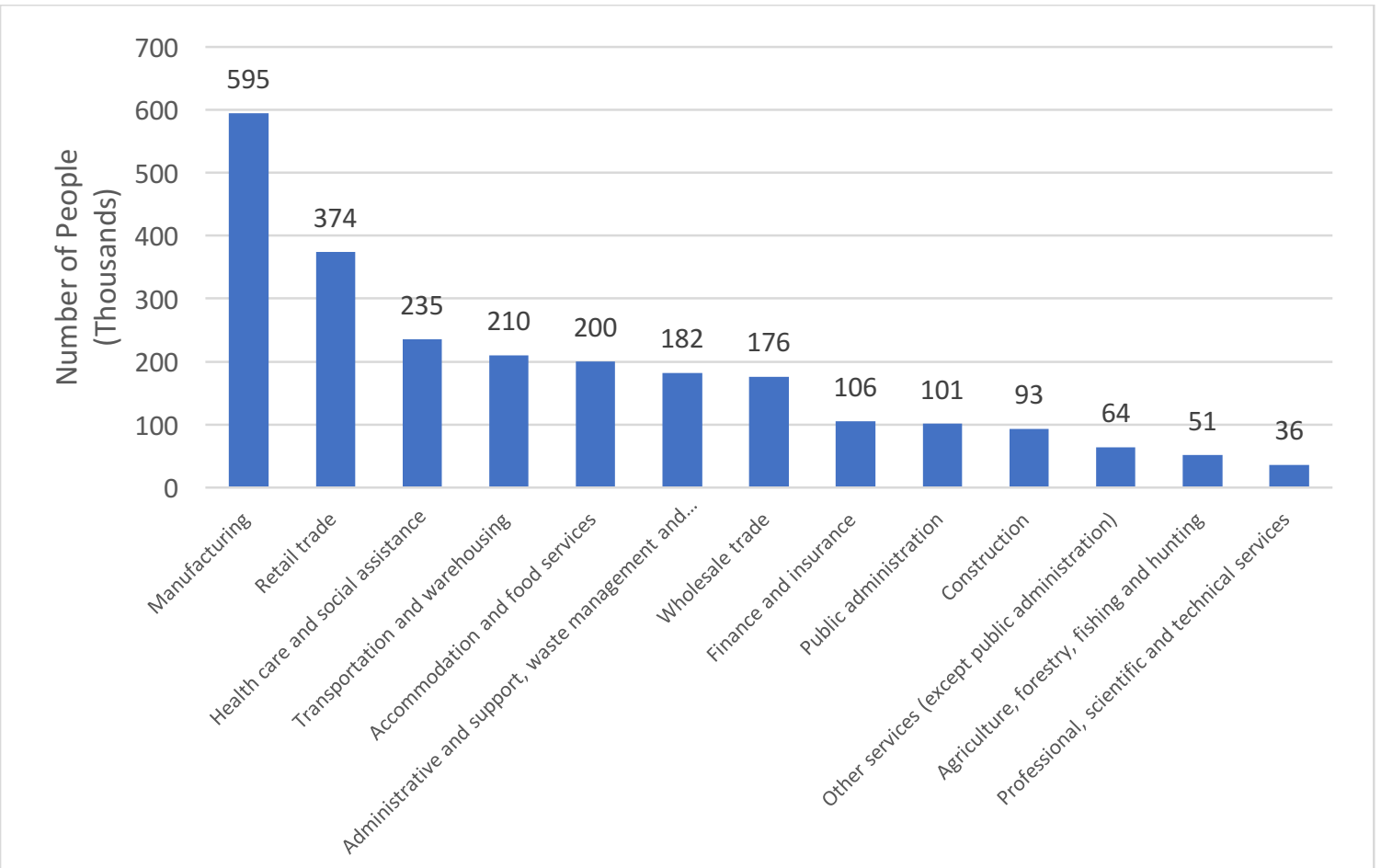

Figure 5: Low-Skilled Workers in Canada are Concentrated in Manufacturing and Retail Industry Sectors - (Source: 2006 Census)

Figure 5 presents the distribution of all low-skilled workers, according to immigration status and the 13 selected industry sectors. This research compares outcomes according to the following three immigration statuses: Canadian-born, immigrant (naturalized Canadians and permanent residents) and Non-Permanent Residents. The data from the 2006 census reflects the low-skilled Canadian economy

\footnotetext{
${ }^{62}$ NAICS is preferred for international comparisons at the industry level in future studies.
} 
prior to the 2008 recession. Manufacturing appears to be the sector with the highest number of low-skilled labourers (600 000), followed by Retail (375 000); Healthcare and Social Assistance (235 000); and, Transportation and Warehousing (210 000). While the manufacturing sector has been an important user of low-skilled workers in the past, more than 320000 jobs have disappeared between 2004 and 2008 (Bernard, 2009).

Regarding employment opportunities for low-skilled workers, Canada continues to need low-skilled workers. In Canada, 8 of the top 10 occupations (low- and highskilled) with the highest vacancies for the third quarter of 2015 were low-skilled, with the highest number of vacancies (27 320) in the retail sector. When considering these figures, it is important to note that the relatively high number of low-skilled job vacancies is not necessarily indicative of growth in low-skilled sectors, but rather of labour market conditions and other characteristics intrinsic to the occupations themselves. For example, as shown in Figure 5, in 2006, the retail industry sector was the second highest employer of low-skilled workers in the Canadian labour market (approximately 374000 low-skilled workers); the next section on occupations shows retail as the occupation with the highest number of low-skilled workers (about 260000 low-skilled workers). While one might expect that such a large number of job openings is simply a function of the size of this sector, it is important to also consider that retail jobs tend to have a high labour turnover rate (Galarneau, 2016). The large number of vacancies may also reflect other aspects of retail jobs, including low wages and a large number of part-time and seasonal positions (Dyson et al., 2013). 


\subsubsection{Low-Skilled Labour in Canada and Occupations}

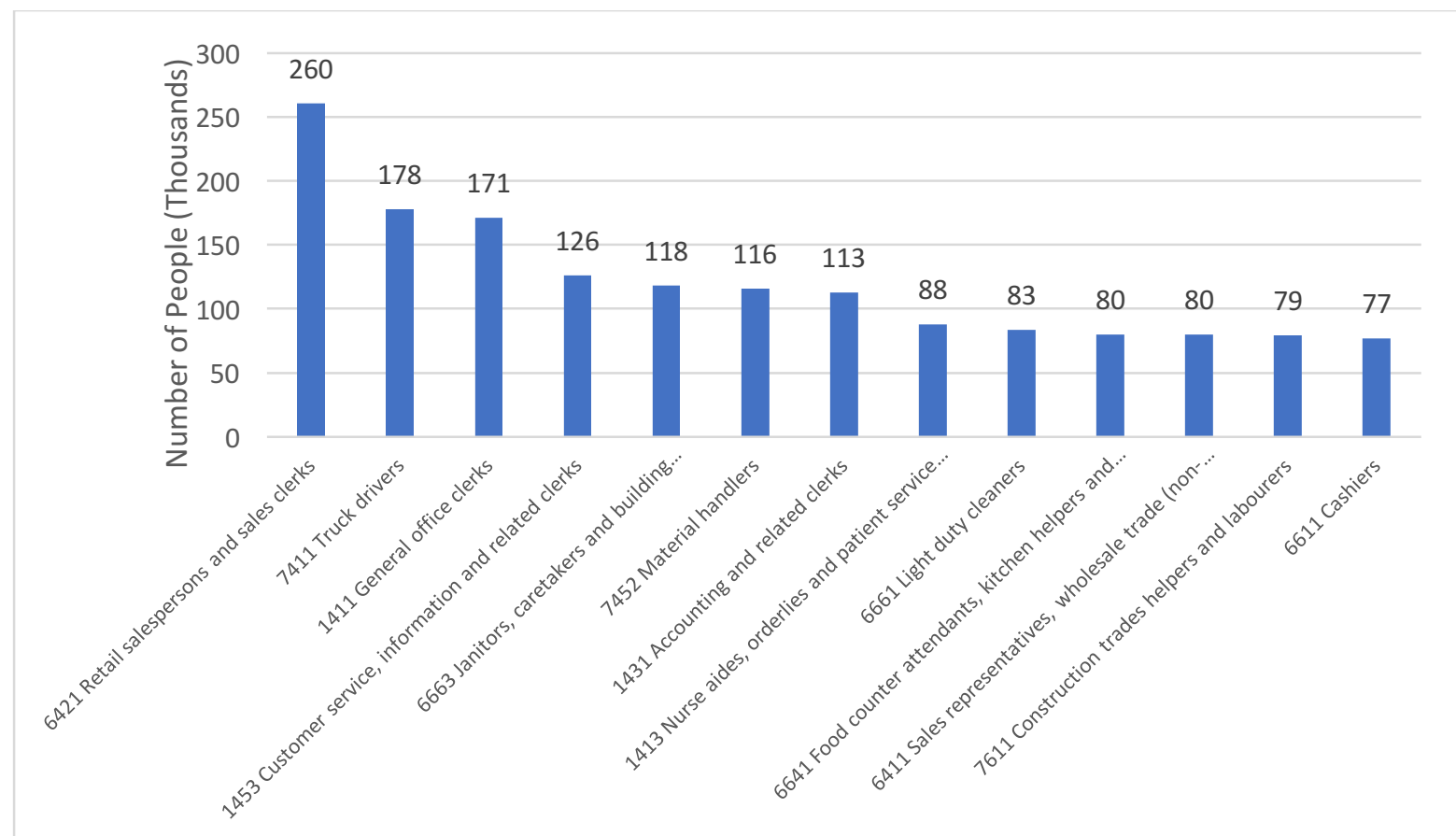

Figure 6: Low-Skilled Full-time Workers in Top 10 Occupations in Canada - (Source: 2006 Census)

While the industry sectors analysis showed retail as the second industry with the highest number of low-skilled workers (after manufacturing), at the occupation level, retail takes the lead. Figure 6 shows occupation NOC 6421 - Retail Salespersons and sales clerks as the number one low-skilled occupation in Canada with about 260000 low-skilled workers. This occupation is followed by occupation NOC 7411 - Truck Drivers with about 178000 low-skilled workers. A list showing the percentage of workers, grouped according to immigration status, for each occupation among the top occupations (Table 3) further nuances these results. ${ }^{63}$

\footnotetext{
${ }^{63}$ Of all low-skilled occupations, this research focuses on those in the 2006 census that had a minimum of 90 NPRs. Occupations 6661 "Light Duty Cleaners"; 6663 "Janitors; Caretakers and Building Superintendents"; 6623 "Other elemental sales occupations"; 9498 "Other assemblers and inspectors"; 9483 "Electronic assemblers, fabricators, and testers"; 6464 "Occupations unique to the armed forces" were left out of the wage analysis because the mean wages by immigrations status (CB, IMM and TFW) were not statistically comparable.
} 


\subsection{How do NPRs Compare to Other Low-Skilled Workers by Occupation?}

\subsubsection{NPR low-skilled workers in Canada concentrate around five}

occupations in caregiving and agriculture. As indicated in Table 3, Retail

Salespersons and sales clerks is the top occupation among the Canadian-born and immigrant populations. In contrast, NOC-6474 Babysitters and Nannies and parents' helpers is the top occupation among NPRs with $27 \%$ of all NPRs in low-skilled occupations.

Among Canadian-born low-skilled workers, the top 3 occupations account for $21.1 \%$ of all CB low-skilled workers. Among the low-skilled immigrant population, the top three occupations represent $15.4 \%$ of all low-skilled immigrants. In contrast, the top three occupations among the NPR population represents $37.6 \%$ of the total of NPRs, indicating that there is a higher concentration of NPRs in fewer occupations. The top occupation (6474 Babysitters, nannies and parents' helpers) alone takes $27 \%$ of all lowskilled NPRs in this study, a very high concentration. The concentration of low-skilled workers in certain occupations, according to their immigration status, points to the importance of investigating their actual wages.

Table 3 presents low-skilled occupations that belong to the skill levels $C$ and $D$. Level $\mathrm{C}$ includes occupations that usually require high school and occupation specific training. Level D classifies occupations that require on-the-job training. In this study, occupations in both levels are grouped together since the final goal is to compare wages of low-skilled workers according to immigration status 


\begin{tabular}{|c|c|c|c|c|c|}
\hline \multicolumn{2}{|l|}{ CB (Percentage per occupation) } & \multicolumn{2}{|l|}{ IMM (Percentage per occupation) } & \multicolumn{2}{|l|}{ NPR (Percentage per occupation) } \\
\hline $\begin{array}{l}1 \text { - } 6421 \text { Retail salespersons } \\
\text { and sales clerks }\end{array}$ & $8.9 \%$ & $\begin{array}{l}1 \text { - } 6421 \text { Retail salespersons and } \\
\text { sales clerks }\end{array}$ & $7.0 \%$ & $\begin{array}{l}1-6474 \text { Babysitters, nannies and } \\
\text { parents' helpers }\end{array}$ & $27.0 \%$ \\
\hline 2 - 7411 Truck drivers & $6.5 \%$ & $\begin{array}{l}2 \text { - } 6663 \text { Janitors, caretakers and } \\
\text { building superintendents }{ }^{\star *}\end{array}$ & $4.2 \%$ & $\begin{array}{l}2 \text { - } 6471 \text { Visiting homemakers, } \\
\text { housekeepers and related } \\
\text { occupations }\end{array}$ & $5.4 \%$ \\
\hline 3 - 1411 General office clerks & $6.0 \%$ & 3 - 1411 General office clerks & $4.2 \%$ & 3 - 8431 General farm workers & $5.2 \%$ \\
\hline $\begin{array}{l}4-1453 \text { Customer service, } \\
\text { information and related clerks }\end{array}$ & $4.3 \%$ & 4 - 6661 Light duty cleaners ${ }^{\star *}$ & $4.0 \%$ & $\begin{array}{l}4 \text { - } 6421 \text { Retail salespersons and } \\
\text { sales clerks }\end{array}$ & $4.6 \%$ \\
\hline 5 - 7452 Material handlers & $3.8 \%$ & $\begin{array}{l}5-1431 \text { Accounting and related } \\
\text { clerks* }\end{array}$ & $3.5 \%$ & $\begin{array}{l}5 \text { - } 8432 \text { Nursery and greenhouse } \\
\text { workers }\end{array}$ & $3.7 \%$ \\
\hline $\begin{array}{l}6-1431 \text { Accounting and related } \\
\text { clerks }^{*}\end{array}$ & $3.7 \%$ & 6 - 7452 Material handlers & $3.5 \%$ & 6 - 6661 Light duty cleaners ${ }^{* *}$ & $3.3 \%$ \\
\hline $\begin{array}{l}7 \text { - } 6663 \text { Janitors, caretakers } \\
\text { and building superintendents** }\end{array}$ & $3.7 \%$ & $\begin{array}{l}7 \text { - } 6641 \text { Food counter attendants, } \\
\text { kitchen helpers and related } \\
\text { occupations }\end{array}$ & $3.5 \%$ & 7 - 7411 Truck drivers & $2.9 \%$ \\
\hline $\begin{array}{l}8 \text { - } 6411 \text { Sales representatives, } \\
\text { wholesale trade (non- } \\
\text { technical)* }\end{array}$ & $2.8 \%$ & $\begin{array}{l}8-1413 \text { Nurse aides, orderlies } \\
\text { and patient service associates }\end{array}$ & $3.4 \%$ & 8 - 7452 Material handlers & $2.6 \%$ \\
\hline $\begin{array}{l}9-7611 \text { Construction trades } \\
\text { helpers and labourers }\end{array}$ & $2.7 \%$ & 9 - 7411 Truck drivers & $3.3 \%$ & $\begin{array}{l}9 \text { - } 6663 \text { Janitors, caretakers and } \\
\text { building superintendents }\end{array}$ & $2.3 \%$ \\
\hline $\begin{array}{l}10-1413 \text { Nurse aides, } \\
\text { orderlies and patient service } \\
\text { associates }\end{array}$ & $2.7 \%$ & $\begin{array}{l}10-1453 \text { Customer service, } \\
\text { information and related clerks }\end{array}$ & $3.3 \%$ & $\begin{array}{l}10-6641 \text { Food counter attendants, } \\
\text { kitchen helpers and related } \\
\text { occupations }\end{array}$ & $2.2 \%$ \\
\hline $\begin{array}{l}11 \text { - } 1414 \text { Receptionists and } \\
\text { switchboard operators }\end{array}$ & $2.6 \%$ & $\begin{array}{l}11-9619 \text { Other labourers in } \\
\text { processing, manufacturing and } \\
\text { utilities }\end{array}$ & $2.7 \%$ & $11-6611$ Cashiers ${ }^{\star *}$ & $2.0 \%$ \\
\hline 12 - 6611 Cashiers ${ }^{* *}$ & $2.5 \%$ & $\begin{array}{l}12-9482 \text { Motor vehicle } \\
\text { assemblers, inspectors and } \\
\text { testers }\end{array}$ & $2.6 \%$ & $\begin{array}{l}12 \text { - } 9619 \text { Other labourers in } \\
\text { processing, manufacturing and } \\
\text { utilities }\end{array}$ & $1.9 \%$ \\
\hline $\begin{array}{l}13 \text { - } 6641 \text { Food counter } \\
\text { attendants, kitchen helpers and } \\
\text { related occupations }\end{array}$ & $2.3 \%$ & $\begin{array}{l}13 \text { - } 9617 \text { Labourers in food, } \\
\text { beverage and tobacco processing }\end{array}$ & $2.6 \%$ & $\begin{array}{l}13-1413 \text { Nurse aides, orderlies } \\
\text { and patient service associates }\end{array}$ & $1.9 \%$ \\
\hline 14 - 6661 Light duty cleaners** & $2.3 \%$ & $\begin{array}{l}14 \text { - } 9451 \text { Sewing machine } \\
\text { operators }\end{array}$ & $2.4 \%$ & $\begin{array}{l}14 \text { - } 9617 \text { Labourers in food, } \\
\text { beverage and tobacco processing }\end{array}$ & $1.9 \%$ \\
\hline $\begin{array}{l}15 \text { - } 6453 \text { Food and beverage } \\
\text { servers }\end{array}$ & $2.1 \%$ & $15-6611$ Cashiers $^{* *}$ & $2.3 \%$ & $\begin{array}{l}15 \text { - } 7611 \text { Construction trades } \\
\text { helpers and labourers }\end{array}$ & $1.7 \%$ \\
\hline $\begin{array}{l}16 \text { - } 7421 \text { Heavy equipment } \\
\text { operators (except crane) }\end{array}$ & $1.9 \%$ & $\begin{array}{l}16 \text { - } 7611 \text { Construction trades } \\
\text { helpers and labourers }\end{array}$ & $2.0 \%$ & $\begin{array}{l}16 \text { - } 6453 \text { Food and beverage } \\
\text { servers }\end{array}$ & $1.7 \%$ \\
\hline $\begin{array}{l}17 \text { - } 7414 \text { Delivery and courier } \\
\text { service drivers* }\end{array}$ & $1.9 \%$ & $\begin{array}{l}17 \text { - } 6453 \text { Food and beverage } \\
\text { servers }\end{array}$ & $1.9 \%$ & $\begin{array}{l}17 \text { - } 1453 \text { Customer service, } \\
\text { information and related clerks }\end{array}$ & $1.6 \%$ \\
\hline $\begin{array}{l}18 \text { - } 1433 \text { Customer service } \\
\text { representatives - financial } \\
\text { services }\end{array}$ & $1.7 \%$ & $\begin{array}{l}18-6411 \text { Sales representatives, } \\
\text { wholesale trade (non-technical) }\end{array}$ & $1.8 \%$ & 18 - 1411 General office clerks & $1.6 \%$ \\
\hline $\begin{array}{l}19 \text { - n6651 Security guards and } \\
\text { related occupations* }\end{array}$ & $1.6 \%$ & $\begin{array}{l}19-1433 \text { Customer service } \\
\text { representatives - financial } \\
\text { services }\end{array}$ & $1.8 \%$ & $\begin{array}{l}19 \text { - } 9462 \text { Industrial butchers and } \\
\text { meat cutters, poultry preparers and } \\
\text { related workers* }\end{array}$ & $1.3 \%$ \\
\hline $\begin{array}{l}20 \text { - } 6472 \text { Elementary and } \\
\text { secondary school teacher } \\
\text { assistants }\end{array}$ & $1.6 \%$ & $\begin{array}{l}20-6651 \text { Security guards and } \\
\text { related occupations* }\end{array}$ & $1.8 \%$ & $\begin{array}{l}20-1431 \text { Accounting and related } \\
\text { clerks* }\end{array}$ & $1.3 \%$ \\
\hline $\begin{array}{l}\text { Other Occupations (78 } \\
\text { occupations) }\end{array}$ & $34.5 \%$ & $\begin{array}{l}\text { Other Occupations (78 } \\
\text { Occupations) }\end{array}$ & $38.4 \%$ & $\begin{array}{l}\text { Other Occupations (78 } \\
\text { Occupations) }\end{array}$ & $23.8 \%$ \\
\hline Total (98 occupations) & $100 \%$ & Total (98 occupations) & $100 \%$ & Total (98 occupations) & $100 \%$ \\
\hline
\end{tabular}


Table 3: Distribution of the Number of Low-Skilled Workers Per Occupation in Each Immigration Status (Source: 2006 Census)

\subsubsection{Province of residence: NPR low-skilled workers have the highest}

share in Ontario. In this research, the distribution of low-skilled workers into categories (CB, IMM and NPR) reflects the general distribution across Canada. In all three immigration categories, the largest percentage of low-skilled workers is based in Ontario, which is the Canadian province with the largest population and the largest economy. When all three categories are combined, Ontario's share of all low-skilled workers in Canada is $38.9 \%$, followed by Quebec (24.1\%), British Columbia (12.0\%) and by Alberta (10.4\%) (see Table 4).

\begin{tabular}{|l|l|l|l|l|}
\hline \multicolumn{5}{|c|}{$\begin{array}{l}\text { Table 4: Distribution of Low-Skilled Workers by Province or Region in Each Immigration Status } \\
\text { (Source: 2006 Census) }\end{array}$} \\
\hline & CB & IMM & NPR & $\begin{array}{l}\text { TOTAL (CB, IMM \& } \\
\text { NPR) }\end{array}$ \\
\hline $\begin{array}{l}\text { AT (NF, PEI, NB \& } \\
\text { NS) }\end{array}$ & $9.9 \%$ & $0.9 \%$ & $1.1 \%$ & $7.8 \%$ \\
\hline QC & $27.8 \%$ & $12.1 \%$ & $15.9 \%$ & $24.1 \%$ \\
\hline ON & $33.2 \%$ & $57.5 \%$ & $51.6 \%$ & $38.9 \%$ \\
\hline MS (MB \& SK) & $7.8 \%$ & $3.9 \%$ & $3.9 \%$ & $6.9 \%$ \\
\hline AB & $10.8 \%$ & $9.1 \%$ & $12.6 \%$ & $10.4 \%$ \\
\hline BC & $10.6 \%$ & $16.5 \%$ & $14.9 \%$ & $12.0 \%$ \\
\hline Total & $100.0 \%$ & $100.0 \%$ & $\mathbf{1 0 0 . 0 \%}$ & $\mathbf{1 0 0 . 0 \%}$ \\
\hline
\end{tabular}

Table 4: Distribution of Low-Skilled Workers by Province or Region in Each Immigration Status - (Source: 2006 Census)

When comparing the low-skilled population within each province or combination of provinces according to immigration status, the Atlantic Provinces (as a group) have the highest proportion of Canadian-born low-skilled workers (97.3\%); the remaining $2.7 \%$ are foreign born (IMM and NPRs) low-skilled workers. The Atlantic provinces are followed by Quebec with 88\% CB, 11.5\% IMM and 0.6\% NPRs. Ontario and British 
Columbia have somewhat similar proportions of CB, IMM and NPRs (approximately $66 \%$ CB, 32\% IMM and 1\% NPRs). Together, Manitoba and Saskatchewan have 79\% CB, $20 \%$ IMM and $1 \%$ NPRs (see Table 5).

Table 5: Distribution of Low-Skilled Workers in Each Province (or Combination of Provinces) by Immigration Status - (Source: 2006 Census)

\begin{tabular}{|l|l|l|l|l|}
\hline & CB & IMM & NPR & $\begin{array}{l}\text { TOTAL (CB, IMM \& } \\
\text { NPR) }\end{array}$ \\
\hline $\begin{array}{l}\text { AT (NF, PEI, NB \& } \\
\text { NS ) }\end{array}$ & $97.3 \%$ & $2.6 \%$ & $0.1 \%$ & $100.0 \%$ \\
\hline QC & $88.0 \%$ & $11.5 \%$ & $0.6 \%$ & $100.0 \%$ \\
\hline ON & $65.2 \%$ & $33.7 \%$ & $1.1 \%$ & $100.0 \%$ \\
\hline MB \& SK & $86.7 \%$ & $12.8 \%$ & $0.5 \%$ & $100.0 \%$ \\
\hline AB & $79.0 \%$ & $20.0 \%$ & $1.0 \%$ & $100.0 \%$ \\
\hline BC & $67.4 \%$ & $31.5 \%$ & $1.1 \%$ & $100.0 \%$ \\
\hline Total & $76.3 \%$ & $22.8 \%$ & $0.9 \%$ & $100.0 \%$ \\
\hline
\end{tabular}

Table 5: Distribution of Low-Skilled Workers in Each Province (or Combination of Provinces) by Immigration Status - (Source: 2006 Census)

The proportion of NPRs among all low-skilled workers for the whole Canadian workforce $(0.9 \%)$ indicates that low-skilled NPRs represent a very small proportion of the entire low-skilled labour force (less than 1\%). CB makes up $76.3 \%$ of the low-skilled labour force and IMM represent $22.8 \%$.

\subsubsection{Sex: NPR low-skilled workers have a higher representation of women} compared to IMM or CB. Canada's low-skilled labour force is predominantly female (57\%). The greatest proportion of women is found among the NPRs $(60 \%)$, the second greatest among the IMM (58\%) and the third greatest among the CB (56\%) (see Figure 7). This predominance of women is driven primarily by occupations in the retail and service industries. Table 6 presents the share of both females and males according to 
occupation. $29 \%$ of low-skilled Canadian-born female workers are concentrated in the top three occupations in this population: occupations related to sales, customer care and retail. $22 \%$ of low-skilled female immigrant workers are concentrated in the top three occupations for this population: occupations related to retail, cleaning and nursesaids. In contrast with these relatively moderate levels of concentration, $62 \%$ of lowskilled female NPRs work in one of the top three occupations for this population

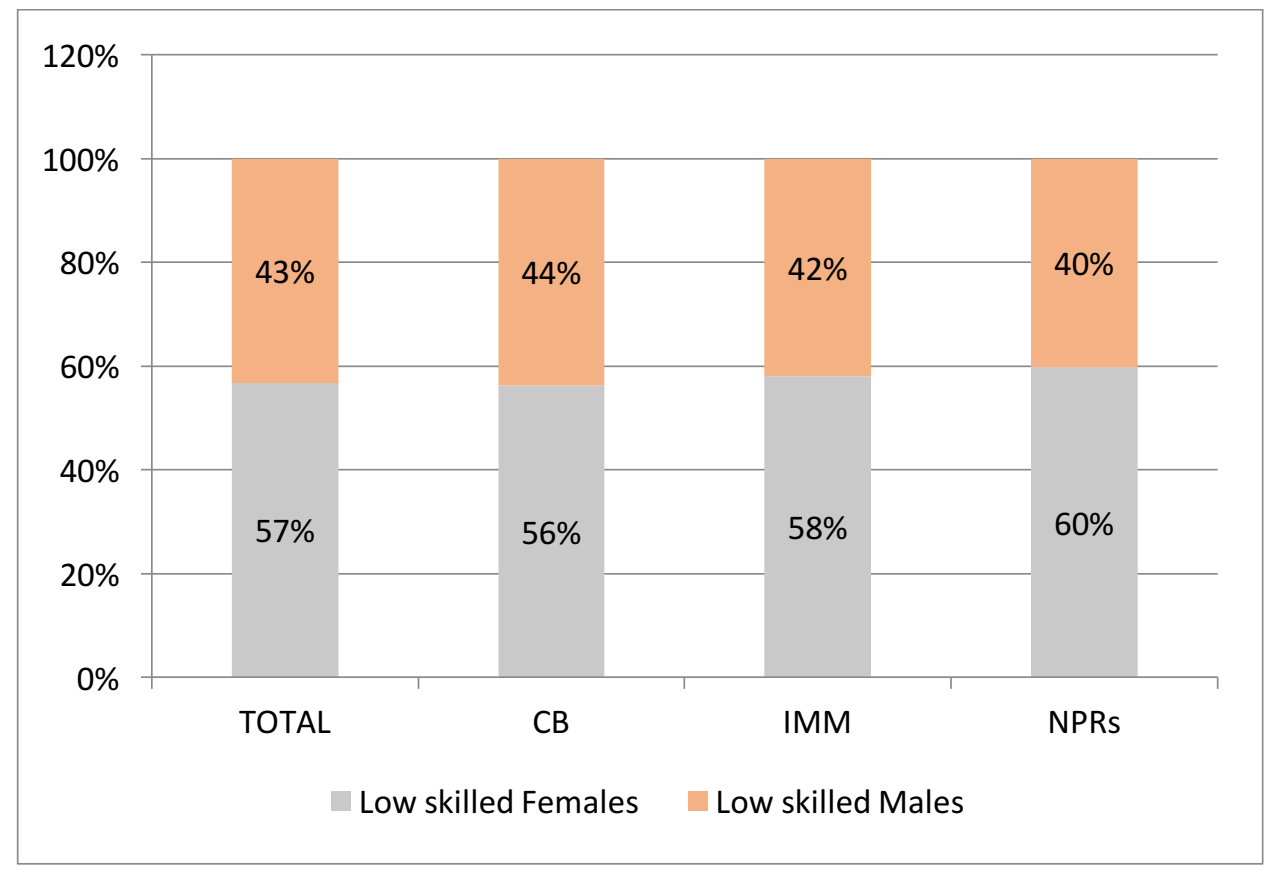

Figure 7: Low-Skilled Workers' Distribution by Sex - (Source: 2006 Census)

Almost half of all NPR female low-skilled workers are concentrated in a single occupation: 6474 -Babysitters and Nannies. This occupation is followed in popularity by 6471 - Visiting Homemakers, housekeepers and related occupations and then by 6661 Light Duty Cleaners. In contrast with their female counterparts, male low-skilled Canadian-born workers are distributed in more diverse types of occupations, including 6421 - Retail salespersons; 7452 - Material handlers; and, 6663 - Janitors, caretakers and building superintendents. Male low-skilled IMM and NPRs also tend to gravitate towards these occupations. 


\begin{tabular}{|c|c|c|c|c|c|}
\hline \multicolumn{6}{|c|}{$\begin{array}{r}\text { Table 6: Low-Skilled Workers Share by Occupa } \\
\text { Females }\end{array}$} \\
\hline \multicolumn{2}{|c|}{ CB (Percentage per occupation) } & \multicolumn{2}{|c|}{ IMM (Percentage per occupation) } & \multicolumn{2}{|c|}{ NPR (Percentage per occupation) } \\
\hline 1 - 1411 General office clerks & $12 \%$ & $\begin{array}{l}\text { 1- } 6421 \text { Retail salespersons and } \\
\text { sales clerks }\end{array}$ & $8 \%$ & $\begin{array}{l}1 \text { - } 6474 \text { Babysitters, nannies and } \\
\text { parents' helpers }\end{array}$ & $48 \%$ \\
\hline $\begin{array}{l}2 \text { - } 6421 \text { Retail salespersons and } \\
\text { sales clerks }\end{array}$ & $10 \%$ & 2 - 1411 General office clerks & $8 \%$ & $\begin{array}{l}2 \text { - } 6471 \text { Visiting homemakers, } \\
\text { housekeepers and related }\end{array}$ & $9 \%$ \\
\hline $\begin{array}{l}3 \text { - } 1431 \text { Accounting and related } \\
\text { clerks }\end{array}$ & $7 \%$ & 3 - 6661 Light duty cleaners & $6 \%$ & 3 - 313 - 6661 Light duty cleaners & $5 \%$ \\
\hline $\begin{array}{l}4-1453 \text { Customer service, } \\
\text { information and related clerks }\end{array}$ & $7 \%$ & $\begin{array}{l}4 \text { - } 1431 \text { Accounting and related } \\
\text { clerks }\end{array}$ & $6 \%$ & \begin{tabular}{|l}
$4-283-6421$ Retail \\
salespersons and sales clerks
\end{tabular} & $4 \%$ \\
\hline $\begin{array}{l}5 \text { - } 1414 \text { Receptionists and } \\
\text { switchboard operators }\end{array}$ & $5 \%$ & $\begin{array}{l}5-1413 \text { Nurse aides, orderlies } \\
\text { and patient service associates }\end{array}$ & $6 \%$ & $\begin{array}{l}5 \text { - } 198 \text { - } 1413 \text { Nurse aides, } \\
\text { orderlies and patient service }\end{array}$ & $3 \%$ \\
\hline 6 - 6611 Cashiers & $5 \%$ & $\begin{array}{l}6 \text { - } 6641 \text { Food counter attendants, } \\
\text { kitchen helpers and related }\end{array}$ & $5 \%$ & 6 - 1411 General office clerks & $2 \%$ \\
\hline $\begin{array}{l}7 \text { - } 1413 \text { Nurse aides, orderlies } \\
\text { and patient service associates }\end{array}$ & $5 \%$ & $\begin{array}{l}7 \text { - } 9451 \text { Sewing machine } \\
\text { operators }\end{array}$ & $5 \%$ & 7 - 6611 Cashiers & $2 \%$ \\
\hline $\begin{array}{l}8-311-6641 \text { Food counter } \\
\text { attendants, kitchen helpers and }\end{array}$ & $4 \%$ & $\begin{array}{l}8 \text { - } 1453 \text { Customer service, } \\
\text { information and related clerks }\end{array}$ & $4 \%$ & $\begin{array}{l}8 \text { - } 6641 \text { Food counter } \\
\text { attendants, kitchen helpers and }\end{array}$ & $2 \%$ \\
\hline $\begin{array}{l}9 \text { - } 6453 \text { Food and beverage } \\
\text { servers }\end{array}$ & $4 \%$ & 9 - 6611 Cashiers & $4 \%$ & $\begin{array}{l}9-1431 \text { Accounting and related } \\
\text { clerks }\end{array}$ & $2 \%$ \\
\hline 10 - 6661 Light duty cleaners & $3 \%$ & $\begin{array}{l}10 \text { - } 9617 \text { Labourers in food, } \\
\text { beverage and tobacco processing }\end{array}$ & $3 \%$ & $\begin{array}{l}10 \text { - } 6453 \text { Food and beverage } \\
\text { servers }\end{array}$ & $2 \%$ \\
\hline Other Occupations & $36 \%$ & Other Occupations & $46 \%$ & Other Occupations & $20 \%$ \\
\hline Total & $100 \%$ & Total & $100 \%$ & Total & $100 \%$ \\
\hline \multicolumn{6}{|c|}{ Males } \\
\hline \multicolumn{2}{|l|}{ CB (Percentage per occupation) } & \multicolumn{2}{|l|}{ IMM (Percentage per occupation) } & \multicolumn{2}{|l|}{ NPR (Percentage per occupation) } \\
\hline $\begin{array}{l}1-6421 \text { Retail salespersons and } \\
\text { sales clerks }\end{array}$ & $13 \%$ & $\begin{array}{l}\text { 1- } 6421 \text { Retail salespersons and } \\
\text { sales clerks }\end{array}$ & $9 \%$ & 1 - 8431 General farm workers & $14 \%$ \\
\hline 2 - 7452 Material handlers & $10 \%$ & $\begin{array}{l}2 \text { - } 6663 \text { Janitors, caretakers and } \\
\text { building superintendents }\end{array}$ & $9 \%$ & $\begin{array}{l}2 \text { - } 8432 \text { Nursery and } \\
\text { greenhouse workers }\end{array}$ & $10 \%$ \\
\hline $\begin{array}{l}3 \text { - } 6663 \text { Janitors, caretakers and } \\
\text { building superintendents }\end{array}$ & $9 \%$ & 3 - 7452 Material handlers & $8 \%$ & 3 - 7452 Material handlers & $7 \%$ \\
\hline $\begin{array}{l}4-7611 \text { Construction trades } \\
\text { helpers and labourers }\end{array}$ & $8 \%$ & $\begin{array}{l}4 \text { - } 7611 \text { Construction trades } \\
\text { helpers and labourers }\end{array}$ & $5 \%$ & $\begin{array}{l}4 \text { - } 6421 \text { Retail salespersons and } \\
\text { sales clerks }\end{array}$ & $6 \%$ \\
\hline $\begin{array}{l}5 \text { - } 6411 \text { Sales representatives, } \\
\text { wholesale trade (non-technical) }\end{array}$ & $6 \%$ & $\begin{array}{l}5 \text { - } 9482 \text { Motor vehicle } \\
\text { assemblers, inspectors and }\end{array}$ & $4 \%$ & $\begin{array}{l}5 \text { - } 36663 \text { Janitors, caretakers } \\
\text { and building superintendents }\end{array}$ & $4 \%$ \\
\hline $\begin{array}{l}6 \text { - } 7414 \text { Delivery and courier } \\
\text { service drivers }\end{array}$ & $5 \%$ & $\begin{array}{l}6 \text { - } 6651 \text { Security guards and } \\
\text { related occupations }\end{array}$ & $4 \%$ & $\begin{array}{l}6 \text { - } 7611 \text { Construction trades } \\
\text { helpers and labourers }\end{array}$ & $4 \%$ \\
\hline $\begin{array}{l}7 \text { - } 1453 \text { Customer service, } \\
\text { information and related clerks }\end{array}$ & $4 \%$ & $\begin{array}{l}7 \text { - } 1453 \text { Customer service, } \\
\text { information and related clerks }\end{array}$ & $3 \%$ & $\begin{array}{l}7 \text { - } 6474 \text { Babysitters, nannies and } \\
\text { parents' helpers }\end{array}$ & $4 \%$ \\
\hline $\begin{array}{l}8 \text { - } 6651 \text { Security guards and } \\
\text { related occupations }\end{array}$ & $4 \%$ & $\begin{array}{l}8 \text { - } 393 \text { - } 7414 \text { Delivery and } \\
\text { courier service drivers }\end{array}$ & $3 \%$ & $\begin{array}{l}8 \text { - } 9619 \text { Other labourers in } \\
\text { processing, manufacturing and }\end{array}$ & $3 \%$ \\
\hline $\begin{array}{l}9-493 \text { - } 9482 \text { Motor vehicle } \\
\text { assemblers, inspectors and }\end{array}$ & $3 \%$ & $\begin{array}{l}9 \text { - } 6411 \text { Sales representatives, } \\
\text { wholesale trade (non-technical) }\end{array}$ & $3 \%$ & $\begin{array}{l}9-312-6651 \text { Security guards } \\
\text { and related occupations }\end{array}$ & $3 \%$ \\
\hline $\begin{array}{l}10 \text { - } 6622 \text { Grocery clerks and } \\
\text { store shelf stockers }\end{array}$ & $3 \%$ & $\begin{array}{l}10 \text { - } 9511 \text { Machining tool } \\
\text { operators }\end{array}$ & $3 \%$ & $\begin{array}{l}10 \text { - } 9462 \text { Industrial butchers and } \\
\text { meat cutters, poultry preparers }\end{array}$ & $3 \%$ \\
\hline Other Occupations & $37 \%$ & Other Occupations & $47 \%$ & Other Occupations & $40 \%$ \\
\hline Total & $100 \%$ & Total & $100 \%$ & Total & $100 \%$ \\
\hline
\end{tabular}

Table 6: Low-Skilled Workers Share by Occupation and Sex - (Source: 2006 Census) 
However, NPRs' major presence is in occupations in the agricultural sector, including 8431-General farm workers and 8432-Nursery and greenhouse workers. The three low-skilled male populations (Canadian-born, immigrants and Non-Permanent Residents) exhibit somewhat similar percentages of concentration in their top three occupations (32\%, $26 \%$ and $31 \%$, respectively).

\subsubsection{Country of birth (COB): NPR low-skilled workers' COB concentrate} around five countries. One of them, the Philippines, has a very high concentration (1 in 3 NPRs). As Table 7 indicates, the presence of low-skilled workers in Canada according to country of birth reflects three main characteristics: 1) most foreign-born low-skilled workers in Canada (including IMM and NPRs) come from the same top source countries as permanent residents (i.e. India, Philippines and China); 2) NPR's countries of birth reflect specific TFW agreements that Canada has made with other countries (i.e. Mexico and Caribbean countries for SAWPs) as well as the absorption of labour coming from traditionally labour-exporter countries (the Philippines for LICs); and 3) some countries of birth reflect traditional nationalities linked to specific occupations (there is, for example, a strong link between the Philippines and child/senior care and Mexico and agriculture).

In this research, the proportions of low-skilled workers according to country of birth follow specific selection criteria. Only those who declared "Canada" as their country of birth and "non-immigrant" as their immigration status were considered as Canadian-born. To avoid double counting, in this section (COB), the research excluded those born in Canada with other nationalities (i.e. dual-citizens). Table 7 presents the 
top 20 countries of low-skilled immigrant and NPR workers.

\section{Table 7: Top 20 Countries of Birth of Low-Skilled Immigrants and Low-Skilled NPRs - (Source: 2006 Census)}

\begin{tabular}{|c|c|c|c|}
\hline Top 20 Countries of Birth of L-S Immigrants & Share & Top 20 Countries of Birth of L-S NPRs & Share \\
\hline 1 - India & $9.9 \%$ & 1 - Philippines & $30.1 \%$ \\
\hline 2 - Philippines & $9.1 \%$ & 2 - Mexico & $8.1 \%$ \\
\hline 3 - China, People's Republic of & $5.7 \%$ & 3 - India & $4.6 \%$ \\
\hline 4 - United Kingdom & $5.6 \%$ & 4 - United Kingdom & $3.2 \%$ \\
\hline 5 - Viet Nam & $4.4 \%$ & 5 - China, People's Republic of & $2.9 \%$ \\
\hline 6 - Portugal & $3.8 \%$ & 6 - United States of America & $2.7 \%$ \\
\hline 7 - Italy & $3.1 \%$ & 7 - Jamaica & $2.5 \%$ \\
\hline 8 - Hong Kong & $3.0 \%$ & 8 - Pakistan & $2.0 \%$ \\
\hline 9 - Jamaica & $3.0 \%$ & 9 - Sri Lanka & $1.8 \%$ \\
\hline 10 - Poland & $2.7 \%$ & 10 - France & $1.5 \%$ \\
\hline 11- Sri Lanka & $2.4 \%$ & 11 - El Salvador & $1.1 \%$ \\
\hline 12 - United States of America & $2.2 \%$ & 12 - Australia & $1.1 \%$ \\
\hline 13 - Guyana & $2.1 \%$ & 13 - Trinidad and Tobago & $1.1 \%$ \\
\hline 14 - Pakistan & $1.5 \%$ & 14 - Japan & $1.0 \%$ \\
\hline 15 - Germany & $1.4 \%$ & 15 - Germany & $1.0 \%$ \\
\hline 16 - El Salvador & $1.4 \%$ & 16 - Nigeria & $0.9 \%$ \\
\hline 17 - Trinidad and Tobago & $1.3 \%$ & 17 - Zimbabwe & $0.8 \%$ \\
\hline 18 - Haiti & $1.2 \%$ & 18 - Korea, South & $0.8 \%$ \\
\hline 19 - Mexico & $1.0 \%$ & 19 - Colombia & $0.8 \%$ \\
\hline 20 - Romania & $0.9 \%$ & 20 - Brazil & $0.7 \%$ \\
\hline Other Countries & $34.3 \%$ & Other Countries & $31.3 \%$ \\
\hline
\end{tabular}

Table 7: Top 20 Countries of Birth of Low-Skilled Immigrants and Low-Skilled NPRs - (Source: 2006 Census)

It is also illuminating to compare the concentration of NPRs with that of the immigrant population. Even if the proportions are similar, concentration seems to be a bit higher for NPRs. The Philippines and Mexico account for $38.2 \%$ of all NPRs in this study. The Philippines alone represents $30 \%$ of all NPRs. India, China, Mexico and the United Kingdom are also among the top countries of birth of low-skilled immigrants and low-skilled NPRs in Canada. 


\section{Summary}

Temporary low-skilled foreign labour has become a way of exploiting accessible and inexpensive labour from developing countries and many TFWs have documented exploitative experiences during their time in Canada (Faraday, 2012a; 2016).

Employers in Canada have four streams to access temporary foreign low-skilled labour. Some of these streams have been either recently modified (Live-in Caregiver Program) or recently added (Agricultural Stream and Low-Wage Stream). While the LIC program is the only program to offer a pathway to permanent residence, recent changes to the program have significantly restricted access to permanent residency and, by extension, to citizenship (Faraday, 2016).

Among all low-skilled workers in full-time jobs, the greatest concentration is in the manufacturing and retail trade industry sectors. More specifically, low-skilled workers have the largest representation in occupation NOC 6421 - Retail Salespersons and sales clerks (approximately 260 000) and occupation NOC 7411 - Truck Drivers (approximately 178 000). While 6421-Retail and Sales Persons is the top occupation among both Canadian-born and immigrant low-skilled workers, occupation NOC-6474 Babysitters and Nannies and parents' helpers is the top occupation among NPRs. The top 20 occupations in the NPR population represent $75 \%$ of the total of NPRs and the top three $37.6 \%$, indicating a higher concentration of NPRs in fewer occupations vis-avis Canadian-born and immigrant workers.

Most low-skilled NPRs are concentrated in Ontario. There is a higher proportion of female to male low-skilled workers among NPRs than among CB and IMM. There is a particularly high concentration of female NPRs in caregiving occupations and of male 
NPRs in agricultural occupations. Mexico and the Philippines are the countries of origin for the highest concentration of NPRs (38\%). The Philippines alone takes about $30 \%$ of the share, that is, nearly one in three low-skilled NPRs is from the Philippines.

Having provided a demographic profile of all low-skilled workers in Canada, the following chapter enhances our understanding of this demographic by presenting the outcomes of the wage analysis (concentration of wages via the quartile analysis and wage differences via the cross-tabulation analysis). 


\section{Chapter Six: Wages and Differences in Citizenship Status \\ by Occupation and Industry}

In this chapter, I introduce the key focus of this dissertation, an exploration of the tangible labour market effects of lack of citizenship on low-skilled workers. To evaluate citizenship's impact on wages, I framed the analysis in three citizenship groups: Canadian-born (CB), Immigrants - including permanent residents (IMM) and NonPermanent Residents (NPRs). In this chapter, I present my findings on wages in three dimensions; 1) absolute average hourly wages for all three of the above categories; 2) the range of wages earned by workers in each occupation; 3) and NPRs wage differences (compared to $\mathrm{CB}$ and IMM). These analyses are done in a range of industry sectors and low-skilled occupations as they play out in the three groups I identified.

This chapter presents results and does not include an analysis of outcomes (i.e. an explanation of wage differences), something that will be covered in chapter nine. The sections are further subdivided in categories and subcategories to help the reader navigate through the specifics in each section ${ }^{64}$

Recall from chapter four that: 1) the absolute and relative wage analysis at the industry sector level includes 13 industry sectors; 2) the NPRs' absolute wage analysis, 43 occupations; 3 ) the concentration of wages analysis at the occupation level, 20 occupations; and, 4) the NPRs' relative wage analysis at the occupation level (NPR compared to $\mathrm{CB}$ and IMM), 35 occupations. All these numbers follow selection criteria that consider number of counts and tests for means comparison ${ }^{65}$. Each of the four

\footnotetext{
${ }^{64}$ This is especially helpful in quantitative analysis.

${ }^{65}$ That is, it includes results with at least 90 counts in the weighted sample and a Bonferroni test result between 0 and $5 \%$ (Bonferroni tests evaluate comparability of mean wages). The number 90 is chosen because it is a large enough sample to ensure no violation of privacy restrictions. It is also important to
} 
types had a process of selection of occupations ${ }^{66}$.

Key findings demonstrate that non-access to citizenship among NPRs negatively impacts both their relative and their absolute wages in the following way: 1) Among lowskilled NPRs, two industry sectors (out of 13 analyzed) exhibited very low absolute wages. Additionally, low-skilled NPRs earned lower wages than the CB and IMM in 11 of the 13 industry sectors analyzed. In the remaining two, NPRs earned higher wages than the CB and IMM. 2) Just over half of all NPRs (52\%) work in only 7 occupations which exhibit high concentration of NPRs in low wages; 12 occupation have a high concentration around high wages (they represent $30 \%$ of all NPRs). 3) The lowest absolute wages were among babysitters and nannies (not counting room and board) followed by low-skilled workers in agriculture. 4) Of the 35 occupations analyzed, in 31 NPRs earn less than CB and/or IMM. In the remaining 4 occupations, NPR relative wages exhibited positive differences (NPRs earning more than CB and IMM). This demonstrates that NPRs had lower wages than immigrants and Canadian-born workers in about $89 \%$ of the 35 occupations analyzed. In only 4 occupations NPRs had higher wages than the Canadian-born and Immigrant populations.

\footnotetext{
have a large enough sample to allow for comparisons between populations (NPRs-CB and NPRsIMM). This is especially relevant among NPRs because the number of low-skilled NPRs is in most cases significantly lower than the number of Canadian-born or immigrant workers. The analysis must be done among samples with a relevant number of observations. NPRs are chosen as the reference group, because the end goal is to evaluate their wages against the wages of those who have access to citizenship (CB and IMM).

${ }^{66}$ Recall from chapter four that 1 ) for the industry sector level analysis, the original number of 21 industry sectors was reduced to 13 by using only cases with a reliable number of counts in the NPR population (per industry sector) and with a statistically significant Bonferroni test; 2) Regarding absolute wage analysis at the occupation level, the total of 98 low-skilled occupations identified was reduced to 43 also by using only cases with a reliable number of counts. The outcomes of this section focus on the top 20 occupations with the highest number of NPRs; 3 ) For the concentration of wages analysis (quartile analysis), of the 43 occupations with a reliable number of counts, also the top 20 occupations were chosen; 4) For the NPR relative wage analysis (NPR-CB and NPR-IMM), the 43 occupations chosen, were reduced to 35 after applying Bonferroni test. Only occupations that passed the test were included.
} 


\subsection{Industry Sector Analysis (Absolute and Relative Wages)}

This section is the introduction to the heart of this dissertation's focal question, the effect of lack of citizenship on wages of NPRs. An industry sector level analysis provides a macroeconomic perspective on the differences in wages, which is the point of departure for this dissertation. This level of analysis will bring to the forefront differences among low-skilled workers working in sectors that rely most on low-skilled temporary foreign labour. It will provide a macroeconomic perspective on the labour market outcomes of low-skilled NPRs in Canada. Having a sound grasp of the wages of low-skilled workers in each industry sector provides information on how to evaluate lowskilled labour gaps in these sectors at the time of the census.

The wage-differences analysis will serve as a means to analyze how wages compare between populations. Wage differences are calculated using the crosstabulation analysis explained in chapter four.

\subsubsection{Absolute wages of NPRs by industry sector. Figure 8 shows an} industry-sector distribution of wages for low-skilled workers in Canada sorted from high to low (with NPRs as the reference). It indicates that NPR wages by industry sector vary from about $\$ 10.10 /$ hour to $\$ 19.10 /$ hour. Low-skilled NPRs working in the Agriculture, forestry, fishing and hunting industry sector earn the lowest wages (an average of $\$ 10.10 /$ hour). The second industry sector includes workers in the 'Other Services' sector (except public administration), averaging approximately $\$ 10.20$ / hour. This is a composite service sector and includes caregiving occupations, which comprise the largest number of NPRs. These results seem rather high. As will be explained, high 
average wages are the consequence of high wage dispersion ${ }^{67}$.

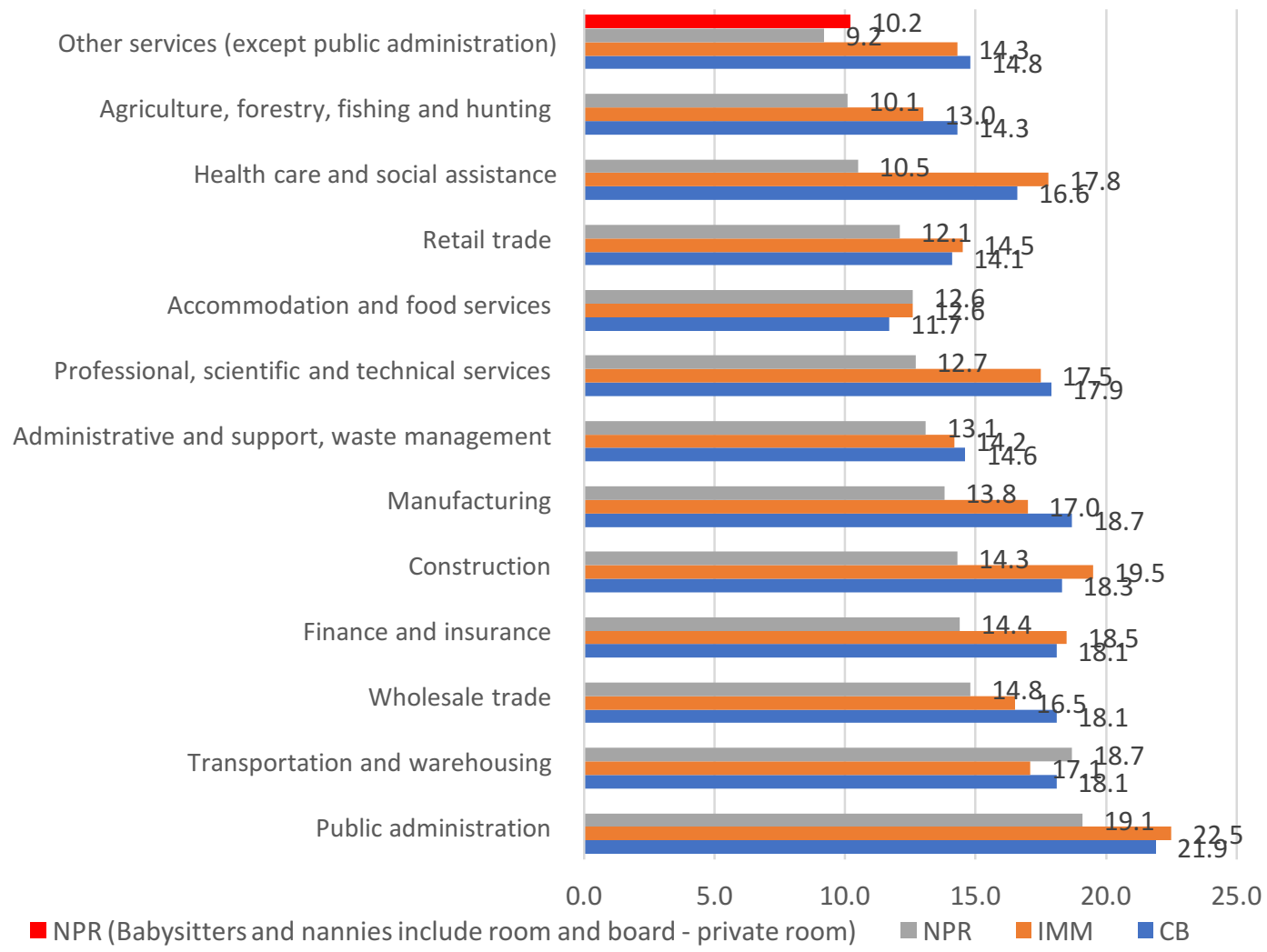

Figure 8: Average Hourly Wages by Industry Sector and Immigration Status Listed lowest to highest for NPRs - (Source: 2006 Census) ${ }^{68}$

Wage dispersion (high standard deviation) skews industry sector outcomes.

Instances of high wages cause high dispersion. This is an important consideration when analyzing wages because even a few cases of high wages can inflate the mean. While wage dispersion in this analysis may be the result of differences in actual skill level or

\footnotetext{
${ }^{67}$ Wage dispersion refers to how wages are spread out in a population. It refers to significant differences in wages even though all work is related to the same occupation.

${ }^{68}$ The Other Services (Except Public Administration) category has four bars unlike three for others because of wage differences among Babysitters, Nannies and Parents' Helpers. They are grouped under Other Services industry sector category. The bright red bar represents the average wage for the industry sector including their compensation represented in room and board. The green one does not include room and board. Babysitters, Nannies and Parents' Helpers represent $83 \%$ of all NPRs in this industry sector. Accounting for room and board (a private room) NPRs in this category represents additional earnings of about $\$ 2 /$ hour.
} 
seniority, other intrinsic sources of wage dispersion (i.e. factors that are introduced either by the government or the local labour market) can be identified. Two main sources of wage dispersion at the industry sector analysis were identified: wage dispersions within sectors and wage dispersion across sectors.

First, wage dispersion within sectors has different possible sources: a) Each industry sector has a broad range of wages. This is linked to the fact that each industry clusters information from occupations and each occupation clusters a broad range of jobs, each with a broad range of wages. b) While Figure 8 introduces the analysis of the statistics of low-skilled wages in Canada, a sector level representation blurs differences not only in the wages, but also in labour conditions of diverse industries and occupations. Some occupations included in each sector, are likely to pay some workers minimum wage, which c) varies from province to province. In short, there are several sources of wage dispersion for each industry sector.

Second, wage dispersion is also present across sectors, which is linked to the nature of each sector. Each sector experiences fluctuations linked to changes in the regional and national economy as well as to changes specific to the sector, all of which are reflected in the NAICS ${ }^{69}$ system (Hiles, 2001; Walker and Murphy, 2001).

Performing a type of analysis that considers how wages are distributed within each population (NPR, CB and IMM) and occupation addresses the gaps linked to wage dispersion. This will be explored later in this chapter. Following, I deepen the analysis on the effects of lack of citizenship on wages. The following section introduces the outcomes of a cross-tabulation analysis at the industry level. It includes the relative wages of NPRs compared to the CB and IMM.

${ }^{69}$ Industry sectors are classified according to the North American Industry Classification System - NAICS. 


\subsubsection{Relative wages of NPRs (Compared to CB and IMM) by Industry}

Sector. Regarding Wage differences by industry sector, Figure 9 presents the statistically significant wage differences by immigration category and industry sectors. To ensure comparability of means in the mean differences analysis, a Post-Hoc test (Bonferroni test) was performed for all differences. Comparing the wages of low-skilled workers by immigration status at the industry sector level reveals patterns among those with an NPR immigration status in relation to those with a permanent status (Canadianborn, naturalized immigrants and permanent residents).

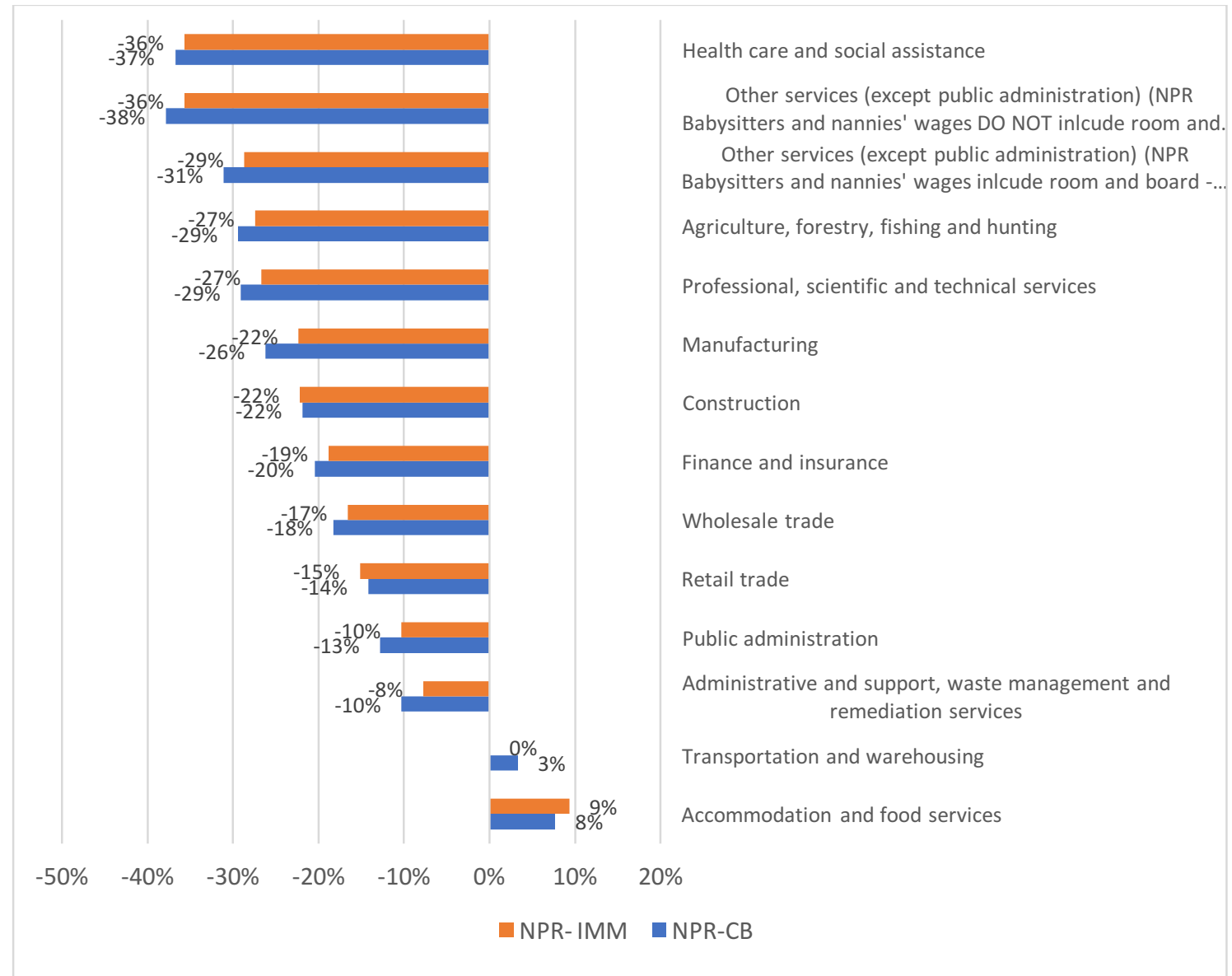

Figure 9: Statistically Significant Average Hourly Wage Differences by Immigration Category and Industry Sector (NPR-CB and NPR-IMM). (Source: 2006 Census).

The figure shows that the categories Health Care and Social Assistance, Other 
services (except public administration), and Agriculture, Forestry, Fishing and Hunting, exhibit the highest negative differences in wages for low-skilled NPRs compared to their Canadian-born and immigrant counterparts.

NPRs in the Health Care and Social Assistance industry sector earn $37 \%$ less than the Canadian-born and $36 \%$ less than the immigrant population. These results begin to reinforce what the literature claims, namely, that in most industry sectors the wage of low-skilled workers without citizenship (NPRs) is lower than that of those with access to citizenship (CB and IMM).

The Other Services category exhibits $31 \%$ and $29 \%$ negative differences between NPRs and IMM and CB, respectively. Agriculture, Forestry, Fishing and Hunting follows with $27 \%$ and $29 \%$ less wage for NPRs compared to the IMM and CB, respectively. Manufacturing also exhibits negative differences. According to Figure 9, NPRs earn $26 \%$ and $22 \%$ less than CB and IMM, respectively. Note that the red bar missing in this figure (in the Transportation and Warehousing Sector) corresponds to a statistically non-significant value (see Bonferroni test in chapter four). Absent bars in all figures will correspond to statistically non-significant values.

NPRs in some industry sectors exhibit higher wages than CB and IMM (i.e. Accommodation and food services -AFS). Given that industry sectors are comprised of different occupations, looking at the different occupations may help to evaluate the veracity of this. Assuming that NPRs in certain occupations earn more than CB and IMM, it is possible that these wages indicate genuine gaps in the labour market in these specific sectors. However, as explained above, wage dispersion affects our reading of wages. 
Although these statistics offer insight into the wage differences among the lowskilled population, analysis at the level of the industry sector, which blurs the diversity of low-skilled occupations in each industry sector, provides a somewhat fuzzy picture. Occupations in various sectors demand specific skills, which may challenge the lowskilled designation of these occupations and may affect wage compensation. This great diversity may also lead to even greater wage dispersion within the sectors themselves. Though relevant, this level of analysis nevertheless falls also short because each industry sector clusters together a diverse number of occupational groups, which represents a significant source of wage dispersion. Therefore, a more granular analysis is also required. More specifically, an occupation level analysis helps reduce the effects of wage dispersion and provides more detailed information about wage discrepancies among low-skilled workers.

\subsection{Occupation Level Analysis - Absolute Wages of NPRs by Occupation}

With NPRs wages ordered lowest to highest, Figure 10A shows a summary of the wages of the top 20 low-skilled occupations (out of the 43 analyzed - see Appendix 10A for wages of NPRs, CB and IMM in all 43 occupations). The chart includes occupations with the highest number of NPRs ${ }^{70}$; wages are organized top to bottom among NPRs. Of the 43 occupations analyzed, Babysitters, nannies and parents' helpers earn the lowest wages (not accounting for room and board), \$8.10/hour. The wages of NPR babysitters and nannies' do not reflect additional compensation (room and board) received by live-in caregivers. In 2012, the Ontario government stipulated

\footnotetext{
${ }^{70}$ The occupations in the chart also allowed a quartile analysis, which was explained in detail in chapter four and is used in the next section of this chapter.
} 
that employers could deduct $\$ 85.25$ weekly from wage payment to live-in-caregivers for room and board in a private room and $\$ 53.55$ weekly in a non-private room (Faraday, 2012a). In October of 2016 the amount remained the same (Ontario Ministry of Labour, 2016). The 2006 census shows an average of 41.17 hours of work for babysitters and nannies. ${ }^{71}$ Hence room and board would represent an additional compensation of about $\$ 2.07 /$ hour in the case of a private room (or $\$ 85.25$ per week/41.17 hours per week) and $\$ 1.30 /$ hour in the case of a non-private room (or $\$ 53.55$ per week/41.17 hours per week).

As already mentioned, the average wage for NPR babysitters and nannies reported in the 2006 census was $\$ 8.10 /$ hour. The great majority of NPRs doing this job, do so as live-in-caregivers. Therefore, calculating the wage of NPRs in this occupation should add the value of room and board provided for the employer. This would raise their 'real' hourly wage to either $\$ 9.40 /$ hour $(8.10+1.30)$ in the case of a non-private private room or $\$ 10.17 /$ hour $(8.10+2.07)$ in the case of a private room. Typically, a private room is provided for accommodation. Accordingly, the narrative and occupationrelated figures to follow will refer to the hourly wage rate in two modalities: census derived wage/census derived wage + private room and board increment.

\footnotetext{
${ }^{71}$ This number of hours is used for calculation purposes. However, it is important to note that live-in caregivers have reported working unreported or under-reported hours (Bakan \& Stasiulis, 2003, as cited in Cheung, 2006).
} 


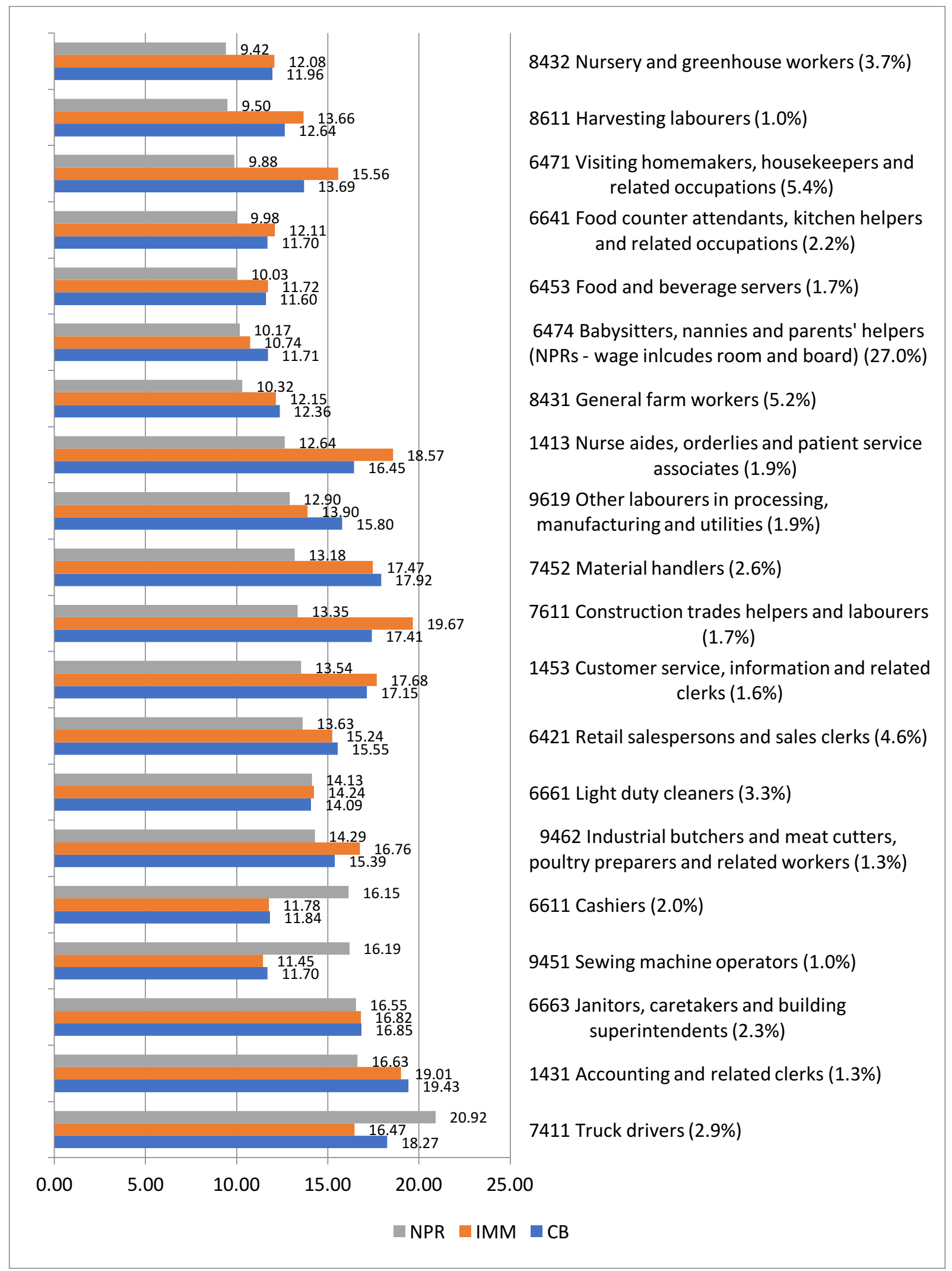

Figure 10A: Average Hourly Wages by Occupation and Immigration Status Listed lowest to highest for NPRs - (In Brackets, Percentage of NPRs out of Total NPRs - Source: 2006 Census) 
With room and board, babysitters and nannies' average wage ( $\$ 10.17 /$ hour) is no longer the lowest ${ }^{72}$, thus, NPR wages range from $\$ 9.42 /$ hour for 8432 - Nursery and greenhouse workers $^{73}$ to $\$ 20.92 /$ hour for 7411 -Truck Drivers. Given that minimum wage at the time of the 2006 Census in provinces were around $\$ 7.50 /$ hour (e.g. in Ontario was $\$ 7.43 /$ hour), as with the industry sector analysis these values seem rather high. As with industry sectors, high mean wages by occupation are also associated to high wage dispersion. Sources of wage dispersion at the occupation level include: 1) NOC 4 occupations group together significantly diverse jobs; and that 2) the wages of most low-skilled occupations are close to the minimum wage, which varies from province to province. A more detailed explanation of each of these causes of wage dispersion is included in appendix eight. Extrinsic factors (i.e. factors less under the control of the government or the local labour market), such as changes in oil prices, are not accounted for in this research. In view of these possible sources of wage dispersion, mean wages alone do not provide a complete picture, especially in low-paying jobs, where many sources of variation outside the domain of local labour markets come into play.

Assessing the degree of dispersion of the sample (or the population) is extremely important since a significantly high dispersion translates into high mean wages. In this analysis, dispersion is measured through the Standard Deviation $(\sigma)$, which provides information on how spread out the data is.

Since wages generally tend to have high levels of dispersion (high standard

\footnotetext{
${ }^{72}$ Although not the lowest, accounting for room and board makes babysitters and nannies' average wage the sixth lowest of all occupations.

${ }_{73}$ Note that another agricultural occupation follows as the second lowest (8611-Harvesting Labourers with $\$ 9.50 /$ hour)
} 
deviation), the mean wage provides a partial view of wages among low-skilled workers. It is accordingly imperative to complement the analysis of wage differences (NPR-CB and NPR-IMM), which will be presented later in this chapter) with a quartiles analysis. When high dispersion is present, a quartile analysis helps identify the concentration of wages. As will be shown, although some values are significantly high (which results in high means), most of the values are concentrated in the first three quartiles (low wage quartiles).

\subsection{Assessing Wage Dispersion (Broad Wage Range) in Absolute Wages - Quartile Analysis}

Why is a quartile analysis important? What does it reveal? How does it reveal? A quartile analysis is important because it reveals the distribution of workers' wages in each occupation. This is important to identify whether there are concentrations within occupations of workers at a low end or a high end, of reported earnings for that occupation. Undertaking quartile analysis entails two stages: first, is dividing the full range of reported wages into four equal quartiles of reported data. The second stage, is distributing the total number of workers in an occupation into those wage quartiles to identifying any clustering. Recall, the quartile divides wage ranges in equal parts and not number of workers in equal parts.

Once we stablished wage quartiles, we can then identify how many people are included in each quartile; it helps to see whether many people concentrate in either lowwage or high-wage quartiles. 


\begin{tabular}{|c|c|c|c|c|c|c|c|c|c|c|c|c|c|c|}
\hline \multicolumn{15}{|c|}{ Table 8 - Low-Skilled NPR Quartiles - top 20 Occupations - (Sc } \\
\hline \multicolumn{15}{|c|}{ LOW-SKILLED NON- PERMANENT RESIDENTS } \\
\hline & \multicolumn{7}{|c|}{ SHARE BY QUARTILE } & \multicolumn{7}{|c|}{$\begin{array}{c}\text { AVERAGE WAGES PER HOUR BY QUARTILE } \\
\text { (\$/hour) }\end{array}$} \\
\hline $\begin{array}{l}\text { OCCUPATION } \\
\text { (NOC code / Name) }\end{array}$ & Q1 & Q2 & $\mathrm{Q1+Q2}$ & Q3 & $\mathrm{Q1+Q2+Q3}$ & Q4 & Total & Q1 & Q2 & $\begin{array}{l}\text { Average } \\
\text { Q1+Q2 }\end{array}$ & Q3 & $\begin{array}{l}\text { Average } \\
Q 1+Q 2+Q 3\end{array}$ & Q4* & \begin{tabular}{|l} 
Total (AVG \\
PER OCC.)
\end{tabular} \\
\hline Total & $27 \%$ & $24 \%$ & $51 \%$ & $21 \%$ & $72 \%$ & $28 \%$ & $100 \%$ & 4.75 & 8.07 & 6.29 & 10.44 & 7.49 & 22.29 & 11.63 \\
\hline $\begin{array}{l}6474 \text { Babysitters, nannies and } \\
\text { parents' helpers }\end{array}$ & $39 \%$ & $38 \%$ & $77 \%$ & $17 \%$ & $94 \%$ & $6 \%$ & $100 \%$ & 5.01 & 8.03 & 6.52 & 10.20 & 7.18 & 21.82 & 8.10 \\
\hline $\begin{array}{l}6474 \text { Babysitters, nannies and } \\
\text { parents' helpers (NPR wages include } \\
\text { room \& board - private room) }\end{array}$ & & & & & & & & 7.08 & 10.1 & & 12.27 & & 23.89 & 10.17 \\
\hline 8431 General farm workers & $24 \%$ & $29 \%$ & $52 \%$ & $30 \%$ & $82 \%$ & $18 \%$ & $100 \%$ & 5.29 & 8.17 & 6.87 & 10.32 & 8.12 & 20.45 & 10.32 \\
\hline $\begin{array}{l}8432 \text { Nursery and greenhouse } \\
\text { workers }\end{array}$ & $19 \%$ & $28 \%$ & $47 \%$ & $40 \%$ & $87 \%$ & $13 \%$ & $100 \%$ & 4.94 & 8.11 & 6.81 & 10.19 & 8.38 & 16.71 & 9.42 \\
\hline $\begin{array}{l}6471 \text { Visiting homemakers, } \\
\text { housekeepers and related } \\
\text { occupations }\end{array}$ & $36 \%$ & $30 \%$ & $65 \%$ & $17 \%$ & $83 \%$ & $17 \%$ & $100 \%$ & 4.83 & 8.03 & 6.28 & 10.37 & 7.15 & 22.86 & 9.88 \\
\hline $\begin{array}{l}6421 \text { Retail salespersons and } \\
\text { sales clerks }\end{array}$ & $23 \%$ & $14 \%$ & $37 \%$ & $23 \%$ & $59 \%$ & $40 \%$ & $100 \%$ & 4.52 & 7.78 & 5.72 & 10.39 & 7.51 & 22.71 & 13.63 \\
\hline 6661 Light duty cleaners & $22 \%$ & $25 \%$ & $47 \%$ & $22 \%$ & $69 \%$ & $31 \%$ & $100 \%$ & 4.49 & 8.05 & 6.36 & 10.76 & 7.75 & 28.44 & 14.13 \\
\hline $\begin{array}{l}6641 \text { Food counter attendants, } \\
\text { kitchen helpers and related } \\
\text { occupations }\end{array}$ & $36 \%$ & $21 \%$ & $58 \%$ & $20 \%$ & $78 \%$ & $22 \%$ & $100 \%$ & 4.29 & 8.08 & 5.70 & 10.30 & 6.86 & 20.92 & 9.98 \\
\hline 6611 Cashiers & $33 \%$ & $21 \%$ & $54 \%$ & $20 \%$ & $74 \%$ & $25 \%$ & $100 \%$ & 5.43 & 8.28 & 6.53 & 10.40 & 7.57 & 41.85 & 16.15 \\
\hline $\begin{array}{l}1413 \text { Nurse aides, orderlies } \\
\text { and patient service associates }\end{array}$ & $20 \%$ & $19 \%$ & $39 \%$ & $23 \%$ & $62 \%$ & $38 \%$ & $100 \%$ & 4.82 & 7.86 & 6.30 & 10.40 & 7.83 & 20.59 & 12.64 \\
\hline 7452 Material handlers & $18 \%$ & $11 \%$ & $29 \%$ & $17 \%$ & $46 \%$ & $54 \%$ & $100 \%$ & 3.81 & 8.29 & 5.49 & 10.78 & 7.47 & 17.98 & 13.18 \\
\hline $\begin{array}{l}6663 \text { Janitors, caretakers and } \\
\text { building superintendents }\end{array}$ & $28 \%$ & $8 \% \ddagger$ & $36 \%$ & $25 \%$ & $60 \%$ & $41 \%$ & $100 \%$ & 3.97 & 7.95 & 4.82 & 10.81 & 7.27 & 30.28 & 16.55 \\
\hline 8611 Harvesting labourers & $\begin{array}{l}21 \% \\
t\end{array}$ & $\begin{array}{l}29 \% \\
\mathrm{t}\end{array}$ & $50 \%$ & $38 \%$ & $88 \%$ & $\begin{array}{l}13 \% \\
t\end{array}$ & $100 \%$ & 4.81 & 8.39 & 6.86 & 10.23 & 8.30 & 17.40 & 9.50 \\
\hline $\begin{array}{l}9619 \text { Other labourers in } \\
\text { processing, manufacturing and } \\
\text { utilities }\end{array}$ & $20 \%$ & $\begin{array}{l}11 \% \\
\pm\end{array}$ & $31 \%$ & $25 \%$ & $57 \%$ & $43 \%$ & $100 \%$ & 4.96 & 8.01 & 6.04 & 10.27 & 7.93 & 19.36 & 12.90 \\
\hline $\begin{array}{l}1453 \text { Customer service, } \\
\text { information and related clerks }\end{array}$ & $\begin{array}{l}13 \% \\
\ddagger\end{array}$ & $\begin{array}{l}18 \% \\
\pm\end{array}$ & $31 \%$ & $24 \%$ & $55 \%$ & $45 \%$ & $100 \%$ & 5.23 & 8.17 & 6.93 & 10.86 & 8.64 & 19.31 & 13.54 \\
\hline 7411-Truck Drivers & $25 \%$ & $\begin{array}{l}11 \% \\
\pm\end{array}$ & $36 \%$ & $\begin{array}{l}11 \% \\
\mathrm{t}\end{array}$ & $47 \%$ & $53 \%$ & $100 \%$ & 3.80 & 7.96 & 5.06 & 10.73 & 6.38 & 33.78 & 20.92 \\
\hline $\begin{array}{l}6453 \text { Food and beverage } \\
\text { servers }\end{array}$ & $37 \%$ & $14 \%$ & $51 \%$ & $\begin{array}{l}16 \% \\
t\end{array}$ & $67 \%$ & $32 \%$ & $100 \%$ & 4.34 & 8.04 & 5.35 & 10.53 & 6.60 & 17.35 & 10.03 \\
\hline $\begin{array}{l}9462 \text { Industrial butchers and } \\
\text { meat cutters, poultry preparers } \\
\text { and related workers }\end{array}$ & $\begin{array}{l}10 \% \\
\pm\end{array}$ & $4 \%$ & $\begin{array}{l}14 \% \\
\pm\end{array}$ & $31 \%$ & $46 \%$ & $54 \%$ & $100 \%$ & 3.63 & 8.35 & 5.05 & 10.88 & 9.06 & 18.68 & 14.29 \\
\hline $\begin{array}{l}7611 \text { Construction trades } \\
\text { helpers and labourers }\end{array}$ & $26 \%$ & $9 \% \ddagger$ & $35 \%$ & $\begin{array}{l}18 \% \\
\mathrm{t}\end{array}$ & $53 \%$ & $47 \%$ & $100 \%$ & 4.47 & 8.41 & 5.46 & 10.90 & 7.27 & 20.02 & 13.35 \\
\hline $\begin{array}{l}1431 \text { Accounting and related } \\
\text { clerks* }\end{array}$ & $14 \%$ & $\begin{array}{l}13 \% \\
\pm\end{array}$ & $27 \%$ & $\begin{array}{l}19 \% \\
\mathrm{t}\end{array}$ & $46 \%$ & $54 \%$ & $100 \%$ & 5.22 & 8.32 & 6.69 & 10.61 & 8.28 & 23.46 & 16.63 \\
\hline $\begin{array}{l}9451 \text { Sewing machine } \\
\text { operators }\end{array}$ & $\begin{array}{l}11 \% \\
t\end{array}$ & $\begin{array}{l}32 \% \\
t\end{array}$ & $43 \%$ & $\begin{array}{l}22 \% \\
\mathrm{t}\end{array}$ & $65 \%$ & $\begin{array}{l}35 \% \\
\mathrm{t}\end{array}$ & $100 \%$ & 3.62 & 8.47 & 7.26 & 10.93 & 8.48 & 31.11 & 16.19 \\
\hline
\end{tabular}

Table 8: Low-Skilled NPR Quartiles by Occupation - top 20 Occupations - (Source: 2006 Census) 
Thus, this section serves the purpose of examining the detail within the wage ranges in the occupations analyzed. It is important for the whole analysis because it helps identify the pockets of concentration of wages (high and low) in the low-skilled occupations analyzed. Table 8 presents the mean wages per quartile and occupation for the NPR populations (For the CB and IMM population distribution by quartiles see Appendices $10 \mathrm{~B}$ and $10 \mathrm{C}$ ). The table also present the wages and proportions of the groups for the first two and three quartiles. They present the share in each quartile and the average wage for each quartile (for the top 20 occupations employing NPRs, the main target group). Finally, they include the share and wages of grouping together the first two and the first three quartiles for NPRs, CB and IMM, respectively. Altogether, there is considerable data in this table (and on those in the appendices), which, in turn, reflects the significance of the data produced by this research.

Table 8 includes information on the distribution of the population in each occupation and quartile for NPRs. The first column the table lists the type of occupation. The sections to the right include the distribution by quartile (columns Q1, Q2, Q3 and Q4) and the combination of quartiles $(\mathrm{Q} 1+\mathrm{Q} 2)$ and $(\mathrm{Q} 1+\mathrm{Q} 2+\mathrm{Q} 3)$; the average wage by quartile (\$/hour for Q1, Q2, Q3 and Q4); and the average wages for the combined quartiles $(Q 1+Q 2)$ and $(Q 1+Q 2+Q 3)$. This information helps to see the actual concentration of workers around low wages and the average wage in the merged lower quartiles. For example, babysitters and nannies are distributed in the following way: $39 \%$ in the first quartile, $38 \%$ in the second quartile; for a total of $77 \%$ concentrated in the combined quartiles Q1 and Q2 (Q1+Q2); and 17\% in the third quartile. If we merge the first three quartiles $(Q 1+Q 2+Q 3)$, the share rises to $94 \%$. The fourth quartile has 
only $6 \%$ of all babysitters and nannies. The average wage of those in the first quartile is $\$ 5.01 /$ hour; in the second quartile $\$ 8.03 /$ hour. The average wage for the combined Q1 and Q2 $(\mathrm{Q} 1+\mathrm{Q} 2)$ is $\$ 6.52 /$ hour. The average for those in the third quartile is $\$ 10.20$ /hour and for the first three quartiles $(\mathrm{Q} 1+\mathrm{Q} 2+\mathrm{Q} 3)$ is $\$ 7.20 /$ hour. The average wage for those in the fourth quartile ${ }^{74}$ is $\$ 22.30 /$ hour. The following three subsections introduce relevant outcomes extracted from the quartile analysis in table 8.

\subsubsection{NPR cases with high concentration in the first three quartiles. Among}

NPRs, seven occupations stand out as having a high concentration of cases in the first three quartiles, which refer to occupations with people earning very low wages; they represent $52 \%$ of all low-skilled. Table 8 shows that for the NPR population, of the top 20 occupations, 7 have more than $74 \%$ of the population in the first three quartiles ${ }^{75}$. This indicates that a significant portion of workers in these occupations are concentrated in the lowest three quartiles, which means they earn low wages. These occupations are:

- 6474-Babysitters, nannies and parents' helpers, ${ }^{76}$

- 8431-General farm workers;

- 8432-Nursery and greenhouse workers;

- 6471-Visiting homemakers, housekeepers and related occupations;

- 6641-Food counter attendants, kitchen helpers and related occupations;

\footnotetext{
${ }^{74}$ Note that averages in the fourth quartile all exhibit significantly high dispersion (i.e. significantly high standard deviation). This indicates that wage values in this quartile are dispersed.

${ }^{75}$ Recall that quartiles are wage-range based and NOT population-range based. So, $74 \%$ represents a high proportion of low-skilled workers that coincidentally is close to $75 \%$. It is not expected equal proportion of populations in each quartile.

${ }^{76}$ As explained its inclusion here does not account for room and board.
} 
- 6611-Cashiers; and

- 8611-Harvesting labourers

As previously mentioned, $77 \%$ of workers in occupation $6474-$ Babysitters, nannies and parents' helpers concentrate in the first two quartiles, with an average wage for the two quartiles combined of $\$ 6.52 /$ hour (see Table 8 ) or $\$ 8.59 /$ hour including room and board (private room). For the first three quartiles combined, the average rises to $\$ 9.25 /$ if including room and board (private room). The average wage for the six occupations (in the first three quartiles combined in each occupation and excluding babysitters and nannies) is $\$ 7.73 /$ hour per hour which is close to the average minimum wage in 2005 in Canada ( $\$ 7.15 /$ hour). This begins to show a pattern: occupations in caregiving and agriculture are concentrated around low wages. ${ }^{77}$

These results are encapsulated in the total for all low-skilled occupations. Table 8 shows that the Total Average Wage for all occupations in the first three quartiles (which includes $72 \%$ of all low-skilled NPRs) was $\$ 7.49$ /hour, which is close to provincial minimum wages in 2005 (ex. in Ontario it was $\$ 7.43 /$ hour).

\subsubsection{NPR cases with high concentration in the fourth quartile. Among}

NPRs, 12 of the remaining 13 occupations ${ }^{78}$ have a high concentration of cases in the fourth quartile (very high wages); in these 12 occupations, between $31 \%$ and $54 \%$ of all workers (per occupation) concentrate in the fourth quartile; and all NPRs in these 12 occupations represent $30 \%$ of all NPRs.

\footnotetext{
${ }_{77}^{77}$ Other occupations with low wages are Food Counter Attendants and Cashiers.

${ }^{78}$ Occupation 9451 - Sewing machine operators is left out of the total for the $4^{\text {th }}$ quartile because it has fewer than 90 counts in the $4^{\text {th }}$ quartile. Note that $65 \%$ of the workers in this occupation are concentrated in the first three quartiles (see Table 8).
} 
As Table 8 shows, of the remaining 13 occupations among NPRs, 12 exhibit a medium to high concentration in the fourth quartile (between $31 \%$ and $54 \%$ of all NPRs in each occupation). NPRs in these 12 occupations represent less than one third (30\%) of all NPRs in this study. This means that, although the number of occupations is high (12 of the top 20), the actual number of people is low (31\%) compared to the number of people in low wages $(52 \%) .{ }^{79}$ The 13 occupations are:

- 6421-Retail salespersons and sales clerks

- 6661-Light duty cleaners

- 1413-Nurse aides, orderlies and patient service associates

- 7452-Material handlers

- 6663-Janitors, caretakers and building superintendents

- 9619-Other labourers in processing, manufacturing and utilities

- 1453-Customer service, information and related clerks

- 7411-Truck Drivers

- 6453-Food and beverage servers

- 9462-Industrial butchers and meat cutters, poultry preparers and related workers

- 7611-Construction trades helpers and labourers

- 1431-Accounting and related clerks

- 9451-Sewing machine operators (not included because it has less than 90 counts in the $4^{\text {th }}$ quartile)

Of the 12 occupations with more than 90 counts (9451-Sewing machine

\footnotetext{
${ }^{79}$ The remaining $18 \%$ corresponds to NPRs in occupation 9451 - Sewing machine operators plus those distributed in occupations outside the top 20 occupations for NPRs. These occupations had a very small number of NPRs per occupation and did not permit a quartile analysis.
} 
operators excluded), 8 have between $53 \%$ and $69 \%$ of their populations in the first three quartiles. This still reflects an important degree of concentration around low wages even though they have a high wage in the fourth quartile. Workers with wages in the fourth quartile in these occupations have average wages ranging from $\$ 28.40 /$ hour (6661Light duty cleaners) to $\$ 33.80 /$ hour (7411-Truck Drivers). As a vivid example of how high wages can increase the mean, in the fourth quartile, NPRs in occupation 6611-Cashiers earn $\$ 41.90 /$ hour (the highest average wage in the fourth quartile). Yet only $25 \%$ of all NPRs in this occupation have wages in this quartile. Referencing data from the 2011 National Household Survey, ${ }^{80}$ Service Canada reports that $44.9 \%$ of cashiers earn between $\$ 20$ 000/year and $\$ 49$ 999/year and 1.5\% of cashiers earn above $\$ 50$ 000/year (Service Canada, 2015). Even though the wages cited are annual, this example helps illustrate how a very small group of cashiers with very high wages $(1.5 \%$ of the population with wages above $\$ 50$ 000/year) can significantly alter the average wage for the fourth quartile ${ }^{81}$. Whatever the reason for this increase, it is striking that the remaining $75 \%$ of cashiers recorded earning an average of $\$ 7.60 /$ hour (See Table 8 ), a significantly low average wage (compared with the average of those in the last quartile). This discrepancy makes this occupation a good candidate for future, more in-depth, research.

Generally, high wages in the fourth quartile may also relate to the fact that some employees are paid more according to seniority (ex. seasonal workers coming to

\footnotetext{
${ }^{80}$ As explained in chapter four, Statistics Canada has deemed the 2011 NHS reliable at the occupation level.

${ }^{81}$ This pattern is apparent in almost all occupations analyzed in this research. Such high wages may correspond with people who were recorded in the census who were paid overtime for a small number of reported hours or were recorded as being employed but were perhaps relatives of the business owners (ex. a relative brought to Canada to work in a family business as a TFW).
} 
Canada every year). ${ }^{82}$ The fact that some occupations include a broad range of jobs, may also contribute to these high wages. It is possible for people to earn different salaries for doing different jobs in the same occupation. For a detailed analysis of this phenomenon see appendix eight. Although instances of workers earning high wages in the fourth quartile distort the mean for its corresponding occupation, they are nevertheless still part of the population and need to be included since outliers have already been withdrawn. It would be worth further examining high wages (in the fourth quartile) in all low-skilled occupations in future research work.

6.3.3. NPR cases with very low wages in the first quartile. In all analyzed occupations, the average wage in the first quartile is below the minimum wage. According to Table $8,27 \%$ of all NPR cases included in this research, all located in the first quartile, had an average wage of $\$ 4.80 /$ hour (which is below minimum wage).

In addition to cases of people who may have been "lawfully" paid wages below minimum wage, some cases of low recorded wages may be the outcome of the data itself. The hourly wage, for example, is calculated by dividing the 2005 weekly wage by the number of hours worked during the week prior to the census, which in some cases may have been higher than usual, making the wage lower than usual. While it is important to identify possible reasons for incidents of low recorded wages, the overall number of cases is small and are all part of the first quartile and wages in the other quartiles are more likely to correspond to a more accurate wage. Even if the mean wages in the first quartile correspond to disproportions between the number of hours

\footnotetext{
${ }^{82}$ The census does not trace seniority for TFWs, so it was not possible to include this consideration in the analysis.
} 
and the wage received in 2005, they nevertheless need to be included ${ }^{83}$.

In summary, as the table show, the quartiles analysis is imperative since it unveils the real issue of many low-skilled workers' wages concentrated around low wages and some around high wages. The quartile analysis also shows that the average wage of the whole population per occupation does not provide the whole truth with respect to wages. Some occupations with high average wages have a significant number of people concentrated in low-wage quartiles (first three). Appendix 10D gathers a summary of the average wages per quartile in the three immigration categories. It is important to note that the quartile analysis revealed a significant concentration of wages around low values, generally around minimum wage (see Table 8) primarily in occupations in caregiving and agriculture. Nevertheless, still we need to know how NPRs fare against CB and IMM. To address this, it is worth analyzing wage differences of NPRs compared top CB and IMM ${ }^{84}$ in the occupations themselves. This is presented in the following section on relative wages of NPRs (compared to CB and IMM) by occupation.

\subsection{Relative wages of NPRs (compared to CB and IMM or NPR-CB and NPR-IMM) by Occupation}

Comparing the wages of Canadian-born and immigrant workers with those of the

\footnotetext{
${ }^{83}$ It is important to note that these cases are most evident among NPRs (see proportion of cases in the first quartile in Tables $8,9,10)$. The opposite possible outcome, that is, that very high reported wages linked to inaccuracies in calculation are most likely to appear in the fourth quartile, is ruled out because all cases included in this study report working 30 or more hours a week. There are no cases with a lower number of hours (see selection of populations in chapter four). Therefore, those in the fourth quartile can be counted as genuine cases of high wages. Accordingly, the wage analysis presented in this chapter includes the whole population, even if the average wages per occupation appear significantly high.

${ }^{84}$ Mean wage differences in this research distinguish those that are statistically significant from those that are not. The statistical significance comes from the post hoc tests explained in chapter four.
} 
low-skilled NPR population will provide a window into their labour market performance.

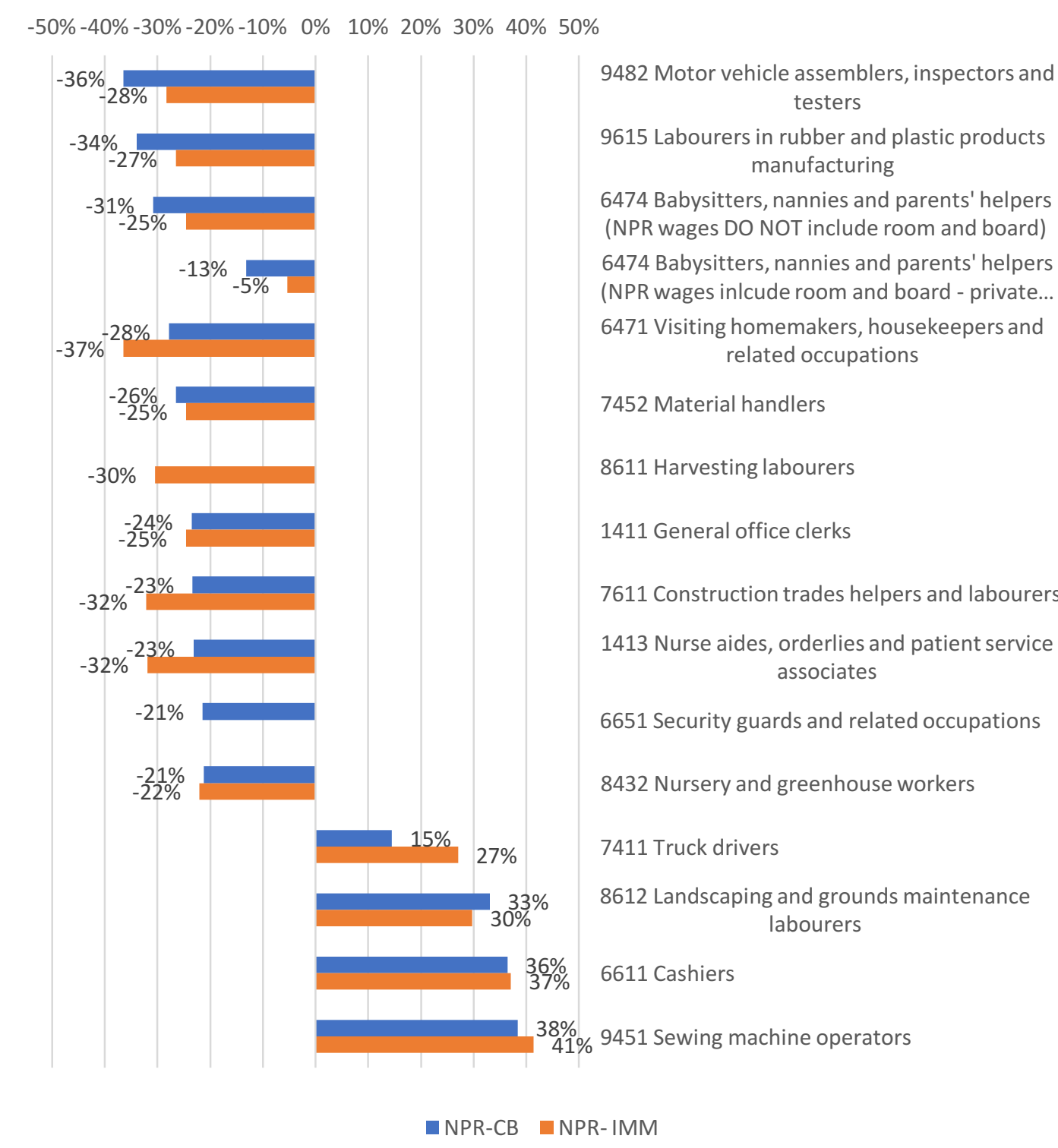

Figure 10B: Statistically Significant Average Hourly Wage Differences by Occupation (selected occupations) - wages of NPR Babysitters and nannies account for room and board (Source: 2006 Census).

Regarding wage differences, Figure 10B presents statistically significant differences in wages between the Canadian-born and the NPR populations (blue) and between the immigrant and the NPR populations (red) in selected occupations. A more 
detailed comparison of NPR wages against those of the Canadian-born population and the immigrant population is included in Appendix 10E. The analysis shows that, of the 35 occupations analyzed, 31 had negative differences and 4 had positive differences. This means that NPRs had lower wages than immigrants and Canadian-born workers in about $89 \%$ of the occupations analyzed. In only 4 occupations NPRs had higher wages than the immigrant and Canadian-born populations.

Negative differences. While the lowest average hourly wages were among babysitters \& nannies and agricultural workers, the greatest difference in average hourly wages between the Canadian-born and the NPR populations is found in the NOC-9482 Motor Vehicle Assemblers occupation. NPRs earn 36\% less than Canadian born workers in this occupation. The NOC 6471 - Visiting homemakers, housekeepers and related occupations, exhibit the largest average hourly wage difference between the immigrant and NPR populations. NPRs in this occupation earn $36 \%$ less than the immigrant population. This data supports a trend already identified in different academic articles: in most low-skilled occupations NPRs have lower wages than their Canadianborn and immigrant counterparts. It is also worth noting that although the differences between NPRs and CB and between NPRs and IMM employed as babysitters and nannies or in agriculture are not the greatest, they are still significant. Not accounting for compensation for room and board, NPRs working in occupation 6474-Babysitters and Nannies earn $31 \%$ less than CB and 25\% less than IMM. When accounting for room and board (with a private room), the average wage raises from $\$ 8.10 /$ hour to $\$ 10.17 /$ hour, which reduces the wage differences. Nevertheless, the wage difference remains negative (i.e. NPRs earn $13 \%$ less than CB and $5 \%$ less than IMM). By the 
same token, NPRs working in occupation 8434-Nursery and Greenhouse Workers earn $21 \%$ less than $\mathrm{CB}$ and $22 \%$ less than IMM. These preliminary results suggest that most NPRs in the Canadian labour force earn lower wages than Canadian-born and immigrant workers, which will be further confirmed in the regression analysis.

Positive differences. The four occupations that exhibit positive differences (higher wages) among the NPR population vis-à-vis Canadian-born and immigrant workers are: 9451-Sewing machine operators; 6611-Cashiers; 7411-Truck drivers; and 8612Landscaping and grounds maintenance labourers. The first three occupations (9451, 6611 and 7411 ) had enough cases to allow a quartile analysis. In the first two occupations (9451 and 6611), although the average was high, most cases concentrated in the first three quartiles with a low average wage (see Table 8). Wages in occupations in which NPRs earn more than CB and IMM correspond most likely to situations in which there is a concentration of a few cases with very high wages in the fourth quartile (the highest one) - see Table 8. For example, NPRs in occupation 6611-Cashiers, exhibit higher wages than CB and IMM. Of all NPRs in Canada working in this occupation (and included in this study), only $25 \%$ of the cases are concentrated in the fourth quartile, but their average wage is $\$ 41.90 /$ hour. As previously shown, data from the 2011 National Household Survey shows more than 40\% cashiers earning between $\$ 20,000 /$ year and $\$ 49,999 /$ year and $1.5 \%$ of cashiers earning above $\$ 50,000 /$ year.

For 7411 - Truck Drivers, on the contrary, more than half of the cases (53\%) were concentrated in the fourth quartile. This indicates that there is a genuinely high number of NPRs earning high wages. The specific case of truck drivers is further analyzed in chapter nine. 


\section{Summary}

Wages of low-skilled NPRs compared to those of CB and IMM, provides a good picture of the labour market experiences of low-skilled NPRs. Low-skilled workers in the Agriculture, forestry, fishing and hunting industry sector earn the lowest absolute wage. They were followed by workers in the 'Other Services' sector (except public administration). Low-skilled NPRs exhibited low relative wages (lower than CB and IMM) in 11 out of the 13 industry sectors analyzed. In the remaining two, NPRs exhibited a higher mean wage than the CB and IMM. Not accounting for room and board, Babysitters, Nannies and Parents' Helpers exhibited the lowest mean absolute wage of all 43 occupations analyzed. They were followed by low-skilled workers in agriculture (Nursery and Greenhouse Workers and Harvesting Labourers). The quartile analysis reveals a high concentration of low-skilled workers around low wages in some occupations. Occupations with these characteristics include: 8431-General farm workers; 8432-Nursery and greenhouse workers; 6471-Visiting homemakers, housekeepers and related occupations; 6474-Babysitters, nannies and parents' helpers; 6641-Food counter attendants, kitchen helpers and related occupations; 6611-Cashiers; and 8611-Harvesting labourers. Most workers in these occupations are concentrated around wages close to the minimum wage (more than three quarters in each occupation have wages close to minimum wage). ${ }^{85}$

Low-skilled NPRs earn lower wages than Canadian-born and immigrant workers across most occupations. This is also evident when comparing quartile by quartile. Quartile differences confirm those calculated with the averages of the populations by immigration status (NPR-CB and NPR-IMM) in each occupation. Occupation NOC 8432

\footnotetext{
${ }^{85}$ Excepting babysitters and nannies when room and board is accounted for.
} 
Nursery and Greenhouse Workers is among the occupations with the lowest wages

among the NPR population. Workers in this occupation were also among the workers with the greatest wage differences when compared with Canadian-born and immigrant

workers. Surmounting the interpretative difficulties that arise when wage dispersion

affects averages and their comparability, the quartile analysis confirmed what was found

in the samples with high dispersion. A condensed and punctual summary of the

outcomes of this chapter framed by the first hypothesis outlined in chapter two is

presented in the following table (Table 9).

Table 9- Summary of Hypothesis/Chapter Findings (Cross-Tabulation Absolute Wages)

\begin{tabular}{|l|l|}
\hline Hypotheses & Findings \\
\hline $\begin{array}{l}\text { 1. NPRs earn } \\
\text { lower wages } \\
\text { than CB and } \\
\text { IMM in all } \\
\text { industry } \\
\text { sectors and } \\
\text { occupations in } \\
\text { this study. }\end{array}$ & $\begin{array}{l}\text { 1.1. Low-skilled workers in the Agriculture, forestry, fishing and hunting industry sector } \\
\text { earn the lowest wages (an average of \$10.10/hour). They were followed by workers in } \\
\text { the 'Other Services' sector (except public administration), averaging approximately } \\
\text { (wages include room and board), which comprise the largest number of NPRs. } \\
\text { 1.2. Low-skilled NPRs earned lower wages than CB and IMM in } 11 \text { out of the 13 } \\
\text { industry sectors analyzed. However, large wage dispersion (a few cases with high } \\
\text { wages in each occupation) makes an occupation level analysis necessary. } \\
\text { 2. Babysitters and nannies had the lowest absolute wages (not accounting for room } \\
\text { and board) among the 43 occupations analyzed. They were followed by low-skilled } \\
\text { workers in agricultural occupations. However, mean wages were rather high. High } \\
\text { mean wages are related to wage dispersion. } \\
\text { 3. Just over half of all NPRs (52\%) work in only 7 occupations which exhibit high } \\
\text { concentration of NPRs in low wages; } 12 \text { occupation have a high concentration around } \\
\text { high wages (they represent 30\% of all NPRs) } \\
\text { 4. Low-skilled NPRs reported lower wages than CB and IMM in most occupations. Of } \\
\text { the 43 analyzed, 35 occupations passed the Bonferroni test and had enough counts } \\
\text { (more than 90). Of these 35 occupations, in 31 NPRs had lower wages than CB and } \\
\text { IMM. In the remaining four occupations, the NPR mean wages were above CB and } \\
\text { IMM mean wages. The quartile analysis showed that out of these four, only one (Truck } \\
\text { Drivers) offered genuinely higher wages for NPRs. Occupations 6474-Babysitters, } \\
\text { Nannies and Parents Helpers; 8432 Nursery and Greenhouse Workers and 8433- } \\
\text { General Farmworkers are among the occupations with the lowest wages among the } \\
\text { NPR population and with the highest wage differences compared with CB and IMM. }\end{array}$ \\
\hline
\end{tabular}

Table 9: Summary of Hypotheses/Chapter Findings (Cross-Tabulation Absolute Wages) 


\section{Chapter Seven: Wage Analysis Considering Intrinsic Characteristics of Workers and Occupations}

As seen in the previous chapter, low-skilled NPRs' absolute and relative wages (when compared to the CB and IMM) at the industry and occupation levels are generally

disadvantaged by a lack of citizenship. The analysis now shifts to evaluate the effects of intrinsic characteristics of occupations (province of residence, rural/urban place of work) and of NPR workers (sex, level of education, knowledge of English or French and Country of Birth) on the wages of low-skilled NPRs. Introducing intrinsic characteristics to the occupation-level analysis, further strengthens the analysis, by yielding outcomes that are even closer to the lived experiences of the individuals examined. This type of analysis is also relevant because it provides information about the independent effects (positive or negative) each of those characteristics may have on low-skilled NPRs' wages, additional to that of lack of citizenship. The analysis in this section dives deeper by engaging in a more granular way the likely effects of those intrinsic characteristics on the wages of NPRs. This chapter presents the cross-tabulation of the relative wages of NPRs (compared to CB and IMM) in each occupation and each category of each intrinsic characteristic. Such outcomes are further complemented by a regression analysis in the following chapter.

Some methodological considerations worth recalling include: the number of occupations analyzed change from one characteristic to the next because the number of cases by occupation an population gets subdivided even further in each characteristic. Characteristics with more options subdivide even more the populations, which constrains even more the number of occupations possible to analyze. For 
example, the number of occupations analyzed by sex (only two categories - male, female) is higher that the number of occupations by province of residence. Additionally, categories in each characteristic are not subdivided equally (e.g. provinces have significantly different populations).

Five outcomes worth highlighting are: 1) Low-skilled NPRs tend to have larger negative wage differences (when their wages are compared to those of the $C B$ and IMM) in Ontario than those of low-skilled workers in other provinces; 2) Wage differences (of NPRs compared to the CB and IMM) in rural areas are negative and larger (in absolute value) than those in urban areas (which are all negative too); 3) Both male and female low-skilled NPRs earn less wage than their CB and IMM counterparts in all occupations analyzed in each category; 4) A hierarchy of occupations by country of birth was also identified. Those coming from mostly European countries with high official language ability work in the better paid low-skilled occupations. In contrast, highly physically demanding occupations are filled with workers coming mostly from the developing world; 5) In some occupations wages improve when citizenship is accounted for among foreign-born con-nationals. For example, though still less than Canadianborn workers, the wages of Mexican immigrants (i.e. those with access to citizenship) working in occupation 8431-General farm workers are considerably higher than those of Mexican NPRs working in the same occupation.

The chapter is organized in six sections each addressing each one of the intrinsic characteristics of workers (sex, level of education, knowledge of official language and country of birth) and their occupations (province of residence, rural-urban location) analyzed. As with chapter six, this chapter presents results and does not include an 
analysis of outcomes (i.e. an explanation of wage differences), something that will be covered in chapter nine. The quartile analysis was also used a s a way to corroborate outcomes in this chapter. The first two sections focus on the intrinsic characteristics of occupations; the remaining four on the intrinsic characteristics of NPRs.

\subsection{Wage differences by Province of Residence}

Wages follow the behaviour of regional economies. While the aggregate wage level provides an indicator of wages nationwide at the occupation level, there are embedded distortions stemming from different factors. One such factor is the regional behaviour of the labour market. While a close look into regional labour markets would ideally explore wages at a sub-provincial level, restrictions in sample size limit the focus of this research to the Canadian provinces only. Even in regions that group together different provinces, like the Atlantic provinces, sample size did not provide a significant number of NPRs to be able to do a reliable comparison by immigration status at the occupation level. After merging Manitoba and Saskatchewan in the effort to obtain a reliable sample size, sample sizes nevertheless only permitted a limited number of occupations.

Table 10 introduces the wage differences NPR - Canadian-born (NPR-CB) and NPRImmigrants (NPR-IMM) by province. The table includes selected occupations with a significant number of NPRs in more than one province, which allows for interprovincial comparisons. 


\begin{tabular}{|c|c|c|c|c|c|c|c|c|c|c|c|c|}
\hline \multicolumn{13}{|c|}{ Table 10 - Provincial Wage Differences in Selected Occupations } \\
\hline \multirow[b]{2}{*}{$\begin{array}{l}\text { NOC4 - } \\
\text { Occupation Name }\end{array}$} & \multicolumn{6}{|c|}{ Difference in Wages (NPR-CB) } & \multicolumn{6}{|c|}{ Difference in Wages (NPR-IMM) } \\
\hline & AT & QC & ON & $\begin{array}{l}\text { MB } \\
\& \\
\text { SK }\end{array}$ & $A B$ & BC & AT & QC & ON & $\begin{array}{l}\text { MB \& } \\
\text { SK }\end{array}$ & $A B$ & BC \\
\hline $\begin{array}{l}1413 \text { Nurse aides, orderlies and } \\
\text { patient service associates }\end{array}$ & & & $-22 \%$ & & $-30 \%$ & & & & $-32 \%$ & & $-31 \%$ & \\
\hline $\begin{array}{l}6421 \text { Retail salespersons and sales } \\
\text { clerks }\end{array}$ & & $15 \% *$ & $-25 \%$ & & $-18 \%$ & $-17 \%$ & & $17 \%$ & $-19 \%$ & & $-14 \%$ ** & $-14 \%$ ** \\
\hline 6453 Food and beverage servers & & & $-3 \%$ ** & & $-0.1 \% *$ & $-33 \%$ & & & $-11 \%$ ** & & $-8.2 \%^{*}$ & $-29 \%$ \\
\hline $\begin{array}{l}6471 \text { Visiting homemakers, } \\
\text { housekeepers and related } \\
\text { occupations }\end{array}$ & & $-26 \%$ & $-29 \%$ & & $-41 \%$ & $-40 \%$ & & $-13 \%$ & $-37 \%$ & & $-40 \%$ & $-46 \%$ \\
\hline \begin{tabular}{|l|}
6474 Babysitters, nannies and \\
parents' helpers (NPR wages DO \\
NOT include room and board)
\end{tabular} & & $-26 \%$ & $-34 \%$ & $-50 \%$ ** & $-25 \%$ & $-20 \%$ & & $-25 \%$ & $-29 \%$ & $-45 \%$ ** & $-18 \%$ & $-13 \%$ \\
\hline \begin{tabular}{|l|}
6474 Babysitters, nannies and \\
parents' helpers (NPR wages include \\
room and board - private room)
\end{tabular} & & $-6 \%$ & $-17 \%$ & $-35 \%$ ** & $-6 \%$ & $-2 \%$ & & $-5 \%$ & $-10 \%$ & $-29 \%$ ** & $-1 \%$ & $7 \%$ \\
\hline $\begin{array}{l}6641 \text { Food counter attendants, } \\
\text { kitchen helpers and related } \\
\text { occupations }\end{array}$ & & & $-30 \%$ & & $26 \%$ & $-24 \%$ ** & & & $-35 \%$ & & $19 \%{ }^{*}$ & $-19 \%^{*}$ \\
\hline 6661 Light duty cleaners & & $-22 \%$ & $21 \%$ & & $-1 \%$ & $-18 \%$ & & $-15 \%$ ** & $22 \%$ & & $-8 \%$ & $-24 \%$ \\
\hline 7411 Truck drivers & & & $80 \%$ ** & $-19 \%$ & $-23 \%$ & & & & $102 \%$ ** & $-17 \%$ & $-13.5 \%^{* *}$ & \\
\hline 7452 Material handlers & & $-35 \%$ & $-24 \%$ & & & & & $-21 \%$ & $-20 \%$ & & & \\
\hline 8431 General farm workers & & $-9 \%$ & $-20 \%$ & & & & & $-7 \%$ ** & $-14 \%$ ** & & & \\
\hline $\begin{array}{l}8432 \text { Nursery and greenhouse } \\
\text { workers }\end{array}$ & & $-20 \%$ & $-15 \%$ & & & & & $-32 \%$ & $-24 \%$ & & & \\
\hline $\begin{array}{l}9462 \text { Industrial butchers and meat } \\
\text { cutters, poultry preparers and related } \\
\text { workers }\end{array}$ & & & $-34 \%$ & $12 \% *$ & $-25 \%$ & & & & $-24 \%$ & $6.4 \%^{* \star}$ & $-33 \%$ & \\
\hline $\begin{array}{l}9617 \text { Labourers in food, beverage and } \\
\text { tobacco processing }\end{array}$ & & $-38 \%$ & $-26 \%$ & & $-2.5 \%$ ** & & & $-20 \%^{* *}$ & $-18 \%$ & & $-6 \% * *$ & \\
\hline $\begin{array}{l}9619 \text { Other labourers in processing, } \\
\text { manufacturing and utilities }\end{array}$ & & $-43 \%$ & $-18 \%$ & & & & & $-29 \%^{* *}$ & $0.3 \%^{* *}$ & & & \\
\hline 1411 General office clerks & & & $-24 \%$ & & & $-33 \%$ & & & $-24 \%$ & & & $-23 \%$ ** \\
\hline $\begin{array}{l}1453 \text { Customer service, information } \\
\text { and related clerks }\end{array}$ & & $-30 \%$ & $-21 \%$ & & & & & $-19 \%$ & $-23 \%$ & & & \\
\hline $\begin{array}{ll}- & { }^{*} \text { Interpret with caution } \\
- & { }^{* *} \text { Unreliable value }(p \\
- & \text { AT }=\text { Atlantic Provinces } \\
& \text { Columbia }\end{array}$ & $\begin{array}{l}\text { n }(5 \% \\
>10^{\circ} \\
\text { s; QC }\end{array}$ & $\begin{array}{l}>p>1 \\
\%)-p \text { va } \\
=\text { Queb }\end{array}$ & $\begin{array}{l}\%)-p \\
\text { ue (not } \\
\text {; ON }\end{array}$ & $\begin{array}{l}\text { lue (not } \\
\text { the tabl } \\
\text { Ontario; }\end{array}$ & $\begin{array}{l}\text { the table) } \\
\text { extracted } \\
3 \text { \& SK = }\end{array}$ & $\begin{array}{l}\text { extracte } \\
\text { I from } \mathrm{Pc} \\
\text { Manitob }\end{array}$ & D & $\begin{array}{l}\text { Post-Ho } \\
\text { tests } \\
\text { Saskatch }\end{array}$ & newan; $A B$ & $B=A l b \epsilon$ & $\mathrm{ta} ; \mathrm{BC}=\mathrm{Br}$ & British \\
\hline
\end{tabular}

Table 10: Provincial Wage Differences in Selected Occupations

According to the table, across most occupations and provinces, wages of NPRs

tend to be lower than those of their Canadian-born and immigrant counterparts.

Occupation-specific comparisons have different patterns. The highest differences are

distributed mostly across Quebec and Ontario. In at least five occupations, Ontario's 
NPR-CB wage differences are highest compared to other provinces. These occupations are:

1. 6421 Retail salespersons and sales clerks (-25\%);

2. 6471 Visiting homemakers, housekeepers and related occupations (-29\%);

3. 6474 Babysitters, nannies and parents' helpers (-17\%);

4. 6641 Food counter attendants, kitchen helpers and related occupations (-30\%); and 5. 9462 Industrial butchers and meat cutters, poultry preparers and related workers.

Quebec's NPR-CB wage differences are highest compared with other provinces, in at least six occupations. These occupations are:

1. 6661 Light duty cleaners $(-22 \%)$;

2. 7452 Material handlers (-35\%);

3. 8432 Nursery and greenhouse workers $(-20 \%)$;

4. 9617 Labourers in food, beverage and tobacco processing (-38\%);

5. 9619 Other labourers in processing, manufacturing and utilities (-43\%); and

6. 1453 Customer service, information and related clerks (-30\%).

Occupations exhibiting the highest wage discrepancies are primarily in the main economic sectors that drive Quebec's and Ontario's economies (Agriculture, Services and Manufacturing). Wage differences in BC for 6453-Food and beverage servers are significantly high and provide an illuminating case study. While wage differences in this occupation in other provinces were not statistically significant, in British Columbia very low wages are concentrated in a significant proportion of NPRs (See Table 8 in chapter 
six) ${ }^{86} \mathrm{~A}$ section in chapter nine focuses on this case.

Regarding occupation specific differences, occupation 6474-Babysitters, Nannies and Parent Helpers is the occupation with the highest representation of NPRs in most provinces. In this occupation, Ontario is the province with the highest wage discrepancy ( $17 \%$ and $10 \%$ less for NPRs compared to CB and IMM, respectively). Ontario is followed by Quebec, where NPRs earn 6\% and 5\% less than CB and IMM, respectively.

Occupation 8432-Nursery and Greenhouse Workers exhibits the highest NPRsCB and NPR-IMM wage differences in Quebec. Table 10 shows that NPRs earn $20 \%$ and $32 \%$ less than Canadian-born and immigrant workers. In Ontario these differences are also unfavourable to NPRs. They earn $15 \%$ and $24 \%$ less than their Canadian-born and immigrant counterparts.

\subsection{Wage Differences by Rural-Urban Location}

Urban areas in the census refer to concentrations of at least 1000 people with a density of at least 400 persons per square kilometer; "all territory outside urban areas is considered rural" (Census 2006, Codebook, p.18). Most occupations in Canada group together jobs based in urban settings, where most industries develop their activities. Yet a significant part of low-skilled labour also takes place in rural areas. Occupations related to the agribusiness, for examples, mostly take place in rural Canada, although some of those activities also take place in urban areas.

\footnotetext{
${ }^{86}$ This is also the case in occupation 6641-Food counter attendants, kitchen helpers and related occupations. Both cases will be analyzed in more detail in chapter eight.
} 
Wage Differences - Rural. Figure 11 shows the statistically significant wage differences of Canadian-born and immigrant workers compared to NPRs working in rural Canada. As explained, most rural occupations are in the agricultural sector. However, compared with other occupations in rural areas, wage differences in the agricultural sector are not as dramatic as in occupation 6471-Visiting Homemakers. NPRs earn between $15 \%$ and $31 \%$ less than Canadian-born workers and approximately $15 \%$ less than immigrants working in occupation 8432-Nursery and greenhouse workers. In occupation NOC 6471-Visiting Homemakers, wages of NPRs are approximately $37 \%$ less than Canadian-born workers and $37 \%$ less than immigrants. Comparable differences are also evident in urban areas.

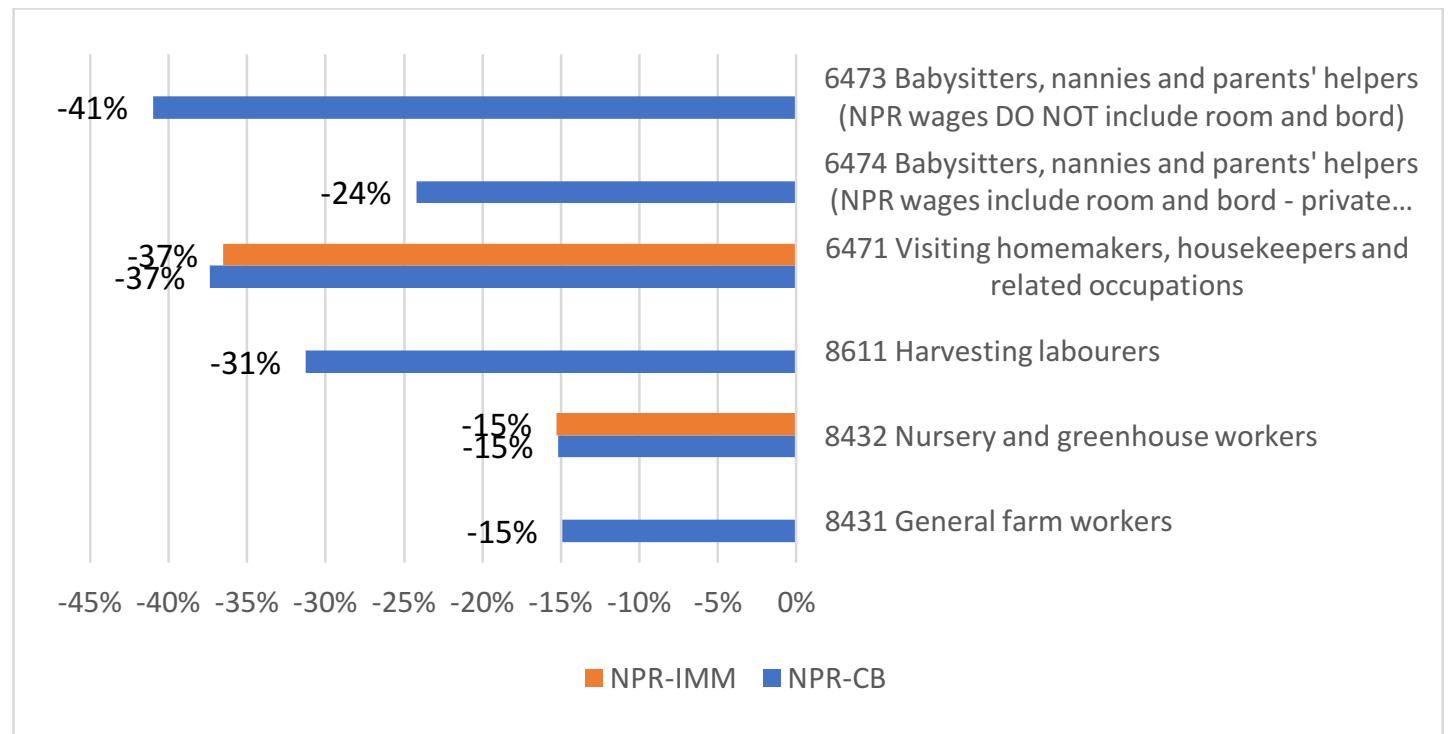

Figure 11: Statistically Average Hourly Wage Differences in a Rural Location (Source: 2006 Census)

Wage Differences - Urban. Figure 12 introduces the statistically significant wage differences of Canadian-born and immigrant workers compared to NPRs working in urban areas. It is worth mentioning that NPRs in occupations 6611-Cashiers and 7411- 
Truck drivers exhibited statistically significant positive wage differences compared to their Canadian-born and immigrant counter-parts. In other words, NPRs appeared to have earned higher wages than CB and IMM in these occupations. The results of the quartile analysis, however, reveal that wage differences for the second and third quartile were negative (with NPRs earning an average wage lower than that of either CB or IMM). As explained earlier, the difference between the analysis of the whole population in each of these two occupations and the quartile analysis is a function of wage dispersion. Due to this discrepancy, outcomes in these occupations were not included in Figure 14.

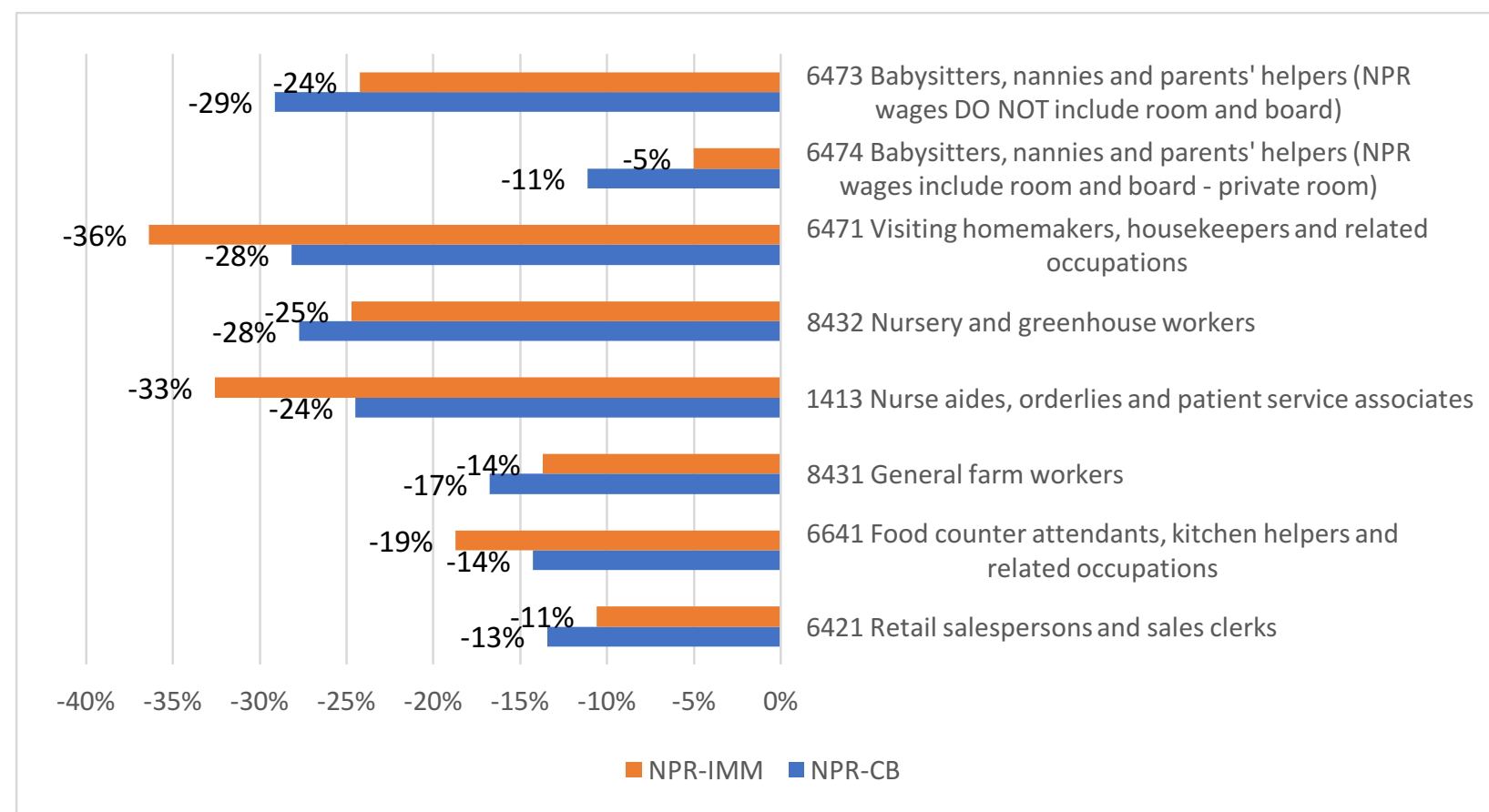

Figure 12: Statistically Significant Average Wage Differences in an Urban Location (Source: 2006 Census)

Most occupations in urban settings replicate the results found in the general summary provided at the beginning of this chapter. Some occupations worth mentioning are 1413-Nurse aides, orderlies and patient service associates and 6471-Visiting 
homemakers, housekeepers and related occupations. NPRs in these occupations recorded wages $33 \%$ and $36 \%$, respectively, lower than immigrants. It is worth mentioning though that some occupations appearing in rural areas are also found in urban areas, including Babysitters and Nannies (NOC-6474), Visiting Homemakers (NOC-6471) and Nursery and greenhouse workers (NOC-8432), in which the wage discrepancies are not as large. For example, when accounting for room and board (private room or $\$ 2.07 /$ hour additional compensation), while NPR babysitters and nannies earn $24 \%$ less than their Canadian-born counterparts in rural areas, in urban areas this difference is only $11 \%$. It is also worth noting that wages, and the cost of living in general, is lower in rural areas, though poverty in these areas remains prominent. The analysis will now switch to the intrinsic characteristics of NPRs including sex, level of education and country of birth.

\subsection{Wage Differences Within Each Sex by Immigration Status}

Sex influences wage behaviour by distinguishing between males and females in specific occupations. Given that this research examines differences according to immigration status, this part of the analysis will not compare differences between sexes, but rather differences within one sex by immigration status

\subsubsection{Wage differences (NPR-CB and NPR-IMM) for females. Figure 13}

shows the statistically significant wage differences among female low-skilled workers. In keeping with the overall trend thus far, female NPRs also experience lower wages than female Canadian-born workers and female immigrants in the same occupation. The 
highest wage difference is found in occupation 6474-Babysitters, nannies and parents' helpers (not accounting for live-in conditions), with female NPRs earning 31\% less than their Canadian-born counterparts. Accounting for live-in conditions, differences decrease but remain negative ( $8 \%$ less than $\mathrm{CB}$ and $6 \%$ less than IMM). This is followed by 9619-Other labourers in processing, manufacturing and utilities, where female NPRs earn $27 \%$ less than female Canadian-born workers. Compared to lowskilled female immigrants, low-skilled female NPRs had the greatest negative difference in occupation 6471-Visiting homemakers, housekeepers and related occupations (35\% less wage), followed by 1413-Nurse aides, orderlies and patient service associates (34\% less wage). As we will see, low-skilled male NPRs also exhibit lower wages than their Canadian-born and Immigrant counterparts.

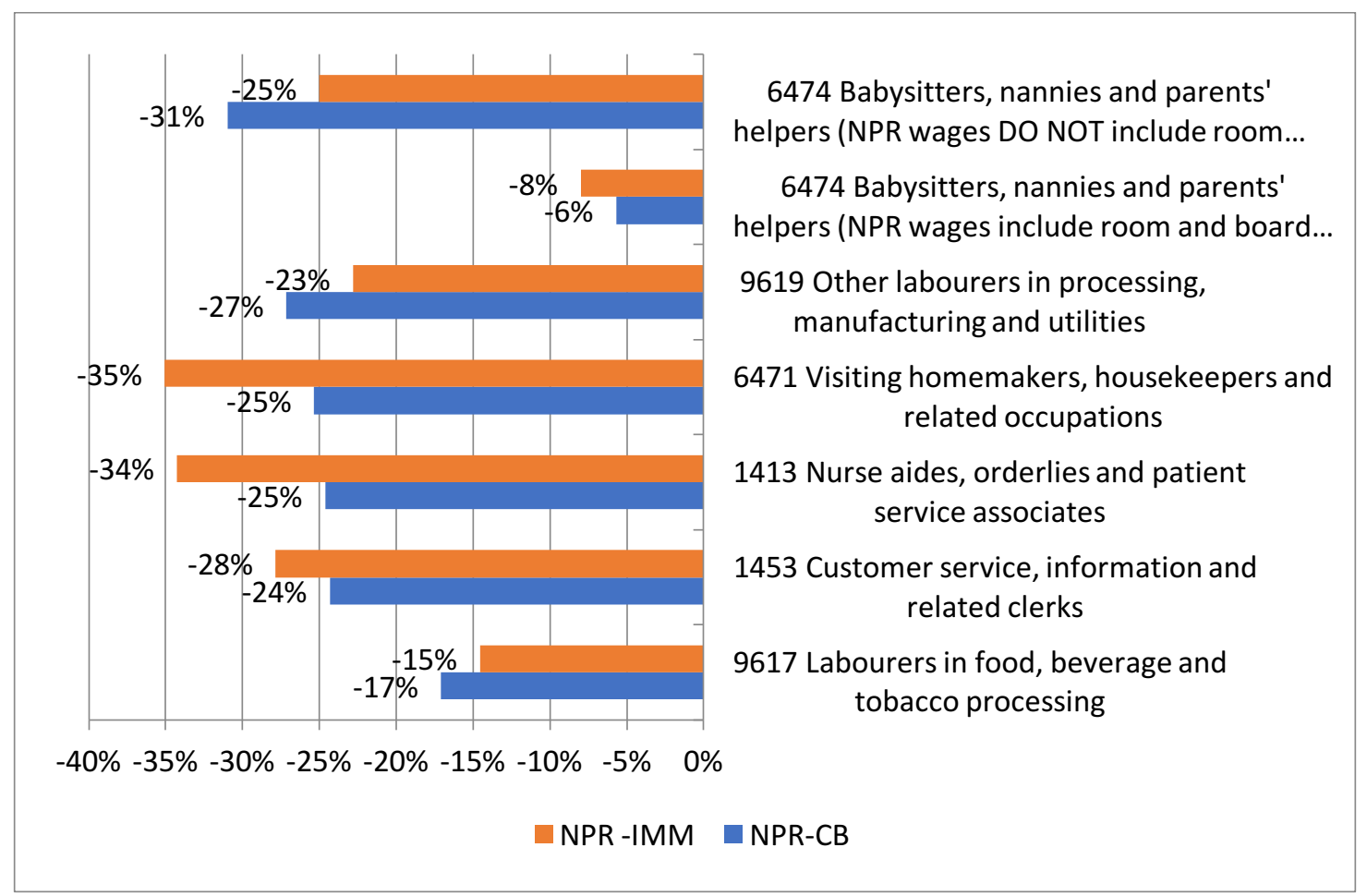

Figure 13: Statistically Significant Average Hourly Wage Differences by Sex - Females (CB-NPR) and (IMM-NPR) (Source: 2006 Census). 
Note that combined wages of second and third quartiles are used to corroborate mean wage differences for both males and females when their wages are compared against those of their CB and IMM counterparts. This process was done for the characteristics and occupations that allowed a quartile analysis (enough number of counts in the $2^{\text {nd }}$ and $3^{\text {rd }}$ quartile). Given that this research compares the wages of NPRs against those of CB and IMM, the second and third quartiles are chosen as representatives of the population in each occupation. These quartiles are chosen because they represent the center of the range in each occupation $(25 \%$ to $75 \%$ of the wage range). Appendix nine includes figures that compare the wages of NPRs in the second and third quartile against the wages of $C B$ and IMM in the second and third quartiles. Such figures support comparisons drawn for the entire population. If, for example the wage difference in occupation $x$ is negative for the population and negative for the second and third quartiles, then it is most likely negative. If differences for entire populations are positive but negative for quartiles, then the unmerged quartiles provide information about these discrepancies (ex. occupations with a high concentration in the fourth quartile). Appendix nine presents wage differences by sex, province of residence, rural/urban, language ability (English) and level of education. Figures A9.1. to A9.5. present these results.

\subsubsection{Wage differences (NPR-CB and NPR-IMM) for males. Figure 14} presents the statistically significant average wage differences among the top 10 lowskilled occupations for male workers. Male NPRs working in occupation 6471-Visiting homemakers, housekeepers and related occupations have the largest negative difference in wages compared to both Canadian-born employees (46\%) and immigrants 
(48\%) working in the same occupation. Male NPRs working as 8432-Nursery and Greenhouse workers (8432) also have a significant wage difference compared to male IMM in the same occupation (29\% less wage).

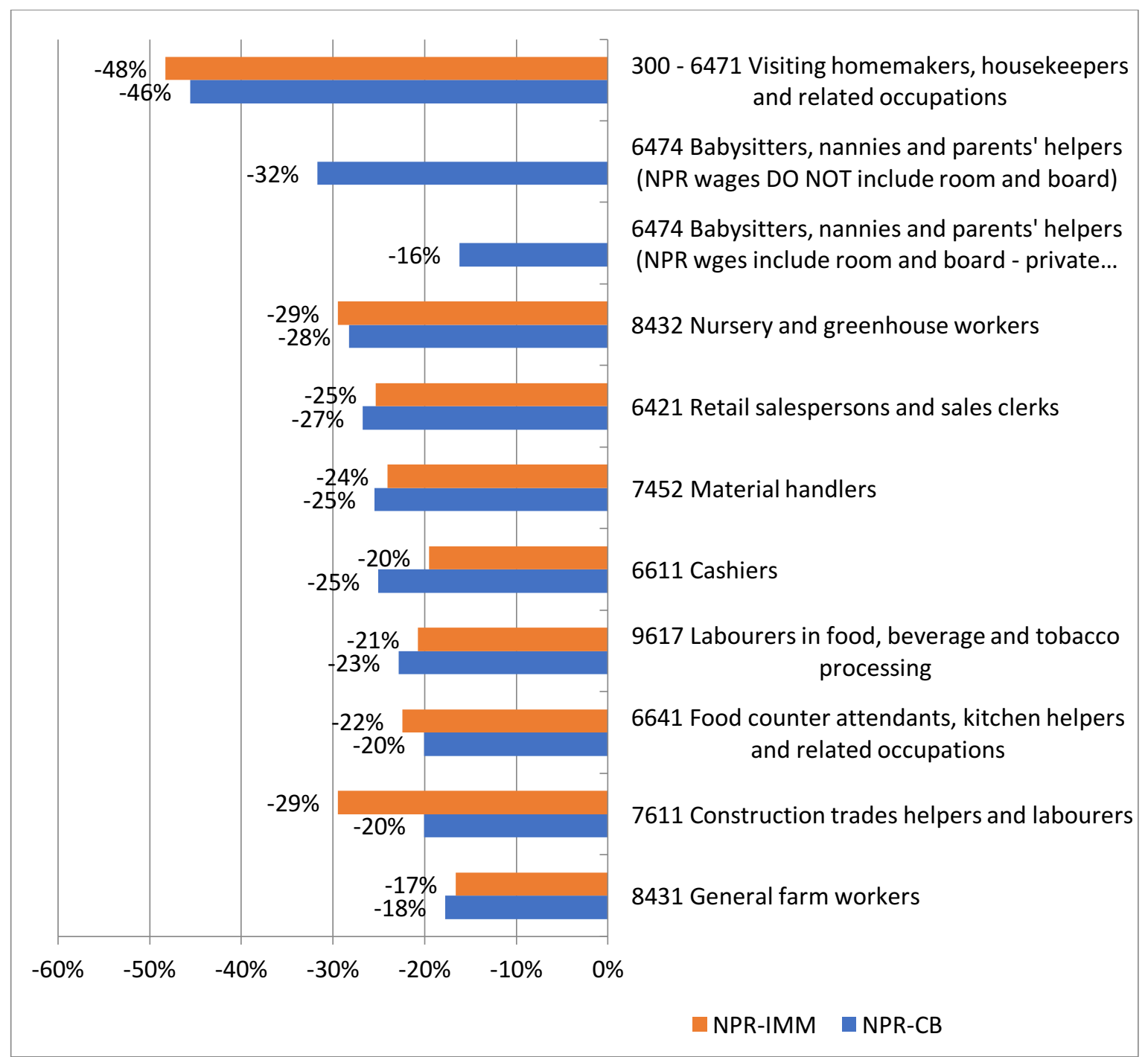

Figure 14: Average Hourly Wage Differences by Sex - Males (it ONLY includes statistically significant differences) - (Source: 2006 Census)

Given that labour market conditions are region specific, analyzing regional differences and intrinsic characteristics may shed light on the rationale behind wage differences. The next section explores wage differences by level of education. 


\subsection{Wage Differences by Level of Education}

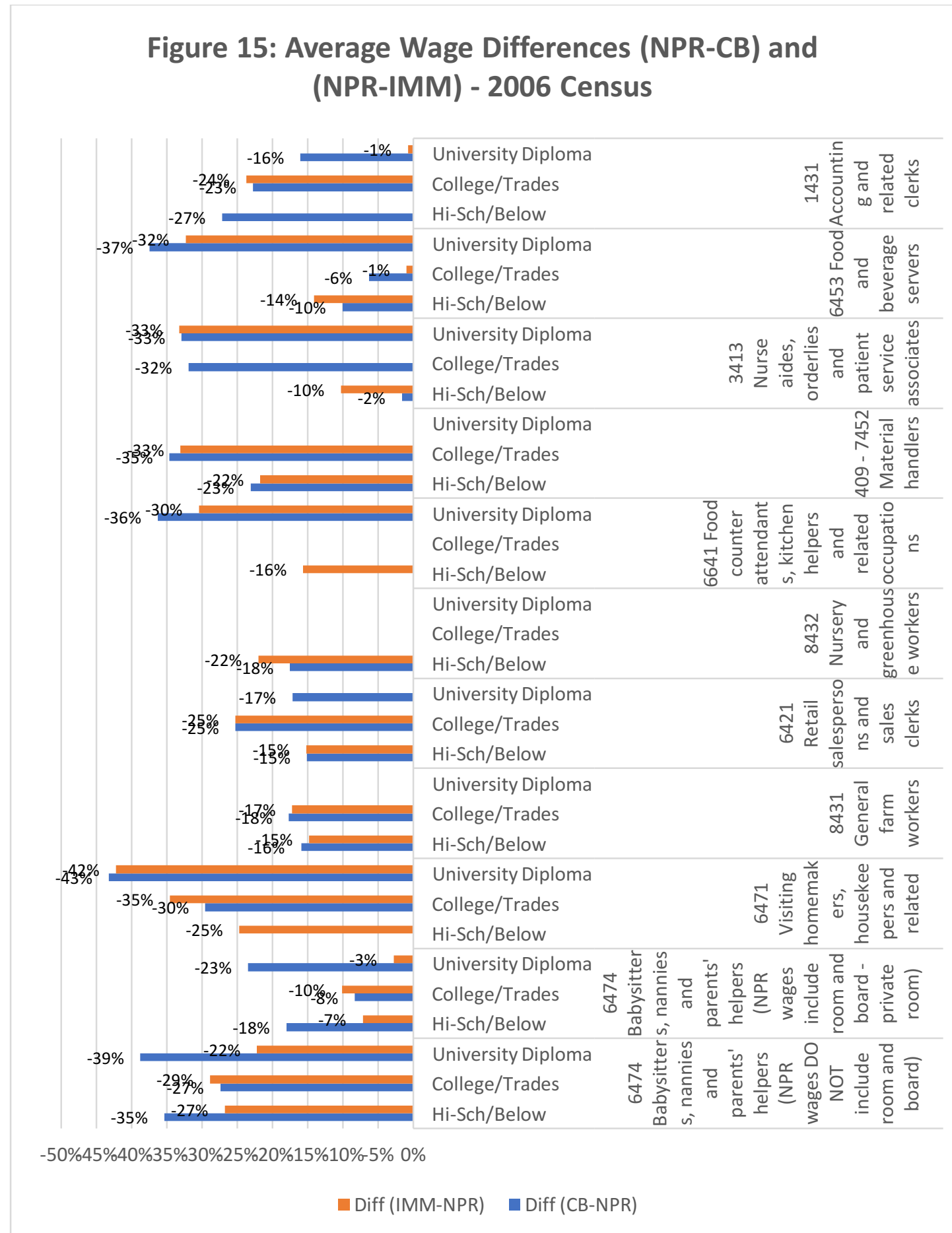

Figure 15: Statistically Significant Average Hourly Wage Differences (NPR-CB) and (NPR-IMM) (Source: 2006 Census).

Figure 15 presents wage differences between NPR-CB and NPR-IMM with statistically 
significant outcomes among the top 10 occupations tested. Wage differences by level of education in the top 10 occupations tested in this section were all negative. That is, in all cases tested, NPRs earned less than CB and IMM. Three cases are worth presenting.

First, in occupation 1431-Accounting and Related Clerks wage gaps are smaller among those with university degrees than among those with high school education or less. Stated otherwise, in this occupation, a university degree helps NPRs to earn wages closer to those of Canadian-born and immigrant workers. Second, in three occupations $(6474,6453$ and 1431) the NPR-IMM wage gap for those with college degrees or trades certificates is smaller than the wage gap of those with high school certificates or less. Further research could help to explain this.

Third, in the remaining five occupations analyzed, the opposite tendency occurred. That is, the wage gap among those with post-secondary education was bigger than the wage gap among those with high school education or less. Thus, in those occupations, having a university diploma has no positive effect on the wage gap. Examples of these are workers in occupations 6471-Visiting Homemakers and Housekeepers, 8431-General farm workers and 3113-Nurse Aides, Orderlies and Patient Service Associates.

Occupations like 8431-General Farm Workers value experience. Most NPRs working in farm-related work, also do it in their countries of origin and, for the most part, lack formal education. It is possible that most of them have no formal education whatsoever, but rather experience in farm-related labour. For example, of all NPRs in occupation 8431-General Farm Workers, 89\% had a high school diploma or less and 
experience working in farm-related labour; this is a requirement to work in agricultural occupations. Work related experience in their countries of origin and in Canada increases NPRs' chances of earning higher wages and, by extension, of diminishing the wage gap between NPRs and Canadian-born or immigrant populations. Many farm workers come year after year, which may also increase NPRs' seniority and, over time, their wages.

\subsection{Wage Differences by Knowledge of First Official Languages}

This section explores the impact of speaking one of Canada's official languages (English or French). This part of the analysis uses the variable (FOL- First Official Language spoken) reported in the census, which is self-reported and may not accurately measure one's capacity to speak either official language.

Given the subjective characteristic of this variable, results may need further investigation. That said, the variable FOL nevertheless provides initial insight into the effect of official language ability on labour market outcomes among the low-skilled population. Figure 16 shows statistically significant wage differences between NPRs and IMM who report speaking English. In all occupations included in this section, NPRs showed lower wages than immigrants. As previously mentioned, differences between NPRs and CB workers are not reported since the latter are expected to speak English. Although it would have been ideal to compare the wages of those who do not speak English with those who do, sample sizes among those who do not speak English precluded such analysis. 


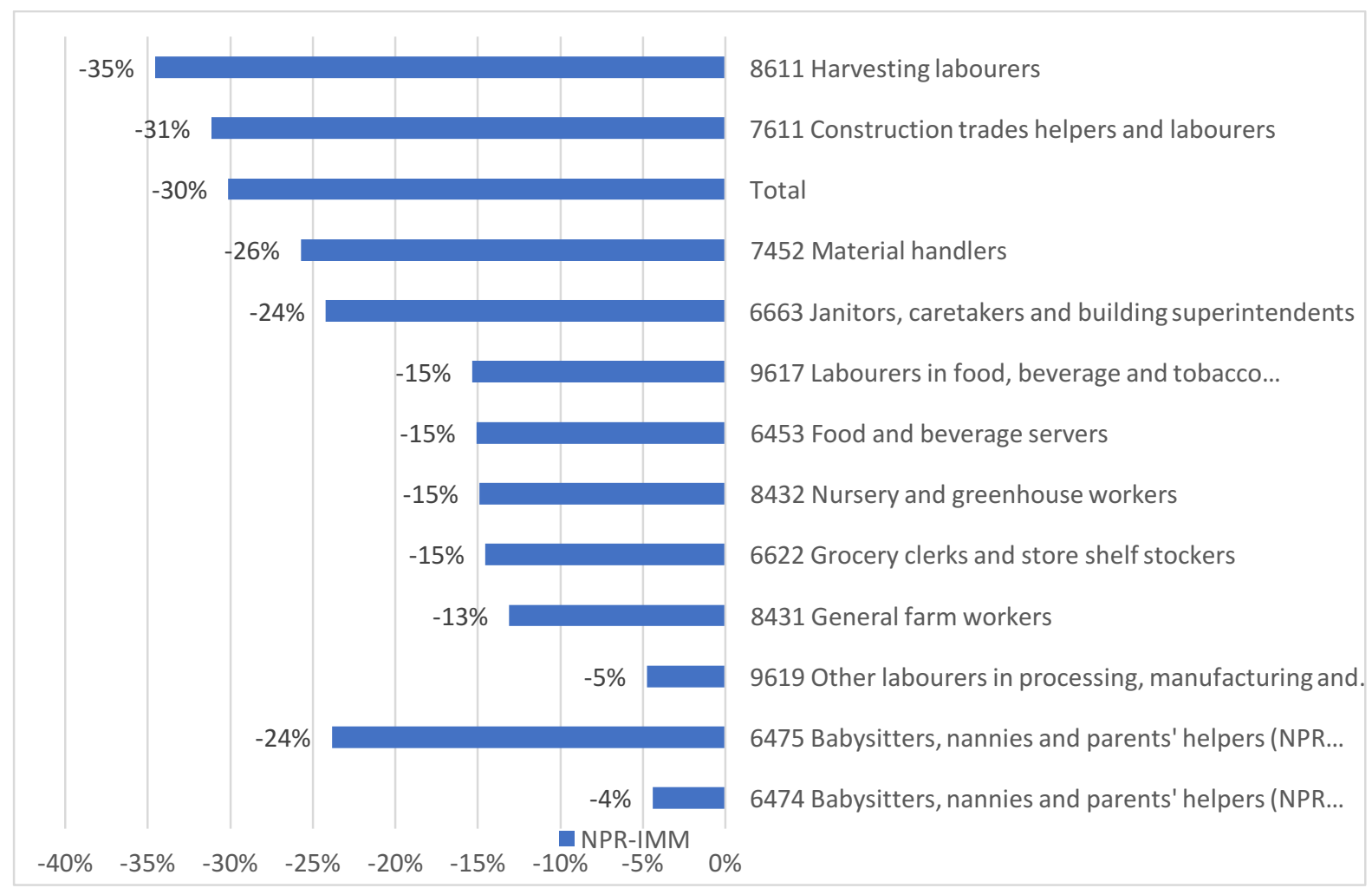

Figure 16: Average Hourly Wage Differences Speaking English (NPR-IMM) - (Source: 2006 Census)

Since occupations in which one is expected to speak either English or French (i.e. 6474-Babysitters, nannies and parents' helpers) are not worth exploring, attention was paid to occupations with no language requirements, but with a significant number of NPRs, like 8432-Nursery and greenhouse workers. Figure 16 shows NPRs in this occupation who report speaking English earning 15\% less than IMM. In contrast, wage differences at the population level (Figure 10) show NPRs (mostly non-English speakers) ${ }^{87}$ earning $22 \%$ less than IMM, which indicates that speaking English has a positive effect on wages in this occupation.

Another occupation that does not require English is 8431-General Farm workers. In contrast with the wage difference for the whole population (Figure 10), of which the

\footnotetext{
${ }^{87}$ Most workers in this in this occupation come from Mexico (80\%) and Jamaica (11\%) (2006 Census).
} 
group of primarily non-English speaking NPRs ${ }^{88}$ earns $15 \%$ less than IMM, when language is introduced the wage gap reduces by two percentage points to $13 \%$ (Figure 16). Once again, speaking English seems to have a positive effect on NPRs' wages. A clearer picture will emerge with the regression analysis. Unfortunately, no occupation had a sample size big enough to allow a comparison at the occupation level between NPRs and IMM who speak French.

\subsection{Wage Differences by Country of Birth (COB)}

Country of birth provides a closer look at the impact of ethnic origin, which can be proxy-ed and more closely targeted through the country of birth, on wages. An analysis of wages by immigration status and country of birth required selecting NPRs in a specific occupation from a specific country and comparing them with immigrants from the same country and with Canadian-born working on those occupations. Coinciding with the variety of countries of birth, there is a variety of wage distribution by country of birth per occupation. Table 11 presents the wages of low-skilled workers by country of birth in selected occupations (appendix 11 includes an extended version of this table, with outcomes for the 24 occupations ${ }^{89}$ analyzed in this section). The table gathers information about wages, according to immigration status and country of birth as well as the wage differentials. Four trends were identified:

\footnotetext{
${ }^{88}$ Most NPRs in this occupation come from Mexico (55\%), Jamaica (16\%) and Trinidad and Tobago (8\%) (2006 Census).

89 The 24 occupations correspond to the number of occupations with enough counts (90) and with statistically significant outcomes.
} 


\begin{tabular}{|c|c|c|c|c|c|c|c|}
\hline \multicolumn{8}{|c|}{ Table 11: Wage Differences by Occupation, Immigration Status and Country of Birth } \\
\hline \multirow[t]{2}{*}{ Census code, NOC 4, Name } & \multirow{2}{*}{$\begin{array}{l}\text { Country of Birth } \\
\text { (IMM and NPR) }\end{array}$} & \multicolumn{3}{|c|}{ Mean Hourly Wage } & \multicolumn{3}{|c|}{ Differences } \\
\hline & & CB & IMM & NPR & NPR-CB & NPR-IMM & $\begin{array}{l}\text { IMM- } \\
\text { CB }\end{array}$ \\
\hline \multirow{3}{*}{$\begin{array}{l}6474 \text { Babysitters, nannies and } \\
\text { parents' helpers (wages of NPRs } \\
\text { include room and board - private }\end{array}$} & 2 Canada & 11.72 & & & & & \\
\hline & 209 Philippines & & 10.68 & 10.12 & $-14 \%$ & $-9 \%$ & $-5 \%$ \\
\hline & 215 India & & 10.89 & 10.45 & $-10.8 \%{ }^{*}$ & $-7 \%^{* *}$ & $-7 \%^{* *}$ \\
\hline \multirow{2}{*}{$\begin{array}{l}6471 \text { Visiting homemakers, } \\
\text { housekeepers and related }\end{array}$} & 2 Canada & 13.69 & & & & & \\
\hline & 209 Philippines & & 14.82 & 9.87 & $-28 \%$ & $-33 \%$ & $8 \%$ \\
\hline \multirow[t]{4}{*}{8431 General farm workers } & 2 Canada & 12.35 & & & & & \\
\hline & 23 Mexico & & 11.43 & 9.85 & $-20 \%$ & $-14 \%$ & $-7 \%$ \\
\hline & 39 Jamaica & & & 13.06 & $5.7 \%^{* *}$ & $14.3 \%$ ** & \\
\hline & 47 Trinidad and & & & 9.79 & & & \\
\hline \multirow{9}{*}{$\begin{array}{l}6421 \text { Retail salespersons and sales } \\
\text { clerks }\end{array}$} & 2 Canada & 15.55 & & & & & \\
\hline & 17 USA & & 15.28 & 15.01 & $-3.5 \%^{* *}$ & $-1.8 \%^{* *}$ & - \\
\hline & 95 UK & & 16.85 & & & & $8 \%$ \\
\hline & 209 Philippines & & 14.40 & & & & $-7 \%$ \\
\hline & 218 Pakistan & & 13.36 & & & & $-14 \%$ \\
\hline & 215 India & & 15.44 & & & & - \\
\hline & 194 China & & 12.62 & & & & $-19 \%$ \\
\hline & 68 Germany & & 15.36 & & & & - \\
\hline & 79 Poland & & 13.73 & & & & $-12 \%$ \\
\hline \multirow{4}{*}{$\begin{array}{l}8432 \text { Nursery and greenhouse } \\
\text { workers }\end{array}$} & 2 Canada & 11.99 & & & & & \\
\hline & 23 Mexico & & 10.82 & 9.17 & $-24 \%$ & $-15.3 \%^{* *}$ & - \\
\hline & 39 Jamaica & & & 11.31 & $-5.7 \%^{* *}$ & & \\
\hline & 215 India & & 11.80 & & & & - \\
\hline \multirow[t]{4}{*}{7411 Truck drivers } & 2 Canada & 18.27 & & & & & \\
\hline & 95 UK & & 18.73 & 12.99 & $-29 \%$ & $-31 \%$ & $2.5 \%^{* *}$ \\
\hline & 215 India & & 13.80 & 14.55 & $-20 \%$ & $5.4 \%$ ** & $-24 \%$ \\
\hline & 79 Poland & & 16.55 & & & & $-9.4 \%$ * \\
\hline \multirow{6}{*}{$\begin{array}{l}6663 \text { Janitors, caretakers and building } \\
\text { superintendents }\end{array}$} & 2 Canada & 16.86 & & & & & \\
\hline & 23 Mexico & & 14.24 & & & & $-16 \%$ \\
\hline & 209 Philippines & & 17.16 & & & & $1.8 \%^{* *}$ \\
\hline & 215 India & & 14.04 & & & & $-17 \%$ \\
\hline & 101 Italv & & 19.08 & & & & $13 \%$ \\
\hline & 79 Poland & & 17.65 & & & & $4.7 \%^{* \star}$ \\
\hline \multirow{5}{*}{$\begin{array}{l}6641 \text { Food counter attendants, kitchen } \\
\text { helpers and related occupations }\end{array}$} & 2 Canada & 11.69 & & & & & \\
\hline & 194 China & & 10.14 & & & & $-13 \%$ \\
\hline & 215 India & & 12.04 & & & & $2.9 \%^{* *}$ \\
\hline & 219 Sri Lanka & & 11.38 & & & & - \\
\hline & 209 Philippines & & 14.48 & & & & $24 \%$ \\
\hline \multirow{4}{*}{$\begin{array}{l}1413 \text { Nurse aides, orderlies and } \\
\text { patient service associates }\end{array}$} & 2 Canada & 16.45 & & & & & \\
\hline & 209 Philippines & & 18.55 & 10.88 & $-34 \%$ & $-41 \%$ & $13 \%$ \\
\hline & 38 Haiti & & 16.74 & & & $-35 \%^{* *}$ & $1.8 \%^{* *}$ \\
\hline & 215 India & & 18.79 & & & $-42 \%$ & $14 \%$ \\
\hline \multirow{3}{*}{$\begin{array}{l}7611 \text { Construction trades helpers and } \\
\text { labourers }\end{array}$} & 2 Canada & 17.42 & & & & & \\
\hline & 53 Brazil & & 35.60 & & & & $104 \%$ * \\
\hline & 103 Portuqal & & 25.00 & & & & $43 \%$ ** \\
\hline 75 - 1411 General office clerks & 2 Canada & 19.28 & & & & & \\
\hline & 17 USA & & 18.94 & & & & - \\
\hline & 194 China & & 15.75 & & & & $-18 \%$ \\
\hline & 95 UK & & 22.33 & & & & $16 \%$ \\
\hline & 209 Philippines & & 19.25 & & & & - \\
\hline & 101 Italv & & 21.50 & & & & $12 \%$ \\
\hline 1431 Accounting and related clerks & 2 Canada & 19.43 & & & & & \\
\hline & 194 China & & 16.70 & & & & $-14 \%$ \\
\hline & 209 Philippines & & 18.67 & & & & $-3.9 \% *$ \\
\hline & 95 UK & & 22.59 & & & & $16 \%$ \\
\hline & 195 Honq Konq & & 17.80 & & & & $-8 \%$ \\
\hline Note: Column "CB", category "Canada" & "excludes those & $\overline{a d c}$ & al citize & ip(s) & oid do & le counts & \\
\hline${ }^{*}=$ Interpret with caution, $5 \%<p<15 \%$ & & & & & & & \\
\hline$* *=p>15 \%$ & & & & & & & \\
\hline
\end{tabular}

Table 11: Wage Differences by Occupation, Immigration Status and Country of Birth 


\subsubsection{Concentration around low-paid occupations or with significant wage}

difference (compared to CB and IMM). Low-skilled workers from developing world countries concentrate around physically demanding occupations. They are present in large numbers and mainly come from the Philippines, China, India and Mexico. India, the Philippines and China are the top three countries of origin among the immigrant population in Canada, making up approximately $25 \%$ of low-skilled immigrants (see Table 7 in chapter five). These same three countries are among the top five countries of origin among the NPR populations representing approximately $38 \%$ of all low-skilled NPRs. Viewed together these three countries are significant in the low-skilled Canadian labour force. Filipinos (joined by Mexicans) are amongst the lowest earners. Indians and Chinese are middle to low earners. Their wage differences compared with those of Canadian-born workers are significant. For instance, Indian-born NPR truck drivers have wages $20 \%$ lower than Canadian-born truck drivers.

NPR workers from Mexico work in physically demanding occupations (Basok, 2002) with very low wages. Workers in this group are clustered in occupations including 8431-General farm workers, 8432-Nursery and greenhouse workers. Those from the Philippines work primarily in caregiving and domestic labour. Mexican NPRs in occupation 8431 and 8432 earn $20 \%$ and $24 \%$ less, respectively, than Canadian-born employees.

7.6.2. Concentration around the highest paying low-skilled jobs. Low-skilled workers from western and southern Europe concentrate around the highest paying lowskilled jobs. A certain kind of job hierarchy, according to country of origin, seems to 
emerge. Workers coming from developed nations (United Kingdom, United States, and Germany) tend to gather around clerical jobs, which are among the highest paid lowskilled jobs. In some cases, these workers earn higher wages than their Canadian-born counterparts. Low-skilled immigrant workers from the United Kingdom appear to have the highest wages. Occupations in this group include: 1411-General Office Clerks, 1431-Accounting and related clerks. Although these occupations are included among the low-skilled, they are within the skill level group $C$, which requires high school or occupation specific training. As outlined above, this level is above level D. Other skills may also improve access to these jobs, for example, knowledge of either official language and additional education or training. In some occupations, even after having Canadian citizenship, wage differences are positive for workers coming from developed nations (i.e. UK) and negative for those coming from developing nations (i.e. China). British-born low-skilled immigrant workers in occupation 1431-Accounting and related clerks earn $16 \%$ more wage than Canadian born workers. In contrast, Chinese-born workers in the same occupation earn $14 \%$ less than their Canadian-born counterparts. Even if both (British and Chinese) have Canadian citizenship, those from China have a significant wage difference compared to those from the UK.

\subsubsection{Niche-occupation concentration around certain countries of origin.}

Some occupations exhibit niche-occupation concentration around certain countries of origin including Mexico, Philippines, Portugal and Italy. Occupation 6663 Janitors, caretakers and building superintendents also exhibits a kind of hierarchy. Low-skilled Italian-born immigrants earn the highest wages, 13\% higher than Canadian-born workers, who earn the second highest wages, followed by Mexican and Indian workers, 
who earn $16 \%$ and $17 \%$ less than Canadian-born employees. One possible argument to explain these differences is a sort of niche behaviour among certain ethnic groups.

Another niche occupation is 6474-Babysitters, nannies and parents' helpers, who come primarily from the Philippines. Their supremacy is not reflected in wages but in the number of workers. Low-skilled immigrants from the Philippines are reported in 13 of the 24 occupations analyzed in this section and tend to be middle to low earners in each occupation. Other ethnic communities also have a strong presence, reflected in numbers rather than in wages. Low-skilled Indian immigrants work in 14 of the 24 occupations reported; low-skilled Chinese immigrants work in eight. Mexican presence is also significant in occupations in agriculture.

It is also worth highlighting that Portuguese-speaking low-skilled workers have a significant participation in occupation 7611-Construction trades helpers and labourers. Of all immigrants who reported working in this occupation, $27.6 \%$ are from either Brazil or Portugal. Clifton (2008) presents the case of Portuguese workers in construction.

7.6.4. Wages improve when citizenship is accounted for. Wages improve in some occupations when citizenship is accounted for among foreign-born individuals born in the same country. Access to citizenship generally improves wage, although, Canadian-born workers still earn higher wages after citizenship is accounted for among foreign-born low-skilled workers. Mexican NPRs working in occupation 8431-General farm workers earn $20 \%$ less wage than their Canadian-born counterparts. In contrast, Mexican-born immigrants (i.e. with access to citizenship) working in the same occupation earn $7 \%$ less than Canadian-born workers. While less than Canadian-born 
workers, the wages of Mexican immigrants are higher than those of Mexican NPRs.

Thus, Mexican immigrants, with access to citizenship (naturalized Mexicans) or with the possibility of becoming Canadian citizens (permanent resident Mexicans) earn 14\% more than their NPR compatriots. This tendency is also found among Filipino workers in occupation 6474-Babysitters, nannies and parents' helpers. Filipino NPRs earn 14\% less than Canadian-born workers and 9\% less than Filipino immigrants. Differences in wages decrease if citizenship is accounted for, since Filipino immigrants earn $5 \%$ less than $\mathrm{CB}$.

NPR Truck drivers (NOC 7411) from the United Kingdom earn $29 \%$ less than Canadian-born workers and 31\% less than UK-born immigrants (see Table 11), indicating that citizenship also makes a difference in this occupation.

\section{Summary}

Wages of low-skilled NPRs compared to those of CB and IMM, accounting for characteristics explored in this chapter, provides a good picture of the experiences of low-skilled workers without citizenship.

Low-skilled NPRs earn lower wages than Canadian-born and immigrant workers across most occupations and across most of the subcategories of the characteristics analyzed (sex, province of residence, level of education, rural/urban location, first official language ability, and country of birth). This is also evident when comparing quartile by quartile. Surmounting the interpretative difficulties that arise when wage dispersion affects averages and their comparability, quartile differences confirm those calculated with the averages of the populations by immigration status (NPR-CB and NPR-IMM) in 
each occupation. Occupation NOC 8432 Nursery and Greenhouse Workers is among the occupations with the lowest wages among the NPR population in most characteristics analyzed. Workers in this occupation were also among the workers with the greatest wage differences when compared with Canadian-born and immigrant workers across intrinsic characteristics.

A hierarchy of occupations by country of birth was also identified. Those coming from mostly European countries with high official language ability work in the better paid low-skilled occupations. In contrast, highly physically demanding occupations are filled with workers coming mostly from the developing world. As with the previous chapter, the following table presents a condensed and punctual summary of the outcomes of this chapter framed by the hypotheses outlined in chapter two (Table 11A).

Table 11A - Summary of Hypotheses/Chapter Findings (Cross- Tabulation Relative Wages)

\begin{tabular}{|l|l|}
\hline Hypotheses & Findings \\
\hline $\begin{array}{l}\text { 1. NPRs earn } \\
\text { lower wages than } \\
\text { CB and IMM by } \\
\text { sex and } \\
\text { occupation } \\
\text { analyzed in this } \\
\text { section. }\end{array}$ & $\begin{array}{l}\text { 2.1. Females: Of the 14 top occupations tested, six had statistically significant } \\
\text { outcomes, all of which with NPR wages lower than CB and IMM wages. } \\
\text { 2.2. Males: Of the top 14 occupations for males tested, six exhibited statistically } \\
\text { significant lower wages for NPRs compared with CB. 10 of the 14 exhibited } \\
\text { statistically significant lower wages for NPRs compared with IMM. }\end{array}$ \\
\hline $\begin{array}{l}\text { 2. NPRs earn } \\
\text { lower wages than } \\
\text { CB and IMM in all } \\
\text { provinces in each } \\
\text { occupation } \\
\text { analyzed in this } \\
\text { section. }\end{array}$ & $\begin{array}{l}\text { 2. Province of Residence: Wage differences among NPRs compared to CB and } \\
\text { statistically significant results, NPR wages were lower than those of CB. } \\
\text { Occupation 6474-Babysitters, Nannies and Parents Helpers displayed the largest } \\
\text { differences. }\end{array}$ \\
\hline $\begin{array}{l}\text { 3. NPRs earn } \\
\text { lower wages than } \\
\text { CB and IMM in } \\
\text { rural and urban } \\
\text { locations in each } \\
\text { occupation }\end{array}$ & $\begin{array}{l}\text { 3.1. Rural: Wages among NPRs are lower than those of IMM in the two } \\
\text { occupations with statistically significant results. Differences with the CB population } \\
\text { were negative in the five occupations with statistically significant results. } \\
\text { 3.2. Urban: NPR wages were lower than those of CB and IMM in all seven } \\
\text { occupations with statistically significant outcomes. Differences in Urban settings } \\
\text { were larger for 6474-Babysitters, Nannies and Parents Helpers. }\end{array}$ \\
\hline
\end{tabular}




\begin{tabular}{|c|c|}
\hline $\begin{array}{l}\text { analyz } \\
\text { section }\end{array}$ & \\
\hline $\begin{array}{l}\text { 4. NPRs earn } \\
\text { lower wages than } \\
\text { CB and IMM by } \\
\text { level of education } \\
\text { in each } \\
\text { occupation } \\
\text { analyzed in this } \\
\text { section. }\end{array}$ & $\begin{array}{l}\text { 4. In the top } 10 \text { occupations tested, NPRs earn less than CB and IMM in the three } \\
\text { levels of education. Three cases are worth presenting. } \\
\text { - First, in occupation } 1431 \text {-Accounting and Related Clerks the wage gap is } \\
\text { smaller among those with a university degree (UD) than among those with high } \\
\text { school or less. } \\
\text { f Second, in three occupations ( } 6474,6453 \text { and } 1431) \text { the NPR-IMM wage-gap } \\
\text { for those with college degrees or trades certificates (CD-TC) is smaller than the } \\
\text { wage gap of those with high school or less. } \\
\text { - Third, in the remaining five occupations the wage gap among those with post- } \\
\text { secondary education (UD or CD-TC) was bigger than the wage gap of those with } \\
\text { high school or less. }\end{array}$ \\
\hline $\begin{array}{l}\text { 5. NPRs who } \\
\text { report speaking } \\
\text { English or French } \\
\text { earn lower wages } \\
\text { than IMM who } \\
\text { also report } \\
\text { speaking English } \\
\text { or French in each } \\
\text { occupation. } \\
\text { Additionally, } \\
\text { speaking either } \\
\text { official language } \\
\text { reduces NPRs' } \\
\text { wage gap } \\
\text { (compared to } \\
\text { IMM). }\end{array}$ & $\begin{array}{l}\text { In all cases NPRs earned less than CB and IMM. } \\
\text { 5.1. English: Occupations in which NPRs are expected to speak English (i.e. } 6474- \\
\text { Babysitters, nannies and Parents' helpers) were not examined, since speaking } \\
\text { English has no effect on their wages. Other occupations were worth pursuing. In at } \\
\text { least two occupations considered, where there is no expectation to speak English, } \\
\text { a positive effect on wages among NPRs who reported speaking English was found. } \\
\text { Their wage differences were smaller than those of the whole population in that } \\
\text { occupation. This is a valid inference, since most NPRs in those occupations come } \\
\text { from non-English speaking countries. } \\
\text { 5.2. French: Sample size did not allow an evaluation of effects by occupation } \\
\text { among those who reported speaking French. Nonetheless, all NPRs who reported } \\
\text { speaking French earned } 13 \% \text { less than immigrants. This difference is smaller than } \\
\text { that for the whole population ( } 27.3 \% \text { less for NPRs compared with immigrants). } \\
\text { Therefore speaking French seems to also have a positive effect on wages. }\end{array}$ \\
\hline $\begin{array}{l}\text { 6. NPRs earn } \\
\text { lower wages than } \\
\text { CB and IMM by } \\
\text { country of birth in } \\
\text { the occupations } \\
\text { analyzed in this } \\
\text { section. }\end{array}$ & $\begin{array}{l}\text { The country of birth influences the wages of low-skilled temporary foreign workers. } \\
\text { NPRs coming from Mexico and the Caribbean tend to work in occupations in } \\
\text { agriculture which have lower wages. NPRs from the Philippines mostly work in } \\
\text { caregiving occupations, which are among the occupations with the low wages and } \\
\text { with the large wage differences compared to CB and IMM. NPRs coming from the } \\
\text { UK tend to work in occupations with higher wages. Having citizenship reduces the } \\
\text { wage gap between Mexican-born low-skilled workers and Canadian-born low- } \\
\text { skilled workers. }\end{array}$ \\
\hline
\end{tabular}

Table 11A: Summary of Hypotheses/Chapter Findings (Cross -Tabulation Relative Wages) 


\section{Chapter Eight: Regression Analysis}

The previous two chapters introduced the wage differences of NPRs compared to the CB and IMM. This type of study though relevant is still limiting because some variables may have effects on others that are not captured in a cross-tabulation analysis. This previous analysis provided a partial picture because it was done one variable at a time, independently. Thus, the analysis now shifts to a type of analysis that considers all variables at the same time. Regression analysis further enriches our findings by providing outcomes of the effect of lack of citizenship on wages in relation to the intrinsic characteristics studied in the previous chapter. A regression analysis is necessary because, although the outcomes of the descriptive analysis (chapters five, six and seven) provide a good overview of the demographics and the wages of NPRs, it is comprised of isolated, unrelated pieces. To evaluate the labour market outcomes of citizens against those of noncitizen NPRs, while accounting for characteristics such as sex, province of residence and country of birth, it is helpful to consider these factors all interrelated rather than in isolation, which the regression analysis enables. By allowing for a multivariable analysis, regression permits all characteristics to be considered all at the same time, while providing information about the separate effect of changes in each characteristic on wages. In short, it provides a nuanced view of the effects of citizenship (or lack thereof) on wages.

In this dissertation, regression is a mathematical tool used to explore the changes of a dependent variable in relation to changes in a series of independent variables, all explored at the same time. More specifically, in this study, regression analysis helps evaluate the change in a dependent variable (wages) in relation to a 
percentage change in each of the independent variables (all other characteristics including age, sex, immigration status and level of education). The "effects" on wages in a multiple regression analysis are understood to be causal (Engelhardt \& Stukel, 2001). Applying the logarithm (LOG) ${ }^{90}$ to the dependent variable (wage) allows for this type of evaluation.

This chapter presents the outcomes of the regression analysis according to eleven different models separated in two categories. The first model uses all 98 occupations included in the analysis. Recall that the original number of 98 occupations was further reduced to 43 and 35 to perform absolute and relative wage analysis via cross-tabulation (chapter six). The reductions of occupations took place to account for restrictions in the number of counts and statistical tests of comparability of means. The regression analysis in this model uses all occupations as well as all characteristics. It evaluates their effects on the wages of low-skilled workers, especially the effect of lack of citizenship seen as part of the set of characteristics in this analysis. The remaining ten models correspond to the analysis of ten selected NPR-relevant specific occupations. These ten models provide a more focused analysis of the effects of the intrinsic characteristics (of workers and their occupations) on the wages of low-skilled workers in each specific occupation. As with the first model that uses all occupations, the ten occupation specific models treat lack of citizenship as part of set of

\footnotetext{
90 "LOG" refers to the mathematical function "Natural Logarithm." When a variable has a positive skew (a few very high values), taking the natural logarithm helps fit the variable into a regression model by normalizing the variable's distribution (see section 8.1. in this chapter). Wage is a variable that generally tends to have a positive skew, therefore a LOG transformation is essential. The outcomes of the Log-ed wages in a regression analysis are approximately a percent variation on the independent variables (not the LOG-ed value of each independent variables), because "when the dependent variable but not an independent variable is logged (sic), a one-unit change in the independent variable is associated with a 100 times the coefficient percent change in the dependent variable" (Princeton University Library - Data and Statistical Services, 2008)
} 
characteristics.

As a whole, the regression analysis confirms what was found in the crosstabulation analysis, namely that low-skilled NPRs earn lower wages than their Canadian-born and immigrant counterparts. As we will see, this is especially evident among agricultural workers. This chapter focuses primarily on the outcomes of the regression models and includes a preliminary analysis of the results. Together with the outcomes of chapters five, six and seven these outcomes will also be incorporated in the discussion found in chapter nine.

This chapter is organized into three main sections. In the first section, I contextualize the use of regression analysis in this dissertation and introduce the two model types used: type one uses all 98 occupations and all characteristics; type two focuses on specific NPR-relevant occupations. In the second section, I introduce the outcomes of the one type one model; and, in the third section I present the outcomes of ten type two models.

\subsection{Regression Models}

As previously explained, this research uses Linear Multiple Regression (see section 4.2.2. in chapter four) with categorical variables. This method has several requirements including the following: 1) each category of independent variables must be transformed into dummies; 2) the number of categories transformed into dummies minus one is then introduced into each of the models developed; 3 ) the dependent variables are to be normally distributed; and 4) there is to be no co-linearity between subcategories in a variable or between variables (Stockburger, 1998). 
The effects of the independent variables (age, sex, etc.), excluding immigration status, will be contrasted against the subcategory "Non-Permanent Resident (Temporary Foreign Worker and Refugee Claimant)" under "Immigration Status." The regression analysis will test whether being a NPR (lacking citizenship) represents a significant negative effect on wage compared to being Canadian-born.

The next sections explain in highly technical fashion the models created to perform the regression analysis. It is of interest to see in each model the variables included and their associated coefficients (Betas). Each coefficient, beta, will provide information on the percentage variation of wages associated to the respective independent variable. Betas are listed in tables 12 and appendix 14B (Type one model - all occupations included) and tables 13 and 14 (Type two models - occupation level models).

Type One Model (with All 98 Occupations and All Characteristics) evaluates the effects of all independent variables influencing wages, including all low-skilled occupations, as predictors. It serves as a means for gauging relationships between outcomes in the labour market (wages) of low-skilled workers and all characteristics (sex, age, regions of the world, etc.), as experienced in all occupations. This type of model provides information about relationships among occupations as well as the impact that citizenship (or lack thereof) has on wages.

It is important to clarify that this kind of model is designed to evaluate the effects of characteristics, either of the workers (age, immigration status, level of education, etc.) or of the geography (province of residence, rural/urban location) or of the jobs 
themselves (type of occupation). It does not account for any macro-economic effects, which therefore limits its predictive power. Note that as explained wages are LOG-ed. For readers interested in the mathematical formulae deployed to derive regression calculations, they are provided below (for the model type one) and in the subsequent section (for models type two).

LOG Hourly Wages

$$
\begin{aligned}
& =\alpha+\beta_{1}(\text { Age })+\beta_{2}(\text { Sex })+\beta_{3}(\text { Rural } / \text { Urban Location }) \\
& +\beta_{4}(\text { Province of Residence })+\beta_{5}(\text { Level of Education }) \\
& +\beta_{6}(\text { Knowledge of first of ficial language })+\beta_{7}(\text { Region of Origin }) \\
& +\beta_{8}(\text { Immigration Status })+\beta_{9}(\text { Occupation })
\end{aligned}
$$

Type Two Models (Ten Occupation-Level Models) focuses exclusively on specific occupations. This type of models is needed because it provides more detailed information on the relations between outcomes in the labour market (wages) and the characteristics (age, sex, province of residence, etc.,) in each specific occupation analyzed. Its narrower focus makes it possible to recognize relationships between dependent and independent variables for each occupation in isolation. This refines the analysis and helps to see how citizenship (in relation to characteristics, including age and sex) relates to the wages in each occupation with the highest presence of lowskilled NPRs. A unique model was designed for each analyzed occupation. These models evaluate the effects of the independent variables (age, sex, etc.,) on the dependent variables (wage) in each occupation. These occupations were selected as relevant for NPRs either because they employ a significant number of NPRs or because 
they provide a pathway to citizenship via the Provincial Nominee Program (PNP) offered in some provinces (this is the case of Truck Drivers and Industrial Butchers). Ten occupations were considered: the occupations associated to each model are:

a. 6474 - Babysitters, Nannies and Parents' Helpers (females only)

b. 6474 - Babysitters, Nannies and Parents' Helpers (all workers)

c. 6471 - Visiting Homemakers, Housekeepers and Related Occupations

d. 8431 - General Farm Workers

e. 8432 - Nursery and Greenhouse Workers

f. 7411 - Truck Driver

g. 6641 - Food counter attendants, kitchen helpers and related occupations

h. 6661 - Light Duty Cleaners

i. 6421 - Retail Salespersons and Sales Clerk

j. 9462 - Industrial Butchers and Meat Cutters, Poultry Preparers and Related Workers

The models are:

a. 6474 - Babysitters, Nannies and Parents' Helpers (Male and Female Model) LOG Hourly Wages

$$
\begin{aligned}
& =\alpha+\beta_{1}(\text { Mean Centered Age })+\beta_{2}(\text { Sex })+\beta_{3}(\text { Immigration Status }) \\
& +\beta_{4}(\text { Rural/Urban Location })+\beta_{5}(\text { Province of Residence }) \\
& +\beta_{6}(\text { Level of Education })
\end{aligned}
$$

b. Females b. 6474 - Babysitters, Nannies and Parents' Helpers (Females only Model) 
LOG Hourly Wages

$$
\begin{aligned}
& =\alpha+\beta_{1}(\text { Mean Centered Age })+\beta_{2}(\text { Immigration Status }) \\
& +\beta_{3}(\text { Rural/Urban Location })+\beta_{4}(\text { Province of Residence }) \\
& +\beta_{5}(\text { Level of Education })+\beta_{6}(\text { First Official Language Spoken })
\end{aligned}
$$

\section{c. 6471 - Visiting Homemakers, Housekeepers and Related Occupations}

LOG Hourly Wages

$$
\begin{aligned}
& =\alpha+\beta_{1}(\text { Mean Centered Age })+\beta_{2}(\text { Sex })+\beta_{3}(\text { Immigration Status }) \\
& +\beta_{4}(\text { Province of Residence })+\beta_{5}(\text { Level of Education }) \\
& +\beta_{6}(\text { Knowledge of first official language })
\end{aligned}
$$

\section{d. 8431 - General Farm Workers}

LOG Hourly Wages

$$
\begin{aligned}
& =\alpha+\beta_{1}(\text { Mean Centered Age })+\beta_{2}(\text { Sex })+\beta_{3}(\text { Immigration Status }) \\
& +\beta_{4}(\text { Rural/Urban Location })+\beta_{5}(\text { Province of Residence })
\end{aligned}
$$

\section{e. 8432 - Nursery and Greenhouse Workers}

LOG Hourly Wages

$$
\begin{aligned}
& =\alpha+\beta_{1}(\text { Mean Centered Age })+\beta_{2}(\text { Sex })+\beta_{3}(\text { Immigration Status }) \\
& +\beta_{4}(\text { Rural/Urban Location }) \\
& +\beta_{5}(\text { Province of Residence })+\beta_{6}(\text { Level of Education })
\end{aligned}
$$

\section{f. 7411 - Truck Drivers}


LOG Hourly Wages

$$
\begin{aligned}
& =\alpha+\beta_{1}(\text { Mean Centered Age })+\beta_{2}(\text { Sex })+\beta_{3}(\text { Immigration Status }) \\
& +\beta_{4}(\text { Rural/Urban Location })+\beta_{5}(\text { Province of Residence }) \\
& +\beta_{6}(\text { Level of Education })+\beta_{7}(\text { First Official Language Spoken })
\end{aligned}
$$

g. 6641 - Food counter attendants, kitchen helpers and related occupations

LOG Hourly Wages

$$
\begin{aligned}
& =\alpha+\beta_{1}(\text { Mean Centered Age })+\beta_{2}(\text { Sex })+\beta_{3}(\text { Immigration Status }) \\
& +\beta_{4}(\text { Rural } / \text { Urban Location })+\beta_{5}(\text { Province of Residence }) \\
& +\beta_{5}(\text { Level of Education })+ \\
& \quad \beta_{7}(\text { Knowledge of first of ficial language })
\end{aligned}
$$

\section{h. 6661 - Light Duty Cleaners}

LOG Hourly Wages

$$
\begin{aligned}
& =\alpha+\beta_{1}(\text { Mean Centered Age })+\beta_{2}(\text { Sex })+\beta_{3}(\text { Immigration Status }) \\
& +\beta_{4}(\text { Province of Residence })+\beta_{5}(\text { Level of Education }) \\
& +\beta_{6}(\text { Knowledge of first official language })
\end{aligned}
$$




\section{i. 6421 - Retail Salespersons and Sales Clerk}

LOG Hourly Wages

$$
\begin{aligned}
& =\alpha+\beta_{1}(\text { Mean Centered Age })+\beta_{2}(\text { Sex })+\beta_{3}(\text { Immigration Status }) \\
& +\beta_{4}(\text { Rural/Urban Location })+\beta_{5}(\text { Province of Residence }) \\
& \left.+\beta_{6} \text { Level of Education }\right) \beta_{7}(\text { Regions of the World }) \\
& \left.+\beta_{8} \text { (Knowledge of first of ficial language }\right)
\end{aligned}
$$

j. 9462 - Industrial Butchers and Meat Cutters, Poultry Preparers and Related Workers LOG Hourly Wages

$$
\begin{aligned}
& =\alpha+\beta_{1}(\text { Mean Centered Age })+\beta_{2}(\text { Sex })+\beta_{3}(\text { Immigration Status }) \\
& +\beta_{4}(\text { Province of Residence }) \\
& +\beta_{5}(\text { Knowledge of first official language })
\end{aligned}
$$

\subsection{Outcomes Regression Model Type One - Including All 98 Low-Skilled Occupations Considered in This Study}

The model tests whether, controlling for age, sex, immigration status, province of residence, work location (rural/urban), level of education, ability to speak English or French and place of birth, being a Non-Permanent Resident has a significant negative impact on wage compared to being Canadian-born. A list of decisions related to how the populations associated to the variables introduced were grouped and recoded in this model is included in appendix 14A. 
Table 12: Regression Model for All Occupations (Dependent Variable: LOG Hourly Wages)

\begin{tabular}{|c|c|c|}
\hline \multirow{2}{*}{ Independent Variables } & \multicolumn{2}{|c|}{ Outcomes } \\
\hline & B & Sig \\
\hline (Constant) & 2.621 & .000 \\
\hline Mean-Centered Age & .009 & .000 \\
\hline \multicolumn{3}{|l|}{ Immigration Status - Canadian-born recoded (Reference Category) } \\
\hline Immigration Status Recoded (Immigrant and Permanent Resident) older than 10 years of age at arrival & -.059 & .000 \\
\hline Immigration Status - Non-Permanent Resident (TFW and Refugee Claimant) & -.188 & .000 \\
\hline \multicolumn{3}{|l|}{ SEX $=$ Male (Reference Category) } \\
\hline SEX = Female & -.142 & .000 \\
\hline \multicolumn{3}{|l|}{ Province or Territory (Quebec) - (Reference Category) } \\
\hline Province or Territory of Residence (Atlantic Provinces) & -.134 & .000 \\
\hline Province or Territory of Residence (Ontario) & .054 & .000 \\
\hline Province or Territory of Residence (Manitoba, Saskatchewan and Alberta) & -.046 & .000 \\
\hline Province or Territory of Residence (British Columbia) & .059 & .000 \\
\hline Province or Territory of Residence (Territories) & .180 & .000 \\
\hline \multicolumn{3}{|l|}{ Rural/Urban Location (Urban Location) - (Reference Category) } \\
\hline Rural/Urban Location (Rural Location) & -.042 & .000 \\
\hline \multicolumn{3}{|l|}{ Level of Education - High School and Less - (Reference Category) } \\
\hline Level of Education - College or Trade Certificate & .058 & .000 \\
\hline Level of Education - University (Bachelor's degree and Above) & .072 & .000 \\
\hline \multicolumn{3}{|l|}{ First Official Language Spoken (Speaking either official language) - (Reference Category) } \\
\hline First Official Language Spoken (Not speaking either official language). & -.122 & .000 \\
\hline \multicolumn{3}{|l|}{ Regions of the World 2-3 = Canada, United States, Greenland and St. Pierre et Miquelon (Reference Category) } \\
\hline Regions of the World 4= Latin America and the Caribbean & -.035 & .000 \\
\hline Regions of the World 5 = West, North and Central Europe (rich Europe) & .013 & .014 \\
\hline Regions of the World 6 = Eastern Europe and USSR (all ex-Soviet Union countries and Eastern Europe) & -.041 & .000 \\
\hline Regions of the World 7 = South Europe - (Spain, Portugal, etc.) & .083 & .000 \\
\hline Regions of the World 8 = Sub-Saharan Africa (Except South Africa, Namibia and Swaziland) & -.037 & .000 \\
\hline Regions of the World 9 = South Africa, Swaziland, Namibia and Oceania & -.003 & .802 \\
\hline Regions of the World 10= North Africa and the Middle East (it includes Turkey and Cyprus) & -.099 & .000 \\
\hline Regions of the World $11=$ India & -.156 & .000 \\
\hline Regions of the World 12 = Far East Asia 1 (Japan, South Korea, etc.) & -.091 & .000 \\
\hline Regions of the World 13 = Far East Asia 2 (Cambodia, Vietnam, etc.) & .001 & .927 \\
\hline Regions of the World 14 = East Asia (Pakistan, Sri Lanka, Afghanistan, excepting India) & -.166 & .000 \\
\hline Regions of the World $15=$ China & -.097 & .000 \\
\hline Occupations outcomes (see appendix 14B) & & \\
\hline
\end{tabular}

Table 12: Regression Model for All Occupations (Dependent Variable: LOG Hourly Wages)

Table 12 shows the outcomes of the regression model for hourly wages of all 98 low- 
skilled occupations that include temporary foreign labour. The relation between the independent variables (age, immigration status, etc.) and the dependent variable (wages) are expressed through the B coefficients (see column B: 'Outcomes'). Given that wages are LOG-ed, the B coefficient is a reliable approximation of a percent variation of the independent variable with respect to the dependent variable in each model. For example, in this model, the category 'Female' of the variable 'Sex' has a B of -0.142 . This represents a decrease (negative sign) of about $14.2 \%$ in wages compared to males. Following, the analysis draws on this table to present the outcomes of model one, which ratify the fact that lack of citizenship penalizes NPRs significantly. The outcomes are introduced with an underlined statement that provides information on relevant outcomes. These outcomes will be used together with outcomes of chapter five, six and seven in the next chapter that compares the findings of this dissertation against the literature.

This model makes it possible to examine all 98 low-skilled occupations as a whole and to make comparisons among them. Each occupation may correspond to a different economic sector and each is likely to have completely different labour conditions. Some may be more seasonal, others more physically demanding, etc. A comparison among occupations is relevant since all low-skilled occupations are regulated under the same policy structure. It also unveils patterns within economic sectors or industries vis-a-vis wages, which allows an indirect cross-industry comparison. By retrieving information on the effects of sex, age, immigration status, etc. on low-skilled workers it becomes possible to measure the general state of low-skilled labour in Canada.

8.2.1. Immigration status. Immigration status presents what is perhaps the most 
striking outcome of all the characteristics that may influence hourly wages. According to Table 12, the "Immigration Status - Non-Permanent Resident" category has a B of 0.188. This means that, compared to Canadian-born workers, Non-Permanent Residents earn $18.8 \%$ less. Stated otherwise, lacking citizenship has a large negative effect ( $18.8 \%$ less wage).

The regression model corroborates what is presented in the descriptive analysis in the previous chapters. In comparison with low-skilled Canadian-born workers, lowskilled Immigrants earn just under $6 \%$ less $(B=-0.059)$, which is not very distant from the wages earned by those born in Canada. In view of this, relatively small, wage gap, the wage discrepancy between those with citizenship and those without it is striking. To reiterate: low-skilled workers without citizenship earn almost 19\% less than their Canadian born counterparts. This indicates that access to citizenship indeed increases the possibility of earning higher wages. Seniority may also have an influence on wages. However, the census did not allow evaluating seniority among the NPR population (the main population in this study) because such information is not collected. ${ }^{91}$ In general, non-citizenship has a significant negative impact on the wages of NPRs. This was also corroborated across the entire descriptive analysis in chapters five and six and will become even more evident (focalized) when analyzing specific occupations. These findings are very important, since it is often argued that non-citizenship is not related to the level of wages of temporary residents, especially of temporary foreign workers. It has been posited that "employers pay the temporary foreign workers the prevailing wage rate for jobs of that type in the particular region" (Fudge \& MacPhail, 2009). However, "how the prevailing wage rate is set [was] both controversial and opaque"

${ }^{91}$ Some seasonal TFWs come year after year. 
(Fudge \& MacPhail, 2009).

While the data from this research is from 2006, when the number of TFWs was not as significant as it is now, it nevertheless corroborates what more recent research suggests. In Saskatchewan, for example, the highest growth of low-skilled TFWs has taken place in industries with the lowest paying jobs: "Between 2005 and 2012, food counter attendants, kitchen helpers and related occupations registered as the top occupational group by number of foreign workers in Saskatchewan in three of the eight years...Indeed, the top TFW occupations have shifted from high skilled health care practitioners to food service workers, giving substance to the claim that the Program is being used to feed industries that are hungry for low-wage (and largely non-unionized) labour" (Stevens, 2014, p.9).

8.2.2. Age. According to the regression analysis, age has a negligible impact on low-skilled workers in Canada. Each additional year of work represents less than 1\% additional wage.$^{92}$ This is not surprising since most workers considered in this research (71\%) are between the ages of 25 and 54 . Theoretically, age has an effect on labour market outcomes insofar as it is associated with the capacity to increase productivity. Research that draws from several data sources finds that although experience is, by and large, rewarded, job performance generally begins to decrease at about 50 years of age; this is particularly evident in jobs that require problem-solving, quick-thinking and adaptation-to-new-knowledge skills. In jobs where experience and verbal skills are relevant, aging workers are expected to maintain high productivity (Skirbekk, 2004).

While some low-skilled jobs may reward experience, the regression model

${ }^{92}$ Although, as mentioned, seniority may also influence wages. 
indicates that, if measured via increments in age, the effect is marginal. While seniority may contribute to wage increases, other factors such as labour market fragility, instability and high job-rotation, which are all characteristics of low-skilled jobs, may impede an increase in seniority. Low-skilled jobs are, by definition, jobs that require either high school or occupation specific training (jobs in skill level C) or on the job training (jobs in skill level D). While age may have an effect at the moment of hiring, this effect does not seem to have any permanence. Further studies should look into the effect of job tenure on wages in low-skilled occupations. Other characteristics like sex and immigration status may have a more direct effect on wage.

8.2.3. Sex. With respect to wages, our findings show that taking all low-skilled workers across all occupations into account, female low-skilled workers earn lower wages than low-skilled male workers. According to the regression models, low-skilled females working in low-skilled occupations earn $14 \%$ less than males also working in low-skilled occupations. In Canada, women historically have earned lower salaries than men as reported in the literature (Baker \& Drolet 2010; Baker et al., 1995; Doiron \& Riddell 1994; Drolet 2002; Fortin \& Schirle 2006; Gunderson 1979, as cited in Morisette et al., 2013, p.12). Although the wage gap between men and women has been decreasing, it is nevertheless still present. In 1981, the male/female wage ratio was $74 \%$ (26\% gap). In 2006 (the year of the census referenced in this study), the ratio increased to about $85 \%$ (15\% gap). In 2011, the gap has decreased to $13 \%$ (Morissette et al., 2013). According to Stats Canada, women tend to work more in part-time jobs compared to men and generally tend to work fewer hours than males (Ferraro, 2010), 
which reduces their income.

Though evident across the labour force, the impact of the wage gap between males and females is particularly felt in low-skilled occupations, where a $14 \%$ increase in wages could stand to improve the actual wellbeing of an entire family.

8.2.4. Province of Residence. According to Table 12, larger wages correspond with larger economies: in comparison with Quebec (province of reference) ${ }^{93}$, working in Ontario or British Columbia has a positive effect on the wages of low-skilled workers (low-skilled workers in these provinces earn higher wages than in Quebec). In contrast, working in one of the smaller provinces has a negative effect (low-skilled workers in these provinces earn lower wages than in Quebec). While workers in Ontario and British Columbia earn $5.4 \%$ and $5.9 \%$ more, respectively, than workers in Quebec, workers in Atlantic Canada and in the Prairie provinces earn $13.4 \%$ and $4.6 \%$ less, respectively, than workers in Quebec. It is important to remember that the data used in this analysis still does not reflect the significant increase in low-skilled TFWs these provinces have had (especially Alberta and Saskatchewan), since this increase took place after 2006. More recent data would perhaps present a different picture of low-skilled labour in these provinces. Low-skilled workers employed in the territories exhibit the highest wage difference (18.0\% more than in Quebec), which is in keeping with the fact that wages generally tend to be higher in the territories because of the scarcity of labour supply.

8.2.5. Rural- Urban Location. According to the model, working in rural areas

\footnotetext{
${ }^{93}$ To identify provincial comparison among NPRs, a given province must be selected as the point of comparison. In this process, Quebec was selected as the base comparator.
} 
represents $4.2 \%$ less wage than working in urban areas. This decrease in wages confirms the wage-difference that in many cases serves as a motivator for rural to urban migration (Brueckner \& Lall, 2015) ${ }^{94}$. Even though the wage discrepancy is not very significant, a more focused analysis at the occupation level may provide clearer outcomes of rural-urban wage differences. Studying rural-urban differences may yield better results if nuanced for certain occupations, since most occupations are in urban areas. Effective rural-urban comparisons may take place in occupations located in both rural and urban settings.

8.2.6. Level of Education. Having a postsecondary degree has a positive effect on the wages of low-skilled workers. Compared to those with a high school degree or less, having a college degree or a trades certificate represents a $5.8 \%$ increase in wage and having a university degree represents an increase of $7.2 \%$ (see Table 12). Descriptive data on education level shows that the total low-skilled population with University degrees working in low-skilled occupations tends to have higher average wages than all low-skilled workers with college degrees or trade certificate $(\$ 17.74 /$ hour and $\$ 17.54 /$ hour, respectively). Their wage is also higher than that of those with high school education or less ( $\$ 16.32 /$ hour). However, when the focus is narrowed down to each of the three populations (CB, IMM and NPR) the differences vary. On average, Canadian-born employees with university degrees working in low-skilled occupations earn about $9 \%$ more than those with a college degree or trades certificate working in low-skilled occupations. When compared with Canadian-born workers with high school

\footnotetext{
${ }^{94}$ A study of wage differences among large, middle and small size settlement in British Columbia using 1996 census data showed that income and labour force participation tended to be higher outside the Vancouver metropolitan area (Bauder, 2003a).
} 
level education or less, Canadian-born with university degrees working in low-skilled occupations earn about $15 \%$ more. For the immigrant population, these differences switch to $-6 \%$ ( $6 \%$ less wage) and $4 \%$. Among NPRs, those with university degrees earn an average of $1 \%$ less than NPRs with trade certificates and $11 \%$ less than NPRs with high school or less. Given that the Canadian-born and immigrant populations are significantly larger, the general effect seen in the regression analysis follows the patterns found among the Canadian-born and immigrant populations.

While these results are relevant and provide important general information, these differences also need to be nuanced at the occupation level, which, to a certain extent, is taken up in the descriptive analysis. The regression analysis of certain specific occupations also sheds some light on this.

8.2.7. First Official Language Spoken. Not speaking either official language has a negative effect on wage. Not speaking either English or French represents a $\underline{12.2 \%}$ decrease in wage compared to those who report speaking either official language. This outcome would also need to be nuanced by the type of occupation. Some occupations, even if they are low-skilled, require speaking either English or French and most respondents to the census speak either official language. All Canadian-born citizens (100\%), 92\% of immigrants (including permanent residents) and $88 \%$ of Non-Permanent Residents reported speaking either official language. Besides, most low-skilled workers are either Canadian-born or immigrants (more than 99\%) and less than $1 \%$ are Non-Permanent Residents. As a result, the wage difference between those who speak and those who do not speak either official language may not be 
directly related to speaking the language. Rather, the difference is most likely linked to the temporariness of NPRs' legal status. Differences may also be nuanced by other factors, including seniority. Older immigrants working in low-skilled occupations tend to speak non-official languages at work (Thomas, 2009).

8.2.8. Place of Birth (Region of the World) ${ }^{95}$. The impact that place of birth has on low-skilled workers' wages is positive if the workers are born in West, North, Central or Southern Europe. If the workers are born anywhere else in the world (with statistically significant outcomes), the effect is negative. According to the regression analysis, the wage model shows that, except for those born in Region 9 [South Africa, Swaziland, Namibia and Oceania] and Region 13 [Far East Asia (Cambodia, Vietnam, etc.)], all foreign-born individuals exhibit statistically significant differences compared to those born in North America (Canada, United States, Greenland and St. Pierre et Miquelon). These results will be analyzed in the next chapter.

Low-skilled workers born in Latin-America (immigrants and NPRs) earn an average of $3.5 \%$ less than those born in North America. The difference increases if the group compared against low-skilled North-Americans are those born in Arab countries. Low-skilled workers born in North Africa and Arab countries earn $9.9 \%$ less and those born in India earn $15.6 \%$ less than low-skilled workers born in North America. These results resonate with the fact that India is the first source country of low-skilled immigrants and the third source country of low-skilled NPRs (see Table 7 in chapter five).

\footnotetext{
${ }^{95}$ For the exact list of country codes included in each group, see appendix three: Variable Place of Birth Country.
} 
At the other end of the spectrum, low-skilled workers from Europe report earnings higher than those born in North America. Low-skilled workers from region 5 (West, North and Central Europe) earn 1.3\% higher wages than low-skilled workers born in North America. Workers born in region 7 (South Europe including Spain, Portugal and Italy) earn 8.3\% higher wages than low-skilled workers born in NorthAmerica. These results complement what was found in the cross-tabulation analysis for country of birth (see chapter five). Additionally, the number of cases by country of origin tends to be higher among immigrants than among NPRs, so the weight is higher among those with access to citizenship than those without it.

8.2.9. Occupations. This section presents the outcomes for all low-skilled workers (NPR, CB and IMM together) working in all 98 occupations included in this analysis. The outcomes for all low-skilled occupations examined in this section, are found in appendix 14B. Among the 98 low-skilled occupations considered in this analysis (including one of reference), ${ }^{96} 36$ have a wage below the average for all lowskilled occupations (of which 34 are statistically significant). In contrast, 62 have a wage above the average (of which 57 are statistically significant).

Low-skilled workers in occupation 7413 - Taxi and limousine drivers and chauffeurs had the lowest wage difference compared to workers earning the average wage of all low-skilled workers. These workers earn $49.9 \%$ less than workers in occupation 6663 Janitors, caretakers and building superintendents (or than the average

\footnotetext{
${ }^{96}$ Occupation 6663-Janitors, caretakers and building superintendents was chosen as the control occupation. This occupation has the closest average hourly wage to the mean for all occupations. Contrary to the cross-tabulation analysis, the regression analysis allows including all $\mathbf{9 8}$ occupations originally chosen.
} 
for all low-skilled occupations). They are followed by 6474 Babysitters, nannies and parents' helpers, whose wage is $41.6 \%$ lower than the average for all low-skilled occupations. Other occupations worth mentioning are: 6621 Service station attendants (31.1\% less wage); 6452 Bartenders (26.6\% less wage); 8431 General farm workers (25.1\% less wage); 6641 Food counter attendants, kitchen helpers and related occupations (23.4\% less wage) and 8611 Harvesting labourers (22.9\% less wage). Some of these occupations also appeared in the descriptive analysis (chapters five, six and seven) among the ones with the highest wage differences between Non-Permanent Residents and Canadian-born workers. Most of these occupations tend to be physically demanding (agricultural-related), seasonal (agricultural-related), or less stable and more prone to abuse and exploitation (Babysitters, Nannies and Parents' Helpers and agriculture-related occupations).

Of the 62 occupations that have average wages above the average for all lowskilled occupations, 28 have wages $20 \%$ higher than the average for all low-skilled occupations. Low-skilled workers in occupation 6464 Occupations Unique to the Armed Forces had the highest positive wage difference (52.1\%) compared to workers earning the average wage for all low-skilled workers. They are followed by 9482 Motor vehicle assemblers, inspectors and testers (39.1\% higher than the average wage), and by 1432 Payroll clerks (39.6\% higher). Other occupations worth mentioning are 9424 Water and waste plant operators (38.3\% higher); 1434 Banking, insurance and other financial clerks (34.8\% higher) and 6434 Ticket agents, cargo service representatives and related clerks (except airline) (32.7\% higher). It is also worth noting that occupations in this group (above the average) tend to be part of industries with secure labour 
conditions (ex. the armed forces) or in unionized environments (ex. motor vehicle assemblers) or less physically demanding and more in office-related environments (ex. payroll clerks). All these outcomes call for a more focalized analysis, an analysis at the occupation level.

\subsection{Outcomes Regression Models Type Two (Selected Occupations)}

Each model tests whether controlling for age, sex, immigration status and province of residence, or work location (rural/urban), or level of education, or ability to speak English or French or place of birth, being a Non-Permanent Resident has a significant negative impact on wage compared to being Canadian-born. This section introduces the outcomes of the occupation-specific regression analysis. For details on why type two models were built see section 8.1.

A total of 10 models were built for nine occupations, one per occupation. This is the case in all occupations except 302 - 6474 Babysitters, nannies and parents' helpers, for which two models were built, one for the whole population in that occupation and one for females only. The occupations were chosen according to their relevance to NPRs, either because they have been amply studied (Babysitters and Nannies, General Farm Workers or Greenhouse Workers); or because they appear to have a significant number of TFWs (Babysitters and Nannies, General Farm Workers or Greenhouse Workers; Food counter attendants, kitchen helpers and related occupations); or, because they have a significant number of low-skilled workers in general (with and without citizenship) (Retail); or because, according to national projections, they are projected to be in short supply (Truck Drivers, Light Duty Cleaners); or because they 
have a pathway to citizenship (Babysitters and Nannies, Truck Drivers in Alberta and $\mathrm{BC}$, Industrial butchers and meat cutters in Manitoba). The variable "Regions of the World" is included in only one occupation (Retail) because it has a sample size that allows this variable to be included in the model.

\begin{tabular}{|c|c|c|c|c|c|}
\hline \multicolumn{6}{|c|}{ Table 13: Regression Models Occupations - Group 1} \\
\hline \multicolumn{6}{|c|}{$\begin{array}{l}\text { 1. } 6474 \text { Babysitters, nannies and parents' helpers (Females ONLY models) } \\
\text { 2. } 6474 \text { Babysitters, nannies and parents' helpers ((Males and Females models) } \\
\text { 3. } 6471 \text { Visiting homemakers, housekeepers and related occupations } \\
\text { 4. } 8431 \text { General farm workers } \\
\text { 5. } 8432 \text { Nursery and greenhouse workers }\end{array}$} \\
\hline \multicolumn{6}{|c|}{ Dependent Variable: LOG Hourly Wages ** $0>p>0.05 ;{ }^{*} 0.05>p>0.15$} \\
\hline & \begin{tabular}{|l|}
6474 \\
Babysitter \\
s, nannies \\
and \\
parents' \\
helpers \\
(Males and \\
Females)
\end{tabular} & \begin{tabular}{|l|}
6474 \\
Babysitters, \\
nannies and \\
parents' \\
helpers \\
(Females \\
only)
\end{tabular} & \begin{tabular}{|l|}
6471 \\
Visiting \\
homemaker \\
s, \\
housekeepe \\
rs and \\
related \\
occupations
\end{tabular} & $\begin{array}{l}8431 \\
\text { General farm } \\
\text { workers }\end{array}$ & $\begin{array}{l}8432 \\
\text { Nursery } \\
\text { and } \\
\text { greenhous } \\
\text { e workers }\end{array}$ \\
\hline Independent Variables & B & B & B & B & B \\
\hline (Constant) & $1.92^{* *}$ & $1.91^{* \star}$ & $2.42^{* *}$ & $2.54^{\star \star}$ & $2.46^{\star *}$ \\
\hline Mean-centered Age & 0.00 & 0.00 & $0.04^{* *}$ & $0.01^{* *}$ & $0.00^{\star *}$ \\
\hline SEX = Female & -.01 & & $-0.07^{* *}$ & $-0.14^{\star *}$ & $-0.19^{* *}$ \\
\hline $\begin{array}{l}\text { Immigration Status Recoded (Immigrant and Permanent } \\
\text { Resident) older than } 10 \text { years of age at arrival }\end{array}$ & $0.14^{* *}$ & $0.15^{\star \star}$ & -0.01 & $-0.07^{* \star}$ & $0.07^{\star}$ \\
\hline $\begin{array}{l}\text { Immigration Status - Non-Permanent Resident (TFW and } \\
\text { Refugee Claimant) }\end{array}$ & $-0.08^{* *}$ & $-0.08^{\star *}$ & $-0.45^{* *}$ & $-0.10^{* *}$ & $-0.14^{* *}$ \\
\hline Rural/Urban Location (Rural Location) & $-0.13^{* *}$ & $-0.14^{\star *}$ & & $-0.21^{* *}$ & $-0.08^{* *}$ \\
\hline Province or Territory of Residence (Atlantic Provinces) & -0.04 & -0.02 & $-0.28^{* \star}$ & -0.04 & -0.05 \\
\hline Province or Territory of Residence (Ontario) & 0.04 & 0.05 & $0.04^{*}$ & $-0.05^{*}$ & $-0.11^{* \star}$ \\
\hline $\begin{array}{l}\text { Province or Territory of Residence (Manitoba, Saskatchewan } \\
\text { and Alberta) }\end{array}$ & 0.00 & 0.02 & $-0.09^{* *}$ & $-0.17^{* *}$ & $-0.14^{* *}$ \\
\hline Province or Territory of Residence (British Columbia) & $0.10^{\star *}$ & $0.11^{\star *}$ & $0.09^{* \star}$ & -0.03 & -0.06 \\
\hline Province or Territory of Residence (Territories) & 0.03 & 0.11 & $0.36^{* *}$ & 0.29 & 0.10 \\
\hline Level of Education - College or Trade Certificate & $0.06^{* *}$ & 0.05 & $0.13^{* *}$ & & $0.14^{* *}$ \\
\hline $\begin{array}{l}\text { Level of Education - University (Bachelor's degree and } \\
\text { Above) }\end{array}$ & $0.11^{\star *}$ & $0.11^{* \star}$ & $0.20^{* *}$ & & 0.04 \\
\hline $\begin{array}{l}\text { First Official Language Spoken (Not speaking either official } \\
\text { language). }\end{array}$ & & & $-0.41^{* *}$ & & \\
\hline
\end{tabular}

Table 13: Regression Models Occupations - Group 1 


\begin{tabular}{|c|c|c|c|c|c|}
\hline \multicolumn{6}{|c|}{ Table 14: Regression Models Occupations - Group 2} \\
\hline \multicolumn{6}{|c|}{$\begin{array}{l}\text { 1. } 7411 \text { - Truck drivers } \\
\text { 2. } 6641 \text { Food counter attendants, kitchen helpers and related occupation } \\
\text { 3. } 6661 \text { Light duty cleaner } \\
\text { 4. } 6421 \text { Retail salespersons and sales clerks } \\
\text { 5. } 9462 \text { Industrial butchers and meat cutters, poultry preparers and related workers }\end{array}$} \\
\hline \multicolumn{6}{|c|}{ Dependent Variable: LOG Hourly Wages ${ }^{* *} 0>p>0.05 ;{ }^{*} 0.05>p>0.15$} \\
\hline & $\begin{array}{l}7411 \text { - Truck } \\
\text { drivers }\end{array}$ & \begin{tabular}{l|}
6641 Food \\
counter \\
attendants, \\
kitchen \\
helpers and \\
related \\
occupations
\end{tabular} & $\begin{array}{l}6661 \text { Light } \\
\text { duty cleaners }\end{array}$ & \begin{tabular}{|l|}
6421 Retail \\
salespersons \\
and sales \\
clerks
\end{tabular} & $\begin{array}{l}9462 \text { Industrial } \\
\text { butchers and } \\
\text { meat cutters, } \\
\text { poultry } \\
\text { preparers and } \\
\text { related } \\
\text { workers }\end{array}$ \\
\hline Independent Variables & $B$ & $B$ & $B$ & $B$ & $B$ \\
\hline (Constant) & $2.73^{* *}$ & $2.32^{* *}$ & $2.52^{\star *}$ & $2.60^{* *}$ & $2.67^{* \star}$ \\
\hline Mean-centered Age & $0.01^{* *}$ & $0.01^{* *}$ & $0.01^{* *}$ & $0.01^{* *}$ & $0.01^{* \star}$ \\
\hline SEX = Female & $-0.21^{* *}$ & $-0.07^{* *}$ & $-0.16^{* *}$ & $-0.22^{\star \star}$ & $-0.13^{\star *}$ \\
\hline $\begin{array}{l}\text { Immigration Status Recoded (Immigrant and Permanent } \\
\text { Resident) older than } 10 \text { years of age at arrival }\end{array}$ & $-0.26^{\star \star}$ & $-0.04^{* *}$ & -0.01 & $-0.08^{* \star}$ & $0.03^{*}$ \\
\hline $\begin{array}{l}\text { Immigration Status - Non-Permanent Resident (TFW and } \\
\text { Refugee Claimant) }\end{array}$ & $-0.38^{* *}$ & $-0.23^{* *}$ & $-0.15^{\star *}$ & $-0.19^{\star *}$ & -0.05 \\
\hline Rural/Urban Location (Rural Location) & $-0.05^{* *}$ & 0.00 & & $-0.05^{\star *}$ & \\
\hline Province or Territory of Residence (Atlantic Provinces) & $-0.10^{\star *}$ & $-0.09^{\star \star}$ & $-0.16^{* \star}$ & $-0.09^{\star *}$ & -0.01 \\
\hline Province or Territory of Residence (Ontario) & $0.07^{\star \star}$ & -0.01 & -0.01 & $0.08^{\star \star}$ & $0.08^{\star \star}$ \\
\hline $\begin{array}{l}\text { Province or Territory of Residence (Manitoba, Saskatchewan } \\
\text { and Alberta) }\end{array}$ & $-0.03^{* *}$ & -0.20 & $-0.11^{* *}$ & $0.04^{\star *}$ & -0.04 \\
\hline Province or Territory of Residence (British Columbia) & $0.08^{* *}$ & $0.04^{* *}$ & $0.06^{* *}$ & $0.10^{* *}$ & 0.04 \\
\hline Province or Territory of Residence (Territories) & $0.24^{* *}$ & $0.24^{* *}$ & 0.09 & $0.15^{\star *}$ & -0.24 \\
\hline Level of Education - College or Trade Certificate & $-0.03^{\star \star}$ & $0.13^{\star *}$ & $0.08^{\star *}$ & $0.07^{* *}$ & \\
\hline $\begin{array}{l}\text { Level of Education - University (Bachelor's degree and } \\
\text { Above) }\end{array}$ & $-0.04^{\star \star}$ & $0.10^{\star *}$ & $0.07^{\star \star}$ & $0.12^{* *}$ & \\
\hline R.W.- Central America, South America and the Caribbean & & & & -0.03 & \\
\hline R.W.- West, North and Central Europe (rich Europe) & & & & 0.03 & \\
\hline $\begin{array}{l}\text { R.W.- Eastern Europe and USSR (all ex-Soviet Union } \\
\text { countries and Eastern Europe) }\end{array}$ & & & & $-0.07^{\star *}$ & \\
\hline R.W.- South Europe - (Spain, Portugal, etc.) & & & & $0.06^{* *}$ & \\
\hline $\begin{array}{l}\text { R.W.- Sub Saharan Africa (except South Africa, Namibia and } \\
\text { Swaziland) }\end{array}$ & & & & $-0.14^{\star *}$ & \\
\hline R.W.- South Africa, Swaziland, Namibia and Oceania & & & & 0.04 & \\
\hline $\begin{array}{l}\text { R.W.- Arab countries (North Africa and Arab countries } \\
\text { including Turkey and Cyprus) }\end{array}$ & & & & $-0.06^{* *}$ & \\
\hline R.W.- India & & & & $-0.25^{\star \star}$ & \\
\hline R.W.- Far East Asia 1 (Japan, South Korea, etc.) & & & & $-0.11^{* \star}$ & \\
\hline R.W.- Far East Asia 2 (Cambodia, Vietnam, etc.) & & & & -0.03 & \\
\hline $\begin{array}{l}\text { R.W.- East Asia excluding India (Pakistan, Sri Lanka, } \\
\text { Afghanistan, Nepal, etc.) }\end{array}$ & & & & $-0.21^{* *}$ & \\
\hline R.W.- China & & & & $-0.09^{* *}$ & \\
\hline $\begin{array}{l}\text { First Official Language Spoken (Not speaking either official } \\
\text { language). }\end{array}$ & $-0.09^{*}$ & $-0.23^{* *}$ & $-0.19^{* *}$ & $-0.28^{* *}$ & $-0.13^{* *}$ \\
\hline
\end{tabular}

Table 14: Regression Models Occupations - Group 2 
Tables 13 and 14 present the outcomes of the occupation level models (five models in each table). These outcomes are relevant because they provide more nuanced information on the effect of lack of citizenship (as part of a set of intrinsic characteristics) on wages in each specific occupation. After, the information in those tables is used to describe the effects each variable has on wages. Trends that repeat across all models (extracted from the variables with statistically significant outcomes) include:

\subsubsection{Effect of lack of citizenship on wages. Lacking citizenship has a} negative effect on wage. This is evident in eight of the nine occupations analyzed in this section. Lacking citizenship among workers in occupation 6471-Visiting homemakers, housekeepers and related occupations represents earning $45 \%$ less. This is the occupation with the largest negative effect, followed by 7411 -Truck drivers (38\% less), 6641-Food counter attendants, kitchen helpers and related occupation (23\% less), 6421-Retail salespersons and sales clerks (19\% less), 6661 Light duty cleaner (15\% less) and 8432-Nursery and greenhouse workers (14\% less). In occupation 9462Industrial Butchers and Meat Cutters, Poultry Preparers and Related Workers a lack of citizenship had no statistically significant effect on wage.

8.3.2 Females' wages versus males' wages. Females have lower wages than males in all nine occupations. This confirms what is amply reported in the literature and will be explored in more detail in the following chapter. However, the model for Babysitters, nannies and parents' helpers that includes both males and females does not account for the fact that female NPRs receive additional compensation (room and 
board). This is relevant in this model because NPR babysitters and nannies have significant weight in the total of low-skilled workers for this occupation (they represent more than one third of all babysitters and nannies in Canada). Nonetheless, this does not affect the analysis for other occupations or the male-female analysis in model type one because babysitters and nannies in the context of the whole group of low-skilled workers in all immigration categories is minimal. Accounting for all three categories (CB, IMM and NPR) babysitters and nannies represent only $0.6 \%$ of all low-skilled workers.

8.3.3 Provincial comparison. Compared to working in Quebec $^{97}$, working in Ontario and British Columbia represents a positive effect on wages for the occupations with statistically significant outcomes. The exception to this is in agriculture occupations in Ontario. 8431-General farm workers and 8432-Nursery and greenhouse workers has a negative effect on wages.

8.3.4. Working in rural areas versus urban areas. Working in a rural location has a negative effect on wages compared to working in an urban location in all six occupations with statistically significant outcomes. This is especially apparent among 8431-General farm workers (21\% less) and 6474-Babysitters and Nannies - Females only (15\% less).

8.3.5. Level of education and wages. Except for Truck Drivers, having a post$\underline{\text { secondary degree (either a college degree/trades certificate or a University degree) has }}$

\footnotetext{
${ }^{97}$ To identify provincial comparison among NPRs, models type two also required a given province to be selected as the point of comparison. In this process, Quebec was also sleeted as the base comparator.
} 
a positive effect on wage. The effect of education probably contains other effects not accounted for in the regression model. For example, it is likely that other attributes such as experience or availability are preferred over education and, by extension, may receive a slightly higher reward. Further research (i.e. other models) that account for other effects not considered in this analysis should be developed.

\subsubsection{Effect of speaking either English or French on wages. Not speaking} either English or French has a negative effect on wages. This is especially apparent among workers in occupation 6471-Visiting homemakers, housekeepers and related occupations (41\% lower wage) and 6641-Food counter attendants, kitchen helpers and related occupations (23\% lower wage). India and the Philippines make about $25 \%$ of all the foreign-born population in this occupation (6641). In addition to those born in the Philippines, it is likely that a significant number of Canadian-born workers in this occupation consider themselves of Filipino ethnic origin. Thus, higher wages are likely to be linked to the fact that they not only speak English, but also have a strong presence in Canada.

8.3.7. Effect of place of birth on wages. The place of birth affects wages either positively or negatively. Only occupation 6421-Retail salespersons and sales clerks allowed this variable ("Regions of the World") to be included. This occupation contains the highest number of workers of all low-skilled occupations. About 260000 reported working in this occupation in the 2006 census. "Regions of the World" has statistically significant outcomes in nine of the 13 regions analyzed. Of these nine regions, only low- 
skilled workers born in one region (Southern Europe - Spain, Italy, Portugal, etc.), working in retail had higher wages than those also working in retail who were born in North America (6\%). Among retail workers, the remaining eight regions all had negative wage effects (i.e. lower wages than the wages of those born in North America). The three largest negative differences (compared with those born in North America) appears among those from South Saharan Africa (14\% less), East Asia, excluding India (Pakistan, Bangladesh, Nepal, etc.), (21\% less) and India (25\% less).

8.3.8. Effect of age on wages. Age has a marginal effect on wage (less than $1 \%$ variation) and is always positive. However, seniority may affect wages, but as explained, it was not possible to include this variable in the analysis.

\section{Summary}

Immigration status presents the most striking outcome of all the characteristics that influence hourly wages. Compared to low-skilled Canadian-born workers, lowskilled foreign-born individuals with citizenship (naturalized immigrants) or the possibility of acquiring it (permanent residents) earn $7 \%$ less, which is not very distant from the wages of the Canadian-born. In contrast, low-skilled workers without citizenship earn almost $20 \%$ less than those born in Canada. This means that for the most part having access to citizenship does indeed increase the possibility of earning better wages. According to the regression model, working in rural areas represents $4 \%$ lower wages than working in urban areas. The regression analysis corroborates what has been found in the cross-tabulation analysis: low-skilled NPRs earn significantly lower wages. 
When the focus is on specific occupations, the outcomes are even more striking. Compared to Canadian-born workers, a lack of citizenship negatively affects NPRs' wages in the following occupations: 6471-Visiting homemakers, housekeepers and related occupations (45\% less wage); 7411 - Truck drivers (38\% less wage); 6641 Food counter attendants, kitchen helpers and related occupations (23\% less wage); and, 8432 - Nursery and greenhouse workers (14\% less wage). Accounting for whether the work place is either in a rural or urban area has a significant impact on agricultural occupations. Agricultural workers in occupation 8431-General farm workers in a rural area earn $21 \%$ less than those in an urban area. In occupation 6474-Babysitters, nannies and parents' helpers, not speaking either official language represents a likelihood of earning $29.2 \%$ less than those who speak either one.

Given the large amount of detail presented in this chapter it may help to see schematically what its main finding are. They are presented in the following table (15), which identifies the hypothesis and findings explored in this chapter. For a summary of all hypotheses see Appendix 16.

Table 15: Summary of Hypotheses/Chapter Findings

\begin{tabular}{|c|c|}
\hline Hypotheses & Findings \\
\hline \multirow[t]{2}{*}{$\begin{array}{l}\text { 1. In the model for all occupations, controlling for } \\
\text { age, sex, immigration status, province of } \\
\text { residence, work location (rural/urban), level of } \\
\text { education, ability to speak English or French and } \\
\text { place of birth, being a NPR has a significant } \\
\text { negative impact on wages compared to being } \\
\text { Canadian-born. } \\
\text { 2. In each occupational level model, controlling for } \\
\text { age, sex, immigration status and province of } \\
\text { residence, work location (rural/urban), level of } \\
\text { education, ability to speak English or French and }\end{array}$} & $\begin{array}{l}\text { Being a NPR has a large negative effect (19\% less } \\
\text { wage). } \\
\text { Lacking citizenship (being a NPR) had a significant } \\
\text { negative effect on wage in eight out of the nine } \\
\text { occupations with individual models. Only in } \\
\text { occupation } 9462-\text { Industrial Butchers and Meat } \\
\text { Cutters, Poultry Preparers and Related Workers, did } \\
\text { being a NPR have no statistically significant effect } \\
\text { on wages. }\end{array}$ \\
\hline & $\begin{array}{l}\text { Age has a negligible positive effect for low-skilled } \\
\text { workers in Canada. }\end{array}$ \\
\hline
\end{tabular}




\begin{tabular}{|c|c|}
\hline \multirow[t]{6}{*}{$\begin{array}{l}\text { place of birth, being a NPR has a significant } \\
\text { negative impact on wages compared to being } \\
\text { Canadian-born. }\end{array}$} & $\begin{array}{l}\text { Low-skilled female workers earn lower wages than } \\
\text { low-skilled male workers. According to the } \\
\text { regression models, low-skilled females working in } \\
\text { low-skilled occupations earn } 14 \% \text { less wage than } \\
\text { males. }\end{array}$ \\
\hline & $\begin{array}{l}\text { 4.1. Province of Residence: among low-skilled } \\
\text { workers, working in provinces with the largest } \\
\text { economies has a positive effect on wages compared } \\
\text { to working in Quebec. In contrast, working in smaller } \\
\text { provinces has a negative effect compared to working } \\
\text { in Quebec. } \\
\text { While workers in Ontario and British Columbia earn } \\
5.4 \% \text { and } 5.9 \% \text { more than in Quebec, workers in } \\
\text { Atlantic Canada and the Prairie provinces earn } \\
13.4 \% \text { and } 4.6 \% \text { less than in Quebec. } \\
4.2 \text {. Location of Work (Rural-Urban): According to } \\
\text { the model, working in rural areas represents } 4.2 \% \\
\text { less than working in urban areas. }\end{array}$ \\
\hline & $\begin{array}{l}\text { Having a postsecondary degree has a positive effect } \\
\text { on wages. Compared to those with a high school } \\
\text { degree or less, having a college degree or a trades } \\
\text { certificate represents } 5.8 \% \text { more in wages. For } \\
\text { those with university degrees the premium rises to } \\
7.2 \% \text { on hourly wages (see Table } 12 \text { ). }\end{array}$ \\
\hline & $\begin{array}{l}\text { Not speaking either official language has a negative } \\
\text { effect on wage. More specifically, not speaking either } \\
\text { English or French represents } 12.2 \% \text { less in wages } \\
\text { compared to those who report speaking either } \\
\text { official language. }\end{array}$ \\
\hline & $\begin{array}{l}\text { The effect of place of birth on wages among low- } \\
\text { skilled workers is positive if the workers are born in } \\
\text { West, North, Central or Southern Europe. If the } \\
\text { workers are born anywhere else in the world (with } \\
\text { statistically significant outcomes), the effect is } \\
\text { negative. }\end{array}$ \\
\hline & $\begin{array}{l}\text { Among the } 98 \text { low-skilled occupations considered in } \\
\text { this analysis (plus one for reference), } 36 \text { have a } \\
\text { wage below the average for all low-skilled } \\
\text { occupations ( } 34 \text { of which are statistically significant). } \\
\text { In contrast, } 62 \text { have a wage above the average ( } 57 \\
\text { of which are statistically significant). }\end{array}$ \\
\hline
\end{tabular}

Table 15: Summary of Hypotheses/Chapter Findings 


\section{Chapter Nine: Place of the Findings in the Literature}

In this chapter, I compare my outcomes against the outcomes found in the literature. I compare to the literature to see whether my findings contrast or align with the literature. As we will see, the findings of this dissertation align very close with the literature. The more general qualitative work found in the literature reinforces the innovative quantitative outcomes of this dissertation. This review of the literature serves to explore what is behind wage differences in relation to specific occupations (as defined in this dissertation $)^{98}$ and other characteristics that influence how much lowskilled workers earn. This chapter presents the outcomes (by each of the variables analyzed) of the previous quantitative chapters (chapters five, six, seven and eight) and explores their place in the literature on low-skilled labour in Canada.

I organized this chapter into eight sections. In the first seven sections, I compare and contrast the outcomes for each of the variables with the relevant literature. The chapter mainly focuses on occupations with an additional brief reference to the top two industry sectors identified in the analysis (Healthcare and Social Assistance and Agriculture, Forestry, Fishing and Hunting). The analysis focuses on those two industries because each contain the two types of occupations most relevant for NPRs identified in this dissertation, namely Babysitters Nannies and Parents' Helpers (mainly included in Healthcare and Social Assistance) and occupations in agriculture (mainly included in Agriculture, Forestry, Fishing and Hunting). Literature on low-skilled labour in

\footnotetext{
98 Recall that occupations in this dissertation follow the NOC 4 classification of occupations, which is the smallest unit of classification available for research in the NOC system of classification of occupations (see appendix 3C). NOC4 occupations group different types of jobs. Ideally it would have helped to have more granular information (i.e. information about actual jobs), but it is not available. The analysis of the outcomes in previous chapters is of jobs grouped in NOC4 occupations (see chapter four and appendix $3 \mathrm{C}$ for detailed explanations).
} 
other industry sectors is rather scarce.

Variables that are considered include: industry sectors; occupations (caregiving, agriculture and other selected low-skilled occupations); geography (province of residence and rural/urban work location); sex; first official language spoken; level of education; and place of birth (regions of the world). In the eighth section, I present the final considerations of the chapter. Each section contains an underlined statement that highlights the main trend/outcome in it. All outcomes and statistics in this chapter refer to chapter five (when referring to outcomes of the profile), six (when referring to absolute or relative wages ${ }^{99}$ by occupation or industry), seven (when referring to wage differences in relation to intrinsic characteristics of workers and their occupations) or eight (when referring to outcomes of the regression analysis).

\subsection{Industry Sectors and Occupations - General Overview \\ Healthcare and Social Assistance and Agriculture, Forestry, Fishing and Hunting exhibit the highest negative differences in the wages of low-skilled NPRs compared to their Canadian-born and immigrant counterparts.}

The literature on the labour market and workforce reinforces the association of these two industrial sectors with low-wage work. An important component of the Health Care and Social Assistance sector is what Cervena, (2009) calls the 'Service Class.' In her analysis, she describes this class as a group of "low paying service jobs" that are present across different industries in Canada. A significant number of women work in this class. In general, Health Care and Social Assistance contains an overrepresentation of females with significantly low wages (Cervenan, 2009; Ostry \&

\footnotetext{
${ }^{99}$ NPR wages compared to CB and IMM
} 
Spiegel, 2004). Cervena's research shows that across all industries (including those with a small number of women), service class jobs have the largest male to female wage gap (Cervena, 2009). Although most TFWs working in occupational group ${ }^{100}$ 6474-Babysitters and Nannies and Parents' Helpers are classified within the "Other services" category (which is not a sector per se), the highest proportion of TFWs in the Health Care and Social Assistance (45\%) are babysitters and nannies. Research suggests that low wages and precariousness in the healthcare sector are on the rise (Ostry \& Spiegel, 2004). After the rapid expansion of globalization in the 1970s, the service sector in first world countries have faced "high unemployment, increased skill requirements for most jobs, and a rise in non-traditional work arrangements" (Ostry \& Spiegel, 2004, p.368). Downsizing the healthcare sector in the 1990s in countries including Canada led to detriments in general working conditions (Ostry \& Spiegel, 2004).

The second sector identified for its high negative difference in the wages of lowskilled NPRs compared to their Canadian-born and immigrant counterparts is Agriculture, Forestry, Fishing and Hunting. These quantified wage discrepancies add further testimony to research that shows the incidence of low wages among low-skilled temporary foreign workers in the agro-business (Basok, 2000a; Preibisch, 2004; Sharma, 2001). According to Employment and Social Development Canada (ESDC), this sector contains the largest number of temporary foreign worker positions with (approved) labour market impact assessments (LMIAs) ${ }^{101}$ (ESDC, 2016f). Not only is it

\footnotetext{
${ }^{100}$ Note that the term "occupational group" and the word "occupation" are equally used

${ }^{101}$ For a definition of LMIA, see footnote 24 in chapter two. The statistic presented here corresponds with counts made after the policy changes of June 2014. After these changes, the LMO (Labour Market Opinion) was renamed Labour Market Impact Assessment (LMIA) and the program was divided into
} 
the industry sector with the largest number of TFWs, but the number continues to grow. Between 2009 and 2012 this sector exhibited a 9.5\% increase in the number of positive LMOs from 35967 in 2009 to 39414 in 2012 (ESDC, 2016f). While these sectors exhibit wage differences between Canadian-born workers and NPRs, it is important to note that such information is gathered from very diverse occupational groups. As a result, an industry sectors analysis provides only an approximate picture. To gain insight into wage differences between those with and without citizenship, it is therefore important to complement an industry sector analysis with an analysis focussed on occupational groups.

Although low-skilled NPRs earn lower wages than CB and IMM in almost all occupations, a lack of citizenship affects workers in different occupations differently. Caregiving and agricultural occupations stand out for their large wage differences between NPRs and CB and IMM. The specific occupations worth highlighting are: Caregiving:

1. 6474-Babysitters, nannies and parents' helpers;

2. 6471-Visiting homemakers, housekeepers and related occupations.

Agriculture:

3. 8431-General farm workers;

4. 8432-Nursery and greenhouse workers;

Other occupations stood out not for their wage differences but for the concentration of a significant number of NPRs around low wages. Occupations worth highlighting in

Temporary Foreign Worker Program (those needing LMIA) and International Mobility Program (those not needing LMIA). 
this category are:

5. 6641-Food counter attendants, kitchen helpers and related occupations;

6. 6453-Food and beverage servers.

Truck driving presented a special case because this occupation exhibited polarized outcomes in the quartile analysis but a positive wage difference overall. Slightly more than half of NPRs had wages above those of CB and IMM. The other half had very low wages. However, wage differences for the whole NPR population (compared to CB and IMM) were positive.

These results are in keeping with the evolution of temporary foreign labour policies in Canada presented in chapter three. Thus, three distinct groups of occupations have been identified for closer analysis because they have significant numbers of NPRs earning wages significantly lower than those of Canadian-born workers and immigrants. The groups are: occupations in caregiving, in agriculture and in other selected occupations including: 6453-Food and beverage servers; 7411-Truck Drivers; 6641Food counter attendants, kitchen helpers and related occupations; 6661-Light duty cleaners; 9482-Motor Vehicle Assemblers; 6661-Light duty cleaners; and 6421-Retail salespersons and sales clerks.

9.1.1. Caregiving occupations. The outcomes of this dissertation show that when room and board is not accounted for, NPRs in occupation 6474-Babysitters, Nannies and Parents' Helpers had the lowest wages and had significantly large wage differences in comparison with CB and IMM. When room and board is accounted for, differences with the CB and IMM decrease but remain negative (i.e. NPRs still earn less 
than CB and IMM). NPR 6474-Babysitters and Nannies and 6471-Visiting Homemakers and Housekeepers were among the top six occupations with negative wage differences for NPRs compared to CB and IMM when room and board is not accounted for (see Appendix 10B). Research shows that, of all temporary foreign workers in Canada, those categorized under "Babysitters, Nannies and Parents' Helpers" - approximately $57 \%$ of all workers in the early childhood education workforce (Beach \& Costigliola, 2005) - had the lowest average wage of all Non-Permanent Residents (Fudge, 2012) ${ }^{102}$. Accounting for room and board ( $\$ 2.07 /$ hour), ${ }^{103}$ wage increases from an average of $\$ 8.10 /$ hour to $\$ 10.17 /$ hour (with a private room). Wage differences reduce from $31 \%$ less (NPRs compared to the CB) and $29 \%$ less (NPRs compared to IMM) to $8 \%$ and $6 \%$ less respectively. Research shows that caregivers purportedly earn an average of $\$ 10.25 /$ hour, with a maximum reported wage of $\$ 11.05 /$ hour; many caregivers have themselves reported being paid between only $\$ 1000$ and $\$ 1300$ a month regardless of the number of hours worked, although they report working about 60 hours per week (Faraday, 2014). The monthly wages reported by Faraday will be equivalent to between $\$ 6.25 /$ hour to $\$ 8.13 /$ hour (with an average of 40 hours/week or 160 hours/month), or between $\$ 4.16 /$ hour to $\$ 5.41 /$ hour (with an average of 60 hours/week or 240 hours/month). These values echo the average wage for the lowest wage-range quartile for babysitters and nannies in this research ( $\$ 5.01 /$ hour - not including room and board), which gathers $39 \%$ of all NPR babysitters and nannies, (see Table 8 in chapter six).

Research also indicates that differences in wages among workers in domestic

\footnotetext{
${ }^{102}$ Fudge's information was also extracted from the 2006 Census.

${ }^{103}$ As seen in chapter six, $\$ 2.07=\$ 85.25$ per week $/ 41.17$ hours per week, where $\$ 85.25$ per week is the amount employers are allowed to deduct for room and board, and 41.17 hours per week is the average number of hours worked by babysitters and nannies in the 2006 census.
} 
labour can partially be explained when accounting for whether or not the work is carried out in a "live-in" workplace. In 2006 , close to $33 \%$ of NPRs, $7 \%$ of CB and $5 \%$ of established immigrants in domestic-related occupations were living in their workplace ${ }^{104}$ (Thomas, 2010), a situation of considerable vulnerability, in which workers are frequently victims of unpaid overtime (Bakan \& Stasiulis, 1997). Compounding the fact that live-in caregivers are the lowest registered earners (undocumented workers may earn even lower wages), is the fact that they often have significant expenses. Research from 1998 indicates that landing costs (including recruiting fees) could be as high as CDN $\$ 8300$ (Grandea \& Kerr, 1998). Just accounting for price indexation, those costs would be significantly higher now (35.3\% or $\$ 2929$ higher). ${ }^{105}$

In general, low wages among babysitters and nannies may be associated with a low value attached to domestic labour and child-rearing. Significant opportunity costs linked to child-rearing - calculated in terms of unearned income - create an incentive for parents not only to outsource child care, but also to find affordable child care (i.e. to pay less for child care than they can earn). Calculations for Australian women, for example, show that the total life earnings of women with secondary education are reduced by approximately 160000 dollars when they care for one child, and is reduced even more for additional children (Chapman, Dunlop, Gray \& Liu, 2001). In Canada, access to a vast global market of temporary and cheap labour is also driving forces behind the low wages associated with these occupations. In other words, temporary foreign workers enable the undervaluation of child-care. This pattern is not exclusive to caregivers, but is also found in agricultural occupations and all other temporary low-

\footnotetext{
${ }^{104}$ Other NPRs in non-domestic-related occupations, such as those working in agriculture, also live with their employers (Faraday, 2012a).

${ }^{105}$ Statistics Canada Consumer Price Index 1996-2015.
} 
skilled occupations.

9.1.2. Agricultural occupations. NPR Agricultural workers in occupations 8431 General farm workers, 8432-Nursery and greenhouse workers and 8611-Harvesting labourers had significantly large wage differences compared to CB and IMM. At the time of the 2006 census, in May 2006, SWAP workers were purportedly paid according to the "provincial statutory minimum wage, the rate determined annually by HRSDC to be the prevailing wage rate for the type of agricultural work being carried out by the worker in the province in which the work will be done; or, the rate being paid by the employer to his Canadian workers performing the same type of agricultural work" (Verma, 2002, p.11). Currently, according to Employment and Social Development Canada (ESDC), TFWs are paid at the "the prevailing wage rate [which] is identified as the median hourly wage (or annual salary as published on Job Bank) or higher for the particular occupation and work location" (ESDC, 2016g). In addition to having the same negative wage outcomes (as shown in previous chapters) generally associated with temporary labour, program fees and deductions specifically applied to agricultural workers further reduce agricultural workers' wages. For example, while employers pay a visa processing fee of $\$ 150$ upfront for each worker, this fee is later recovered via deductions from each worker's paycheck; Mexican workers get $5 \%$ of their income deducted to cover transportation fees; and workers contribute to the Canadian Pension Plan, Employment Insurance and all due taxes (Hennebry \& Preibisch, 2012). While some agricultural workers in Ontario "earn slightly above the Ontario minimum wage, a quarter of their salary is taken by income tax, C.P.P., E.I. and other costs associated 
with their transportation" (Brem, 2006; Faraday, 2012 as cited in Saez, 2013, p.35).

On top of earning low wages and having to pay taxes, program-related fees and general labour fees, the net income of some agricultural workers is further reduced by mandatory savings schemes. For example, before the practice was eliminated in mid2015 (Faraday, 2016), Caribbean workers often saw their paycheques reduced by $25 \%$ under the pretence of helping them save money for when they return. However, when they returned to their countries of origin, they were reimbursed only $19 \%$ and "the remaining six percent [was used to help] fund the government agents stationed in Canada" (Hennebry \& Preibisch, 2012, p.32). Not surprisingly, workers expressed their preference for having the freedom to save the money that they earn as they please (Hennebry \& Preibisch 2012).

A recent report from the Conference Board of Canada shows that labour demands in agriculture have doubled and are currently estimated at 59200 people, which is expected to double again in 2025 to 113800 (Conference Board of Canada, 2016). The report also indicates that these demands have resulted in the sector's heavy reliance on temporary foreign labour: currently 1 out of every 10 agricultural workers is a temporary foreign worker. Some of the factors contributing to labour shortages in the agricultural sector include an aging workforce, the rural location of farm work, and negative perceptions about agricultural work (Conference Board of Canada, 2016). Such labour shortages, in turn, demand of those who do work, to work longer hours. On average, workers in agriculture work longer (approximately 44.8 hours per week) than the average in all other sectors (approximately 35.9 hours) (Conference Board of Canada, 2016). These findings are significant because they demonstrate the ways in 
which longer hours in the agriculture sector can be attributed to labour shortages.

The report also addresses the wage gap that exists between the agricultural sector and other low-skilled occupations and the declining number of Canadian workers in this sector. Wages in agriculture are below the average wages provided in other sectors ( $\$ 684 /$ week compared to $\$ 923 /$ week). Although the gap has been closing over time "with agricultural wages rising from two thirds (about 66\%) of the average for all sectors in 2000 to 74 per cent in 2015" (Conference Board of Canada, 2016), the number of Canadian workers willing to work in this sector continues to decline.

One of the major disincentives to working in agriculture is the significant labour fluctuations in this sector (they are the highest of any major sector). That is, while hours of work in the agricultural business tend to be long, they are also seasonal (Conference Board of Canada, 2016). At the seasonal peak, employment is $30 \%$ above the seasonal low: "the sector's demand for labour is heavily influenced by the seasonal changes in Canada's climate, with agriculture employing more than 100000 additional people in the peak summer months compared with the winter low period" (Conference Board of Canada, 2016, p.8).

Highlighting how underpaid the agriculture sector is, the Conference Board of Canada compares it with construction, which is also a seasonal occupation, where average weekly wages are $\$ 1137 /$ week. If the agriculture sector were to provide the same wages as the construction sector, this would imply a $66 \%$ increase in wages, which is simply not feasible. Such an increase would make Canadian farms completely uncompetitive on the market, where prices are regulated by regional and global markets) (Conference Board of Canada, 2016). 
Due to the difficulty in securing Canadian workers, over the past 50 years, employers in the agricultural sector, especially in Ontario, have become accustomed to meeting labour demands with a foreign labour force. The long-term use of this practice has contributed to its normalization. In Canada, agriculture "has arisen as a low-wage labour market segment, where employers rely more upon Mexican workers than resident workers. This has suppressed wages, weakened health and safety protections and permitted the workforce to become marginalized both in the labour market and the communities in which they live" (Foster, 2012, p.40). Low prices of agriculture in the United States, enabled by the hiring of undocumented workers, may also drive in part this practice in Canada. The American Farm Bureau Federation estimates "that between half and three-quarters of farm labourers are unauthorized workers in the United States" (Conference Board of Canada, 2016, p.11) who may be paid even lower wages than TFWs in Canada.

9.1.3. Other selected low-skilled occupations. Workers in occupations $9482-$ Motor Vehicle Assemblers and 7411-Truck Drivers had the largest wage-discrepancies (the former negative and the latter positive). While literature pertaining to the wages of caregivers and agricultural workers is prolific, secondary sources on other low-skilled workers is relatively sparse. This section focuses on the general outcomes of two other occupations: 9482-Motor Vehicle Assemblers, because it was affected by changes in the economy at the time of the 2006 census, and 7411-Truck Drivers, because it displays a non-wage related scarcity of labour.

Statistics Canada reports that between 2001 and 2006, motor vehicle 
assemblers experienced significant job losses, the majority of which were in the middle to lower end of the pay range (Lin, 2008). As with other occupational groups, occupation 9482-Motor Vehicle Assemblers, Inspectors and Testers refers to a considerable number of various job titles. According to ESDC (2016h), this occupational group includes more than 190 job titles in the 2011 NOC classification. Of all workers in this occupational group (9482-Motor Vehicle Assemblers, Inspectors and Testers in 2006 about 55000 workers), less than $0.5 \%$ were NPRs. Although the number of foreign workers is small (about 275 reported in the census after the population selection for this research ${ }^{106}$ ) and the wage dispersion may be significant, the wage differences between NPRs and CB and IMM is nevertheless striking.

While NPRs exhibited lower wages than CB and IMM in a significant number of occupations, there were some occupations with the opposite outcome. At least four occupations exhibited positive differences (i.e. higher wages among the NPR population vis-à-vis the Canadian-born and immigrant populations), one of which is 7411-Truck Drivers $^{107}$. These positive differences may be an indication of tightness between supply and demand in the labour market. Other factors that may drive these differences include: regional differences in wages and wage dispersion caused by cases with very high wages. In the case of NOC 7411-Truck drivers, wage dispersion is a significant factor behind these differences. Truck drivers' wages in British Colombia, for example, range between $\$ 18 /$ hour and $\$ 39 /$ hour (ESDC, 2017). Accounting for this wide wage

\footnotetext{
${ }^{106}$ See chapter four.

107 Labour shortages in Alberta (north of Alberta) may be a possible explanation for this anomaly (high wages among the truck drivers in the fourth quartile). It may be likely that a few of those reporting high wages were recruited to supply labour needs in the north of Alberta, which, at the time of the 2006 Census was an area with high cost of living. If that is the case, they were able to command a premium wage, but it should not be forgotten that they found themselves in a great cost of living location. I attempted to explore this through my research; the data did not permit that level of analysis.
} 
dispersion, there are more than 61 types of jobs grouped together in this single occupation, each requiring different types of skills and expertise. These jobs range from "automobile carrier driver" to "fuel oil truck driver" and "log hauler."

A quartile analysis for truck drivers reveals that NPRs with wages in the second and third quartiles have average wages below those of Canadian-born (39\% lower) and immigrant (37\% lower) workers (see appendix 9). In contrast, NPRs in the fourth quartile earn an average of $15 \%$ more than CB and the number of NPRs in the fourth quartile is higher than the number of NPRs in the first, second, and third quartiles put together. This explains why wages in the fourth quartile inflate the average for the entire NPR population in this occupation, and make the differences positive. In this case, the wage dispersion caused by a wide diversity of jobs explains why the average differences are positive for the whole sample and negative for the central (second and third) quartiles.

In the trucking sector, an overall increase (of approximately $4.9 \%$ ) in wages during the years prior to the census, along with the revaluation of the Canadian currency and rising prices of crude oil, was a significant contributing factor to the overall increase in operating costs (Transport Canada, 2005). According to Transport Canada (2005), the wage increase between 2003 and 2005 was driven by driver shortages. This reported labour shortage may also help explain the relatively high wages among NPRs (compared to CB and IMM) documented by this research. That said, future longitudinal studies examining changes in these occupations in different census years will help shed light on whether this pattern repeats over time.

Note that occupations 6453-Food and beverage servers and 6641-Food counter 
attendants, kitchen helpers and related occupations are also noteworthy because they concentrate a significant number of workers around very low wages. These occupations are referred to in sections three (province of residence, for occupation 6453), five (first official language spoken), and seven (country of birth, for occupation 6641).

\subsection{Geography (Province of Residence and Rural/Urban Work Location)}

Ontario and Quebec are the provinces with the largest wage differences (NPRs wages compared to the $\mathrm{CB}$ and IMM), found primarily in agriculture and caregiving. These occupations also displayed significant differences in rural and urban contexts. The provincial analysis reinforces the trend of NPRs earning lower wages than their Canadian-born and immigrant counterparts. While Ontario had the largest net increase in TFWs during the last decades, Alberta had the most rapid increase. Between 1998 and 2008 , Ontario exhibited a $128 \%$ (or 37575 ) increase in the number of temporary foreign worker initial entries; British Columbia a 289\% (or 34 890) increase; and Alberta a 433\% (or 39890 ) increase (CIC, Facts and Figures, 2007 as cited in Fudge \& MacPhail, 2009).

In this dissertation the same criteria for examining wage differences was used for both the entire population and at the provincial level: that is, 1) the research only considered occupations with a sufficient number of NPRs to enable wage comparisons with $\mathrm{CB}$ and IMM; and, 2) only differences with statistically significant values were included. Based on this method, Ontario tended to have the greatest number of negative differences (i.e. the greatest number of NPRs exhibiting lower wages than CB and IMM). These negative differences are especially evident in occupations 6474- 
Babysitters, nannies and parents' helpers (34\% lower in Ontario; 26\% in Quebec; 25\% in Alberta; and 20\% in BC) and 8431-General Farm Workers (20\% lower in Ontario and $9 \%$ in Quebec). The proportion of workers in those occupations is significantly high in Ontario (compared to the other provinces). While Quebec employs $10 \%$ of all NPRs in in occupation 6474 Babysitters, Nannies and Parents' Helpers, Alberta 16\%, and British Columbia $21 \%$, Ontario employs $49 \%$ of all NPRs in that occupation. Concentration is even higher among workers in occupation 8431-General farm workers: whereas Quebec employs $12 \%$ of all NPRs in that occupation, Ontario employs $81 \%$.

As a result of their very distinct economies, provinces exhibit differences in wages and in employment and unemployment rates. Even regional analyses within provinces show differences in employment and unemployment trends. For example, the Ontario Chamber of Commerce's 2017 Economic Outlook presents 11 economic regions in Ontario with unemployment rates varying from $4.2 \%$ in the Stratford/Bruce Peninsula to $7.5 \%$ in Northwest Ontario (Ontario Chamber of Commerce, 2017). The wage for a specific occupation in rural Northern Ontario, for example, can vary significantly in comparison with the wage for the same occupation in Toronto, the urban capital of Ontario.

In contrast, differences related to immigration status have characteristics that replicate across provinces and territories. In this case, wage differences are linked not to an actual tightness between demand and supply but rather to actually lower wages among TFWs (Preibisch \& Binford, 2007) or other factors linked to exploitation, including unpaid wages and overtime hours (Fudge \& MacPhail, 2009). Officials in Alberta, for example, discovered an employment agency that did not pay wages to at 
least 132 workers between April and July of 2007 (Fudge \& MacPhail, 2009).

Inspections also revealed that $74 \%$ of Albertan employers with TFWs had not abided by employment standards, with one of the most frequent breaches being unpaid statutory holidays (Foster, 2012). Other research shows that about $43 \%$ of TFWs never received overtime payment (Walsh, 2014).

Tracing the changes in wages across occupations and industries brings some clarity to the dynamics between supply and demand in the labour market. If there was no access to foreign labour, wages in occupations under economic pressure would tend to increase. However, "the fact that the wages of most of the occupations under pressure in Alberta and British Columbia had not increased more than the wages in other occupations suggests that the low-skilled streams of the TFWP operate as a device to regulate the Canadian labour market by lowering wages and conditions of employment" (Fudge \& MacPhail, 2009, p.43). While the TFW program is supposed to supply labour needs in regions where there is scarcity, in reality it "distorts regional labour market patterns by suppressing inter-regional labour mobility from provinces of higher unemployment to areas of low unemployment" (Gross \& Schmitt 2010; Gross 2010, as cited in Foster, 2012 p.39).

Occupation 6453-Food and beverage servers exhibits a significant number of NPRs concentrated around a very low wage. British Columbia reported significant wage differences in this occupation. The 2002 report on the tourism sector in British Columbia shows this occupation has the highest number of employees of all occupations in this industry (CS/Resors Ltd., Bird \& Emery, 2002). Most of them were female (78\%) and most of them had high school education or below (43\%) (Bird and Emery, 2002). This 
occupation exhibited the second lowest income, $\$ 9$ 753/year (after 6641-Food counter attendants, kitchen helpers and related occupations, who had the lowest average income: \$6 987/year). The report also showed a 1.4\% expected growth between 2000 and 2010 , which as an average growth compared to other occupations in this industry (CS/Resors et al., 2002). The significant negative wage differences between Canadianborn and NPR workers introduce the potential to use a workers' lack of citizenship as a means for even lower-wage labour. This case study in BC is reflective of the use of TFW labour in Canada.

New Brunswick has also followed the upward trend of TFWs exhibited in other provinces. Most temporary foreign labour in New Brunswick is considered to be lowwage. Some of these workers come to fill gaps in the fish and seafood processing sector, which is another sector of the economy requiring seasonal labour (Thomas \& Belkhodja, 2014). Labour needs in New Brunswick and the use of foreign labour collides with some demographic challenges: a scarcity of jobs with wages above minimum wage or requiring high skills, are driving youth away from rural areas and away from the province. It has also been argued that this relatively recent access to cheaper labour does not provide an incentive for employers to find other ways to hire Canadians, such as by increasing wages or improving labour conditions (Thomas \& Belkhodja, 2014).

Some communities, for example, Brandon, Manitoba, have been proactive in attracting and retaining immigrants (Palacio, 2010). Many workers coming to Manitoba, in butchering, meat- packing and food processing occupations, come to Canada initially as low-skilled temporary foreign workers who later transition into permanent residents (Palacio, 2010). The University of Brandon has documented strategies to retain 
immigrants from the perspectives of both employers and employees in small- and medium-size food processing businesses in rural Manitoba. A combination between competitive compensation and fair workplace treatment were found as the most effective means for retention (Ashton \& Wayne, 2013). According to workers, although wage is the most significant element to decide whether to stay in a job in a small, rural community, other factors, including the way they are treated, are also important considerations in the decision-making process (Ashton \& Wayne, 2013).

\subsection{Sex}

Two types of comparison for the variable "sex" took place: 1) a comparison within each category (male and female) by immigration status in the cross-tabulation analysis and 2) the influence on wages of being female (compared to being male) in the regression analysis. The cross-tabulation analysis for sex in chapter seven showed that, both NPR men and women earn less than their CB and IMM counterparts. Such wage differences are most prominent for both males and females in occupation 6476- visiting homemakers, housekeepers and related occupations; male NPRs in agricultural occupations also exhibit significantly negative wage differences compared to male $\mathrm{CB}$ and male IMM. The regression analysis in chapter eight showed that, males earn more than females. Workers' sex represents another characteristic that relativizes migrant labour and wage differences in Canada. Differences in wages by sex and immigration status replicate the pattern seen for the whole population in each occupation. As detailed in chapter seven, NPR women tend to earn lower wages than Canadian-born and immigrant women. A similar pattern is also evident among men, although to a lesser 
degree.

The regression analysis showed that, accounting for all low-skilled workers in all 98 low-skilled occupations in this research, low-skilled females earned $14.2 \%$ less than low-skilled males (see Table 12 in chapter eight). Wage differences between the sexes are linked to a long history of male hegemony. Although such disparity has decreased in most developed nations, it nevertheless persists. In Canada, females earn about 0.8 dollars for every dollar that males earn working in similar occupations (Stats Canada, 2016b). Ontario has been working on reducing the wage gap, although differences remain significant. In April 2015, the Ontario government appointed a steering committee to develop a wage gap strategy (Ontario Government - Ministry of labour, 2015) and the committee is expected to report back to the government in early 2016.

In some sectors of the economy the labour force tends to be predominantly male. According to the 2006 census, of 45000 agricultural workers in the three occupational groups that rely most on low-skilled TFWs (8431-General farm workers, 8432-Nursery and greenhouse workers and 8611 -Harvesting labourers), about $34 \%$ were females and $66 \%$ were males. These ratios, however, vary significantly when accounting for legal status. There were $31 \%$ females and $69 \%$ males among Canadian-born workers; $51 \%$ females and $49 \%$ males among immigrants; and $6 \%$ females and $94 \%$ males among NPRs. While TFW males are overrepresented in the agricultural sector, there is a great predominance of females in the caregiving sector, which illustrates labour segmentation in specific occupations along sex lines (Preibisch \& Grez, 2014). The significance of these differences is particularly weighted since these occupations also have the highest number of TFWs and the lowest wages (see chapters five and seven). 
The regression analysis in this dissertation shows that females in occupations 8431-General farm workers and 8432-Nursery and greenhouse workers tend to earn $14 \%$ and $19 \%$ less than males, respectively (see Table 12 in chapter eight). The outcomes in occupation 6474-Babysitters, nannies and parents' helpers were not statistically significant in the male-female model, though it was nevertheless evident that this occupation is heavily sexed, with females taking approximately $96 \%$ of these jobs. As detailed in chapter seven, there is only slight variation in the gender gap when accounting for immigration status: among Canadian-born workers and NPRs, $4 \%$ were males and $96 \%$ were females and among immigrants, $2 \%$ were males, $98 \%$ were females.

Female domination in this occupation can be traced back to the ways in which child-rearing and general caregiving tasks have been socially constructed as female tasks: "In many different cultures, being female is associated with care for others...Gender norms governing interpretation of appropriate behaviour for women and men are closely linked to socially constructed concepts of familial altruism and individual self-interest. Women who seem highly independent or ambitious, like men who seem highly dependent or family-oriented, are often considered sexually unattractive" (Badgett \& Folbre, 1999, p.311).

In the case of agricultural labour, the literature shows that, while males are considered suitable for all types of jobs, females are selected for only a few jobs, which reflects a highly patriarchal scheme of labour allocation (Preibisch \& Grez, 2014). According to a civil servant interviewed by Preibisch (2002) as cited in Preibisch and Grez (2014), hiring women in the agriculture sector implies having to make 
accommodations related to the tasks associated with the job. Tasks are already associated with a specific sex: "Because women are great if they're standing and working with their hands, which is what food processing is all about, or packing, if you're packing fruit . . . but if you put a female into a tobacco priming aid ... [employers] may find they may not be as durable, or the longevity of females may not be as great over time. ... I'm not saying [women] can't do it [but] employers are leery about making wholesale changes." As this commentary indicates, a woman's perceived capacity to develop certain tasks, either low- or high-skilled, is often limited by preconceived ideas about women, their capacities, skills, interests and goals that tend to classify them in lower positions, minor jobs and therefore with lower wages.

\subsection{First Official Language Spoken}

Not speaking either English or French reduces the wages of low-skilled workers. In general, an increase in proficiency in either of Canada's official languages is linked to increase in earnings (Chiswick, 1991). The regression analysis showed that, considering all 98 low-skilled occupations included in this research, not speaking either official language represents almost $14 \%$ less in wages than speaking it (see Table 12 in chapter eight). This is particularly telling since reading and writing skills are more statistically relevant vis-a-vis labour market outcomes than speaking skills (Chiswick, 1991).

When the analysis focuses on specific occupations, differences become more acute. As Table 14 in chapter eight shows, whereas workers in occupation 7411-Truck Drivers, who do not speak either official language earn $3 \%$ less in wages, those in 
occupation 6641-Food counter attendants, kitchen helpers and related occupations and 6661-Light duty cleaners earn 19\% less; and those in 6421-Retail salespersons and sales clerks earn $\underline{28 \%}$ less. Often, those who report speaking languages other than English or French at work, tend not to speak either official language, although this is not always the case (Thomas, 2009). These immigrants are likely to report education levels below high school, to have landed at an older age and to speak a language of Asian origin at work (Thomas, 2009). Thus, language fluency can be a means to better labour market outcomes among low-skilled workers. In general, NPRs are likely to work in smaller ethnic restaurants where official language requirements are less pressing. Workers with low official language proficiency tend to work in jobs in the service or manufacturing industries (Boyd, 2009).

The ability to speak either official language is an asset that some employers actively seek while others deliberately avoid. On the one hand, proficiency in English, for example, has been reported as a desirable skill that some farmers value. On the other hand, some employers prefer workers who do not question authority or voice their rights. From this perspective, those who do not (or cannot) challenge anything are considered "good" workers and Mexican workers are preferred for their inability to speak English, which limits "backchat" (Preibisch \& Binford, 2007). A lack of language proficiency is also used as a means to control relations among workers. Female Mexican agricultural workers (Spanish speakers) are often mixed with male Caribbean workers (English speakers) to prevent personal exchanges (Preibisch \& Santamaria, 2006, as cited in Preibisch \& Binford, 2007). I

As these examples indicate, the ability to speak the language of the region of 
one's workplace makes a difference. The basic human need to communicate and to engage in social exchange is greatly restricted in the case of Mexican workers working on Canadian farms. In contrast, the ability among Caribbean workers to speak English provides freedom to move and to engage socially with their entourage (Preibisch \& Binford, 2007). Except for Ontario, which offers English and French classes to lowskilled refugee claimants and live-in caregivers (Ontario Ministry of Citizenship and Immigration, 2016), low-skilled NPRs have no access to language training. While the Canadian government offers English and French classes to permanent residents it does not provide instruction for temporary residents. It is not considered economically viable to provide language classes to people who are not going to stay in Canada (which is the case of almost all low-skilled workers).

In this way, a lack of citizenship presents a concrete barrier to integration. When NPRs lack language skills, it not only impedes their integration via citizenship; it also makes them more easily exploitable and less aware of their rights. It undermines their humanity and, by extension, ours. We, as Canadians, miss the opportunity to learn from their experiences and to explore other approaches to labour relations. Ideally, labour exchanges should not be reduced to a mere transaction of goods, but should consider the whole of humanity attached to each worker (i.e. their families as well as their social, psychological and political needs). Conversely, when NPRs cannot speak an official Canadian language, they also miss the opportunity to learn about us. In view of these considerations, all temporary foreign workers, especially low-skilled TFWs who provide Canadians with affordable food, services or products, should be allowed to receive government subsidized English or French classes. 


\subsection{Level of Education}

Generally, post-secondary education does not favour the wages of low-skilled NPRs and it does those of low-skilled CB and IMM. While language ability clearly makes a difference in labour market outcomes, a worker's level of education has mixed effects that differ from occupation to occupation in the cross tabulation analysis. The regression analysis from chapter eight (Table 12) for all low-skilled workers (CB, IMM and NPRs) with a trade certificate or a college degree represents a $5.7 \%$ increase in wages. By the same token, having a university degree represents a $6.4 \%$ increase. When focusing on specific occupations, however, outcomes vary. Table 13 in chapter eight shows that, among Babysitters, nannies and parents' helpers (NOC 6474), a university degree represents $10 \%$ higher wages than a high school degree. Among Visiting Homemakers (NOC 6471) it represents 19\% more. Table 14 (also in chapter eight) shows that among truck drivers, a college degree represents $4 \%$ more in wages than a high school degree; among food counter attendants, kitchen helpers and related occupations (NOC 6641) 8\% more; and among retail salespersons and sales clerks (NOC 6421) it represents $11 \%$ more. A trades certificate or a college degree among nursery and greenhouse workers (NOC 8432) translates into $14 \%$ more income than a high school degree; and among light duty cleaners (NOC 6661) and retail salespersons and sales clerks (NOC 6421) it represents $7 \%$ more.

In some occupations, the level of education does not always make a positive difference. Figure 15 from chapter seven shows that NPRs with a university degree in occupation 6453- Food and Beverage Servers have significantly lower wages than their $\mathrm{CB}$ and IMM counterparts. In contrast, those with a high school or college degree have 
a significantly lower negative difference. Restaurant workers with post-secondary education tend to have better labour conditions, better wages and more labour mobility than workers without it (Denstedt, 2008).

It is worth noting that this research only includes cases of full-time employment, which the census denotes as working 30 hours or more per week, whether in one or more jobs. As a result, while the models in chapter eight indicate that postsecondary degrees have some effects on wages, it is likely that some of these workers work in more than one job, perhaps one that requires education (a high-skilled one) and another that does not (a low-skilled one). Another factor to keep in mind is the broad range of job titles and, by extension educational requirements that each occupational group has. Further research could address these nuances.

Among NPRs, the effects of having a trade certificate, college degree or university degree tend to be neutral. This is not surprising considering that low-skilled TFWs usually come to Canada to work in occupations that do not require postsecondary education. The cross tabulation analysis shows different patterns of increase/decrease in wages as the level of education increases or decreases. While not the primary goal of this research, it is nevertheless worth mentioning the skill underutilization of immigrants in Canada.

Immigrants with post-secondary education working in low-skilled jobs signal a significant problem in labour market integration: all things equal, post-secondary education should lead to high skilled employment. According to the 2006 census, of the total (some 707 000) Immigrants (naturalized Canadians plus permanent residents) 
working in the 98 low-skilled occupational groups included in this research, ${ }^{108} 51 \%$ reported having high school degree or less, while the remaining $49 \%$ reported having post-secondary education. Of that $49 \%, 26 \%$ reported having a trade certificate or college degree and $23 \%$ a university degree. This misuse of skills comes at a cost for Canada. In 1996, for example, Canadian losses amounted to 2.4 billion dollars in skill underutilization and 12.6 billion dollars in pay inequity (Reitz, 2001). This significant underutilization of immigrants' skills has been presented from different angles: as a critique of the human capital selection model ${ }^{109}$ (Ferrer et al., 2004; Sweetman, 2005; 2006; Sweetman \& S. McBride, 2004 as cited in Hawthorne, 2007), and differences in labour market outcomes compared to the Canadian-born population (Picot \& Hou, 2003; Picot 2004; Reitz 2005; Thompson \& Worswick, 2004 as cited in Hawthorne, 2007). A lack of work experience gained in Canada is one of the main barriers facing foreigners who are trying to integrate into the Canadian labour market (Reitz, 2005), one that can, negatively affect earnings (Chiswick \& Miller, 2002). In the attempt to overcome this obstacle, the Ontario Human Rights Commission introduced a policy in 2013 to remove the "Canadian experience barrier." This policy provides directions on best practices to employers, representatives of employers and regulatory bodies (OHRC, 2013). Despite this policy change, there are still considerable challenges facing foreign workers trying to find employment in Canada: a lack of proficiency in one of Canada's official languages, for example, limits integration into the Canadian labour market (Chiswick \& MIller, 2002) and the non-recognition of foreign credentials or foreign experience excludes "immigrants from the upper segments of the labour market" (Bauder, 2003,

\footnotetext{
${ }^{108}$ That is, the 98 low-skilled occupational groups that report use of NPRs.

109 'Human capital selection model' refers to the selection of immigrants based on the possession of postsecondary education as is the case in Canada.
} 
p.699).

\subsection{Country of Birth - Regions of the World}

Being born in developed countries leads to positive wage differences and being born in developing countries leads to negative wage differences. Canadian citizenship makes a difference among Mexican-born workers. Statistically significant wage differences according to one's country of birth indicate that some foreign workers earn more than those born in Canada and some earn less. Four trends were identified in chapter seven, some of which were also corroborated through the regression analysis in chapter eight:

\subsubsection{Concentration by country of birth around certain niche occupations.}

Workers from certain countries of origin concentrate around certain niche occupations. Italians are well represented and have the highest outcomes in occupation 6663Janitors, caretakers and building superintendents, earning $13 \%$ more than their Canadian-born colleagues. According to the 2011 National Household Survey, ${ }^{110}$ about 260250 people reported being born in Italy and 1488425 reported having Italian ethnic origin (this includes single and multiple ethnic origin responses). In the effort to understand the relatively high wages earned by Italians, it is helpful to note that a significant number of Italian immigrants came to Canada after WWI and WWII, that is, at a time when immigration was not attached to skills and it was easier to unionize. If workers are in industries that allow unionizing, wages tend to be higher and higher standards of working conditions tend to prevail. According to the research conducted by

\footnotetext{
${ }^{110}$ For an explanation of the reliability of the 2011 NHS see chapter four.
} 
Mandarino (2009) on the Italian-Canadian community in Toronto, first-generation males generally tend to work in construction and manufacturing, while first-generation females tend to be concentrated in low-skilled service occupations.

Portuguese-speaking low-skilled workers tend to congregate in occupation 7611Construction trades helpers and labourers. This research shows that of all immigrants who reported working in this occupation, $27.6 \%$ were from either Brazil or Portugal. According to the 2011 National Household Survey, about 429850 people reported Portuguese ethnic origin (this includes single and multiple ethnic origin responses) and 140310 people reported Portugal as their place of birth (Statistics Canada, 2017). Clifton (2008) presents the case of Portuguese workers in construction.

Another niche occupation is 6474-Babysitters, nannies and parents' helpers, where the majority of workers come from the Philippines. This pattern is welldocumented in the literature (Cohen, 2000; Faraday, 2012a; Gardiner, 1997).

\subsubsection{Concentration around occupations with the highest wages. Low-} skilled workers from Western and Southern Europe concentrate around the highest paid low-skilled jobs. The regression analysis in chapter eight showed that labour market experiences of Europeans are different from the experiences of workers coming from developing countries. On average, those born in Western, Central and Northern Europe are likely to earn $1.3 \%$ higher wages than North American-born low-skilled workers. In some occupations, this positive difference is particularly pronounced. In occupation 1431-Accounting and related clerks, for example, low-skilled workers from Britain earn $16 \%$ more than those born in Canada; and those born in southern Europe (Italy, Spain, 
Portugal) are likely to earn $8.3 \%$ more than North American-born workers. These examples illustrate the supremacy granted certain nationalities in some occupations in the Canadian labour market.

In some occupations, even after Canadian citizenship is granted, wage differences persist, with positive outcomes for workers coming from developed nations (ex. UK) and negative outcomes for those coming from developing nations (ex. China). These findings help corroborate existing research. For example, it has been documented that among immigrants with citizenship in Canada, those born in OECD ${ }^{111}$ countries receive a premium attached to their human capital, while those from Asia "experience a devaluation in their credentials" (Devoretz \& Pivnenko, 2004, p.25). As a result, immigrants born in OECD countries paid even more taxes than those born in Canada (Bevelander \& Devoretz, 2008).

9.6.3. Concentration around occupations with the lowest wages. Low-skilled workers from developing countries tend to concentrate around occupations with very low wage. They are present in large numbers and come primarily from Mexico, the Philippines, China and India. Low-skilled workers from less developed countries have very different outcomes than UK-born low-skilled workers. Low-skilled workers from Mexico, India and China tend to work in more physically demanding occupations and to earn lower wages than those born in Canada. Mexican workers mainly work in agricultural occupations. While Filipino workers are distributed throughout several occupations, Filipino NPRs are highly represented in caregiving occupations. Chinese and Indian low-skilled workers are distributed in other occupations, including 6641-Food

${ }_{111}$ Organisation for Economic Co-operation and Development. 
counter attendants, kitchen helpers and related occupations and 6421-Retail salespersons and sales clerks.

Chapter five shows that China is the third and fifth source of immigrants and NPRs, respectively, in the Canadian low-skilled labour force. The regression analysis in this dissertation shows that being born in China represents a likelihood of earning $9.7 \%$ less than those born in North America. The literature shows that the economic returns of Chinese immigrants working in enclaves (that most likely have low human capital) are lower than those of their counterparts working in the mainstream economy (Xiaoling Li \& $\mathrm{Li}, 2016)$. Although outcomes are low and the mainstream economy offers better opportunities, enclaves offer a cushion that reduces disparities (compared to working in mainstream economies) (Xiaoling Li \& Li, 2016).

Finally, chapter five also shows that India is the top source of low-skilled immigrant workers and the third source of low-skilled NPR workers in Canada. Indianborn low-skilled workers (including both NPRs and IMM) are likely to earn $15.6 \%$ less than North American-born low-skilled workers. This outcome echoes findings in other studies, which find that unemployment rates among Indian-born immigrants are higher than those of the Canadian-born workers (Agrawal \& Lovell, 2010, as cited in George \& Chaze, 2016) and that the proportion of Indian low earners is higher than that of Canadian-born low earners because of a "lack of effective and vast networks within the Indian community" (George and Chaze, 2016, p.93).

Mexican migration to Canada has been steadily growing. Census information shows the that number of Mexicans in Canada (IMM and NPRs) who work in both lowand high-skilled jobs, increased from about 22000 in 1991 to 42000 in 2001 (a 98\% 
increase) (Mueller, 2005). The increasing number of Mexicans coming through humanitarian pathways may hinder their possibilities for integration in the Canadian labour market (Mueller, 2005). Despite the significant hardships and exploitation that agricultural labour in Canada imposes on Mexican workers without access to citizenship, it nevertheless provides them with good source of income. Though low by Canadian standards, the eight-month wage of a SAWP worker is equivalent to five years of work in Mexico (Lustig, 2001, as cited in Silverman \& Hari, 2016). This serves as an introduction to the next trend addressed in this analysis, which examines how access to citizenship improves labour market outcomes of Mexicans.

\subsubsection{Wages by country of birth when citizenship is accounted for. When} citizenship is accounted for, wages among foreign-born citizens ('immigrants' in this dissertation) improve in agricultural occupations and in truck driving. When accounting for immigration status (where NPR numbers allow statistically significant comparisons), low-skilled NPRs earn significantly lower wages than Canadian-born and immigrant workers. Mexican NPRs in occupation 8431-General Farm Workers, for example, earn $20 \%$ less than CB and $14 \%$ less than IMM. However, when citizenship is granted, differences decrease. Mexican immigrants and permanent residents working in the same occupation, 8431-General Farm Workers, earn only 7\% less than Canadian-born workers.

Differences in wages based on country of origin have been registered in legal actions initiated by unions. In British Columbia, for example, the Construction and Specialized Workers Union (CSWU) complained to the provincial labour relations board 
about unfair labour practices. According to CSWU, a Canadian joint venture was paying significantly lower wages to workers from Latin America than what they were promised and what European workers were being paid (about $30 \%$ more) (Fudge \& MacPhail, 2009). The venture was mandated to pay compensation to the workers, however the decision was appealed by the employer and the minister of immigration at the time, $\mathrm{J}$. Kenney, expressed concerned with the tribunal's decision and also expressed "intention to decertify the union that filled the complaint" (Fudge and MacPhail, 2009, p.40). The Supreme Court re-sent the case to the board for an unbiased decision (Fudge \& MacPhail, 2009). In 2012, the tribunal had valued the damages done to the workers as "\$2.4 million (the largest human rights award in Canadian history) that had increased to \$2.5 million with interest by late 2012" (Mandryk, 2012, p.22). In December 2012, the workers agreed to a negotiated settlement for an undisclosed sum (Mandryk, 2014). This case is an example of how hard and lengthy it can be to make legal claims in favour of temporary foreign workers when their rights are violated (Fudge and McPhail, 2009).

Labour market differentials by country of birth show that immigrants from the Philippines tend to earn similar wages to those born in Canada (Gilmore, 2008). This study also finds that, in some occupations, immigrants from the Philippines tend to have similar and sometimes higher wages than their Canadian-born counterparts.

Nonetheless, in a few occupations, immigrants from the Philippines earn less than those born in Canada. In occupation 6421-Retail salespersons and sales clerks, for example, immigrants from the Philippines earn 7\% less than Canadian-born workers.

In some cases, immigrants from certain countries tend to have negative 
differentials compared to Canadian-born workers, although those differentials tend to decrease as their time in Canada increases. The wage difference between immigrants from Africa and Canadian-born workers, however, persists over time (Gilmore, 2008). As these examples indicates, a worker's country of origin makes a difference when examining wages, an observation that resonates with outcomes commonly found in the literature. However, when the focus is limited to low-skilled workers, other characteristics, such as immigration status, have a greater weight than country of origin does. Immigration status significantly changes the wage differentials of low-skilled workers by country of origin. For example, British-born NPR truck drivers earn significantly less than Canadian-born truck drivers; in contrast British-born immigrant truck drivers earn significantly more than Canadian-born truck drivers. This pattern was evident among workers that showed statistically significant outcomes when comparisons between CB and the other two categories (IMM and NPRs) took place (ex. Mexicans in occupation 8431-General farm workers).

\subsection{Final Considerations}

Of all the costs that a business owner faces, wages are among the most elastic. In addition, some employers have the possibility of accessing foreign workers who are willing to perform jobs that locals would not do for a low wage. Low wages among lowskilled temporary foreign workers are the outcome of many converging forces. Two of those forces are: 1) employers willing to draw on a labour force of unemployed or underemployed people willing to work for lower wages than locals ${ }^{112}$ are; and 2) a foreign labour force eager to work for wages that are significantly higher than what they

${ }^{112}$ From the region within the province/territory where the jobs are 
could earn in their homeland. While local (regional) and national market forces usually define the wage equilibrium through the supply and demand of labour, in the case of temporary foreign labour, a mix of local, national and foreign forces work together to define local wages.

While Canada's capacity to influence foreign forces is limited, it nevertheless does have a measure of control over domestic forces. For example, the Canadian government can install monitoring mechanisms that enforce better wages ${ }^{113}$. Yet, as explained at the beginning of this chapter, although Canada currently has such mechanisms in place, they are not very effective. One of the main challenges in the current globalized world is that domestic parameters are defined by forces that seem to operate outside the nation-state. This situation begs the question: if domestic workers are not willing to perform certain jobs at a minimum wage, some of which are highly physically demanding, is it ethical for workers from other countries to do so? Is it ethical to allow foreign workers to perform jobs that are underpaid by local standards just because they are above the wages that these workers would earn in their countries of origin? To what extent can the government intervene by advocating for wages defined by local conditions? Is a minimum wage sufficient to avoid underpayment?

Looking at the wages paid to low-skilled temporary foreign agricultural workers, their wages are significantly lower than the wages of Canadian-born and immigrant workers performing the same jobs. Compared to other low-skilled jobs, agricultural jobs are among the most physically demanding and, as this research shows, they are among

\footnotetext{
${ }^{113}$ Some caregivers and agricultural workers report working longer hours that go unpaid, which makes real wages very low (Bakan \& Stasiulis, 1997; Fudge \& MacPhail, 2009), in some cases even lower than minimum wage (Faraday, 2014).
} 
the lowest paid. The low wages in the agricultural sector are the outcome of a transnational labour situation that has gradually been accepted to the point that it is no longer seen as cause for concern. For the most part, it has been accepted that the local labour market is regulated by a labour price dictated by forces outside our borders.

But, then the question persists: why do people with citizenship (Canadian-born and immigrant) earn higher wages? Perhaps, this discrepancy is not the result of equilibrium of supply and demand, but rather reflects a situation in which, by accepting lower wages, temporary foreign workers compensate the higher wages paid to locals in the same occupations. To test this, future research account for different types of occupations because, although most low-skilled non-citizens earn less than nationals, variations are linked to type of occupation.

Two main high-level outcomes stand out: first, citizenship status has a broad impact or correlation on wages therefore non-citizenship is costly to NPRs. There is a non-citizenship penalty (when it comes to wages) assigned to Non-Permanent Residents. Second, among NPRs with no pathway to citizenship, there is a hierarchy; some variables relatively identify a kind of pecking order for low-skilled NPRs. There is a penalty but it is not an equalized penalty, an order of NPR low-skilled wage levels in the Canadian labour market. Thus, sex, region or country of birth, province of residence and rural or urban place of work matter.

\section{Summary}

While TFWs are officially entitled to the same wages as Canadian-born and immigrant employees working in the same occupation, research indicates that these 
workers typically earn lower wages. 8431-General Farm Worker NPRs exhibited lower wages than CB (20\% lower in Ontario and 9\% in Quebec) and Babysitters, nannies and parents' helper NPRs, even after accounting for room and board, also exhibited lower wages than $\mathrm{CB}(17 \%$ less in Ontario, $6 \%$ in Quebec, $6 \%$ in Alberta and $2 \%$ in $\mathrm{BC}$ ). Wage differences across provinces are affected by the fact that provinces have different economies. Other effects not accounted for in this analysis may also affect wages including seniority. Regional analyses within provinces show differences in employment patterns across regions within provinces (see Ontario Chamber of Commerce Projections, 2016). However, Ontario is the largest user of low-skilled temporary foreign workers in agriculture (see chapter five). The literature confirms these outcomes.

While NPRs in a significant number of occupations exhibited lower wages than CB and IMM, there were some occupations with the opposite outcome. At least four occupations exhibited positive differences (higher wages among the NPR population vis-à-vis the Canadian-born and immigrant populations). These positive differences may be an indication of tightness between demand and supply in the labour market, regional differences in wages, a higher number of weeks/hours worked during the year 2005, and wage dispersion.

Workers' country of origin does influence wage discrepancies and the type of employment, however when citizenship is accounted for, wage differences decrease. The literature also demonstrates that legal processes in favour of foreign workers can be lengthy and require the support of unions to stand the many challenges ahead.

Wage dispersion is a significant factor behind wage differences. A quartile analysis for truck drivers reveals that those with wages in the second and third quartiles 
have average wages below those of Canadian-born and immigrant workers (See Appendix 9). Wages in the fourth quartile inflate the overall average for the NPR population in this occupation, making the differences positive. A high wage dispersion, caused by the diversity of jobs in this occupational group, explains why the average differences for the whole sample are positive while remaining negative for the central (second and third) quartiles. The next chapter will elaborate on the fact that the state often functions as a broker with a preference for capital and will outline the theoretical contributions of this dissertation. 


\section{Chapter Ten: Theoretical and Analytical Contributions}

This chapter discusses the outcomes of the present research within the context of theories of migration, the state and citizenship. The first part focuses primarily on migration theories. The second part explores Bob Jessop's theoretical treatment of the role of the state, which are essentially neo-Marxist. The third part presents citizenship as a means by which a vulnerable foreign workforce is brought in to the country mostly as cheap labour. Both the Rational Choice Theory and Critical Social Theory illuminate the outcomes of this dissertation in two fundamentally different ways. As explained in chapter two, Rational Choice Theory and Critical Social Theory can inform from very different analytical perspectives the quantitative analyses presented in chapters five, six, seven and eight. This chapter contests the outcomes of those quantitative chapters by incorporating theories of migrations, the state and citizenship offered by Critical Social Theory.

\subsection{Migration Theories}

10.1.1. Neoclassical Theory of Migration. As discussed in chapter two, neoclassical theoretical approaches maintain that migrants find work outside of their countries of origin because of a combination of pull forces (better wages) in their destination countries and push forces (low wages and generally terrible labour conditions) in their countries of origin (Binford, 2009). This theory highlights geographic differences in the supply and demand of labour (Massey et al., 1993). For example, from a macro perspective, TFWs from Mexico and the Caribbean move from a labourabundant location to one that is scarce in labour. From this perspective, TFWs' decision 
to move to Canada for work is a rational one, based on the following considerations: labour shortages and better wages in Canada and labour excess and hostile labour conditions in the workers' countries of origin. In this way, labour migration optimizes the redistribution of production factors by benefiting both sending and receiving countries (Haas, 2010).

The dissertation findings suggest that a neoclassical reading of migration assumes the existence of a supply-demand equilibrium that regulates the price of labour. It encourages the increase of temporary foreign labour as a response to labour scarcity in the destination countries and labour abundance in the countries of origin, which causes wages to sink (to the legal minimum) (see appendix 15). However, such rational market models do not entirely explain the economic reality of temporary foreign labour, since they cannot account for why the wages of low-skilled temporary labourers tend to be lower than those of the Canadian and immigrant populations in a specific occupation (see chapters six, seven and eight).

It is worth making clear that other theoretical perspectives describe that labour is not as mobile as capital. Other perspectives argue that is not labour scarcity but wage scarcity (people that work for those low wages) what drives most low-skilled labour migration. Low-skilled workers are not as free to move as the theory implies. Additionally, the rational model does not address values such as fairness or human rights. Nor does it account for the reasons behind the labour scarcity and abundance in countries of destination and of origin, respectively. In particular, it does not account for the structures that created high wages and scarcity of labour in some regions and an abundance of labour and horrible labour conditions in other regions. Moreover, it does 
not account for the consequences of the increase in low-skilled temporary foreign labour in Canada, that is, a deterioration of local wages. Neo-Marxist theories of migration help address these deficits by illuminating other forces at play in economic developments. The Historical Structural Theory (and its dependant Segmented Labour Theory) shed some light in the next section on the fact that even if Canada benefits from the low wages of skilled temporary foreign workers, this benefit comes under an indentured structure via several characteristics including ethnic origin, sex and low wages. As Zolberg (1991a, 1991b) presents, global asymmetries in the labour market have origins in slavery and are the outcome of the interplay of competing forces at play via concepts like sovereignty, citizenship and national identity.

10.1.2. Historical Structural Theory. The significant number of Caribbean and Mexican workers presented in my findings in chapter five are not only a response to neoliberal policies introduced in Canada that are designed to benefit employers, but are also the consequence of a colonial relation with the British West Indies and Spanish America that can be traced back to the eighteen and nineteenth centuries (Plascencia, 2016), what Anibal Quijano calls the "Coloniality of Power" (as cited in Plascencia, 2016, p.231). That is, over an extended history of exploitation, workers from these countries were constructed to be especially suitable at performing the activities demanded by labour-intensive occupations. For example, Mexicans were constructed to be docile and to have the requisite stamina to perform physically demanding labour without protesting (Plascencia, 2016; Preibisch \& Binford, 2007). My findings show that Mexican workers are indeed confined to physically demanding occupations (e.g. agriculture) while some 
from European origin work in less physically demanding occupations. As this example indicates, classifications based on race are essential for such constructed modes of production to work. Accordingly, the historical structural approach also includes a theory that helps account for the segmentation of workers' experience, which, as this research confirms, often takes place along the lines of race and gender.

More specifically, the dissertation shows that place of birth (as a proxy of ethnic origin) is associated to the type of occupation and level of wage, particularly in occupations that are physically demanding (like occupations in agriculture). This is consistent with the stereotypes associated with certain occupations described in the literature (e.g. babysitters and nannies are female workers from the Philippines). Race and ethnic origin have been central to the use of low-skilled temporary foreign labour (Hennebry, 2012; Preibisch \& Binford, 2007; Sharma, 2001). These two elements, along with a lack of official language skills, have been the means for indentured labour in Canadian agriculture via temporary foreign low-skilled labour programs (Preibisch, 2010).

This dissertation provides quantitative evidence to support on the Historical Structural Theories, the Segmented Labour Market Theory. It demonstrates that three main groups of low-skilled workers (in agriculture, caregiving and in other low-skilled occupations) each exhibit different types of segmentation. For all low-skilled workers, segmentation of different wage brackets is enabled by a lack of citizenship. In addition to wage-related segmentation, agricultural workers also experience race-related segmentation, with Caribbean workers being constructed as valuable for certain agricultural activities and Mexicans for others. Live-in caregivers are segmented 
according to gender and country of origin. The significant concentration of female workers from the Philippines in caregiving occupations demonstrates this as well as the segmentation associated with non-citizenship, even though, unlike other groups, LICs have a possible pathway to citizenship (which is now more restricted).

\subsection{The Role of the State}

As outlined in chapter two, Bob Jessop is one of the renowned state theorists whose neo-Marxist approach to Critical Social Theory explores the role of stakeholder interests in shaping state policymaking, as the state essentially acts (passes policies, laws, regulations) in response to their competing interests and power. This conceptualization of the state is particularly germane to this dissertation, especially in relation to power.

If we understand power to be economically and socially embedded, it is critical to consider the ways in which different stakeholders and interests shape the structures and processes, which, in turn, affect wages of low-skilled labourers in Canada. My findings show that a lack of citizenship negatively affects the wages of NPRs. This research has also shown that, to a lesser degree, other characteristics seem to affect workers' wages in different ways. In addition to the common negative labour market outcomes associated with a lack of citizenship, there are differentiated negative outcomes linked to various characteristics, including the type of occupation, sex, province of residence, ethnic origin and country of origin. Similarly, when the workers are separated according to the three identified groups (live-in caregivers, agricultural workers and other low-skilled workers in selected occupations) a lack of citizenship 
negatively affects their labour market outcomes. Nevertheless, each group's set of policies has been segmented according to different policy pathways. Those specific labour market experiences are the outcome of a combination of forces and, in some cases, is channeled through the state via policies (Satzewich, 2008). The state has become the vehicle for a kind of economic class domination via policy (Satzewich, 2008).

Currently, economics, especially liberal economics, dominates the paradigm in which policies are developed. The social role of the state has shifted from provider to "entrepreneur" with the "market" considered to be the main solution to many policy issues (Painter \& Pierre, 2005).

The organization of labour is directly linked to the social relations of production in economic class domination. This is what drives the tensions between the two main actors (capital and labour). This dissertation provides evidence to show that temporary foreign labour in Canada makes a striking example of how labour is reorganized to predominantly favour the economy (Satzewich, 2008). This is especially evident in policies that allowed employers to have easy and 'on-time' access to temporary labour (Gross, 2014; Hennebry, 2012) at lower wages than Canadian-born and immigrant. Drawing on an example from the agricultural sector, Satzewich (2008) reports that policymakers responded to different opposing forces and the outcome solved some social issues, for example, hyper-exploited undocumented Mexican labour in southern Ontario. Those same policies, however, also created conditions for perennial access to cheap foreign agricultural labour, which continues to be exploitative (Basok, 2002; Preibisch, 2007), if to a lesser degree than what was reported in the late 1960s in 
Satzewich's research (2008). Even if this is the case for the most part, it is worth mentioning that the state also responds to stakeholders' pressures (including advocacy groups), albeit in a way that favours capital.

The introduction of regulations curbing temporary low-skilled foreign labour reflects policymaking that predominantly responds to political pressures and neoliberal agendas rather than to evidence. The state in this case acts as a not entirely neutral broker of political pressures, a broker with a penchant towards capital. The evidence of this dissertation does suggest that by opening doors to temporary foreign labour, the government, to a certain extent, manipulates the conditions of the domestic labour market. Wages are not measured according to local economic standards, but rather to international standards, and are low for locals but relatively high for foreigners. In this system, employers have the best of both worlds: local production with foreign (lower) wages. In other words, the displacement of local low-skilled labour takes place via wages ${ }^{114}$ rather than geography. Nevertheless, Canadian employers (e.g. farmers) are in a way also powerless vis-à-vis international wages. They may be competing against products harvested at even lower costs of labour. A study among low skilled workers in the USA found that "undocumented migrants earn about 20 percent less, on average, than legal immigrants, while temporary legal workers earn around 13 percent less" (Massey and Gentsch, 2014, p.491).

The outcomes of this research work also suggest that temporary foreign labour programs are part of the same neoliberal agenda that erodes the social responsibility of government and places the apparatus of the state at the service of the market, a market

\footnotetext{
${ }^{114}$ Unfortunately, the present analysis, which is made at the occupation level, is not granular enough to uncover wage differences associated with actual jobs. This information is currently unavailable.
} 
free from state interventions. It has been claimed that the government of Prime Minister Stephen Harper enhanced conditions that significantly increased the use of the temporary foreign worker program (Gross, 2014), resulting in an expansion of exploitation (Strauss \& McGrath, 2016; UFCW, 2015). My findings capture the beginning of this era. Prime Minister Harper's neoliberal ideology was evident throughout his time as Prime Minister, which was especially evident in his interest in Latin-America and his alignment with like-minded economies in the region (Macdonald, 2016). This is of relevance to an analysis of temporary foreign low-skilled labour (lowskilled non-citizens) in Canada, given the significant dominance of low-skilled Mexican labour in agriculture.

Based on the evidence, the low wage of non-citizen low-skilled workers and their inability to acquire citizenship are consistent with the state's non-neutral brokerage role. While the ideologies of bureaucrats have been shown to influence policy (Satzewich, 2008), the government's role as a biased broker of competing interests has also been documented, especially when pressures from different advocacy groups are mounting (Faraday 2016; Satzewich, 2008). However, the ways in which the state is not classneutral become evident when policies that respond to pressures from advocacy groups nevertheless end up aligning with the advancement of capital. This is evident in the 2014 changes in TFW policy, introduced in chapter three, which addressed some of the concerns expressed by academics and advocacy groups but opened other avenues for even greater exploitation (Faraday, 2016). The incidence of lobbying initiatives has also been evaluated. Rheault (2013) explores the incidence of lobbying efforts on immigration policy in Canada. Rheault's study shows that there is a direct relation 
between the number of lobbying meetings between corporations and the federal government with policies created to increase the number of temporary foreign workers. Nevertheless, he does not make the distinction between low and high skilled workers which is key in policy design (of TFW programs).

Although most of the exponential growth of the TFW programs took place during the government of Prime Minister Harper, TFW programs were mainly a Liberal creation (Satzewich, 2008). Prior to the introduction of the Low-Skilled Pilot Program in 2002, during the Liberal government of Jean Chretien the Temporary Foreign Worker Program was only for live-in caregivers and agricultural workers through the SAWP ${ }^{115}$ (see chapter three). Chretien opened the doors for temporary migration in a broad range of low-skilled occupations (Curry, 2014). He widened the door to low-skilled labour to satisfy employers' needs:

Then Canadian Prime Minister Jean Chretien, in Mexico in March 2003, said: 'This program where your farmers can come and work in Canada has worked extremely well and now we are exploring (ways) to extend that to other sectors. The bilateral seasonal agricultural workers program has been a model for balancing the flow of temporary foreign workers with the needs of Canadian employers.' (Mueller, 2005 p.45)

As this example indicates, both Conservative and Liberal government leaders have been involved in promoting the advance of capital over the interests of low-skilled workers. However, as presented in the literature review, the state is neither a subject nor a thing but an "ensemble of institutions and organizations that exercises power to the extent that it does so successfully through an institutionally mediated condensation of the changing balance of forces oriented to exercise state capacities" (Jessop, 2014,

${ }^{115}$ These two programs were also introduced by Liberal governments. 
40:07). State "powers" are "activated by changing sets of politicians and officials located in specific sites acting in specific conjunctures with specific horizons of action" (Jessop, $2014,44: 39)$. In this way, the state is also a mediator of forces. Therefore, in the case of low-skilled temporary foreign labour, the state, via policymakers, navigates different competing interests, a process that is heavily marked by the ideologies and agendas of elected officials and, to some degree, of bureaucrats. This is central to this dissertation, because the state as a biased broker crafts polices that ease the access to low-wage labour. This happens even when the state responds to complaints of exploitation linked to those same low wages presented in this dissertation. As the outcome of various social relations, Bob Jessop has noted that state policies themselves vary and are marked by what he describes as selectively shifting biases:

in analyzing the strategic selectivities (s.i.c.) of the state as a social relation, its bias as a strategic site of political action must be connected to specific strategies pursued by specific forces (or specific sets of such forces) with specific identities in order to advance specific interests over specific spatial and temporal horizons relative to specific other forces, each advancing their own interests through their own strategies over their own spatial and temporal horizons. Particular forms of state privilege the access of some forces over others, some strategies over others, some interests over others, some spatial and temporal horizons of action over others, and some coalition possibilities over others. This suggests in turn that a change in the self-identity of political forces, the pursuit of different interests, the development of different strategies, the adoption of different spatial and/or temporal horizons of action, or the building of different blocs, strategic alliances, or temporary coalitions could well lead to different outcomes, making it easier or harder to achieve specific objectives in and through a given type of state, a given state form, or a given form of regime. It also suggests that reorganizing the state - its modes of representation, its internal articulation, its modes of intervention, its social bases, the currently dominant state project or mode of political legitimation, or, where relevant, the state's broader hegemonic project for the wider society - will change its strategic selectivities. (Jessop, 1999, p.54-55)

This variation in policies in the case of low-skilled TFW policy is evident in the way in 
which the government of P. M. Harper shifted policies from openness between 2006 and 2013 to restricted openness in 2014 (recall that that year the government introduced several measures to reduce the flow mainly of low-skilled temporary foreign workers, as discussed earlier in chapter three). In 2014, the government did introduce regulations to curb low-skilled temporary foreign labour, for example, by capping the proportion of low-wage temporary foreign labour. The shift happened in response to variations in the forces at play, in the form of pressures from the media (Beatty, 2014; Valiani, 2013; Healy and Trew, 2015), advocacy groups, academics, the workers themselves (HUMA, 2016), as well as growing expressions of concern from the Conservative Party's own traditional base of support critical of the erosion of employment opportunities due to the growth of the temporary foreign worker program (Wingrove and Curry, 2014). However, by so doing, it introduced regulations that actually increased precariousness among low-skilled workers, by, for example, capping the number of LICs who can apply for permanent residence, and that negatively affected some industry sectors, for example, the hotel industry (Faraday, 2016). Nevertheless, as Jessop proposes, not just employers' efforts in-form policy but many forces at play including advocacy groups, employers, unions, the media, etc.

\subsection{Citizenship}

This section will engage in a critical analysis of citizenship, from a theoretical perspective, and its effect on low-skilled TFWs in Canada. The data shows consistently that citizenship as the main element differentiating outcomes for TFWs and CB and IMM and critically examines the current citizenship structure in Canada, which allows some 
low-skilled foreign nationals to work under conditions that Canadians, by and large, do not accept. This is particularly daunting since the most exploited among these workers (agricultural workers and live-in caregivers, who in this dissertation are among the workers with the largest negative wage differences) provide the very products and services that allow Canadians not only to prosper economically, but to actually live and be productive. They harvest the food we eat and look after our children, our sick and our elderly; they allow us to actually live by releasing us from the activities that are essential for our survival. ${ }^{116}$

In Canada, citizenship defines the relationship between an individual and the Canadian state either by birth or by naturalization (these being the two main ways of acquiring citizenship in the Canadian territory) (Canadian Citizenship Act, 1976).

Citizenship is central to this dissertation because citizenship, as demonstrated by this research, significantly defines the differentials in wages of low-skilled workers working in Canada. The existence of those differentials between citizens (and permanent residents) and non-citizens challenge citizenship in two ways: 1) as argued in the previous chapter, citizenship is used as a means to allow conditions that create wage differentials; and 2) the presence of non-citizens in Canada earning lower wages than nationals challenge core values associated with citizenship such as justice, fairness and universal access to rights while within Canadian territory. This section focuses on the first consideration. The following section then explores citizenship as a vehicle to construct migrants as workers willing to accept low wages, as presented in previous chapters.

\footnotetext{
${ }^{116}$ Other low-skilled workers develop activities that permit Canadians to have comfortable lives (i.e. lowskilled workers in the service industry sector) and they also earn lower wages than CB and IMM.
} 


\subsubsection{Othering and citizenship as means of constructing low-skilled}

TFWs. Citizenship is a means used by policy to construct otherness (Sharma, 2001) and to consolidate ideologies based on race, ethnic origin or religion. Othering and the construction of differences serves not only ideological purposes but also economic and political ends, functioning to justify the current order (Van Houtum \& Van Naerssen, 2002). The outcomes of the data analysis also align with the current global context, in which Canada uses both non-citizenship and its position as a country with power inherited from a colonial past to access cheaper labour (Plascencia, 2016).

The immigration system is designed in a way that positions high-skilled workers as potential citizens and low-skilled labourers as precarious non-citizens (Goldring \& Landolt, 2013) with wages below those of the Canadian-born and immigrant. The data shows that 'Low-skilled non-citizen' is the category that reflects policies that allow Canadian employers in some occupations to respond to profit targets. But this is not the case in all occupations, as was shown for occupations in the care and nursing sector. Some occupations genuinely exhibit shortages that only foreign labour can fulfill. Nonetheless, what is particularly problematic is not the temporality of their labour situation but the permanency of their temporality (Hennebry, 2012). Even if there is a genuine demand for their labour, they should not be excluded from the possibilities of integration associated with citizenship.

The low wages of non-citizens reflect the fact that citizenship constructs binary categories that define people's experiences within the confines of geopolitical borders, including protected/unprotected; covered/uncovered; with access to/without access to; belong/do not belong, temporary/permanent; foreign/national; migrant non- 
citizen/immigrant citizen. Most of these differences respond to a call to protect those members of the polity, at the same time enabling indentured labour and therefore a reorganization of the labour market to the benefit of mainly "capital investors" (Sharma, 2001, p.427). As Sharma (2001) observes:

continued reference to protecting the "nation," and by extension those seen as "belonging" to it, allows those working within the apparatuses of the Canadian state to reorganize the labour market in Canada by recruiting workers categorized as "non-immigrants" (or in the vernacular, as "migrant workers"). (p.418)

The conflict arises from implementing means of protection at the expense of legitimizing a utilitarian difference, a difference that benefit us, a difference that is not diverse but unequal (Sharma, 2001). Thus, labour market regulation takes place via migrant labour: "International migrants serve as an illustrative example of the significance of nonmarket-driven processes of labor-market regulation through citizenship" (Bauder, 2008a). Low-skilled temporary foreign workers then become the place of encounter for foreign labour markets acting within the boundaries of the nation-state: "The dual construction of a "domestic" and a "foreign" labour market within the space occupied by Canada is accomplished through the category migrant worker" (Sharma, 2001, p.426). Canada's history of policymaking is no exception to these types of constructions. Before 1967, the year in which the point system of immigrant selection was implemented, race was the main means for selection and hence for granting citizenship (Kelley \& Trebilcock, 1999). Together, segregating along the lines of race and non-citizenship have allowed Canadian growers to compartmentalize labour, for example, by using Caribbean and Mexican workers in specific agricultural fields, and to become competitive (Gabriel 2016; Preibisch \& Binford, 2007). It is the outcome of a long history of colonial domination over the Caribbean and Mexico (Gabriel, 2016), as also 
presented in chapter three.

\subsubsection{Non-citizenship, a means to become globally competitive. The} Canadian government has recognized that depriving citizenship to low-skilled foreign workers allows the country to enhance competitiveness by locking low-skilled TFWs into low-skilled occupations. While the Canadian government did try to increase the wages of low-skilled workers in agriculture in the early stages of the program (Satzewich, 2008), this made them less competitive on the market, so wage was, once again lowered (Satzewich, 2008). Subjected to the global forces of the market, the Canadian government has, in a way, lost its power to regulate internal markets (Somers, 2008b). This is the consequence of choosing to organize societies based primarily on market principles (Somers, 2008b) as they are reflected in power relations: "More than ever, economics has become ingrained in power relationships, and leaders are just beginning to sort out how it can be made to serve larger strategic and power ends" (Gelb, 2009, p.39). In response to competitive global prices, the state constructs a portion of its labour market by denying them right to permanency. A lack of labour mobility (dependency on the employer) is a key element in the structure of competitiveness (Gabriel, 2016). In this way, migrant workers (predominantly low-skilled workers) are doubly unfree: 1) they are not free to remain in their home countries given the lack of possibilities of living a human life with a livable wage; 2 ) when in Canada they are not free to walk away and sell their labour to a better employer or to negotiate their own labour (Gabriel, 2016). This lack of freedom has been enforced by policy (Satzewich, 2008; Sharma, 2006), which creates a vulnerable exploitable labour force whose 
exploitation is enshrined through a combination of a lack of mobility, precarious employment and restrictions on bargaining power (Strauss \& McGrath, 2016).

\subsubsection{Non-citizenship in combination with skills (occupations) as another}

means of constructing labour. Through their elected officials, nation-states construct populations (including migrant workers) mainly to respond to their electoral agendas (Schneider \& Ingram, 1993). Decisions made at the level of policy to respond to pressures coming from different stakeholders in specific moments in history make migrants indispensable to fulfill economic goals (Satzewich, 2008). Constructing the "other" as "alien," a foundational element of the current nation-state (Sassen, 2003), becomes a means to reap economic benefits and to enhance power (Sharma, 2006). Everything beyond its borders is seen as a potential contribution to the economy of the nation-state. However, in the current model of immigration in Canada, the type of construction of the other depends on its human capital (skills). Some skills are constructed as necessary and some are blocked via political action (Steinberg, 1990). Through an economic lens, considered in terms of the value of various skills, policy designates the other according to its potential to either contribute to the economic system or drain its resources. But those who "threaten" the system are not entirely discarded. They are recognized for their potential to contribute to the economy in a temporary way.

Elected officials and bureaucrats (as mediators between the polity, stakeholders and their own ideologies) construct, under degrees of being "essential," those who exist outside their borders according to their skills. This construction (via citizenship and 
skills) reflects structures of power and privilege that reinforce the class preference identified by Jessop (2014), referred to in the previous section: "Insofar as skill is used to justify pay, power and privilege, then it should be possible to analyze skill as an ideological discourse" (Steiger, 1993, p.555).

In this dissertation, wage differences show that the type of occupation, in combination with citizenship, constructs a hierarchy that reinforces structures of power and privilege already present in society: "Although different occupations develop different justifications for their pay, power and privilege, there are also basic, more commonly shared, social values about skills (i.e. preferences for men over women, or whites over black, mental over manual skills)" (Steiger, 1993, p.555). Only those with skills that align with the structures of power are embraced as citizens; those considered to be unfit are embraced only by the labour market, embraced by temporality via noncitizenship; citizenship (or lack thereof) transforms them into mere instruments for productivity and economic growth. The rest of their humanity is left behind (contrary to high-skilled workers, those with low skills are not allowed mobility in the labour market, not allowed to receive official language classes, not allowed to bring their families, and are more susceptible to exploitation) (Basok, 2002; Binford, 2009; Faraday, 2012a). Non-citizenship has a specific value: it allows employers to access a labour force that is more flexible (and thereby more valuable) than a Canadian labour force that could do the same work (Bauder, 2007). As citizenship is seen as a form of capital (Bauder 2008b), non-citizenship could also be seen as a form of capital that has value not to migrants but to employers; this is a capital whose primary currency is flexible low-skilled foreign labour. 
Foreign low-skilled labour, then, greatly benefits Canada, by providing a source of capital that makes the Canadian economy more competitive. But, to what extent can we call those outcomes "benefits" if they are obtained at the expense of those outside the circle of belonging, by subjecting them to exploitative conditions? What we call 'benefits' (i.e. affordable food prices, higher productivity, etc.) are the direct result of the diminishment of other people's capacity to live human lives (through exploitation, living and working in fear of losing their jobs, broken families, broken societies in their countries of origin, lower wages, etc.). Is it ethically justifiable to offer TFWs work that is better than any work they would have in their countries of origin but with conditions below those of citizens in Canada? Does this exploitative situation coincide with Canada's charter of rights and freedoms? Is it Canada's responsibility to care about the fate of TFWs' families and their societies? If belonging via citizenship is a way to address these concerns, further research should focus on the morality of granting/denying rights (including citizenship) to low-skilled foreign nationals.

\subsubsection{Citizenship, recognition and the importance of collective living.}

Hannah Arendt provides a foundation to justify both the importance of low-skilled labour and its inclusion in a society. To Arendt, the Greek polis represents one of the greatest accomplishments of humanity in terms of social organization. She argues that the best form of collective life emerges in an organization (like a nation-state or a city-state) that allows citizens to live a political life as was lived by the citizens of the ancient Greek polis. Similarly, the data suggests that non-citizens allow citizens to pursue other activities (especially in occupations where non-citizen workers experience the larges 
wage differences compared to citizens). The ancient Greeks recognized that the power to create emerges only when individuals are released from necessity and can exchange in issues that pertain to the polis. Freedom was understood as an essentially political act, reserved for those who engage in the public sphere; it emerges only when individuals have been freed from the necessities of life to engage in political issues and act upon matters of the communities in which they reside and work. Inspired by Aristotle, Arendt maintains that freedom requires "full independence" from "the necessities of life and the relationships they originate" (Arendt, 1998, p.13-4). Canadian citizens' ability to exercise their rights and freedoms is facilitated by the marginalization (oppression) of non-citizen low-skilled workers.

Necessity, Arendt explains, is marked by the activities that pertain to the actual human biological living, like the occupations dominated by the outcomes of this dissertation. These include food production, cooking, housekeeping, etc. Thus, citizens in the Greek polis possessed the logistical conditions that allowed them the time, independence and peace of mind to participate in decision-making processes of the polis. In Ancient Greece times, slaves allowed this freedom to happen. Nowadays we are in a similar situation in which low-skilled workers (especially those with the lowest wages) perform the activities that slaves developed in the past. While Arendt acknowledges the importance of low-skilled labour in facilitating citizens' participation in the matters of the polis, she also recognizes the relevance (for the individual and the collective) of recognition (inclusion via citizenship) and the relevance of embracing the other. To use Arendt's well known phrase, citizenship has been a means to the "right to have rights" (Arendt, 1976, p.296). Her claim brings to the surface the relevance of 
recognition in the context of the nation-state (Somers, 2008a).

The limitation of this recognition is that it was conceived based on the idea of a general individual, a human being, with no characteristics linked to a state. This idea of attaching rights to the individual and to a nation-state comes from the denial of rights experienced by refugees after the Second World War (Somers 2008). The horrors of Europe in the 1930s and 1940s engendered a global awareness of human rights across the western world. States embraced a need to have stronger commitments to protecting rights of individuals and collectives. In time this would lead to the Universal Declaration of Human Rights and the Geneva Declaration of Protection of Refugees. This also had some influence on governments moving away (officially) from race-based immigrant selection polices. This situation prompted the recognition that if rights are denied by states, there still remains the rights of 'man' (Arendt, 1976), referring to the rights inherent to being human, that is, human rights.

All in all, Arendt advises that acknowledging plurality (as opposed to individuality) is the key for community living for "men exist in the plural;" no human being exists in the singular. From this perspective, it is compelling to think of human existence not just as an independent biological experience but as both individual and collective, which translates into considering the essence of humans in the context of living with other humans, acknowledging their right to have rights, in the same way as a member of the polis do. Those living in my midst, living human lives, require recognition within the circle of belonging, which is granted by citizenship. My human life is only human insofar as those living in my midst also live human lives, and human life is only lived when their rights are recognized, when they are citizens. 


\subsection{A Way Forward with Citizenship (No to Non-citizenship)}

The previous sections have all approached the analysis on a theoretical level. This section will now gather the outcomes of the previous sections and will propose citizenship for low-skilled temporary foreign workers to mitigate the differences they experience compared with Canadian-born workers and immigrants.

From a Rational Theory perspective, low-skilled temporary foreign workers make the decision to move to Canada to perform low-skilled jobs after pondering the pros and cons of staying in their home country or moving temporarily to Canada. Advantages include higher wages; better labour conditions in Canada than in their countries of origin; the possibility of education for their children; better quality of life for their children; housing improvements; the possibility of investing back in their countries of origin and in their local communities of origin (Binford, 2009; Carvajal \& Stallman, 2016).

Disadvantages include separation of the family; children growing up without one of their parents (sometimes both); housing and labour confinement in Canada; likelihood of being exploited in Canada (contrasted against the possibility of even greater exploitation in their countries of origin); compared to Canadians, poor living conditions (which are even worse in their home country); highly physically demanding activities (similar to those in their country of origin) and likely health and safety issues (that may trigger deportation) (Basok, 2001a; Carvajal \& Stallman, 2016; Hennebry, 2012; Preibisch, 2014; Preibisch \& Binford, 2007).

Power asymmetries inherited from a colonial past, in combination with policies designed to favour the few in Canada, use and abuse Canada's position of power at the expense of those with no possibilities in their countries of origin. This use is presented 
as being beneficial for all (country of origin, country of destination, employers and workers). And in many ways it is. Workers' families do have a possibility of a better living and children do have improved access to education and communities in the countries of origin do improve. However, the program as it is, that is, without access to citizenship, creates subclasses in Canada (low-skilled temporary, undocumented, racialized groups) and fractures societies abroad. It is a system that not only validates but makes use of the exploitative structures operative in the workers' countries of origin. It is a system that that achieves competitive prices here by dividing families and eroding societies abroad.

As a non-neutral broker (mediator of shifting forces and interests), the Canadian state has designed non-citizenship programs that benefit Canada economically. While this is true, it is also true that Canada is immersed in a larger economic system that transcends its borders. From an economic perspective, external forces rule over Canada's productivity in some industries. This is especially evident in agriculture, where Canadian businesses face significant challenges to hire Canadian-born or immigrants (Conference Board of Canada, 2016). Canadian decision-makers, however, especially in the era of P. M. Harper, went beyond the demands of global competition by creating policies that plummeted wages. Policies encouraged employers to access increasingly cheaper labour. Neoliberal ideologies looking for markets 'free' from government intervention (or even deeper government intervention by lowering barriers to cheap foreign labour) set in motion a system of permanent temporality, which catalyzed a race to bottom of the lowest wages legally allowed in Canada. Additionally, the Canadian state also constructs in a top-down way skills and occupations through a system blind to skills essential to the economy. In contrast, the outcomes of this dissertation (and their 
associated critique) could provide a way to rethink the system with a bottom-up approach, by creating new categories that better respond to the reality of low-skilled labour in the context of the current global labour market. Future studies could explore a new structure created from the data itself and not from pre-conceived categories.

Although some low-skilled non-citizens are paid high wages in some occupations (see section 6.3.2. in chapter six), many are paid at wages lower than Canadian born and immigrant workers. As chapter six showed, low-skilled workers in seven occupations (mainly in agriculture and caregiving) have a high concentration in the lowest wage quartiles (see section 6.3.1. in chapter six). These seven occupations represent $52 \%$ of all NPRs (see Table 8 in chapter six). Some have wages even lower than minimum wage (see section 6.3.3. in chapter six) and some are paid lower wages than Canadian-born workers or immigrant employed in the same occupation. A lack of citizenship has become the primary means for policymakers to construct both a need for foreign labour and the foreign labourers themselves: only non-nationals from specific countries are capable and willing to perform those activities. Thus, globalization, neoliberal ideologies, lack of citizenship, power asymmetries on a global scale and a loss of power at the national level have been the key contributing factors driving the current system that provides Canada with cheap labour.

Ideally, it should be possible for globalization to work for all. But humanity first needs to move toward a system of global democracy, this referring to processes of decision making. Global democracy will need to be accompanied by processes of inclusion of minorities, of acceptance of diverse populations and of redistribution of wealth. A system that protects individual economies continues to divide and reap 
benefits at the expense of others with less power. Some people are trapped in the misfortune of being born in countries with "bad" citizenship. Those in the global North may be counted as having the fortune of free movement between countries and better labour conditions. In contrast, those in the global South have the misfortune of restrictions to move to the global North and of being locked in low-skilled/low-wage occupations. However, neoliberalism also transforms the reality of those with "good" citizenships, as evidenced by sharply rising levels of income inequality in most Western countries (Piketty, 2014). A global democracy that looks after the entire human race should be a long-term goal (Sassen, 2003).

In the meantime, countries like Canada, that use foreign labour and have immigration policies in place, should allow low-skilled workers a pathway to citizenship. This should be done because it is just (it is, in the words of Arendt, "human") to allow every person who works on Canadian soil and contributes to the Canadian economy to have the same treatment and same benefits that citizens have. As long as global economic forces outside Canada continue to influence the national economy, while the world reaches a situation that leads it into global governance, Canada should find a better balance between its economic goals and the demands for justice stemming from the Canadian Charter of Rights and Freedoms.

Agricultural workers, the group most exploited among low-skilled workers, should be the first to be considered. The Conference Board of Canada showed the increased need for agricultural workers and the desire of employers in agriculture to have a pathway to permanent residence for agricultural workers (Conference Board of Canada, 2016). Manitoba is already using the PNP as a way to solve agricultural labour needs 
(Conference Board of Canada, 2016). The primary limitation is that there are no federal pathways for low-skilled workers (other than LICs). A question that still remains is, if a pathway to permanent residence (and citizenship) is granted to agricultural workers, would they stay in agriculture? This would require further research. However, most of these workers are agricultural workers in their countries of origin (e.g. Mexico). One potential approach could be applying the pathway to citizenship of the Live-in Caregiver Program to agricultural workers. Given that the Canadian Charter of Rights and Freedoms guarantee freedom of mobility, the workers could not be attached to an industry as permanent residents nor as citizens. Research shows that involving communities and employers working together in settlement activities help in retaining foreign workers (Palacio, 2010). Therefore, the federal government could put in place a type of time-bounded initial temporary resident status (with guaranteed permanent residence) attached to the industry. The temporary status would serve as a period to help in the process of integration between the workers and the communities while they remain in the same industry. For example, three years in a temporary resident status linked to agriculture, but with the freedom to change employers if needed. Then they would have ensured permanent residence. The temporary status would grant workers freedom to move between their country of origin and Canada, while allowing them to work in agriculture only for the length of the temporary status. Afterwards they would be free to change industries (if desired), although the hope is for them to stay in both the industry and the communities of residence.

In spite of its hardships, the agricultural program is a program that Mexican workers seek (Carvajal \& Stallman, 2016). Each year, about 26000 workers come to 
Canada to work in Canadian farms on a temporary basis. Of the 26000 , more than $90 \%$ have come more than once (IRCC, 2016b) to work in Canada, pay taxes and contribute to Canada Pension Plan (Faraday, 2012a). Some of them have been coming for more than 25 years (Faraday, 2012a). One worker was found to have been coming for 31 years (Carvajal \& Stallman, 2016). While many of them would like to move to Canada, it may not be easy as they have deep roots in Mexico. Others would prefer to continue to come and go between Canada and Mexico (Carvajal \& Stallman, 2016). Not all would want to move to Canada, but they should have the option of doing so.

Workers in other occupations should also be given the chance to become permanent residents since many of them end up staying for up to four years, working and paying taxes. In response to those who would like the possibility of moving freely between Canada and their country of origin, the Canadian government might consider a type of citizenship that eases their mobility. This citizenship has to guarantee that they receive all the benefits that Canadians have, including access to language classes, equal wages to Canadian-born and immigrant workers and education for their children, when desired.

\section{Summary}

In addition to the discussion in this chapter, this thesis makes significant empirical and theoretical contributions. This dissertation provides three significant takeaways from the quantitative analysis, all presented in chapters five, six, seven and eight.

First, in scoping out a profile of low-skilled labour in Canada, this study uncovers 
its prevalence in three occupations: retail, caregiving and agriculture. Second, citizenship matters; there is a non-citizenship wage penalty for NPRs; there are variations in labour market experiences linked to citizenship status. As chapter six shows, 1) Of the 35 occupations analyzed for wage differences, 31 had negative differences and 4 had positive differences. This demonstrates that non-citizens had lower wages than immigrants and Canadian-born workers in about $89 \%$ of the occupations analyzed. 2) In some occupations wages improve when citizenship is accounted for among foreign-born low-skilled workers born in the same country. Third, wages and labour market experiences exhibit hierarchical structures among NPRs. Wages and general labour market experiences linked to specific characteristics like province of residence, rural/urban location and country of birth, exhibit hierarchical structures. As chapter seven shows, 1) Low-skilled NPRs tend to have larger negative wage differences (when their wages are compared to those of the CB and IMM) in Ontario than those of low-skilled workers in other provinces; 2) Wage differences (of NPRs compared to the CB and IMM) in rural areas are negative and larger (in absolute value) than those in urban areas (which are all negative too); 3) Those coming from mostly European countries with high official language ability work in the better paid lowskilled occupations. In contrast, highly physically demanding occupations are filled with workers coming mostly from the developing world; 4) In some occupations wages improve when citizenship is accounted for among foreign-born con-nationals. For example, cross-tabulation shows that the wages of Mexican-born immigrants (with citizenship) working in occupation 8431-General farm workers are considerably higher than those of Mexican NPRs working in the same occupation. This is also confirmed via 
regression analysis. Compared to low-skilled Canadian-born workers, low-skilled immigrants earn $7 \%$ less, which is not very distant from the wages of the Canadianborn. In contrast, low-skilled NPRs (without citizenship) earn almost $20 \%$ less than those born in Canada. This means that for the most part having access to citizenship does indeed increase the possibility of earning better wages.

Other relevant contributions include a detailed description of the place of lowskilled labour in Canada and a ground-breaking demographic profile of low-skilled labour, both in chapter five. The profile draws on the 2015 labour force survey as well as on the 2006 census data providing two different time frames (2006 and 2015) and general overview characteristics of low-skilled labour with citizenship in contrast with low-skilled labour without citizenship. The analysis showed that whereas retail is the occupation with the highest number of low-skilled workers in Canada, caregiving and agriculture have the highest number of low-skilled non-citizens (NPRs). It also shows that sex, not surprisingly, is a factor among low-skilled NPRs concentrated in caregiving. Additionally, the Philippines and Mexico were the dominant countries of origin for noncitizens.

The regression analysis in chapter eight introduces 11 regression models to analyze low-skilled labour in Canada. The outcomes of those models confirm what I showed in the descriptive chapters (six and seven), namely, that low-skilled non-citizens earn lower wages than their Canadian-born and immigrant counterparts. Chapter nine shows that the literature corroborates what was systematically shown in this dissertation: differences in labour market outcomes are linked to a lack of citizenship My dissertation also presents contributions at the level of policy, methodology 
and theory. In chapter three, the dissertation provides a critical historical analysis of the emergence of Canadian policies on low-skilled temporary foreign labour and the factors which it shaped it. The analysis confirms the policy origins of low wages among lowskilled non-citizens and reaffirms the policy process reflecting the emergence of stereotypes linked to constructed characteristics of workers including skills capacity, work ethic and sex.

As described in chapter four, the methodology of my dissertation makes a contribution by using 2006 census data and quantitative methods, including cross tabulation and regression analysis to show the impact that a lack of citizenship has on low-skilled workers' wages. The use of the 2006 census is critically important because it captures the beginning of the exponential increase of low-skilled temporary foreign labour in Canada described in the literature. Additionally, this analysis considers variables that have not been previously analyzed together in the context of all lowskilled occupations in Canada. Variables include sex, province of residence, rural/urban location and country of birth. This study takes a deep dive into low-skilled labour data that has not been explored before. The level of granularity this study engages yields also granular outcomes permitting a more focalized use for policy and program development.

Finally, chapter ten provides a theoretical contribution. This chapter has shown that a Rational Choice lens (understood as decisions reached according to self-interest) does not provide the entire picture of the situation of low-skilled workers. A Critical Social lens sheds critical light on the way in which the state, as a biased negotiator of powers, uses a lack of citizenship as a means to favour capital (in a capital labour 
dynamic). This chapter showed that agendas based on individualistic principles have benefited Canada's use of low-skilled labour but all too often at the expense of the lives of people without Canadian citizenship. It elaborates the ways in which a policy design based exclusively on Rational Choice Theory keeps noncitizens captive in a perennial cycle of non-belonging. Perennial non-citizenship in low-skilled occupations should therefore not be the means to increasing productivity. Canada could and should lead the way towards justice and fairness by providing low-skilled workers with a pathway to citizenship. This should be a pathway that ensures low-skilled TFWs' equal wages and labour experiences than those of the CB and IMM as well as a steady and stable supply of low-skilled labour to the Canadian economy. Low-skilled TFWs should also be eligible for access to language training and other settlement services. As evidenced in this dissertation, ability to speak one of Canada's official languages is one of the elements that structures a hierarchy of occupations among NPRs. Allowing low-skilled TFWs access to language training would be a way to level a hierarchy created by a system that constructs skills, occupations and wages differences. By providing a pathway to citizenship and access to settlement services to low-skilled workers (especially agricultural workers) Canada would lead the way in promoting economic efficiency as cherished by Neoclassical Economics in a context of social justice as cherished by Critical Social Theory. 


\section{Appendix 1 - Regression - Ordinary Least Square method.}

In a binary relationship of two variables (one dependent variable and one independent variable), this method looks for the closest estimated parameters of a line that would pass through a set of observed values of both dependent and independent variables.

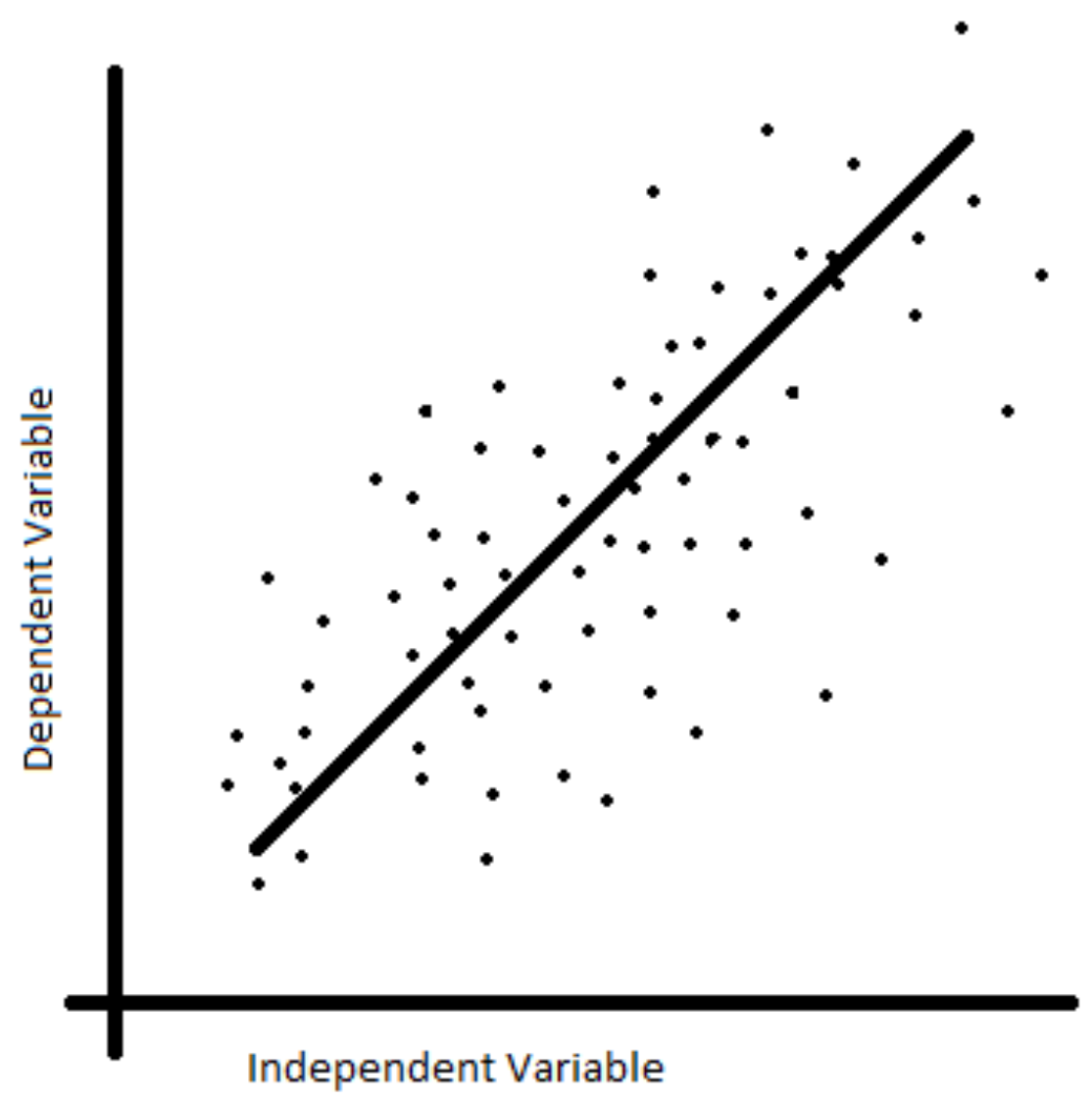

For a set of observed values (a set of values of the independent variable), $X$ can be established a linear relationship with a set of observed values of a dependent variable $y$. For a set of observed values, this relationship can be expressed as follows:

$$
y=\beta X+\varepsilon
$$


The OLS method looks for the smallest distance between the observed values and a fitted line. The method minimizes the differences between each observation and the estimated values of a line that passes through the observations.

Thus for a straight line $y=\alpha+\beta$

The OLS looks for the minimal distance vis-a-vis the observed values. The method minimizes the sum of squared residuals (errors) which is equivalent to minimizing the sum of squared differences between the observed dependent values and the observed independent values. For one set of observations of a single independent variable related to one set of observations of one dependent variable, the problem to be solved would be:

$\begin{aligned} \operatorname{Min} R(\alpha, \beta) \text { where } R(\alpha, \beta) & =\sum_{i=1}^{n} \varepsilon_{i}^{2} \\ & =\sum_{i=1}^{n}\left(y_{i}-\alpha-\beta x_{i}\right)^{2}\end{aligned}$

Where:

$$
\begin{aligned}
& \alpha=\text { Intercept } \\
& \beta=\text { Coefficients } \\
& \varepsilon=\text { Error }
\end{aligned}
$$

The solution to this problem of minimization lies in finding the coefficients (betas) and the intercept (alpha) that makes those distances minimal. Using different mathematical procedures (including derivatives), the estimated betas and the alpha are 
calculated. These coefficients (betas) provide information about the relationship of variability between the independent variable and the dependent variable, when the other predictors are held constant (so their variability or derivative with respect to the dependent variable is equal to 1). Transformations and considerations specific to the regression analysis are included in the chapter five (on regression analysis). 


\section{Appendix 2 - Research data Centre - Project proposal - Nelson Palacio}

1. Title of the Project

The value of citizenship: A comparison of labour market outcomes of low-skilled temporary foreign workers with those of other low-skilled workers in Canada.

2. Rationale and objectives of the study

- Clearly identify the specific questions or objectives of the project.

- State how the research will contribute to the knowledge in the field of study by summarizing the current literature and identifying the gap(s) to be addressed.

This research focuses on low-skilled workers and citizenship. It has generally been assumed that citizens have better lives than non-citizens, as citizenship is seen as the mechanism providing workers with an instrument of legal and economic protection as well as status. But does citizenship make a difference vis-à-vis the outcomes in the labour market when a worker is low-skilled? To answer this question, my research will compare the outcomes in the labour market of three groups of low-skilled workers: Lowskilled Non-Permanent Residents - LS-NPRs (in this research, low-skilled refugees and low-skilled TFWs), low-skilled immigrants (permanent residents and naturalized immigrants - LS-IMM) and low-skilled Canadian-born workers (LS-CB).

My PhD research will answer the question: How do the outcomes in the labour market of low-skilled citizens and permanent resident workers compare to those of lowskilled temporary foreign workers in Canada? Some research that looks into the outcomes in the labour market of low-skilled workers can be cited. High-skilled immigrant workers in the United States (Borjas, 1985) and in Canada (Janz, 2004) have higher earnings growth than low-skilled immigrant workers. In Canada elements like country of origin significantly determine wage growth (Aydemir \& Skuterud, 2005; Bloom et al.,1995; Pendakur \& Pendakur, 2002;); low-skilled immigrants in the United States drive wages down on low-skilled intensive jobs (Cortes, 2008). No definitive negative effects on the native-born wages in the United States are observed in places where immigrants reside (Borjas, 1996). Others found that evidence that low-skilled immigrants harm the native-born opportunities is scant (Card, 2005). In Canada, Zhang (2002) shows that less skilled immigrants' accumulation of skills and labour stability increases wage growth among low-skilled immigrants.

A gap in the literature can be identified for there are not many quantitative approaches that exclusively address low-skilled labour in Canada. Contrary to the exploration of rights-related aspects of low-skilled labour migration, econometric and quantitative analysis of the broader low-skilled labour in Canada has not been widely examined. Derrick Thomas (2010) from Stats Canada presents an examination of temporary foreign workers in Canada. His study makes a profile of LS-NPRs in Canada. While this study identifies some differences between LS-NPRs and provides information 
on some low-skilled NPRs, the focus of the study is the broader group of TFWs. This research addresses that gap.

The research will address this question through two theoretical lenses: Rational Theory (RT) and Social Critical Theory (SCT). RT is chosen because it provides a framework for systematic quantitative analysis to analyse patterns and because it is broadly used in policymaking circles. However, this theory may be blind to ethical issues that may arise. Therefore, the study will also draw on a Social Critical Theory lens (based on Marxist analysis), which provides a framework to evaluate value-related issues. Social Critical Theory will be especially useful to reinterpret the quantitative analysis, especially the evaluation of the value of citizenship as a means for economic betterment.

This question is relevant for three reasons: First, there seems to exist a sort of hierarchy of labour market outcomes. LS-NPRs may be near the bottom of this hierarchy. This research intends to gauge the extent to which this is true. Second, comparing labour market outcomes among LSNPRs, LS-IMM and LS-CB provide another piece of information that will contribute to the debate on the integration in the labour market of low-skilled workers. Third, the research will enhance the debate on the value of citizenship as a door to better labour market outcomes and as an instrument for economic protection.

Keeping in mind that the labour market is sensitive to industries and occupations, considering the labour market outcomes of LS-NPRs and other low-skilled workers in the Canadian labour market leads to the following hypothesis:

1. LS NPRs employment income is much lower than that of LS-CB or than that of LS-IMM, or than that of HSILS.

2. LS-NPRs work more hours per week than LS-CB and more than LS-IMM

3. Proposed data analysis and software requirements

- What is the proposed statistical methodology? How is it suitable for this project?

This research has two main components: one that requires a quantitative analysis and one that requires qualitative analysis. The confidential data will be used in the quantitative part. The qualitative part will use the outcomes of the quantitative part to question the value of citizenship among low-skilled individuals vis-à-vis their outcomes in the labour market. The quantitative part will use 2006 census data. The analysis will focus on the labour-market outcomes by occupation and industry for each of the groups under scrutiny (LS- NPRs, LS-IMM and LS-CB).

Using statistical analysis methods, the research will look into variables that represent the outcomes in the labour market of low-skilled workers and will gauge their relationship with variables that either represent intrinsic characteristics or external determinants. To accomplish this, the analysis will focus on comparing variables within the groups and between groups. The analysis will require the following statistical 
methodologies:

Variable correlation analysis to evaluate correlations between intrinsic characteristics of the workers and their outcomes. These characteristics will include gender, age and education. This type of analysis will keep in mind the types of variables ${ }^{117}$ to be compared and the number of independent variables. For example, if both independent and dependent variables are categorical their relationship will be tested using Chisquare Test.

Linear Regression analysis to gauge the effects of the explanatory variables in each group including gender, age, province of residence, level of education, industry and occupation on the variables chosen to evaluate the outcomes in the labour market (namely, wages and hour of labour). This will provide another element of analysis to quantify how much these variables contribute to changes on the variables that represent the outcomes in labour market.

Regression analysis to predict the effect of each independent variable on the dependent variables.

- Will the volume of descriptive statistics be greater than that of a typical $R D C$ proposal (i.e., 35-50 frequencies or crosstabs)? If yes, please explain.

No

- What software will be utilized?

The research will use SPSS

4. Data requirements

The research will use 2006 census data. Census data is preferred since, contrary to other databases with labour force information, the census contains information of all groups to be compared including TFWs. The research will only choose low-skilled workers (LS-NPRs, LS-CB and LS-IMM)

- An explanation of why access to the confidential data (as opposed to public use microdata files) is necessary.

The research was initially going to use the 2006 Public Use Microdata File (PUMF). However, the PUMF data file was insufficient. Selection of low-skilled temporary foreign worker cases was based on the following criteria: those who are employed; between the ages of 18-65; those whose earnings are between 0 dollars and 99,000 dollars; working full time; selecting only those who are TFWs and refugee claimants (excluding foreign students from the temporary resident population). After this selection, a cross tabulation of the immigration status variable with the occupations variable and selecting only those in low-skilled occupations, the total cases of lowskilled TFWs was reduced to (563). This number in the sample is too small, which make comparisons with the other populations of low-skilled workers difficult.

${ }^{117}$ There are three types of variables: 
Therefore, the next step is to use the entire population present in the 2006 census. The whole population of NPRs in the 2006 census is over 112000 cases (Thomas, 2010). Having access to the entire population from the 2006 census solves the difficulties that the PUMF sample presents regarding sample size and allows a more solid analysis. The entire population permits a more comprehensive comparison between LS-NPRs with LS-CB and LS-IMM.

- Which survey file/files or cycles are to be used?

- Will the number of data sets be greater than that of a typical RDC proposal (i.e., 1-3 datasets)? If yes, please explain.

No

- Will datasets be linked in any fashion to other Statistics Canada datasets or other data sets? If you plan to combine data from more than one source in your analysis, please provide adequate detail on how the data from each source will be combined in this analysis. In particular, your description should outline whether you plan to combine data from 2 or more sources to increase your sample size; or to link aggregate contextual data to the micro-records; or whether your plan is to link micro- record to micro-record together from 2 or more sources. Should you plan latter please be advised that a second approval process is required by senior management at Statistics Canada and that the linkage must be conducted at Statistics Canada. Additionally, there may be a fee for these services. If yes, please explain the nature of this record linkage and its intended purpose.

No other datasets will be used

- Provide a statement that the confidential data file(s) identified is (are) in fact suitable for the proposed research.

- What are the variables to be used?

This research will require looking at several variables including: employment earnings, hours of labour and type of work. These will be considered in relation to variables including gender, age, education, immigrant status, occupation and industry of labour. Using social critical theory, the qualitative part will analyze the quantitative findings through the light of the main developments on citizenship from a value perspective. The labour market outcomes will be analyzed in terms of the following key variables.

\section{Dependent Variables}

wages Wages and salary income

hrswrk Hours worked for pay or in self-employment

Independent variables

Geographic variables 
pr Province

cma Census Metropolitan Area

\section{Demographic variables}

agegrp Age groups: Refers to the age at last birthday (as of the census reference date, May 16, 2006). This variable is derived from date of birth.

sex Sex

Place of birth, immigration and citizenship

citizen Citizenship

immstat Immigrant status

pob Place of birth of respondent (country of birth)

yrimm Year of immigration

Visible minority

vismin Visible minority population

Language

fol First official language spoken

\section{Education}

attsch Attendance at school: Refers to attendance during the nine -month period between September 2005 and May 16, 2006.

hdgree Highest certificate, diploma or degree

\section{Labour market activities}

cow Class of worker: This variable classifies persons who reported a job into the following categories: (a) paid worker (b) self-employed worker

fptwk Full-time or part-time weeks worked in 2005

hrswrk Hours worked for pay or in self-employment

Ifact Labour force activity: Refers to the labour market activity of the population 15 years

of age

and over in the week (Sunday to Saturday) prior to the day of the census (May 16, 2006). Respondents

were classified as 'Employed', 'Unemployed', or 'Not in the labour force.'

naics Industry (based on the 2002 North American Industry Classification System [NAICS 2002])

nochrd Occupation (Employment equity designations - based on the National

Occupational Classification): Refers to the kind of work persons were doing during the reference week, as determined by their kind of work and the description of the main activities in their job. Employment equity groups are defined based on the National Occupational Classification (NOC).

- What is the specific population of interest in the required data set(s)?

The populations of interests are:

1. Low-skilled temporary foreign workers

2. Low-skilled immigrants 


\section{Low-skilled Canadian-born}

4. High-skilled immigrants working in low-skilled occupations

- What is the expected sample size of the population of interest? Is this sufficient to complete the analysis as well as respect the confidentiality of the respondents? Please explain

The whole population of NPRs in the 2006 census is over 112000 cases (Thomas, 2010). Having access to the entire population from the 2006 census solves the difficulties that the PUMF sample presents regarding sample size and allows a more solid analysis.

- Does geography play a role in the data analysis? If it is based on small levels of geography please describe how it will be defined, what variables will be used and the potential implications this may have on the sample size.

A dummy variable will be created using the Census Metropolitan Area - cma and province $p r$ to established a difference cma versus non-cma outcomes.

5. Expected project start and end dates:

Start date: July 2013

End date: September 2014

6. Expected product: Graduate level thesis or dissertation

7. References

Aydemir A., \& Skuterud, M. (2005). Explaining the Deteriorating Entry Earnings of Canada's Immigrant Cohorts, 1966 - 2000. The Canadian Journal of Economics / Revue canadienne d'Economique, 38(2), 641-671.

Bloom, D.E., Grenier G. \& Gunderson M., (1995). The Changing Labour Market Position of Canadian Immigrants. Canadian Journal of Economics, 28, 987-1005.

Borjas, G. (1985). Assimilation, Changes in Cohort Quality, and the Earnings of Immigrants. Journal of Labor Economics, 3(4), 463-489.

Borjas, G. (1996). The New Economics of Immigration. The Atlantic Monthly, 278(5), 7280.

Card, D. (2005). Is the New Immigration Really So Bad? National Bureau of Economic Research. Working Paper 11547. Retrieved from http://www.nber.org/papers/w11547

Cortes, P. (2008). The Effect of Low-Skilled Immigration on U.S. Prices: Evidence from CPI Data. Journal of Political Economy, 2008, 116(3), 381-422.

Janz, T. (2004). Low-paid Employment and Moving Up: A Closer Look at Full-time, Fullyear Workers, 1996-2001. Income Statistics Division; Catalogue no. 75F0002MIE2004009.

Pendakur, K. \& Pendakur, R. (2002). Colour my World: Have Earning Gaps for Canadian-born Ethnic Minorities Changed Over Time? Canadian Public Policy- 
Analyse de politiques, 28(4), 489-512.

Thomas, D. (2010, Winter). Foreign National Working Temporarily in Canada, in Canadian Social Trends. No 90. Statistics Canada.

Zhang, X. (2002). Wage Progression of Less Skilled Workers in Canada: Evidence from the SLID (1993-1998). No 194, 11F0019MIE. ISSN: 1205-9153 ISBN: 0-66233013-7. Business and Labour Market Analysis Division, Statistics Canada. 


\section{Appendix 3A - Distribution in the Unweighted PUMF files}

From an immigration status perspective, Table A1 presents the distribution of the subsample (the unweighted PUMF file). Calculations in this section are only indicative. They only demonstrated the unsuitability of the PUMF files.

\begin{tabular}{|l|r|r|}
\hline \multicolumn{2}{|l|}{ Table A1: Unweighted PUMF files distribution by immigration status } \\
\hline Immigration Status (immstat) & Frequency & Percentage \\
\hline $\begin{array}{l}\text { Non-Permanent Residents (TFWs, foreign students } \\
\text { and refugee claimants) }\end{array}$ & 7,104 & $0.8 \%$ \\
\hline Canadian-born individuals & 670,441 & $79.4 \%$ \\
\hline Immigrants & 166,881 & $19.8 \%$ \\
\hline Total & 844,476 & $100.0 \%$ \\
\hline
\end{tabular}

The distribution of the unweighted PUMF files already makes evident the smallness of the populations in the PUMF files (especially the temporary resident population). The approximate 7K NPRs in the PUMF files contrast with the 112 identified by Thomas (2010) for the entire Census. This raises a flag indicating the PUMF files may not be enough and that the research may have to use the whole census.

Continuing with the PUMF files analysis, an even smaller population was required for the analysis: the low-skilled population.

Population required: Individuals who in 2005 ,

- were working in low-skilled occupations,

- who were employed in a paid full-time job, 
- between the ages of 18 to 65 ,

- with earnings not higher than 99,000 dollars per year (used only as an indicative value).

- Some variables were used to select the population.

\section{Case Selection}

For mathematical and analytical considerations, the populations of low-skilled workers need to be comparable. The following are the criteria used to select the population in the PUMF files:

- Employed (vis-a-vis unemployed): All TFWs are employed. Hence, individuals in the other two populations (low-skilled CB and and low-skilled IMM) must also be employed. The variable "labour force activity" Ifact allows selecting only those employed. 'Labour force activity' refers to the "labour market activity of the population 15 years of age and over in the week (Sunday to Saturday) prior to Census Day (May 16, 2006)." (Respondents were classified as 'Employed,' 'Unemployed,' or 'Not in the labour force.'

- Employed (vis-a-vis self-employed): All TFWs are employed, not self-employed. The variable "class of worker" cow, permits this selection. This variable classifies persons who reported a job into the following categories: (a) paid worker (b) selfemployed worker.

- Between the ages of 18-65. This was done through the variable agegrp

- With employment earnings below 99000 dollars: Although it is very unlikely that there will be low-skilled workers with high levels of income, this first approach considers only those whose earnings are between 0 dollars and 99000 dollars 
during the year 2005. This was done through the variable wage.

- Working in full-time jobs: Temporary Foreign Workers coming under Foreign Worker Programs work in full-time jobs. Individuals in the other populations must be working in full-time jobs. The full-time or part-time" variable (fptwk) allowed this selection.

- Excluding foreign students and including TFWs and refugee claimants. From the group of Non-Permanent Residents (TFWs, foreign students, refugee claimants, and people with temporary resident visas under humanitarian grounds). With the PUMF sample the initial focus was on TFWs, but it was not possible to separate the three groups. Only foreign students could be separated from the sample. The variable "attendance at school" attsch was used to extract foreign students from the sample. A more detailed explanation on the selection of refugees and the extraction of foreign students from the NPR population is included later in this chapter (in the section Selection of population: criteria and considerations prior data extraction).

Without separating low-skilled from high-skilled, a cross tabulation with the immigration status variable shows the distribution in Table A2:

\begin{tabular}{|c|r|r|}
\hline \multicolumn{3}{|l|}{ Table A2: High- and Low-Skilled Reported in PUMF files } \\
\hline Immigration status & \multicolumn{1}{|c|}{ Frequency } & \multicolumn{1}{c|}{ Percent } \\
\hline 1. Non-Permanent Res. & 1,283 & $0.6 \%$ \\
\hline 1. Canadian born & 160,837 & $78.7 \%$ \\
\hline 1. Immigrant & 42,332 & $20.7 \%$ \\
\hline Total & 204,446 & $100.0 \%$ \\
\hline
\end{tabular}


- Low-skilled only: Using the variable nochrd, low-skilled workers were selected by choosing only those working in low-skilled occupations. Nochrd, refers to the "kind of work persons were doing during the reference week, as determined by their kind of work and the description of the main activities in their job.

Employment equity groups are defined based on the National Occupational Classification (NOC)" (PUMF files dictionary 2006, page 65). The following table (Table A3) shows the distribution after separating the low-skilled population.

Table A3: Distribution by Immigration Status, Separating Low- from High-Skilled

\begin{tabular}{|l|c|c|c|c|}
\hline & $\begin{array}{c}\text { Non- } \\
\text { Permanent } \\
\text { Resident }\end{array}$ & Canadian-born & Immigrant & Total \\
\hline High-skilled & 720 & 114,856 & 27,861 & 143,431 \\
\hline Low-skilled & 563 & 45,981 & 14,471 & 61,015 \\
\hline Total & 1,283 & 160,837 & 42,332 & 204,446 \\
\hline
\end{tabular}

The total number of low-skilled temporary foreign workers (563) in the sample is too small, which makes comparisons among low-skilled workers difficult. This is the case because this research explores the outcomes in the labour market of different kinds of low-skilled workers, which requires dividing the sample even more. Therefore, the next possible option is using the entire population present in the 2006 census, for the entire population of TFWs in it is over 112000 cases.

Accessing this information required presenting a project plan to the Stats Canada Research Data Centre (RDC) at the University of Toronto, (see Appendix 2). Having access to the entire population from the 2006 census solves the difficulties that the 
PUMF sample presents regarding sample size and allows a more solid analysis. 


\section{Appendix 3B - Variables Definitions extracted from the Stats Canada's 2006}

\section{Census 2006}

According to information gathered from the Statistics Canada website, the 2006 census has six main questionnaires: the 2B (long form), the one used in this research. The Form 2B, or long Population Questionnaire, "collects information of 1/5 of all usual residents of all private dwellings." (Statistics Canada, 2013). The long form samples one in five households (20\%). This form used to be mandatory but was replaced by a voluntary form in 2011. This new form provided the information collected in the 2011 National Household Survey (NHS). These changes have introduced problems of reliability to the information collected. According to Elliot (2010), the change from mandatory to voluntary is problematic in three different ways: 1) communities with low response rates are suppressed, which leaves some communities with no reliable information. 2) a significant level of non-response bias appears when the characteristics of respondents and non-respondents are different. Large non-response rates, as it is the case in the $2011 \mathrm{NHS}$, exacerbate biases. 3) the information is used as a reference for other surveys, which in a way replicates the inaccuracy present in the NHS.

Following I include the list of literal definitions of the variables I used in the analysis, they are extracted from the 2006 Census Codebook:

Aboriginal Status and Visible Minority Status (DVISMIN):"The visible minority group to which the respondent belongs. The Employment Equity Act defines visible minorities as 'persons, other than Aboriginal peoples, who are nonCaucasian in race or non-white in colour'. 'South Asian' includes, for example, East Indian, Pakistani, Sri Lankan, etc. 'Southeast Asian' includes, for example, Vietnamese, Cambodian, Malaysian, Laotian, etc. 'West Asian' includes, for example, Iranian, Afghan, etc. 'Visible minority n.i.e.' includes respondents who reported a write-in response such as Guyanese, West Indian, Kurd, Tibetan, Polynesian, Pacific Islander, etc. 'Multiple visible minority' includes respondents who reported more than one visible minority group by checking two or more 
mark-in circles, e.g., 'Black' and 'South Asian'. 'Aboriginal self-reporting 'includes respondents who reported 'Yes' to the Aboriginal identity question (Question 18): these respondents were not required to answer the Population Group question" (Statistics Canada, 2008b, p.969).

Attendance to School: "Attendance at school - refers to attendance during the nine-month period between September 2005 and May 16, 2006. An individual's attendance could be either full-time or part-time (day or evening), even if the individual dropped out after registration. Attendance was counted only for courses which could be used as credits towards a certificate, diploma or degree from a recognized educational institution (elementary or secondary school, registered apprenticeship programs, trade schools, colleges, CEGEPS and universities). Recognized education institutions also included seminaries, schools of nursing, private business schools, private or public trade schools, institutes of technology, vocational schools, or schools for people who are deaf or blind. School attendance was not counted for training received" (Statistics Canada, 2008b, p.85).

The categories of this variable are:
Code Description
$1 \quad$ Did not attend school
2 Attended school
3 Not applicable (Institutional residents)

Age (AGE): Is described as "the age at last birthday (as of the census reference date, May 16, 2006). This variable is derived from date of birth" (Statistics Canada, 2008b, p. 30).

Class of Worker Derived (COWD): "classifies persons who reported a job into the following categories: (a) persons who worked mainly for wages, salaries, commissions, tips, piece-rates, or payments 'in kind' (payments in goods or services rather than money); (b) persons who worked mainly for themselves, with or without paid help, operating a business, farm or professional practice, alone or in partnership; (c) persons who worked without pay in a family business, farm or professional practice owned or operated by a related household member. Note: work without pay in a family business does not include unpaid housework, unpaid child-care, unpaid care to seniors and volunteer work. The job reported was the one held in the week (Sunday to Saturday) prior to enumeration (May 16, 2006) if the person was employed, or the job of longest duration since January 1,2005 , if the person was not employed during the reference week. Persons with two or more jobs in the reference week were asked to provide information for the job at which they worked the most hours" (Statistics Canada, 2008b, p. 624).

The categories of this variable are: 
Code Description

1 Unpaid family workers - Worked without pay for a relative in a family business or farm

2 Not applicable

3 Paid worker - Originally self-employed without paid help, incorporated

$4 \quad$ Paid worker - Originally self-employed with paid help, incorporated

5 Paid Worker - Working for wages, salary, tips or commission

6 Self-employed without paid help, not incorporated

$7 \quad$ Self-employed with paid help, not incorporated

Only those with code " 5 " were selected.

Full-time - Part-time Weeks Worded (FPTIM): Applies to persons 15 years of age and over, excluding institutional residents, who worked for pay or in selfemployment in 2005. These persons were asked to report whether the weeks they worked in 2005 were full-time weeks (30 hours or more per week) or not, based on all jobs held. Persons with a part-time job for part of the year and a fulltime job for another part of the year were to report the information for the job at which they worked the most weeks" (Statistics Canada, 2008b, p. 619).

The categories of this variable are:

\section{Code Description}

$1 \quad$ Worked mainly full-time weeks in 2005

2 Not applicable, <15 years, institutional residents, did not work in 2005

3 Worked mainly part-time weeks in 2005

Only those with code "1" were selected.

Immigration Status (IMMDER): "Indicates whether the respondent is a nonimmigrant, an immigrant or a Non-Permanent Resident. Non-immigrants are persons who are Canadian citizens by birth. Immigrants are persons who are, or have ever been, landed immigrants in Canada (includes immigrants who landed in Canada prior to Census Day, May 16, 2006). Non-Permanent Residents are persons from another country who, at the time of the census, held a Work or Study Permit, or who were refugee claimants, as well as family members living with them in Canada" (Statistics Canada, 2008b, p. 402).

The categories of this variable are:

\section{Code Description}


$1 \quad$ Not applicable (Institutional resident ${ }^{118}$ )

2 Non-immigrants

3 Immigrants

$4 \quad$ Non-Permanent Residents

Industry (NAICSECF): "Refers to the general nature of the business carried out in the establishment where the person worked. If the person did not have a job during the week (Sunday to Saturday) prior to enumeration (May 16, 2006), the data relate to the job of longest duration since January 1, 2005. Persons with two or more jobs were required to report the information for the job at which they worked the most hours. The 2006 Census industry data are produced according to the 2002 NAICS. The NAICS provides enhanced industry comparability among the three North American Free Trade Agreement (NAFTA) trading partners (Canada, United States and Mexico). This classification consists of a systematic and comprehensive arrangement of industries structured into 20 sectors, 103 subsectors and 328 industry groups. The criteria used to create these categories are similarity of input structures, labour skills or production processes used by the establishment. For further information on the classification, see North American Industry Classification System, Canada,2002, Catalogue No. 12-501XPE" (Statistics Canada, 2008b, p. 615).

The variable includes the following categories:

\section{Code Description}

1 Not applicable, age < 15 years, worked before 2000 or never worked

211 Agriculture, forestry, fishing and hunting

321 Mining and oil and gas extraction

422 Utilities

523 Construction

$6 \quad 31-33$ Manufacturing

$7 \quad 41$ Wholesale trade

8 44-45 Retail trade

9 48-49 Transportation and warehousing

$10 \quad 51$ Information and cultural industries

1152 Finance and insurance

1253 Real estate and rental and leasing

1354 Professional, scientific and technical services

1455 Management of companies and enterprises

1556 Services administratives

\footnotetext{
${ }^{118}$ An Institutional Resident is a "Person, other than a staff member and his or her family, who lives in an institution, such as a hospital, a nursing home or a jail. It refers to a resident of an 'institutional' collective dwelling, other than staff members and their families" (Statistics Canada, 2008a).
} 
61 Educational services

$17 \quad 62$ Health care and social assistance

1871 Arts, entertainment and recreation

1972 Accommodation and food services

2081 Other services (except public administration)

2191 Public administration

Hours: "The actual number of hours that persons 15 years of age and over, excluding institutional residents, worked for pay or in self-employment at all jobs held in the week (Sunday to Saturday) prior to Census Day (May 16,2006). This includes hours worked for wages, salaries, tips, commissions, piece-rate payments or payments 'in kind' (payments in goods or services rather than money). Hours worked in one's own business, farm or professional practice or hours worked without pay in a family business, or farm or professional practice, owned or operated by a relative living in the same household are also included" (Statistics Canada, 2008b, p. 620).

Labour Market Activities (LFTAG): "labour market activity of the population 15 years of age and over, excluding institutional residents, in the week (Sunday to Saturday) prior to Census Day (May 16 2006). Respondents were classified as either 'Employed', or 'Unemployed', or 'Not in the labour force'. The labour force includes the employed and the unemployed" (Statistics Canada, 2008b, p. 624).

The categories of this variable are:

\section{Code Description}

1 Employed - Worked in reference week - Armed Forces

2 Employed - Worked in reference week - Civilian

3 Employed - Absent in reference week - Armed Forces

4 Employed - Absent in reference week - Civilian

5 Unemployed - Temporary layoff - Experienced - Did not look for work

6 Unemployed - Temporary layoff - Experienced - Looked for full-time work

$7 \quad$ Unemployed - Temporary layoff - Experienced - Looked for part-time work

8 Unemployed - New job - Experienced - Did not look for work

$9 \quad$ Unemployed - New job - Experienced - Looked for full-time work

10 Unemployed - New job - Experienced - Looked for part-time work

11 Unemployed - New job - Inexperienced - Did not look for work

12 Unemployed - New job - Inexperienced -Looked for full-time work

13 Unemployed - New job - Inexperienced - Looked for part-time work

14 Unemployed - Looked for full-time work - Experienced

15 Unemployed - Looked for part-time work - Experienced

16 Unemployed - Looked for full-time work - Inexperienced 
17 Unemployed - Looked for part-time work - Inexperienced

18 Not in labour force - Last worked in 2006

19 Not in labour force - Last worked in 2005

20 Not in labour force - Last worked before 2005

$21 \quad$ Not in labour force - Never worked

22 Not applicable, < 15 years, institutional residents

Only those with code $<5$ ( 1 to 4 ) were selected.

Level of Education (HCDD): "Information indicating the person's most advanced certificate, diploma or degree. This is a derived variable obtained from the educational qualifications questions, which asked for all certificates, diplomas and degrees to be reported...users should be aware that underreporting of high school completions contributed to elevated results for the less than high school category in censuses prior to 2006, as well as impacted the data for high school graduation" (Stats Canada, 2008b, p. 1001).

The variable is originally coded as:

\section{Code Description}

$1 \quad$ None

2 High school graduation certificate or equivalency certificate

3 Other trades certificate or diploma

$4 \quad$ Registered apprenticeship certificate.

5 College, CEGEP or other non-university certificate or diploma from a program of 3 months to less than 1 year

6 College, CEGEP or other non-university certificate or diploma from a program of 1 year to 2 years

7 College, CEGEP or other non-university certificate or diploma from a program of more than 2 years

8 University certificate or diploma below bachelor level

9 Bachelor's degree

10 University certificate or diploma above bachelor level

11 Degree in medicine, dentistry, veterinary medicine or optometry

12 Master's degree

13 Earned doctorate degree

Occupation (NOCHRD): "based on the 2006 National Occupational Classification- Refers to the kind of work persons were doing during the reference week, as determined by their kind of work and the description of the main activities in their job. Data are available for persons 15 years of age and over, excluding institutional residents ("person other than a staff member and his or her family, who lives in an institution, such as a hospital, a nursing home or a jail" (Stats Canada, 2017b). If the person did not have a job during the week prior to enumeration, the data relate to the job of longest duration since January 1 , 2005. Persons with two or more jobs were to report the information for the job at 
which they worked the most hours" (Statistics Canada, 2008b, p. 626).

Place of Birth - Country (POB_CNTRY) ("Regions of the World"): "It refers to the country where the respondent was born. The abbreviation "n.o.s." means "not otherwise specified". Data for provinces and territories of birth should be used with caution due to data quality concerns that are linked to the functionality of the selection mechanism for choosing a province of birth on the 2006 Census Internet 2B Questionnaire. Data for provinces and territories of birth are not comparable to data collected in previous censuses" (Statistics Canada 2008b, p. 41).

This variable has 241 categories. This variable was recoded and renamed "Regions of the World" for the regression analysis. The categories of the old variable were regrouped according to the criteria in each new group as it is described:

\section{Code Description}

2 = Canada $(1=2)(2=2)$

$3=$ USA, St Pierre et Miquelon \& Greenland (15 thru 17=3) (For sample size purposes, this subcategory was merged with Canada in all models)

$4=$ Latin America and the Caribbean (18 thru 64=4)

$5=$ West, North and Central Europe (65 thru 73=5) and (89 thru 95=5)

$6=$ Eastern Europe and USSR (all ex-Soviet Union countries and Eastern Europe) (74 thru 88=6), (106 thru 111=6) and (186 thru 193=6)

7 = South Europe - (Spain, Portugal, Italy etc.) (96 thru 105=7)

$8=$ Sub-Saharan Africa (Excepting South Africa, Namibia and Swaziland) (112 thru 147=8) and (155 thru 165=8)

9 = South Africa, Swaziland, Namibia and Oceania (220 thru 241=9) and (166 thru 168=9)

$10=$ North Africa and Middle East (including Turkey and 
Cyprus) (148 thru 154=10) and (170 thru $185=10)$

$11=$ India

12 = Far East Asia 1 (Japan, South Korea, etc.) (195 thru 201=12)

$13=$ Far East Asia 2 (Cambodia, Vietnam, etc.) (202 thru 212=13)

14 = East Asia (Pakistan, Sri Lanka, Afghanistan, Nepal, Bhutan, (216 thru $219=14)$ and $(169=14)$

15 = China $(215=15)$

Rural Urban (RUIndFG): "An urban area has a minimum population concentration of 1,000 persons and a population density of at least 400 persons per square kilometre, based on the current census population count. All territory outside urban areas is classified as rural. On-reserve CSDs are excluded from this category. A census metropolitan area (CMA) is a large urban area and has a population of at least 100,000 . Urban non-census metropolitan areas are smaller urban areas with a population of less than 100,000. Rural areas include remote and wilderness areas and agricultural lands, as well as small towns, villages and other populated places with a population of less than 1,000. On-reserve CSDs (CENSUS SUBDIVISIONS) are excluded from this category" (Statistics Canada, 2008b, p. 17).

Wages: "Refers to gross wages and salaries before deductions for such items as income tax, pensions, employment insurance, etc. Included in this source are military pay and allowances, tips, commissions and cash bonuses, benefits from wage-loss replacement plans, taxable benefits, research grants and royalties, as well as all types of casual earnings in the 2005 calendar year" (Statistics Canada, 2008b, p. 997).

Note 1:" For the 2006 Census, $89.1 \%$ of the consenting respondents were found in the

2005 tax file" (Olson \& Maser, 2010).

Note 2:

"In all censuses, the income concept excluded gambling gains and losses, lottery prizes, money inherited during the year in a lump sum, capital gains or losses, receipts from the sale of property, income tax refunds, loan payments received, lump-sum settlements of insurance policies, rebates received on property taxes, refunds of pension contributions as well as all income 'in kind', such as free meals, living accommodations, or agricultural products produced and consumed on the farm" (Statistics Canada, 2009a).

Note 3:

"To better approximate the concept of income under the taxation system, the following changes were made to source components for 2005. Taxable benefits, 
research grants and royalties are now included as part of Wages and salaries. The latter two items were formerly included as part of Other money income while taxable benefits and allowances were formerly excluded. Regular payments to motor vehicle accident victims from provincial or territorial governments, formerly included in Other income from government sources, are now excluded" (Statistics Canada, 2009a).

Components of Income in 2005

\begin{tabular}{|c|c|c|}
\hline $\begin{array}{l}\text { Market income } \\
\text { Employment income } \\
\text { Wages and salaries } \\
\text { Self-employment income } \\
\text { - Net farm income } \\
\text { Net non-farm income from } \\
\text { unincorporated } \\
\text { business/professional } \\
\text { practice } \\
\text { Dividends, interest and } \\
\text { other investment income } \\
\text { Retirement pensions, } \\
\text { superannuation and } \\
\text { annuities } \\
\text { Other money income }\end{array}$ & + & \begin{tabular}{l}
\multicolumn{1}{c}{$\begin{array}{c}\text { Government transfer } \\
\text { payments }\end{array}$} \\
Old Age Security pension \\
and Guaranteed Income \\
Supplement \\
Canada and Quebec \\
Pension Plan benefits \\
Employment Insurance \\
benefits \\
Child benefits \\
Other income from \\
government sources
\end{tabular} \\
\hline & & \\
\hline \multicolumn{3}{|c|}{ Total income } \\
\hline & $=$ & \\
\hline Income tax paid & + & After-tax income \\
\hline
\end{tabular}

Source: Statistics Canada, Census Subject Matter Program.

Weeks: "This variable is intended for the population 15 years of age and over, excluding institutional residents. Refers to the number of weeks in 2005 during which persons worked for pay or in self-employment at all jobs held, even if only for a few hours. It includes weeks of paid vacation, weeks on sick leave with pay, and all weeks in which training was paid for by the employer" (Statistics Canada, 2008b, p. 681). 


\section{Appendix 3C - 2006 NOC System of Classification of Occupations}

The 2006 NOC classification groups more than 30000 job titles in 520 occupational groups (NOC 4). Occupational groups refer to the grouping of jobs according to skill types, skill levels, industry and occupational mobility. Occupational groups are also known as NOC4 occupations and it refers to the four-digit label assigned to each occupational group. NOC4 occupational groups are regrouped in 3 digit groups, also known as NOC3 groups. These groups are subsequently grouped into two digit groups, also known as NOC2 groups or Major Groups. These groups are subsequently grouped in 1 digit groups, also known as NOC1 groups or Skill Type groups.

For example, NOC1 group "8" corresponds to the Skill Type Group "Natural Resources, Agriculture and Related Production Occupations". This group is made up of the following NOC2 groups (two digit groups):

- Major Group 82 - Supervisors and technical occupations in natural resources, agriculture and related production

- Major Group 84 - Workers in natural resources, agriculture and related production

- Major group 86 - Harvesting, landscaping and natural resources labourers The Major Group 84 gathers the following NOC3 subgroups (3 digits groups):

- 841 - Mine service workers and operators in oil and gas drilling

- 842 - Logging and forestry workers

- 843 - Agriculture and horticulture workers

- 844 - Other workers in fishing and trapping and hunting occupations 
The NOC3 group 843 "Agriculture and horticulture workers" gathers the following NOC4 occupational groups (4 digit groups):

- 8431 - General Farm Workers

- 8432 - Nursery and Greenhouse Workers

NOC 1 groups or skill type groups sort occupations according to broad groups that can be either "a function (management, clerical, sales) or a subject matter, (science, health, social science, culture, skilled trade) or industry (primary industry, manufacturing)" (Roberts, 2003, p.5). Ten skill types are identified. Skill types are the following:

- 0 - Management

- 1 - Business, Finance \& Administration;

- 2 - Natural and Applied Science, and Related Occupations;

- 3 - Health Occupations;

- 4 - Occupations in Social Science, Education, Government Service and Religion;

- 5 - Occupations in Art, Culture, Recreation and Sport;

- 6 - Sales and Service;

- 7 - Trades and Skilled Transport and Equipment Operators;

- 8 - Occupations unique to Primary Industry;

- 9 - Occupations unique to processing, manufacturing, and utilities.

These classifications are then presented in a matrix ${ }^{119}$ that includes the occupational groups, occupation types and skill levels.

\footnotetext{
${ }^{119}$ ESDC presents a detailed description of the NOC system as well as the matrix (ESDC, 2016a).
} 


\section{Appendix 4 - Table A4: List of 157 Low-Skilled Occupations}

\begin{tabular}{|c|c|c|}
\hline \# & Codes in Database & Low-Skilled Occupation- NOC4 2006 \\
\hline 1 & 75 & 1411 General office clerks \\
\hline 2 & 76 & 1413 Records management and filing clerks \\
\hline 3 & 77 & 1414 Receptionists and switchboard operators \\
\hline 4 & 78 & 1422 Data entry clerks \\
\hline 5 & 79 & 1423 Desktop publishing operators and related occupations \\
\hline 6 & 80 & 1424 Telephone operators \\
\hline 7 & 81 & 1431 Accounting and related clerks \\
\hline 8 & 82 & 1432 Payroll clerks \\
\hline 9 & 83 & 1433 Customer service representatives - financial services \\
\hline 10 & 84 & 1434 Banking, insurance and other financial clerks \\
\hline 11 & 85 & 1435 Collectors \\
\hline 12 & 89 & 1451 Library clerks \\
\hline 13 & 90 & 1452 Correspondence, publication and related clerks \\
\hline 14 & 91 & 1453 Customer service, information and related clerks \\
\hline 15 & 92 & 1454 Survey interviewers and statistical clerks \\
\hline 16 & 197 & 3411 Dental assistants \\
\hline 17 & 198 & 1413 Nurse aides, orderlies and patient service associates \\
\hline 18 & 199 & 3414 Other assisting occupations in support of health services \\
\hline 19 & 282 & 6411 Sales representatives, wholesale trade (non-technical) \\
\hline 20 & 283 & 6421 Retail salespersons and sales clerks \\
\hline 21 & 284 & 6431 Travel counsellors \\
\hline 22 & 285 & 6432 Pursers and flight attendants \\
\hline 23 & 286 & 6433 Airline sales and service agents \\
\hline 24 & 287 & 6434 Ticket agents, cargo service representatives and related clerks (except airline) \\
\hline 25 & 288 & 6435 Hotel front desk clerks \\
\hline 26 & 289 & 6441 Tour and travel guides \\
\hline 27 & 290 & 6442 Outdoor sport and recreational guides \\
\hline 28 & 291 & 6443 Casino occupations \\
\hline 29 & 292 & 6451 Maîtres d'hôtel and hosts \\
\hline 30 & 293 & 6452 Bartenders \\
\hline 31 & 294 & 6453 Food and beverage servers \\
\hline 32 & 295 & 6461 Sheriffs and bailiffs \\
\hline 33 & 296 & 6462 Correctional service officers \\
\hline 34 & 297 & 6463 By-law enforcement and other regulatory officers, n.e.c. \\
\hline 35 & 298 & 6464 Occupations unique to the Armed Forces \\
\hline 36 & 299 & 6465 Other protective service occupations \\
\hline 37 & 300 & 6471 Visiting homemakers, housekeepers and related occupations \\
\hline 38 & 301 & 6472 Elementary and secondary school teacher assistants \\
\hline 39 & 302 & 6474 Babysitters, nannies and parents' helpers \\
\hline 40 & 303 & 6481 Image, social and other personal consultants \\
\hline 41 & 304 & 6482 Estheticians, electrologists and related occupations \\
\hline 42 & 305 & 6483 Pet groomers and animal care workers \\
\hline 43 & 306 & 6484 Other personal service occupations \\
\hline 44 & 307 & 6611 Cashiers \\
\hline 45 & 308 & 6621 Service station attendants \\
\hline 46 & 309 & 6622 Grocery clerks and store shelf stockers \\
\hline 47 & 310 & 6623 Other elemental sales occupations \\
\hline 48 & 311 & 6641 Food counter attendants, kitchen helpers and related occupations \\
\hline 49 & 312 & 6651 Security guards and related occupations \\
\hline 50 & 313 & 6661 Light duty cleaners \\
\hline 51 & 314 & 6662 Specialized cleaners \\
\hline 52 & 315 & 6663 Janitors, caretakers and building superintendents \\
\hline 53 & 316 & 6671 Operators and attendants in amusement, recreation and sport \\
\hline 54 & 317 & 6672 Other attendants in accommodation and travel \\
\hline 55 & 318 & 6681 Dry cleaning and laundry occupations \\
\hline 56 & 319 & 6682 Ironing, pressing and finishing occupations \\
\hline 57 & 320 & 6683 Other elemental service occupations \\
\hline 58 & 390 & 7411 Truck drivers \\
\hline 59 & 391 & 7412 Bus drivers and subway and other transit operators \\
\hline 60 & 392 & 7413 Taxi and limousine drivers and chauffeurs \\
\hline 61 & 393 & 7414 Delivery and courier service drivers \\
\hline 62 & 394 & 7421 Heavy equipment operators (except crane) \\
\hline 63 & 395 & 7422 Public works maintenance equipment operators \\
\hline 64 & 396 & 7431 Railway yard workers \\
\hline 65 & 397 & 7432 Railway track maintenance workers \\
\hline
\end{tabular}




\begin{tabular}{|c|c|c|}
\hline 66 & 398 & 7433 Deck crew, water transport \\
\hline 67 & 399 & 7434 Engine room crew, water transport \\
\hline 68 & 400 & 7435 Lock and cable ferry operators and related occupations \\
\hline 69 & 401 & 7436 Boat operators \\
\hline 70 & 402 & 7437 Air transport ramp attendants \\
\hline 71 & 403 & 7441 Residential and commercial installers and servicers \\
\hline 72 & 404 & 7442 Waterworks and gas maintenance workers \\
\hline 73 & 405 & 7443 Automotive mechanical installers and servicers \\
\hline 74 & 406 & 7444 Pest controllers and fumigators \\
\hline 75 & 407 & 7445 Other repairers and \\
\hline 76 & 408 & 7451 Longshore workers \\
\hline 77 & 409 & 7452 Material handlers \\
\hline 78 & 410 & 7611 Construction trades helpers and labourers \\
\hline 79 & 411 & 7612 Other trades helpers and labourers \\
\hline 80 & 412 & 7621 Public works and maintenance labourers \\
\hline 81 & 413 & 7622 Railway and motor transport labourers \\
\hline 82 & 429 & 8411 Underground mine service and support workers \\
\hline 83 & 430 & 8412 Oil and gas well drilling workers and services operators \\
\hline 84 & 431 & 8421 Chain-saw and skidder operators \\
\hline 85 & 432 & 8422 Silviculture and forestry workers \\
\hline 86 & 433 & 8431 General farm workers \\
\hline 87 & 434 & 8432 Nursery and greenhouse workers \\
\hline 88 & 435 & 8441 Fishing vessel deckhands \\
\hline 89 & 436 & 8442 Trappers and hunters \\
\hline 90 & 437 & 8611 Harvesting labourers \\
\hline 91 & 438 & 8612 Landscaping and grounds maintenance labourers \\
\hline 92 & 439 & 8613 Aquaculture and marine harvest labourers \\
\hline 93 & 440 & 8614 Mine labourers 440 \\
\hline 94 & 441 & 8615 Oil and gas drilling, servicing and related labourers \\
\hline 95 & 442 & 8616 Logging and forestry labourers \\
\hline 96 & 460 & 9411 Machine operators, mineral and metal processing \\
\hline 97 & 461 & 9412 Foundry workers \\
\hline 98 & 462 & 9413 Glass forming and finishing machine operators and glass cutters \\
\hline 99 & 463 & 9414 Concrete, clay and stone forming occupations \\
\hline 100 & 464 & 9415 Inspectors and testers, mineral and metal processing \\
\hline 101 & 465 & 9421 Chemical plant machine operators \\
\hline 102 & 466 & 9422 Plastics processing machine operators \\
\hline 103 & 467 & 9423 Rubber processing machine operators and related workers \\
\hline 104 & 468 & 9424 Water and waste plant operators \\
\hline 105 & 469 & 9431 Sawmill machine \\
\hline 106 & 470 & 9432 Pulp mill machine operators \\
\hline 107 & 471 & 9433 Papermaking and finishing machine operators \\
\hline 108 & 472 & 9434 Other wood processing machine operators \\
\hline 109 & 473 & 9435 Paper converting machine \\
\hline 110 & 474 & 9436 Lumber graders and other wood processing inspectors and graders \\
\hline 111 & 475 & 9441 Textile fibre and yarn preparation machine operators \\
\hline 112 & 476 & 9442 Weavers, knitters and other fabric-making occupations \\
\hline 113 & 477 & 9443 Textile dyeing and finishing machine operators \\
\hline 114 & 478 & 9444 Textile inspectors, graders and samplers \\
\hline 115 & 479 & 9451 Sewing machine operators \\
\hline 116 & 480 & 9452 Fabric, fur and leather \\
\hline 117 & 481 & 9453 Hide and pelt processing workers \\
\hline 118 & 482 & 9454 Inspectors and testers, fabric, fur and leather products manufacturing \\
\hline 119 & 483 & 9461 Process control and machine operators, food and beverage processing \\
\hline 120 & 484 & 9462 Industrial butchers and meat cutters, poultry preparers and related workers \\
\hline 121 & 485 & 9463 Fish plant workers \\
\hline 122 & 486 & 9464 Tobacco processing machine operators \\
\hline 123 & 487 & 9465 Testers and graders, food and beverage processing \\
\hline 124 & 488 & 9471 Printing machine operators \\
\hline 125 & 489 & 9472 Camera, platemaking and other pre-press occupations \\
\hline 126 & 490 & 9473 Binding and finishing machine operators \\
\hline 127 & 491 & 9474 Photographic and film processors \\
\hline 128 & 492 & 9481 Aircraft assemblers and aircraft assembly inspectors \\
\hline 129 & 493 & 9482 Motor vehicle assemblers, inspectors and testers \\
\hline 130 & 494 & 9483 Electronics assemblers, fabricators, inspectors and testers \\
\hline 131 & 495 & 9484 Assemblers and inspectors, electrical appliance, apparatus and equipment manufacturing \\
\hline 132 & 496 & 9485 Assemblers, fabricators and inspectors, industrial electrical motors and transformers \\
\hline 133 & 497 & 9486 Mechanical assemblers and inspectors \\
\hline 134 & 498 & 9487 Machine operators and inspectors, electrical apparatus manufacturing \\
\hline 135 & 499 & 9491 Boat assemblers and inspectors \\
\hline 136 & 500 & 9492 Furniture and fixture assemblers and inspectors \\
\hline
\end{tabular}




\begin{tabular}{|c|c|c|}
\hline 137 & 501 & 9493 Other wood products assemblers and inspectors \\
\hline 138 & 502 & 9494 Furniture finishers and refinishers \\
\hline 139 & 503 & 9495 Plastic products assemblers, finishers and inspectors \\
\hline 140 & 504 & 9496 Painters and coaters, industrial \\
\hline 141 & 505 & 9497 Plating, metal spraying and related operators \\
\hline 142 & 506 & 9498 Other assemblers and inspectors \\
\hline 143 & 507 & 9511 Machining tool operators \\
\hline 144 & 508 & 9512 Forging machine operators \\
\hline 145 & 509 & 9513 Woodworking machine \\
\hline 146 & 510 & 9514 Metalworking machine operators \\
\hline 147 & 511 & 9516 Other metal products machine operators \\
\hline 148 & 512 & 9517 Other products machine operators \\
\hline 149 & 513 & 9611 Labourers in mineral and metal processing \\
\hline 150 & 514 & 9612 Labourers in metal fabrication \\
\hline 151 & 515 & 9613 Labourers in chemical products processing and utilities \\
\hline 152 & 516 & 9614 Labourers in wood, pulp and paper processing \\
\hline 153 & 517 & 9615 Labourers in rubber and plastic products manufacturing \\
\hline 154 & 518 & 9616 Labourers in textile processing \\
\hline 155 & 519 & 9617 Labourers in food, beverage and tobacco processing \\
\hline 156 & 520 & 9618 Labourers in fish processing \\
\hline 157 & 521 & 9619 Other labourers in processing, manufacturing and utilities \\
\hline
\end{tabular}




\section{Appendix 5 - Table A5: List of 98 Occupations Included in the Analysis, Ordered top to Bottom by Census Code}

\begin{tabular}{|c|c|c|}
\hline \begin{tabular}{|l|} 
Codes in \\
Database
\end{tabular} & NOC4 2006 - Low-Skilled Occupation & Level \\
\hline 75 & 1411 General office clerks & $\mathrm{C}$ \\
\hline 76 & 1413 Records management and filing clerks & C \\
\hline 77 & 1414 Receptionists and switchboard operators & $\mathrm{C}$ \\
\hline 78 & 1422 Data entry clerks ${ }^{\star *}$ & $\mathrm{C}$ \\
\hline 81 & 1431 Accounting and related clerks* & $\mathrm{C}$ \\
\hline 82 & 1432 Payroll clerks & $\mathrm{C}$ \\
\hline 83 & 1433 Customer service representatives - financial services & $\mathrm{C}$ \\
\hline 84 & 1434 Banking, insurance and other financial clerks & $\mathrm{C}$ \\
\hline 85 & 1435 Collectors & $\mathrm{C}$ \\
\hline 91 & 1453 Customer service, information and related clerks & $\mathrm{C}$ \\
\hline 92 & 1454 Survey interviewers and statistical clerks & $\mathrm{C}$ \\
\hline 197 & 3411 Dental assistants & $\mathrm{C}$ \\
\hline 198 & 1413 Nurse aides, orderlies and patient service associates & C \\
\hline 282 & 6411 Sales representatives, wholesale trade (non-technical)* & $\mathrm{C}$ \\
\hline 283 & 6421 Retail salespersons and sales clerks & $\mathrm{C}$ \\
\hline 284 & 6431 Travel counsellors & $\mathrm{C}$ \\
\hline 287 & 6434 Ticket agents, cargo service representatives and related clerks (except airline) & $\mathrm{C}$ \\
\hline 288 & 6435 Hotel front desk clerks ${ }^{\star *}$ & C \\
\hline 289 & 6441 Tour and travel guides & $\mathrm{C}$ \\
\hline 291 & 6443 Casino occupations & $\mathrm{C}$ \\
\hline 292 & 6451 Maîtres d'hôtel and hosts & $\mathrm{C}$ \\
\hline 293 & 6452 Bartenders & $\mathrm{C}$ \\
\hline 294 & 6453 Food and beverage servers & $\mathrm{C}$ \\
\hline 298 & 6464 Occupations unique to the Armed Forces ${ }^{\star \star}$ & $\mathrm{C}$ \\
\hline 300 & 6471 Visiting homemakers, housekeepers and related occupations & $\mathrm{C}$ \\
\hline 301 & 6472 Elementary and secondary school teacher assistants & $\mathrm{C}$ \\
\hline 305 & 6483 Pet groomers and animal care workers & $\mathrm{C}$ \\
\hline 307 & 6611 Cashiers ${ }^{\star \star}$ & $\mathrm{D}$ \\
\hline 308 & 6621 Service station attendants & $\mathrm{D}$ \\
\hline 309 & 6622 Grocery clerks and store shelf stockers ${ }^{\star \star}$ & $\mathrm{D}$ \\
\hline 310 & 6623 Other elemental sales occupations ${ }^{\star \star}$ & $\mathrm{D}$ \\
\hline 311 & 6641 Food counter attendants, kitchen helpers and related occupations & $\mathrm{D}$ \\
\hline 312 & 6651 Security guards and related occupations* & $\mathrm{D}$ \\
\hline 313 & 6661 Light duty cleaners ${ }^{\star \star}$ & $\mathrm{D}$ \\
\hline 314 & 6662 Specialized cleaners & $\mathrm{D}$ \\
\hline 315 & 6663 Janitors, caretakers and building superintendents ${ }^{\star \star}$ & $\mathrm{D}$ \\
\hline 316 & 6671 Operators and attendants in amusement, recreation and sport & $\mathrm{D}$ \\
\hline 317 & 6672 Other attendants in accommodation and travel & $\mathrm{D}$ \\
\hline 318 & 6681 Dry cleaning and laundry occupations & $\mathrm{D}$ \\
\hline 319 & 6682 Ironing, pressing and finishing occupations & $\mathrm{D}$ \\
\hline 320 & 6683 Other elemental service occupations & $\mathrm{D}$ \\
\hline 390 & 7411 Truck drivers & $\mathrm{C}$ \\
\hline 391 & 7412 Bus drivers and subway and other transit operators & $\mathrm{C}$ \\
\hline 392 & 7413 Taxi and limousine drivers and chauffeurs & $\mathrm{C}$ \\
\hline 393 & 7414 Delivery and courier service drivers* & C \\
\hline 394 & 7421 Heavy equipment operators (except crane) & $\mathrm{C}$ \\
\hline 395 & 7422 Public works maintenance equipment operators & $\mathrm{C}$ \\
\hline 403 & 7441 Residential and commercial installers and servicers & $\mathrm{C}$ \\
\hline 409 & 7452 Material handlers & $\mathrm{C}$ \\
\hline 410 & 7611 Construction trades helpers and labourers & $\mathrm{D}$ \\
\hline
\end{tabular}




\begin{tabular}{|c|c|c|}
\hline 412 & 7621 Public works and maintenance labourers & $\mathrm{D}$ \\
\hline 433 & 8431 General farm workers & $\mathrm{C}$ \\
\hline 434 & 8432 Nursery and greenhouse workers & $\mathrm{C}$ \\
\hline 437 & 8611 Harvesting labourers* & $\mathrm{D}$ \\
\hline 438 & 8612 Landscaping and grounds maintenance labourers & $\bar{D}$ \\
\hline 442 & 8616 Logging and forestry labourers & $\bar{D}$ \\
\hline 462 & 9413 Glass forming and finishing machine operators and glass cutters & $\mathrm{C}$ \\
\hline 463 & 9414 Concrete, clay and stone forming occupations & $\mathrm{C}$ \\
\hline 466 & 9422 Plastics processing machine operators & $\mathrm{C}$ \\
\hline 467 & 9423 Rubber processing machine operators and related workers & $\mathrm{C}$ \\
\hline 468 & 9424 Water and waste plant operators & $\mathrm{C}$ \\
\hline 472 & 9434 Other wood processing machine operators & $\mathrm{C}$ \\
\hline 473 & 9435 Paper converting machine & $\mathrm{C}$ \\
\hline 476 & 9442 Weavers, knitters and other fabric-making occupations & $\mathrm{C}$ \\
\hline 479 & 9451 Sewing machine operators & $\mathrm{C}$ \\
\hline 480 & 9452 Fabric, fur and leather & $\mathrm{C}$ \\
\hline 482 & 9454 Inspectors and testers, fabric, fur and leather products manufacturing & $\mathrm{C}$ \\
\hline 483 & 9461 Process control and machine operators, food and beverage processing & $\mathrm{C}$ \\
\hline 484 & 9462 Industrial butchers and meat cutters, poultry preparers and related workers* & $\mathrm{C}$ \\
\hline 485 & 9463 Fish plant workers & $\mathrm{C}$ \\
\hline 488 & 9471 Printing machine operators & $\mathrm{C}$ \\
\hline 489 & 9472 Camera, platemaking and other pre-press occupations & C \\
\hline 490 & 9473 Binding and finishing machine operators & C \\
\hline 493 & 9482 Motor vehicle assemblers, inspectors and testers & $\mathrm{C}$ \\
\hline 494 & 9483 Electronics assemblers, fabricators, inspectors and testers & $\mathrm{C}$ \\
\hline 495 & 9484 Assemblers and inspectors, electrical appliance, apparatus and equipment manufacturing & C \\
\hline 500 & 9492 Furniture and fixture assemblers and inspectors ${ }^{\star}$ & $\mathrm{C}$ \\
\hline 501 & 9493 Other wood products assemblers and inspectors ${ }^{\star \star}$ & $\mathrm{C}$ \\
\hline 502 & 9494 Furniture finishers and refinishers & C \\
\hline 503 & 9495 Plastic products assemblers, finishers and inspectors & $\mathrm{C}$ \\
\hline 504 & 9496 Painters and coaters, industrial & $\mathrm{C}$ \\
\hline 506 & 9498 Other assemblers and inspectors & C \\
\hline 507 & 9511 Machining tool operators & C \\
\hline 509 & 9513 Woodworking machine & C \\
\hline 510 & 9514 Metalworking machine operators & C \\
\hline 512 & 9517 Other products machine operators & $\mathrm{C}$ \\
\hline 513 & 9611 Labourers in mineral and metal processing & $\mathrm{D}$ \\
\hline 514 & 9612 Labourers in metal fabrication & $\mathrm{D}$ \\
\hline 515 & 9613 Labourers in chemical products processing and utilities & $\mathrm{D}$ \\
\hline 516 & 9614 Labourers in wood, pulp and paper processing & $\mathrm{D}$ \\
\hline 517 & 9615 Labourers in rubber and plastic products manufacturing & $\mathrm{D}$ \\
\hline 518 & 9616 Labourers in textile processing & $\mathrm{D}$ \\
\hline 519 & 9617 Labourers in food, beverage and tobacco processing & $\bar{D}$ \\
\hline 520 & 9618 Labourers in fish processing & $\mathrm{D}$ \\
\hline 521 & 9619 Other labourers in processing, manufacturing and utilities & $\mathrm{D}$ \\
\hline
\end{tabular}




\section{Appendix 6 - Procedure to Calculate the Anova (Sirkin, 2006)}

1. The sum of squares within groups is calculated (SSWG). This is equal to summing the squared differences of each observation minus the mean.

$$
\sum_{i=1}^{n}\left(x_{i}-\mu_{k}\right)^{2} \text { This is repeated for each of the groups to be compared }
$$

Where,

$\mathrm{n}=$ number of observations in each group (same for all)

$\mu_{k}=$ Mean of group $\mathrm{k}$

$m=$ Number of groups

Then, all totals of each sum are added. The SSWG then is:

$$
S S W G=\left(\sum_{i=1}^{m}\left(\sum_{i=1}^{n}\left(x_{i}-\mu_{k}\right)^{2}\right)\right)
$$

2. The observations of all groups are put together and treated as one supergroup. The mean and variance (squared differences of observations minus the mean) for this supergroup is calculated. The same procedure used for the samples in step 1 is followed for this new supergroup. Then, the Total Sum of Squares (TSS) is:

$T S S=\sum_{i=1}^{l}\left(x_{i}-\underline{\mu}\right)^{2}$

$\underline{\mu}=$ Mean of the supergroup

$l=$ Total number of observations of supergroup 
3. Then, the Sum of Squares Between Groups (SSBG) is calculated. This requires summing the squared differences between the mean of each group and the mean of the super group. Then this result is multiplied by the number of cases, which is the same in each group.

$$
S S B G=n * \sum_{i=1}^{m}\left(\mu_{k}-\underline{\mu}\right)^{2}
$$

4. As a test, $T S S=S S W G+S S B G$

5. Then, each sum of squares is divided by its number of degrees of freedoms.

Each division is the Mean Square Between Groups (MSB) and the Mean Square Within Groups (MSw) respectively.

a. $\mathrm{MSb}=(S S B G /($ Degrees of Freedom $))=S S B G /($ Number of Groups 1)

$$
\mathrm{MSb}=(S S B G /(\text { Degrees of Freedom }))=\operatorname{SSB} G /(m-1)
$$

b. $\mathrm{MSW}=(S S W G /($ Degrees of Freedom $))=S S W G /(n-m)$

$$
\mathrm{MSW}=(S S W G / \text { Degrees of Freedom }))=S S W G /(n-m)
$$

6. The the $F$ value (the ratio between these two relations) is calculated:

$$
\begin{gathered}
F=(S S B G /(m-1)) /((S S W G /(n-m)) \\
F=M S b / M S W
\end{gathered}
$$

7. F value and the degrees of freedom (of SSBG and of SSWG) are contrasted in an F distribution to see whether the null hypothesis is accepted or rejected. 
Appendix 7 - Bonferroni Test: According to Williams (2004), The Least Significant Difference Test between group $i$ and group $j$ consists of:

$$
\operatorname{LSD}_{i j}=\frac{\widehat{\mu}_{t}-\widehat{\mu_{J}}}{S_{\widehat{\mu}_{i}-\widehat{\mu}_{j}}} \widehat{\mu}_{i}=\text { Mean of Group } i
$$

$\hat{\mu}_{j}=$ Mean of Group $j$

$S_{\mu_{i}-\mu_{j}}=$ Standard Error of the difference between groups $i$ and $j$

The outcome has a T distribution with N-J degrees of Freedom, where

$\mathrm{N}=$ Number of observations

$\mathrm{J}=$ Number of Groups

According to Williams, the Bonferroni test, "multiplies each of the significance levels from the LSD test by the number of tests performed, i.e. $J^{*}(J-1) / 2$. If this value is greater than 1, then a significance level of 1 is used." (Williams, 2004). 


\section{Appendix 8 - Low-Skilled population, wage dispersion (broad wage range) and high wages in the fourth quartile}

As explained in chapter five, high dispersion leads to high wages in the fourth quartile and, by extension, to high mean wages for the whole population in each occupation. Therefore, it is important to try to explain why high dispersion (high wages) occurs. Different sources of wage dispersion have been identified:

1. In terms of numbers of workers and numbers of occupations, there are differences linked to the actual skill level. Skill level C includes a higher number of workers and occupations than skill level D. Whereas level C has 70 low-skilled occupations with NPRs, level D has only 28.

2. Differences are also reflected in wage levels. Occupations in level $C$ tend to have higher wages than occupations in level D. Average wages for skill level $C$ vary from $\$ 14.35$ /hour for the NPR population to $\$ 17.37 /$ hour for the Canadian-born population. In contrast, average wages for the skill level $D$ vary from $\$ 13.08 /$ hour for the NPR population to $\$ 15.57 /$ hour for the Canadian born population. But variation is not only caused by the skill level; there is also variation within each occupation. While these averages are high (above minimum wage), in Annex 9 (Quartile analysis), about half of NPRs in almost each occupation earn wages around the average minimum wage. The next section provides a more detailed account of how wages are distributed in each occupation in the quartiles analysis.

3. Wage variation is not only caused by the differences in skill levels; other factors also affect wage dispersion. As with the industry sector classification, wages at 
the occupational group level, though more precise in terms of zeroing in on the activities for which remuneration is received, still have significant occupational variance group-wide. Besides, even though NOC 4 occupations are the last level (publicly available) in which labour activities are classified and accounted for, NOC 4 occupations also groups significantly diverse jobs. For example, whereas occupation NOC 6474 (Babysitters, Nannies and Parent Helpers) groups 10 possible job titles, occupation 8431 - General Farm Workers groups more than 160 job titles. Jobs in this occupation include: apiarian technician, general farm worker, harvester machine operator and milking machine tender (Government of Canada, 2017). This broad diversity of jobs may also have an impact on wage dispersion. Thus, a limitation of this research is that, even in the smallest available category (occupational groups or NOC4 occupations), some of the wages group together a significant number of jobs. This affects wage dispersion within each occupational group. Given that there is no information about wages at the actual job level, it is not possible to know the jobs of those with low wages and of those with high wages within each occupational group.

4. Another source of dispersion is linked to the fact that wages of most low-skilled occupations are close to the minimum wage, which varies from province to province. The minimum wage in Canadian provinces in 2005 varied from $\$ 6.15 /$ hour in Newfoundland to $\$ 8.0 /$ hour in British Columbia. In 2005 , the minimum wage in Ontario was $\$ 7.43 /$ hour, in Quebec $\$ 7.55 /$ hour and in Alberta \$6.27/hour (Government of Canada, 2016).

5. While wages in some low-skilled occupations are close to the minimum, not all 
are remunerated at a minimum wage. For example, according to the The Government of Canada's tool, job bank, the average for Ontario in occupation 9482 "Motor vehicle assemblers, inspectors and testers" ranged from $\$ 15.75 /$ hour to $\$ 35 /$ hour (Government of Canada, 2017a). The 2006 census identified some NPRs working in this occupation.

6. Dispersion is also the consequence of different levels of seniority in each occupation. High wages may reflect high levels of seniority in a job. Wages in all immigration statuses are not all entry-level wages. Wages reported in this research correspond to the average wage of both those who worked for the first time in 2005 in a specific low-skilled occupation and those who have been working for many years in the same occupation. Some low-skilled NPRs in the agricultural sector come year after year to work in the same occupation (Basok, 2000). Finally, not all occupations classified as low-skilled are low wage. 


\section{Appendix 9 - Quartiles Analysis}

This appendix presents the wage differences of the combined second and third quartiles by province of residence; sex; rural/urban location; prime age; speaking/not speaking English; speaking/not speaking French; and level of education. Average wages for NPRs, CB and IMM per quartiles are presented top to bottom for the top 20 occupations of NPRs.

Average wages of NPRs in the first and second quartiles in most occupations exhibit wages below the minimum wage. When the third quartile is added, wages are a little above the average minimum wage for Canada in 2005 ( $\$ 7.15 /$ hour).

\section{A9.1 - Figure A1: Wage Differences by Sex - Second and Third Quartiles}

\section{AVERAGE HOURLY WAGE DIFFERENCES (2ND AND 3RD QUARTILES)-SEX - CENSUS 2006}

-TFW-CB घTFW-IMM

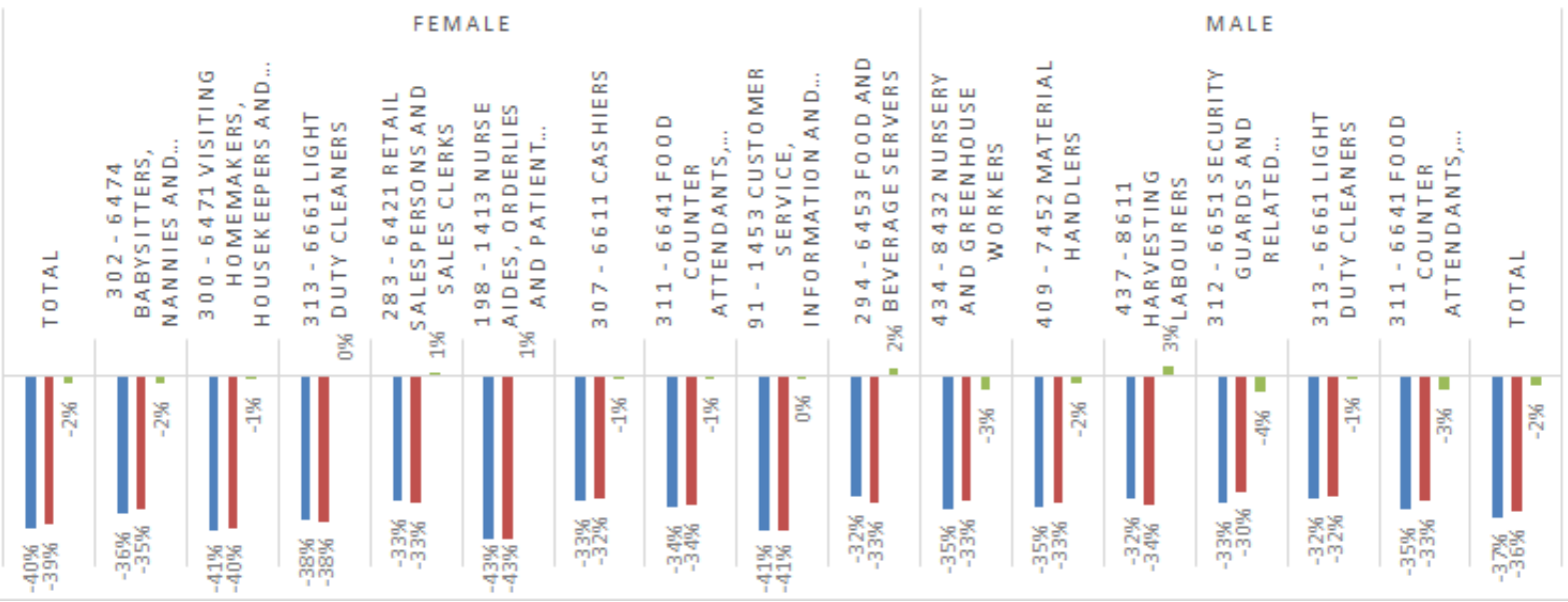




\section{A9.2. - Figure A2: Wage differences by Province Residence - Second and Third Quartiles}

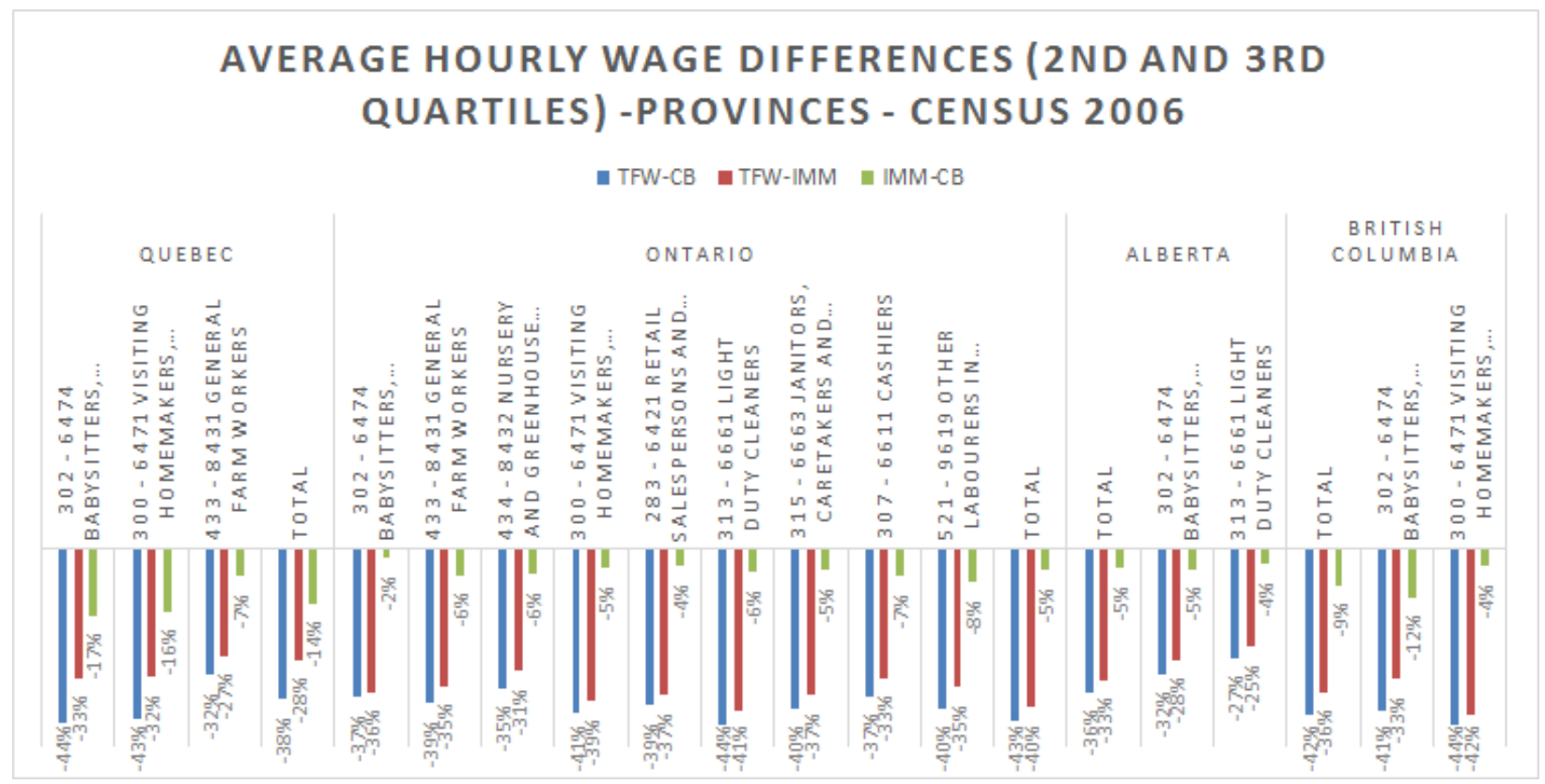

A9.3 - Figure A3: Wage Differences - Rural/Urban Second and Third Quartiles
AVERAGE HOURLY WAGE DIFFERENCES (2ND AND 3RD QUARTILES) - RURAL/URBAN

-TFW-CB —TFW-IMM Ш IMM-CB

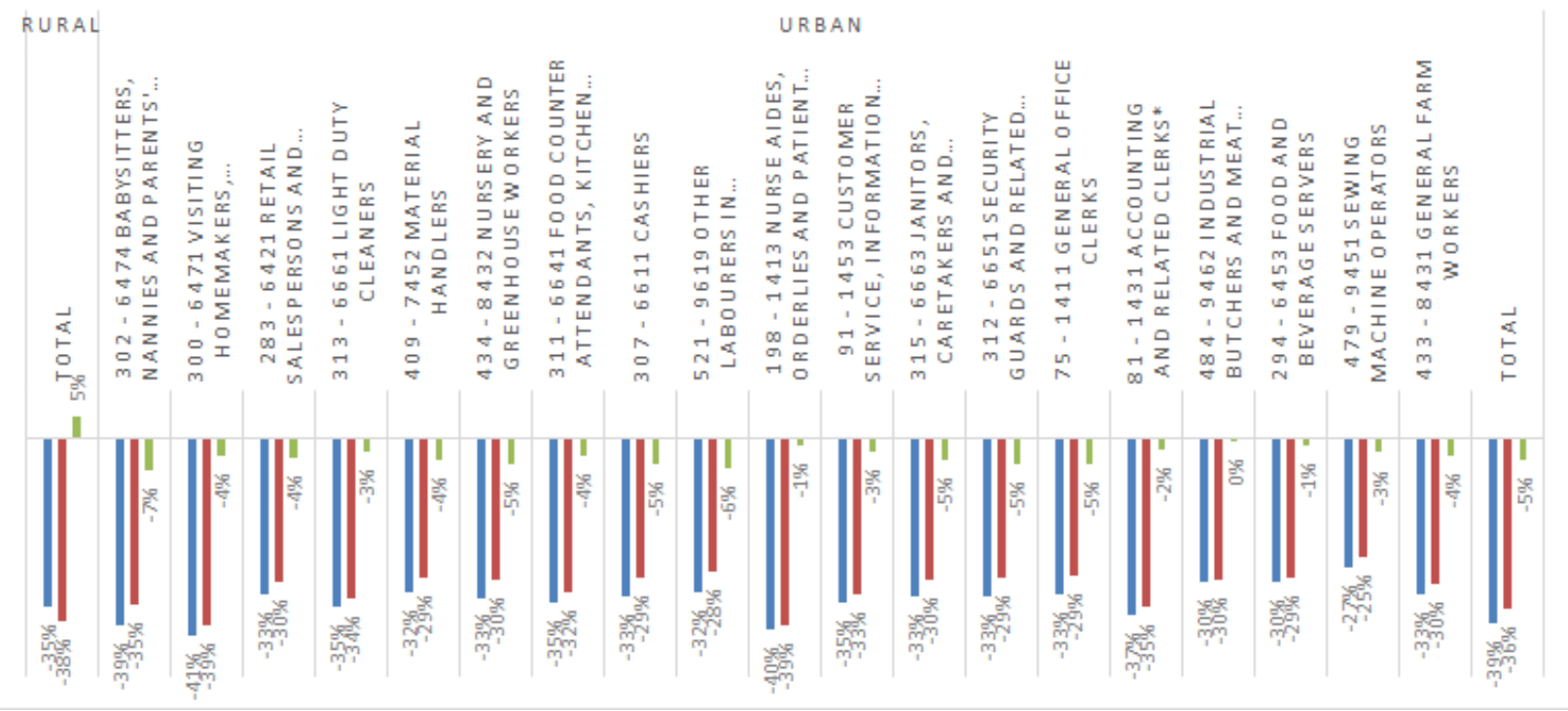


A9.4 - Figure A4: Wage Differences - Speaking/Not Speaking English, Second and Third Quartiles

\section{AVERAGE HOURLY WAGE DIFFERENCES (2ND AND 3RD QUARTILES) - SPEAKING/NOT SPEAKING ENGLISH}

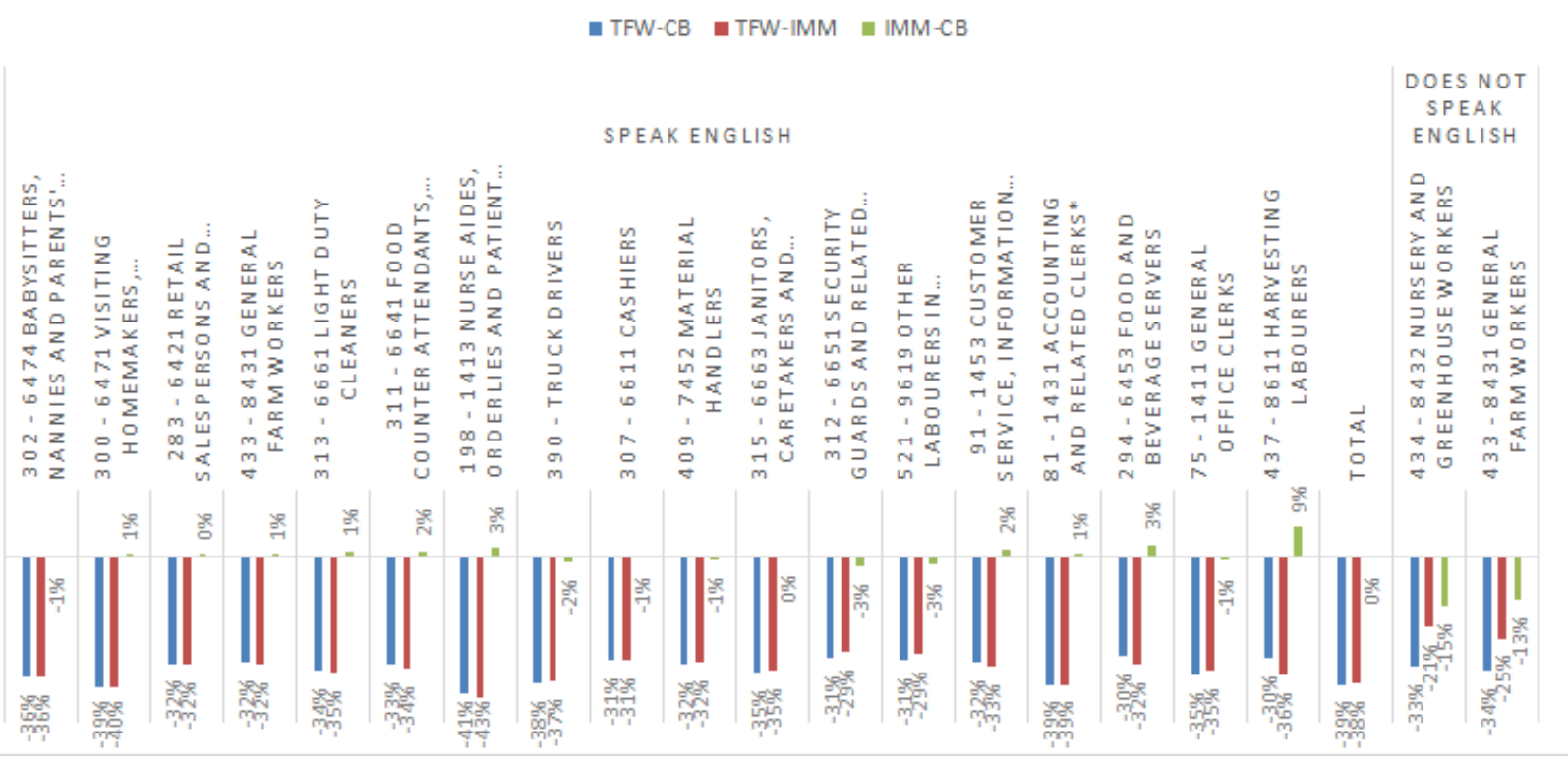

A9.5 - Figure A5: Wage Differences - Level of Education - Second and Third

\section{Quartiles}

AVERAGE HOURLY WAGE DIFFERENCES (2ND AND 3RD QUARTILES) - EDUCATION

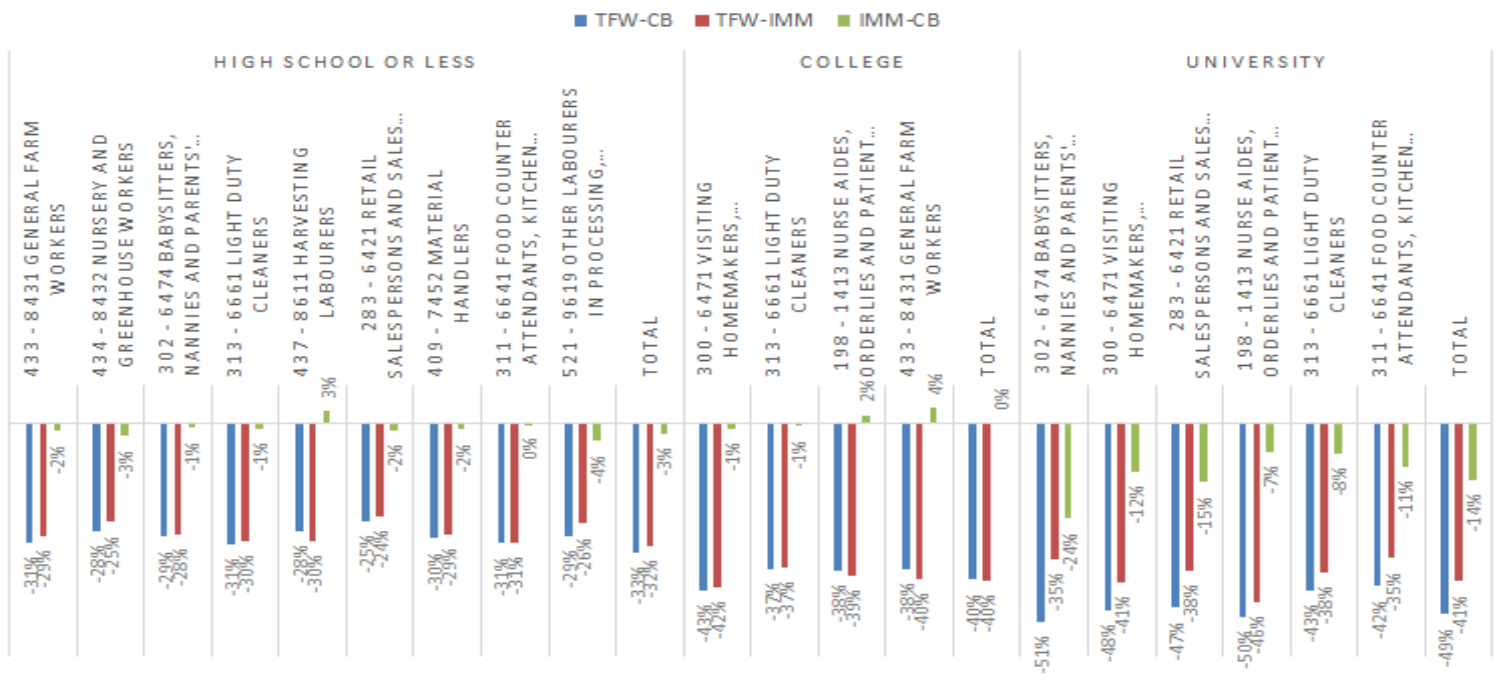


Appendix 10A - Figure A6: Absolute Wages - 43 Low-Skilled Occupations by Immigration Class

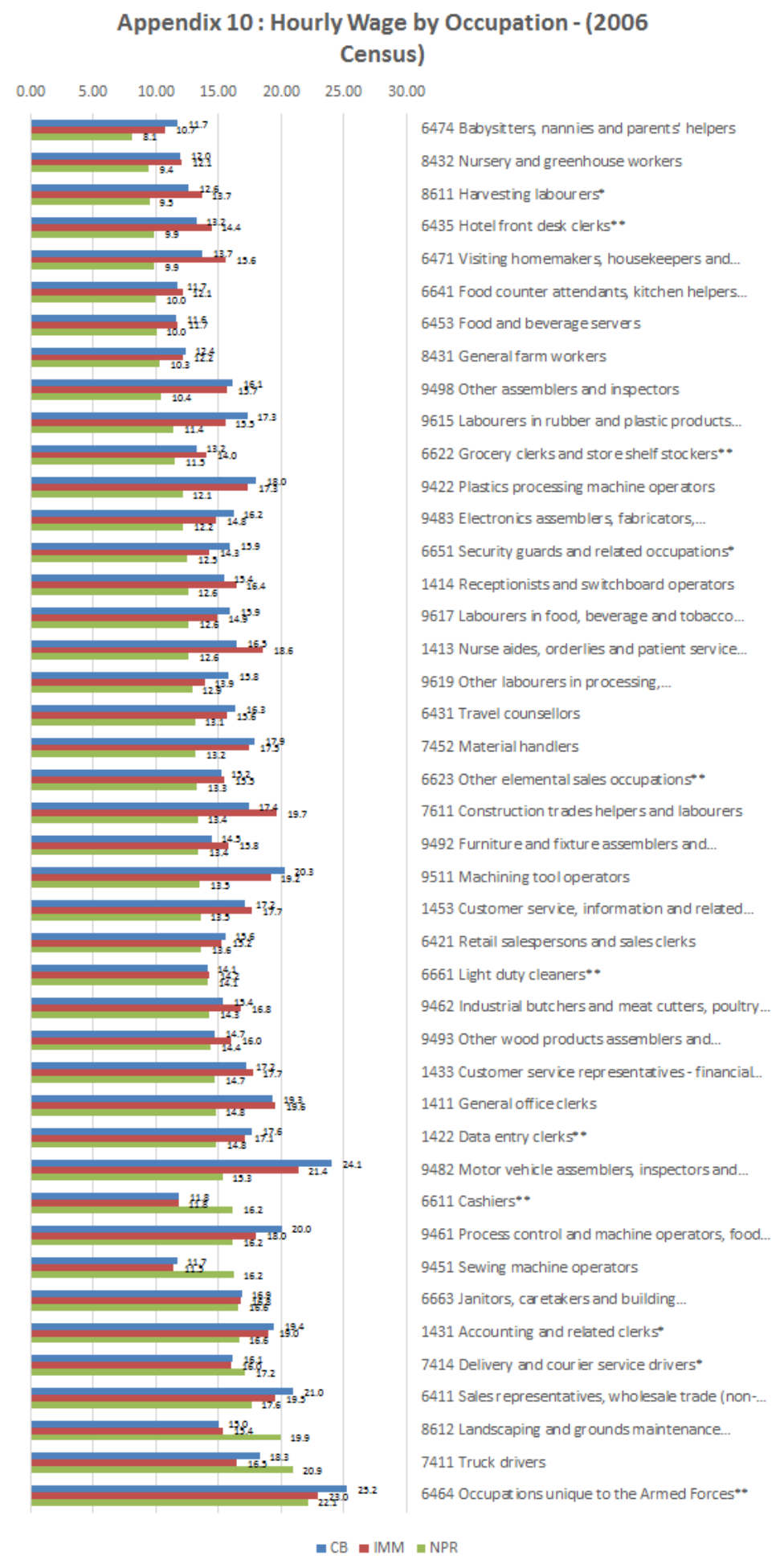


Appendix 10B - Table A6: Quartiles - Low-Skilled Canadian-born ${ }^{120}$

\begin{tabular}{|c|c|c|c|c|c|c|c|c|c|c|c|c|c|c|}
\hline \multicolumn{15}{|c|}{ Low-Skilled CB Quartiles - Top 20 Occupations - (Source: 2006 Census) } \\
\hline \multicolumn{15}{|c|}{ LOW-SKILLED CANADIAN-BORN } \\
\hline & \multicolumn{7}{|c|}{ SHARE BY QUARTILE } & \multicolumn{7}{|c|}{$\begin{array}{c}\text { AVERAGE WAGES PER HOUR BY QUARTILE } \\
(\$ / \text { Hour })\end{array}$} \\
\hline $\begin{array}{l}\text { OCCUPATION } \\
\text { (NOC code / Name) }\end{array}$ & Q1 & Q2 & Q1+Q2 & Q3 & $\mathrm{Q1+Q2+Q3}$ & Q4 & Total & Q1 & Q2 & Q1+Q2 & Q3 & $\mathrm{Q1+Q2+Q3}$ & Q4* & $\begin{array}{l}\text { Total (AVG PER } \\
\text { OCC.) }\end{array}$ \\
\hline Total & $25 \%$ & $25 \%$ & $50 \%$ & $25 \%$ & $75 \%$ & $25 \%$ & $100 \%$ & 7.02 & 12.54 & 9.81 & 17.33 & 12.35 & 29.26 & 16.58 \\
\hline $\begin{array}{l}6474 \text { Babysitters, nannies and } \\
\text { parents' helpers - } 6474 \\
\text { Babysitters, nannies and parents' } \\
\text { helpers }\end{array}$ & $67 \%$ & $15 \%$ & $83 \%$ & $8 \%$ & $91 \%$ & $9 \%$ & $100 \%$ & 5.57 & 12.17 & 6.78 & 17.07 & 7.69 & 50.46 & 11.71 \\
\hline 8431 General farm workers & $46 \%$ & $29 \%$ & $75 \%$ & $15 \%$ & $89 \%$ & $11 \%$ & $100 \%$ & 6.46 & 12.36 & 8.73 & 17.12 & 10.10 & 31.49 & 12.36 \\
\hline $\begin{array}{l}8432 \text { Nursery and greenhouse } \\
\text { workers }\end{array}$ & $54 \%$ & $26 \%$ & $79 \%$ & $12 \%$ & $92 \%$ & $9 \%$ & $100 \%$ & 6.87 & 12.13 & 8.58 & 16.92 & 9.68 & 36.46 & 11.96 \\
\hline $\begin{array}{l}6471 \text { Visiting homemakers, } \\
\text { housekeepers and related } \\
\text { occupations }\end{array}$ & $37 \%$ & $26 \%$ & $63 \%$ & $25 \%$ & $88 \%$ & $12 \%$ & $100 \%$ & 6.66 & 12.52 & 9.08 & 16.98 & 11.30 & 31.42 & 13.69 \\
\hline $\begin{array}{l}6421 \text { Retail salespersons and } \\
\text { sales clerks }\end{array}$ & $32 \%$ & $28 \%$ & $59 \%$ & $19 \%$ & $78 \%$ & $22 \%$ & $100 \%$ & 7.25 & 12.34 & 9.62 & 17.25 & 11.46 & 29.87 & 15.55 \\
\hline 6661 Light duty cleaners & $35 \%$ & $32 \%$ & $66 \%$ & $23 \%$ & $89 \%$ & $11 \%$ & $100 \%$ & 6.91 & 12.55 & 9.59 & 17.01 & 11.51 & 35.78 & 14.09 \\
\hline $\begin{array}{l}6641 \text { Food counter attendants, } \\
\text { kitchen helpers and related } \\
\text { occupations }\end{array}$ & $56 \%$ & $23 \%$ & $79 \%$ & $14 \%$ & $92 \%$ & $8 \%$ & $100 \%$ & 6.84 & 12.35 & 8.46 & 16.92 & 9.71 & 35.79 & 11.70 \\
\hline 6611 Cashiers & $55 \%$ & $24 \%$ & $79 \%$ & $11 \%$ & $90 \%$ & $10 \%$ & $100 \%$ & 7.12 & 12.07 & 8.62 & 17.22 & 9.64 & 31.90 & 11.84 \\
\hline $\begin{array}{l}1413 \text { Nurse aides, orderlies and } \\
\text { patient service associates }\end{array}$ & $18 \%$ & $25 \%$ & $43 \%$ & $41 \%$ & $84 \%$ & $16 \%$ & $100 \%$ & 7.07 & 12.88 & 10.48 & 17.15 & 13.74 & 30.72 & 16.45 \\
\hline 7452 Material handlers & $18 \%$ & $24 \%$ & $42 \%$ & $26 \%$ & $68 \%$ & $32 \%$ & $100 \%$ & 7.10 & 12.59 & 10.19 & 17.41 & 12.98 & 28.57 & 17.92 \\
\hline $\begin{array}{l}6663 \text { Janitors, caretakers and } \\
\text { building superintendents }\end{array}$ & $21 \%$ & $24 \%$ & $44 \%$ & $32 \%$ & $76 \%$ & $24 \%$ & $100 \%$ & 6.87 & 12.63 & 9.94 & 17.45 & 13.09 & 29.03 & 16.85 \\
\hline 8611 Harvesting labourers & $54 \%$ & $27 \%$ & $80 \%$ & $10 \%$ & $90 \%$ & $10 \%$ & $100 \%$ & 6.71 & 12.69 & 8.69 & 16.92 & 9.59 & 40.85 & 12.64 \\
\hline $\begin{array}{l}9619 \text { Other labourers in } \\
\text { processing, manufacturing and } \\
\text { utilities }\end{array}$ & $28 \%$ & $28 \%$ & $56 \%$ & $22 \%$ & $78 \%$ & $22 \%$ & $100 \%$ & 7.01 & 12.51 & 9.79 & 17.27 & 11.92 & 29.81 & 15.80 \\
\hline $\begin{array}{l}1453 \text { Customer service, } \\
\text { information and related clerks }\end{array}$ & $20 \%$ & $25 \%$ & $45 \%$ & $26 \%$ & $71 \%$ & $29 \%$ & $100 \%$ & 7.26 & 12.51 & 10.21 & 17.44 & 12.84 & 27.47 & 17.15 \\
\hline 7411-Truck Drivers & $15 \%$ & $23 \%$ & $38 \%$ & $31 \%$ & $69 \%$ & $31 \%$ & $100 \%$ & 6.72 & 12.76 & 10.43 & 17.41 & 13.57 & 28.76 & 18.27 \\
\hline 6453 Food and beverage servers & $56 \%$ & $25 \%$ & $81 \%$ & $10 \%$ & $92 \%$ & $8 \%$ & $100 \%$ & 6.81 & 12.22 & 8.49 & 17.03 & 9.44 & 35.01 & 11.60 \\
\hline $\begin{array}{l}9462 \text { Industrial butchers and meat } \\
\text { cutters, poultry preparers and } \\
\text { related workers }\end{array}$ & $19 \%$ & $31 \%$ & $51 \%$ & $34 \%$ & $84 \%$ & $16 \%$ & $100 \%$ & 7.24 & 12.69 & 10.63 & 17.11 & 13.23 & 27.15 & 15.39 \\
\hline 7611 Construction trades helpers & $26 \%$ & $24 \%$ & $50 \%$ & $23 \%$ & $73 \%$ & $27 \%$ & $100 \%$ & 6.67 & 12.49 & 9.50 & 17.38 & 11.97 & 31.94 & 17.41 \\
\hline
\end{tabular}

${ }^{120}$ Note that while totals in Appendices $10 \mathrm{~B}$ and $10 \mathrm{C}$ show $25 \%$ in each quartile, the actual numbers are not equal (differences between quartiles are very small and percentages are not exactly $25 \%$ ). The value of $25 \%$ comes after rounding. Additionally, the total percentages in those tables differ from those in table 8. The reason for those differences relates to the actual number of cases per quartile. While Appendix $10 \mathrm{~B}$ (CB) and Appendix 10C (IMM) gather hundreds of thousands of cases per quartile, table 8 (NPRs) gathers only a few thousands per quartile. This also reflects the very low proportion of TFWs in the labour force (about 1.7\%) described in chapter one. 


\begin{tabular}{|l|l|l|l|l|l|l|l|l|l|l|l|l|l|l|}
\hline and labourers & & & & & & & & & & & & & & \\
\hline $\begin{array}{l}1431 \text { Accounting and related } \\
\text { clerks }\end{array}$ & $9 \%$ & $23 \%$ & $32 \%$ & $34 \%$ & $65 \%$ & $35 \%$ & $100 \%$ & 7.44 & 12.82 & 11.35 & 17.41 & 14.48 & 28.76 & 19.43 \\
\hline 9451 Sewing machine operators & $46 \%$ & $38 \%$ & $84 \%$ & $9 \%$ & $93 \%$ & $7 \%$ & $100 \%$ & 7.62 & 12.09 & 9.64 & 16.90 & 10.37 & 30.25 & 11.70 \\
\hline
\end{tabular}

${ }^{*}=$ very high standard deviation 


\section{Appendix 10C - Table A7: Quartiles - Low-Skilled Immigrants}

\begin{tabular}{|c|c|c|c|c|c|c|c|c|c|c|c|c|c|c|}
\hline \multicolumn{15}{|c|}{ Low-Skilled IMM Quartiles - Top 20 Occupations - (Source: 2006 Census) } \\
\hline \multicolumn{15}{|c|}{ LOW-SKILLED IMMIGRANTS (Naturalized Canadians and Permanent Residents) } \\
\hline & \multicolumn{7}{|c|}{ IMMIGRANT SHARE BY QUARTILE } & \multicolumn{7}{|c|}{$\begin{array}{c}\text { AVERAGE WAGES PER HOUR BY QUARTILE } \\
(\$ / \text { Hour })\end{array}$} \\
\hline $\begin{array}{l}\text { OCCUPATION } \\
\text { (NOC code / Name) }\end{array}$ & Q1 & Q2 & $Q 1+Q 2$ & Q3 & \begin{tabular}{|l|}
$1+Q 2+Q$ \\
3
\end{tabular} & Q4 & Total & Q1 & Q2 & $Q 1+Q 2$ & Q3 & $\mathrm{Q} 1+\mathrm{Q} 2+$ & $\widehat{Q 4^{*}}$ & \begin{tabular}{|l|} 
Total (AVG PER \\
OCC.)
\end{tabular} \\
\hline Total & $25 \%$ & $25 \%$ & $50 \%$ & $25 \%$ & $75 \%$ & $25 \%$ & $100 \%$ & 6.77 & 12.21 & 9.49 & 16.92 & 11.96 & 28.69 & 16.11 \\
\hline $\begin{array}{l}6474 \text { Babysitters, nannies and } \\
\text { parents' helpers - } 6474 \text { Babysitters, } \\
\text { nannies and parents' helpers }\end{array}$ & $56 \%$ & $26 \%$ & $82 \%$ & $11 \%$ & $93 \%$ & $7 \%$ & $100 \%$ & 6.52 & 11.97 & 8.24 & 16.35 & 9.19 & 32.18 & 10.74 \\
\hline 8431 General farm workers & $44 \%$ & $29 \%$ & $73 \%$ & $16 \%$ & $90 \%$ & $10 \%$ & $100 \%$ & 6.41 & 12.06 & 8.65 & 16.77 & 10.14 & 29.45 & 12.15 \\
\hline $\begin{array}{l}8432 \text { Nursery and greenhouse } \\
\text { workers }\end{array}$ & $45 \%$ & $33 \%$ & $77 \%$ & $13 \%$ & $91 \%$ & $9 \%$ & $100 \%$ & 6.98 & 11.70 & 8.98 & 16.49 & 10.08 & 31.85 & 12.08 \\
\hline $\begin{array}{l}6471 \text { Visiting homemakers, } \\
\text { housekeepers and related } \\
\text { occupations }\end{array}$ & $25 \%$ & $31 \%$ & $56 \%$ & $26 \%$ & $82 \%$ & $18 \%$ & $100 \%$ & 6.34 & 12.30 & 9.67 & 16.89 & 11.99 & 31.67 & 15.56 \\
\hline $\begin{array}{l}6421 \text { Retail salespersons and } \\
\text { sales clerks }\end{array}$ & $32 \%$ & $27 \%$ & $59 \%$ & $19 \%$ & $78 \%$ & $22 \%$ & $100 \%$ & 6.78 & 12.11 & 9.23 & 16.80 & 11.09 & 29.72 & 15.24 \\
\hline 6661 Light duty cleaners & $31 \%$ & $32 \%$ & $62 \%$ & $26 \%$ & $88 \%$ & $12 \%$ & $100 \%$ & 6.83 & 12.26 & 9.59 & 16.71 & 11.69 & 33.22 & 14.24 \\
\hline $\begin{array}{l}6641 \text { Food counter attendants, } \\
\text { kitchen helpers and related } \\
\text { occupations }\end{array}$ & $49 \%$ & $27 \%$ & $75 \%$ & $16 \%$ & $91 \%$ & $9 \%$ & $100 \%$ & 6.82 & 11.95 & 8.64 & 16.71 & 10.05 & 33.54 & 12.11 \\
\hline 6611 Cashiers & $50 \%$ & $28 \%$ & $77 \%$ & $12 \%$ & $90 \%$ & $10 \%$ & $100 \%$ & 6.85 & 11.81 & 8.61 & 16.79 & 9.74 & 29.93 & 11.78 \\
\hline $\begin{array}{l}1413 \text { Nurse aides, orderlies and } \\
\text { patient service associates }\end{array}$ & $13 \%$ & $18 \%$ & $32 \%$ & $40 \%$ & $71 \%$ & $29 \%$ & $100 \%$ & 6.65 & 12.55 & 10.07 & 17.00 & 13.92 & 30.01 & 18.57 \\
\hline 7452 Material handlers & $18 \%$ & $24 \%$ & $42 \%$ & $26 \%$ & $68 \%$ & $32 \%$ & $100 \%$ & 6.78 & 12.30 & 9.98 & 16.97 & 12.67 & 27.68 & 17.47 \\
\hline $\begin{array}{l}6663 \text { Janitors, caretakers and } \\
\text { building superintendents }\end{array}$ & $22 \%$ & $22 \%$ & $44 \%$ & $30 \%$ & $74 \%$ & $26 \%$ & $100 \%$ & 6.73 & 12.21 & 9.51 & 17.13 & 12.58 & 28.72 & 16.82 \\
\hline 8611 Harvesting labourers & $50 \%$ & $21 \%$ & $71 \%$ & $19 \%$ & $90 \%$ & $10 \%$ & $100 \%$ & 6.40 & 11.88 & 8.05 & 16.82 & 9.90 & 48.21 & 13.66 \\
\hline $\begin{array}{l}9619 \text { Other labourers in } \\
\text { processing, manufacturing and } \\
\text { utilities }\end{array}$ & $33 \%$ & $30 \%$ & $63 \%$ & $22 \%$ & $85 \%$ & $15 \%$ & $100 \%$ & 7.13 & 12.07 & 9.48 & 16.71 & 11.33 & 28.65 & 13.90 \\
\hline $\begin{array}{l}1453 \text { Customer service, } \\
\text { information and related clerks }\end{array}$ & $17 \%$ & $23 \%$ & $39 \%$ & $27 \%$ & $67 \%$ & $33 \%$ & $100 \%$ & 7.03 & 12.29 & 10.07 & 17.03 & 12.93 & 27.26 & 17.68 \\
\hline 7411-Truck Drivers & $25 \%$ & $20 \%$ & $45 \%$ & $25 \%$ & $70 \%$ & $30 \%$ & $100 \%$ & 5.57 & 12.27 & 8.52 & 17.03 & 11.59 & 27.80 & 16.47 \\
\hline 6453 Food and beverage servers & $53 \%$ & $23 \%$ & $76 \%$ & $13 \%$ & $88 \%$ & $12 \%$ & $100 \%$ & 6.61 & 12.01 & 8.25 & 16.62 & 9.44 & 29.12 & 11.72 \\
\hline $\begin{array}{l}9462 \text { Industrial butchers and meat } \\
\text { cutters, poultry preparers and } \\
\text { related workers }\end{array}$ & $14 \%$ & $24 \%$ & $38 \%$ & $37 \%$ & $74 \%$ & $26 \%$ & $100 \%$ & 6.43 & 12.45 & 10.25 & 16.92 & 13.53 & 26.08 & 16.76 \\
\hline $\begin{array}{l}7611 \text { Construction trades helpers } \\
\text { and labourers }\end{array}$ & $18 \%$ & $17 \%$ & $35 \%$ & $19 \%$ & $54 \%$ & $46 \%$ & $100 \%$ & 5.99 & 12.15 & 9.03 & 17.03 & 11.87 & 29.00 & 19.67 \\
\hline $\begin{array}{l}1431 \text { Accounting and related } \\
\text { clerks* }^{*}\end{array}$ & $9 \%$ & $20 \%$ & $29 \%$ & $36 \%$ & $64 \%$ & $36 \%$ & $100 \%$ & 7.00 & 12.59 & 10.85 & 17.06 & 14.30 & 27.55 & 19.01 \\
\hline 9451 Sewing machine operators & $46 \%$ & $37 \%$ & $83 \%$ & $12 \%$ & $94 \%$ & $6 \%$ & $100 \%$ & 7.29 & 11.90 & 9.35 & 16.64 & 10.25 & 31.46 & 11.45 \\
\hline
\end{tabular}

${ }^{*}=$ very high standard deviation 
Appendix 10D - Table A8: Quartile Low-Skilled NPR, CB and IMM - Summary

\begin{tabular}{|c|c|c|c|c|c|c|c|c|c|c|c|c|c|c|c|}
\hline \multicolumn{16}{|c|}{$\begin{array}{l}\text { Appendix 10B: LOW-SKILLED WORKER HOURLY WAGES BY OCCUPATION, IMMIGRATION } \\
\text { STATUS AND QUARTILES (Source: Census 2006) - Canadian Dollars of } 2005\end{array}$} \\
\hline \multirow[b]{2}{*}{ Occupation } & \multicolumn{5}{|c|}{ Average Wages NPRs } & \multicolumn{5}{|c|}{ Average Wages CB } & \multicolumn{5}{|c|}{ Average Wages IMM } \\
\hline & Q1 & Q2 & Q3 & Q4 & $\begin{array}{l}\text { Total } \\
\text { (AVG } \\
\text { PER } \\
\text { OCC.) }\end{array}$ & Q1 & Q2 & Q3 & Q4 & $\begin{array}{l}\text { Total } \\
\text { (AVG } \\
\text { PER } \\
\text { OCC.) }\end{array}$ & Q1 & Q2 & Q3 & Q4 & $\begin{array}{l}\text { Total } \\
\text { (AVG } \\
\text { PER } \\
\text { OCC.) }\end{array}$ \\
\hline Total & 4.75 & 8.07 & 10.44 & 22.29 & 11.63 & 7.02 & 12.54 & 17.33 & 29.26 & 16.58 & 6.77 & 12.21 & 16.92 & 28.69 & 16.11 \\
\hline $\begin{array}{l}6474 \text { Babysitters, nannies and } \\
\text { parents' helpers }\end{array}$ & 5.01 & 8.03 & 10.20 & 21.82 & 8.10 & 5.57 & 12.17 & 17.07 & 50.46 & 11.71 & 6.52 & 11.97 & 16.35 & 32.18 & 10.74 \\
\hline $\begin{array}{l}6474 \text { Babysitters, nannies and } \\
\text { parents' helpers (NPR wages } \\
\text { include room \& board - private } \\
\text { room) }\end{array}$ & 7.08 & 10.10 & 12.27 & 23.89 & 10.17 & & & & & & & & & & \\
\hline 8431 General farm workers & 5.29 & 8.17 & 10.32 & 20.45 & 10.32 & 6.46 & 12.36 & 17.12 & 31.49 & 12.36 & 6.41 & 12.06 & 16.77 & 29.45 & 12.15 \\
\hline $\begin{array}{l}8432 \text { Nursery and greenhouse } \\
\text { workers }\end{array}$ & 4.94 & 8.11 & 10.19 & 16.71 & 9.42 & 6.87 & 12.13 & 16.92 & 36.46 & 11.96 & 6.98 & 11.70 & 16.49 & 31.85 & 12.08 \\
\hline $\begin{array}{l}6471 \text { Visiting homemakers, } \\
\text { housekeepers and related } \\
\text { occupations }\end{array}$ & 4.83 & 8.03 & 10.37 & 22.86 & 9.88 & 6.66 & 12.52 & 16.98 & 31.42 & 13.69 & 6.34 & 12.30 & 16.89 & 31.67 & 15.56 \\
\hline $\begin{array}{l}6421 \text { Retail salespersons and } \\
\text { sales clerks }\end{array}$ & 4.52 & 7.78 & 10.39 & 22.71 & 13.63 & 7.25 & 12.34 & 17.25 & 29.87 & 15.55 & 6.78 & 12.11 & 16.80 & 29.72 & 15.24 \\
\hline 6661 Light duty cleaners & 4.49 & 8.05 & 10.76 & 28.44 & 14.13 & 6.91 & 12.55 & 17.01 & 35.78 & 14.09 & 6.83 & 12.26 & 16.71 & 33.22 & 14.24 \\
\hline $\begin{array}{l}6641 \text { Food counter attendants, } \\
\text { kitchen helpers and related } \\
\text { occupations }\end{array}$ & 4.29 & 8.08 & 10.30 & 20.92 & 9.98 & 6.84 & 12.35 & 16.92 & 35.79 & 11.70 & 6.82 & 11.95 & 16.71 & 33.54 & 12.11 \\
\hline 6611 Cashiers & 5.43 & 8.28 & 10.40 & 41.85 & 16.15 & 7.12 & 12.07 & 17.22 & 31.90 & 11.84 & 6.85 & 11.81 & 16.79 & 29.93 & 11.78 \\
\hline $\begin{array}{l}1413 \text { Nurse aides, orderlies and } \\
\text { patient service associates }\end{array}$ & 4.82 & 7.86 & 10.40 & 20.59 & 12.64 & 7.07 & 12.88 & 17.15 & 30.72 & 16.45 & 6.65 & 12.55 & 17.00 & 30.01 & 18.57 \\
\hline 7452 Material handlers & 3.81 & 8.29 & 10.78 & 17.98 & 13.18 & 7.10 & 12.59 & 17.41 & 28.57 & 17.92 & 6.78 & 12.30 & 16.97 & 27.68 & 17.47 \\
\hline $\begin{array}{l}6663 \text { Janitors, caretakers and } \\
\text { building superintendents }\end{array}$ & 3.97 & 7.95 & 10.81 & 30.28 & 16.55 & 6.87 & 12.63 & 17.45 & 29.03 & 16.85 & 6.73 & 12.21 & 17.13 & 28.72 & 16.82 \\
\hline 8611 Harvesting labourers & 4.81 & 8.39 & 10.23 & 17.40 & 9.50 & 6.71 & 12.69 & 16.92 & 40.85 & 12.64 & 6.40 & 11.88 & 16.82 & 48.21 & 13.66 \\
\hline $\begin{array}{l}9619 \text { Other labourers in } \\
\text { processing, manufacturing and } \\
\text { utilities }\end{array}$ & 4.96 & 8.01 & 10.27 & 19.36 & 12.90 & 7.01 & 12.51 & 17.27 & 29.81 & 15.80 & 7.13 & 12.07 & 16.71 & 28.65 & 13.90 \\
\hline $\begin{array}{l}1453 \text { Customer service, } \\
\text { information and related clerks }\end{array}$ & 5.23 & 8.17 & 10.86 & 19.31 & 13.54 & 7.26 & 12.51 & 17.44 & 27.47 & 17.15 & 7.03 & 12.29 & 17.03 & 27.26 & 17.68 \\
\hline 7411 Truck Drivers & 3.80 & 7.96 & 10.73 & 33.78 & 20.92 & 6.72 & 12.76 & 17.41 & 28.76 & 18.27 & 5.57 & 12.27 & 17.03 & 27.80 & 16.47 \\
\hline $\begin{array}{l}6453 \text { Food and beverage } \\
\text { servers }\end{array}$ & 4.34 & 8.04 & 10.53 & 17.35 & 10.03 & 6.81 & 12.22 & 17.03 & 35.01 & 11.60 & 6.61 & 12.01 & 16.62 & 29.12 & 11.72 \\
\hline 9462 Industrial butchers and & 3.63 & 8.35 & 10.88 & 18.68 & 14.29 & 7.24 & 12.69 & 17.11 & 27.15 & 15.39 & 6.43 & 12.45 & 16.92 & 26.08 & 16.76 \\
\hline
\end{tabular}




\begin{tabular}{|c|c|c|c|c|c|c|c|c|c|c|c|c|c|c|c|}
\hline $\begin{array}{l}\text { meat cutters, poultry preparers } \\
\text { and related workers }\end{array}$ & & & & & & & & & & & & & & & \\
\hline $\begin{array}{l}7611 \text { Construction trades } \\
\text { helpers and labourers }\end{array}$ & 4.47 & 8.41 & 10.90 & 20.02 & 13.35 & 6.67 & 12.49 & 17.38 & 31.94 & 17.41 & 5.99 & 12.15 & 17.03 & 29.00 & 19.67 \\
\hline $\begin{array}{l}1431 \text { Accounting and related } \\
\text { clerks* }\end{array}$ & 5.22 & 8.32 & 10.61 & 23.46 & 16.63 & 7.44 & 12.82 & 17.41 & 28.76 & 19.43 & 7.00 & 12.59 & 17.06 & 27.55 & 19.01 \\
\hline 9451 Sewing machine operators & 3.62 & 8.47 & 10.93 & 31.11 & 16.19 & 7.62 & 12.09 & 16.90 & 30.25 & 11.70 & 7.29 & 11.90 & 16.64 & 31.46 & 11.45 \\
\hline
\end{tabular}


Appendix 10E - Figure A7: Relative Wages (NPR-CB and NPR-IMM) - 35

\section{Occupations}

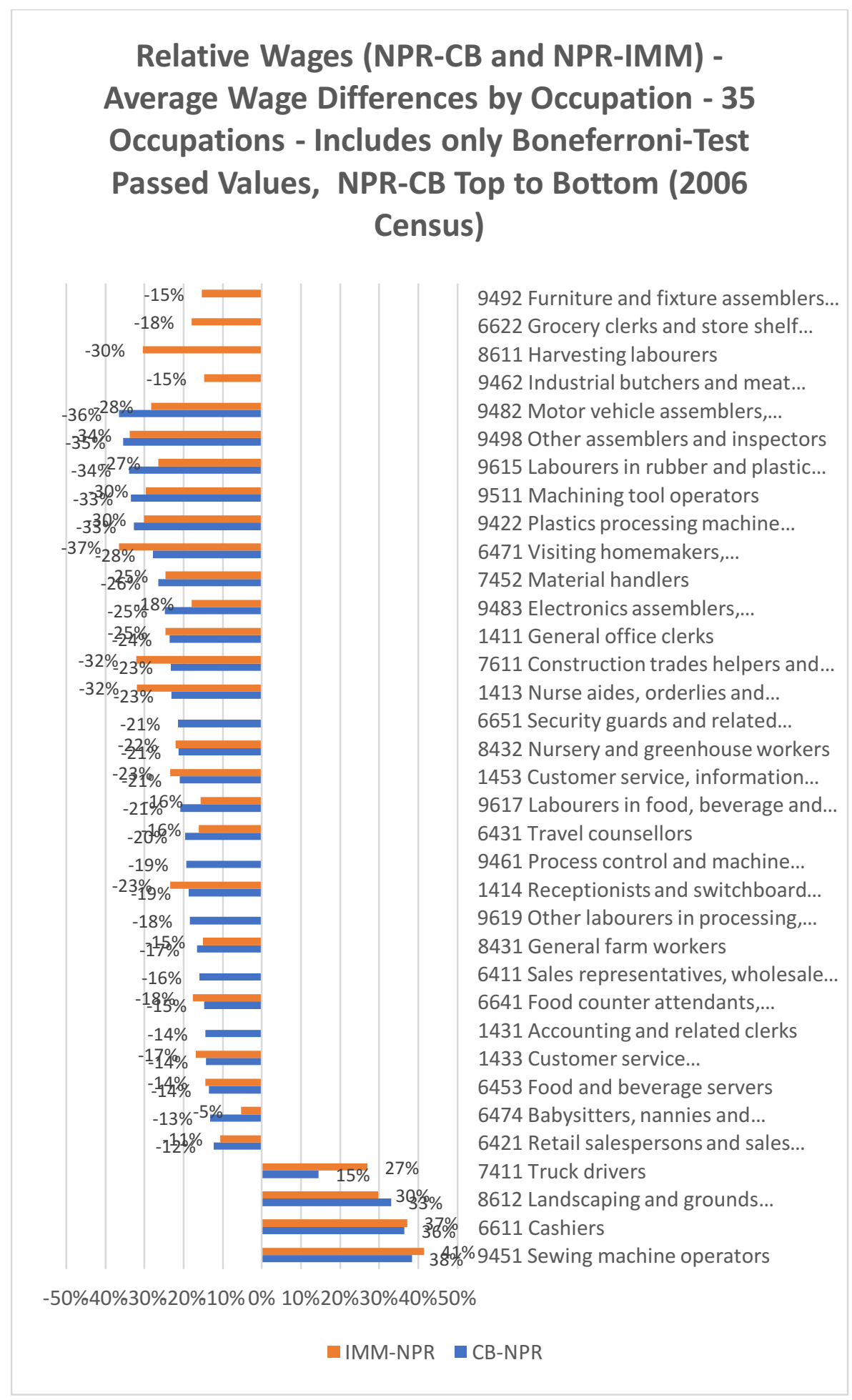




\section{Appendix 11 - Table A9: Hourly Wages and Wage Differences by Occupation and}

\section{Country of Birth}

\begin{tabular}{|c|c|c|c|c|c|c|c|}
\hline \multicolumn{8}{|c|}{ Wage Differences by Occupation, Immigration Status and Country of Birth } \\
\hline \multirow[t]{2}{*}{ Census code, NOC 4, Name } & \multirow{2}{*}{$\begin{array}{l}\text { Country of Birth } \\
\text { (IMM and NPR) }\end{array}$} & \multicolumn{3}{|c|}{ Mean Hourly Wage } & \multicolumn{3}{|c|}{ Differences } \\
\hline & & СВ & IMM & NPR & NPR-CB & $\begin{array}{l}\text { NPR- } \\
\text { IMM }\end{array}$ & IMM-CB \\
\hline \multirow{3}{*}{$\begin{array}{l}\text { 302-6474 Babysitters, nannies and parents' } \\
\text { helpers }\end{array}$} & 2 Canada & 11.72 & & & & & \\
\hline & 209 Philippines & & 10.68 & 8.05 & $-31 \%$ & $-25 \%$ & $-9 \%$ \\
\hline & 215 India & & 10.89 & 8.38 & $-28.5 \% *$ & $-26.6 \%$ ** & $-7 \%$ ** \\
\hline \multirow{2}{*}{$\begin{array}{l}300 \text { - } 6471 \text { Visiting homemakers, } \\
\text { housekeepers and related occupations }\end{array}$} & 2 Canada & 13.69 & & & & & \\
\hline & 209 Philippines & & 14.82 & 9.87 & $-28 \%$ & $-33 \%$ & $8 \%$ \\
\hline \multirow[t]{4}{*}{433 - 8431 General farm workers } & 2 Canada & 12.35 & & & & & \\
\hline & 23 Mexico & & 11.43 & 9.85 & $-20 \%$ & $-14 \%$ & $-7 \%$ \\
\hline & 39 Jamaica & & & 13.06 & $5.7 \%$ ** & $14.3 \%$ ** & \\
\hline & $\begin{array}{l}47 \text { Trinidad and } \\
\text { Tobago }\end{array}$ & & & 9.79 & $-21 \%$ & $-14 \%$ & \\
\hline \multirow{9}{*}{$\begin{array}{l}283 \text { - } 6421 \text { Retail salespersons and sales } \\
\text { clerks }\end{array}$} & 2 Canada & 15.55 & & & & & \\
\hline & 17 USA & & 15.28 & 15.01 & $-3.5 \%$ ** & $-1.8 \%$ ** & $-1.7 \%$ ** \\
\hline & 95 UK & & 16.85 & & & & $8 \%$ \\
\hline & 209 Philippines & & 14.40 & & & & $-7 \%$ \\
\hline & 218 Pakistan & & 13.36 & & & & $-14 \%$ \\
\hline & 215 India & & 15.44 & & & & $-0.7 \%$ ** \\
\hline & 194 China & & 12.62 & & & & $-19 \%$ \\
\hline & 68 Germany & & 15.36 & & & & $-1.2 \% * *$ \\
\hline & 79 Poland & & 13.73 & & & & $-12 \%$ \\
\hline \multirow[t]{4}{*}{434 - 8432 Nursery and greenhouse workers } & 2 Canada & 11.99 & & & & & \\
\hline & 23 Mexico & & 10.82 & 9.17 & $-24 \%$ & $-15.3 \% * *$ & $-9.8 \%{ }^{* *}$ \\
\hline & 39 Jamaica & & & 11.31 & $-5.7 \%$ ** & & \\
\hline & 215 India & & 11.80 & & & & $-1.6 \% * *$ \\
\hline $313-6661$ Light duty cleaners & 2 Canada & 14.09 & & & & & \\
\hline
\end{tabular}




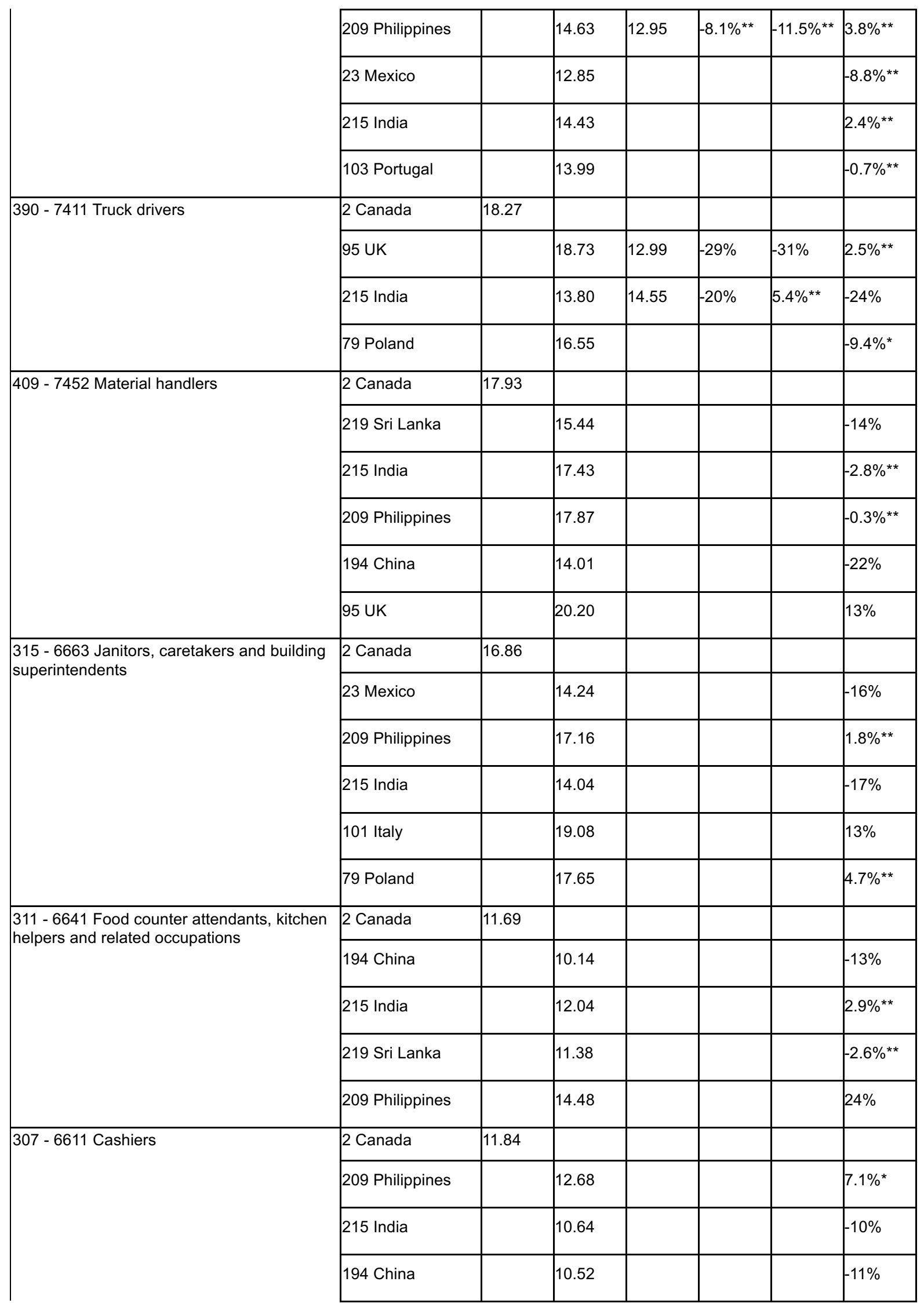




\begin{tabular}{|c|c|c|c|c|c|c|c|}
\hline \multirow{3}{*}{$\begin{array}{l}521 \text { - } 9619 \text { Other labourers in processing, } \\
\text { manufacturing and utilities }\end{array}$} & 2 Canada & 15.81 & & & & & \\
\hline & 219 Sri Lanka & & 12.29 & & & & $-22 \%$ \\
\hline & 215 India & & 12.59 & & & & $-20 \%$ \\
\hline \multirow{4}{*}{$\begin{array}{l}198 \text { - } 1413 \text { Nurse aides, orderlies and patient } \\
\text { service associates }\end{array}$} & 2 Canada & 16.45 & & & & & \\
\hline & 209 Philippines & & 18.55 & 10.88 & $-34 \%$ & $-41 \%$ & $13 \%$ \\
\hline & 38 Haiti & & 16.74 & & & $-35 \% * *$ & $1.8 \%$ ** \\
\hline & 215 India & & 18.79 & & & $-42 \%$ & $14 \%$ \\
\hline \multirow{3}{*}{$\begin{array}{l}519 \text { - } 9617 \text { Labourers in food, beverage and } \\
\text { tobacco processing }\end{array}$} & 2 Canada & 15.90 & & & & & \\
\hline & 194 China & & 12.72 & & & & $-20 \%$ \\
\hline & 209 Philippines & & 15.51 & & & & $-2.5 \%$ ** \\
\hline \multirow{3}{*}{$\begin{array}{l}410 \text { - } 7611 \text { Construction trades helpers and } \\
\text { labourers }\end{array}$} & 2 Canada & 17.42 & & & & & \\
\hline & 53 Brazil & & 35.60 & & & & $104 \%$ ** \\
\hline & 103 Portugal & & 25.00 & & & & $43 \% * *$ \\
\hline \multirow[t]{3}{*}{294 - 6453 Food and beverage servers } & 2 Canada & 11.59 & & & & & \\
\hline & 194 China & & 9.87 & & & & $-15 \%$ \\
\hline & 195 Hong Kong & & 11.38 & & & & $-2 \%$ \\
\hline \multirow{5}{*}{$\begin{array}{l}91 \text { - } 1453 \text { Customer service, information and } \\
\text { related clerks }\end{array}$} & 2 Canada & 17.15 & & & & & \\
\hline & 215 India & & 17.33 & & & & $1.0 \%$ ** \\
\hline & 95 UK & & 18.31 & & & & $7 \%$ \\
\hline & 209 Philippines & & 17.45 & & & & $1.7 \%$ ** \\
\hline & 39 Jamaica & & 18.88 & & & & $10 \%$ \\
\hline \multirow[t]{6}{*}{75 - 1411 General office clerks } & 2 Canada & 19.28 & & & & & \\
\hline & 17 USA & & 18.94 & & & & $-1.8 \%$ ** \\
\hline & 194 China & & 15.75 & & & & $-18 \%$ \\
\hline & 95 UK & & 22.33 & & & & $16 \%$ \\
\hline & 209 Philippines & & 19.25 & & & & $-0.2 \%$ ** \\
\hline & 101 Italy & & 21.50 & & & & $12 \%$ \\
\hline \multirow{2}{*}{$\begin{array}{l}484 \text { - } 9462 \text { Industrial butchers and meat } \\
\text { cutters, poultry preparers and related workers }\end{array}$} & 2 Canada & 15.39 & & & & & \\
\hline & 20 - El Salvador & & 16.27 & 15.69 & $1.9 \%$ ** & $-3.6 \%$ ** & $5.7 \%$ ** \\
\hline $81-1431$ Accounting and related clerks & 2 Canada & 19.43 & & & & & \\
\hline
\end{tabular}




\begin{tabular}{|c|c|c|c|c|c|c|c|}
\hline & 194 China & & 16.70 & & & & $-14 \%$ \\
\hline & 209 Philippines & & 18.67 & & & & $-3.9 \% *$ \\
\hline & 95 UK & & 22.59 & & & & $16 \%$ \\
\hline & 195 Hong Kong & & 17.80 & & & & $-8 \%$ \\
\hline \multirow{2}{*}{$\begin{array}{l}312 \text { - } 6651 \text { Security guards and related } \\
\text { occupations }\end{array}$} & 2 Canada & 15.88 & & & & & \\
\hline & 215 India & & 12.55 & & & & $-21 \%$ \\
\hline \multirow[t]{4}{*}{437 - 8611 Harvesting labourers } & 2 Canada & 12.64 & & & & & \\
\hline & 39 Jamaica & & & 9.37 & $-26 \%$ & & \\
\hline & 23 Mexico & & & 8.60 & $-32 \%$ & $-28.7 \%$ ** & \\
\hline & 215 India & & 12.06 & & & & $-5 \%$ \\
\hline \multirow{2}{*}{$\begin{array}{l}282 \text { - } 6411 \text { Sales representatives, wholesale } \\
\text { trade (non-technical) }\end{array}$} & 2 Canada & 20.98 & & & & & \\
\hline & 95 UK & & 21.98 & & & & $5 \%$ \\
\hline \multirow{2}{*}{$\begin{array}{l}83 \text { - } 1433 \text { Customer service representatives - } \\
\text { financial services }\end{array}$} & 2 Canada & 17.19 & & & & & \\
\hline & 215 India & & 16.71 & & & & $-2.8 \%^{* *}$ \\
\hline \multicolumn{8}{|c|}{ Note: The number of people from Canada in the column "CB" excludes those born in Canada with another citizenship to avoid double counting } \\
\hline \multicolumn{8}{|c|}{ * = Interpret with caution, $5 \%<p<15 \%$} \\
\hline & & & & & & & ${ }^{* *}=p>15 \%$ \\
\hline
\end{tabular}




\section{Appendix 12 - Figure A8: Weekly Hours of Labour By Occupation}

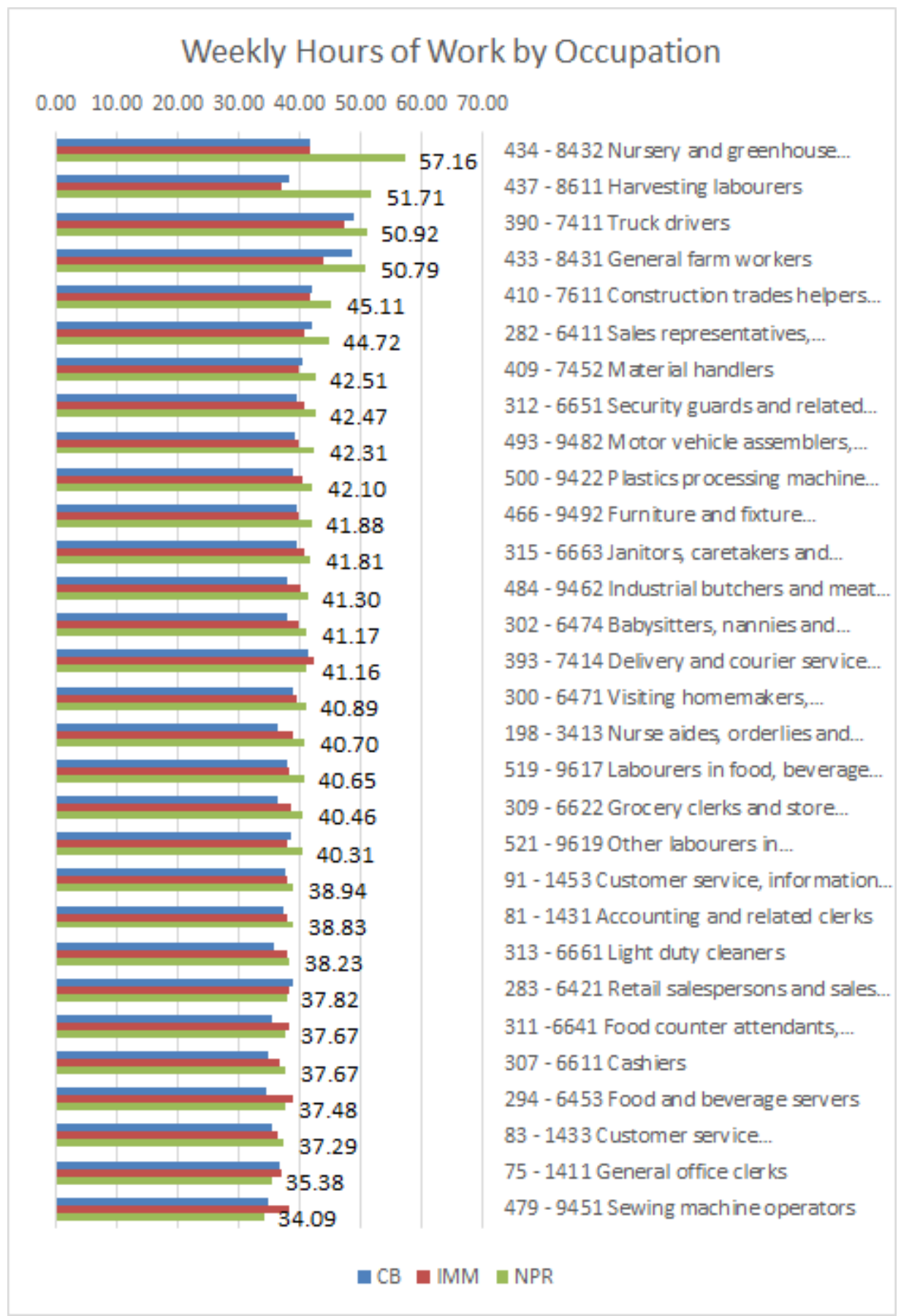


Appendix 12A - Table A10: Minimum Wage in Canada - 2005

\begin{tabular}{|c|c|c|c|}
\hline Jurisdiction & Valid some time in 2005 & Valid on Dec 2005 & Average \\
\hline \multirow[t]{2}{*}{ Alberta } & 01-Oct.-99 & 01-Sep-05 & \\
\hline & $\$ 5.90$ & $\$ 7.00$ & $\$ 6.27$ \\
\hline \multirow[t]{2}{*}{ British Columbia } & 01-Nov.-01 & 01-nov.-01 & \\
\hline & $\$ 8.00$ & $\$ 8.00$ & $\$ 8.00$ \\
\hline \multirow[t]{2}{*}{ Manitoba } & 01-Apr.-04 & 01-Apr-05 & \\
\hline & $\$ 7.00$ & $\$ 7.25$ & $\$ 7.19$ \\
\hline \multirow[t]{2}{*}{ New Brunswick } & 01-Jan-05 & 01-Jan-05 & \\
\hline & $\$ 6.30$ & $\$ 6.30$ & $\$ 6.30$ \\
\hline \multirow{2}{*}{$\begin{array}{l}\text { Newfoundland and } \\
\text { Labrador }\end{array}$} & 01-Nov-02 & 01-Jun-05 & \\
\hline & $\$ 6.00$ & $\$ 6.25$ & $\$ 6.15$ \\
\hline \multirow[t]{2}{*}{ Northwest Territories } & 28-Dec.-03 & 28-Dec.-03 & \\
\hline & $\$ 8.25$ & $\$ 8.25$ & $\$ 8.25$ \\
\hline \multirow[t]{2}{*}{ Nova Scotia } & 01-Apr-04 & 01-Oct-05 & \\
\hline & $\$ 6.50$ & $\$ 6.80$ & $\$ 6.58$ \\
\hline \multirow[t]{2}{*}{ Nunavut } & 03-Mar-03 & 03-Mar-03 & \\
\hline & $\$ 8.50$ & $\$ 8.50$ & $\$ 8.50$ \\
\hline \multirow[t]{2}{*}{ Ontario } & 01-Feb-04 & 01-Feb-05 & \\
\hline & $\$ 7.15$ & $\$ 7.45$ & $\$ 7.43$ \\
\hline \multirow[t]{2}{*}{ Prince Edward Island } & 01-Jan-05 & 01-Jan-05 & \\
\hline & $\$ 6.80$ & $\$ 6.80$ & $\$ 6.80$ \\
\hline \multirow[t]{2}{*}{ Quebec } & 01-May-04 & 01-May-05 & \\
\hline & $\$ 7.45$ & $\$ 7.60$ & $\$ 7.55$ \\
\hline \multirow[t]{2}{*}{ Saskatchewan } & 01-Nov-02 & 01-Sep-05 & \\
\hline & $\$ 6.65$ & $\$ 7.05$ & $\$ 6.78$ \\
\hline \multirow[t]{2}{*}{ Yukon } & $01-O c t-98$ & $01-$ Oct-98 & \\
\hline & $\$ 7.20$ & $\$ 7.20$ & $\$ 7.20$ \\
\hline
\end{tabular}

Source: Statistics Canada 


\section{Appendix 13 - Table A11: Weekly Hours of Labour by Country of Birth}

\begin{tabular}{|c|c|c|c|c|c|c|c|}
\hline \multicolumn{8}{|c|}{ Differences in Weekly Hours of Labour by Occupation, Immigration Status and Country of Birth } \\
\hline \multirow[t]{2}{*}{ Census code, NOC 4, Name } & \multirow{2}{*}{$\begin{array}{l}\text { Country of Birth } \\
\text { (IMM and NPR) }\end{array}$} & \multicolumn{3}{|c|}{ Mean Weekly Hours } & \multicolumn{3}{|c|}{ Differences } \\
\hline & & CB & IMM & NPR & NPR-CB & $\begin{array}{l}\text { NPR- } \\
\text { IMM }\end{array}$ & IMM-CB \\
\hline \multirow{3}{*}{$\begin{array}{l}\text { 302-6474 Babysitters, nannies and parents' } \\
\text { helpers }\end{array}$} & 2 Canada & 38.01 & & & & & \\
\hline & 209 Philippines & & 40.33 & 41.32 & $9 \%$ & $2 \%$ & $6 \%$ \\
\hline & 215 India & & 37.15 & 40.78 & $7 \%$ & $10 \% *$ & $-2 \%$ ** \\
\hline \multirow{2}{*}{$\begin{array}{l}300 \text { - } 6471 \text { Visiting homemakers, } \\
\text { housekeepers and related occupations }\end{array}$} & 2 Canada & 38.88 & & & & & \\
\hline & 209 Philippines & & 40.06 & 40.77 & $5 \%$ & $2 \%$ ** & $3 \%$ \\
\hline \multirow[t]{4}{*}{433 - 8431 General farm workers } & 2 Canada & 48.40 & & & & & \\
\hline & 23 Mexico & & 49.78 & 52.55 & $9 \%$ & $6 \%$ & $3 \%$ \\
\hline & 39 Jamaica & & & 46.92 & $-3 \%$ ** & & \\
\hline & 47 Trinidad and & & & 47.32 & $-2 \% *$ & & \\
\hline \multirow{9}{*}{$\begin{array}{l}283 \text { - } 6421 \text { Retail salespersons and sales } \\
\text { clerks }\end{array}$} & 2 Canada & 38.79 & & & & & \\
\hline & 17 USA & & 38.40 & 35.27 & $-9 \%$ & $-8 \%$ & $-1 \%$ ** \\
\hline & 95 UK & & 38.69 & 33.53 & $-14 \%$ & $-13 \%$ & $0 \%$ ** \\
\hline & 209 Philippines & & 37.47 & & & & $-3 \%$ \\
\hline & 215 India & & 39.00 & & & & $1 \%$ ** \\
\hline & 218 Pakistan & & 38.79 & & & & $0 \%$ ** \\
\hline & 194 China & & 39.29 & & & & $1 \% *$ \\
\hline & 68 Germany & & 39.12 & & & & $1 \% * *$ \\
\hline & 79 Poland & & 37.43 & & & & $-4 \%$ ** \\
\hline \multirow[t]{4}{*}{434 - 8432 Nursery and greenhouse workers } & 2 Canada & 41.54 & & & & & \\
\hline & 23 Mexico & & 44.40 & 59.16 & $42 \%$ & $33 \%$ & $7 \%$ \\
\hline & 39 Jamaica & & & 49.85 & $20 \%$ & & \\
\hline & 215 India & & 40.63 & & & & $-2 \% *$ \\
\hline \multirow[t]{5}{*}{313 - 6661 Light duty cleaners } & 2 Canada & 35.80 & & & & & \\
\hline & 209 Philippines & & 39.09 & 35.73 & $-0.2 \%{ }^{* *}$ & $-9 \%$ & $9 \%$ \\
\hline & 23 Mexico & & 34.56 & & & & $-3 \%$ ** \\
\hline & 215 India & & 38.24 & & & & $7 \%$ \\
\hline & 103 Portugal & & 38.22 & & & & $7 \%$ \\
\hline \multirow[t]{4}{*}{390 - 7411 Truck drivers } & 2 Canada & 48.98 & & & & & \\
\hline & 95 UK & & 47.49 & 61.52 & $26 \%$ & $30 \%$ & $-3 \%$ \\
\hline & 215 India & & 46.97 & 47.98 & $-2 \%$ ** & $2 \%$ ** & $-4 \%$ \\
\hline & 79 Poland & & 52.77 & & & & $8 \%$ \\
\hline \multirow[t]{2}{*}{409 - 7452 Material handlers } & 2 Canada & 40.47 & & & & & \\
\hline & 219 Sri Lanka & & 43.72 & & & & $8 \%$ \\
\hline
\end{tabular}




\begin{tabular}{|c|c|c|c|c|c|c|c|}
\hline & 215 India & & 37.75 & & & & $-7 \%$ ** \\
\hline & 209 Philippines & & 41.05 & & & & $1 \%$ \\
\hline & 194 China & & 38.42 & & & & $-5 \%$ \\
\hline & 95 UK & & 39.13 & & & & $-3 \%$ \\
\hline \multirow{6}{*}{$\begin{array}{l}315 \text { - } 6663 \text { Janitors, caretakers and building } \\
\text { superintendents }\end{array}$} & 2 Canada & 39.43 & & & & & \\
\hline & 23 Mexico & & 38.92 & & & & $-1 \%$ \\
\hline & 209 Philippines & & 41.69 & & & & $6 \%$ ** \\
\hline & 215 India & & 40.84 & & & & $4 \%$ \\
\hline & 101 Italy & & 38.88 & & & & $-1 \% *$ \\
\hline & 79 Poland & & 41.76 & & & & $6 \%^{*}$ \\
\hline \multirow{5}{*}{$\begin{array}{l}311-6641 \text { Food counter attendants, kitchen } \\
\text { helpers and related occupations }\end{array}$} & 2 Canada & 35.50 & & & & & \\
\hline & 194 China & & 38.49 & 38.01 & $7 \%$ & $-1 \% * *$ & $8 \%$ \\
\hline & 215 India & & 37.60 & & & & $6 \%$ ** \\
\hline & 219 Sri Lanka & & 40.46 & & & & $14 \%$ \\
\hline & 209 Philippines & & 38.47 & & & & $8 \%$ \\
\hline \multirow[t]{4}{*}{307 - 6611 Cashiers } & 2 Canada & 34.87 & & & & & \\
\hline & 209 Philippines & & 39.34 & & & & $13 \%$ \\
\hline & 215 India & & 36.59 & & & & $5 \%$ \\
\hline & 194 China & & 37.48 & & & & $7 \%$ \\
\hline \multirow{4}{*}{$\begin{array}{l}198-1413 \text { Nurse aides, orderlies and patient } \\
\text { service associates }\end{array}$} & 2 Canada & 36.28 & & & & & \\
\hline & 209 Philippines & & 40.41 & 42.55 & $17 \%$ & $5 \% *$ & $11 \%$ \\
\hline & 38 Haiti & & 38.42 & & & & $6 \%$ \\
\hline & 215 India & & 37.55 & & & & $4 \%$ \\
\hline \multirow{3}{*}{$\begin{array}{l}521 \text { - } 9619 \text { Other labourers in processing, } \\
\text { manufacturing and utilities }\end{array}$} & 2 Canada & 38.39 & & & & & \\
\hline & 219 Sri Lanka & & 39.39 & & & & $3 \%$ \\
\hline & 215 India & & 36.22 & & & & $-6 \%$ \\
\hline \multirow{3}{*}{$\begin{array}{l}519 \text { - } 9617 \text { Labourers in food, beverage and } \\
\text { tobacco processing }\end{array}$} & 2 Canada & 37.95 & & & & & \\
\hline & 194 China & & 38.21 & & & & $1 \%$ ** \\
\hline & 209 Philippines & & 37.85 & & & & $0 \%$ \\
\hline \multirow{3}{*}{$\begin{array}{l}410 \text { - } 7611 \text { Construction trades helpers and } \\
\text { labourers }\end{array}$} & 2 Canada & 41.99 & & & & & \\
\hline & 53 Brazil & & 39.35 & & & & $-6 \% *$ \\
\hline & 103 Portugal & & 41.36 & & & & $-2 \%$ \\
\hline \multirow[t]{3}{*}{294 - 6453 Food and beverage servers } & 2 Canada & 34.39 & & & & & \\
\hline & 194 China & & 38.89 & & & & $13 \%$ \\
\hline & 195 Hong Konq & & 39.96 & & & & $16 \%$ \\
\hline \multirow[t]{3}{*}{75 - 1411 General office clerks } & 2 Canada & 36.68 & & & & & \\
\hline & 17 USA & & 38.29 & & & & $4 \%$ \\
\hline & 194 China & & 36.74 & & & & $0 \%$ ** \\
\hline
\end{tabular}




\begin{tabular}{|c|c|c|c|c|c|c|c|}
\hline & 95 UK & & 35.91 & & & & $-2 \%$ \\
\hline & 209 Philippines & & 35.90 & & & & $-2 \%$ \\
\hline & 101 Italy & & 36.66 & & & & $0 \%$ \\
\hline \multirow{5}{*}{$\begin{array}{l}91-1453 \text { Customer service, information and } \\
\text { related clerks }\end{array}$} & 2 Canada & 37.69 & & & & & \\
\hline & 215 India & & 37.49 & & & & $-1 \%$ ** \\
\hline & 95 UK & & 38.12 & & & & $1 \%$ ** \\
\hline & 209 Philippines & & 37.69 & & & & $0 \%$ ** \\
\hline & 39 Jamaica & & 35.82 & & & & $-5 \%$ ** \\
\hline \multirow[t]{5}{*}{$81-1431$ Accounting and related clerks } & 2 Canada & 37.32 & & & & & \\
\hline & 194 China & & 37.19 & & & & $0 \%$ ** \\
\hline & 209 Philippines & & 38.63 & & & & $4 \%$ \\
\hline & 95 UK & & 37.61 & & & & $1 \%$ ** \\
\hline & 195 Hong Kong & & 39.13 & & & & $5 \%$ \\
\hline \multirow{2}{*}{$\begin{array}{l}484 \text { - } 9462 \text { Industrial butchers and meat } \\
\text { cutters, poultry preparers and related workers }\end{array}$} & 2 Canada & 37.91 & & & & & \\
\hline & 20 - El Salvador & & 41.43 & 42.11 & $11 \%$ & $2 \%$ ** & $9 \%$ \\
\hline \multirow{2}{*}{$\begin{array}{l}312 \text { - } 6651 \text { Security guards and related } \\
\text { occupations }\end{array}$} & 2 Canada & 39.56 & & & & & \\
\hline & 215 India & & 42.17 & & & & $7 \%$ \\
\hline \multirow[t]{4}{*}{437 - 8611 Harvesting labourers } & 2 Canada & 38.32 & & & & & \\
\hline & 39 Jamaica & & 43.88 & 47.66 & $24 \%$ & $9 \%^{* *}$ & $15 \% *$ \\
\hline & 23 Mexico & & 42.27 & 57.29 & $50 \%$ & $36 \%$ & $10 \%$ \\
\hline & 215 India & & 36.72 & & & & $-4 \%$ \\
\hline \multirow{2}{*}{$\begin{array}{l}282 \text { - } 6411 \text { Sales representatives, wholesale } \\
\text { trade (non-technical) }\end{array}$} & 2 Canada & 41.88 & & & & & \\
\hline & 95 UK & & 41.30 & & & & $-1 \% *$ \\
\hline \multirow{2}{*}{$\begin{array}{l}83 \text { - } 1433 \text { Customer service representatives - } \\
\text { financial services }\end{array}$} & 2 Canada & 35.38 & & & & & \\
\hline & 215 India & & 37.20 & & & & $5 \%$ \\
\hline \multicolumn{8}{|c|}{$\begin{array}{l}\text { Note: The number of people from Canada in the column "CB" excludes those born in Canada with another citizensh } \\
\text { to avoid double counting }\end{array}$} \\
\hline \multicolumn{8}{|l|}{${ }^{*}=$ Interpret with caution, $5 \%<p<15 \%$} \\
\hline$* *=p>15 \%$ & & & & & & & \\
\hline
\end{tabular}




\section{Appendix 14A - Regression Analysis -Considerations (Decisions).}

This section presents the decisions made throughout the regression analysis. It reports on the categories chosen as reference in each variable and helps to clarify both the meaning of the outcomes as well as how to read them. Several transformations took place to evaluate the effect of the independent variables (age, sex, level of education, occupation, etc.) on the dependent variables (average hourly wages):

- Hourly wages transformed into LOG hourly wages. This transformation makes it possible to gather information in percentages on the impact that changes in the independent variables (characteristics) have on the dependent variable (hourly wages). Transforming wages into LOG wages also helps normalize the distribution of wages, which, as mentioned above, is a requirement of regression analysis.

\section{-. Immigration Status: Three categories are included in this variable.}

a. Canadian-born (Reference category/control) ${ }^{121}$

b. Immigrant and Permanent Resident

c. Non-Permanent Resident (Temporary Foreign Worker and Refugee Claimant).

For the regression analysis, it was necessary to split the immigrant group: immigrants who came to Canada at the age of 10 or younger were added to the group of Canadian-born workers. This transformation was needed to correct effects for collinearity. ${ }^{122}$ It also reflects the observation that immigrants who arrive in Canada at an

\footnotetext{
${ }^{121}$ Regression analysis requires one of the subcategories in each independent variable to be the group against which the other subcategories in that variable are compared when the other independent variables are held constant.

${ }^{122}$ Collinearity effects between two or more categories/variables are present when the observations in each of them are similar in magnitude, proportion or value. Having different categories/variables with similar magnitudes/proportions/values in a regression model makes it difficult to separate the effects of each of them on a dependent variable.
} 
early age tend to have better official language skills than those who arrive later in life. First language proficiency, in turn, facilitates a smoother integration into the Canadian labour market, comparable to that of a Canadian-born worker. As chapter six demonstrated, the mean wage of immigrants, considered as a whole, is a bit lower than that of Canadian-born workers, but not as low as that of NPRs (see Table 13). In contrast, the mean wage of low-skilled immigrants who were 10 or younger upon arrival in Canada is slightly above that of Canadian-born workers ( $7 \%$ higher). Their labour market outcomes (in terms of wages) are closer to the CB population than to the immigrant population (as a whole). As a result, including this subpopulation with the $\mathrm{CB}$ group enriches the analysis not only because it avoids collinearity effects, but also because it places a subpopulation with a population that has similar outcomes (wages). This was also the most elegant solution in view of the sample size of this group, which is too small to be considered as a separate population but too large to be withdrawn from the population without distorting results by excluding an important part of the labour force.

The new group, entitled "Canadian-born recoded," is the immigration status control group, since it is worth seeing how the other two groups (NPRs and IMM) fare against the CB. Hence, the group "Immigrants" in the regression analysis includes only immigrants who arrived after the age of 10 who are either naturalized citizens or permanent residents. As in the cross tabulation analysis, the group "NPRs" includes TFWs, refugee claimants and people with temporary resident visa on humanitarian grounds. 
-. Rural-Urban location. As with the Wage differences analysis, the regression analysis also includes a rural / urban analysis. This part of the analysis considers Urban as the reference category.

-. Provinces and Territories Groups: Some provinces and territories had to be grouped together regionally because of sample size. The number of low-skilled workers, especially TFWs, was so small that a provincial level analysis by immigration status was not possible. While this grouping allows analysis of a region at the occupation level, it may also hinder the analysis since economies vary from province to province. The following groupings took place:

1. Atlantic Provinces were grouped together as one region.

2. Manitoba, Saskatchewan and Alberta were also grouped together as a single region.

3. All Territories were grouped together as one region.

Quebec was chosen as the control province because it has a large economy and a significant degree of variability in terms of the number of low-skilled occupations. Having Quebec as the control province also facilitates analysis of outcomes in Ontario, which is the province with the largest number of TFWs and the greatest variability vis-avis the number of low-skilled occupations using temporary foreign labour.

- Level of education: Cases were divided into to three categories.

1. High school and less (reference category)

2. College degree and trade certificate

3. University degrees (including Bachelor, Master and PhD) 
High school and less was chosen as the control group to highlight the effect of earning an education on employees working in low-skilled occupations.

- World regions: 13 world regions of origin were considered including,

- 2 - 3 Canada, United States, Greenland and St. Pierre et Miquelon (reference category - control region.)

- 4 - Central America, South America and the Caribbean

- 5 - West, North and Central Europe

- 6 - Eastern Europe and USSR (all ex-Soviet Union countries and Eastern Europe)

- 7 - Southern Europe - (e.g. Spain and Portugal)

- 8 - Sub Saharan Africa (except South Africa, Namibia and Swaziland)

- 9 - South Africa, Swaziland, Namibia and Oceania ${ }^{123}$

- 10 - North Africa and the Middle East (it includes Turkey and Cyprus)

- 11 - India

- 12 - Far East Asia 1 (e.g. Japan and South Korea)

- 13 - Far East Asia 2 (e.g. Cambodia and Vietnam)

- 14 - South East Asia excluding India (e.g. Pakistan, Sri Lanka, Afghanistan and Nepal)

- 15 - China

\footnotetext{
${ }^{123}$ This group gathers those not fitting in the other groups; their outcomes were not statistically significant due to very small sample size.
} 
Age. In this analysis age was mean centered, which means that the mean age was subtracted from each recorded age. This makes it possible to recognize the contribution of age in determining wages. Since this is a continuous variable, the variations between age and the dependent variables were measured by each additional year.

First official language spoken. All cases were grouped according to two specific groups:

1. Speaking either official language (English, French and Bilinguals) (reference category)

2. Not speaking either official language

Sex: Male (reference category) and females: The regression analysis compares the wages of all low-skilled females against the wages of all low-skilled males included in this study, females being the reference group. This comparison aims to evaluate the incidence of being female on wages vis-à-vis males.

Low-Skilled Occupations (98 Occupations). Control Occupation Census code 315 (NOC 4 code - 6663) Janitors, caretakers and building superintendents was chosen as the control occupation. This occupation has the closest average hourly wage to the mean for all occupations. It is also the occupation with the highest number of cases close to the mean (for all occupations). By including all occupations, it is possible to gauge how each occupation fares against the average low-skilled wage, which, in turn, provides an indication of the differences among low-skilled occupations in the Canadian labour market. 


\section{Appendix 14B - Table A12: Regression Analysis - Outcomes of Model Type 1 (All Occupations) - Occupations' Outcomes}

\begin{tabular}{|c|c|c|}
\hline $\begin{array}{l}\text { Table 16: Regression Model for all occupations } \\
\text { Dependent Variable: LOG Hourly Wages } \\
\text { Independent variables: Age, Immigration Status, Rural/Urban location, Province of } \\
\text { Residence, Level of Education, First Official Language Spoken, Population Group, Region of } \\
\text { Origin (Region of the World). }\end{array}$ & \multicolumn{2}{|c|}{$\begin{array}{c}\text { Model } \\
\text { Log Hourly Wages } \\
\text { Outcomes }\end{array}$} \\
\hline 75 - 1411 General office clerks & .293 & 0.000 \\
\hline 76 - 1413 Records management and filing clerks & .302 & .000 \\
\hline 77 - 1414 Receptionists and switchboard operators & .090 & .000 \\
\hline 78 - 1422 Data entry clerks & .199 & .000 \\
\hline $81-1431$ Accounting and related clerks & .292 & 0.000 \\
\hline 82 - 1432 Payroll clerks & .396 & 0.000 \\
\hline 83 - 1433 Customer service representatives - financial services & .235 & .000 \\
\hline 84 - 1434 Banking, insurance and other financial clerks & .348 & 0.000 \\
\hline 85 - 1435 Collectors & .215 & .000 \\
\hline 91 - 1453 Customer service, information and related clerks & .178 & .000 \\
\hline 92 - 1454 Survey interviewers and statistical clerks & .128 & .000 \\
\hline 197 - 3411 Dental assistants & .287 & .000 \\
\hline $198-1413$ Nurse aides, orderlies and patient service associates & .125 & .000 \\
\hline 199 - 3414 Other assisting occupations in support of health services & .190 & .000 \\
\hline 282 - 6411 Sales representatives, wholesale trade (non-technical) & .281 & 0.000 \\
\hline 283 - 6421 Retail salespersons and sales clerks & -.020 & .000 \\
\hline 284 - 6431 Travel counsellors & .126 & .000 \\
\hline $286-6433$ Airline sales and service agents & .326 & .000 \\
\hline 287 - 6434 Ticket agents, cargo service representatives and related clerks (except airline) & .327 & .000 \\
\hline 288 - 6435 Hotel front desk clerks & -.103 & .000 \\
\hline $289-6441$ Tour and travel guides & -.096 & .002 \\
\hline 291 - 6443 Casino occupations & .256 & .000 \\
\hline 292 - 6451 Maîtres d'hôtel and hosts & -.188 & .000 \\
\hline 293 - 6452 Bartenders & -.266 & .000 \\
\hline $294-6453$ Food and beverage servers & -.231 & .000 \\
\hline 298 - 6464 Occupations unique to the Armed Forces & .521 & 0.000 \\
\hline 300 - 6471 Visiting homemakers, housekeepers and related occupations & -.113 & .000 \\
\hline $301-6472$ Elementary and secondary school teacher assistants & .228 & .000 \\
\hline 302 - 6474 Babysitters, nannies and parents' helpers & -.416 & 0.000 \\
\hline 304 - 6482 Estheticians, electrologists and related occupations & -.148 & .000 \\
\hline $305-6483$ Pet groomers and animal care workers & -.202 & .000 \\
\hline $307-6611$ Cashiers & -.201 & .000 \\
\hline
\end{tabular}




\begin{tabular}{|c|c|c|}
\hline $308-6621$ Service station attendants & -.311 & .000 \\
\hline $309-6622$ Grocery clerks and store shelf stockers & -.117 & .000 \\
\hline 310 - 6623 Other elemental sales occupations & -.112 & .000 \\
\hline 311 - 6641 Food counter attendants, kitchen helpers and related occupations & -.234 & 0.000 \\
\hline 312 - 6651 Security guards and related occupations & -.078 & .000 \\
\hline 313 - 6661 Light duty cleaners & -.113 & .000 \\
\hline 314 - 6662 Specialized cleaners & -.136 & .000 \\
\hline 316 - 6671 Operators and attendants in amusement, recreation and sport & -.007 & .677 \\
\hline 317 - 6672 Other attendants in accommodation and travel & -.023 & .345 \\
\hline 318 - 6681 Dry cleaning and laundry occupations & -.063 & .000 \\
\hline $319-6682$ Ironing, pressing and finishing occupations & -.165 & .000 \\
\hline 320 - 6683 Other elemental service occupations & -.110 & .000 \\
\hline 390 - 7411 Truck drivers & .067 & .000 \\
\hline 391 - 7412 Bus drivers and subway and other transit operators & .169 & .000 \\
\hline 392 - 7413 Taxi and limousine drivers and chauffeurs & -.499 & 0.000 \\
\hline 393 - 7414 Delivery and courier service drivers & -.040 & .000 \\
\hline 394 - 7421 Heavy equipment operators (except crane) & .279 & 0.000 \\
\hline 395 - 7422 Public works maintenance equipment operators & .262 & .000 \\
\hline 403 - 7441 Residential and commercial installers and servicers & .014 & .187 \\
\hline 409 - 7452 Material handlers & .124 & .000 \\
\hline 410 - 7611 Construction trades helpers and labourers & .057 & .000 \\
\hline 412 - 7621 Public works and maintenance labourers & .184 & .000 \\
\hline 433 - 8431 General farm workers & -.251 & .000 \\
\hline $434-8432$ Nursery and greenhouse workers & -.212 & .000 \\
\hline 437 - 8611 Harvesting labourers & -.229 & .000 \\
\hline 438 - 8612 Landscaping and grounds maintenance labourers & -.106 & .000 \\
\hline 442 - 8616 Logging and forestry labourers & .092 & .000 \\
\hline 462 - 9413 Glass forming and finishing machine operators and glass cutters & .155 & .000 \\
\hline 463 - 9414 Concrete, clay and stone forming occupations & .205 & .000 \\
\hline 466 - 9422 Plastics processing machine operators & .154 & .000 \\
\hline 467 - 9423 Rubber processing machine operators and related workers & .321 & .000 \\
\hline 468 - 9424 Water and waste plant operators & .383 & .000 \\
\hline 472 - 9434 Other wood processing machine operators & .254 & .000 \\
\hline 473 - 9435 Paper converting machine & .303 & .000 \\
\hline 476 - 9442 Weavers, knitters and other fabric-making occupations & .043 & .035 \\
\hline 479 - 9451 Sewing machine operators & -.159 & .000 \\
\hline 480 - 9452 Fabric, fur and leather & -.121 & .000 \\
\hline 482 - 9454 Inspectors and testers, fabric, fur and leather products manufacturing & -.098 & .008 \\
\hline 483 - 9461 Process control and machine operators, food and beverage processing & .244 & .000 \\
\hline 484 - 9462 Industrial butchers and meat cutters, poultry preparers and related workers* & .117 & .000 \\
\hline 485 - 9463 Fish plant workers & -.041 & .020 \\
\hline 488 - 9471 Printing machine operators & .181 & .000 \\
\hline 489 - 9472 Camera, platemaking and other pre-press occupations & .272 & .000 \\
\hline
\end{tabular}




\begin{tabular}{|c|c|c|}
\hline 490 - 9473 Binding and finishing machine operators & .121 & .000 \\
\hline 493 - 9482 Motor vehicle assemblers, inspectors and testers & .396 & 0.000 \\
\hline 494 - 9483 Electronics assemblers, fabricators, inspectors and testers & .074 & .000 \\
\hline 495 - 9484 Assemblers and inspectors, electrical appliance, apparatus and equipment manufacturing & .102 & .000 \\
\hline 500 - 9492 Furniture and fixture assemblers and inspectors & .010 & .311 \\
\hline 501 - 9493 Other wood products assemblers and inspectors & .031 & .014 \\
\hline 502 - 9494 Furniture finishers and refinishers & .017 & .383 \\
\hline 503 - 9495 Plastic products assemblers, finishers and inspectors & .063 & .000 \\
\hline 504 - 9496 Painters and coaters, industrial & .194 & .000 \\
\hline 506 - 9498 Other assemblers and inspectors & .060 & .000 \\
\hline 507 - 9511 Machining tool operators & .261 & .000 \\
\hline 509 - 9513 Woodworking machine & .017 & .267 \\
\hline 510 - 9514 Metalworking machine operators & .246 & .000 \\
\hline 512 - 9517 Other products machine operators & .105 & .000 \\
\hline 513 - 9611 Labourers in mineral and metal processing & .294 & .000 \\
\hline 514 - 9612 Labourers in metal fabrication & .127 & .000 \\
\hline 515 - 9613 Labourers in chemical products processing and utilities & .159 & .000 \\
\hline 516 - 9614 Labourers in wood, pulp and paper processing & .218 & .000 \\
\hline 517 - 9615 Labourers in rubber and plastic products manufacturing & .100 & .000 \\
\hline 518 - 9616 Labourers in textile processing & -.080 & .000 \\
\hline 519 - 9617 Labourers in food, beverage and tobacco processing & .053 & .000 \\
\hline 520 - 9618 Labourers in fish processing & -.093 & .000 \\
\hline 521 - 9619 Other labourers in processing, manufacturing and utilities & -.022 & .002 \\
\hline
\end{tabular}




\section{Appendix 15 - Supply-Demand Analysis}

From a labour economics perspective, some industries/occupations may be seen as supply-excess driven. In these cases, wage is mostly defined by external forces. Thus, the fact that NPRs have lower wages than "nationals" could be interpreted as an alteration of the regular labour conditions of a "controlled" labour market in specific occupations.

Graph1: Labour demand and supply in a supply-excess situation.

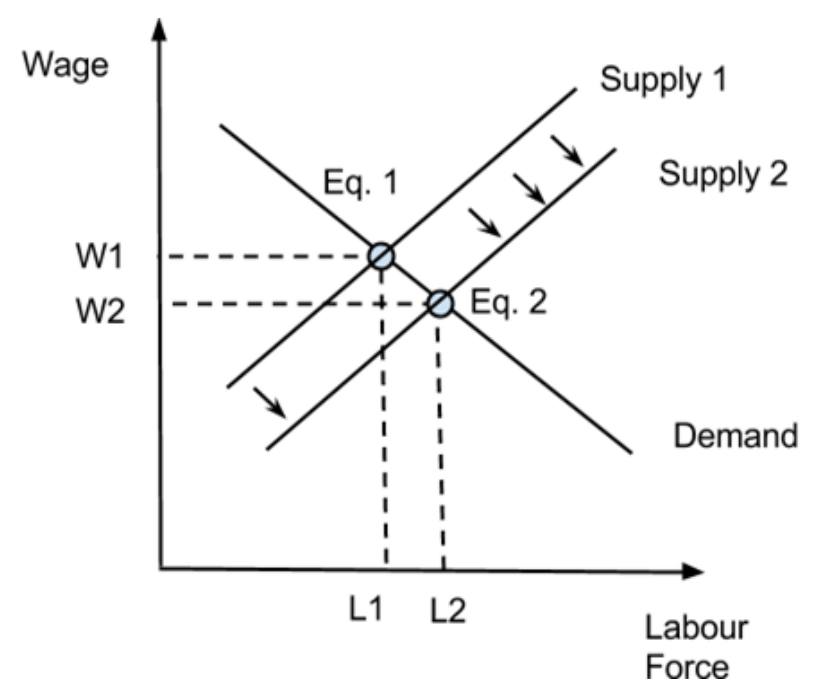

Graph 1 shows the effects on the labour force of foreign labour working for lower wages. The graph shows that for a labour demand in an industry/occupation $x$ there is a labour supply that is satisfied with the defined labour market (national labour market) in an equilibrium, Eq. 1, with wages, W1. When those conditions are altered by a labour force that is willing to do the same jobs for lower wages, W2, the equilibrium between demand and supply moves to a new position, Eq. 2, with lower wages and a larger labour force. However, a new equilibrium with lower wages has been shown to also affect the wages of nationals in those specific industries/occupations (Borjas, 2004). 


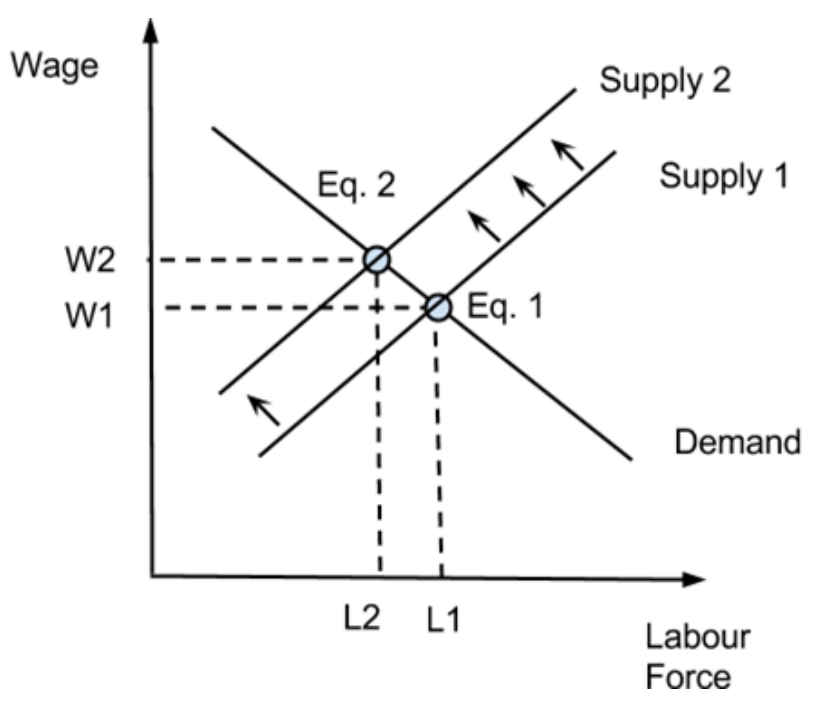

Graph 2: Labour demand and supply in a supply-deficit situation

Other occupations may be seen more on the supply-deficit driven side. Some occupations experience a genuine supply shortage. Supply makes demand move to a new equilibrium with higher wages. Thus, on the other extreme of the industrial spectrum there are industries with NPRs earning wages above those of the Canadianborn and immigrant population. While this may be the case, it is important to remember that a significant dispersion is present on the hourly wages of low-skilled workers. This may mean that averages are not very representative of the sample. This will be later addressed at the occupation level with the quartile analysis (included in the annexes section). 


\section{Appendix 16 - Table A13: Summary of All Hypotheses}

\begin{tabular}{|c|c|}
\hline \multicolumn{2}{|r|}{ Table $14 \mathrm{C}$ - Summary of All Hypothesis/ } \\
\hline \multicolumn{2}{|r|}{ Cross-Tabulation- Absolute Wages } \\
\hline Hypothesis & Findings \\
\hline $\begin{array}{l}\text { 1. NPRs earn lower } \\
\text { wages than CB and } \\
\text { IMM in all industry } \\
\text { sectors and occupations } \\
\text { in this study. }\end{array}$ & 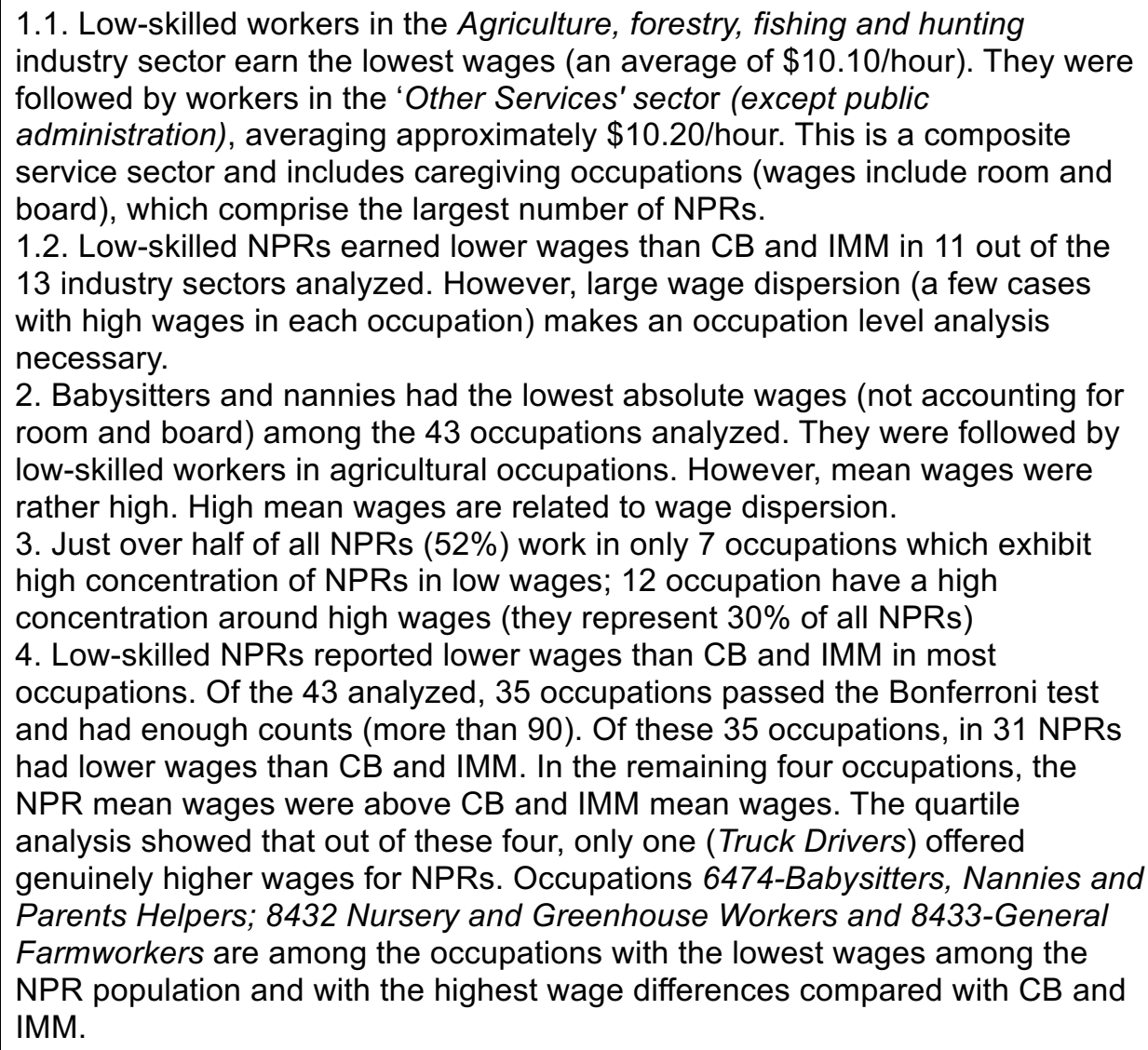 \\
\hline \multicolumn{2}{|r|}{ Cross- Tabulation Relative Wages } \\
\hline Hypotheses & Findings \\
\hline $\begin{array}{l}\text { 1. NPRs earn lower } \\
\text { wages than CB and } \\
\text { IMM by sex and } \\
\text { occupation analyzed in } \\
\text { this section. }\end{array}$ & $\begin{array}{l}\text { 2.1. Females: Of the } 14 \text { top occupations tested, six had statistically significant } \\
\text { outcomes, all of which with NPR wages lower than CB and IMM wages. } \\
\text { 2.2. Males: Of the top } 14 \text { occupations for males tested, six exhibited } \\
\text { statistically significant lower wages for NPRs compared with CB. } 10 \text { of the } 14 \\
\text { exhibited statistically significant lower wages for NPRs compared with IMM. }\end{array}$ \\
\hline $\begin{array}{l}\text { 2. NPRs earn lower } \\
\text { wages than CB and } \\
\text { IMM in all provinces in } \\
\text { each occupation } \\
\text { analyzed in this section. }\end{array}$ & $\begin{array}{l}\text { 2. Province of Residence: Wage differences among NPRs compared to CB } \\
\text { and IMM are greater in Ontario than in other provinces. In all occupations with } \\
\text { statistically significant results, NPR wages were lower than those of CB. } \\
\text { Occupation } 6474-\text { Babysitters, Nannies and Parents Helpers displayed the } \\
\text { largest differences. }\end{array}$ \\
\hline 3. NPRs earn lower & 3.1. Rural: Wages among NPRs are lower than those of IMM in the two \\
\hline
\end{tabular}




\begin{tabular}{|c|c|}
\hline $\begin{array}{l}\text { wages than CB and } \\
\text { IMM in rural and urban } \\
\text { locations in each } \\
\text { occupation analyzed in } \\
\text { this section. }\end{array}$ & $\begin{array}{l}\text { occupations with statistically significant results. Differences with the CB } \\
\text { population were negative in the five occupations with statistically significant } \\
\text { results. } \\
\text { 3.2. Urban: NPR wages were lower than those of CB and IMM in all seven } \\
\text { occupations with statistically significant outcomes. Differences in Urban } \\
\text { settings were larger for } 6474-\text { Babysitters, Nannies and Parents Helpers. }\end{array}$ \\
\hline $\begin{array}{l}\text { 4. NPRs earn lower } \\
\text { wages than CB and } \\
\text { IMM by level of } \\
\text { education in each } \\
\text { occupation analyzed in } \\
\text { this section. }\end{array}$ & $\begin{array}{l}\text { 4. In the top } 10 \text { occupations tested, NPRs earn less than CB and IMM in the } \\
\text { three levels of education. Three cases are worth presenting. } \\
\text { - First, in occupation } 1431 \text {-Accounting and Related Clerks the wage gap is } \\
\text { smaller among those with a university degree (UD) than among those with } \\
\text { high school or less. } \\
\text { g Second, in three occupations ( } 6474,6453 \text { and } 1431 \text { ) the NPR-IMM wage- } \\
\text { gap for those with college degrees or trades certificates (CD-TC) is smaller } \\
\text { than the wage gap of those with high school or less. } \\
\text { - Third, in the remaining five occupations the wage gap among those with } \\
\text { post-secondary education (UD or CD-TC) was bigger than the wage gap of } \\
\text { those with high school or less. }\end{array}$ \\
\hline $\begin{array}{l}\text { 5. NPRs who report } \\
\text { speaking English or } \\
\text { French earn lower } \\
\text { wages than IMM who } \\
\text { also report speaking } \\
\text { English or French in } \\
\text { each occupation. } \\
\text { Additionally, speaking } \\
\text { either official language } \\
\text { reduces NPRs' wage } \\
\text { gap (compared to IMM). }\end{array}$ & $\begin{array}{l}\text { In all cases NPRs earned less than CB and IMM. } \\
\text { 5.1. English: Occupations in which NPRs are expected to speak English (i.e. } \\
6474-B a b y s i t t e r s, \text { nannies and Parents' helpers) were not examined, since } \\
\text { speaking English has no effect on their wages. Other occupations were worth } \\
\text { pursuing. In at least two occupations considered, where there is no } \\
\text { expectation to speak English, a positive effect on wages among NPRs who } \\
\text { reported speaking English was found. Their wage differences were smaller } \\
\text { than those of the whole population in that occupation. This is a valid inference, } \\
\text { since most NPRs in those occupations come from non-English speaking } \\
\text { countries. } \\
5.2 \text {. French: Sample size did not allow an evaluation of effects by occupation } \\
\text { among those who reported speaking French. Nonetheless, all NPRs who } \\
\text { reported speaking French earned } 13 \% \text { less than immigrants. This difference is } \\
\text { smaller than that for the whole population ( } 27.3 \% \text { less for NPRs compared with } \\
\text { immigrants). Therefore speaking French seems to also have a positive effect } \\
\text { on wages. }\end{array}$ \\
\hline $\begin{array}{l}\text { 6. NPRs earn lower } \\
\text { wages than CB and } \\
\text { IMM by country of birth } \\
\text { in the occupations } \\
\text { analyzed in this section. }\end{array}$ & $\begin{array}{l}\text { The country of birth influences the wages of low-skilled temporary foreign } \\
\text { workers. NPRs coming from Mexico and the Caribbean tend to work in } \\
\text { occupations in agriculture which have lower wages. NPRs from the Philippines } \\
\text { mostly work in caregiving occupations, which are among the occupations with } \\
\text { the low wages and with the large wage differences compared to CB and IMM. } \\
\text { NPRs coming from the UK tend to work in occupations with higher wages. } \\
\text { Having citizenship reduces the wage gap between Mexican-born low-skilled } \\
\text { workers and Canadian-born low-skilled workers. }\end{array}$ \\
\hline \multicolumn{2}{|r|}{ Regression } \\
\hline Hypotheses & Findings \\
\hline $\begin{array}{l}\text { 1. In the model for all } \\
\text { occupations, controlling } \\
\text { for age, sex, } \\
\text { immigration status, }\end{array}$ & $\begin{array}{l}\text { Being a NPR has a large negative effect ( } 19 \% \text { less wage). } \\
\text { Lacking citizenship (being a NPR) had a significant negative effect on wage in } \\
\text { eight out of the nine occupations with individual models. Only in occupation } \\
\text { 9462-Industrial Butchers and Meat Cutters, Poultry Preparers and Related }\end{array}$ \\
\hline
\end{tabular}


province of residence, work location

(rural/urban), level of education, ability to speak English or French and place of birth, being a NPR has a significant negative impact on wages compared to being Canadian-born. 2. In each occupational level model, controlling for age, sex, immigration status and province of residence, work location (rural/urban), level of education, ability to speak English or French and place of birth, being a NPR has a significant negative impact on wages compared to being Canadian-born.
Workers, did being a NPR have no statistically significant effect on wages.

Age has a negligible positive effect for low-skilled workers in Canada.

Low-skilled female workers earn lower wages than low-skilled male workers. According to the regression models, low-skilled females working in low-skilled occupations earn $14 \%$ less wage than males.

4.1. Province of Residence: among low-skilled workers, working in provinces with the largest economies has a positive effect on wages compared to working in Quebec. In contrast, working in smaller provinces has a negative effect compared to working in Quebec.

While workers in Ontario and British Columbia earn $5.4 \%$ and $5.9 \%$ more than in Quebec, workers in Atlantic Canada and the Prairie provinces earn $13.4 \%$ and $4.6 \%$ less than in Quebec.

4.2. Location of Work (Rural-Urban): According to the model, working in rural areas represents $4.2 \%$ less than working in urban areas.

Having a postsecondary degree has a positive effect on wages. Compared to those with a high school degree or less, having a college degree or a trades certificate represents $5.8 \%$ more in wages. For those with university degrees the premium rises to $7.2 \%$ on hourly wages (see Table 12 ).

Not speaking either official language has a negative effect on wage. More specifically, not speaking either English or French represents $12.2 \%$ less in wages compared to those who report speaking either official language.

The effect of place of birth on wages among low-skilled workers is positive if the workers are born in West, North, Central or Southern Europe. If the workers are born anywhere else in the world (with statistically significant outcomes), the effect is negative.

Among the 98 low-skilled occupations considered in this analysis (plus one for reference), 36 have a wage below the average for all low-skilled occupations (34 of which are statistically significant). In contrast, 62 have a wage above the average (57 of which are statistically significant). 


\section{References}

Akbari, A., and DeVoretz, D. (1992, August). The Substitutability of Foreign-born Labor in Canadian Production: Circa 1980. Canadian Journal of Economics, 25(3), 604-614.

Al-Rodhan, N. (Ed). (2006). Policy Briefs on the Transcultural Aspects of Security and Stability. Geneva, Switzerland: LIT Verlag.

Alberta Canada. (2017, January 30). Semi-Skilled Worker Criteria. Retrieved from http://www.albertacanada.com/opportunity/programs-and-forms/ainp-edssemi-skilled-criteria.aspx

Amine, S. (2012). Low-Skilled Work in Canada. The Economic and Labour Relations Review, 23(4), 91-100. Retrieved from http://journals.sagepub.com/doi/abs/10.1177/103530461202300407

Andre, I. (1990). Genesis and Persistence of the Commonwealth Caribbean Seasonal Agricultural Workers Program in Canada, Osgoode Hall Law Journal, 28(2), $243-301$.

Andrews, D.F., and Pregibon, D. (1978). Finding the Outliers that Matter. Journal of the Royal Statistical Society. Series B (Methodological). 40(1), 85-93.

Retrieved from https://www.jstor.org/stable/pdf/2984869.pdf?seq=1\#page_scan_tab_content S

Antonio, R. (1981, September). Immanent Critique as the Core of Critical Theory: Its Origins and Developments in Hegel, Marx and Contemporary Thought. The 
British Journal of Sociology, 32(3), 330-345. Retrieved from

http://www.jstor.org/stable/pdf/589281.pdf

Arendt, H. (1976). The Origins of Totalitarianism. New York (New York): Harcourt.

Arendt, H. (1998). The Human Condition. Chicago (Illinois): The University of Chicago Press.

Ashton, W., and Wayne, K. (2013, March). Job Creation and Food Processing in Rural Manitoba. Retrieved from

https://www.brandonu.ca/rdi/files/2015/08/Job Creation and Food Processi $\underline{\text { ng in Rural Manitoba.pdf }}$

Askanius, T., and Mylonas, Y. (2015). Extreme-right Responses to the European Economic Crisis in Denmark and Sweden: The Discursive Construction of Scapegoats and Lodestars. Journal Javnost - The Public Volume, 22(1), 5572. Retrieved from http://www.tandfonline.com/doi/abs/10.1080/13183222.2015.1017249

Aydemir A., \& Skuterud, M. (2005). Explaining the Deteriorating Entry Earnings of Canada's Immigrant Cohorts, 1966 - 2000. The Canadian Journal of Economics / Revue canadienne d'Economique, 38(2), 641-671.

Badie, B. (1993). Flux Migratoires et Relations Transnationales (Migration Flows and Transnational Relations). Études internationales, 24(1), 7-16.

Badgett, M., and Folbre, N. (1999). Assigning Care: Gender Norms and Economic Outcomes. International Labour Review, 138(3), 311-326. Retrieved from http://onlinelibrary.wiley.com/doi/10.1111/j.1564913X.1999.tb00390.x/abstract 
Bakan, A., and Stasiulis, D. (1994). Foreign Domestic Worker Policy in Canada and the Social Boundaries of Modern Citizenship. Science and Society, 58(1), 733.

Bakan, A., and Stasiulis, D. (1997). Not One of the Family: Foreign Domestic Workers in Canada. Toronto: University of Toronto Press.

Bakan, A., and Stasiulis, D. (2002). Negotiating the Citizenship Divide: Foreign Domestic Worker Policy and Legal Jurisprudence. In R. Jhappan (Ed.), Women's Legal Strategies in Canada (pp. 237-94). Toronto: University of Toronto Press.

Bakan, A., and Stasiulis, D. (2012). The Political Economy of Migrant Live-in Caregivers: A Case of Unfree Labour? In P.T. Lenard and C. Straehle (Eds.) Legislated Inequality: Temporary Labour Migration in Canada (pp. 202-226). Montreal: McGill-Queen's University Press.

Bandali, F. (2015, March). Work Interrupted: How Federal Foreign Worker Rule Changes Hurt the West; A Report of the Canada West Foundation. Retrieved from http://cwf.ca/wp-

content/uploads/2015/10/CWF HCP TFWPWorklnterrupted_Report MAR20 15.pdf

Basok, T. (2000, Spring). Migration of Mexican Seasonal Farm Workers to Canada and Development: Obstacles to Productive Investment. The International Migration Review, 34(1), 79-97. Retrieved from http://www.jstor.org/stable/2676013?seq=1\#page scan tab contents 
Basok, T. (2002). Tortillas and Tomatoes. Mexican Transmigrant Harvesters in Canada. Montreal: McGill-Queen's Press.

Basok, T. (2003, April). Human Rights and Citizenship: The case of Mexican Migrants in Canada. Centre for Comparative Immigration Studies; Working Papers. Retrieved from http://escholarship.org/uc/item/3m1168t3\#page-1

Basok, T. (2004, March). Post-National Citizenship, Social Exclusion and Migrants Rights: Mexican Seasonal Workers in Canada. Journal of Citizenship Studies, 8(1), 47-64.

Basok, T. (2006a). Citizenship, Human Rights and Social Justice. Citizenship Studies, 10(3), 267-73.

Basok, T. (2006b). In the Name of Human Rights: Global Organizations and Participating Citizens. Citizenship Studies, 10(3), 309-27.

Basok, T. (2007, November 12). Canada's Temporary Migration Program: A Model Despite Flaws. Retrieved from http://www.migrationpolicy.org/article/canadas-temporary-migration-program$\underline{\text { model-despite-flaws }}$

Basok, T. (2009). Counter-hegemonic Human Rights Discourses and Migrant Rights Activism in the US and Canada. International Journal of Comparative Sociology, 50(2), 183-205.

Basok, T. (2010). Introduction: Opening a Dialogue on Migrant (Rights) Activism. Studies in Social Justice, 4(2), 97-100. 
Bauböck, R. (2001). International Migration and Liberal Democracies: The Challenge of Integration; Patterns of Prejudice, Institute for Jewish Policy Research, 35(4), 33-49.

Bauböck, R. (2000, May 7). Political Community Beyond the Sovereign State: Supranational Federalism and Transnational Minorities. Austrian Academy of Sciences (ÖAW). Retrieved from https://eif.univie.ac.at/downloads/workingpapers/IWE-Papers/WP7.pdf Bauder, H. (2003 September). Brain Abuse, or the Devaluation of Immigrant Labour in Canada. Antipode, 35(4), 699-717. Retrieved from http://onlinelibrary.wiley.com/doi/10.1046/j.1467-8330.2003.00346.x/abstract.

Bauder, H. (2003a). Immigrants in Urban Labour Markets: Place of Birth and Immigrant Concentrations in British Columbia. Canadian Journal of Urban Research 12(2): 179-204

Bauder, H. (2006). Labour Movements: How Migrations Regulate Labour Markets. Oxford: Oxford University Press.

Bauder, H. (2007). Citizenship, Distinction and Exclusion: The Case of Migrant Labour. Paper presented at the Citizenship, Identity, and Social Justice Conference, Windsor, ON.

Bauder, H. (2008a). The Economic Case for Immigration: Neoliberal and Regulatory Paradigms in Canada' s Press. Studies in Political Economy, 82, 131-152.

Bauder, H., (2008b). Citizenship as Capital: The Distinction of Migrant Labor. Alternatives 33 (2008), 315-333. 
Beach, J., and Costigliola, B. (2005). Child Care Wages and a Quality Childcare System. Retrieved from http://ccsccssge.ca/sites/default/files/uploads/Projects-Pubs-Docs/Wages-QualitySystem Eng.pdf

Beatty, P. (2014, May 24). Should the Temporary Foreign Worker Program Be Used to Hike Wages? Retrieved from http://www.chamber.ca/media/blog/140524should-tfw-program-be-used-to-hike-wages/

Behrens, K., and Sato, Y. (2010). Migration, Skill Formation, and the Wage Structure. Journal of Regional Science, 20(10), 1-26.

Bernard, A. (2009, Spring). Trends in Manufacturing Employment. Perspectives on Labour and Income, 21(1), 27-35.

http://search.proquest.com/docview/213994623?accountid=13631

Bevelander, P., and Devoretz, D. (Eds.). (2008). The Economics of Citizenship. Retrieved from http://dspace.mah.se/bitstream/handle/2043/7487/The $\% 20$ economics $\% 20 \mathrm{M}$ UEP.pdf?sequenc

Binford, L. (2002). Social and Economic Contradictions of Rural Migrant Contract Labor Between Tlaxcala, Mexico and Canada; Culture, Agriculture, Food and Environment. The Journal of Culture and Agriculture, 24(2), 1-19.

Binford, L. (2006). The Seasonal Agricultural Workers Program and Mexican Development. Ottawa: Canadian Foundation for the Americas (FOCAL). 
Binford, L. (2008). Social and Economic Contradictions of Rural Migrant Contract Labour Between Tlaxcala, Mexico and Canada. Culture \& Agriculture, 24(2), $1-19$.

Binford, L. (2009). From Fields of Power to Fields of Sweat: The Dual Process of Constructing Temporary Migrant Labour in Mexico and Canada. Third World Quarterly, 30(3), 503-517.

Bloemraad, I. (2000). Citizenship and Immigration: A Current Review. Journal of International Migration and Integration, 1(1), 9-37.

Bloemraad, I. (2006). Becoming a Citizen in the United States and Canada: Structured Mobilization and Immigrant Political Incorporation. Social Forces, 85(2), 667-695.

Bloom, D.E., Grenier G. \& Gunderson M., (1995). The Changing Labour Market Position of Canadian Immigrants. Canadian Journal of Economics, 28, 9871005.

Bonacich, E. A. (1972). Theory of Ethnic Antagonism: The Split Labor Market. American Sociological Review, 37(5), 547-559.

Borjas, G. (1985). Assimilation, Changes in Cohort Quality, and the Earnings of Immigrants; Journal of Labor Economics, 3(4), 463-489.

Borjas, G. (1995). The Economic Benefits of Immigration. The Journal of Economic Perspectives, 9(2), 3-22.

Borjas, G. (1996). The New Economics of Immigration. The Atlantic Monthly, 278(5), $72-80$. 
Borjas, G. (2004). Increasing the Supply of Labor Through Immigration Measuring the Impact on Native-born Workers. Centre for Immigration Studies Backgrounder, May 2004. Retrieved from:

https://www.hks.harvard.edu/fs/gborias/publications/popular/CIS2004.pdf

Borjas, G., Grogger, J., and Hanson G. (2008, March). Imperfect Substitution

Between Immigrants and Natives: A Reappraisal. NBER Working Series, Working Paper 13887. Retrieved from http://www.nber.org/papers/w13887

Bourgeault, I., Parpia, R., and Atanackovic, J. (2010). Canada's Live-in Caregiver

Program: Is it an Answer to the Growing Demand for Elderly Care?

Population Aging, 3, 83-102.

Boyd, M. (2009). Immigration Trends, Language Skills and Labour Market Integration of Recent Immigrants. Paper presented at the Language Matters Symposium, Ottawa, Canada. Retrieved from

http://www.metropolis.net/events/metropolis presents/LanguageSeminar/Pre sentations/Boyd_Lang_LM_paper_e.pdf

Braverman, H. (1974). Labor and Monopoly Capital: The Degradation of Work in the Twentieth Century. New York: Monthly Review Press.

Brem, M. (2006). Migrant Workers in Canada: A Review of the Canadian Seasonal Agricultural Workers Program - Policy Brief. A Report for the North South Institute. Retrieved from http://www.nsi-ins.ca/wpcontent/uploads/2012/10/2006-Migrant-Workers-in-Canada-A-review-of-theCanadian-Seasonal-Agricultural-Workers-Program.pdf 
Brickner, R. and Straehle, C. (2010). The Missing Link: Gender, Immigration Policy and the Live-in Caregiver Program in Canada. Policy and Society, 29, 309320.

British Columbia Provincial Nominee Program (2017). Entry Level and Semi-skilled. Retrieved from https://www.welcomebc.ca/Immigrate-to-B-C/BC-PNP-Skills$\underline{\text { Immigration/Entre-Level-and-Semi-Skilled }}$

Brueckner, J., and Lall, S. (2015). Cities in Developing Countries: Fueled by RuralUrban Migration, Lacking in Tenure Security, and Short of Affordable Housing. In G. Duranton, J.V. Henderson, and W. Strange (Eds.) Handbook of Regional and Urban Economics (pp. 1399-1455). Retrieved from http://ac.els-cdn.com/B9780444595317000211/1-s2.0B9780444595317000211-main.pdf? tid=a0b32f14-f265-11e6-b98e-

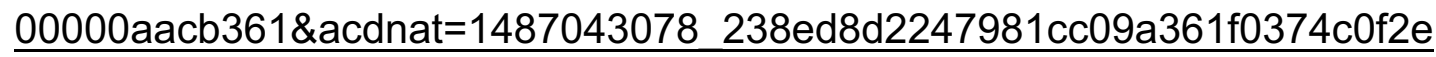

Budnik, K. (2011). Temporary Migration in Theories of International Mobility of Labour. Bank i Kredyt, 42(6), 7-48. Retrieved from http://bankikredyt.nbp.pl/content/2011/06/bik_06_2011_01_art.pdf

Card, D. (2005). Is the New Immigration Really So Bad? NBER Working Series, Working Paper 11547. Retrieved from http://www.nber.org/papers/w11547

Card, D. (2009 November 7). Immigration and Inequality. CReAM Discussion Paper Series. Retrieved from http://discovery.ucl.ac.uk/14325/1/14325.pdf

Carens, J. (1987). Aliens and Citizens: The Case for Open Borders. The Review of Politics, 49(2), 252-273. 
Carens, J. (2008). The Rights of Irregular Migrants. Ethics \& International Affairs, 22(2), 163-186.

Carlassare, E. (2010). Socialist and Cultural Ecofeminism: Allies in Resistance.

Ethics and Environment, 5(1), 89-106. Retrieved from

http://journals1.scholarsportal.info/details/10856633/v05i0001/89 saceair.xml Inopdf

Carty, R.K., Cross, W., and Young, L. (2007). Rebuilding Canadian Party Politics. Vancouver: UBC Press.

Carvajal, L. and Stallman, J. (2016, January 27). Canada's Seasonal Agricultural Workers Program: Motivations of Mexican Workers [Webinar]. In Columbia Basin Rural Development Institute Webinar Series. Retrieved from http://www.cbrdi.ca/wp-content/uploads/2016.01.27-motivations-webinar.pdf Cassiano, M., Doerksen, C., Dorow, D (2015, January). Live-in Caregivers in Fort McMurray: A Socioeconomic Footprint. Retrieved from http://www.onthemovepartnership.ca/wp-content/uploads/2015/01/Live-inCaregivers-in-Fort-McMurray-Dorow-et-al.-January-2015.pdf

Castles, S. (2005, October). Hierarchical Citizenship in a World of Unequal NationStates. PS: Political Science \& Politics, 38(04), 689-692. Retrieved from http://journals.cambridge. org/action/displayAbstract?fromPage=online\&aid=3 $\underline{42367 \& \text { fileld }=S 1049096505050353}$

Cervenan, A. (2009, March). Service Class Prosperity in Ontario. Working Paper Series: Ontario in the Creative Age. Martin Prosperity Institute. Retrieved 
from http://martinprosperity.org/media/pdfs/Service Class Prosperity$\underline{\text { ACervenan.pdf }}$

Chapman, B., Dunlop, Y., Gray, M., and Liu, A. (2001). The Impact of Children on the Lifetime Earnings of Australian Women: Evidence from the 1990s. The Australian Economic Review, 34(4), 373-389.

Cheung, L. (2006). Living on the Edge: Long Employment Gaps for Temporary Migrant Workers Under the Live-in Caregiver Program (LCP) (Master's Thesis). Simon Fraser University. Retrieved from: http://mbc.metropolis.net/assets/uploads/files/Cheung.pdf

Chiswick, B.R. (1991). Speaking, Reading and Earnings Among Low-Skilled Immigrants. Journal of Labor Economics, 9(2), 149-170.

Chiswick and Miller (2002). The Complementarity of Language and Other Human Capital: Immigrant Earnings in Canada. IZA Discussion Paper 451. Retrieved from http://www.chicagobooth.edu/assests/stigler/148.pdf

Citizenship and Immigration Canada - CIC. (2014). Changes to the Temporary Foreign Worker Program. Retrieved from

http://www.cic.gc.ca/english/department/acts-regulations/forward-regulatoryplan/changes-tfwp.asp

Citizenship and Immigration Canada - CIC. (2015). Find out if you need a Labour Market Impact Assessment. Retrieved from http://www.cic.gc.ca/english/work/employers/applywho.asp?_ga=1.142714933.1409533144.1493511519 
Citizenship and Immigration Canada - CIC. (2016). Determine your Eligibility Live-in caregivers. Retrieved from http://www.cic.gc.ca/english/work/caregiver/apply-who.asp

Clark, D. (2002, December). Neoliberalism and Public Service Reform: Canada in Comparative Perspective. Canadian Journal of Political Science / Revue Canadienne de Science Politique, 35(4), 771-793.

http://journals1.scholarsportal.info.ezproxy.lib.ryerson.ca/pdf/00084239/v35i0 $\underline{004 / 771 \text { napsrcicp.xml }}$

Clifton, J. (2008, October 1). Deserving Citizenship? Canadian Immigration Policy and 'Low Skilled' Portuguese Workers in Toronto (Master's Thesis). Available from University of British Columbia's Open Collections. Retrieved from https://open.library.ubc.ca/clRcle/collections/ubctheses/24/items/1.0066654

Cohen, R. (2000). 'Mom is a Stranger': The Negative Impact of Immigration Policies on the Family of Filipina Domestic Workers. Canadian Ethnic Studies, 322(3), 76-88.

Conference Board of Canada (2016, December 1). Sowing the Seeds of Growth: Temporary Foreign Workers in Agriculture. Retrieved from http://www.conferenceboard.ca/e-library/abstract.aspx?did=8363

CS/Resors Ltd., Bird, G., and Emery, R. (2002). The Tourism Sector in British Columbia: Literature Review, Labour Market Projections and Training Gap Analysis. Retrieved from https://www.go2hr.ca/sites/default/files/legacy/reports/Tourism Sector in BC . $\mathrm{pdf}$ 
Cortes, P. (2008). The Effect of Low-Skilled Immigration on U.S. Prices: Evidence from CPI Data. Journal of Political Economy, 2008, 116(3), 381-422.

Curry, B. (2014, May 2) Everything You Need to Know About Temporary Foreign Workers. The Globe and Mail, Retrieved from http://www.theglobeandmail.com/news/politics/temporary-foreign-workerseverything-you-need-to-know/article18363279/

Daenzer, P. (1991). Unemployment and Minority Immigrants in Canada. International Journal of Sociology and Social Policy, 11(1/2/3), 29-50.

Retrieved from http://www.emeraldinsight.com/doi/pdfplus/10.1108/eb013125

Daenzer, P. (1997). An Affair Between Nations: International Relations and the Movement of Household Service Workers. In A.B. Bakan and D.K. Stasiulis (Eds.) Not One of the Family: Foreign Domestic Workers in Canada. (pp. 81118). Toronto: University of Toronto Press.

Dahl, R. (1957). The Concept of Power: Systems Research. Behavioural Science, 2(3), 201-215.

Dauvergne, C. (2000). Citizenship, Migration Laws and Women: Gendering Permanent Residency Statistics. Melbourne University Law Review, 24, $280-$ 309.

De Luna-Villalón, (2011). Mexican Temporary Agricultural Workers in Canada: A Language and Migration Approach (Master's Thesis). University of Western Ontario.

Delanty G. and Strydom P. (2003). Philosophies of Social Science; the Classic and Contemporary Readings. Philadelphia: Open University Press. 
Denstedt, M. (2008). Precariousness on the Menu: Restaurant Work and Labour Mobility Within Low-wage Service Industry (Master's Thesis). Available from QSpace. Retrieved from http://qspace.library.queensu.ca/handle/1974/1333

Devoretz, D., and Pivnenko, S. (2004). The Economic Causes and Consequences of Canadian Citizenship. IZA Discussion Paper 1395. Retrieved from http://anon-ftp.iza.org/dp1395.pdf

Doeringer, P. and Piore, M. (1971). Internal Labor Markets and Manpower Analysis. Lexington: D.C. Heath \& Co.

Dungan, P., Fang, T., and Gunderson, M. (2012). Macroeconomic Impacts of Canadian Immigration: Results from a Macro-Model. IZA Discussion Paper 6743. Retrieved from http://ftp.iza.org/dp6743.pdf

Dyson D., Goldring, L., Lafleche, M., Lewchuk, W., Meisner, A., Procyk, S., . . . Vrankulji, S. (2013, February). It's More than Poverty; Employment Precarity and Household Well-being. Retrieved from https://pepsouwt.files.wordpress.com/2013/02/its-more-than-poverty-feb2013.pdf

Dyson D., Goldring, L., Lafleche, M., Lewchuk, W., Meisner, A., Procyk, S., . . . Peter Viducis. (2015, May). The Precarity Penalty: The Impact of Employment Precarity on Individuals, Households and Communities —and what to do about it. Retrieved from http://www.unitedwaytyr.com/document.doc?id=307

Elliot, D., (2010). Response Rates to the National Household Survey. Western Policy Analysis, Johnson Shoyama Graduate School of Public Policy 4(5) 68. Retrieved from 
https://www.usask.ca/cfbsjs/research/pdf/research reports/Perceptions\%20a nd\%200pinions \%20about $\% 20$ Crime $\% 20$ and\%20Justice $\% 20$ in $\% 20$ Saskatch ewan.pdf

Employment and Social Development - ESDC (2014). Overhauling the Temporary Foreign Worker Program: Putting Canadians First. WP-191-06-14E.

Retrieved from http://publications.gc.ca/collections/collection 2014/edscesdc/Em4-1-2014-eng.pdf

Employment and Social Development Canada - ESDC. (2016a). National Occupation Classification. Retrieved from http://noc.esdc.gc.ca/English/noc/Tutorial.aspx?ver=16\#23

Employment and Social Development Canada - ESDC. (2016b). Welcome to the National Occupation Classification 2006. Retrieved from http://noc.esdc.gc.ca/English/NOC/welcome.aspx?ver=06

Employment and Social Development Canada - ESDC. (2016c). Hire a Temporary Worker as an In-home Caregiver; Overview. Retrieved from https://www.canada.ca/en/employment-socialdevelopment/services/foreign-workers/foreign-workers-hirecaregiver/overview.html

Employment and Social Development Canada - ESDC. (2016d). Hire a Temporary Foreign Agricultural Worker; Overview. Retrieved from https://www.canada.ca/en/employment-socialdevelopment/services/foreign-workers/hire/agricultural.html 
Employment and Social Development Canada - ESDC. (2016e). Streams for Highwage or Low-wage Positions. Retrieved from https://www.canada.ca/en/employment-socialdevelopment/services/foreign-workers/hire/median-wage.html

Employment and Social Development Canada - ESDC. (2016f). Annual Labour Market Impact Assessment Statistics 2008-2015 by North American Industry Classification System - 2002 (NAICS). Retrieved from https://www.canada.ca/en/employment-social-development/services/foreignworkers/reports/2014/Imia-annual-statistics/industry-classification.html\#h2.15 Employment and Social Development Canada - ESDC. (2016g). Hire a Temporary Foreign Worker in a Low-wage Position; Wages, Working Conditions and Occupations. Retrieved from https://www.canada.ca/en/employment-socialdevelopment/services/foreign-workers/hire/median-wage/low/workingconditions.html\#wage

Employment and Social Development Canada - ESDC. (2016h). 9482 Motor Vehicle Assemblers, Inspectors and Testers. Retrieved from http://noc.esdc.gc.ca/English/noc/ViewAllTitlesQuickSearch.aspx?ver=06\&val65= $\underline{9482 \& \mathrm{val}=9 \& \mathrm{val} 1=9482}$

Employment and Social Development Canada - ESDC. (2016i). Reports and Publications: Temporary Foreign Worker Program; Quarterly Labour Market Impact Assessment Statistics. Retrieved from https://www.canada.ca/en/employment-socialdevelopment/services/foreign-workers/reports.html 
Employment and Social Development Canada - ESDC. (2017). Explore Careers Job Market Report - Truck Drivers - (Canada Wage Ranges). Retrieved from http://www.jobbank.gc.ca/reporteng.do?area=6261\&lang=eng\&noc=7511\&action=final\&ln=n\&regionKeyword=Ha $\underline{\text { milton } \% 2 C+O n t a r i o \& s=1 \& \text { source=1\&titleKeyword=truck+driver\#wages }}$

Engelhardt, G., and Stukel, T. (2001). The Basics of Multiple Regression. In Factors Related to Wages in the Current Population Survey. Retrieved from https://math.dartmouth.edu/ mqed/eBookshelf/statistics/WageFactors.html

Esposto, A. (2008). Skill: An Elusive and Ambiguous Concept in Labour Market Studies. Australian Bulletin of Labour, 34(1). 100-124. Retrieved from http://search.proquest.com/docview/1609169289?pq-origsite=summon

Evans, M. (1998, Summer). Choosing to be a Citizen: The Time-Path of Citizenship in Australia, The International Migration Review, 22(2), 243-264. Retrieved from http://www.jstor.org/stable/2546649?seq=1\#page scan tab_contents

Faraday F. (2012a, September). Made in Canada: How the Law Constructs Migrant Workers' Insecurity. Metcalf Foundation Summary Report. Retrieved from http://metcalffoundation.com/wp-content/uploads/2012/09/Made-in-Canada-FullReport.pdf

Faraday, F. (2012b, September). Made in Canada: How the Law Constructs Migrant Workers' Insecurity. Metcalf Foundation Summary Report. Retrieved from http://metcalffoundation.com/wp-content/uploads/2012/09/Made-in-Canada$\underline{\text { Summary-Report.pdf }}$ 
Faraday F. (2014). Profiting from the Precarious: How Recruitment Practices Exploit Migrant Workers. Metcalf Foundation Summary Report. Retrieved from http://metcalffoundation.com/wp-content/uploads/2014/04/Profiting-from-thePrecarious-Summary-Report.pdf

Faraday F. (2016, June). Canada's Choice: Decent Work or Entrenched Exploitation for Canada's Migrant Workers. Metcalf Foundation. Retrieved from http://metcalffoundation.com/wp-content/uploads/2016/06/Canadas-Choice-2.pdf

Ferraro, V. (2010). Paid Work. Women in Canada: A Gender-based Statistical

Report. Catalogue. Retrieved from http://www.statcan.gc.ca/pub/89-503$\underline{x / 2010001 / a r t i c l e / 11387-e n g . p d f}$

Form, W. (1987, August). On the Degradation of Skills. Annual Review of Sociology, 13(1), 29-47.

http://www.annualreviews.org/doi/pdf/10.1146/annurev.so.13.080187.000333

Fortin, N. and Huberman, M. (2002, May). Occupational Gender Segregation and Women's Wages in Canada: An Historical Perspective. Canadian Public Policy, 28(1), 11-39.

Foster, J. (2012). Making Temporary Permanent: The Silent Transformation of the Temporary Foreign Worker Program. Just Labour: A Canadian Journal of Work and Society, 19, 22-46.

Foster, J., and Barneston, B. (2015). The Construction of Migrant Work and Workers by Alberta Legislators, 2000-2011. Canadian Ethnic Studies, 47(1), 2015. Retrieved from https://muse.jhu.edu/article/577759 
Friedman D., and Hechter M. (1988, Autumn). The Contribution of Rational Choice Theory to Macrosociological Research. Sociological Theory, 6(2) (Autumn, 1988), 201-218. Retrieved from http://www.jstor.org/stable/pdf/202116.pdf

Freeman, M., França, E., \& Vasconcelos, E. (2010, Fall). Critical Social Theory: Core Tenets, Inherent Issues. Critical Social Theory and Evaluation Practice; New Directions for Evaluation, 127, 7-19.

Frenette, Y. (2014, Spring). Conscripting Canada's Past: The Harper Government and the Politics of Memory. Canadian Journal of History, 49-65.

Fuatai, T. (2016, April 12). From Exploitation to Employment: Undoing Canada's Sheltered Workshop System. Rabble.ca. Retrieved from http://rabble.ca/news/2016/04/exploitation-to-employment-undoing-canadassheltered-workshop-system

Fudge, J. (2012). Precarious Migrants' Status and Precarious Employment: The Paradox of International Rights for Migrant Workers. Comparative Labour Law Policy Journal, 34(81), 95-131.

Fudge, J., and MacPhail, F. (2009), Temporary Foreign Worker Program in Canada: Low-Skilled Workers as an Extreme Form of Flexible Labor. Comparative Labour Law Policy Journal, 31(5), 5-45.

Gabriel, C., and Macdonald, L. (2011). Citizenship at the Margins: The Canadian Seasonal Agricultural Worker Program and Civil Society Advocacy. Politics \& Policy, 39(1), 45-67.

Gabriel, C., and Pelerin, H. (2012). Governing International Labour Migration: Current Issues, Challenges and Dilemmas. London: Routledge. 
Gabriel, C. (2016). 'Advantage Canada' and the Contradictions of Im(migration) Control, Constructing and Imagining Labour Migration: Perspectives of Control from Five Continents. Guild E. and Mantu, S. (Eds.). Netherlands: Routledge Galarneau, D., and Morissette R. (2008, December). Immigrants' Education and Required Job Skills. Statistics Canada - Perspectives. Catalogue no. 75-001-X. Retrieved from http://www.statcan.gc.ca/pub/75-001-x/2008112/pdf/10766eng.pdf

Galarneau, D. (2016, March 18). Job Vacancies in 2011: Results of the Workplace Survey. Labour Statistics: Research Papers. Catalogue no. 75-004. Retrieved from http://www.statcan.gc.ca/pub/75-004-m/75-004-m2016001-eng.pdf Gardiner Barber, P. (1997). Transnationalism and the Politics of "Home" for Philippine Domestic Workers. Anthropologica, 39, (1/2) (1997), 39-52. http://www.jstor.org/stable/25605850?seq=1\#page scan tab contents

Gelb, L. (2009). What Power is and What Power Isn't. In Power Rules (pp. 26-43). New York: Harper Perennial.

Gellatly, M., Grundy, J., Kiran, M., Perry, J.A., Thomas, M., and Vosko, L. (2011). 'Modernising' Employment Standards? Administrative Efficiency and the Production of the Illegitimate Claimant in Ontario, Canada. Economic and Labour Relations Review, 22(2), 81-106.

George, U., and Chaze, F. (2016). Migration, Mobility and Multiple Affiliations:

Punjabs in a Transnational World. S. Irudaya Rajan, V. J. Varghese, and Aswini Kumar Nanda (Eds.) India: Cambridge University Press. 
Gilmore, J. (2008). The Canadian Immigrant Labour Market in 2006: Analysis by Region or Country of Birth. Statistics Canada. Catalogue no. 71-606-X2008002. Retrieved from http://www.statcan.gc.ca/pub/71-606-x/71-606-x2008002-eng.pdf Glick-Schiller, N. (2011). A Global Perspective on Migration and Development. In Thomas Faist, Margit Fauser and Peter Kivisto (Eds.) The Migrationdevelopment Nexus: A Transnational Perspective (pp. 29-56). Basingstoke: Palgrave Macmillan.

Gokanksel, B., and Smith, S. (2016, July). "Making America Great Again”?: The Fascist Body Politics of Donald Trump, Political Geography, 54, 1-3. Retrieved from https://www.researchgate.net/publication/305698350_Making_America_great_ag ain_The_fascist_body_politics_of_Donald_Trump

Goldring, L and Joly, M.P. (2014, Autumn). Immigration, Citizenship and Racialization at Work: Unpacking Employment Precarity in Southwestern Ontario. Just Labour: A Canadian Journal of Work and Society, 22, 94-121. Retrieved from http://www.justlabour.yorku.ca/volume22/pdfs/07 goldring joly press.pdf Goldring, L., and Landolt, P. (2012, October). The Impact of Precarious Legal Status on Immigrants' Economic Outcomes. IRPP Study. No. 35. Retrieved from http://irpp.org/wp-content/uploads/assets/research/diversity-immigration-andintegration/the-impact-of-precarious-legal-status-on-immigrants-economicoutcomes/IRPP-Study-no35.pdf 
Goldring, L., and Landolt, P. (2013). Producing and Negotiating Non-citizenship: Precarious Legal Status in Canada. Toronto: University of Toronto Press.

Goldring, L. (2014). Resituating Temporariness as the Precarity and Conditionality of Non-citizenship. In Leah F. Vosko, Valerie Preston, Robert Latham (Eds.) Liberating Temporariness: Migration, Work, and Citizenship in an Age of Insecurity in Canada (pp. 218-254). Montreal: McGill-Queen's University Press.

Government of Canada, Hourly Minimum Wages in Canada for Adult Workers, retrieved online on July 4th , 2016 from: http://srv116.services.gc.ca/dimt-wid/sm$\underline{\mathrm{mw} / \mathrm{rpt} 2 \cdot \operatorname{aspx}}$

Government of Canada, (2017). List of Job Titles - General Farm Workers (NOC $8431-$ C). retrieved from:

http://www.jobbank.gc.ca/job titleseng.do?area=6261\&lang=eng\&noc=8431\&bac kurl=\%2Freport-eng.do\%3Farea\%3D6261\%26lang\%3Deng\%26noc\%3D8431

Government of Canada, (2017a). Explore Careers - Job Market Report Occupational Outlook - Motor Vehicle assemblers, Inspectors and Testers. Retrieved from: http://www.jobbank.gc.ca/reporteng.do?area $=8848 \&$ lang=eng\&noc $=9522 \&$ action $=$ final\&ln=p\&regionKeyword=Dryden $\% 2 C+$ Ontario $\& s=1 \&$ source $=1 \&$ titleKeyword $=$ automobile+inspector+and+tester+-+motor+vehicle+manufacturing\#wages

Gradstein, M. and Schiff, M. (2004, April 15). The Political Economy of Social Exclusion with Implications for Immigration Policy. IZA Discussion Paper 1087. Retrieved from https://papers.ssrn.com/sol3/papers2.cfm?abstract id=526007 
Grandea, N., and Kerr, J. (1998). 'Frustrated and Displaced': Filipina Domestic Workers in Canada. Gender and Development, 6(1), 7-12.

Gross, D. (2004). Impact of Immigrant Workers on a Regional Labour Market. Applied Economics Letters, 11(7): 405-408.

Gross, D. (2014). Temporary Foreign Workers in Canada: Are they Really Filling Labour Shortages? A C.D. Howe Institute. Commentary No 407. Retrieved from http://www.everyoneschance.ca/wpcontent/uploads/2014/04/commentary 407.pdf

Gruchy, A. (1984, June). Institutionalism, Post Keynesianism, and Neo-Marxism: An Evaluation. Journal of Economic Issues (pre-1986), 547-556. Retrieved from http://search.proquest.com/docview/206759758?pq-origsite=summon

Gutstein, D. (2014). Harperism: How Stephen Harper and His Think Tank Colleagues Have Transformed Canada. Toronto: James Lorimier \& Company Ltd., Publishers.

Haas, De H. (2010). Migration and Development: A Theoretical Perspective. International Migration Review, 44(1), 227-264.

Hahamovitch, C. (2003). Creating Perfect Immigrants: Guestworkers of the World in Historical Perspective. Labour History, 44(1), 69-94. Retrieved from http://www.tandfonline.com/doi/abs/10.1080/0023656032000057010

Hanley J., and Shragge E. (2009). Organizing for Immigrant Rights: Policy Barriers and Community Campaigns. Journal of Community Practice 17, 184-206.

Harling-Stalker, L., and Phyne, J. (2014). The Social Impact of Out Migration: A Case Study from Rural and Small Town Nova Scotia, Canada. Journal of Rural 
and Community Development, 9(3), 203-226. Retrieved from

http://journals.brandonu.ca/jrcd/article/view/919/206

Harsanyi, J. (1969, July). Rational-Choice Models of Political Behavior vs.

Functionalist and Conformist Theories. World Politics, 21(4), 513-538. Retrieved

from .http://www.jstor.org/stable/pdf/2009665.pdf? $=1465344072585$

Hawthorne, L. (2007, April). Labour Market Outcomes for Migrant Professional:

Canada and Australia Compared. Retrieved from

http://publications.gc.ca/site/archivee-

archived.html?url=http://publications.gc.ca/collections/collection_2010/cic/Ci64-12007-eng.pdf

Healy, T., and Trew, S., (2015), The Harper Record, 2008-2015. Ottawa: Canadian

Centre for Policy Alternatives, 2015 (In Press). Retrieved from, http://voicesvoix.ca/sites/voices-voix.ca/files/harper_record_.pdf\#page $=141$

Henry, F. (1968, March). The West Indian Domestic Scheme in Canada. Social and Economic Studies, 17(1), 83-91. Retrieved from

http://s3.amazonaws.com/migrants heroku production/datas/164/Henry 1968 o riginal.pdf?1311859194

Hennebry, J. (2012, February). Permanently Temporary? Agricultural Migrant Workers and their Integration. IRPP Study. No. 26. Retrieved from http://irpp.org/wp-content/uploads/assets/research/diversity-immigration-andintegration/permanently-temporary/IRPP-Study-no26.pdf 
Hennebry J. L. and Preibisch, K. (2012). A Model for Managed Migration? Re-

Examining Best Practices in Canada's Seasonal Agricultural Worker Program. International Migration, 50(1), 19-40.

Hennebry, J., McLaughlin, J., and Preibisch, K. (2015). Addressing the Agricultural Migrant Protection. Changing Workplaces Review. Retrieved from http://www.migrantworkersalliance.org/wpcontent/uploads/2015/11/HennebryMcLaughlinPreibisch ESA$\underline{\text { ReviewSubmissionSept18.pdf }}$

Hennebry, J., and Preibisch, K. (2016). Out of the Loop: (In)access to Healthcare for Migrant Workers in Canada. Journal of International Migration and Integration, 17(2), 521-538. Retrieved from http://journals2.scholarsportal.info.ezproxy.lib.ryerson.ca/details/14883473/v17i0 $\underline{002 / 521 \text { ootlthcfmwic.xml }}$

Herb, G. (1999). National Identity and Territory. In G.H. Herb and D.H. Kaplan (Eds.) Nested Identities: Nationalism, Territory and Scale (pp. 9-30). Lenham: Rowman \& Littlefield Publishers.

Herf, J. (2012, Fall). Dialectic of Enlightenment Reconsidered. New German Critique, 117(3), 81-89. Retrieved from http://journals2.scholarsportal.info/pdf/0094033x/v39inone/81 doer.xml Hiles, D. (2001). First Look at Employment and Wages Using NAICS. A Monthly Labor Review, 124, 22-31. Retrieved from http://heinonline.org/HOL/Page?handle=hein.journals/month124\&id=1290\&collec $\underline{\text { tion=journals }}$ 
Hodge, J. (2006). Unskilled Labour: Canada's Live-in Caregiver Program.

Undercurrent, 3(2), 60-66. Retrieved from

https://www.researchgate.net/publication/240612448 Unskilled_Labour_Canada'

$\underline{\text { s Live-in Caregiver Program }}$

Hsiung, P., and Nichol, K. (2010). Policies on and Experiences of Foreign Domestic Workers in Canada. Sociology Compass, 4(9), 766-778.

Hughes, C. (2012). Costly Benefits and Gendered Costs: Guatemalans'

Experiences of Canada's 'Low-Skilled Pilot Project.' In P.T. Lenard and C.

Straehle (Eds.) Legislated Inequality: Temporary Labour Migration in Canada

(pp. 139-157). Montreal: MacGill-Queen's University Press.

HUMA - Standing Committee on Human Resources, Skills and Social Development and the Status of Persons with Disabilities. (2016, September). Report of the Standing Committee on Human Resources, Skills and Social Development and the Status of Persons with Disabilities. Retrieved from

http://www.parl.gc.ca/Content/HOC/Committee/421/HUMA/Reports/RP8374415/

421 HUMA Rpt04 PDF/421 HUMA Rpt04-e.pdf

Immervoll, H., Jenkins, S., Königs, S. (2015, January). Are Recipients of Social

Assistance ‘Benefit Dependent'? Concepts, Measurement and Results for

Selected Countries. IZA Discussion Paper 8786. Retrieved from http://anon-

ftp.iza.org/dp8786.pdf

Inglehart, R., and Norris, P. (2016, July 26). Trump, Brexit, and the Rise of

Populism: Economic Have-Nots and Cultural Backlash. HKS Working Paper No. 
RWP 16-026. Retrieved from

https://papers.ssrn.com/sol3/papers2.cfm?abstract id=2818659

IRCC - Immigration, Refugees and Citizenship Canada. (2016a, June 22). Changes

to the International Student Program. Retrieved from

http://www.cic.gc.ca/english/study/study-changes.asp

IRCC - Immigration, Refugees and Citizenship Canada. (2016b, December 13).

Government of Canada Takes Early Action to Improve the Temporary Foreign

Worker Program. Retrieved from http://news.gc.ca/web/article-

en.do?nid=1168949

IRCC - Immigration, Refugees and Citizenship Canada. (2016c). Facts \& Figures

2015: Immigration Overview - Temporary Residents. Retrieved from

http://open.canada.ca/data/en/dataset/052642bb-3fd9-4828-b608-

c81dff7e539c? ga=1.259179722.1981317549.1487562723

IRCC - Immigration, Refugees and Citizenship Canada. (2017). How Express Entry

Works. Retrieved from http://www.cic.gc.ca/english/express-entry/

International Labour Organization -ILO. (2009). Facts on New Wage Challenges:

Trends and Policy Issues. International Labour Organization. Retrieved from

http://www.ilo.org/wcmsp5/groups/public/@dgreports/@dcomm/documents/public

ation/wcms 101660.pdf

Isin, E., and Wood, P. (1999). Citizenship and Identity. A Theory, Culture and

Society Series. Sage Publications. Online ISBN: 781446218129

Jackson S., and Bauder H. (2013). Neither Temporary, Nor Permanent: The

Precarious Employment Experiences of Refugee Claimants in Canada. Journal 
of Refugee Studies, 27(3), 360-81.

http://journals2.scholarsportal.info/details/09516328/v27i0003/360 ntnptpeorcic.x

$\underline{\mathrm{ml}}$

Janz, T. (2004). Low-paid Employment and Moving Up: A Closer Look at Full-time,

Full-year Workers, 1996-2001. Income Statistics Division; Catalogue no.

75F0002MIE2004009.

Jessop, B. (1982). The Capitalist State: Marxist Theories and Methods. Oxford:

Martin Robertson and Company Ltd.

Jessop, B. (1999). The Strategic Selectivity of the State: Reflections on a Theme of

Poulantzas, Journal of the Hellenic Diaspora, 25 (1-2), 1-37.

Jessop, B. (2002, July). Liberalism, Neoliberalism and Urban Governance: A State-

Theoretical Perspective. Antipode, 34(3), 452-472.

Jessop, B. (2009). Avoiding Traps, Rescaling the State, Governing Europe. In R.

Keil and R. Mahon (Eds.) Leviathan Undone? Towards a Political Economy of

Scale (pp. 87-104). Vancouver: University of British Columbia Press.

Jessop B. (2011). 'Poulantzas's State, Power, Socialism as a modern classic.' In L.

Bretthauer et al. (Eds) Reading Poulantzas (pp. 42-55). London: Merlin.

Retrieved from https://bobjessop.org/2014/03/27/poulantzass-state-power-

socialism-as-a-modern-classicl

Jessop, B. (2012). Marxist Approaches to Power. In E. Amenta., K. Nash, and A.

Scott (Eds.) The Willey-Blackwell Companion to Political Sociology (pp. 3-14).

Wiley Blackwell. 
Jessop, B. (2014, October 18). States and State Power: A Strategic-Relational Approach. Paper presented at the "Capital, the State and European Integration" Symposium, Zagreb, Croatia.

Jessop (2015, July 20). UK Politics and Global Capitalism. Bob Jessop. Retrieved from https://bobjessop.org/2015/07/20/the-conjuncture-in-britain-new-labour-thepolitics-of-austerity-and-the-greek-tragedy/ Jessop, B., and Jones, M. (2010). Thinking State/Space Incompossibly. Antipode 42(5), 1119-1149.

Johnson, G. (2005). Taking Stock: The Normative Foundations of Positivist and Non-Positivist Policy Analysis and Ethical Implications of the Emergent Risk Society. Journal of Comparative Policy Analysis: Research and Practice, 7(2), $137-153$.

Jonassen, D. (2011). Learning to Solve Problems, A Handbook for Designing Problem-Solving Learning Environments. New York: Routledge, Taylor and Francis Group.

Jonna, J., and Foster, J. (2014, October). The Complex Relation Between the Labor Process on the One Hand, and the Changing Structure and Composition of the Working Class and its Reserve Armies on the Other. Monthly Review, 65(1), 123. Retrieved from http://search.proquest.com/docview/1609169289?pqorigsite=summon Justice for Migrant Workers (2006, March 23). The Seasonal Agricultural Workers Program: The Issues. Retrieved from http://www.justicia4migrantworkers.org/saw new.htm 
Kahn, L. (2015, April). Wage Compression and the Gender Pay Gap. IZA World of Labor 2015. Retrieved from http://wol.iza.org/articles/wage-compression-andgender-pay-gap.pdf

Kelley, N., and Trebilcock, M. (1999). The Making of the Mosaic, a History of Canadian Immigration Policy. Toronto: University of Toronto Press.

King, R. (2012, March). Theories and Typologies of Migration: An Overview and a Primer. Willy Brant Series of Working Papers in International Migration and Ethnic Relations. Retrieved from https://www.mah.se/upload/Forskningscentrum/MIM/WB/WB\%203.12.pdf

Kurjata, A. (2015, November 14). Prince George Homeless Men Paid Below Minimum Wage to Work at Dinosaur Exhibit: Discover the Dinosaurs Contractor Claims Men Were Volunteers - Not Employees. CBC News British Columbia. Retrieved from http://www.cbc.ca/news/canada/british-columbia/prince-georgehomeless-men-paid-below-minimum-wage-to-work-at-dinosaur-exhibit-

\subsection{5}

Kustek, S. (2012 June). The Role of Migrant Labour Supply in the Canadian Labour Market. Citizenship and Immigration Canada, Research and Evaluation.

Retrieved from http://www.cic.gc.ca/english/resources/research/2012migrant/documents/pdf/migrant2012-eng.pdf

Langevin, L. (2007). Trafficking in Women in Canada: A Critical Analysis of the Legal Framework Governing Immigrant Live-in Caregivers. International Journal of Comparative and Applied Criminal Justice, 31(2), 123-145. 
Langevin, M. (2010, March). Minimum Wage - Perspectives on Labour and Income. A Statistics Canada Publication. Catalogue No. 75-001-XIE. Retrieved from http://www.statcan.gc.ca/pub/75-001-x/topics-sujets/pdf/topicssujets/minimumwage-salaireminimum-2009-eng.pdf

Law, L. and Nadeau, K. (1999). Globalization, Migration and Class Struggles: NGO Mobilization for Filipino Domestic Workers. Kasarinlan Philippine Journal of Third World Studies, 15(3), 51-68.

Lenard P., and Straehle C. (2011). Temporary Labour Migration, Global Redistribution and Democratic Justice. Politics Philosophy Economics, 11(2), 206-230.

Lenard P., and Straehle C. (2012). Introduction. In P.T. Lenard and C. Straehle (Eds.) Legislated Inequality: Temporary Labour Migration in Canada (pp. 3-25). Montreal: MacGill-Queen's University Press.

Lewchuk, W., and Lefleche, M. (2014, Autumn). Precarious Employment and Social Outcomes. Just Labour: A Canadian Journal of Work and Society, 22, 45-50. Retrieved from http://www.justlabour.yorku.ca/volume22/pdfs/04 lewchuk lafleche press.pdf Lin, J. (2008, September). Trends in Employment and Wages, 2002 to 2007. Perspectives. Catalogue no. 75-001-X. Retrieved from http://www.statcan.gc.ca/pub/75-001-x/2008109/pdf/10694-eng.pdf Lindström, V. (2010). "I won’t be a Slave!": Finish Domestics in Canada (1911 - 30). Book chapter - I won't be a Slave: Selected Articles on Finish Canadian Women's History. Aspasia Books, Beaverton, Ontario. 
Lister, M., and Pia, E. (2008). Citizenship in Contemporary Europe. Edinburgh: Edinburgh University Press.

Macdonald, L. (2016). Canada in the Post-Hegemonic Hemisphere: Evaluating the Harper Government's Americas Strategy. Studies in Political Economy _97(1), 2016. Retrieved from http://www.tandfonline.com/doi/full/10.1080/07078552.2016.117446

Macklin, A. (1992). Foreign Domestic Worker: surrogate housewife or mail ordered servant? McGill Law Journal/Revue de droit de McGill, 37(3), 681-760 Madiraju, S. K. (1996). Discourse on Rationality: Rational Choice and Critical Theory (Doctoral Dissertation). Available from Glasgow Thesis Service. Retrieved from http://theses.gla.ac.uk/6102/1/1996.Madiraju.PhD.pdf Mandarino, P. (2009). Employment Across Generations: Italian Men in Toronto (Master's Thesis). Available from uO Research. Retrieved from https://www.ruor.uottawa.ca/bitstream/10393/28154/1/MR58183.PDF

Manitoba Provincial Nominee Program Website. (2017). Language Proficiency. Retrieved from http://www.immigratemanitoba.com/immigrate-tomanitoba/general-mpnp-policies/language-proficiency/ Marinetto, M. (2007). Social Theory, the State and Modern Society: The State in Contemporary Social Thought. New York: Open University Press.

Massey D., Arango, J., Hugo, G., Kouaouci A., Pellegrino A., Taylor, E. (1993). Theories of International Migration: A Review and Appraisal. Population and Development Review, 19(3), 431-466. Retrieved from 
http://media.library.ku.edu.tr/reserve/resfall05 06/INTL\%20450\%20Ahmet\%20lc duygu/Theories\%20of\%20International\%20Migration.pdf

Massey, D., and Gentsch, K., (2014). Undocumented Migration to the United States and the Wages of Mexican Immigrants. International Migration Review, 48(2), 482-499. Retrieved from:

http://onlinelibrary.wiley.com/doi/10.1111/imre.12065/epdf

McGrew, A. (2011). The Logics of Economic Globalization. In J. Ravenhill (Ed.) Global Political Economy. $-5^{\text {th }}$ Edition (pp. 255-286). Oxford: Oxford University Press.

Mikita, J. (1994, March). State Policy and the Migration of Foreign Domestic Workers to Canada: The Migration of Filipina Nannies to Vancouver, British Columbia (Master's Thesis). Available from Summit-Institutional Repository. Retrieved from http://summit.sfu.ca/item/4992

Monbiot, G. (2016, April 16). Neoliberalism; the Ideology at the Root of All Our Problems, The Guardian. Retrieved from https://www.theguardian.com/books/2016/apr/15/neoliberalism-ideology-problemgeorge-monbiot

Movilla, M. (2010, October 20). Temp Agencies Paying Immigrants Below Minimum Wage. CBC News Montreal. Retrieved from http://www.cbc.ca/news/canada/montreal/temp-agencies-paying-immigrantsbelow-minimum-wage-1.955141

Moriseette, R., Picott G., and Lu, Y. (2013). The Evolution of Canadian Wages over the Last Three Decades. Statistics Canada. Analytical Studies Branch Research 
Paper 11F0019M. Retrieved from

http://www.statcan.gc.ca/pub/11f0019m/11f0019m2013347-eng.pdf

Mueller, R. (2005). Mexican Immigrants and Temporary Residents in Canada:

Current Knowledge and Future Research. Migraciones Internacionales, 3(1), 32-

56. Retrieved from

http://scholar.ulethbridge.ca/sites/default/files/mueller/files/mig.internacionales.ja n2005.pdf

Mysyk, A., England, M., and Avila-Gallegos, J. (2009). Case for Certified

Interpreters for Participants in the Canada/Mexico Seasonal Agricultural Workers

Program. Human Organization, 68(3), 318-328.

Nakache, D., and Kinoshita P. (2010). The Canadian Temporary Foreign Worker

Program: Do Short Term Economic Needs Prevail Over Human Rights

Concerns? IRPP Study. No. 5. Retrieved from http://irpp.org/researchstudies/study-no5/

Nonimi, D. (2012). Theorizing Transnational Movement in the Current Conjuncture:

Examples from/of/in the Asia Pacific. In P Gardnier and W. Lern (Eds.) Migration in the 21st century: Political Economy and Ethnography (64-88). New York:

Routledge.

Ocak, O. (2016). Immigration and French National Identity Under Neoliberalism:

Sarkozy's Selective Immigration Politics as a Performance of

Sovereignty. Patterns of Prejudice, 50(1), 82-95. Retrieved from

http://www.tandfonline.com/doi/abs/10.1080/0031322X.2015.1127642?tokenDo

$\underline{\text { main=eprints\&tokenAccess=Q93j5hZVKiEica6T8ncp\&forwardService=showFullT }}$ 
ext\&doi $=10.1080 \% 2 F 0031322 X .2015 .1127642 \&$ doi $=10.1080 \% 2 F 0031322 X .201$

\section{$\underline{5.1127642 \& \text { journalCode=rpop20 }}$}

Olson, E., and Maser, K. (2010, April). Comparing Income Statistics from Different Sources: Aggregate Income, 2005. Income Research Paper Series. Catalogue no. 75F0002M. Retrieved from http://www.statcan.gc.ca/pub/75f0002m/75f0002m2010002-eng.pdf

Ontario Chamber of Commerce. (2017). Ontario Economic Report. Retrieved from http://www.occ.ca/wp-content/uploads/2017/02/ontarioeconomicreport2017.pdf

Ontario Government Ministry of Labour. (2015). Ontario Takes Another Step to Close the Gender Wage Gap. Retrieved from https://news.ontario.ca/mol/en/2015/04/ontario-takes-another-step-to-close-thegender-wage-gap.html

Ontario Human Rights Commission - OHRC. (2013). Policy on Removing the "Canadian experience" Barrier. Retrieved from http://www.ohrc.on.ca/en/policyremoving-\%E2\%80\%9Ccanadian-experience $\%$ E2\%80\%9D-barrier

Ontario Ministry of Citizenship and Immigration. (2016). Learn English or French. Retrieved from http://www.citizenship.gov.on.ca/english/keyinitiatives/language.shtml Ontario Ministry of Labour. (2016). Domestic Workers. Retrieved from https://www.labour.gov.on.ca/english/es/pubs/factsheets/fs domestics.php

Osborne J., and Overbay, A. (2004). The Power of Outliers (and Why Researchers Should Always Check for Them). Practical Assessment Research \& Evaluation. 9(6), 1-8. Retrieved from http://pareonline.net/getvn.asp?v=9\&n=6 
Ostry, A. and Spiegel, J.M. (2004). Labor Markets and Employment Insecurity: Impacts of Globalization on Service and Healthcare-sector Workforces. International Journal of Occupational and Environmental Health, 10(4), 368-374. Retrieved from http://www.tandfonline.com/doi/pdf/10.1179/oeh.2004.10.4.368

Oxfam International. (2017, January). An Economy for the 99\%: It's Time to Build a Human Economy That Benefits Everyone, Not Just the Privileged Few. Oxfam Briefing Paper. Retrieved from https://www.oxfam.org/sites/www.oxfam.org/files/file attachments/bp-economyfor-99-percent-160117-en.pdf

Painter, M. and Pierre, J. (2005). Unpacking Policy Capacity: Issues and Themes. In M. Painter \& J. Pierre (Eds.) Challenges to State Policy Capacity: Global Trends and Comparative Perspectives (pp. 1-18). New York: Palgrave MacMillan.

Palacio, N., M. (2009). An Evaluation of Geopolitical Borders, Journal of Poverty, 13(3), 266- 275.

Palacio, N. M. (2010). Integration of Low-Skilled Immigrants through Manitoba's Provincial Nominee Program (Master's Thesis) Ryerson University.

Pellerin, M. (2015). The Evolution of Hourly Compensation in Canada between 1980 and 2010 (Master's Thesis). Retrieved from www.theses.ulaval.ca/2015/32005/32005.pdf

Pendakur, K. \& Pendakur, R. (2002). Colour my World: Have Earning Gaps for Canadian-born Ethnic Minorities Changed Over Time? Canadian Public PolicyAnalyse de politiques, 28(4), 489-512. 
Piché, V., Pelletier, E., and Epale, D. (2006, August). Identification of Obstacles to Canada's Ratification of the International Convention on the Protection of the Rights of All Migrant Workers and Members of Their Families. Report Commissioned by UNESCO. Retrieved from http://unesdoc.unesco.org/images/0014/001473/147310E.pdf

Piketty, T., (2014). Capital in the Twenty-First Century. Translated by Arthur Goldhammer - Copyright - Harvard College - United States

Plascencia, L. (2016). State-Sanctioned Coercion and Agricultural Contract Labour: Jamaican and Mexican Workers in Canada and the United States, 1909-2014. In M. M. Linden and M. R. Garcia (Eds.) On Coerced Labor: Work and Compulsion After Chattel Slavery (pp. 225-67). Boston: Brill.

Postone, M. (2005). Critical Social Theory and the Contemporary World. International Journal of Politics, Culture, and Society,19(1), 69-79. Retrieved from http://link.springer.com/article/10.1007\%2Fs10767-007-9012-6

Pratt, G. (2006, Spring). Separation and Reunification Among Filipino Families in Vancouver. In VanderPlaat (Ed.) Canadian Issues; Immigration and Families (pp. 46-49). Retrieved from http://canada.metropolis.net/pdfs/CITC Spring06 Families FINALFullVersion.pdf

Preece, J. (1977, Spring-Summer). The Myth of the Red Tory. Canadian Journal of Political and Social Theory, 1,3-28.

Preibisch, K. (2004). Migrant Agricultural Workers and Processes of Social Inclusion in Rural Canada: Encuentros and Desencuentros. Canadian Journal of Latin 
American and Caribbean Studies, 29(57-58), 203-239. Retrieved from http://www.tandfonline.com/doi/pdf/10.1080/08263663.2004.10816857

Preibisch, K., and Hermoso, S. L. (2006). Engendering Labour Migration: The Case of Foreign Workers in Canadian Agriculture. In E. Tastsoglou and A. Dobrowolsky (Eds.) Women, Migration and Citizenship: Making Local, National and Transnational Connections (pp. 107-30). London: Ashgate Press.

Preibisch K., and Binford L. (2007, February). Interrogating Racialized Global Labour Supply: An Exploration of the Racial/National Replacement of Foreign Agricultural Workers in Canada. Canadian Review of Sociology, 44(1), 5-36. http://onlinelibrary.wiley.com/doi/10.1111/j.1755-618X.2007.tb01146.x/epdf

Preibisch, K. (2010, June). Pick-Your-Own Labor: Migrant Workers and Flexibility in Canadian Agriculture. International Migration Review, 44 (2), 404-441. Retrieved from http://journals1.scholarsportal.info/pdf/01979183/v44i0002/404 plmwafica.xml Preibisch, K. (2012). Migrant Workers and Changing Workplace Regimes in Contemporary Agricultural Production in Canada. International Journal. of Society of Agriculture \& Food, 19 (1), 62-82. Retrieved from https://www.ids.ac.uk/files/dmfile/migrantworkersandchangingworkplaceregimes.pdf

Preibisch, K. L., and Grez, E. E. (2014). The Other Side of el Otro Lado: Mexican Migrant Women and Labor Flexibility in Canadian Agriculture. Signs, 35(2), 289316. Retrieved from http://dx.doi.org/10.1086/605483 
Princeton Library - Data and Statistical Services, (2008). Log Transformations. Retrieved from: http://dss.princeton.edu/online help/stats packages/stata/log.html

Quirk, T.J. (2012). Excel 2010 for Social Science Statistics: A Guide to Solving Practical Problems, New York: Springer.

Reed, A.J. (2008, Spring). Canada's Experience with Managed Migration. International Journal, 469-484.

Reitz, J. G. (2001). Immigrant Skill Utilization in the Canadian Labour Market: Implications of Human Capital Research. Journal of International Migration and Integration, 2(3), 347-378.

Reitz, J.G. (2005, February). Tapping Immigrants' Skills: New Directions for Canadian Immigration Policy in the Knowledge Economy. IRPP, 11(1), 1-18. Retrieved from http://irpp.org/wp-content/uploads/assets/research/diversityimmigration-and-integration/new-research-article-4/vol11no1.pdf

Rheault, L., (2013) Corporate Lobbying and Immigration Policies in Canada. Canadian Journal of Political Science, 46(3), 691-722.

Roberts, M. (2003, January). Matrix of Skills Transferability. Report Prepared for the Labour Market Policy Directorate Human Resources and Skills Development Canada. Retrieved from http://www.publications.gc.ca/collections/collection_2008/hrsdc-rhdsc/HS3-1587-04-04E.pdf

Roe, M. J. (2003). Political Determinants of Corporate Governance. Oxford: Oxford University Press. 
Ronquillo, C., Boschma,G., Wong S., and Quiney L. (2011). Beyond Greener Pastures: Exploring Contexts Surrounding Filipino Nurse Migration in Canada through Oral History. Nursing Inquiry, 18(3), 262-275. Retrieved from http://onlinelibrary.wiley.com/doi/10.1111/j.1440-1800.2011.00545.x/epdf

Ruhs, M., and Martin, P., (2008). Numbers vs. Rights: Trade-Offs and Guest Worker Programs. International Migration Review, 42(1), 249-265.

Saez, C. (2013). The Seasonal Moral Contract: The Legitimization of the Abusive Treatment of Caribbean Workers in Ontario. The Caribbean Quilt, 3, 33-42. Retrieved from http://jps.library.utoronto.ca/index.php/cquilt/article/viewFile/22590/18424

Sassen, S. (2003). The Participation of States and Citizens in Global Governance. Indiana Journal of Global Legal Studies, 10(1), 5-28.

Satzewich, V. (2008). Business or Bureaucratic Dominance in Immigration Policymaking in Canada: Why was Mexico Included in the Caribbean Seasonal Agricultural Workers Program in 1974? Journal of International Migration \& Integration 8(3). 255-275. Retrieved from http://link.springer.com/article/10.1007/s12134-007-0026-8\#/page-1

Scott, J. (1978, March). Critical Social Theory: An Introduction and Critique. The British Journal of Sociology, 29(1), 1-21. Retrieved from http://www.jstor.org/stable/pdf/589216.pdf? $=1465512481052$

Scott, J. (2000). Rational Choice Theory. In G. Browning, A. Halcli, and F. Webster (Eds.) Understanding Contemporary Society: Theories of The Present. Sage 
Publications. Retrieved from

http://www.soc.iastate.edu/SAPP/soc401rationalchoice.pdf

Sen, Amartya (1977, Summer). Rational Fools: A Critique of the Behavioral

Foundations of Economic Theory. Philosophy \& Public Affairs, 6(4), 317-344.

Retrieved from https://www.ucl.be/cps/ucl/doc/cr-

cridis/documents/sen on TCR rational fools.pdf

Service Canada. (2015). Cashiers - Service Canada. Retrieved from

http://www.servicecanada.gc.ca/eng/qc/job futures/statistics/6611.shtml.

Sharma, N. (2001). On Being Not Canadian: The Social Organization of "Migrant Workers" in Canada, CRSN/RCSA, 38(4), 415-439. Retrieved from

http://journals2.scholarsportal.info/details/17556171/v38i0004/415 obnctsoowic.x $\underline{\mathrm{ml}}$

Sharma, N. (2006). Home Economics: Nationalism and the Making of 'Migrant Workers' in Canada. Toronto: University of Toronto Press.

Sharma, N. (2012). The "Difference" that Borders Make: "Temporary Foreign Workers" and the Social Organization of Unfreedom in Canada. In P.T. Lenard and C. Straehle (Eds.) Legislated Inequality: Temporary Labour Migration in Canada (pp. 26-47). Montreal: MacGill-Queen's University Press.

Schneider, A., and H. Ingram, H. (1993, June). Social Construction of Target Populations: Implications for Politics and Policy. The American Political Science Review, 87(2), 334-347. Retrieved from https://www.researchgate.net/profile/Helen Ingram/publication/259427630 The 
Social Construction of Target Populations/links/548093c90cf22525dcb5f698.p

$\underline{\mathrm{df}}$

Siemiatycki M. (2010, Spring). Marginalizing Migrants: Canada's Rising Reliance on Temporary Foreign Workers. In Christopher Worwick (Ed.) Canadian Issues; Temporary Foreign Workers (pp. 60-64). Metropolis Project.

Silverman, S., and Hari, A. (2016). Troubling the Fields: Choice, Consent, and Coercion of Canada's Seasonal Agricultural Workers. International Migration, 54(5), 91-104. Retrieved from http://onlinelibrary.wiley.com/doi/10.1111/imig.12266/abstract

Simon, H. (1955, February). A Behavioral Model of Rational Choice. The Quarterly Journal of Economics, 69(1), 99-118. Retrieved from http://www.jstor.org/stable/pdf/1884852.pdf

Sirkin, M. (2006). Statistics for the Social Sciences. California: Sage Publications. Skirbekk, V. (2004, August). Age and Individual Productivity: A Literature Survey Vienna Yearbook of Population Research. Retrieved from http://www.researchgate.net/profile/Vegard Skirbekk/publication/4862787 Age and individual productivity a literature survey/links/0deec52c52ffb267fa00000 $\underline{0 . p d f}$

Soysal, Y. (2006). Postnational Citizenship: Reconfiguring the Familiar Terrain. In K. Nask and A. Scott (Eds.) The Blackwell Companion to Political Sociology (pp. 336-337). Massachusetts: Blackwell Publishing. 
Soysal, Y. (2012). Postnational Citizenship: Rights and Obligations of Individuality. In E. Amenta, K. Nash, and A. Scott (Eds.) The Wiley-Blackwell Companion to Political Sociology (pp. 383-396). Malden: Wiley-Blackwell.

Statistics Canada. (2004, March). Minimum Wage Workers. Perspectives on Labour and Income, 5(3). Retrieved from http://www.statcan.gc.ca/pub/75-001x/10304/6824-eng.htm

Statistics Canada (2008a, April 10). Institutional Resident. Retrieved from http://www12.statcan.ca/census-recensement/2006/ref/dict/pop053-eng.cfm. Statistics Canada. (2008b, October). 2006 Census Code Book. Statistics Canada, Census Operations Division.

Statistics Canada. (2009a, November 20). More Information on Total Income. Retrieved from http://www12.statcan.gc.ca/censusrecensement/2006/ref/dict/pop123a-eng.cfm.

Statistics Canada. (2009b). Non-Permanent Residents. Retrieved from http://www12.statcan.ca/census-recensement/2006/ref/dict/pop100-eng.cfm Statistics Canada. (2010, March). Minimum Wage. Perspectives on Labour and Income. Retrieved from http://www.statcan.gc.ca/pub/75-001-x/topicssujets/minimumwage-salaireminimum/minimumwage-salaireminimum-2009eng.htm

Statistics Canada. (2013). Variant for Analysis by NOC Skill Level. Retrieved from http://www23.statcan.gc.ca/imdb/p3VD.pl?Function=getCET Page\&VD=136582 $\underline{\text { \&ltem }=136599}$ 
Statistics Canada, (2015). Base Population and Components of Population Growth.

Retrieved from http://www.statcan.gc.ca/pub/91-215-x/2012000/technotenotetech1-eng.htm.

Statistics Canada. (2016a). Table 282-0142 - Labour Force Survey (LFS) Estimates, by National Occupation Classification (NOC) and Sex. Retrieved from http://www23.statcan.gc.ca/imdb/p2SV.pl?Function=getSurvey\&SDDS=

Statistics Canada. (2016b). Table 282-0072 - Labour Force Survey (LFS)

Estimates; Wages of Employees by Type of Work, North American Industry Classification System (NAICS), Sex and Age Group. Retrieved from http://www5.statcan.gc.ca/cansim/pick-choisir?lang=eng\&p2=33\&id=2820072

Statistics Canada. (2017). 2011 National Household Survey; Table: 99-010X2011026. Retrieved from https://www12.statcan.gc.ca/nhs-enm/2011/dp-pd/dt-

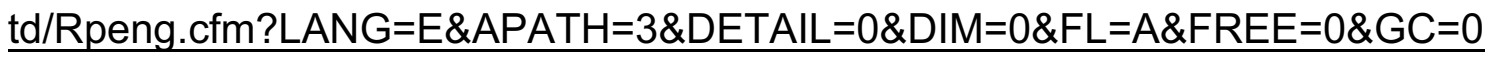
$\& G I D=0 \& G K=0 \& G R P=0 \& P I D=105411 \& P R I D=0 \& P T Y P E=105277 \& S=0 \& S H O W$ $\underline{A L L=0 \& S U B=0 \& T e m p o r a l}=2013 \& T H E M E=95 \& V I D=0 \& V N A M E E=\& V N A M E F=$ Statistics Canada. (2017a). 2011 National Household Survey: Data tables. Retrieved from https://www12.statcan.gc.ca/nhs-enm/2011/dp-pd/dt-td/Rpeng.cfm? $L A N G=E \& A P A T H=3 \& D E T A I L=0 \& D I M=0 \& F L=A \& F R E E=0 \& G C=0 \& G I D$ $=0 \& G K=0 \& G R P=0 \& P I D=106738 \& P R I D=0 \& P T Y P E=105277 \& S=0 \& S H O W A L L=0$ $\& S U B=0 \&$ Temporal $=2013 \&$ THEME $=98 \& \mathrm{VID}=0 \& \mathrm{VNAMEE}=\& \mathrm{VNAMEF}=$ Statistics Canada. (2017b). 2006 Census of Population. Retrieved from http://www12.statcan.gc.ca/census-recensement/2006/index-eng.cfm 
Steiger, T. (1993). Construction Skill and Skill Construction. Work, Employment and Society, 7(4), 535-560. Retrieved from http://wes.sagepub.com.ezproxy.lib.ryerson.ca/content/7/4/535.full.pdf+html Steinberg, R. (1990). Social Construction of Skill, Gender, Power and Comparable Worth. Journal of Work and Occupations, 17(4), 449-482. Retrieved from http://wox.sagepub.com/content/17/4/449.full.pdf

Stevens, A. (2014, July 8). Temporary Foreign Workers in Saskatchewan's "Booming" Economy. Canadian Centre for Policy Alternatives. Retrieved from https://www.policyalternatives.ca/publications/reports/temporary-foreign-workerssaskatchewans-booming-economy

Stockburger, D. (1998, March). Multiple Regression with Categorical Predictor Variable. Psychological Statistics at Missouri State University. Retrieved from http://www.psychstat.missouristate.edu/multibook/mlt08.htm

Stratemeyer-Trinczek, Y. (2012). The Vulnerability of Domestic Workers: Analysis of Labour Exploitation Under Canada's Live-in Caregiver Program (Master's Thesis). Retrieved from http://yanastrinczek.ca/uploads/3/5/2/7/3527222/yana major paper.pdf Strauss, K., and McGrath, S. (2016, January 29). Temporary Migration, Precarious Employment and Unfree Labour Relations: Exploring the 'Continuum of Exploitation' in Canada's Temporary Foreign Worker Program. Retrieved from http://journals1.scholarsportal.info.ezproxy.lib.ryerson.ca/pdf/00167185/unassign ed/nfp tmpeauictfwp.xml 
Stuart, M., and Hugh, M. (2007). Bringing Minimum Wages Above the Poverty Line. Canadian Centre for Policy Alternatives; An Economic Security Project Report. Retrieved from http://books1.scholarsportal.info/viewdoc.html?id=/ebooks/ebooks0/gibson cppc/ $\underline{2009-12-01 / 5 / 206342 \# \text { tabview=tab1 }}$

Somers, M. (2008a, Fall). Imperiled Citizenship and the Market. The Hedgehog Review, 10(3), 80.

Somers, M. (2008b). Genealogies of Citizenship: Markets, Statelessness and the Right to Have Rights. New York: Cambridge University Press.

Sweetman, A., and Warman, C. (2010, Spring). 'Canada's Temporary Foreign Worker Programs'. In C. Worwick (Ed.) Canadian Issues; Temporary Foreign Workers (pp. 19-24). Metropolis Project.

Surak, K., (2013). Guestworker Regimes: A Taxonomy. The New Left Review 84, Nov -Dec, 84-102.

'T Hart, P. (2010). Political Psychology. In D. Marsh and G. Stoker (Eds.) Theory and Methods in Political Science (pp.99-113). Basingstoke: Palgrave Macmillan.

Tambini, D. (2001, March). Postnational Citizenship. Ethnic and Racial Studies, 24(2), 195-217.

Termote, M. (1993). Causes et Conséquences Économiques de la Migration Internationale: Théorie et Réalité (Economic Causes and Consequences of International Migration: Theory and Reality). Études Internationales, 24(1), 51-61.

Therborn, G. (2006). After Dialectics: Postmodernity, Post-Marxism, and Other Posts and Positions. In G. Delanty (Ed.) Handbook of Contemporary European 
Social Theory (pp. 185-202). New York: Routledge International Handbooks.

Retrieved from

http://14.139.206.50:8080/jspui/bitstream/1/1856/1/Delanty,\%20Gerard\%20-

\%20Contemporary\%20European\%20Social\%20Theory.pdf

Thomas, D. (2009). Immigrants in Canada Who Work in a Language Other than English or French. Canadian Social Trends. Catalogue 11-008.

Thomas, D. (2010, June 8). Foreign Nationals Working Temporarily in Canada.

Canadian Social Trends. Catalogue 11-008-X.

Thomas, E., and Belkhodja, C. (2014). Temporary Foreign Workers in New

Brunswick's Rural Communities. Journal of New Brunswick Studies, (5), 55-80.

Retrieved from

https://journals.lib.unb.ca/index.php/JNBS/article/view/22338/25942

Thompson, N. (2008). Hollowing Out the State: Public Choice Theory and the Critique of Keynesian Social Democracy. Contemporary British History, 22(3), $355-382$.

Torpey, J. (2000). The Invention of the Passport: Surveillance, Citizenship and the State. Cambridge: Cambridge University Press.

Torres, C. (2012, July). Critical Social Theory: A Portrait. Ethics and Education, 7(2),115-124. Retrieved from http://journals2.scholarsportal.info/pdf/17449642/v07i0002/115_cstap.xml

Torres, S., Spitzer, D., Hughes, K., Oxman-Martinez, J., and Hanley, J. (2012). From Temporary Worker to Resident: The LCP and its Impacts through an Intersectional Lens. In P.T. Lenard and C. Straehle (Eds.) Legislated Inequality: 
Temporary Labour Migration in Canada (pp. 227-44). Montreal: MacGill-Queen's University Press.

Transport Canada. (2005). Operating Costs of Trucks in Canada. Transport Canada. File Number: T8080-05-024.

Triadafilopoulos, T. (2004). Building Walls, Bounding Nations: Migration and Exclusion in Canada and Germany, 1870-1939. Journal of Historical Sociology, 17(4), 385-427. Retrieved from

https://triadafilopoulos.files.wordpress.com/2010/07/triadafilopoulos buildingwalls johs.pdf

Triadafilopoulos, T. (2011). Illiberal Means to Liberal Ends? Understanding Recent Immigrant Integration Policies in Europe. Journal of Ethnic and Migration Studies, 37(6), 861-880.

Trumper, R., and Wong, L. (2010, Spring). Temporary Workers in Canada: A National Perspective. In C. Worwick (Ed.) Canadian Issues. Temporary Foreign Workers (pp. 83-89). Metropolis Project.

Tu, Jiong. (2010, August). The Impact of Immigration on the Labour Market Outcomes of Native-Born Canadians. IZA. Discussion Paper 5129.

Tversky A. and Kahneman, D. (1974, September 27). Judgment under Uncertainty: Heuristics and Biases. Science, New Series, 185(4157), 1124-1131. Retrieved from http://www.jstor.org/stable/pdf/1738360.pdf? $=1465255055573$

United Food and Commercial Workers (UFCW). (2015). The Status of Migrant Farm Workers in Canada. Retrieved 
from http://www.ufcw.ca/templates/ufcwcanada/images/directions15/october/158 6/MigrantWorkersReport2015 EN_email.pdf

United Food and Commercial Workers (UFCW). (2014, March). The Great

Canadian Rip-Off! An Economic Case for Restoring Full El Special Benefits

Access to SAWP Workers. Retrieved from

http://www.ufcw.ca/templates/ufcwcanada/images/directions14/march/1420/The-

Great-Canadian-Rip-Off-An-Economic-Case-for-Restoring-Full-El-Special-

Benefits-Access-to-SAWP-Workers.pdf

Valiani, S. (2013). The Shifting Landscape of Contemporary Canadian Immigration

Policy: The Rise of Temporary Migration and Employer-Driven immigration. In L.

Goldring and P. Landolt (Eds.) Producing and Negotiating Non-citizenship:

Precarious Legal Status in Canada (pp. 55-70). Toronto: University of Toronto

Press.

Valpy, M. (2015, September 22). The Fraying of Canada's Social Fabric. The

Toronto Star. Retrieved from

https://www.thestar.com/opinion/commentary/2015/09/22/the-fraying-of-canadas$\underline{\text { social-fabric.html }}$

Van Houtum, H., and Van Naerssen, T. (2002). Bordering, Ordering and Othering.

Tijdschrift voor Economische en Sociale Geografie, 93(2), 125-136.

Verma, V. (2002, November 14). The Mexican and Caribbean Seasonal Agricultural Workers Program: Regulatory and Policy Framework, Farm Industry Level Employment Practices, and the Future of the Program under Unionization.

Retrieved from http://www.nsi-ins.ca/publications/the-mexican-and-caribbean- 
seasonal-agricultural-workers-program-regulatory-and-policy-framework-farmindustry-level-employment-practices-and-the-future-of-the-program-underunionization/

Verma, V. (2003). The Mexican and Caribbean Seasonal Workers Program: Regulatory and Policy Framework, Farm Industry Level Employment Practices, and the Future of the Program under Unionization. The North South Institute. Retrieved from http://www.nsi-ins.ca/wp-content/uploads/2012/11/2002-TheMexican-and-Caribbean-Seasonal-Agricultural-Workers-Program-Regulatoryand-Policy-Framework-Executive-Summary.pdf

Verret, F., (2013). The Estimation Methodology of the 2011 National Household Survey; Online Proceedings of the Survey Research Methods Section, American Statistical Association (2013) Session 365 Topics in Complex Survey Data Analysis - Chair(s): Trent Buskirk, Nielson

Walker, J., and Murphy, J. (2001). Implementing the North American Industry Classification System at BLS. Monthly Labor Review, 124(12), 15-21.

Walsh, J. (2014, November). From Nations of Immigrants to States of Transience: Temporary Migration in Canada and Australia. International Sociology, 29(6), 584-606.

Wedel, J., Shore, C., Feldman, G., and Lathrop, S. (2005, July). Toward an Anthropology of Public Policy. Annals of the American Academy of Political and Social Science, 600, 30-51. 
Weiner, M. (1996, Spring). Ethics, National Sovereignty and the Control of Immigration. The International Migration Review, 30(1), 171-197. Retrieved from http://www.jstor.org/stable/pdf/2547466.pdf

Wells, D., McLaughlin, J., Lyn, A., Díaz Mendiburo, A. (2014, Autumn). Sustaining Precarious Transnational Families: The Significance of Remittances from Canada's Seasonal Agricultural Workers Program. Just Labour: A Canadian Journal of Work and Society, 22, 144-167. Retrieved from http://scholars.wlu.ca/cgi/viewcontent.cgi?article=1012\&context=hesc faculty

Weston, A. and Scarpa de Masellis, L. (2003). L. Hemispheric Integration and Trade Relations: Implications for Canada's Seasonal Agricultural Workers Program, The North-South Institute, Ottawa.

Williams, R (2004), Fall 2004 Course Notes, Statistics I, retrieved online on May 14, 2015 from: https://www3.nd.edu/ rwilliam/stats1/x53.pdf

Wingrove, J., and Curry, B., (2014), June 13, Alberta MPs Say Foreign Worker Program Changes Will Exacerbate Labour Shortage. The Globe and Mail, Retrieved from http://www.theglobeandmail.com/news/politics/alberta-mps-sayforeign-worker-program-changes-will-hurt-labour-shortage/article19151552/

Xiaoling Li E., and Li, P. (2016). Immigrant Enclave Thesis Reconsidered: Case of Chinese Immigrants in the Enclave and Mainstream Economy in Canada. Journal of International Migration and Integration, 17, 131-151.

Zhang, X. (2002, December). Wage Progression of Less Skilled Workers in Canada: Evidence from the SLID (1993-1998). Research Paper Series. No. 194. Ottawa: Statistics Canada. Retrieved from 
http://publications.gc.ca/Collection/Statcan/11F0019MIE/11F0019MIE2002194.p

$\underline{\mathrm{df}}$

Zolberg, A., (1987). Wanted but Not Welcome: Alien Labor in Western

Development. In W. Alonso (Ed.), Population in an Interacting World, Cambridge, Harvard University Press.

Zolberg, A., (1991). Bounded States in a Global Market: The Uses of International Labor Migrations. In P. Bourdieu and J. S. Coleman (Eds.), Social Theory for a Changing Society, New York: Russell Sage Foundations; Boulder, Colo., Westview Press. 